Universidad Nacional de La Plata

Facultad de Arquitectura y Urbanismo

Doctorado en Arquitectura y Urbanismo

Tesis de Doctorado:

\title{
Mario Palanti: la búsqueda de una nueva arquitectura
}

Doctoranda: Virginia Bonicatto

Director: Dr. Fernando Aliata

Codirectora: Dra. María Mercedes Bares 


\section{Índice}

$\begin{array}{ll}\text { Abreviaturas } & 1\end{array}$

Agradecimientos 2

Introducción Mario Palanti, arquitecto 5

1. Los primeros aportes historiográficos 10

2. La construcción del mito 13

3. Nuevas miradas 15

4. La divulgación masiva y el interés en el tema 17

5. Referentes teóricos y organización del texto 18

Capítulo I. Milán 1900. Los años formativos 23

1. Una arquitectura para la Italia unida 25

2. El Medioevo moderno. 28

3. La figura del arquitecto civil 33

4. Mario Palanti: pensamientos sobre arquitectura 40

Capítulo II. Buenos Aires 1910. La experiencia metropolitana 51

1. Imágenes de modernidad 53

2. Prins y Ranzanhofer: la experiencia técnica en la metrópoli 62

3. Tensión con la Sociedad Central de Arquitectos 64

4. Mario Palanti, Il cortesano. El vínculo con la committenz̧a 66

5. Avenida de Mayo 695: el estudio particular 81

6. Experimentación y ensayos en la obra porteña 85

Capítulo III. El primer rascacielos: el Pasaje Barolo en Buenos Aires 92

1. Un colosal encargo 92

2. Resolver un problema: la morfología del rascacielos 94

3. Estrategias proyectuales 99

4. Experimentaciones técnicas 108

5. Símbolos y alegorías en el pasaje: El Danteum 112

6. El mausoleo metropolitano 114

7. La mala prensa: críticas desde el ámbito disciplinar 120 
Capítulo IV. Superar su marca: el Palacio Salvo en Montevideo

1. "La lucha por la felicidad" 125

2. La materialización de una trayectoria: la construcción del Palacio 130

3. El esqueleto 134

4. La continuidad de un método 138

5. El rascacielos en los medios 148

6. Una catedral para la industria uruguaya 152

Capítulo V. Regresos a Italia 157

1. Un rascacielos para el Duce 157

2. Los concursos para el PNF 165

3. Sobrellevar las críticas 176

4. E'42. un nuevo material para una nueva arquitectura 181

5. Antiguas invenciones técnicas 185

Capítulo VI. Buenos Aires 1948. E1 viaje de la esperanza 195

1. Arquitectura para todos 195

2. De la casa al rascacielos. El Estado como comitente 199

3. Una regresión oportunista. Monumentos metropolitanos 207

4. El desencanto. Problemas legales en torno a la profesión de arquitecto 216

5. Un nuevo rascacielos para Buenos Aires 220

6. Arquitectura de papel 227

VII. Palabras finales. Las torres de Babel 233

Apéndice documental 236

$\begin{array}{lr}\text { Fuentes y Bibliografía } & 258\end{array}$ 


\section{Abreviaturas}

BPUNLP Biblioteca Pública de la Universidad nacional de La Plata

MGG Museo Galería Güemes, Buenos Aires

IHCBA Instituto Histórico de la Ciudad de Buenos Aires

HCD Honorable Concejo Deliberante, Buenos Aires

BSCA Biblioteca Sociedad Central de Arquitectos, Buenos Aires

AGN Archivo General de la Nación, Buenos Aires

BN Biblioteca Nacional, Buenos Aires

AAySA Archivo Aguas y Saneamientos Argentinos S.A., Buenos Aires

SCA Sociedad Central de Arquitectos, Buenos Aires

IHA Instituto de Historia de la Arquitectura, Montevideo

AGNM Archivo General de la Nación, Montevideo

AIHA Archivo del Instituto de Historia de la Arquitectura, Facultad de Arquitectura, UdeLaR, Montevideo

SAU Sociedad de Arquitectos del Uruguay

CPAU Consejo Profesional de Arquitectos y Urbanistas, Buenos Aires

ACS-SPD Archivio Centrale dello Stato - Segretaria Particolare del Duce, Roma

AGEP Archivo Privado Guido y Emilio Palanti, Milán

AP Archivo Palanti, Milán

ASV Archivio Segreto Vaticano, Roma

ASAL Archivio Accademia Lincei, Roma

GRI The Getty Research Institute, Los Angeles, CA (910002) 


\section{Agradecimientos}

La presente tesis es el resultado de una experiencia formativa como alumna del Doctorado en Arquitectura y Urbanismo de la Facultad de Arquitectura y Urbanismo de la Universidad Nacional de La Plata.

A lo largo de estos años, han sido muchas las personas quienes, a través del dialogo, discusiones e intercambio de experiencias, fueron parte de mi formación.

En primer lugar, quiero agradecer en especial a mi director: Fernando Aliata. A él debo no sólo pacientes lecturas, agudos comentarios y enriquecedoras sugerencias sino también una inagotable generosidad y constante apoyo. Él ha sido mi maestro en este camino que comencé hace ya tiempo y que hoy da como resultado esta tesis.

Junto con Fernando Gandolfi y Eduardo Gentile fueron quienes supieron despertar en mí el interés por la historia a través de la experiencia formativa desarrollada, primero como alumna y luego como parte del equipo docente en el taller Vertical de Historia de la Arquitectura que dirigen en la FAU-UNLP y del HiTePAC.

Asimismo, agradezco a mi codirectora, María Mercedes Bares de la Universita degli Studi di Palermo, por sus lecturas, material y apoyo durante mi estadía en Italia y a Marco Rosario Nobile de la Universita degli Studi di Palermo.

Este trabajo no hubiera sido posible sin el soporte económico necesario para dedicarse de manera exclusiva a las tareas de investigación. Para ello conté con el apoyo de una beca doctoral del Conicet con sede en el HiTePAC (FAU-UNLP). Los viajes de relevamiento que permitieron la recolección de material en distintos repositorios y países fueron en gran medida posibles a través de una Library Grant del Getty Research Institute y los Subsidios de Viaje recibidos por parte de la Universidad Nacional de La Plata.

Una especial mención merecen aquellos quienes desde archivos y bibliotecas hicieron materialmente posible esta tesis: Ricardo Gasalla de la Sociedad Central de Arquitectos, el personal de las bibliotecas del Centro Argentino de Ingenieros, de la Universidad Torcuato di Tella, de la biblioteca y archivo del CeDIAP, del Centro Profesional de Arquitectura y Urbanismo, así como del Archivo General de la Nación. 
En particular quiero agradecer a los familiares de Mario Palanti: Edoardo Romagnoli, Guido y Emilio Palanti, Angela y Cristina Palanti quienes abrieron las puertas de su casa y me recibieron con tanta generosidad. Gracias a ellos he tenido acceso a material inédito que enriqueció el contenido de esta tesis. A ellos toda mi gratitud.

No puedo dejar de mencionar a los enamorados de los edificios siempre dispuestos a colaborar con material o información: el Arq. Fernando Carral quien trabaja en el Barolo, Abelardo García Viera quien me recibió en la torre del Salvo y el "cazador de arquitectura" Alejandro Machado.

Quiero reconocer, además, el apoyo recibido “del otro lado del río”: Andrés Mazzini y el equipo que conforman el Instituto de Historia de la Arquitectura de la Facultad de Arquitectura en Montevideo, quienes tantas veces recibieron mis visitas, respondieron mis pedidos y contestaron mis preguntas. Quiero agradecer también a Santiago Medero, Jorge Sierra y a Willy Rey por los comentarios y material. Asimismo, el personal de las bibliotecas del Palacio Legislativo, de la Sociedad de Arquitectos de Uruguay y de la Facultad de Arquitectura de la Universidad de la República y del Archivo General de la Nación, ambos en la ciudad de Montevideo.

Tampoco pueden estar ausentes aquellos con quienes a lo largo de estos años intercambié opiniones, lecturas y comentarios. Los integrantes del taller Vertical $n^{\circ} 1$ de Historia de la Arquitectura y el Taller Vertical n³ de Teoría de la Arquitectura de la FAU UNLP, los integrantes de "La Cueva" en Montevideo, y el grupo completo de "hitepaqueras".

Agradezco a quienes en el ámbito del HiTePAC generaron un clima de intercambio de ideas y experiencias: Fernando Williams, Omar Loyola, Cecilia Bravo, Teresa Zweifel, Virginia Galcerán y Fabiana Carbonari. Entre ellos, Rosana Obregón, Florencia Minatta y Natalia Salcedo hicieron suya la cruzada y buscaron bibliografía, tradujeron textos y compartieron libros. Tambien mi reconocimiento a Estela Mantz por su ayuda.

Quiero agradecer a mis compañeras de ruta y de vocación que hicieron parecer que este trabajo es resultado de una elaboración colectiva. Mery Méndez con quien, además de la pasión por la historia, compartimos amistad, mates, discusiones y aventuradas visitas a las entrañas del Salvo. A Valeria Gruschetsky, detenida lectora y paciente consejera, cuyas observaciones siempre resultaron de un valor inestimable y, por supuesto, a Ana Gomez Pintus y Mariana Santangelo.

Un agradecimiento especial merecen Susana Cricelli y Magalí Franchino: gracias por 
reiteradas lecturas, atinadas observaciones, mates, risas y compañía.

Finalmente, están quienes por fuera del ámbito académico ayudaron a seguir adelante en los momentos difíciles propios de la realización de una tesis, permitiendo que este trabajo fuera posible.

Cuando hace tiempo leí, emocionada, las palabras preliminares de El color del río, no imaginé que un día las sentiría tan propias. Porque hacer una tesis con dos bebés es un esfuerzo muy grande, imposible de realizar sin el constante apoyo y contención de la familia y amigos.

En efecto, no es retórico el agradecimiento hacia ellos, es desde el fondo del corazón: a mis amigas, a mi familia en Montevideo, a mi abuelo y a mi madre Cecilia cuyo ejemplo me hizo siempre seguir adelante. A mi hermana y mi cuñado, que teniendo dos niños se hacían cargo de los ajenos. Todos ellos supieron entender mis ausencias y compartieron mis ratos de ocio.

Y por último, a Javier, quien, con una inagotable paciencia apoyó cada momento de esta intensa etapa y cuya compañía me resulta imprescindible. Y claro, a mis amores Julia y Pedro: ellos son parte de este camino que empecé sola y hoy terminamos de a cuatro. 


\section{Introducción. Mario Palanti, arquitecto}

Todas las formas del arte y el pensamiento modernistas tienen un carácter dual: son a la vez expresiones del proceso de modernización y protestas contra él (...). En los países relativamente atrasados, donde el proceso de modernización todavía no se ha impuesto, el modernismo, allí donde se desarrolla, adquiere un carácter fantástico, porque está obligado a nutrirse no de la realidad social sino de fantasías, espejismos, sueños.

(Marshall Berman, Todo lo sólido se desvanece en el aire: la experiencia de la modernidad, 1982)

Todos los nuevos elementos de la vida moderna, vendrán a imponer sus características e imprimir su huella en el derrotero de la nueva arquitectura, ya que ésta ha de contemplarlos todos y armonizarse con todos ellos.

(Mario Palanti, "La era moderna tiene orientaciones nuevas en arquitectura", 1922)

El hallazgo de material inédito en un archivo privado debe ser uno de los momentos más apasionantes para quienes nos dedicamos (o intentamos) escribir historia. Sobre todo, si ese conjunto de piezas conforma el rastro de alguien que, hasta el momento, prácticamente no había dejado huellas. Si las había, muchas de ellas eran erradas, como la fotografía de un desconocido que varios sitios virtuales muestran con el nombre de Mario Palanti.

Desplegado el material, confrontadas, derrumbadas y rearmadas las hipótesis, comienza la difícil tarea de reconstruir en un relato la multiplicidad de fragmentos que componen una trayectoria. Esto significó, en este caso de estudio, construir una historia de vida sobre la cual podamos avanzar con la voluntad de hacer un aporte al conocimiento.

El estudio que aquí se inicia centra su interés sobre la producción arquitectónica realizada por Mario Palanti, entendida como parte de una búsqueda personal hacia aquello que el arquitecto concibe como una nueva arquitectura.

Formado en la Italia de fines de silgo XIX, Palanti llegó a la Argentina en la primera década del siglo XX, invitado a participar en la construcción del pabellón italiano de la Exposición del Centenario de Mayo. Espíritu inquieto, su trayectoria incluye estadías en Italia, el regreso a Buenos Aires a fines de la década de 1940 y el posterior y ultimo retorno a la península en 1958. 
Más allá de este oscilante derrotero, es en el Rio de la Plata donde se concentra su principal producción arquitectónica que surge como parte del proceso de metropolización de la ciudad de Buenos Aires.

Para afrontar este estudio, como veremos a continuación, se analizarán cuestiones propias de la disciplina arquitectónica como documentación gráfica, fotografías y escritos del arquitecto provenientes de diferentes archivos, como también factores sociales, políticos, culturales y económicos que conformaron el contexto que, efectivamente, permitió la realización de su obra material.

Entre 1910 y 1933, Palanti realizó un total de treinta y siete obras en el Río de la Plata a las que se suman decenas de proyectos. Formado en la Academia di Belle Arti di Brera de la Milán de fines de siglo XIX, el arquitecto puso a prueba su formación académica en su intento por dar solución a los problemas planteados en el contexto metropolitano porteño, como escala, masividad, nuevos programas, etc.-

Precisamente, en la cambiante Capital de principios de siglo XX, entre las colectividades extranjeras, la activa comunidad italiana era la más numerosa entre los inmigrantes europeos. ${ }^{1}$ Esta singular composición social tuvo consecuencias concretas en relación a nuestra disciplina. En ese sentido, Mercedes Daguerre ha señalado las estrechas relaciones que unen al campo arquitectónico lombardo de principios de siglo con los estratos más altos de la colectividad peninsular en el Plata. ${ }^{2}$ Siendo Milán por entonces un activo centro de la renovación arquitectónica italiana, se produce un importante intercambio cultural con la capital argentina, por entonces en constante crecimiento. El contingente de inmigrantes lombardos conjuntamente con ligures y piamonteses constituye el grueso de la presencia peninsular en la Argentina y no es casual que los arquitectos más destacados del mundo milanés realicen en el período previo a la Gran Guerra encargos en nuestro país. Gaetano Moretti, Sebastiano y Atilio Locatti ejecutan obras, se presentan a concursos y abren el camino para que algunos de sus discípulos se trasladen a Buenos Aires como es el caso de Virginio Colombo, Francesco Gianotti, Ferruccio Corbellani y el mismo Palanti. Dentro de los estilos eclécticos vigentes los modernismos, en este caso el Floreale o la recreación boitiana del Románico Lombardo, sirven para caracterizar los emprendimientos de los italianos afincados en la Argentina que abrazan esta corriente estilística con un doble

1 Fernando Devoto, Historia de los Italianos en Argentina (Buenos Aires: Sudamericana, 2006).

2 Mercedes Daguerre, "Milano- Buenos Aires: la perdita del centro". Metamorfosi, quaderni di architettura. Roma, "La Sapienza". No 25/26 (1995). D’Amia, "Architetti lombardi a Buenos Aires" 
propósito: revelar en este extraño baile de estilos en que se ha convertido Buenos Aires la singularidad moderna de sus emprendimientos, pero también mostrarse a la vanguardia en el contexto de sus respectivos círculos nacionales o regionales de emigrados. ${ }^{3}$

En sede milanesa, los años a caballo de la Primera Guerra mundial, encuentran un ámbito cultural atravesado por ciertas contradicciones: allí, la necesidad de referencias cosmopolitas se mezclaba con la valoración y búsqueda de las propias raíces nacionales y regionales. En ese contexto, la indagación de fuentes exóticas como arquitectura khmer, mogol o japonesa se enfrentaba a los modelos provenientes de Europa como la Wagnerschule o a los rascacielos norteamericanos. ${ }^{4}$

A partir del despegue industrial de principios de siglo, las grandes ciudades italianas como Milán incrementaron su expansión. Las transformaciones urbanas trajeron consigo múltiples referencias en la escena con ejemplos desde Haussmann al Cinquecento romano, o a las cúpulas estilo Charles Garnier. ${ }^{5}$ Ante el crecimiento de las ciudades, el enfrentamiento de la arquitectura con la gran dimensión urbana aumentó: hacia 1910 surgió la primera propuesta de grattanuvole para Milán diseñada por Achile Manfredini o las propuestas para una Città Nuova de Antonio Sant'Elia (1913-14). Adjetivos como fantástico, gigantismo, cliclopico, monumentalismo esaltato, archeologia fantástica acompañaban tanto la producción urbana del período como la multiplicidad de proyectos utópicos. Entre ellos, en los años previos y posteriores a la guerra, cobró fuerza el Manifesto dell'architettura futirista (1914) que ensayará propuestas fuera de escala, proyectos como el Cementerio de Monza (1911-12) o la Sede de la Società dei Commersi de Sant'Elia en Como (1914), los mencionados rascacielos u obras como la Estación Central de Milán (1912-1931) de Ulisse Stachini o el Palazzo Berri-Meregalli (1910-12) de Giulio Ulisse Arata.

En este contexto en que, en casi todos los casos, los proyectos colosales no pasaban la fas de proyecto, la figura de Palanti cobra relevancia al considerar que, además de su prolífica producción de obras, tuvo la posibilidad, poco frecuente en la época, de construir dos rascacielos en un lapso de diez años: uno de ellos en Buenos Aires (Pasaje Barolo 1919-1923) y otro en Montevideo (Palacio Salvo 1922-1928).

3 Mercedes Daguerre, "Milano- Buenos Aires: la perdita del centro". Metamorfosi, quaderni di architettura. Roma, "La Sapienza". No 25/26 (1995); Mercedes Daguerre, La construzione di un mito. Ticinesi in Argentina. Commitenza e architettura (1850 1914) (Suiza: Accademia di Architettura di Mendrisio, 1998); Jorge Francisco Liernur, Arquitectura en la Argentina del siglo XX. La construcción de la modernidad (Buenos Aires: Fondo Nacional de las Artes, 2001).

4 Guido Zucconi, "Gli anni dieci tra riscoperte regionali e apertura internazionali" en Storvia dell'architettura italiana. Il primo novecento, Giuogio Ciucci, Giorgio Muratore (a cura di), (Milano Electa 2004), 38-55

5 Zucconi, "Gli anni dieci tra riscoperte regionali e apertura internazionali" 
En este ambiente finisecular, la arquitectura se enfrentó al problema de "producir un lenguaje capaz de ser entendido como figuración de la nueva situación técnica y metropolitana de la sociedad occidental" . Tal condición se extendería durante las primeras décadas de siglo XX involucrando a los más variados personajes, experiencias y lugares: Gaudí en Barcelona, Victor Horta en Bruselas, Sullivan en Chicago, Auguste Perret en Francia, Hendrik P. Berlage en Holanda, Hermann Muthesius en Alemania.?

Al respecto de Gaudí, Berlage y Sullivan, Ignasì de Solà-Morales señala que: "La preocupación por construir lo nuevo, por encontrar una arquitectura que permita sortear el callejón sin salida en que la cultura de fin de siglo se siente atrapada, pasa en los tres arquitectos por el retorno y la invocación de algo originario, que lleva hacia el buen camino del reencuentro de una 'verdad' perdida". ${ }^{8}$

Bajo esta mirada, ¿cabría hacerse la misma pregunta sobre Mario Palanti?

A la luz de estos interrogantes, y ante el reciente descubrimiento de nueva documentación en archivos públicos y privados es posible reconstruir su trayectoria, y validar y refutar hipótesis hasta el momento sostenidas en torno a la producción arquitectónica y proyectual de Palanti.

Efectivamente, en los últimos años, la obra y la figura de Palanti han tenido en nuestro medio una fortuna crítica sorprendente que contrasta con el escaso interés que su producción suscitó durante buena parte del siglo XX. Esta revalorización está necesariamente asociada a la importancia que ha cobrado la singular obra del Palacio Barolo en el contexto del patrimonio edilicio porteño y el Palacio Salvo en la ciudad de Montevideo. Ambos edificios han sido asociados por diversos motivos al mundo de lo esotérico y, en el caso del pasaje Barolo, a una hipótesis de que se trataría de un Danteum; un monumento a la gloria de Dante Alighieri. Esta hipótesis, construida como un creativo ensayo histórico literario por Carlos Hilger (1993) ha tenido a lo largo de los últimos años una inesperada repercusión. Se ha convertido en una verdadera leyenda urbana, repetida incansablemente por la prensa escrita, guías turísticas y medios audiovisuales. Esta historia (no corroborada en fuentes documentales) ha sido foco de atención de los estudios sobre Palanti e impidió una mirada más amplia que tenga en consideración variables como el

6 (Ignasí Sola-Morales, El País, 24 de marzo de 1986)

7 Como es ya sabido, el tema ha sido ampliamente abordado por la historiografía. Sobre siglo XX véase: Manfredo Tafuri y Francesco Dal Co, Arquitectura Contemporánea Vol.1 (Viscontea, 1982), 69, Alan Colquhoun, La arquitectura moderna: una historia desapasionada (Barcelona: GG, 2005) Kenneth Frampton, Historia critica de la arquitectura moderna (Barcelona, Gustavo Gili, 2014)

8 Ignasí Sola-Morales, “Gaudi, Berlage y Sulllivan en la crisis de la arquitectura de la edad clásica”, En Inscripciones (Barcelona: GG, 2003), 111. 
contexto de producción de su arquitectura y las posibles innovaciones tipológicas, lingüísticas y, sobre todo, técnicas.

Avanzando en esta dirección, el objetivo de este trabajo parte de examinar las particularidades que se dieron en la obra de este arquitecto como producto de adaptar su bagaje cultural al contexto metropolitano porteño y estudiar el papel que juega su arquitectura como un ensayo entre la multiplicidad de experiencias modernas.

Además de ello, dentro de la producción de obras del arquitecto, encontramos ejemplos que siguen líneas convencionales mientras que en otros casos desarrolla una arquitectura en la que se verifica una búsqueda a nivel tipológico, técnico y lingüístico. En este marco, nos preguntamos: ¿Cómo proyectaba? ¿Cómo trabajaba?, ¿cuál era su método de proyecto? ¿Cuáles eran sus fuentes de consulta? ¿Qué entendía por "nueva arquitectura”?

Cómo estas innovaciones, persistencias y cambios se presentan en la arquitectura de Palanti es algo que nos interesa explorar: ¿Cuál era su vínculo con las nuevas técnicas?, ¿cómo se dieron en su obra las relaciones entre forma, posibilidad de los materiales y necesidades constructivas?

Para responder a ello, considerando la trayectoria del arquitecto, tomamos el "análisis de edificios y de proyectos no realizados, para verificar básicamente el modo en que las diferentes técnicas de composición fueron aplicadas y en qué contexto especifico han sido desplegadas" (Aliata, 2014: 17). Con este fin se propone una mirada amplia que ubica al objeto dentro un nudo que no es exclusivamente arquitectónico teniendo en cuenta, además de la obra, las condiciones de encargo, las ideas fundantes, los debates teóricos en torno a la arquitectura, el lenguaje y las estrategias proyectuales, sin perder de vista los procesos y los medios productivos que constituyen, inevitablemente, su viabilidad (Tafuri, 1983). Esto permitirá aproximarse no sólo a la problemática intrínseca de la obra de Palanti sino también entender esta arquitectura como parte material del proceso modernizador.

Si bien para nuestro estudio necesariamente tenemos que dar cuenta de la trayectoria de Mario Palanti, el recorte espacio temporal del trabajo no toma la biografía del arquitecto (1885-1978), sino que varía en pos del estudio de aquella obra que consideramos parte de su camino exploratorio y de su contexto de producción.

Así, el estudio centra su enfoque principal en los períodos que el arquitecto permaneció en el Río de la Plata (1910-1933; 1948-1955) -etapas de mayor productividad-que intercala con 
dos viajes esporádicos a Italia (1924, 1926). Su primera estadía en Buenos Aires (1910-1933) es la que llamaremos en esta tesis el "primer período" en la obra y trayectoria de Palanti. Un segundo período de permanencia en la Argentina se da durante el primer gobierno peronista, entre 1948 y 1955.

A fin de comprender la manera de hacer de este arquitecto, el trabajo se complementa -podríamos decir que en un segundo plano- con las estadías de Palanti en Italia (1885-1910), (1933-1948), (1955-1978). En efecto, para el estudio de la formación disciplinar del arquitecto en la Accademia di Belle Arti di Brera, el relato necesariamente se traslada a la Milán de fines de siglo XIX y principios del XX, entre el nacimiento (1885) y 1910, fecha en que emprende el viaje hacia la Argentina. Lo mismo sucede con el período de entreguerras y segunda posguerra (19351948), cuyo análisis es necesario para lograr entender las decisiones, cambios y giros que a nivel proyectual se dan en la obra palantiana y poder comprender su tardío retorno a la Argentina en 1948. La etapa final del arquitecto, desde su regreso a Italia en 1955 a su muerte en 1978, es abordada brevemente como parte del último capítulo de esta tesis -que aborda su último período en Argentina- ya que los proyectos que Palanti realiza durante la misma son resultado de su experiencia en Buenos Aires.

\section{Los primeros aportes historiográficos}

El derrumbe de la idea de "un” Movimiento Moderno canónico tiene sus años y es por todos conocido. Me refiero a esa construcción historiográfica consolidada entre la década de 1920 y 1940, y que "alude a ciertas expresiones de la arquitectura europea y norteamericana en esos años" identificada con los CIAM, idea con la cual se instaló una concepción puramente estilística de la Arquitectura Moderna y con ella -aunque con variaciones- un canon que clausuró un innumerable número de experiencias (Liernur 1986, 2001).

Superada esa etapa, en el presente, como señala Aliata, “(...) en función de los desarrollos historiográficos de las últimas décadas, hoy para nosotros no constituyen una novedad los prestamos y solapamientos entre la tradición y la Modernidad, las crisis y contradicciones entre sus estrategias dentro de un supuesto Movimiento Moderno que presentaba múltiples 
manifestaciones, las búsquedas radicales y los revivals nostálgicos que siguieron a una disolución de la disciplina que parecía definitiva" (Aliata, 2014: 16)

Sin embargo, derribado ese paradigma canónico y reconocida la multiplicidad de experiencias, no existían, hasta la década de 1990 estudios en profundidad sobre la producción palantiana.

En efecto, durante la primera mitad del siglo XX los grandes relatos de la arquitectura soslayaron al Eclecticismo -dentro del cual la obra de Palanti era incluida-cediendo lugar a la construcción del relato del "Movimiento Moderno". Reseñar la totalidad de esa producción historiográfica excede los límites de esta tesis, baste señalar trabajos señeros como los de Nikolaus Pevsner, Sigfried Giedion o Leonardo Benévolo. ${ }^{9}$ En este marco, el caso puntual del Eclecticismo modernista, antiacademicismo o Art Nowveau en sus diferentes vertientes de influencia, y en particular la italiana -bajo la cual se ha etiquetado la producción de Palanti- ha sido, en la mayoría de los casos, abordado de manera tangencial y bajo una visión negativa por la bibliografía especializada. Precisamente, como fue señalado por Graciela Silvestri, entre las décadas de 1920 y 1950, en la búsqueda de una "historia argentina", los principales estudios se enfocaron hacia la arquitectura colonial, en correspondencia con el momento cultural y los trabajos derivados de la Academia Nacional de Historia y de la Comisión Nacional de Monumentos.

Entre los primeros trabajos en sede nacional encontramos aquellos pertenecientes al Instituto de Arte Americano e Investigaciones Estéticas (IAA) que abrió sus puertas en 1947 dando lugar a la primera aproximación científica a la historia de la arquitectura. Si bien de cierto contenido descriptivo, los trabajos tienen el valor de representar la vanguardia en los esfuerzos historiográficos sobre el tema. En ellos la obra de Palanti se plantea de manera periférica como un caso más dentro del Art Nouveau.

Sirvan como ejemplo los textos El Art Nouveau en la Argentina (1960) y La arquitectura en la República Argentina, 1810-1930 (1965) de Mario Buschiazzo. Si bien el autor valora cierto esfuerzo "intrascendente" realizado por el Art Nowveau señala, a su vez, que "la falacia en la arquitectura

9 Me refiero a Pevsner ([1936], 1977); (Giedion [1941], 1978); (Zevi [1950],1950); (Benévolo [1960], 1986). Desde mediados de siglo XIX el concepto de Eclecticismo ha asumido diferentes connotaciones. Dada la extensión del tema haremos referencia a aquellas que son de interés para nuestro trabajo. Hacia 1830 Victor Cousin entendió el Eclecticismo como un procedimiento compositivo y estructurado que parte de una selección de elementos adecuados (Cousin [1829], 1947). A fines del siglo XIX Camillo Boito definió esta operación como un método crítico de selección de estilemas figurativos de la propia tradición como vía antihistoricista de búsqueda proyectual que daba comienzo a un estilo nacional (Boito, 1887; 1893). 
fue total". El eclecticismo era para Buschiazzo un "ladrón de elementos arquitectónicos de otros tiempos" que formaba parte de un "largo proceso de extravíos y anacronismos estilísticos" que la visita de Le Corbusier a la Argentina, en 1929, venía a cerrar. Otra mirada que se entronca en esta línea descriptiva es planteada en La ornamentación en la arquitectura de Buenos Aires, 1900-1940 de J. X. Martini y J. M. Peña (1967) quienes enfocan su obra en los elementos arquitectónicos desde el punto de vista ornamental y decorativo en la cual, como en tantos otros relatos, el Art Nonvean es "rescatado" sólo como un paso que conduce a la "arquitectura moderna".

En la más acotada versión de Ortiz, de Paula, Montero y Gutiérrez publicada en 1968 y titulada La Arquitectura del liberalismo en la Argentina, el Art Nouveau es abordado bajo el título de Antiacademicismo, epidermis y "fenestración" continua, tomando al estilo como algo "superficial e incapaz de superar los tabúes del academicismo". Sin detectar o valorizar las búsquedas o intentos de dar respuestas a la crisis decimonónica del sistema o de dar nuevas alternativas al canon clásico, los autores dedican un párrafo al Art Nouveau de influencia italiana: Mario Palanti es calificado como un "fenómeno difícil de ubicar" de manera de ser "esencialmente italiano y entusiasmado por el fascismo". Su obra como una "especie de expresionismo arquitectónico inédito y barroquizante". Posteriormente, varios de estos artículos fueron recopilados en Documentos para la historia de la arquitectura argentina por Marina Waisman (1978) en los que se refiere al Eclecticismo como "hijo del terror a la hoja en blanco" como un mal que debe ser estudiado, para poder “inocularnos y mantenernos a salvo de esta enfermedad". Entre estos primeros esfuerzos, no podemos dejar de mencionar la historia de la arquitectura construida por Francisco Bullrich, Arquitectura argentina contemporánea (1963) donde se ve el paradigma canónico de la arquitectura moderna argentina que rechazó al Eclecticismo decimonónico inclinándose por lo colonial y el blanco de la modernidad (Silvestri, 2004; 161-162). El tema del Eclecticismo ha sido abordado con una visión hegemónica que evidencia una serie de diferencias ideológicas, teóricas y metodológicas relacionadas a las investigaciones desarrolladas en el marco internacional que tienden a convertir a Palanti en un fenómeno propio de la anormalidad, cuya producción "exótica" lo convierte en un caso inclasificable de arquitecto. En efecto, desde los mencionados trabajos del IAA, la pluralidad lingüística de fines de siglo XIX -y principios del XX- ha sido considerada como agresión europeizante hacia un mítico pasado criollo; visión que se vería reforzada por los estudios del neocolonial y la línea de investigación interesada en la catalogación de valores. 
Al alimentar una línea descriptiva de perspectiva patrimonialista que descuida la dimensión teórica de la historia, este enfoque documental se convertiría en simple instrumento de validación conservativa. Se configura entonces una lectura canónica y operativa del Eclecticismo que, sin analizar motivaciones ideológicas y culturales de los usos estilísticos, los concibe como momento de transición de un proceso que desembocaría en el "movimiento moderno" con una implícita desvalorización de la noción de estilo (Daguerre, 2004).

Hasta aquí, y pese a la importancia de la producción de Mario Palanti en el contexto patrimonial de Buenos Aires, su obra no encuentra lugar más que en breves menciones en la bibliografía general de referencia. Esta ausencia de tratamiento puede explicarse, en principio -y al igual que ocurrió con otros autores- por el rechazo de la historiografía moderna en la Argentina a toda forma de Eclecticismo decimonónico que se entendía como parte del "baile de máscaras" del 900; un producto importado proveniente de países emisores (cultura central) dejando a Buenos Aires como cultura periférica (Buschiazzo, 1966; Ortiz, 1968).

A las exuberantes líneas de la producción palantiana que durante años posicionaron al arquitecto "en la vereda de enfrente" de los relatos "modernos", debemos sumar su declarada filiación hacia el fascismo y la -hasta el momento- falta de documentos que, muy posiblemente, no hayan colaborado a posicionarlo como objeto de estudio.

Durante las últimas décadas del siglo XX esta situación comenzaría a revertirse en concordancia con una nueva mirada preservacionista. En este registro surgen los primeros intentos para la consideración historiográfica de la producción palantiana. Dicha mirada preservacionista en la que persiste el método descriptivo explica su inclusión en las secciones “Tapa Homenaje" y "Campaña para la Preservación del Patrimonio Arquitectónico" de la revista Summa (Cacciatore 1985, 1989) y el ya clásico trabajo de Hunter y Solsona sobre Avenida de Mayo (1990).

\section{La construcción del mito}

A partir de la década de 1990, una importancia singular han cobrado los eruditos ensayos de Carlos Hilger $(1993$, 1996) cuyas hipótesis sobre el Pasaje Barolo causaron gran repercusión en el público en general. Mediante un pormenorizado análisis numérico en relación a la Divina 
Comedia, Hilger presenta al edificio como un mausoleo destinado al Dante. De acuerdo al autor, Palanti y Barolo - miembros de una logia secreta- planeaban traer de Italia los restos del poeta para salvaguardarlos en Buenos Aires en caso de desatarse una segunda guerra (Hilger, 1993).

En el mismo registro, el friso que acompaña las columnas y capiteles del Palacio Salvo es leído por Hilger y Sanchez (2008) como un "microcosmos" repleto de figuras míticas y fabulosas que, en consonancia con el Barolo, constituye un "macrocosmos". A partir de estos textos, principalmente el ensayo de 1993, el enfoque sobre la producción palantiana se vio dirigido de manera casi exclusiva al tema del danteum, pierde de vista fuentes documentales y deja de lado cuestiones relacionadas al contexto, a innovaciones técnicas o, inclusive, lingüísticas que la obra proponía. Estos trabajos fueron reunidos, junto a otros estudios, en un número especial publicado por Summa en el 2004.

A partir de estos ensayos surgen numerosos textos que toman estudios previos sobre la obra de Palanti centrados en el Pasaje Barolo y el Palacio Salvo que, sin ser analizados como rascacielos, identifican al arquitecto con estas dos únicas obras y no con su variada producción. ${ }^{10}$

Durante la década de 1990, encontramos varios trabajos realizados en el Uruguay en los que el Palacio Salvo es abordado de manera tangencial a pesar de la carga simbólica que este edificio representa para la comunidad montevideana - Arana y Garabelli (1995) Antola y Ponte $(1997,2000)$ Lousteau (1998) - o incluyen al edificio dentro de un estudio de mayores dimensiones. Particularmente, podríamos destacar el texto de Pedro Gatti (1995) quien en un breve artículo presenta un cruce de líneas que permite vincular a la arquitectura con los ciclos económicos. En los últimos años se sumaron textos como la compilación sobre arquitectos italianos realizada por el CEDODAL (2004) y el trabajo de Iglesia y Sabugo sobre el edificio Barolo (2006).

$\overline{10}$ Entre los trabajos encontramos el de Juan Vattuone (s/f), un epígrafe hace referencia al nombre "Pasaje Quintana". Guillermo Tella (1995), Leonel Contreras (2005). Un trabajo reciente es el realizado por R. Iglesia y M. Sabugo (2006). Los autores hacen referencia al Barolo como "ese intento de rascacielos latino del Palanti", p. 357. Fabio Grementieri (2005), Rolando Schere (2008). Sobre el Palacio Salvo existen varias novelas: Juan Carlos Reynés (2003), Velarde González Irigoin (2006). 


\section{Nuevas miradas}

En los últimos años el interés de los historiadores por estudiar las primeras décadas del siglo XX se ha visto renovado y una nueva historia de la arquitectura ha empezado a escribirse. A partir de la década de 1970, se asistió a una renovación del corpus teórico que permitió complejizar la mirada y abordar el objeto desde diferentes perspectivas. Desde el Instituto Universitario de Arquitectura de Venecia (IUAV) autores como Massimo Cacciari, Manfredo Tafuri, Francesco Dal Co y Georges Teyssot provocaron un giro en el ámbito de la historia, teoría y crítica de la arquitectura que derrumbó toda certeza y mitos establecidos. En sus textos, el debate en torno al Eclecticismo es planteado como una respuesta que permitía la supervivencia de la disciplina como tal ante la crisis decimonónica (Morachiello y Teyssot, 1980).

La perspectiva que arrojan estos trabajos se entronca con la propuesta metodológica de Jorge F. Liernur quien, al retornar a Buenos Aires en la década de 1980 y tras haber trabajado junto a Tafuri, introdujo, junto con otros colegas, la mirada del IUAV en el grupo de trabajo que funcionó en la Escuelita. ${ }^{11}$ Desde entonces, se incorporó una corriente de investigación que aportó una visión renovadora que permitió complejizar y profundizar la mirada sobre los estudios en historia de la arquitectura. ${ }^{12}$ Esta línea que se encuentra en los trabajos de J. Liernur $(1980,2001)$ y M. Daguerre (1995) plantean la revisión en general del Eclecticismo, etiqueta bajo la cual, como vimos, se englobaba la totalidad de la producción arquitectónica de principios de siglo XX en Buenos Aires. ${ }^{13}$

Dichos estudios mostraron la complejidad del fenómeno y su particular enraizamiento con la situación de transformación que vive la sociedad argentina. Por otra parte, sirvieron de marco inicial en el cual pueden situarse estudios más específicos sobre el tema, como el de Daguerre (1998) acerca de las relaciones entre profesionales y comitentes en el área lombarda, cuyo objetivo central fue señalar la complejidad dialéctica de ida y vuelta que pone en cuestión las ideas tradicionales acerca de la relación entre centro y periferia. El Eclecticismo, sostiene Daguerre, fue adoptado como lenguaje durante el proceso modernizador dando forma al Estado moderno. Dentro del panorama ecléctico argentino es posible, según la autora, establecer las

11 Fundada por los arquitectos Tony Díaz, Ernesto Katzenstein, Rafael Viñoly y Justo Solsona, la Escuelita funcionó entre 1976 y 1983 como espacio alternativo de discusión y enseñanza de la arquitectura

12 Véase voz "Enseñanza de arquitectura" en Diccionario de Arquitectura, Buenos Aires, Clarín, 2004.

13 Otros aportes realizados fueron los realizados en la década de 1980 por R. Fernández (1986) y J. Goldemberg (1985). 
principales tendencias que se asocian a "los modelos culturales a los que hacen referencia". En este registro, en su texto de 2001 y en sintonía con el planteo de Marshall Berman, Liernur estudia el modernismo en Argentina como algo plural y conflictivo, con multiplicidad de líneas que surgen como forma de representar la modernidad y los procesos de modernización. Entre ellas, el "Arte Nuevo" y el art decó en la Argentina son entendidos por el autor como una expresión de sectores emergentes en un intento de renovación generado por un léxico acorde a la nueva realidad metropolitana (Liernur, 2001). Una mirada que toma como hilo conductor el pasaje del mundo urbano al metropolitano y da cuenta, en ese relato, de otras líneas habitualmente no identificadas como "modernas", al considerarlas como manifestaciones de problemas propios de la modernidad (Liernur, 2001:17).

En el contexto internacional tiene singular relevancia el estudio de O. Iolita (1995) quien, en base a un relevamiento de fuentes italianas y uno local realizado por Fernando Aliata, construye una periodización que permite comprender las complejas vicisitudes que rodearon la amplia y contrastante producción del arquitecto durante el período italiano de entreguerras. Iolita considera el debate teórico y político en la Italia de la época para explicar cómo, favorecidas por la particular coyuntura rioplatense, las obras de Palanti encontraron su razón de ser sólo en ese lugar y en ese momento. En esta línea de investigación se enmarca el trabajo de Fernando Aliata quien en 1997 publicó un artículo sobre Palanti que se volvería -hasta hoy- la columna vertebral de textos posteriores.

Justamente, el artículo de Aliata conforma el primer trabajo que realiza una construcción biográfica del arquitecto y una catalogación de sus obras teniendo en cuenta el marco políticocultural del momento. El autor señala la obra del arquitecto como respuesta a la demanda de representación e identidad de grupos de inmigrantes italianos que se expresaron mediante el stile liberty o floreale del norte de Italia. Esto permitió revelar, en el extraño baile de estilos en que se había convertido Buenos Aires, por un lado la singularidad moderna de sus emprendimientos y, por otro, mostrarse a la vanguardia en el contexto de sus respectivos círculos nacionales o regionales de emigrados.

Por último, en el marco de la Universita degli Studi di Palermo, Mercedes Bares escribió sobre el Pasaje Barolo para las revistas especializadas Il tesoro delle cittá e Il disegno di architettura. En sus artículos la autora muestra particular interés en el valor de la representación gráfica en la obra plantiana. Además de entender al Pasaje Barolo como emblema de una utopía visionaria, 
Bares indaga en la formación italiana de Palanti e incorpora útiles datos biográficos que sirven para comprender su arquitectura. Ciertos datos sobre la vida de Palanti se encuentran también en nuevas producciones como la Stefania Tuzi (2014) o Sara Cohen. Esta contribución dada por los trabajos italianos se ha enriquecido en los últimos años con interesantes aportes provenientes de los Estados Unidos que centran el interés en los proyectos de Palanti para la Italia fascista. Si bien las obras de este período han sido estudiadas (Nicoloso, Gentile, Quintana de Uña) el enfoque ha sido siempre periférico como parte de grandes relatos sobre el régimen. Es por ello que cobra singular relevancia el trabajo de John Beldon Scott (2011) sobre el Palazzo Littorio y, particularmente, el pormenorizado estudio de Dietrich Neumann (Spring 2014) sobre la Mole Littoria. Mediante un exhaustivo análisis de fuentes primarias, Neumann sitúa al proyecto en el foco del debate que se da a principios de siglo XX en torno a la construcción en altura. En efecto, a excepción de este trabajo, la postura teórica de Palanti y el debate en torno al tema del rascacielos ha sido prácticamente ignorados por la historiografía, salvo el breve lugar que Liernur le confiere en su texto "Rascacielos de Buenos Aires" (1980) donde señala el rol económico inherente a esta tipología arquitectónica y en el marco de la cual el Barolo es un ejemplo primigenio.

\section{La divulgación masiva y el interés en el tema}

Por otra parte, existe desde la divulgación masiva un sinnúmero de aportes, algunos sumamente valiosos como el blog http://mariopalanti.blogspot.com.ar/ realizado por el periodista y fotógrafo Alejandro Machado, los textos Divino Salvo y Divino Barolo (Dulitsky y Ulanovsky, 2013 y 2014) o la muestra sobre los Palanti que el CEDODAL realizará en 2015. A ello se suma una importante cantidad de relatos informales, pequeñas narraciones que sin el más mínimo cuidado por cotejar sus conclusiones, abonan fantásticas apreciaciones acerca de la raíz esotérica de la obra de Palanti. Un reciente film documental, "El rascacielos latino", de Sebastián Schindel sin detenerse en corroborar fuentes o el curriculum de sus informantes, abona a la construcción de la leyenda urbana del fallido proyecto de la tumba de Dante.

A partir de los textos señalados puede observarse que el estudio de la obra de Palanti realizado hasta el momento puede dividirse en, primero, los textos primigenios que, 
menospreciando esta producción arquitectónica, la ubican dentro de relatos de mayores dimensiones. La mirada que arrojan gran parte de estos trabajos pasa por alto cuestiones relacionadas a la enseñanza académica, principalmente la línea artesanal y formalista de la Ecole des Beaux-Arts parisina; segundo, aquellos textos que toman la obra del arquitecto a partir de la reelaboración de estudios previos, sin verificar fuentes documentales. Principalmente centrados en el Pasaje Barolo y el Palacio Salvo. ${ }^{14}$ Tercero, los estudios de carácter esotérico derivados del texto de Carlos Hilger (1993) basados en la carga simbólica atribuida al Pasaje Barolo y enfocados en la construcción de una figura ficticia del arquitecto que, alejados de la erudición del texto de Hilger, no reparan en la verificación de fuentes de referencia. Finalmente, los trabajos que, partiendo de una perspectiva más amplia, marcan un giro en el enfoque sobre la producción arquitectónica de principios de siglo XX en la Argentina. El saldo de este recorrido historiográfico por el tema indica que todavía quedan pendientes muchos aspectos para analizar sobre su obra. Con base en las limitaciones y ausencias de lo reseñado hasta aquí, el presente estudio pretende centrarse en el cuestionamiento si puede verse en la obra de Mario Palanti un intento de respuesta ante la crisis decimonónica y una propuesta alternativa a las líneas hegemónicas de la modernidad.

\section{Referentes teóricos y organización del texto}

La intención de la propuesta que sigue a continuación no es limitarse a realizar conjeturas sobre aspectos simbólicos sobre la producción arquitectónica de Palanti, sino ir más allá y proponer otro punto de vista desde el cual examinar las particularidades que se dieron en la obra de este arquitecto.

En base a lo dicho, como fue mencionado, se parte de una mirada amplia que, deudora

14 Entre los trabajos encontramos el de Juan Vattuone, El Barolo, Junta Central Histórica de la Ciudad de Bs. As., IHCBA Carpeta 1559, s/f. Un epígrafe hace referencia al nombre "Pasaje Quintana". Véase Guillermo Tella, "Palacio Barolo. Los rasgos de una arquitectura", en Vivienda 395 (Buenos Aires: junio, 1995). Leonel Contreras, Rascacielos porteños. Historia de la Edificación en altura en Buenos Aires (1580-2005) (Buenos Aires: Secretaría de cultura de la nación, Comisión para le preservación del patrimonio histórico cultural, 2005). Un trabajo reciente es el realizado por R. Iglesia y M. Sabugo, La ciudad y sus sitios (Buenos Aires: Nobuko, 2006). Los autores hacen referencia al Barolo como "ese intento de rascacielos latino del Palanti", p. 357. Fabio Grementieri. Buenos Aires Art Nouveau (Buenos Aires: Ediciones Verstraeten, 2005). Rolando Schere, Concursos 1825-2006 (Buenos Aires: SCA, 2008). Sobre el Palacio Salvo: Juan Carlos Reynés, Un dirigible sobre el palacio (Montevideo: Ediciones de la Plaza, 2003). Inclusive una novela remite al Palacio Salvo Velarde González Irigoin, La torre del espejo (Montevideo: Suma, 2006). El edificio ha captado la atención de diferentes medios de divulgación. A lo aquí mencionado se debe agregar los sitios digitales que, dada su cantidad, no enumeraremos. Estos, dirigidos mayormente al turismo, han divulgado la obra de Palanti vinculándola con lo esotérico. 
del análisis tafuriano (Tafuri 1981), ubica al objeto dentro un "nudo que no es exclusivamente arquitectónico" (Tafuri, 1983). En este sentido, trabajos como Fin-de-siecle Viena de Carl Schorske (1980) o La esfera y el laberinto de Manfredo Tafuri (1984), nos permiten comprender cómo una cantidad de variables externas al hecho mismo del proyecto determinan o modifican el carácter del "objeto proyectado". Esto permitirá aproximarse, no sólo a la problemática intrínseca de la obra de Palanti, sino también entender esta arquitectura como parte material del proceso modernizador que tuvo lugar desde fines del siglo XIX y a través de las primeras décadas del XX.

Esto nos conduce a entender la modernidad, modernización y modernismos según la relación planteada por Marshall Berman (1982) donde la ciudad, como gran capital decimonónica, es centro de modernización y escenario de múltiples transformaciones culturales y, por supuesto, los planteos Adrián Gorelik (2003), quien a partir de estas relaciones coloca la ciudad como foco del debate en América Latina. ${ }^{15}$ En efecto, basándose en la relación entre modernidad, modernización y modernismo planteada por Marshall Berman, Gorelik reconoce que una definición de la Modernidad: “(...) aparece como la dialéctica entre la modernización -los procesos duros de transformación, económicos, sociales, institucionales- y el modernismo -las visiones y valores por medio de los cuales la cultura intenta comprender y conducir esos procesos-(...)" mientras que la modernización representa "aquellos procesos duros que siguen transformado materialmente al mundo". (Gorelik, 2003: 14-15).

Como vimos más arriba, en esta línea se inscribe la mirada de Daguerre y Liernur, quienes se alejan de la mirada historiográfica que considera al Eclecticismo como un estilo decadente al explicar que, como parte de la multiplicidad de líneas que surgen para representar la modernidad y los procesos de modernización, la llamada arquitectura ecléctica fue adoptada como lenguaje durante el proceso modernizador y como una respuesta que dio forma a los nuevos programas planteados por los Estados modernos (Daguerre, 1996; Liernur 2001). ${ }^{16}$

15 En este marco, no podemos dejar de mencionar el concepto simmeliano de metrópolis nos permite entender la misma "(...) como el lugar en que se articulaban a la vez el más perfecto dispositivo material de producción, distribución, cambio y consumo de mercancías, y la más acabada metáfora de la economía capitalista." Discurso de Georg Simmel pronunciado en Dresden, 1903 (Simmel, 1998). Véase el trabajo de Liernur, "Acerca de la actualidad del concepto simmeliano de metrópoli” (2003) y David Frisby (2007).

16 En esta línea se inscriben nuevos trabajos que, desde la actualidad, discuten los debates novecentistas en sede académica: la noción de tipo y carácter como expresión exterior del destino del edificio que se da en la Ecole des BeauxArts de París (Vidler 1977; Shmidt 2012). Esta teoría se desarrolla en el seno de la École des Beaux Arts de París así como en los textos de Quatremere de Quincy quien señala que el carácter arquitectónico debía expresar el destino del edificio a través del arte y el rol del arquitecto era "lograr una relación armónica entre tipo y destino". (Shmidt 2012) p.156. Véase voces: Tipo y Carácter según Quatremere de Quincy ([1832], 2007). A lo mencionado se suman los 
Es desde este enfoque que nos interesa analizar la producción arquitectónica entendiendo que la importancia del Eclecticismo - como señala Jean-Pierre Épron - es dar la posibilidad de resolver problemas con un método "pragmático, concreto, eficaz y moderno", que se aleja del historicismo en la medida en que no busca emular un pasado sino justamente responder a problemas del presente (Epron 1997, 11-12). ${ }^{17}$

Precisamente, este tipo de debate es el que atraviesa la obra de Palanti. Un texto que resulta revelador para construir una nueva mirada sobre la producción palantiana es el libro Inscripciones (2003) de Ignasi de Solà-Morales. Como señala el autor, hacia mediados de siglo XIX la línea artesanal y formalista de la Ecole des Beaux-Arts parisina había incorporado cierto componente técnico, de modo tal que la formación del arquitecto no se basaba solamente en los “(...) problemas de aprendizaje del lenguaje clásico o ecléctico historicista y sus leyes de composición, sino que la racionalidad constructiva, el experimentalismo tecnológico, y las posibilidades ofrecidas por el conocimiento positivo de las ciencias naturales aplicadas a la arquitectura y a la construcción eran componentes fundamentales que orientaban la enseñanza.”(Solá-Morales, 2003:102).

A través de las problemáticas en torno a historia, crítica y teoría, el autor plantea como la llama Vidler- una "reinvención de la historia de la arquitectura". El ensayo "Gaudí, Berlage y Sullivan en la crisis de la edad clásica” (1987), incluido en este libro, parte del supuesto de que, “(...) precisamente es en el cambio del siglo XIX al XX y en la obra de arquitectos como los mencionados, en donde se detecta mejor lo que llamamos la crisis de la edad clásica." (Solà-Morales, 2003:100) Solà-Morales se aleja así de las definiciones estilísticas y plantea buscar rasgos de modernidad en personajes que han sido tradicionalmente analizados como parte de la tradición clásica. El énfasis de su trabajo está puesto en la incorporación de la técnica y los nuevos materiales junto con la reconsideración de las formas históricas y su libre reinterpretación. La preocupación de estos arquitectos por construir lo nuevo, por sortear el "callejón sin salida en que la cultura de fin de siglo se siente atrapada" los guió hacia una confrontación crítica con la historia codificada tal como la había establecido el historicismo decimonónico (Solà-

estudios de Arthur Drexler,xs David Van Zanten (1977) y Donald Egbert (1980) sobre el método de composición y enseñanza en la École des Beaux-Arts.

17 Recordemos la definición que toma César Daly proveniente de Eclecticismo en filosofía determinada por Víctor Cousin hacia 1830: un procedimiento compositivo y estructurado a partir de una selección de elementos adecuados. 
Morales, 2003:111).$^{18}$ Esta interpretación permite la elaboración de una nueva lectura de la obra palantiana.

El presente trabajo se divide en seis capítulos y un apéndice. El primer capítulo, “Milán 1900. Los años formativos", estudia el contexto de formación disciplinar del arquitecto en la Academia de Brera de Milán. Allí se hace hincapié en la influencia que éste recibe por parte de sus maestros y que fue decisiva, como vemos al final del capítulo, en la construcción de su pensamiento sobre arquitectura. El capítulo dos, "Buenos Aires 1910", estudia la transformación de la ciudad en metrópolis como lugar que posibilita la obra de Palanti y donde tiene lugar la experiencia moderna: allí circulaban imágenes de futuros posibles que abonaban la invención técnica entre las cuales se encontraba la tipología en altura. Como parte de la experiencia profesional en Buenos Aires se repara en el paso del arquitecto por el estudio de Prins y Ranzanhofer y en las tensiones con la SCA. Finalmente, el capitulo estudia las lógicas de encargo por parte de los comitentes y, a partir de éstos, el desarrollo de innovaciones dentro de su estudio particular.

El tercer y cuarto capítulo analizan los dos principales encargos de Palanti: el Pasaje Barolo en Buenos Aires y el Palacio Salvo en Montevideo en los que se parte de los sistemas constructivos y técnicas disponibles en el contexto rioplatense para luego centrarse en la tipología y la problemática del lenguaje arquitectónico en relación a la construcción en altura para verificar que estos casos despegan de modelos de rascacielos conocidos y realizan innovaciones a nivel tipológico, lingüístico y constructivo.

Los capítulos 5 y 6 están unidos por la búsqueda de Mario Palanti por vincularse a los círculos de poder a fin de promocionar su arquitectura. El capítulo cinco, estudia el regreso del arquitecto a la península y las estrategias -tanto políticas como arquitectónicas- que éste empleó para entrar en contacto con las altas esferas del fascismo, desde la participación en los concursos para el PNF a la publicación de libros publicitarios. Por último, el capítulo seis se centra en el

18 Recordemos los planteos de Reyner Banham (1960) sobre ciertos personajes y obras tratando de alinearlas con la modernidad o con la tradición clásica, según el grado de operatividad de su discurso y la crítica que sobre ello realiza luego Alan Colquhoun (Tornikiotis 1999). La idea de tomar técnica y materiales como "rasgos de modernidad" sería retomada por Kenneth Frampton (2001). Agradezco a Magalí Franchino estas observaciones. 
último período de Palanti en la Argentina. En este marco se analizan los proyectos llevados para el gobierno peronista, la relación del arquitecto con el ambiente disciplinar de ese entonces y la realización de sus últimos proyectos utópicos tras su regreso definitivo a Italia.

La tesis incluye, además, un apéndice documental compuesto por parte de la documentación epistolar relevada en archivos públicos y privados que hemos considerado de relevancia para esta tesis. 


\section{Capítulo I. Milán 1900. Los años formativos}

Può essere che dalla attuale anarchia sorga una vera arte, che è la libertá della fantasia, colla regola della ragione.

(Mario Palanti, Cinque anni di lavoro, 1924)

Mario Palanti nació en Milán el 20 de septiembre 1885, en el seno de una familia humilde y como el menor de dos hermanos. Su padre Giovanni, trabajaba como carpintero y su madre, Virginia De Gasperi, era costurera. Fue el hermano mayor, Giuseppe (1881-1946), quien marcó el camino académico del arquitecto. Con 15 años, mientras trabajaba como diseñador de telas para pagar los estudios, Giuseppe comenzó su formación en la escuela superior de arte del Castillo Sforzesco dedicada a la industria y en la Scuola degli arteficci de la Academia de Brera. Una vez formado como un artista de renombre, se dedicó a dictar clases de pintura en dicha academia. Consiguió formar una familia estable, contrajo matrimonio con Ada Romussi, hija de Carlo Romussi -un importante personaje del ambiente cultural milanés de fines de siglo XIX- y se hizo un lugar en la elite cultural milanesa de principios de siglo XX. ${ }^{1}$

En 1904, siguiendo los pasos de su hermano, Mario Palanti se inscribió en la Academia di Belle Arti di Brera para realizar allí estudios de pintura. Para ello fue beneficiado con la ayuda de la beca Daniele Businello destinada a jóvenes ingeniosos y otorgada por la Cassa di Risparmio delle Provincie Lombarde ayuda sin la cual la experiencia en Brera probablemente se hubiera visto interrumpida. ${ }^{2}$

De acuerdo a la documentación estudiada por Giovanna D’Amia en los Registri d’iscriz̨ione, el joven estudiante realizó allí "el bienio del curso común y luego el trienio del curso especial de arquitectura consiguiendo el diploma de profesor de dibujo arquitectónico en 1909." " $\mathrm{La}$ información disponible sobre el período formativo de Palanti es ambigua y

1 Vittoria Crespi Morbio (a cura di), Giuseppe Palanti: pintura, teatro, publicita, disegno. (Torino: Umberto Alemandi \& C., 2001). Asimismo, Rosana Bosaglia Giuseppe Palanti saggio critico, (La Rete, 1972).

2 El trabajo de archivo fue realizado por Sara Coen y puede verse en su texto "Mario Palanti, architetto e artista multiforme Le sue tracce nell'Archivio storico del Gruppo Intesa Sanpaolo” en Archivio Storico news 15 (Milano, nov. 2012):4

3 Giovanna D'Amia, “Architetti lombardi a Buenos Aires: percorsi formativi e prime occasioni profesionali”, en Contributi italiani all'architettura argentina. Progetti e opere tra il XIX e il XX secolo, (a cura di) Tuzi, Sabugo. (Roma: DEI 


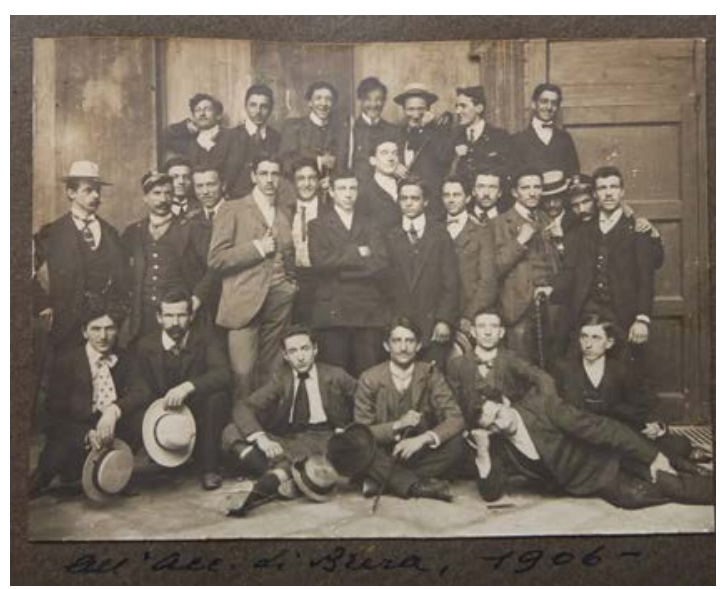

Al' Accademia di Brera. 1906. AGEP

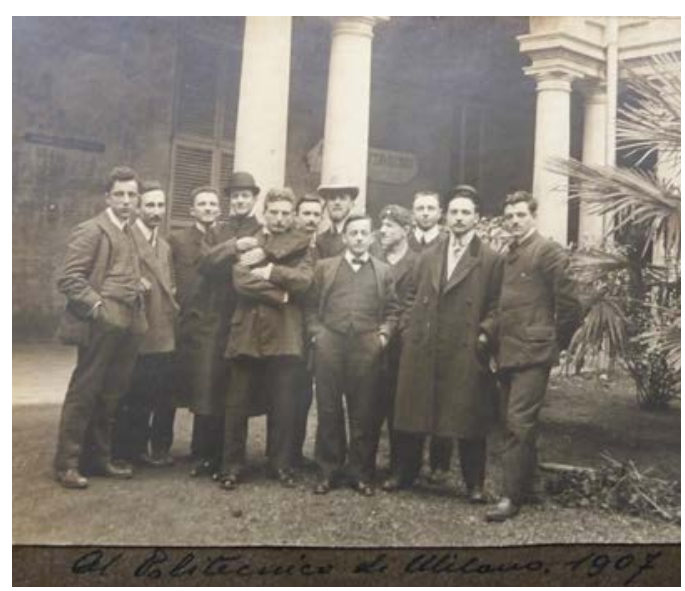

Al Politecnico di Milano. 1907. Archivo Guido y Emilio Palanti (AGEP)

proviene, principalmente, de la introducción a su primer libro escrita por Giulio Carotti quien fue profesor del curso de Historia de la Arquitectura de la Accademia di Belle Arti di Brera a partir de 1903. De acuerdo a Carotti, como alumno, Palanti se destacó en las artes plásticas, estudió con Giuseppe Mentessi, Ferrari y Gaetano Moretti para luego tomar cursos en la escuela especial dirigida por Camillo Boito, cuyas particulares doctrinas serían de gran importancia para el arquitecto en un contexto académico formado de vivos contrastes y debates. ${ }^{4}$ Sin embargo, como señala D’Amia, se debe tener cautela con la información que figura en estos documentos y en algunas notas biográficas ya que, por ejemplo, al contrario de lo que figura en el texto de Carotti, el paso de Palanti por el Politécnico "no está presente en los Registri allievi del Instituto milanés y si allí consigue el diploma." ${ }^{5}$

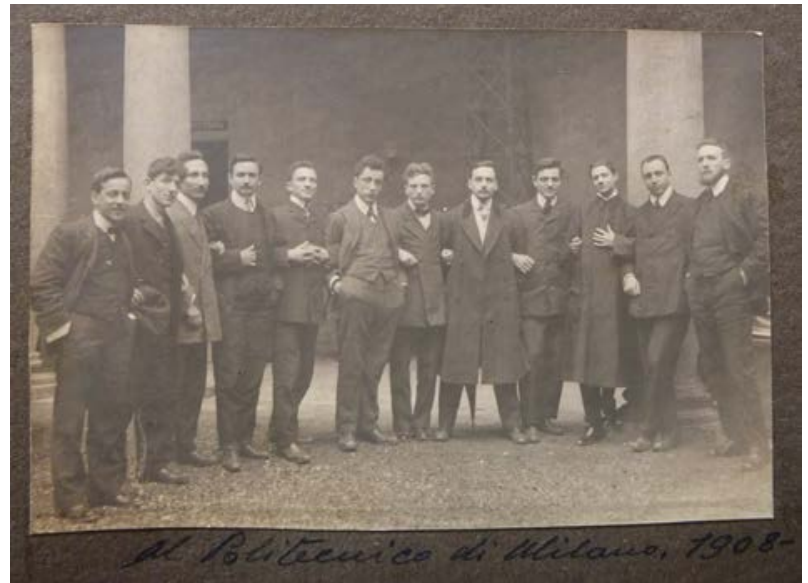

Al Politecnico di Milano.1908. AGEP

Tipografia del genio civile. 2013), 75.

4 Giulio Carotti, Prefazione. Prima esposizione personale d'architettura nella Repubblica Argentina. (Milano: Stab. di arti grafiche Rizzoli e Pizzio, 1917).

5 D’Amia, "Architetti lombardi a Buenos Aires", 76. 


\section{Una arquitectura para la Italia unida}

La formación de Mario Palanti coincide con un momento de cambio en el panorama arquitectónico peninsular. La unidad italiana supuso para la disciplina la necesidad de consolidar una identidad nacional. El consiguiente debate acerca de cuáles debían ser las fuentes de esa identidad fue motivo central en la construcción del campo arquitectónico. Dos tendencias impregnaron las discusiones de la última etapa del siglo XIX: ${ }^{6}$ Por un lado, estaban quienes abogaban por volver a las comunes raíces clásicas con la idea de generar una síntesis que permitiese fundar un estilo nacional unitario; por el otro, encontramos a quienes realizaban la defensa de las identidades locales y las alternativas por fuera del clasicismo en el clima romántico del Risorgimento. En efecto, A partir de la Restauración, los temas y la decoración de la arquitectura medieval comenzaron a penetrar de modo sistemático en Italia. La búsqueda de identidad nacional en el Estado preunitario había elevado el interés en la herencia material del Medioevo en la que la identificación de los monumentos del pasado como el patrimonio de una nación iba acompañada por una actividad intensa de estudio y restauro.?

En esta línea, -que más allá de esta impronta inicial admitía múltiples variantes - Camillo Boito fue sin duda una de las figuras más importantes dentro del ambiente milanés y fue la principal influencia disciplinar para Palanti. Boito se formó en Venecia como discípulo de Piero Selvatico, quien incentivaba a sus alumnos a ejercitarse en los "estilos nacionales del Medioevo" italiano al cual veía como portador de una verdad en relación a las costumbres y civilidad de un pueblo. El desempeño de Boito como profesor, arquitecto, crítico y escritor lo convertiría en un representante del espíritu de una época en la cual el arte, en todas sus expresiones, adquirió el rol de guía e inspiración para la sociedad. ${ }^{8}$ Como señala Robuschi, el ambiente de formación de Boito estaba influenciado por connotaciones sentimentales y morales en el marco de las

6 Véase Alberto Mario Banti, Il Risorgimento italiano (Roma-Bari: Laterza, 2004); Giuliana Ricci, Giovanna D’Amia (eds.), La cultura architettonica nell'età della restauraz̧ione (Milano: Mimesis edizioni, 2002); Maurizio Grandi (a cura di), Architettura a Milano negli anni dell'unità. La trasformazione della città il restauro dei monumenti (Milano: Libraccio Editore, 2012).

7 Ellena Dellapiana, "Il mito del medioevo", en Storia dell' Architettura italiana, l'ottocento, (a cura di) Amerigo Restucci, vol. II (Milano: Electa, 2005), 402-409.

8 Luigi Robuschi, Alla ricerca di un'identità nazionale. La teorizzazione architettonica di Camillo Boito nella Milano post unitaria.https://www.academia.edu/5597542/Alla_ricerca_di_unidentit\%C3\%A0_nazionale._La_teorizzazione_ architettonica_di_Camillo_Boito_nella_Milano_post_unitaria (consultado: 15 de abril de 2015) 
cuales la investigación histórica era utilizada para confirmar ideas estetizantes y como refugio para racionalizar los repentinos y radicales cambios políticos y económicos de la sociedad del

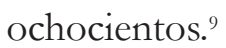

Durante casi medio siglo Boito, como docente y teórico, ejerció una enorme influencia tanto en la Academia di Belle Arti di Brera (1860-1908) como en el Politécnico de Milán (18651908). No sólo creó arquitectura en sentido literal sino que también operó como literato y crítico artístico-histórico, para finalmente lograr la formulación de un verdadero sistema cultural y político, ideal y estético, funcional a la joven Italia. ${ }^{10}$ En este contexto, Boito se presenta como un ejemplo de continuo intercambio entre restauro, estudio arqueológico, sistematización teórica y búsqueda proyectual de una nueva arquitectura italiana. Su mirada iba dirigida a la arquitectura religiosa lombarda como el repertorio ideal de referencia para los arquitectos de la modernidad al momento de reelaborar un lenguaje original como esencia de la lengua italiana. ${ }^{11}$ En sus edificios utilitarios, el maestro aplica una libre interpretación del Medioevo civil lombardo en la
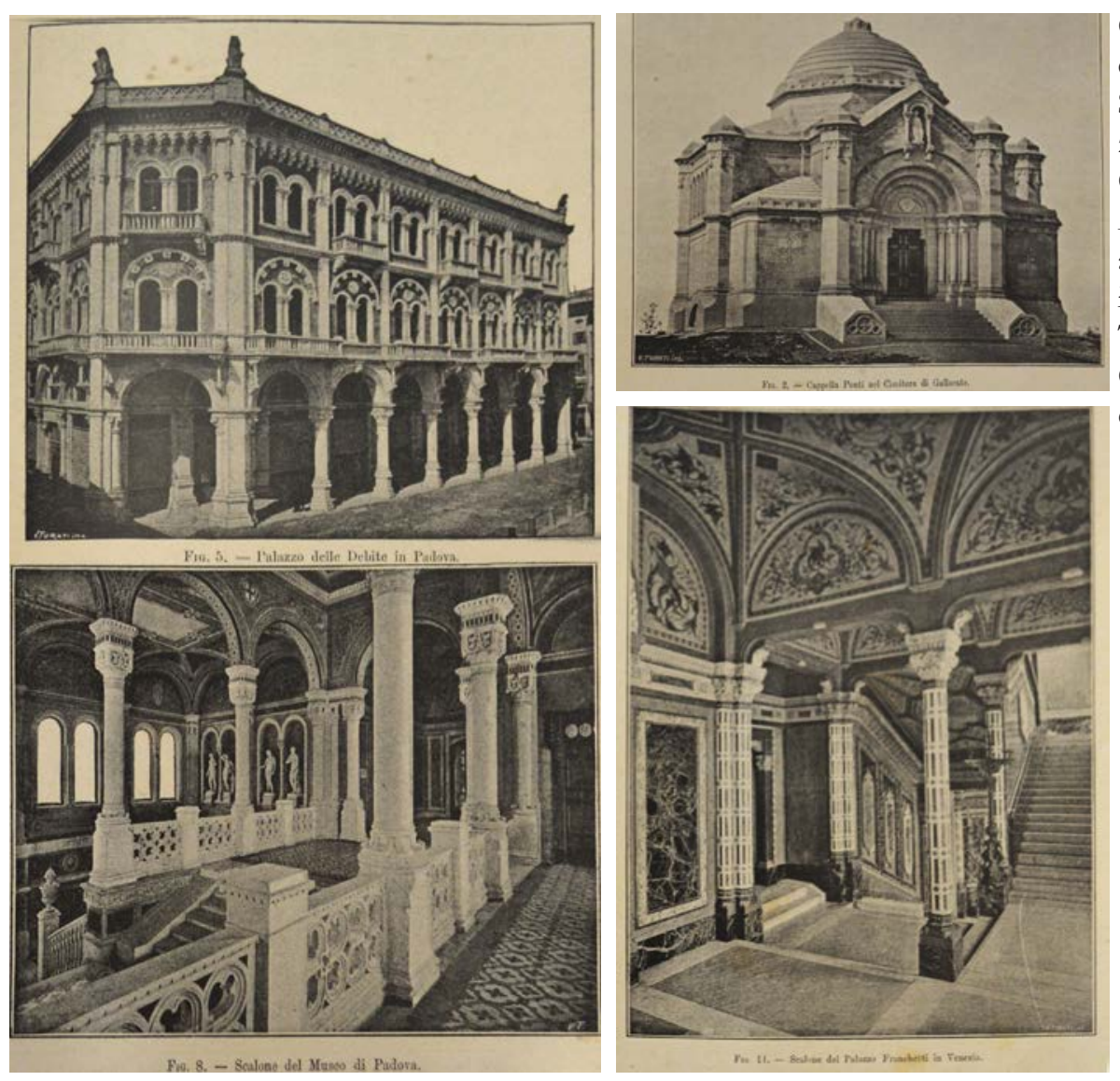

Camillo Boito, Palazzo delle Debite, Padova, Scuole Elementari, Palazzo Franchetti, Venezia, Cimitero di Gallarate. L'Architettura Moderna alla prima esposizione italiana di architettura, Torino 1890. Torino, Camilla e Bertolero

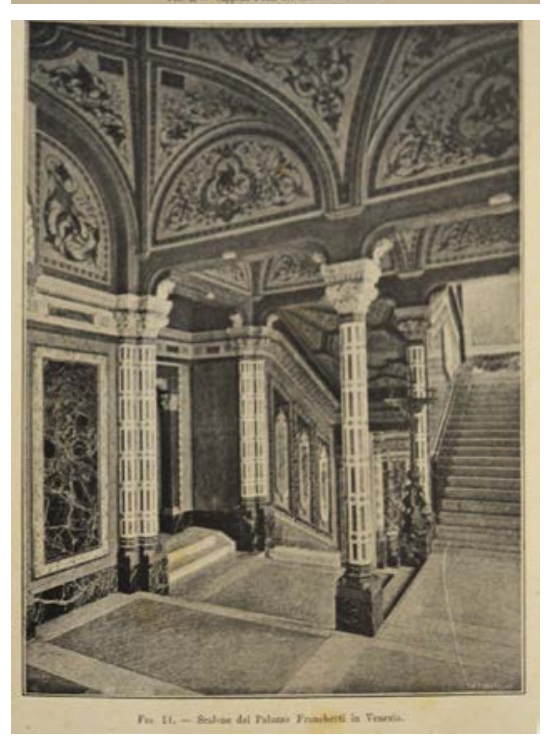
ed.1892.

9 Luigi Robuschi, Alla ricerca di un'identità nazionale.

10 Ellena Dellapiana, "Camillo Boito (1836-1914)", en Storia dell' Architettura italiana, l'ottocento, (a cura di) Amerigo Restucci, vol. II (Milano: Electa, 2005), 622.

11 Dellapiana, "Il mito del medioevo", 409. 
que combina el lenguaje neomedieval con la honestidad estructural y compositiva proveniente de la cultura positivista. ${ }^{12}$ Su manera de operar aún resulta extraña a la poética del romanticismo de la primera mitad del XIX. En ella se ven cuestiones que fueron pilares fundamentales en la obra palantiana como el cruce de elementos históricos destinado a producir un presente de invención lleno de expresión y fantasía pero en relación con los aspectos constructivos y tectónicos. ${ }^{13}$

En efecto, la reconstrucción y la reelaboración de diversos Medioevos se tornaron un instrumento y un concepto de modernidad que, para quienes defendían esta búsqueda, solucionaba el problema de identidad nacional, cultural y social al tiempo que aportaba un empuje a la producción industrial en sí misma y aplicada al proceso edilicio. En este contexto, Boito publicó, en 1880 Architettura del Medioevo in Italia, incluyendo el texto "Introduzione sullo stile futuro dell'Architettura" en el cual declaraba: "Ricercare le condizioni fondamentali di uno stile architettonico il quale, giovandosi dei progresi della scienza e dei nuovi materiali di costruzione, serva ai bisogni, agli usi, ai costumi odierni delle varie province italiane, e ne rappresenti i caratteri naturali e storici." ${ }^{14}$, dando cuenta de la situación italiana como policentrismo comunal. El estilo nacional ${ }^{15}$ debía entonces ser lo suficientemente "elástico" como para poder absorber los innumerables "municipalismos" de modo que fuera capaz de sintetizar lo regional y nacional. ${ }^{16}$ En correspondencia con esta postura, Boito toma los ejemplos de un Medioevo largo que absorbe diversos estilos en el marco del cual estudia la obra de arquitectura a partir de su estructura, decoración, organismo y simbolismo, ofreciendo múltiples variantes a la libre interpretación de la cual -sostiene- surgiría la nueva arquitectura italiana. ${ }^{17}$

La postura de Boito no es aislada: el debate sobre el estilo nacional y la búsqueda de

12 Ellena Dellapiana, "Camillo Boito (1836-1914)", 624. Véase Guido Zucconi, L'invenzione del passato: Camillo Boito e liarchitettura neomedievale, 1855-1890 (Venezia: Marsilio, 1997).

13 Dellapiana, "Il mito del medioevo", 410.

14 Originalmente el artículo fue publicado en 1872 bajo el título "L' Architettura della nuova Italia", Nuova Antologia, XIX (2 aprile 1872): 755-773 y luego presentado como introducción de Architettura del Medio Evo in Italia (Milano: Hoepli, 1880), V-XLVI. Citado por Ornella Selvafolta en "Milano e la Lombardia", en Storia dell' Architettura italiana, l'ottocento, (a cura di) Amerigo Restucci, vol. I (Milano: Electa, 2005), 98.

15 Sobre el debate en torno a la búsqueda de estilos nacionales véase el texto de barry Bergdoll "Nationalism and Stylistic Debates in Architecture en European architecture 1750-1890. (Oxford: Oxford University Press, 2000), 139-172.

16 Luigi Robuschi, Alla ricerca di un'identità naz̧ionale.

17 Dellapiana, "Il mito del medioevo", 412. 
una nueva arquitectura era un tema común a fines de siglo XIX, dentro y fuera de Italia, en relación, al menos, a la enseñanza del arte y la arquitectura. Como señala Dellapiana, el Medioevo reinterpretado, reconstruido, reinventado se difundió en toda Italia postunitaria reforzando las diferentes identidades locales y se volvió un símbolo de riqueza, variedad y opulencia burguesa frente al nuevo siglo. ${ }^{18}$ Sin embargo, el medievalismo no era unánime sino que encontraba una fuerte oposición frente a la tradición clásica y neorrenacimiento desarrollado exitosamente a mediados de siglo.

\section{El Medioevo moderno}

Como fue señalado, Boito en su prédica asignaba al pasado un rol indispensable para operar en el presente: la historia se tornaba un elemento operativo con un rol fundamental como formadora de una cultura erudita y ecléctica que debía servir para estimular la imaginación y la creatividad. ${ }^{19}$ Sus cursos abordaban en primer término la arquitectura antigua, luego la del Renacimiento para finalizar más detenidamente con los estilos medievales, con la idea de utilizar la lógica intrínseca de sus diferentes modalidades estilísticas más que la forma exterior resultante; su esperanza era poder evitar así el surgimiento de un decorativismo superficial. Al igual que Viollet-le-Duc, Boito consideraba a los estilos medievales tales como el Bizantino, el Románico lombardo, el toscano o el gótico como portadores de la génesis de una modernidad que podía conciliar la libertad de invención con la sinceridad constructiva.

En 1862, Viollet-le-Duc fue convocado como jurado para el segundo concurso para la fachada de Santa Maria del Fiore en Florencia en el que resultó vencedor Emilio De Fabris con una propuesta de fachada tripartida que fue duramente criticada por Boito y defendida por Piero Selvatico, su maestro. La postura de Boito fue sostenida por Viollet-le-Duc, quien señaló los límites del sistema tripartito. ${ }^{20}$ Sin embargo, esto no salvó al francés de recibir duras críticas por

18 Dellapiana, "Il mito del medioevo", 414.

19 Ornella Selvafolta, "Milano e la Lombardia", Camillo Boito, I principii del disegno e gli stili dell'ornamento (Milano: Ulrico Hoelpi editore, 1887), 140.

20 María Antonieta Cripa, "Presentazione alla nuova edizione" de E. E. Viollet-le-Duc, en L'architettura ragionata (Milano: Editoriale Jaca Book, 2002). Véase Emilio De Fabris, Del Sistema Tricuspidale per il coronamento della facciata di Santa Maria del Fiore. Seguito alle considerazione pubblicate nel 1864 (Firenze: 
parte de Boito en lo referente al restauro. En efecto, el italiano señalaba la necesidad de realizar la tarea de manera científica.

\begin{abstract}
Quando i restauri sono condotti con la teoría del signor Viollet-le-Duc, la quale si può dire la teoria romantica del restauro, e fino a ier l'altro era universale, e tuttavia è seguita da molti, anzi dai più anche in Italia, io preferisco i restauri mal fatti ai restauri fatti bene. Mentre quelli, in grazia della benefica ignoranza, mi lasciano chiaramente distinguere la parte antica dalla parte moderna (.... ${ }^{21}$
\end{abstract}

Si bien Boito disentía con Viollet-le-Duc en la manera de abordar el restauro de monumentos, concordaba con el francés - a quien en su texto Questionipratiche di Belle Arti de 1893 llamó "gran sacerdote dell'arte ogivale" ${ }^{22}$ sobre las fuentes del pasado que posibilitarían el surgimiento de una nueva arquitectura. Como señalamos, en sintonía con los postulados violletianos, el repertorio de estilemas propuesto por Boito se limitaba al período pre-renacentista, pues el ciclo dominado por el humanismo era, según este razonamiento, el momento en el cual comenzaba la reinterpretación estilística que alejaba a la arquitectura de las "verdades" primigenias. ${ }^{23}$ Hacia 1887, en su texto I principii del disegno e gli stili dell'ornamento Boito señalaba:

\author{
Studiare gli stili ornamentali più notevoli del passato, cercando di scoprire nettamente \\ la ragione e l'indole loro; aplicarli poi alle opere d'oggi in modo che non disturbino in \\ nulla, anzi esprimano al di fuori gentilmente ed efficacemente l'uso pratico od ideale \\ a cui tale opere vengono destinate..$^{24}$
}

\footnotetext{
Tipografia di Barbera, 1864); Voti e pareri diversi sulla facciata del duomo di Firenze pubblicati per cura della deputazione promotrice (Firenze, M. Celini:1865)

21 Camillo Boito, Questioni pratiche di Belle Arti. Restauri, concorsi, legislazione, professione, insegnamento (Milano: Ulrico Hoepli editore, 1893), 4. Cuando las restauraciones son conducidas en base a la teoría del señor Viollet-le-Duc, la cual puede llamarse teoría romántica de la restauración, y hasta el día de ayer era universal, y sin embargo es seguida por muchos, de hecho por la mayoría también en Italia, yo prefiero las restauraciones mal hechas a las restauraciones hechas correctamente. Mientras que aquellas, a favor de la beneficiosa ignorancia, me dejan claramente distinguir la parte antigua de la parte moderna. [Traducción Florencia Minatta]

22 Boito, Questioni pratiche di Belle Arti., 361.

23 Boito, Questioni pratiche di Belle Arti., 142.

24 Boito, I principii del disegno e gli stili dell'ornamento, 140. "Estudiar los estilos ornamentales más notables del pasado, buscando descubrir claramente la razón y la naturaleza de los mismos; aplicarlos luego a las obras de hoy de manera que no molesten en nada, sino que demuestren por fuera gentil y eficazmente el uso práctico e ideal para el cual dichas obras fueron destinadas.'” [Traducción Florencia Minatta]
} 
Centrado en el estudio de la arquitectura gótica, Viollet-le-Duc veía en la arquitectura clásica -más allá de la perfección y materiales- una total ausencia de ideas, mientras que la arquitectura gótica permitía la posibilidad de una codificación racional a partir del estudio de los principios estructurales: “(...) la construcción gótica -señalaba- no es como la antigua, de una pieza, absoluta en sus medios;
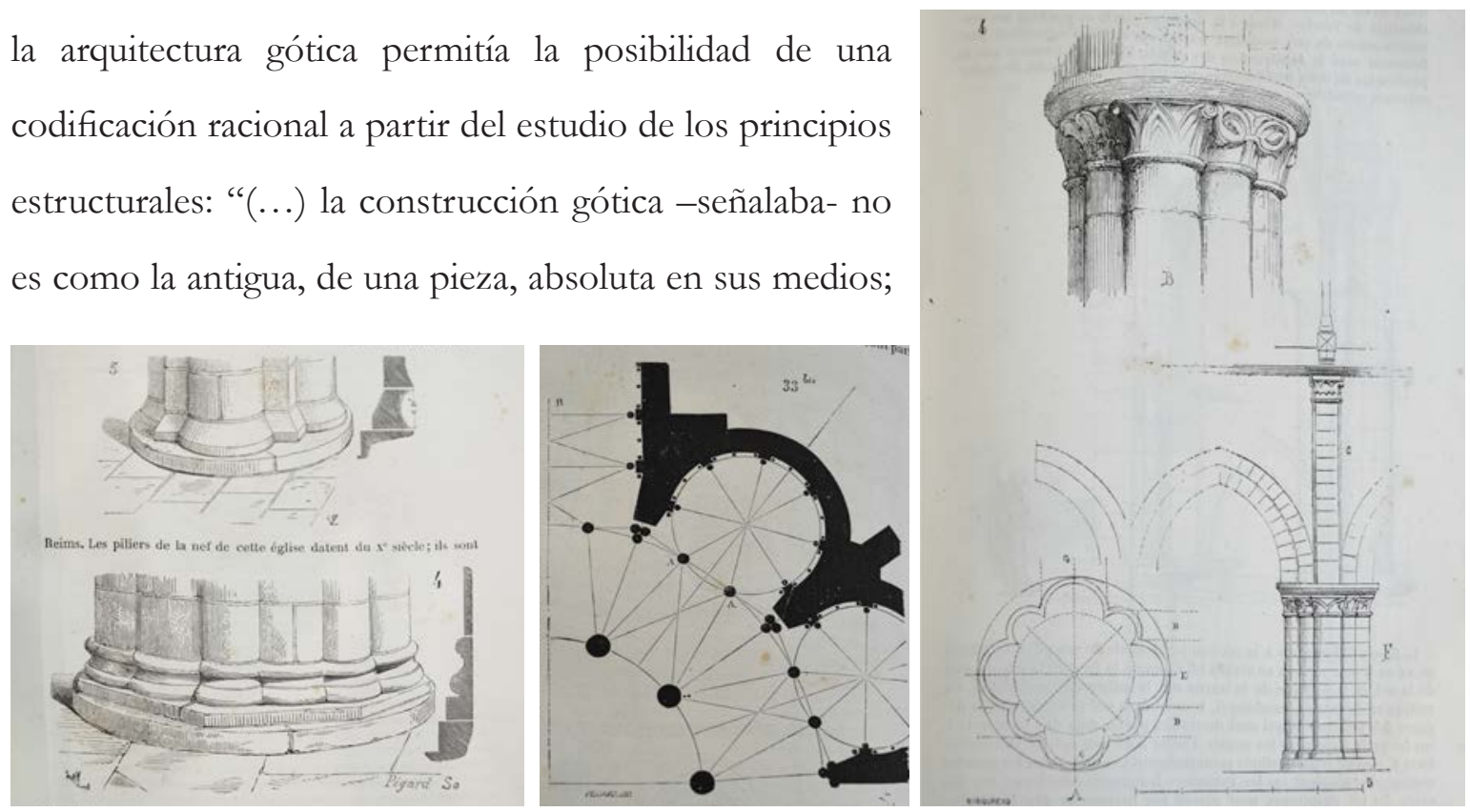

Viollet-le-Duc , Dictionnairse raisonne l'architecture francaise . Vol.II. 127, 157, 158

por el contrario, es ligera, libre e investigadora como el espíritu moderno." ${ }^{25}$ De a cuerdo a su pensamiento, a partir del estudio del pasado los arquitectos podrían construir un bagaje cultural que posibilitaría la comprensión racional de los elementos y brindaría la posibilidad de aplicar a cualquier obra un principio verdadero: es decir, estructural. Este análisis y comprensión racional de la arquitectura permitiría, además, un acercamiento a los problemas del presente. ${ }^{26}$ En sintonía con el debate decimonónico en sede francesa, frente a los historicismos y a la arquitectura producto de la Ecole des Beaux Arts, Viollet-le-Duc planteaba la necesidad de un estilo adecuado del siglo XIX:

\section{(...) ¿estará condenado el siglo XIX a llegar a su fin sin haber conseguido una arquitectura propia? ¿Esta época tan fértil en descubrimientos, que acusa tan vitales potencialidades, no transmitirá a la posteridad ms que pastiches y obras históricas sin carácter de imposible clasificación? ¿Esta situación es consecuencia inevitable de nuestra situación social? ${ }^{27}$}

25 Ignasi de Solà-Morales, "Viollet-le-Duc y la arquitectura moderna", en Inscripciones. (Barcelona: GG, 2003), 55.

26 de Solà-Morales, "Viollet-le-Duc y la arquitectura moderna", 53.

27 Eugène-Emmanuel Viollet-le-Duc, Entretiens sur L'Architecture, vol .I (Paris: A. Morel et Co., 1863), 450. Cit. en "Viollet-le-Duc y la arquitectura moderna",63. 
En este marco, su texto Entretiens sur l'architecture (1863-1872) Viollet-le-Duc presentó a la historia como una herramienta para entender, de manera racional, la forma. El sistema gótico analizado se resume en un mecanismo de esfuerzos que se organizan racionalmente y cuya forma final es el resultado del sistema estructural: esfuerzos pasivos y activos se ven reflejados en la separación de los elementos como columnas, arcos, arbotantes, etcétera. Frente a la arquitectura clásica que absorbe esfuerzos mediante un mecanismo de masas murarías inertes- ${ }^{28}$ el gótico, como gramática anticlásica y como resultado de experiencias estructurales, mostraba múltiples puntos de contacto con la construcción en hierro y presentaba la posibilidad de ser la inspiración para construir un estilo propio de la época que expresara los nuevos sistemas constructivos.

(...) la construcción gótica, a pesar de sus defectos, sus errores, sus investigaciones y tal vez a causa precisamente de todo esto, es un tema de estudio eminentemente útil; es la iniciación más segura para este arte moderno que no existe todavía, pero que busca su propio camino porque ella pone los verdaderos principios a los que todavía hoy debamos seguir sujetos, porque ha roto con las antiguas tradiciones; porque es fecunda en aplicaciones. ${ }^{29}$

En efecto, el análisis de las transformaciones constructivas y los nuevos materiales serían al clave para alcanzar una nueva arquitectura acorde a las técnicas y necesidades decimonónicas. Pero esta nueva tecnología requería necesariamente una nueva figuración, cuestión que se volvería uno de los principales problemas a enfrentar. La crítica violletiana hacia el estilismo ecléctico resultante de las academias denunciaba cierta incapacidad profesional de responder adecuadamente a las nuevas exigencias y a la nueva escala de los problemas de la época. Como luego lo hará Camillo Boito desde la Academia de Brera, Viollet-le-Duc reprochaba el modo de enseñanza académico que no contemplaba problemáticas afines a la labor del arquitecto y a las necesidades de la época, tales como la exigencia de conocimientos sobre las técnicas constructivas, los materiales y su uso o las necesidades del ámbito de la construcción. ${ }^{30}$ En

$\overline{28}$ de Solà-Morales, "Viollet-le-Duc y la arquitectura moderna", 55.

29 Eugène-Emmanuel Viollet-le-Duc, "Intervention de l'état dans l'enseignement des Beaux Arts", Gazette des Beaux Arts (1862): 72. Citado por de Solá-Morales en "Viollet-le-Duc y la arquitectura moderna", 57.

30 Véase el texto de John Summerson, "Viollet-le-Duc and the rational point of view", Architectural Design 3, No 4 (1980): 7-13. 
1863, como profesor de Historia del Arte y Estética en la reorganizada École des Beaux Arts de París, Viollet-le-Duc intentó, sin éxito, llevar a cabo una reforma en la enseñanza a partir de una reestructuración en la formación del arquitecto para ajustarla a las nuevas necesidades. Sin embargo, su innovadora propuesta no generó sino rechazo lo que determinó el abandono del cargo poco tiempo después.

Es que las premisas de la Ecole se basaban la enseñanza en un método de proyecto sustentado en la idea de composición que incorpora progresivamente un vocabulario (parti, point, marche, poche) y, al no tener otra finalidad más que la exploración proyectual, estaba escindido de las condiciones materiales de la obra. ${ }^{31}$ Los escritos de Viollet-le-Duc, por el contrario, presentan un razonamiento que parte de los problemas estructurales y constructivos como foco principal para el entendimiento de la arquitectura. Sin embargo, como señala Solá-Morales, esta mirada prevalentemente técnica, racionalista y con primacía en la construcción no ofrecía una solución al problema formal de la arquitectura y la pregunta sobre cómo deben ser figurativamente las obras de su tiempo carece de respuesta quedando abierta a la invención. En efecto, dado que la nueva arquitectura decimonónica propuesta a partir del planteo violletiano surge de condiciones estructurales y no de una serie de reglas preestablecidas, el código clásico se anula permitiendo la libre creación. Ante la imposibilidad de crear sin referencia alguna, la esencia estructural del gótico ofrecía la posibilidad de pensar formas nuevas partiendo de una base histórica. ${ }^{32} \mathrm{La}$ técnica se transforma entonces en una serie de principios que, sin conformar reglas específicas, permitía construir una nueva arquitectura a partir de la propia tectónica: sería este uno de los principios fundamentales que tomaría el movimiento moderno en las primeras décadas de silgo XX y que, tiempo después, le otorgaría a Viollet-le-Duc un lugar en los relatos de la historia del arquitectura moderna. Su influencia puede verse en la obra de arquitectos que actuaron a caballo de los dos siglos y que desarrollaron, además, una intensa búsqueda personal por fuera de los cánones académicos.33 Ejemplo de ello es la obra de Héctor Guimard (1867-1942), Victor Horta (1861-1947), Louis Sullivan (1856-1924), Anatole De Baudot (1834-1915), Auguste Perret (1874-1954) o Antoni Gaudí (1852-1926), como también Palanti entre otros.

31 Sobre la formación de la Ėcole des Beaux Arts véase: Arthur Drexler (ed.), The Architecture of the École des Beaux-Arts (New York: MoMA, 1977).

32 de Solà-Morales, "Viollet-le-Duc y la arquitectura moderna", 67-68.

33 Nos referimos al sistema definido de procedimientos para elaborar cualquier tipo de edificio que se desarrolla en Francia a lo largo del siglo XIX y que se expande en Europa y América, precisamente en las academias y escuelas de arquitectura. 146 
Los postulados de Viollet-le-Duc fueron, en gran medida, fuente de inspiración para Camillo Boito, principalmente en lo que respecta al rol del arquitecto y al conocimiento estructural de la obra de arquitectura. Hacia fines de siglo XIX, al igual que lo había hecho Viollet-le-Duc, Boito cuestionaba la ausencia de un estilo propio de la época: "(...) in questi ultimi anni, benché non ci si avvicini affatto a trovare una maniera d'ornato propria al secolo decimonono, nè paia che ci si inizii a rinvenire quella del secolo ventesimo." ${ }_{34}$

\section{La figura del arquitecto civil}

Con 24 años, en 1860 Boito tomó el puesto de Friederich Schmitd en la cátedra de Arquitectura Superior en la Accademia di Belle Arti di Brera donde permanecería por 48 años. Poco después, en 1865, el arquitecto se incorporó al Politécnico de Milán. La Academia ofrecía una curricula que se dividía en dos: un curso de arquitectura elemental de dos años de duración y luego uno superior que se extendía por tres años. ${ }^{35}$

En su rol de docente, Boito sostenía que debía surgir en el alumno una conciencia crítica desde un análisis realizado científicamente que actuase en contra de aquellas operaciones mecánicas promovidas por los manuales, sobre todo en relación al acto proyectual. ${ }^{36}$ Asimismo, le otorgaba al pasado un rol indispensable para operar en el presente. En este marco, la historia tenía una función cultural y operativa capaz de incrementar la erudición y el conocimiento y, a través de estos, la imaginación y creatividad. ${ }^{37}$ Como señala Selvafolta, esto se traducía en un método de enseñanza organizado en fases progresivas en las que el alumno afrontaba la comprensión del ornamento, el esqueleto y el carácter; primero de los estilos clásicos antiguos, luego del Renacimiento y finalmente de los estilos medievales.

34 Boito, I principii del disegno e gli stili dell'ornamento, 139. “(...) en estos últimos años, si bien no nos hemos acercado en absoluto a encontrar una manera de ornamento propia del siglo diecinueve, ni siquiera parece que estemos cerca de descubrir aquella del siglo veinte." [Traducción Florencia Minatta]

35 Giuliana Ricci, "L'Architettura all'Accademia di Belle Arti di Brera: insegnamento e dibattito", en L'Arcbitettura nelle Accademie riformate: insegnamento, dibattito culturale, interventi pubblici (Milano: Angelo Guerini, 1992), 267.

36 Ricci, "L'Architettura all'Accademia di Belle Arti di Brera", 280.

37 Selvafolta, "Milano e la Lombardia", 77. 
Efectivamente, el último año estaba dedicado al estudio de la arquitectura del Medioevo: bizantino, lombardo, ojival, románico, ojival nórdico, gótico italiano, entre otros. El salto cronológico que ubica el estudio del Medioevo al final de la carrera tenía que ver con su rol activo en el método de proyecto. De acuerdo a Boito -y en sintonía con las propuestas violletianas- en la arquitectura del Trecento lombardo se encontraba la cantera imprescindible que posibilitaría el nacimiento de una arquitectura italiana auténticamente moderna, que necesariamente debía abandonar el carácter arqueológico en pos de la invención..$^{38}$

Este sería uno de los planteos que instalaría Boito en el debate de la Academia de Brera y que en la década de 1920 Palanti retomaría en sus textos. ${ }^{39}$ En pleno clima positivista de mediados del ochocientos, el acento en la enseñanza fue puesto en el estudio científico del pasado y en temas sociales y técnicos que sugerían el enriquecimiento de la cultura arquitectónica a partir de algunos temas propios de la sociedad industrial..$^{40}$ De este modo, la presencia de Boito colaboró para que la Escuela de Arquitectura se abriera a la formación de arquitectos en el estudio específico de la materialidad y técnicas constructivas.

A partir de este momento, la escuela se dividió en dos secciones que contemplaban, por un lado pintores, escultores y artesanos que se formaban sin una preferencia estilística y, por el otro, arquitectos y maestros mayores de obra (capomastri) quienes se instruían considerando los elementos que componen los edificios, sus formas y proporciones. ${ }^{41}$

Boito era militante de la doble sede de enseñanza Beaux Arts-Instituto Técnico: "l?" edificio - señalaba- debe uscire armato di tutto punto del cervello del architetto: la fantasia debe bilanciare il giudizio; il bello debe andaré a braccetto con l' utile."'2

Como explica Chiara Occhipinti en su estudio sobre el rol del arquitecto civil en la región lombarda, en septiembre de 1865, el Regio Istituto Tecnico Superiore di Milano obtuvo el permiso para instituir el curso de arquitecto civil que se organizaba en conjunto con la Academia

$\overline{38}$ Dellapiana, "Camillo Boito (1836-1914)", 625.

39 Palanti lo cita a Boito en su texto: Cinque anni di lavoro (Milano: Casa Editrice d'arte Bestetti \& Tumminelli, 1925), 107.

40 Véase el texto ya citado de Ricci, "L'Architettura all'Accademia di Belle Arti di Brera"

41 Ricci, "L'Architettura all'Accademia di Belle Arti di Brera", 257-58. Sobre el tema y su relación con los emigrados a la Argentina véase el trabajo de Giovanna D'Amia, "Architetti lombardi a Buenos Aires",71-78.

42 Dellapiana, "Camillo Boito (1836-1914)", 625. 
de Brera. Mientras que esta última había sido fundada en 1776, el Instituto Técnico había sido creado en 1863 como resultado concreto de las modificaciones económicas, culturales y sociales del momento. Esto significaba la unión de objetivos entre las dos instituciones en la conformación de una sola escuela de grado que se encargaría de formar la figura del arquitecto civil, es decir, de una manera totalmente diferente a la que se aplicaba hasta entonces e intentaba, a su vez, superar la fragmentación en los métodos de enseñanza.

En este afán de lograr una formación que aunara ciencia y arte, el curso para la formación del arquitecto civil se dividía entre la Academia de Brera, donde se tomaban las clases para arquitecto y maestro mayor de obra, y el Instituto Técnico donde se tomaban los cursos destinados al ingeniero civil. El nuevo curso, explica Occhipinti, era la respuesta a las cambiantes condiciones socioeconómicas y políticas que se daban en el marco del proceso de unificación nacional, junto con la expansión demográfica e industrial que modificarían, en un corto plazo, la estructura de producción. ${ }^{43}$

Boito, que en el curso del arquitecto civil se encargaba de la historia de la arquitectura y de la composición arquitectónica, hizo uso de los recursos disponibles: no trazó los límites de una ciencia nueva, sino que se limitó a componer "en positivo" las aportaciones y recursos ya disponibles entre lo artístico y lo técnico. En este sentido, no fundó una facultad especializada entre Facultad y Academia sino que, sin reformular totalmente el programa de enseñanza, integró con realismo la Escuela de aplicación del nuevo Politécnico en un sistema que logró complementar en una síntesis ambos saberes, técnico y artístico. ${ }^{44} \mathrm{El}$ resultado del método de enseñanza fue la formación del ya mencionado arquitecto civil, una figura que conjugaba la construcción técnica con las bellas artes, la composición de las formas y la conciencia histórica.

Convencido del valor de la enseñanza, Boito realizó un tratado escrito de manera epistolar, entre maestro y discípulo, titulado I principii del disegno e gli stili dell'ornamento en el cual,

43 Chiara Occhipinti, "Milano nei progetti dei giovani architetti civili", en Architettura a Milano negli anni dell'unità. La trasformazione della città il restauro dei monumenti, (a cura di) Maurizio Grandi (Libraccio, 2012), 183-202. Véase de Ornella Selvafolta: "Gli studi di ingenieria civile e di architettura al Politecnico di Milano: territorio, costruzioni, architetture”, en L'Università e l'Unità d'Italia (1848-1870), (a cura di) Alessandra Ferraresi, Elisa Signori (Bologna: Clueb, 2012), 255-270; y “Una scuola per il progetto': la formazione di ingegneri e architetti al Politecnico di Milano tra Otto e Novecento", (Marzo, 5, 2013); "Una scuola per l' Italia unita: la formazione di ingegneri e architetti al Politecnico di Milano", en Scienza, tecnica e industria nei 150 anni di unità d'Itaia, (a cura di) C. G. Lacaita, P. P. Poggio (Jaca Book: Milano, 2011), 185-200.

44 Ricci, "L'Architettura all'Accademia di Belle Arti di Brera", 267. L. Barbiano di Belgiojoso, "Gli architetti civili tra cultura accademica e sapere politecnico", Museoscienza (3, 1982): 44. Citado por Chiara Occhipinti, "Milano nei progetti dei giovani architetti civil?’, 185. 
como maestro, le explica de manera simple al joven Giovanni qué condiciones debía seguir un estudiante para ser un arquitecto del futuro. En su método, Boito señalaba la importancia del ejercicio de la mente, del ojo y de la mano como vías para la representación racional de las formas. ${ }^{45}$

(...) non voglio che $i$ dettagli siano copiati. A questo si giunge con l'obbligare $i$ giovani a farsi in un albo moltissime memorie dei particolari di un dato stile; ma a farsele senza toccare mai col compasso l'originale, sen₹a pigliare mai sull'originale né una misura né un rapporto. Hanno a fare insomma con l'architettura come un pittore fa col corpo umano: il compasso nell'occhio. L'occhio a questo modo si esercita a cogliere veramente le proporzioni, la mano a riprodurre giuste le forme e la memoria a serbare forme e proporzioni nel cervello. (...) esercito poi gli allievi nei temi tutti pratici, se non che mi contento per questi, meglio di schizzi che di disegni. Suscito la fantasia dei giovani con le composizioni estemporanee. Ne banno fatto cinque quest'anno: dalla prima all'ultima v'è un passo enorme.46

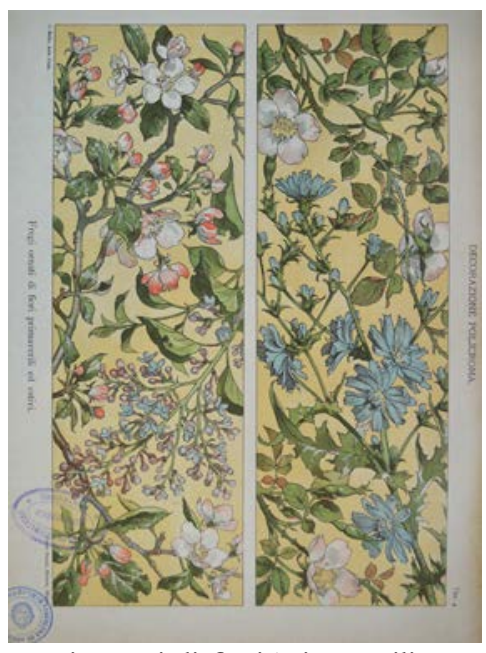

Fregi ornati di fiori 'pimaverili ed estivi. Boito, ARTE UTILE. Decorazione policroma, Milano, Ulrico Hoepli,1894, Tav.4

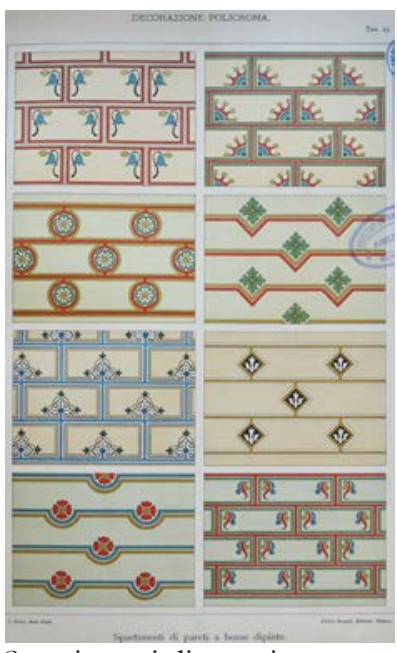

Spartimenti di pareti a bozze dipinte. Boito, ARTE UTILE. Decorazione policroma, Milano, Ulrico Hoepli,1894. Tav.23

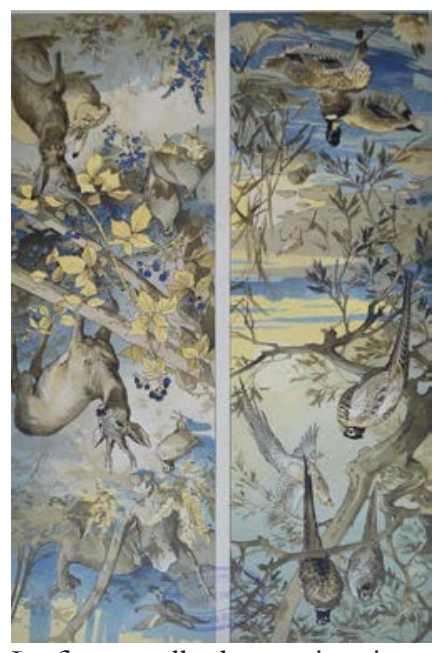

La figura nella decorazionei. Boito, ARTE UTILE. Decorazione policroma, Milano, Ulrico Hoepli,1894

$\overline{45}$ Boito, I principii del disegno e gli stili dell'ornamento, 8.

46 "La Relazione scritta da Camillo Boito è conservata nell'Archivio Storico dell'Accademia di Brera (scatola 11591-G). Tutte le citazioni che seguono provengono da questo documento" citado por Chiara Occhipinti, "Milano nei progetti dei giovani architetti civill”, 190. “(...) no quiero que los detalles sean copiados. A esto se llega al obligar a los jóvenes a realizar un álbum repleto de detalles particulares de un estilo determinado; pero a realizarlos sin tocar nunca con un compás el original, sin tomar nunca del original ni una medida ni una proporción. Tienen que hacer con la arquitectura como un pintor hace con el cuerpo humano: el compás en el ojo. El ojo de esta manera se ejercita a capturar verdaderamente las proporciones, la mano a reproducir las formas justas y la memoria a mantener las formas y las proporciones en el cerebro. (...) ejercito luego a los estudiantes en todas las cuestiones prácticas, y no es que me satisfagan, mejor bocetos que diseños. Despierto la fantasía de los jóvenes con las composiciones improvisadas. Han realizado cinco este año: de la primera a la última existe un paso enorme." [Traducción Florencia Minatta] 
La visión, y la mano debían ser "adiestrados" a la par y responder a las instrucciones de la mente para vincular, en una operación científica, la apariencia de los objetos con su representación geométrica. ${ }^{47} \mathrm{Al}$ iniciarse, el alumno debía ejercitar el relevamiento a mano libera de objetos familiares hasta llegar, con el paso del tiempo, a la descomposición de las formas en figuras geométricas:

Vedi nel primo foglietto la bottiglia tozza? È un rattangolo, sulla base del quale sta un triangolo ottusangolo e sull alto del quale si notano alcune brevi rette convergenti e alcune brevi rette parallele. Vedi il bicchiere? È un tronco di cono: dico male, ̀̀ un trapezio isocele. E guarda la lucerna con il suo capello, e l'armadio. E il calice: tutte figure geometriche arcisemplici, tutte linee rette. ${ }^{48}$

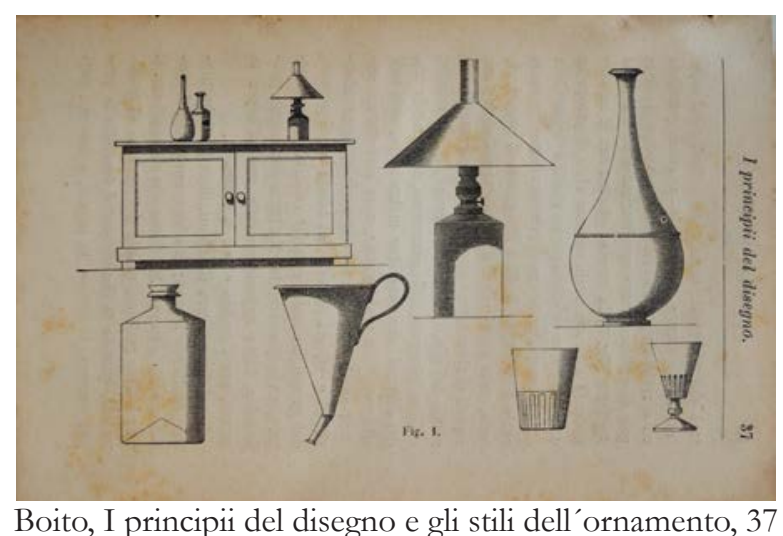

El alumno comenzaría por estudiar y relevar a mano alzada elementos arquitectónicos y de la naturaleza que progresivamente se irían complejizando; luego incorporaría la geometría y, por último, el uso de la perspectiva, los sólidos geométricos y su representación en el espacio. De acuerdo a Boito, toda forma podía descomponerse en una construcción geométrica y la habilidad del alumno consistía en realizar diferentes composiciones para lograr formas y figuras. Ejemplo de ello es la utilización del círculo y la curva en sus más variadas combinaciones elementos a los que Palanti recurriría constantemente en su método proyectual-.49

En cuanto al ornamento, Boito no planteaba su anulación, sino la incorporación de

$\overline{47}$ Boito, I principii del disegno e gli stili dell'ornamento , 32.

48 Boito, I principii del disegno e gli stili dell'ornamento, 36. "¿Ve en la primera hoja de papel la botella maciza? Es un rectángulo, sobre su base se encuentra un triángulo obtusángulo y sobre su cima se notan algunas breves rectas convergentes y algunas breves rectas paralelas. ¿Ve el vaso? Es un tronco de cono: digo mal, es un trapecio isósceles. Y mire la lámpara con su sombrero, y el armario. Y el cáliz: todas figuras geométricas simples, todas líneas rectas."'Traducción Florencia Minatta]

49 Boito, I principii del disegno e gli stili dell'ornamento, 76-78. 
éste a la arquitectura como resultado de la misma. En sintonía con el pensamiento positivista, el alumno debía estudiar el fin práctico del objeto ornamental, su forma geométrica y tener en cuenta cuestiones como la arquitectura, la historia, la civilidad, la fauna y flora de un pueblo si deseaba lograr un ornamento adecuado..$^{50}$
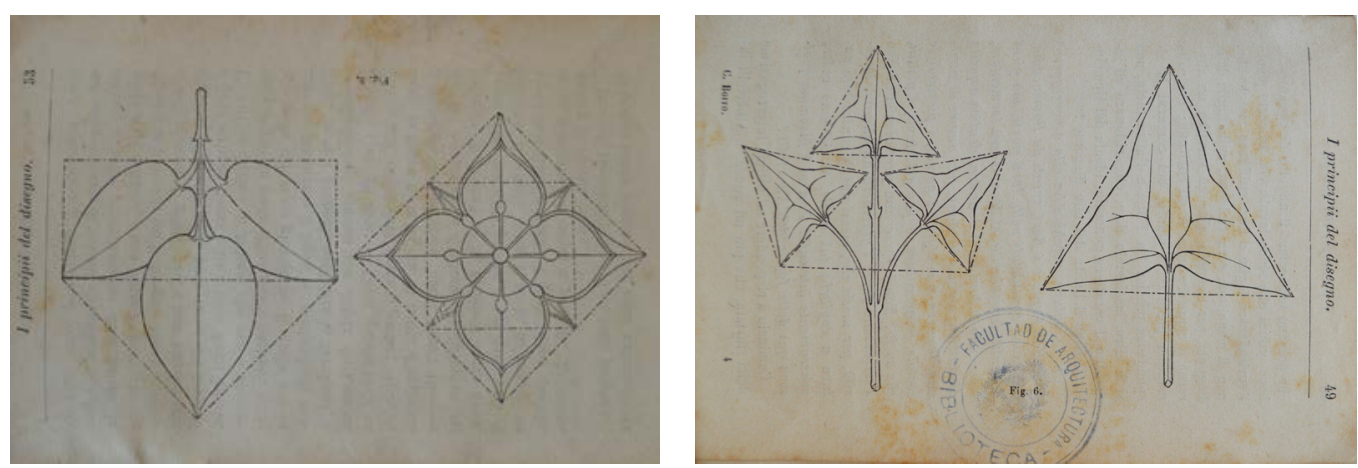

Boito, I principii del disegno e gli stili dell'ornamento, 49 y 53

Para ello el alumno debía, además, conocer en profundidad los estilos arquitectónicos. De acuerdo a los postulados boitianos, éstos se podían dividir en dos grupos: los estilos clásicos dentro de los que ubicaba el griego, romano, renacimiento, risorgimento, renacimiento francés, alemán, barroco, neoclásico; y los románticos o del Medioevo: bizantino, árabe, morisco, lombardo, románico, ojival nórdico, gótico italiano. ${ }^{51}$ Como ya fue señalado, Boito se inclinaba por el segundo grupo ya que -como también sostendría Palanti- consideraba a los estilos posteriores al Renacimiento como una imitación del mundo clásico, una mímesis de segundo grado que no debía ser tomada como referencia. De la misma manera, los materiales constructivos tampoco debían ser imitados pues, de acuerdo a Boito, a cada materia le correspondía una forma determinada y la decoración debía surgir de su propia fuerza, tal como sucedía en el Medioevo. ${ }^{52}$ Asimismo, la pintura debía cooperar con el edificio y, al igual que la decoración, estar siempre subordinada a la arquitectura y ser funcional a la expresión del edificio o del lugar a fin de evitar la monotonía y frialdad que se veía en algunos de los edificios y monumentos de la época..$^{53}$ Efectivamente, el interés de Boito estaba centrado en lograr que el alumno comprendiera el sentido del uso del aparato decorativo en relación al carácter y al sistema constructivo del edificio.

50 De a cuerdo a Boito, para componer un objeto ornamental se debe primero, estudiar el fin al que debe servir; segundo, examinar el estilo del lugar; tercero, indagar en la forma geométrica del estilo -marcadamente geométrico o eurítmico-; cuarto, pensar la naturaleza como fuente y quinto y último, el color. Boito, I principii del disegno e gli stili dell'ornamento, 183-85.

51 Boito, I principii del disegno e gli stili dell'ornamento, 142.

52 Boito, I principii del disegno e gli stili dell'ornamento, 186-187.

53 Boito, I principii del disegno e gli stili dell'ornamento, 190. 
Di ogni stile spiego a più riprese l'organismo statico ed estetico, accennando $i$ suoi legami essenziali con la storia dei popoli; mostro con molti esempi $i$ caratteri distintivi di ciascuna maniera. Uno dei malanni dell'insegnamento eclettico moderno è la confusione che ingenera nelle menti. Or, la confusione è inevitabile se lo scolaro non vede negli stili altro che la forma; bisogna che egli ne veda la ragione. Non è dificile.

\section{(...) Ogni stile è studiato sui monumenti migliori, sui libri che ne riproducono più fedelmente e più artisticamente l'indole e la fisionomia: per il romano a mo' d'esempio, piglio le opere del Piranesi, e pochissimo quelle del Canina. Ai libri, antepongo sempre, quando ci sono, le fotografie. ${ }^{54}$}

Entre las fotografías seleccionadas por Boito, señala Occhipinti, se encuentran imágenes de arquitectura antigua en su contexto urbano como la cuidad de Danzig o aislada del mismo como la catedral de Rouen, junto con algunos proyectos personales como el Cimitero di Gallarate..$^{55}$

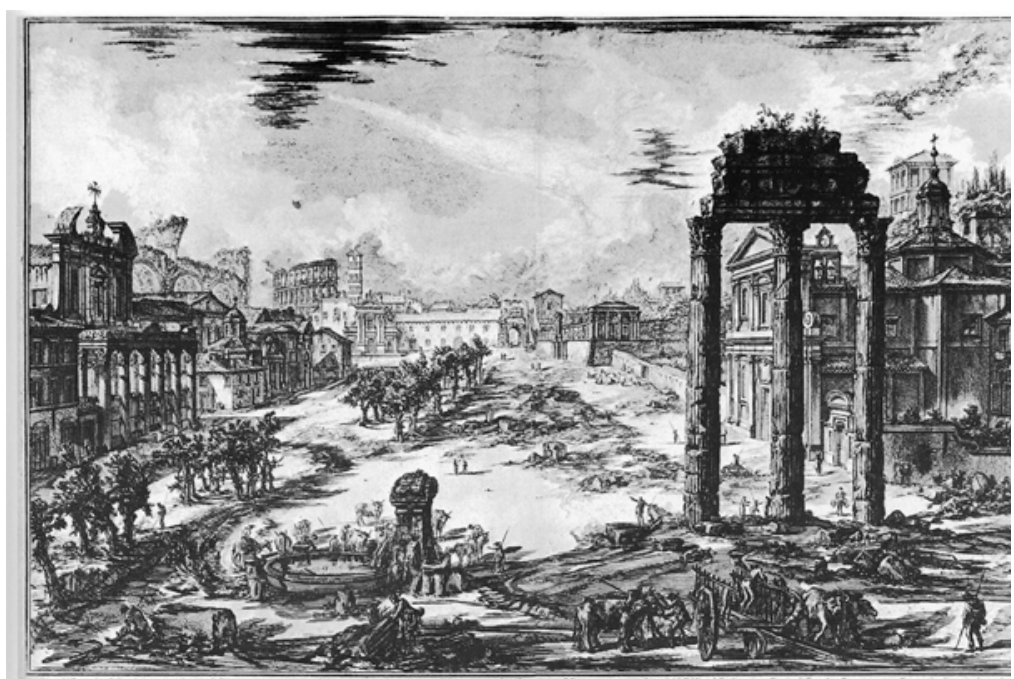

Gian Battista Piranesi, Veduta di Campo Vaccino, Roma

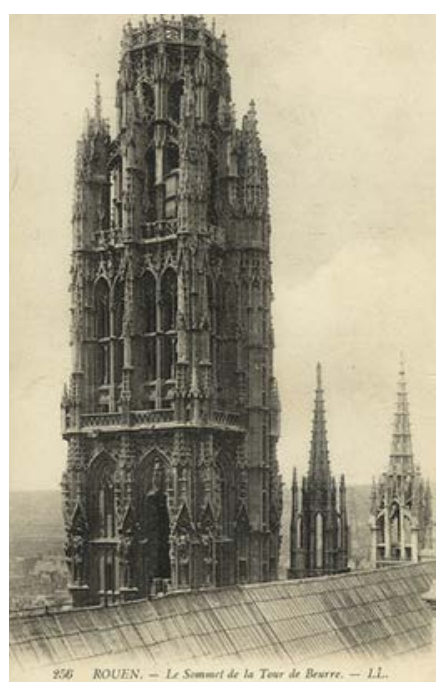

Torre de la catedral de Rouen. Ca. 1905 s/d

Boito hacía explícito el interés en que el alumno estudiara dal vero: insistía en la realización de viajes de relevamiento, en la participación en concursos o en toda aquella experiencia que

54 Boito citado por Occhipinti, "Milano nei progetti dei giovani architetti civill", 189. "De cada estilo explico varias veces el organismo estático y estético, repasando sus relaciones esenciales con la historia de los pueblos; muestro con muchos ejemplos las características distintivas de cada manera. Uno de los males de la enseñanza ecléctica moderna es la confusión que genera en las mentes. Ahora, la confusión es inevitable si el estudiante no ve en los estilos otra cosa que la forma; es necesario que ellos vean la razón. No es difícil. (...) Cada estilo es estudiado sobre los mejores monumentos, sobre los libros que reproducen de manera más fiel y artística su naturaleza y fisonomía: para el romano a modo de ejemplo, miro las obras de Piranesi, y muy poco aquellas de Canina. A los libros, antepongo siempre, cuando las hay, fotografías." [Traducción Florencia Minatta]

55 Occhipinti, "Milano nei progetti dei giovani architetti civili", 189. 
vinculara al alumno con el contexto internacional y su arquitectura. Como explica Occhipinti, el maestro busca un estudio directo de la arquitectura que parte de considerar la imagen final del edificio como el resultado exitoso de un complejo proceso en el que intervienen diferentes aspectos en el cual, por ejemplo, "(...) la scelta di guardare a Piranesi presuppone la necessità di un lavoro immaginifico che lo studente è chiamato a fare sull'architettura antica." ${ }_{56}$ Estas cuestiones que abarcan el conocimiento profundo de los edificios en un plano que estudia la arquitectura como una ciencia compleja y racional que conjuga técnica y arte se verificarían en la obra de Palanti.

\title{
4. Mario Palanti: pensamientos sobre arquitctura
}

\author{
Sarebbe un desiderio logico, giustificato e degno d'essere inculcato \\ a tutti $i$ citadini, quello che si andase formando in questa terra \\ Argentina un'Architettura propia, quasi diremo nazionale, \\ armonizzante strettamente con le necessità della vita attuale, \\ le caratterictiche el clima e la configurazione del suolo.57
}

La cita superior fue publicada por Palanti en el libro dedicado a su primera exposición de arquitectura en la Argentina. El texto, que promueve la búsqueda de una arquitectura propia que considere los aspectos locales, hace clara referencia a los postulados boitianos que fueron la guía principal en el pensamiento del arquitecto y evidencian la impronta del Boito teórico más que del diseñador. Esta puede verse sobre todo en los proyectos especulativos del joven discípulo, donde deja traslucir una creatividad y una imaginación sin frenos que rescata visiones que mezclan el gusto por el mundo medieval con cierta propensión a un gigantismo piranesiano, presente principalmente en sus perspectivas a mano alzada, método al cual Boito,- como ya fue mencionado - daba gran importancia.

56 Occhipinti, "Milano nei progetti dei giovani architetti civili", 189.

57 Mario Palanti, Prima esposiz̨ione personale d'architettura nella Repubblica Argentina. (Milano: Rizzoli, 1917), 14. “Sería un deseo lógico, justificado y digno de ser inculcado a todos los ciudadanos, aquello que se está formando en esta tierra Argentina una Arquitectura propia, casi diremos nacional, que armoniza estrictamente con las necesidades de la vida actual, las características del clima y la configuración del suelo.” [Traducción Florencia Minatta] 
En efecto, Palanti, como alumno, cobró fama entre sus condiscípulos por sus esquicios. En ellos está presente uno de los argumentos que caracterizaba la prédica de Boito: la idea de que la buena disposición de los materiales y la racionalidad constructiva no bastaban para construir la belleza. Ésta se podía conseguir, afirmaba el maestro, mediante alegorías directas o analogías abstractas que debían poseer el indefinible espíritu del arte.

En las primeras décadas de siglo XX, Palanti retoma el debate decimonónico en torno a la búsqueda de una nueva arquitectura. De acuerdo al arquitecto, la disciplina se encontraba

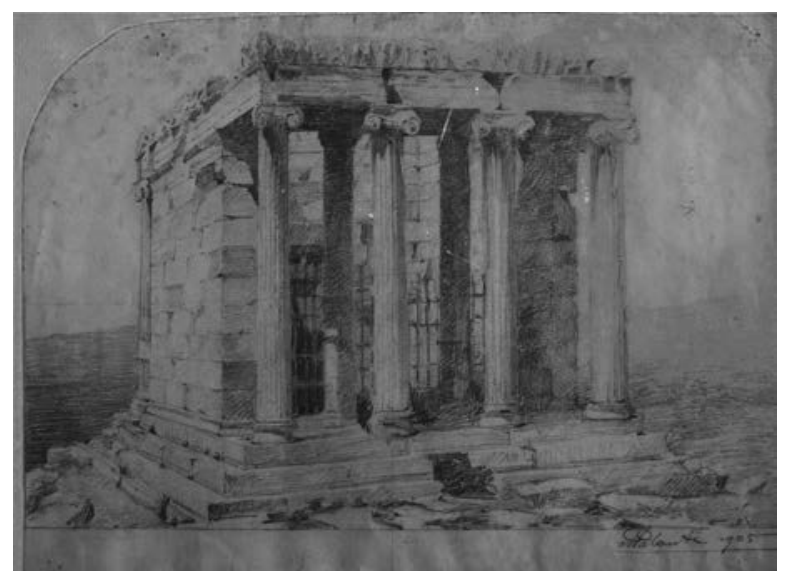

Boceto de un templo griego realizado durante el período de formación en la Academia di Brera, Mario Palanti, 1905. AGEP

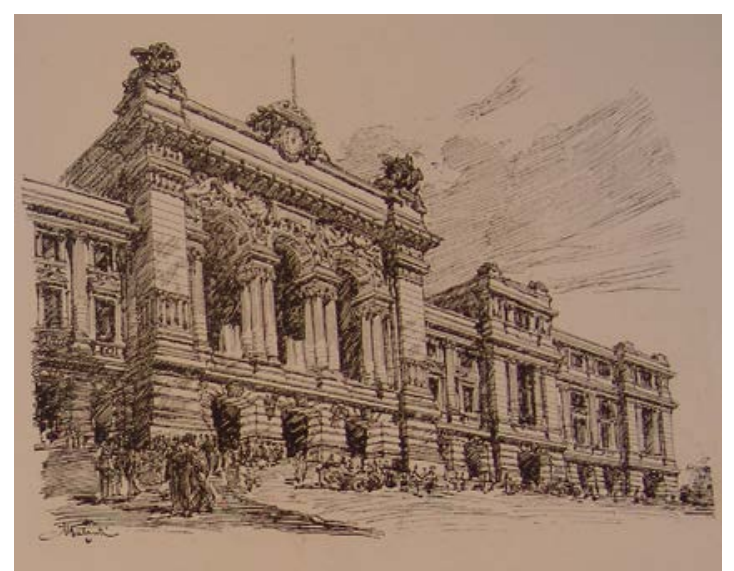

Mario Palanti, Proyecto de estacion ferroviaria. Ca. 1907/8. Prima esposizione personale di architettura.Tav. LXXXIX

"(...) in un periodo convulsivo e caótico, senza unità, senza carattere, senza originalità, senza tendenze definite." "58 La causa principal la adjudicaba al cosmopolitismo generalizado de las metrópolis modernas, que transportaba sin criterio las características de un tiempo y una región sin reparar en su adaptabilidad al medio de implantación: "sia al plagio servile di tutto quanto è bello o non lo è: sia di tante altre circonstanze la cui enumerazione risulterebbe interminabile e senza scopo." ${ }^{59}$ Siguiendo los fundamentos de Boito y en sintonía con la crítica violletiana al sistema clásico, consideraba la "tirannia aritméticamente classica" como un obstáculo que a través de sus reglas condiciona y limita la libre creación:
Come Arte non è logico pretendere di rinchiudere l'Architettura in nessun rigido sistema di leggi e precetti: un Arte non ammette regole. Boito e altre hanno giustamente criticato le teorie del Vignola e del Faurè, che con simili tentativi dissiparono in buona parte la loro meritata fama di arcbitetti. ${ }^{60}$

$\overline{58}$ Palanti, Prima esposizione personale d'architettura, 13. “(...) en un período convulsivo y caótico, sin unidad, sin carácter, sin originalidad, sin tendencias definidas.” [Traducción Florencia Minatta]

59 Palanti, Prima esposiz̨ione personale d'architettura, 14. "sea al plagio servil de todo lo que es bello o no lo es: sea de tantas otras circunstancias cuya enumeración resultaría interminable y sin sentido.” [Traducción Florencia Minatta]

60 Palanti, Prima esposiz̨ione personale d'architettura, 15. "Como Arte no es lógico pretender encerrar la Arquitectura 
El arte era entonces algo que sólo podría lograse mediante la expresión de la poética individual del arquitecto que, sin dejar de lado el carácter y la tradición local, debía generar un carácter propio, una impronta personal irrenunciable. ${ }^{61}$ De acuerdo al pensamiento palantiano, el arquitecto no se limitaba a realizar tareas de cálculo y diseño sino que iba más allá, pues operaba con el sentimiento, la pasión y la inspiración que podían, a través de la obra, convertirse en un hecho material. En palabras que recuerdan al perfil del arquitecto civil boitiano, Palanti se pregunta: "L'Architettura è Scienza o è Arte? Una cosa e l'altra insieme. Arte utile, la più utile di tutte, e Scienza al tempo stesso, Scienza per soddisfare le necesità e le ambizioni dell'Umanità. '*2

Precisamente, en sus escritos Palanti toma de Boito la figura del arquitecto como Genio creador de fantasías individuales para el cual el análisis científico de la historia se tornaba una herramienta imprescindible. Esta invitación a la creatividad individual contrasta en parte con la producción más bien austera y un manejo decoroso de los elementos arquitectónicos medievales que se observa en la obra de Boito como el restauro del Palazzo della Ragione de Verona (1894-97), el Hospital Cívico de Gallarate (finalizada en 1874) o la Casa de Reposo para músicos "Giuseppe Verdi” en Milán (finalizada en 1899), y probablemente ayudó a generar en sus discípulos una tendencia más mundana y recargada, de la cual Palanti resultó un fiel exponente. En sus esquicios de estudiante que incluyen templos votivos, grandes catedrales,

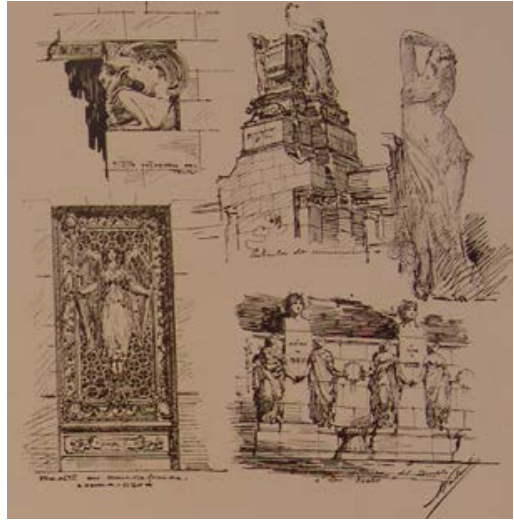

Mario palanti, Estudio para munumento expiatorio, Prima esposizione..

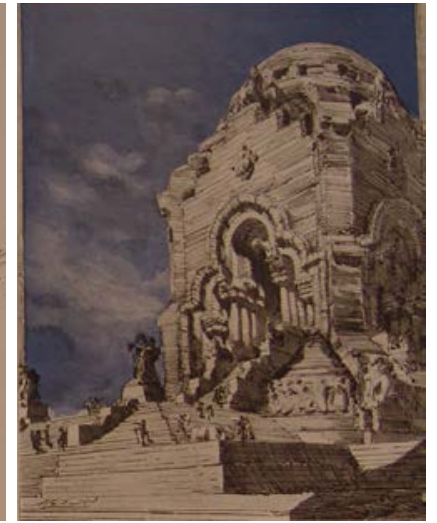

Mario Palanti, Proyecto para iglesia votiva. Prima esposizione personale di architettura.

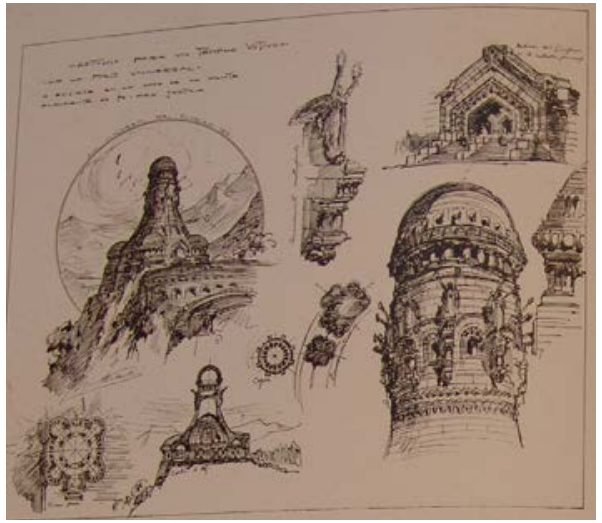

Mario Palanti, Estudio de templo votivo. Ca. 1916. Prima esposizione personale di architettura.Tav. IV

en ningún sistema rígido de leyes y preceptos: un Arte no admite reglas. Boito y otros han criticado justamente las teorías de Vignola y Faurè, que con tentativas similares disiparon en buena parte su meritada fama de arquitectos.’[Traducción Florencia Minatta]

61 Camillo Boito, Architettura del medio evo in Italia con una introduqione sullo stile futuro dell'architettura italiana (Milano: Ulrico Hoelpi editore, 1880). Palanti, Prima esposizione personale d'architettura, 15.

62 Palanti, Prima esposizione personale d'architettura, 15. "¿La Arquitectura es Ciencia o es Arte? Una cosa y la otra juntas. Arte útil, la más útil de todas, y Ciencia al mismo tiempo, Ciencia para satisfacer las necesidades y las ambiciones de la Humanidad." [Traducción Florencia Minatta] 
castillos en las montañas o mausoleos, así como el relevamiento y la realización de bocetos que abarcaban desde fragmentos arquitectónicos hasta grandes obras de arquitectura, se muestra ya una imaginación frondosa. Por otra parte, estos esquicios conformaron una "memoria proyectual", un banco de datos del cual el arquitecto se sirvió durante su larga y prolífica carrera para materializar diversos tipos de programas.

En efecto, muchas veces nos encontramos al analizar su obra con la reutilización de algunos de los trabajos que fueron desarrollados durante su etapa de estudiante. ${ }^{63}$ De todos modos, no podemos hablar de un rasgo puramente personal, ya que su producción inicial de bocetos es resultado de los métodos de enseñanza académicos y del "clima de la época" (consideremos también el trabajo de Gian Giuseppe Mancini, Giulio Ulisse Arata o Angelo Valdemarca, quienes fueron compañeros de estudios de Palanti). Sin embargo, aún moviéndose dentro de este marco general, su habilidad como dibujante lo condujo a obtener, en 1909, una
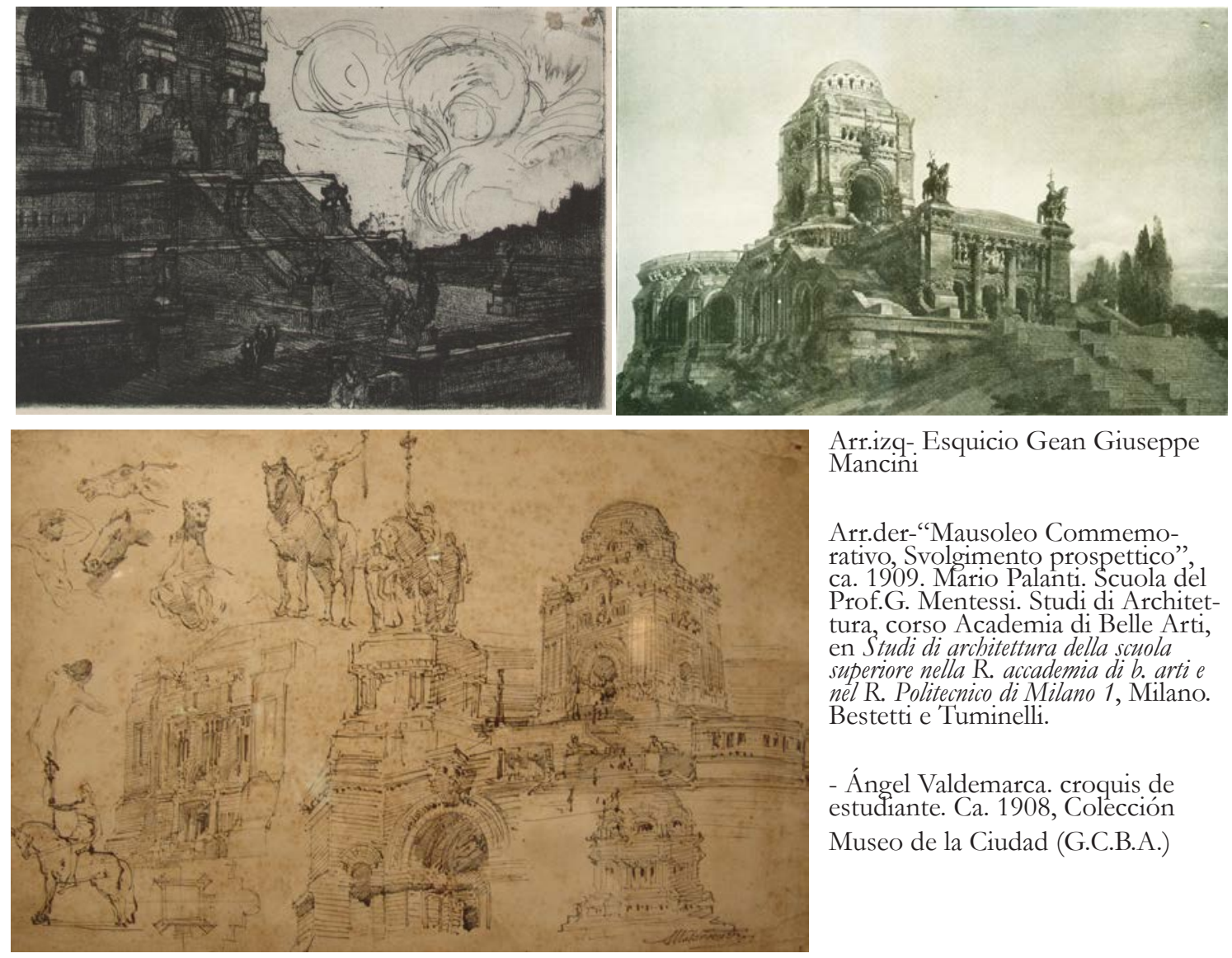

Arr.izq- Esquicio Gean Giuseppe Mancini

Arr.der-"Mausoleo Commemorativo, Svolgimento prospettico", ca. 1909. Mario Palanti. Scuola del Prof.G. Mentessi. Studi di Architettura, corso Academia di Belle Arti, en Studi di architettura della scuola superiore nella R. accademia di b. arti e nel R. Politecnico di Milano 1, Milano. Bestetti e Tuminelli.

- Ángel Valdemarca. croquis de estudiante. Ca. 1908, Colección Museo de la Ciudad (G.C.B.A.)

$\overline{63}$ Mario Palanti, 'Mausoleo Commemorativo', Svolgimento perpetico, Scuola del Prof.G. Mentessi. Studi di Architettura, corso Academia di Belle Arti, en Studi di architettura della scuola superiore nella R. accademia di b. arti e nel R. Politecnico di Milano vol. 1 (Milano: Bestetti e Tuminelli, 1908/9), tav. 1. 
medalla de oro en la Exposición de Bruselas y el Premio de la Fundación Clerichetti, distinciones que permitieron augurar una rápida introducción en el ambiente profesional. ${ }^{64}$

En lo referente al dibujo, una cuestión que sería primordial en el método proyectual de Palanti es la utilización de la geometría. Habiéndose formado en el ejercicio boitiano de descomposición en formas geométricas simples de elementos complejos, utilizó constantemente el círculo como base de sus proyectos. Asimismo, respetaba el principio de la decoración como resultado de una operación de síntesis geométrica: un elemento subordinado a la estructura y no una máscara; la decoración debía ser tratada con cautela y su aplicación justificada como una pieza indispensable que operaba en complemento de una idea fuerte definida y supeditada a los valores tectónicos, buscando su lugar en los intersticios ofrecidos por la construcción. ${ }^{65}$ Esta manera de operar, recuerda al planteo que sobre Gaudí, Sullivan y Berlage realiza Solà-Morales al decir que los tres arquitectos disponen el ornamento:

A veces recubriéndolo todo como una piel encargada de aportar la textura final del material a veces enfatizando los puntos de tensión donde se manifiestan ciertas colisiones o ciertos puntos de máxima tensión tectónica la ornamentación de de estos arquitectos finiseculares constituye un campo inventivo fundamental en la caracterización de su peculiar arquitectura. ${ }^{60}$
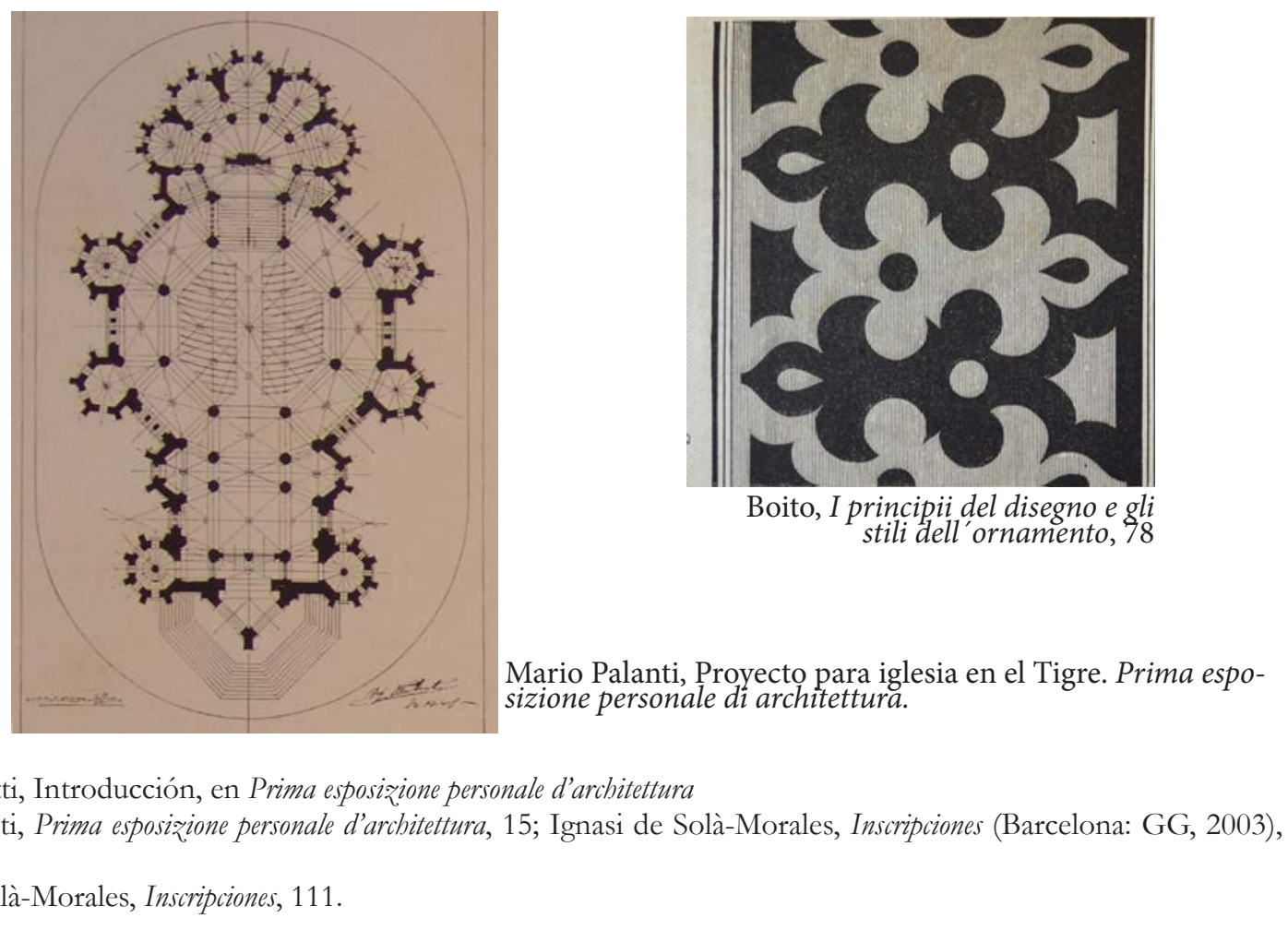

64 Carotti, Introducción, en Prima esposizione personale d'architettura

65 Palanti, Prima esposiz̨ione personale d'architettura, 15; Ignasi de Solà-Morales, Inscripciones (Barcelona: GG, 2003), 111.

66 de Solà-Morales, Inscripciones, 111. 
Asimismo, puede verificarse otro postulado boitiano en el modo de operar de Palanti en la primera etapa de su carrera: la búsqueda de generar un estilo nuevo utilizando material histórico a partir de la construcción de un repertorio de estilemas lo suficientemente amplio como para evitar la copia, ya que consideraba que el haber visto poco contribuía al instinto de imitación pero que era imposible poseer una mente virgen y superior que genere formas nuevas:

Una mente vergine di ongi conoscimento, e dotata di straordiari doni immaginativi e intellettuali, puó generare qualchecos a di completamente nuovo, perchè allora il più probabile è che $i$ fruti che produce non siano una mera ripetizione di quello che è esistito, se non l'ha visto. ${ }^{67}$

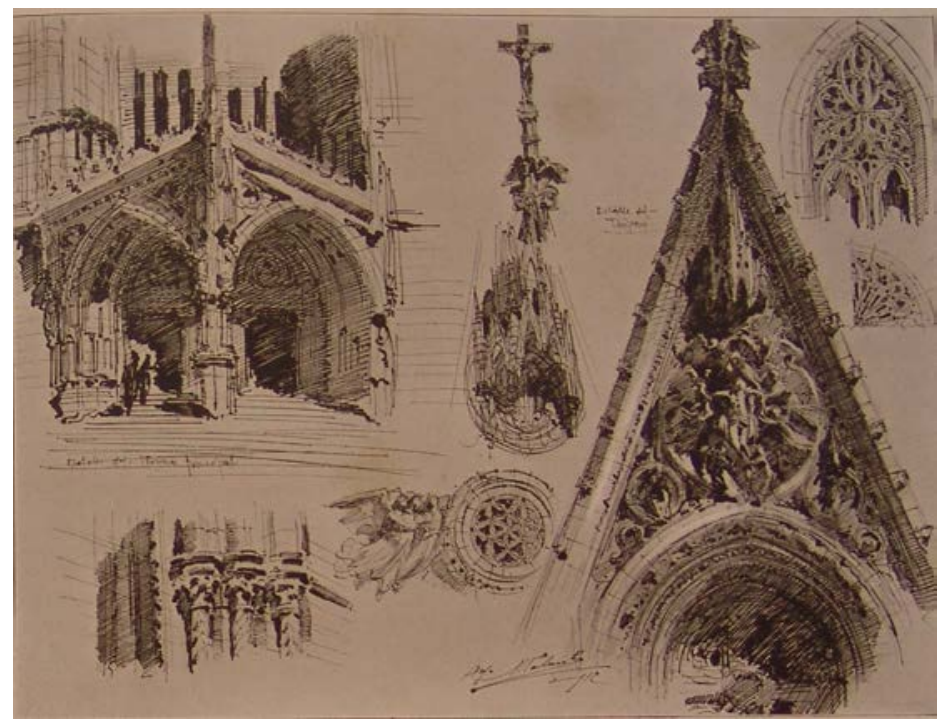

Mario Palanti. Proyecto de catedral.1912 Prima esposizione personale di architettura.Tav.XXI

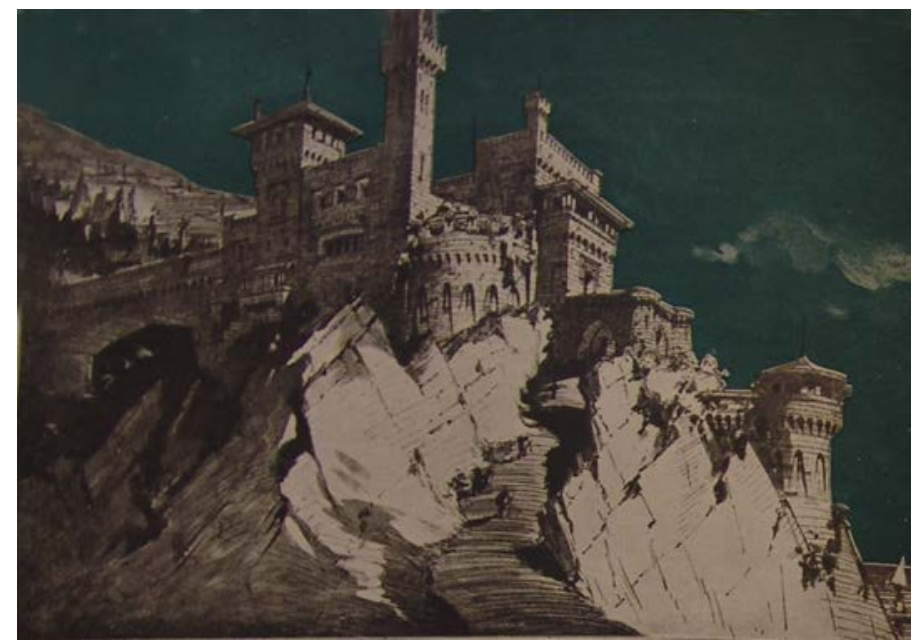

Estudio de castillo medieval M. Palanti. Prima esposizione personale di architetturáTav. LV

$\overline{67}$ Mario Palanti, Cinque anni di lavoro (Milano: Casa Editrice d'arte Bestetti \& Tumminelli, 1924), 105. Una mente virgen de conocimiento, y dotada de extraordinarios dones imaginativos e intelectuales, puede generar cualquier cosa completamente nueva, porque ahora lo más probable es que los frutos que produce no sean una mera repetición de aquello que existió, porque no lo ha visto. [Traducción Florencia Minatta] 
En esta misma línea, el arquitecto sostiene que: 'L' Arte, l'Architettura del Rinascimento, nelle sue diverse manifestazioni regionali e tutte quelle che dietro a lei son venute, non possono ripercuotersi nel lontano avvenire, pochè sono esse stesse reminiscenze di altre più lontane, delle classiche Architetture dei Romani e degli Etruschi." ${ }^{68}$ y, por el contrario, "(...) i portentosi stili medioevali, rappresentano una creazione spontanea dei suoi contemporanei, una fioritura magnifica nata da sè, una stupenda materializzazione dei sogni più irreali di quelle menti esaltate." Frente al universalismo del sistema clasico el Medioevo presentaba multiples variantes estilisticas: "Ogni paese, ogni città, potrebbe dirsi ebbe nel Medio Evo il suo stile speciale e distinto, libro di pietra nel quale leggiamo la sua storia con tutte le sue vicissitudini." ${ }_{9}$

Ante la imposibilidad de desprenderse del pasado es preciso, señala Palanti, seleccionar qué formas arquitectónicas son las adecuadas para que operen como fuente indirecta de inspiración y sean, a su vez, susceptibles de adaptarse a los nuevos avances de la técnica. ${ }^{70}$

De manera ambivalente, el arquitecto exalta la existencia de un presente que debido a los avances técnicos se diferencia de las etapas anteriores y reclama para sí una nueva forma de expresión que, sin embargo, debe nacer de la tradición. La clave está, según el arquitecto, en la manera en que el pasado debe ser imitado: la mímesis con la historia debe ser selectiva. El artista debe entonces adaptar, con criterio y armonía, las formas del pasado a las nuevas circunstancias. $^{71}$

$$
\begin{aligned}
& \text { Attualmente -señalaba en 1924-, epoca delle armature di ferro e di cemento } \\
& \text { armato, scheleti mostruosi che permettono le più arrischiate concerioni dell'Ingegno } \\
& \text { umano, concepisconsi stili più convenienti dei medioevali, fin nella sua stessa } \\
& \text { struttura costruttiva, per ispirarsi e realizare ideali di bellezza e grandiosità? }
\end{aligned}
$$

68 Palanti, Prima esposizione personale d'architettura, 14. "El Arte, la Arquitectura del Renacimiento, en sus diversas manifestaciones regionales y todas aquellas que vinieron después, no pueden repetirse en el futuro lejano, porque son ellas mismas reminiscencias de otras más lejanas, de las clásicas Arquitecturas de los Romanos y de los Etruscos." [Traducción Florencia Minatta]

69 Palanti, Prima esposizione personale d'architettura, 14. “(...) los portentosos estilos medievales, representan una creación espontánea de sus contemporáneos, un florecimiento magnífico nacido de sí mismo, una estupenda materialización de los sueños más irreales de aquellas mentes exaltadas.”(...) “Cada país, cada ciudad, podría decirse que tuvo en la Edad Media su estilo especial y distinguido, libro de piedra en el cual leemos su historia con todas sus vicisitudes." [Traducción Florencia Minatta]

70 Palanti, Cinque anni di lavoro, 110.

71 Palanti, Cinque anni di lavoro, 358.

$72 \mathrm{Al}$ respecto señalaba que en la edad media hubo periodos de esplendor sin igual, se realizaron "meraviglie di costruzioni e di arte, senza ricorrere alle fonti dell'Antichità, con inesauribile ispirazione e originalità" que habían sobrepasado a los clásicos en diversos puntos de vista. Palanti, Prima esposiżione personale d'architettura, 14. Actualmente - señalaba en 1924 -, época de las armaduras de hierro y de cemento armado, esqueletos monstruosos que permiten las más arriesgadas concepciones del Ingenio humano, ¿se conciben estilos más convenientes que los medievales, desde su propia estructura constructiva, para inspirarse y realizar ideales de belleza y grandiosidad? 
Pero la mímesis palantiana no pretende ser imitación sino creación, ya que según su particular enfoque, la imitación es el producto de aquellos que copian directamente un modelo preestablecido. ${ }^{73}$ Desde las experiencias codificadas del pasado se inicia el discurso innovador de la propia obra. En efecto, para Palanti, es inadmisible la imitación y adaptación irracional de construcciones antiguas y modernas. En su visión, operaciones de este tipo -muchas veces producto de la especulación- finalizan en copias malinterpretadas dominadas por la ausencia de carácter. $^{74}$

Frente a este diagnóstico, lo que Palanti recoge de Boito es la idea de una amplísima erudición que permite superar la imitación mecánica y posibilita la creación de formas estilísticas nuevas que, enraizadas en la historia, pueden sintetizar presente y pasado. Pero paradójicamente su resemantización yuxtapuesta de estilemas diversos en un mismo espacio temporal anula, en definitiva, la historia. Este camino de búsqueda de una nueva arquitectura -con influencia de los postulados violletianos- no es exclusivo de Palanti. Como hemos mencionado anteriormente, Solá-Morales se refiere a la obra de arquitectos como Gaudi, Sullivan y Berlage que evadieron el clasicismo y tomaron un camino "paralelo" al delineado por el movimiento moderno. En sus proyectos “(...) la relación con las formas del pasado estalla y se despliega en distintos niveles autónomos, dando lugar a dos tipos de elaboraciones diferentes: la reflexión sobre la estructura portante del edificio y su ornamentación.”75 Antigüedad y Edad Media se transforman así en una cantera de elementos con los cuales obrar en una libertad sólo condicionada por el clima y el medio ambiente de cada sitio. Como señala Solá-Morales para los casos de Gaudi, Sullivan y Berlage, los tres realizan:

$$
\begin{aligned}
& \text { (...) una arquitectura que no es ajena a la experiencia del pasado, pero } \\
& \text { que tampoco se sitúa en continuidad. El material de las arquitecturas } \\
& \text { históricas es objeto de una reinterpretación. No se trata de una cita o } \\
& \text { de una réplica, sino de operaciones de rediseño q actúan como método } \\
& \text { critico, depurativo y transformador de las soluciones codificadas a lo } \\
& \text { largo de la experiencia histórica. }{ }^{76}
\end{aligned}
$$

[Traducción Florencia Minatta]

73 Véase Fernando Aliata, "De la Antigüedad restaurada a la Composición. Desarrollo y crisis de la teoría Clásica" en Estrategias proyectuales. Los géneros del proyecto moderno (Buenos Aires; SCA, 2014)

74 Palanti, Cinque anni di lavoro, 358.

75 de Solà-Morales, Inscripciones, 108-109.

76 de Solà-Morales, Inscripciones, 107-108. 
La utilización de las nuevas técnicas y materiales generaba, de acuerdo a Palanti, cierto grado de confusión y provocaba que en muchos casos la estructura portante de edificio no se reflejara en el exterior generando contraste entre ésta y la forma resultante. En sintonía con las ideas de Viollet-le-Duc, Palanti veía en la estructura y el material una vía para encontrar una respuesta a la búsqueda de nuevas formas: "Non doverebbe essere invece questa differenza nell'elemento costruttivo la principale fonte della ispiraz̧ione rinnovatrice?" 77 La definición de la estructura portante del edificio -la elección de su tecnología- debía ser funcional a la definición del diseño de la obra. ${ }^{78}$ Las transformaciones producidas a partir de los avances científicos y los cambios que se dieron en la sociedad debían reflejarse en el arte mediante una síntesis entre economía y racionalismo que perfeccionara los medios constructivos modernos. Precisamente, para Palanti las posibilidades de los materiales constructivos modernos serían la base para la arquitectura “dell'Era Moderna". ${ }^{79}$ Esta fue una problemática que el arquitecto mantuvo a lo largo de su trayectoria y se reflejó en el uso de los nuevos materiales e, inclusive, en la invención de otros sistemas constructivos como el bloque "Palandomus" que intentaban ser portadores de una nueva estética.

En su artículo contemporáneo- " ¿La era moderna tiene orientaciones nuevas en arquitectura?'-, publicado en Buenos Aires, en El arquitecto constructor de febrero de 1923, Palanti se preocupa por la necesidad de crear una arquitectura que se adapte al medio cultural y a las condiciones ambientales de cada sitio. ${ }^{80}$ Pero a diferencia de los cultores del Neocolonial, el arquitecto italiano enuncia la necesidad de una monumentalidad que, sin perder la resonancia con la historia, incorpore el carácter que los nuevos programas y la ciudad requieren. Desde su punto de vista, la atención y el relevamiento académicos que las arquitecturas del pasado colonial hispánico comienzan a recibir en esos años, no pueden servir de base para la construcción de una nueva disciplina. La modestia de sus resultados las inhibe como modelo para un arte urbano que debe asumir el escenario metropolitano. ${ }^{81}$

$\overline{77}$ Palanti, Cinque anni di lavoro,106. “¿No debería ser en cambio esta diferencia en el elemento constructivo la principal fuente de la inspiración renovadora?” [Traducción Florencia Minatta]

78 Palanti, Cinque anni di lavoro,109.

79 Palanti, Cinque anni di lavoro, 107.

80 Mario Palanti, "La era moderna tiene orientaciones nuevas en arquitectura", El Arquitecto Constructor 258 (Buenos Aires: 1 feb., 1923).

81 Palanti, Cinque anni di lavoro, 361. 
La nueva arquitectura debía seguir la vía del progreso; de acuerdo a Palanti, se diferenciaba de la antigua en dos aspectos: en su organismo distributivo -por el uso de elementos mecánicos, electricidad, ascensores- y en su organismo estático -por el uso de nuevas tecnologías como el cemento armado al que consideraba una "verdadera revolución”-. Su visión de la modernidad le llevaba a preguntarse, inclusive, si sería necesario ubicar en los edificios altos plataformas de aterrizaje para medios de locomoción aéreos..$^{82}$ Precisamente, su búsqueda conjugaba el experimentalismo tecnológico, la racionalidad constructiva y el positivismo decimonónico aplicado a la arquitectura y a la construcción:

Todos los nuevos elementos de la vida moderna, vendrán a imponer sus características e imprimir su huella en el derrotero de la nueva arquitectura, ya que ésta ha de contemplarlos todos y armonizarse con todos ellos. ${ }^{83}$

La confianza en las posibilidades de un pasado reinterpretado que admita los avances tecnológicos del presente guía el trabajo del arquitecto, al menos en su faz teórica durante su primera etapa en la Argentina, y va in crescendo a medida que su producción madura. Una forma particular de modernismo alternativo a las corrientes en boga, basada en la posibilidad excepcional del genio es, entonces, el resultado que Palanti intenta producir a partir de su interpretación de la prédica de Boito. El producto es una arquitectura que incorpora una grandiosidad y dinamismo piranesianos, privilegiando la creación objetual en desmedro de la regularidad urbana. A diferencia de su maestro, el arquitecto intentará construir una poética abierta a un espectro mayor de opciones que incorporan el carácter monumental de la metrópoli.

Esta actitud ante la metrópoli se ve en otros arquitectos de educación boitiana que precedieron a Palanti, como Giulio Ulisse Arata o Giuseppe Sommaruga para quienes la monumentalidad y el eclecticismo fueron una respuesta a los nuevos programas metropolitanos. En el interior de esta generación formada en la Milán de fines de siglo XIX, como señala Mercedes Bares, el eclecticismo se transfigura en una dimensión mística y visionaria. ${ }^{84}$ Esta

82 Palanti, Cinque anni di lavoro, 110.

83 Palanti, "La era moderna tiene orientaciones nuevas en arquitectura"

84 María Mercedes Bares, "La galleria Barolo di Buenos Aires", Il tesoro delle città. Roma, Strenna dell'Associazione Storia della città. Anno V (2007): 48. 
poética podría corresponderse en líneas generales con una serie de búsquedas de matriz ecléctica que envuelven también el experimetalismo mostrado por algunos de los discípulos de Violletle-Duc como Françoise-Henri Sauvage, Hector Guimard o las contemporáneas manifestaciones del Expresionismo centroeuropeo, pensemos en la Alpine Architekture de Bruno Taut, y a ciertas arquitecturas relacionadas con el esoterismo de principios del siglo XX como los edificios patrocinados por Rudolph Steiner.

Pero, a diferencia de muchos de estos arquitectos y de otros formados en la Europa de fines de siglo XIX que realizaron proyectos utópicos, Palanti tuvo la poco frecuente posibilidad de llevar a cabo programas de escala monumental. Como veremos a continuación, la transformación de Buenos Aires en Capital Federal en 1880, su metropolización junto con la llegada masiva de inmigrantes, el incremento de la industria y del consumo, entre otros factores, generaron una coyuntura que el arquitecto supo aprovechar. 


\section{Capítulo II. Buenos Aires 1910, la experiencia metropolitana}

Yo no dejé de sentir la sorpresa general -que observé después en los que desembarcaban- ante aquella ciudad enorme, ante aquella inmensa incógnita que desde hace veinte años crece en silencio sin que sus hermanas latinas tengan a bien notarlo.

(Jules Huret, De Buenos Aires al Gran Chaco, 1911)

En marzo de 1910, el buque Principe Umberto partió de Génova con destino al Río de la Plata. A bordo viajaba la Comisión Oficial italiana encargada de la construcción del pabellón nacional para la Exposición del Centenario de la Revolución de Mayo, próxima a celebrarse en Buenos Aires. Como parte del grupo coordinado por el ingeniero Luigi Luiggi, viajaba un joven

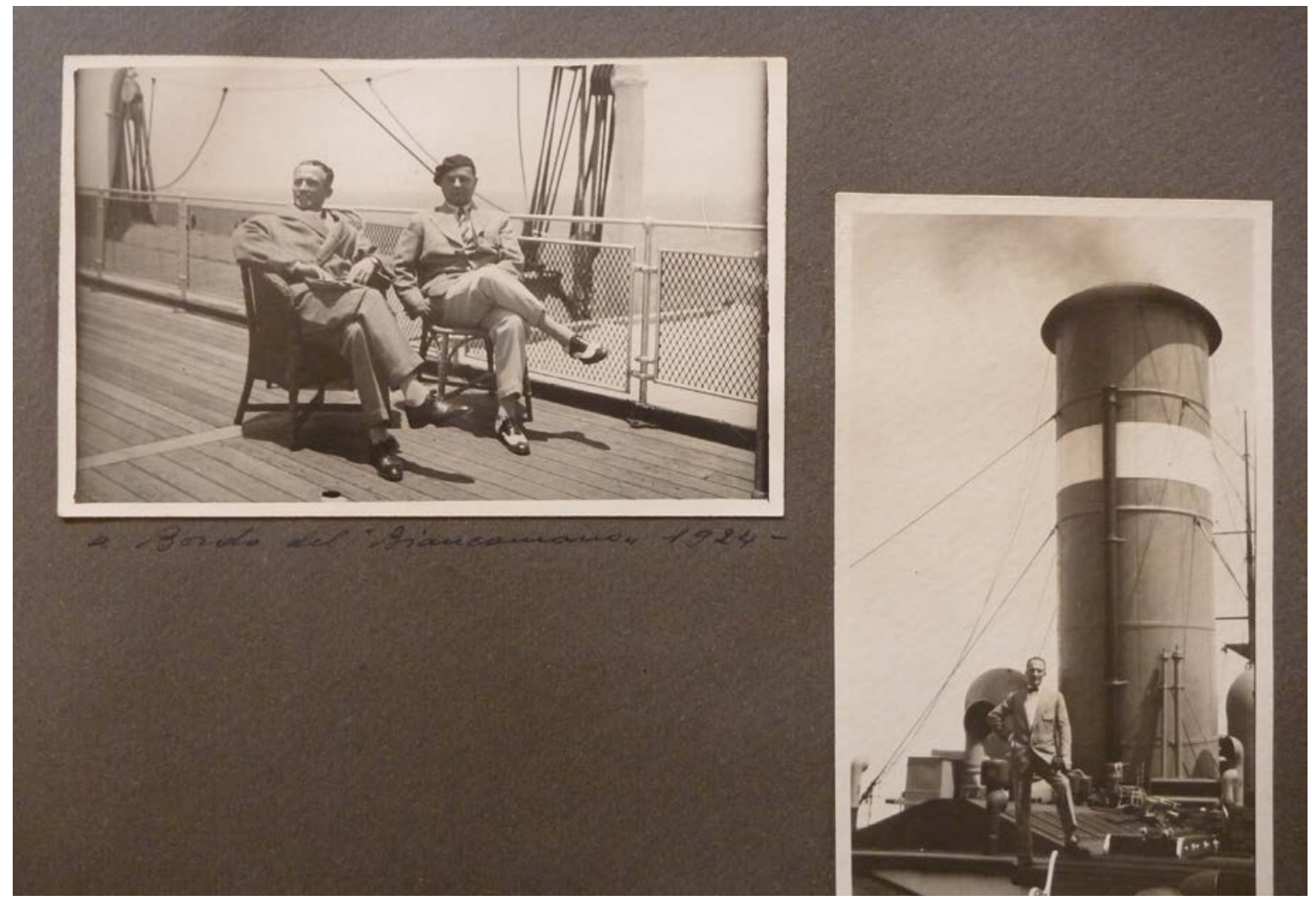

A bordo el Biancamano. 1924. AGEP 


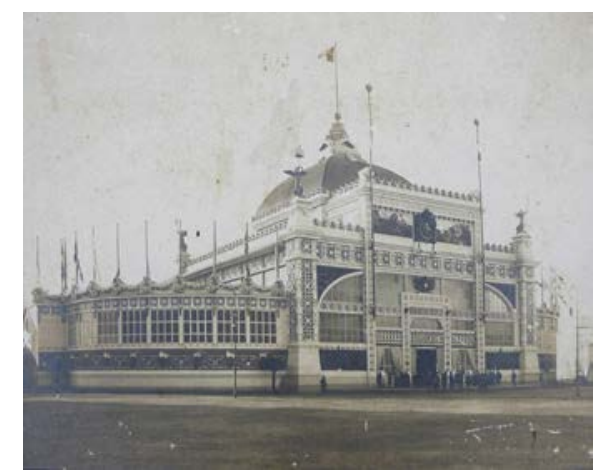

Pabellón italiano para la Exposición del Centenario de la Revolución de Mayo. Buenos Aires.1910. Gaetano Moretti con Francesco Gianotti, Mario Palanti y Angelo Valdemarca. Archivo Guido y Emilio Palanti (AGEP)

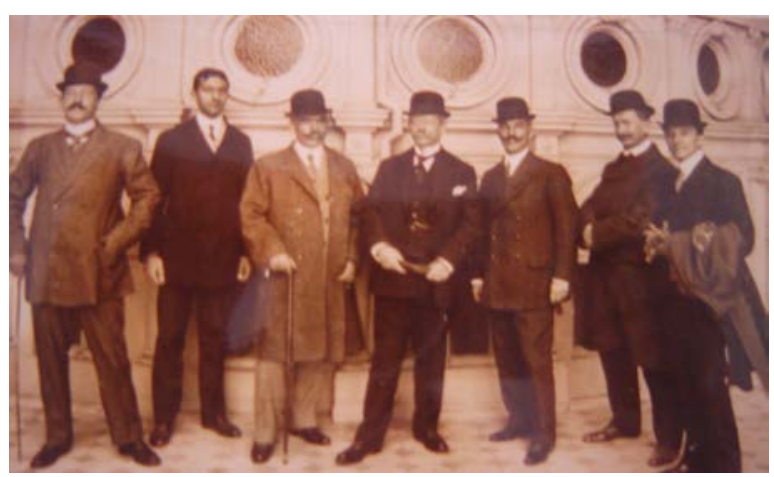

Comisin italiana enviada al Centenario de Mayo. Entre ellos el ing. Luigi Luiggi y Mario Palanti.

arquitecto de veinticinco años que había sido invitado por su maestro, Gaetano Moretti, para participar en la construcción de la obra.

El primero de mayo, el buque atracó en el puerto de Buenos Aires, donde algunos funcionarios y un gentío de curiosos aguardaban la llegada de las comitivas extranjeras. El dos de mayo, como parte del ceremonial que acompañaba el festejo, la Comisión italiana fue recibida por el Presidente de la República. ${ }^{85}$

Una vez instalado en la ciudad, Palanti se sumó a los trabajos en el Pabellón. Las tareas en la construcción contaron, entre otros, con la participación de sus condiscípulos Francisco Gianotti y Angelo Valdemarca. ${ }^{86} \quad$ No sabemos si la tarea de Palanti se limitó solo a una dirección técnica del proyecto de su maestro Gaetano Moretti o tuvo una participación personal en la creación del pabellón. ${ }^{87}$ Hacia el final de la obra, el arquitecto convocó a su hermano para realizar los frescos que decorarían

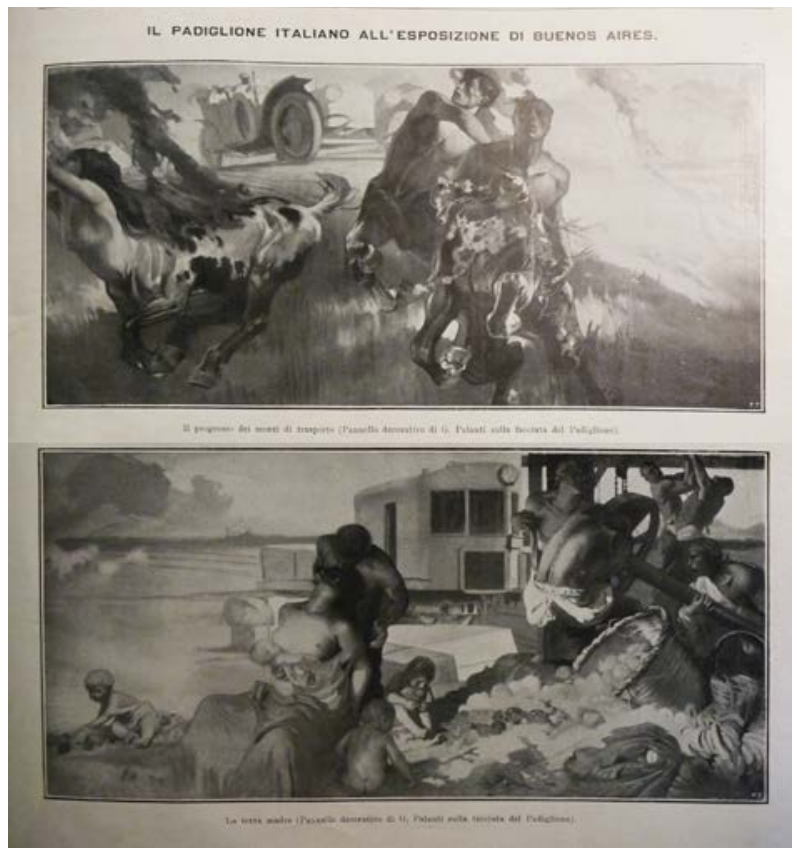

Giuseppe Palanti. "Il progresso dei mezzi di trasporto" y "La terra madre". Pinturas para el pabellón italiano en la Exposición de Buenos Aires. L'Illustrazione italiana 26, junio 1910. la fachada principal. ${ }^{88}$ Desde su taller en

85 Mario Palanti, Curriculum Vitae, Roma, 1958, Archivo privado Guido y Emilio Palanti (AGEP)

86 Raúl Piccioni, "La arquitectura de Buenos Aires bajo el influjo de la Academia de Bellas Artes de Brera. El caso de Angel F. Valdemarca" en VIII Jornadas de Estudios e investigaciones. "Arte y cultura, continuidades y rupturas en vísperas del bicentenario" (Buenos Aires: Instituto de Teoría e Historia del Arte “Julio E. Payró", 2010)

87 Palanti, Curriculum Vitae, Roma, 1958.

88 "Il padiglione italiano all'esposizione di Buenos Aires" en L'Illustrazione Italiana 26, (26 Giugnio 1910) 
Milán, Giuseppe realizó dos frescos que se ubicarían a izquierda y derecha de la entrada y que mostraban figuras alegóricas: "El progreso de los medios de transporte" mostraba un grupo de tres centauros - uno de ellos femenino- huyendo en estampida de un automóvil Isotta Fraschini, mostrando a la mitología escapando ante la llegada del progreso; en una composición similar, "La madre tierra" mostraba una unión entre naturaleza e industria: una mujer amamantando, cestas con frutas y en el ángulo opuesto un grupo de trabajadores y un monorriel que irrumpe en la escena. ${ }^{89}$

Los trabajos en el pabellón se iniciaron en abril y se prolongaron por casi tres meses. Transcurrido este plazo, la Comisión emprendió el regreso a Italia a excepción del joven Palanti, quien decidió permanecer en Buenos Aires ante la oferta de trabajo. Durante casi tres décadas, y de manera ininterrumpida, Palanti trabajó en la Argentina, alternando su estadía con cortos viajes a Italia. En Buenos Aires instaló un estudio particular, se vinculó con sectores del poder local, recibió grandes encargos, construyó rascacielos, participó de concursos e intentó, incansablemente, definir una arquitectura que se adaptara a la modernidad. Esta etapa rioplatense conforma la más productiva de Palanti.

\section{Imágenes de modernidad}

Durante el período que recorre las últimas décadas de siglo XIX y las primeras del XX, la ciudad de Buenos Aires estuvo marcada por la federalización y por la transición de ciudad a metrópolis. Situación que indudablemente seducía a un arquitecto joven y entusiasta que abandonaba el Viejo Continente sin más compromiso que un encargo. La ciudad que recibió a Palanti comenzaba a consolidar su imagen material como Capital Federal, luego de un largo período de reformas constantes que la asemejan a un obrador: el ensanche de calles y avenidas, el extendido de la electrificación, la construcción de escuelas y edificios administrativos la alejaban, de a poco, de una idea de precariedad, de "ciudad efímera". ${ }^{90}$

La llegada masiva de inmigrantes que tuvo lugar desde fines del siglo XIX se hizo evidente hacia 1900 en las calles a través de periódicos, escuelas, formación de colectividades y desarrollo de arquitecturas que hacían referencia a culturas extranjeras. La "Babel” de lenguas que muchos veían

$\overline{89}$ Crespi Morbio, Giuseppe Palanti; "Il padiglione italiano all'esposizione di Buenos Aires".

90 Jorge Francisco Liernur, "La ciudad efímera", en El umbral de la metrópolis: transformaciones técnicas y cultura en la modernización de Buenos Aires (1870-1930), Liernur y Silvestri (Buenos Aires: Sudamericana, 1993). 
en la ciudad incentivó la búsqueda, por parte de las elites, de una "identidad argentina" que intentaría combatir todo rastro "extranjerizante". Desde entonces, y a través de la producción de intelectuales como Ramos Mejía, Ricardo Rojas o Leopoldo Lugones, se intentaba definir $-\mathrm{o}$ construir - una tradición argentina que supuestamente

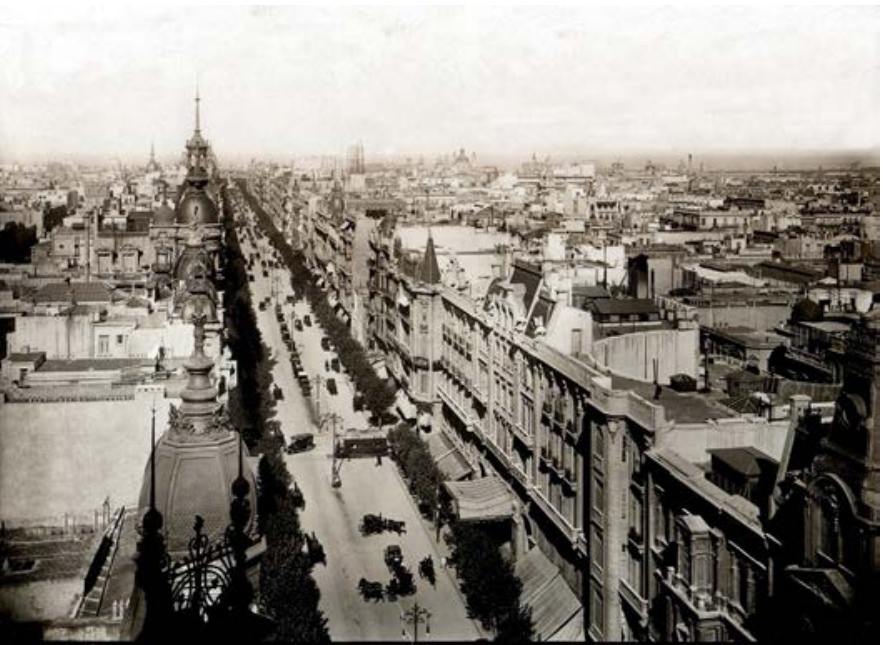

Av de Mayo 1911, s/d encontraría su auge durante los festejos del Centenario de Mayo que operarían como escenario para mostrar los avances técnicos y económicos del país. ${ }^{91}$ En torno al festejo, y sin ausencia de conflictos, los socialistas, anarquistas y radicales, opositores del llamado orden conservador, cobrarían fuerza: luego de la sanción de la Ley Sáenz Peña en 1912, tendrían lugar los comicios presidenciales que consolidaron el triunfo del radicalismo en 1916. La economía, que desde mediados del siglo XIX se apoyaba principalmente en el agro, se incrementó a través de la agroexportación, consolidándose lo suficientemente como para resistir los vaivenes del mercado y las crisis económicas de fines del siglo XIX. Hacia 1900, una considerable y prometedora industria nacional se expandía junto al incremento del consumo, encontrando, durante la Primera Guerra, la posibilidad de crecer ante la

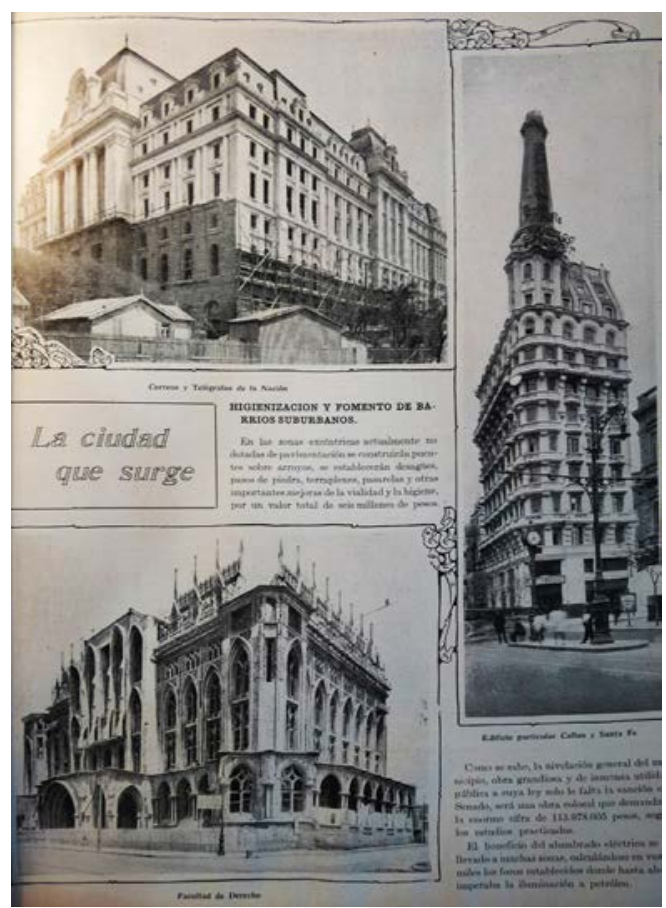

"La ciudad que desaparece y la ciudad que surge" en Almanaque La Razón, 1925, BPUNLP

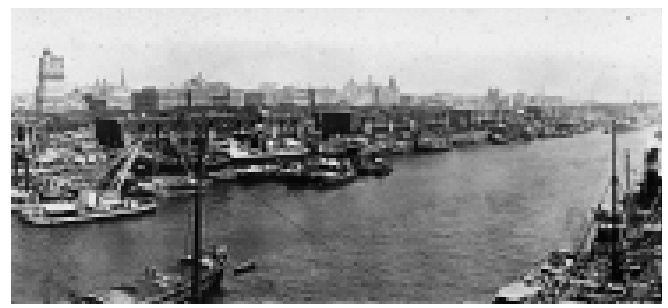

Puerto de Buenos Aires Ca 1911

91 Fernando Devoto y María Inés Barbero, Los Nacionalistas: 1910-1932 (Buenos Aires: CEAL, 1983); Adrián Gorelik, La grilla y el parque. Espacio público y cultura urbana en Buenos Aires, 1887-1936 (Bernal: UNQUI, 1998). La bibliografía sobre la Exposición del Centenario de Mayo es extensa. Particularmente véase: Buenos Aires 1910: Memoria del Porvenir, (Buenos Aires: Gobierno de la Ciudad de Buenos Aires, Facultad de Arquitectura Diseño y Urbanismo, Universidad de Buenos Aires (FADU- UBA), Instituto Internacional de Medio Ambiente y Desarrollo, IIED-América Latina, 1999). 
disminución de las importaciones. ${ }^{92}$

En este clima que conjuga conflictos sociales y políticos, crecimiento urbano y económico y la búsqueda, por parte de un sector dirigente, de una estética nacional, se lleva a cabo gran parte de la edilicia privada y pública que pasaría a caracterizar a Buenos Aires. Es precisamente en este contexto en el que surgen las primeras obras de Mario Palanti.

En esta etapa, Buenos Aires creció de manera notable. Incrementada por la inmigración europea, la población pasó de 177.787 habitantes en 1869 a 1.575 .814 en 1914 -de los cuales 300.000 eran italianos- y 1.700.000 hacia 1919..$^{93}$ Sumado al desarrollo que se daba desde mediados del siglo XIX, la transformación de la ciudad en Capital Federal en 1880 generó la necesidad de realizar nuevas sedes para las nuevas actividades que, como señala Claudia Shmidt, se volverían "un conjunto de piezas significativas en la representación material del Estado." Junto con otros cambios, esta producción de edificios públicos de escala monumental intentaba cambiar a permanente lo que era provisorio. ${ }^{95}$

En torno al Centenario, la ciudad se agitaba. El movimiento de la población se agilizó a través de una red de transporte cada vez más amplia: las líneas de tramways cubrieron gran parte de la ciudad, incluyendo los barrios más alejados que comenzaban a lotearse a bajo costo. A ellas se sumaron, en 1913, el primer subterráneo, la extensión de las líneas férreas existentes y, en la década de 1920, el colectivo.

Para un italiano que arribara al puerto de Buenos Aires, la babélica metrópolis ofrecía espacios de familiaridad. Entre 1891 y 1900 ingresaron al país 426.000 italianos y entre 1901 y 1913 la cifra ascendió a más de un millón. Un gran número se radicaba en el interior del país, pero la mayoría permanecía en la Capital conformando el $20 \%$ de la población. ${ }^{96}$ Como señala

92 Fernando Rocchi, Chimneys in the dessert: industrialization in Argentina during the export boom years, 1870-1930 (Standford University Press, 2006).

93 Censo General de población, Edificación, Comercio e Industrias de la Ciudad de Buenos Aires, Buenos Aires, Compañia Sudamericana de Billetes de Banco, 1905. (levantado entre el 11 y 28 de septiembre de 1904). Censo General de población, Edificación, Comercio e Industrias de la Ciudad de Buenos Aires, Buenos Aires, Compañia Sud-americana de Billetes de Banco, 1910. (levantado en octubre 1909), Censo de 1914 citado por Fernando Devoto en, Historia de los italianos en la Argentina, 303. Véase del mismo autor Historia de la inmigración en Argentina (Buenos Aires: Sudamericana, 2003)._

94 Claudia Shmidt, Palacios sin reyes. Arquitectura pública para la "capital permanente". Buenos Aires, 1880-1890 (Rosario: Prohistoria Ediciones, 2012).

95 Liernur, "La ciudad efímera". Véase también de Liernur, "la construcción del país urbano", en Arquitectura en la Argentina del siglo XX.

96 En 1906, arribaron 127.348 de italianos y en 1910 el número fue de 102.019. Devoto, Historia de los italianos en la Argentina, 237. 
Fernando Devoto, además de contactar amigos o familiares, un inmigrante recién llegado podía comer en una fonda cuyo dueño era italiano, comprar ropa o zapatos en un comercio italiano, ir a un barbero o peluquero de la misma nacionalidad o leer periódicos en su lengua madre. Esta omnipresencia de los italianos en casi todos los rubros abarcaría también, como veremos, el de la industria..$^{97}$

Como parte de la rutina de una ciudad cambiante, las salidas y diversiones en Buenos Aires incluían paseos en la costanera, parques, bailes, cafés, restaurantes, cines y teatros. Las imágenes de estos espacios eran — junto con las de sus visitantes_ frecuentemente publicadas en las revistas de tirada popular que reproducían escenas de la vida metropolitana, mientras que los periódicos se inclinaban a señalar los problemas relacionados a la higiene, la aglomeración, la pobreza y la falta de vivienda que formaban parte de la ciudad.

Como a fines del siglo XIX expresó el periodista y escritor Julián Martel, “(...) la plaza de Mayo era, en aquel día y a aquella hora, un muestrario antitético y curioso de todos los esplendores y de todas las miserias que informan la compleja y agitada vida social de la grande Buenos Aires." ${ }^{\text {98 }}$ Las actividades comerciales y gubernamentales se ubicaban al norte y sur de la Plaza Mayor. ${ }^{99}$ El poder político y las sedes comerciales, bancarias y financieras se ubicaron al Sur, en la zona del bajo, mientras que los bancos, las sedes de las representaciones diplomáticas y los templos de las comunidades extranjeras al Norte.

En los comienzos del siglo XX, las grandes tiendas como Harrods, A la Ciudad de Londres o Gath \& Chaves se ubicaban en los barrios de Montserrat o Socorro; el cementerio, al Norte; el basural al Sur y el mercado al Oeste. ${ }^{100}$ Sin embargo, esta "sectorización" no delimitaba de manera estricta las actividades. Si observamos el plano de Buenos Aires de 1916, podemos ver que la industria se ubicaba al Sur, los mercados, iglesias y teatros primaban hacia el Oeste (entre Cerrito y Entre Ríos) mientras que en la zona cercana a Plaza de Mayo se daba una mayor concentración de actividades financieras y gubernamentales que se entremezcla con algunas iglesias, mercados y actividades universitarias.

97 Devoto, Historia de los italianos en la Argentina, 282.

98 Julián Martel, La Bolsa (El Aleph, 2008 (1891)).

99 Jorge Francisco Liernur, “Área central norte. Reflexiones para una crítica”, Summa No 171/172 (feb/mar, 1982): 27.

100 Liernur, “Área central norte”: 27. 

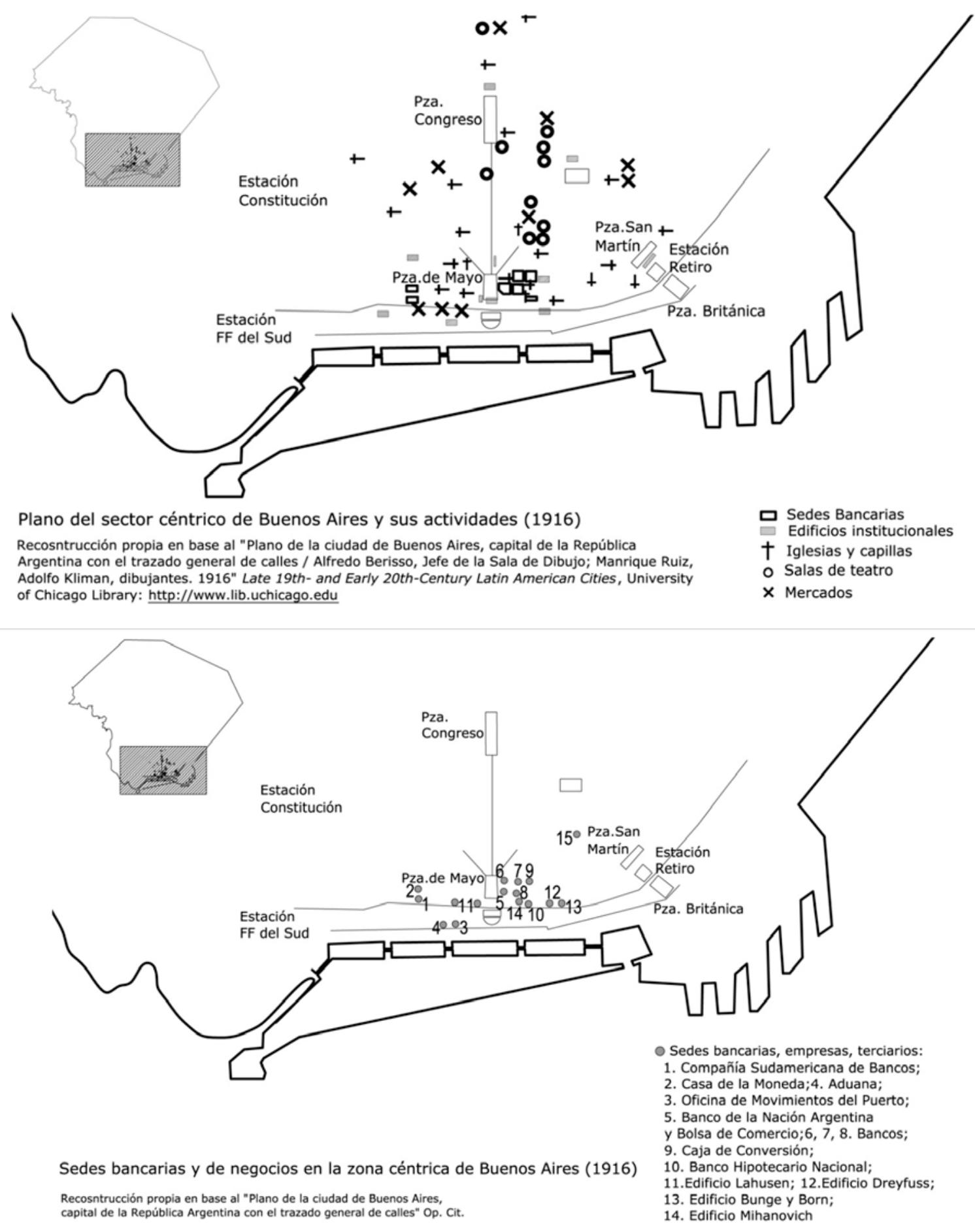

Planos elavorados para mi Tesis de Maestria, Virginia Bonicatto Escribir en el cielo

Hacia fines del siglo XIX, se realizarían diferentes intervenciones físicas sobre Buenos Aires que transformarían radicalmente su imagen. ${ }^{101}$ Si bien muchas de las iniciativas reconocían sus antecedentes en el período rivadaviano, ${ }^{102}$ la federalización, en 1880, dio inicio a una serie 101 Ana María Rigotti, "Many plans, the Plan. Practices on Argentine Cities around 1900”, en Architecture Culture around 1900. Critical Reappraisal and Heritage Preservation, eds. Jorge Francisco Liernur, Fabio Grementieri y Claudia Shmidt (Buenos Aires: UNESCO World's Heritage y UTDT, 2003).

102 Fernando Aliata, La ciudad regular. Arquitectura, programas e instituciones en el Buenos Aires posrevolucionario, 1821 1835 (Bernal: UNQUI-Prometeo, 2006). 
de reformas urbanas que comenzaron con la intendencia de Torcuato de Alvear y se cerraron a mediados de la década de 1930 con la gestión de Mariano de Vedia y Mitre. ${ }^{103}$ Asimismo, se realizaron una serie de planos y proyectos, de los cuales se llevan a cabo unos pocos y en los que se puede ver reflejadas las diferentes voluntades de reforma que fueron transformando al paisaje urbano en “(...) un ensamble de ruinas fáusticas desde las que la ciudad pareció reinventarse.” ${ }^{104}$ En 1887, la ley 2089 incorporó los partidos de Belgrano y Flores y, en 1888, se definió el trazado de la futura General Paz que dio a Buenos Aires una superficie de más de 18.000 hectáreas. ${ }^{105}$ En 1894, se inauguró la Avenida de Mayo y en 1913 comenzó la construcción del primer subterráneo que circulaba bajo dicha Avenida y la obra de la Diagonal Norte.

El contexto disciplinar que acompañaba este proceso de metropolización al momento que arribó Palanti, se caracterizó en ese entonces por la búsqueda, por parte de un sector de profesionales, de una imagen nacional y una "arquitectura argentina" que se desarrollaba desde la federalización de Buenos Aires, la cual se vio incrementada hacia los festejos del Centenario. Al respecto, el libro publicado por el Municipio en conmemoración de la fecha patria, expresaba el descontento por parte de las autoridades ante la producción arquitectónica de las diferentes corrientes inmigratorias que no lograba concretar una imagen homogénea para la Capital. ${ }^{106} \mathrm{Al}$ mismo tiempo, convivían diversas ideas: por un lado, quienes desde el municipio y la cultura

$\overline{103}$ Gorelik, La grilla y el parque.

104 Adrián Gorelik, "Buenos Aires en la encrucijada: modernización y política urbana" (1997), en Miradas sobre Buenos Aires: modernización y politica urbana, (Buenos Aires: Siglo XXI, 2004), 207-208. Entre los proyectos encontramos el Plano de Mejoras de 1898, el Plano de alineación 1904, el de Víctor Julio Jaeschke de 1904, el de Enrique Chanourdie de 1906. Hacia 1907, con la aproximación de los festejos del Centenario de Mayo, la intendencia de Manuel J. Güiraldes (1908-1910) decidió llamar a Joseph Bouvard, Jefe de los Trabajos Públicos de Paris, que operó entre 1907 y 1911 junto a técnicos locales. Resultado de su trabajo fue el Nuevo Plano de 1909. Durante la Intendencia de Joaquín S. de Anchorena (1910-1914), el debate se centró en la controversia entre avenidas y diagonales. Por último, en 1925, durante la intendencia de Carlos M. Noel, se realizó el Plano Regulador y de Reforma de la Capital Federal a cargo de la Comisión de Estética Edilicia que había sido creada por el intendente en 1923. Véase Alicia Novick, "Planes versus proyectos. Algunos problemas constitutivos del Urbanismo Moderno. Buenos Aires (1910-1936)". Revista de Urbanismo, No3 (Universidad de Chile: FAU, Ago. 2000). Disponible en: http:// revistaurbanismo.uchile.cl/n3/index.btml; Jorge Tartarini, "El Plan Bowvard para Buenos Aires (19071911). Algunos antecedentes", Anales 27-28 (Buenos Aires: LAA-FADU-UBA, 1992); Sonia Berjman, "Proyectos de Bowvard para la Buenos Aires del Centenario: Barrio, plazas, hospitaly exposición", DANA, No 37/38 (1995).

105 Gorelik, La grilla y el parque, 13.

106 En la diversidad de estilos encontramos diferentes líneas del art nouveau (Julián J. García Núñez, Alfredo Massüe, Virginio Colombo), usado en casas de renta, el neo Liberty italiano y románico lombardo en viviendas, establecimientos industriales y comerciales (M. Palanti, F. Gianotti, J. Chiogna, L. Broggi). La arquitectura en hierro en las estaciones de ferrocarril (Chambers, Follet, Newbery Thomas). Palacios y petit bôtel de líneas academicistas francesas (Eduardo Le Monnier, Julio Dormal, René Sergent, Louis-Marie Sortais). Todos ellos unidos en una "babel" de estilos arquitectónicos que bien podría ser representada por la Avenida de Mayo. Mercedes Daguerre, voz,"Eclecticismo" en Diccionario de Arquitectura, (Buenos Aires: Clarin, 2004) 
anhelaban la metropolización de la capital y veían en lo "moderno" la materialización del progreso; por otro lado, quienes advertían una ruptura con el pasado a partir de una mirada nostálgica por "la ciudad que fue". ${ }^{107}$ Como fue estudiado por Adrián Gorelik, posturas como la de Manuel Gálvez, Leopoldo Lugones o Ricardo Rojas, que buscaban una ciudad tradicional y de impronta nacionalista, se diferenciaban de la mirada de intelectuales como Alberto Gerchunoff y Enrique Vera González, que alentaban la modernización de Buenos Aires al ver en la transformación material señales de un futuro próspero que garantizaría la igualdad y la justicia social. Esta idea de progreso "era el continuo desarrollo de la conquista de la naturaleza para ponerla al servicio del hombre, de la producción de bienes, de la producción de riquezas, de la producción de bienestar." 108

En el marco de esta discusión en torno a la construcción de una “imagen nacional”, la prensa masiva operó como un enemigo de la "reacción nacionalista", al divulgar con gusto las imágenes del porvenir y la exótica vida metropolitana. ${ }^{109}$ Una respuesta a la gran ciudad que proporcionaba "su propia forma de representar las escenas pintorescas y descontroladas que ocurren día tras día en sus escenarios." ${ }^{110}$

Desde fines del siglo XIX, revistas de tirada popular como Caras y Caretas, Plus Ultra o PBT, como también diarios y revistas como La vie d'italia o Illustrazione italiane, circulaban en Buenos Aires

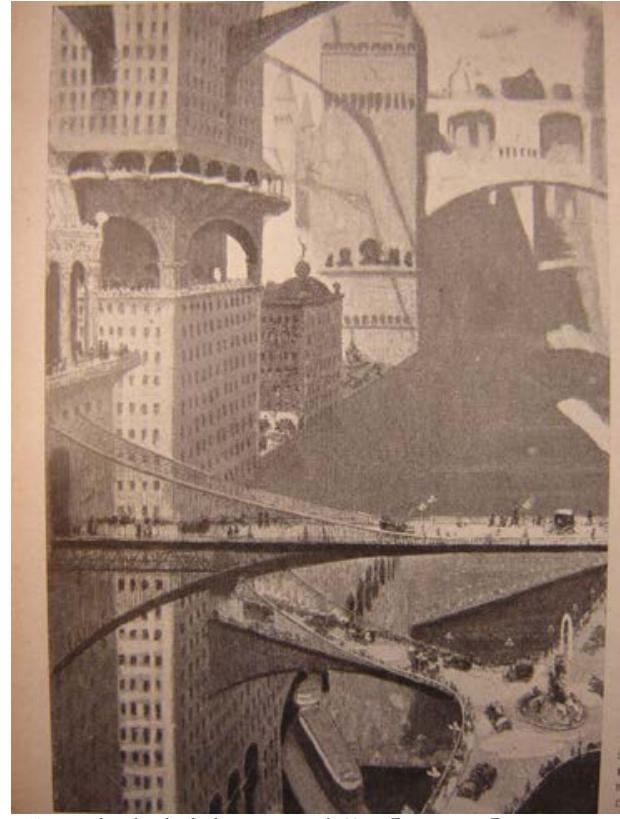

"La ciudad del porvenir", Caras y Caretas, n 601, 9 de abril de 1910, BPUNLP dando cuenta de los cambios y acontecimientos que

107 El libro publicado en conmemoración del Centenario declaraba que "es evidente que esas máximas exageraciones con grotescos adornos de tierra romana, hechos en moldes (que más que pecados de los arquitectos, lo son de los propietarios adinerados), comportan un anhelo de progreso." Carlos María Urien y Ezio Colombo, La República Argentina en 1910. Estudio histórico, físico, político, social y económico. Honorable Comisión del Centenario de la Independencia Argentina y Junta de Historia y Numismática Americana (Buenos Aires: Maucci Hnos, 1910). 108 José Luis Romero, Latianoamérica, las ciudades y las ideas (Buenos Aires: Siglo XXI, 2008 (1976)). 310.

109 Gorelik, 215-216.

110 Peter Fritzsche, Berlín 1900, prensa, lectores y vida moderna (Buenos Aires: Siglo XXI, 2008), 21. Fritzsche señaló cómo la prensa, en general, "se benefició con el nacimiento de un público masivo cuando surgieron las grandes ciudades." Los entonces tiempos “pasivos” dedicados a la espera o viajes en tren, tranvía, subte o colectivo se volvieron momentos ideales para la lectura de un material que aumentaba, junto a la profesionalización del periodismo y "se acomoda mejor a la rutina apretada, inconfundiblemente metropolitana." Pensemos en las Aguafuertes de Roberto Arlt. 
se producían en la metrópolis. ${ }^{111}$ Estas revistas, que utilizaron la fotografía de manera masiva como medio de comunicación, se caracterizaron por impulsar imágenes que representaban la ciudad del futuro y contrastaban con la construcción de una imagen nacional que en reiteradas ocasiones compartía las mismas publicaciones.

Como escenarios que abonaban aquella "invención técnica" planteada por Beatriz Sarlo, ${ }^{112}$ en las páginas de las revistas era común encontrar fotografías, dibujos o grabados que representaban rascacielos iluminados, aviones, vehículos aéreos, calles elevadas que, sin duda Palanti conocía -recordemos la referencia al aterrizaje de vehículos aéreos en rascacielos hecha en el capítulo anterior-. Además de estas figuras imaginarias, varias notas informaban sobre los grandes hoteles neoyorquinos, los rascacielos y la ciudad, acompañadas por ilustraciones que mostraban los “avances” de la vida moderna. Imágenes de edificios como el Singer Building, el Flatiron, el Ansonia Hotel, el Standard Oil o el Woolwoorth Building, eran publicadas para mostrar los logros constructivos norteamericanos. ${ }^{113}$ Asimismo, aunque no destinadas al público masivo, las revistas especializadas publicaban notas tituladas "de actualidad" que daban a conocer las grandes “construcciones yankees”: las últimas técnicas y saberes de la construcción.

Quizás aun más importante que esta difusión de los ejemplos concretos vinculados al hecho construido y a la ciudad, haya sido el uso de la imagen del rascacielos como verdaderas “escenas de modernidad" que, comúnmente han sido puestas en un segundo plano. Precisamente, la imagen del rascacielos era tomada como ejemplo de solidez, inclusive en las publicidades de productos por fuera del ámbito de la construcción. ${ }^{114}$

John Berger señaló cómo las obras de arte son citadas por la publicidad como una "autoridad cultural, una forma de dignidad" que sirve para aumentar la eficacia del mensaje publicitario, cuyo objetivo es incitar al público al consumo de un objeto determinado. ${ }^{115}$ Podemos pensar que este tipo de publicidad — donde la imagen de la construcción en altura era asociada

111 Entre otras revistas encontramos: Plus Ultra, Fray Mocho o La semana gráfica, véase Margarita Gutman, Buenos Aires 1910: memoria del porvenir. (IIED- América Latina, FADU-UBA, The Getty Research Institute, 1999).

112 Hacemos referencia a la Imaginación técnica descripta por Beatriz Sarlo. Una inquietud hacia la invención, la novedad, la técnica, propia de las clases medias emergentes de principios de siglo XX. La imaginación técnica. Sueños modernos de la cultura argentina. (Buenos Aires: Nueva Visión, 1992)

113 "Arquitectura Moderna. El arte de las construcciones elevadas. Su desarrollo en los Estados Unidos". La Nación. 1904; "Las grandes construcciones norteamericanas". La Nación, 21 de julio 1909; "Los hoteles de lujo en Nueva York”. Caras y Caretas, No 487, 1 de febrero 1908.

114 Caras y Caretas, No 487, 1 de febrero 1908; Caras y Caretas, № 596, 5 de marzo 1910 y 25 de mayo 1910. 115 John Berger, Modos de ver (Barcelona: GG, 2005 (1972)): 143-170. Véase, Margarita Gutman y Thomas Reese (eds.), Buenos Aires 1910: el imaginario para una gran capital (Buenos Aires: Eudeba, 1999). 
a la confianza en un producto, a la calidad o al prestigio—, tuvo más importancia que la hasta ahora adjudicada en la conformación de una imagen de firmeza en torno a la tipología del rascacielos. ${ }^{116}$ Dedicadas a persuadir al creciente número de consumidores metropolitanos, estas imágenes eran simples, fáciles de comprender, prácticamente sin texto $\mathrm{y}$ diseñadas para abarcar al totalidad del mercado. ${ }^{117}$

Esta circulación de dibujos, fotografías y relatos que construyó una imagen de modernidad, solidez y prestigio abonada en las representaciones del futuro, la técnica y la construcción en altura, sin duda favoreció la elección del rascacielos

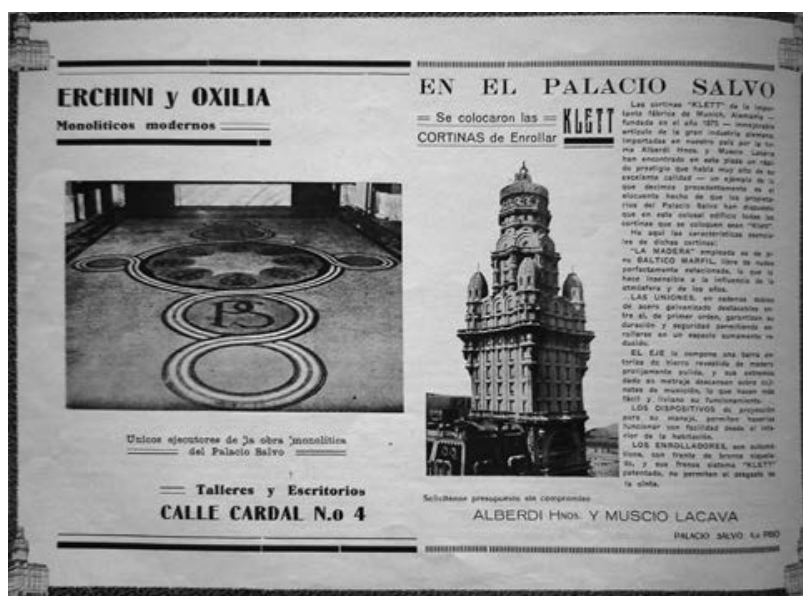

Almanaque del Banco de Seguros del Estado, 1930. IHA

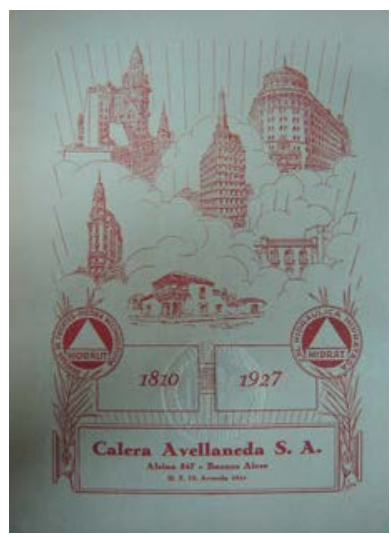

Publicidad de cemento. Revista de Arquitectura de la SCA. Buenos Aires, Julio, 1928

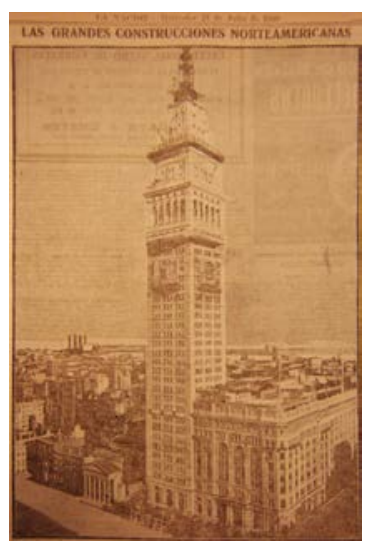

"Las grandes construcciones norteamericanas", 1909 , BPUNLP. La Nación 21 de julio de como símbolo de poder y prosperidad por parte de los comitentes. ${ }^{118}$ Efectivamente, como veremos más adelante, este último tipo de encargos proveniente de particulares fue el que dio a Palanti la posibilidad de experimentar en la tipología en altura. Para un arquitecto joven e inquieto esta cambiante y contrastante Buenos Aires se presentaba como una metrópolis llena de oportunidades. Tal es así que, terminado el edificio, la Comisión Oficial regresó a Italia, a excepción de Mario Palanti quien decidió permanecer en Buenos Aires ante las ofertas de trabajo recibidas durante su estadía. ${ }^{119}$

$\overline{116}$ Virginia Bonicatto, Escribir en el cielo.

117 Fritzsche, Berlin 1900, 145-149.

118 Recordemos que durante el periodo se realizan varias iniciativas por parte del municipio que proponen al rascacielos como ordenador urbano. Entre ellas la planteada por la CEE. Comisión de Estética Edilicia MCBA, Proyecto orgánico para la urbanización del Municipio, Buenos Aires, Talleres Peuser, 1925. También de gran influencia durante el período fue el texto de Werner Hegemann/Elbert Peets/ Alan J. Plattus, The American Vitruvius: an architect's bandbook of Civic Art, (Princeton Architectural Press, 1996) (1922).Sobre la problemática en torno a la implantación de lso rasccielos en Buenos Aires a inicios de siglo XX véase Virginia Bonicatto, "Un lugar para la excepción. Problemáticas en torno a la ubicación del rascacielos en Buenos Aires entre 1909 y 1929" en Anales LAA 41 (Buenos Aires, 2011)

119 Palanti, Curriculum Vitae 1958. 


\section{Prins y Ranzanhofer: la experiencia técnica en la metrópoli}

Precisamente, en 1910, el joven arquitecto aceptó trabajar con un contrato por dos años en el estudio de Arturo Prins - a quien probablemente había conocido como director de obras del Pabellón Principal de la Exposición Industrial del Centenario de Mayo- y Oskar Ranzenhofer. ${ }^{120}$ Como parte de la firma, Palanti participó junto a sus compatriotas Francisco Gianotti y Angel Valdemarca en el proyecto de la Facultad de Derecho (actual Facultad de Ingeniería de la UBA, sede Las Heras). Aunque el concurso llevado a cabo para la elección del proyecto había sido ganado por A. Prins, poco después, la comisión evaluadora sugirió la modificación del lenguaje neoclásico del planteo original ${ }^{121}$ y encargó al estudio de Prins y Ranzanhofer quienes, luego de estudiar diferentes alternativas adoptaron el lenguaje neogótico, para lo cual Prins contó con la colaboración de Palanti y Valdemarca. Ambos conocían el repertorio de elementos medievales a partir de sus estudios con Camilo Boito. ${ }^{122}$ En efecto, el trazo del arquitecto italiano se hace visible al comparar los esquicios que muestran la fachada e interiores del proyecto para la Facultad con los dibujos presentados como parte del proyecto para la Catedral Metropolitana y los

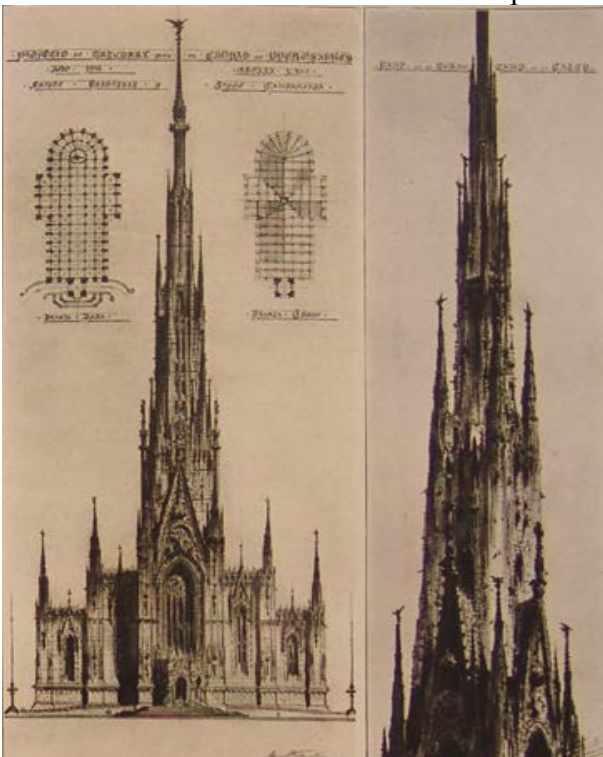

Proyecto para catedral metropolitana, Buenos Aires, 1913. M. Palanti. Prima esposizione personale d'architettura nella Repubblica Argentina. Milán. Stab. di arti grafiche Rizzoli e Pizzio.1917.Tav. XVII

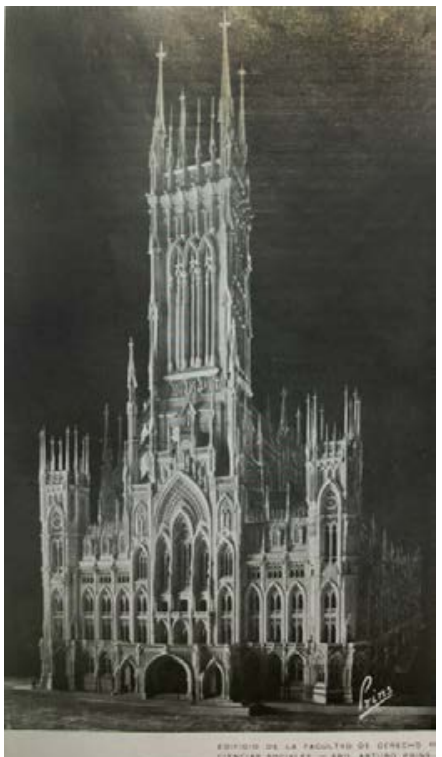

Arturo Prins. Proyecto para la Facultad de Derecho. primeros esquicios que nos revelan, algunos años después, los posibles interiores del Pasaje Barolo. ${ }^{123}$

120 Palanti, Curriculum Vitae 1958.

121 E. Chantecler, "Concurso de la facultad de derecho", Revista de Arquitectura No 62 (marzo y abril, 1910). Arturo Prins, "La arquitectura gótica. Origen y característica de la fórmula gótica”, Revista de Arquitectura, N 2 (1915).

122 Piccioni, "La arquitectura de Buenos Aires bajo el influjo de la Academia de Bellas Artes de Brera.

123 Mario Palanti, "Edificio Luis Barolo" en El Arquitecto N³. Buenos Aires. Feb. 47-49. "Arquitectura religiosa. Proyecto de catedral" en Revista de Arquitectura. Órgano del Centro de Estudiantes de Arquitectura. Nº. Buenos Aires. 22-23. 
Durante su estadía en este estudio Palanti tuvo la posibilidad de familiarizarse con el uso del hormigón armado y la práctica en obra. En efecto, de acuerdo a la documentación existente, la Facultad de Derecho fue su primer acercamiento a un verdadero cantienre. Allí tuvo la posibilidad de estar en contacto con un sistema constructivo que conjugaba el uso de columnas mixtas de perfilería de hierro y refuerzos de hormigón armado.

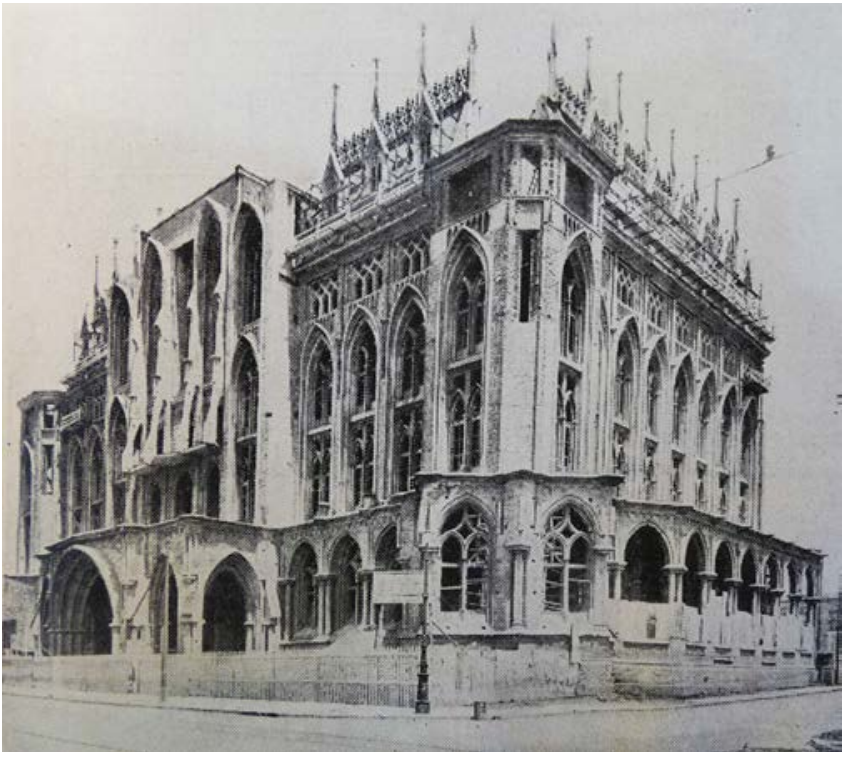

Arturo Prins. Facultad de Derecho. Buenos Aires Por su parte, Ranzenhofer era un fiel militante del sistema constructivo en hormigón armado que ya desde 1910 promocionaba a través de la "Sección Arquitectura" de la revista La Ingeniería del Centro Nacional de Ingenieros. ${ }^{24}$ Allí, en la serie de artículos que explicaban la nueva técnica constructiva, Ranzenhofer se preguntaba si sería ésta la forjadora de una nueva arquitectura: "Nunca el cemento armado vendrá á tener una arquitectura tan pobre y restringida, pues se le despeja delante un campo enorme y sus formas las buscará en la verdad, es decir, en la misma construcción.” ${ }^{125}$ Frente a la rigidez de la producción clásica, el autor veía en la variedad y multiplicidad de formas permitidas por el cemento una técnica que superaría los contratiempos pues:

(...) tendrá siempre el gran mérito de distinguirse de otros estilos históricos, por ser una creación absolutamente nueva, haber nacido científicamente á fuerza de experimentos y cálculos, y formando un estilo que es únicamente resultado de nuestra ingeniería moderna, que se impone lentamente pero con seguridad, y arrastra consigo cualquier otra tendencia á ideas distintas, pues no podrían competir con este material práctico, económico é independiente (...). ${ }^{126}$

124 Oskar Ranzenhofer, "El cemento armado en la arquitectura. Expresión de sus fuerzas internas" en $L a$ Ingeniería 1 (Enero 1910): 9-11.

125 Ranzenhofer, "El cemento armado en la arquitectura", 10.

126 Ranzenhofer, "El cemento armado en la arquitectura". 
Considerando lo dicho, podemos pensar en la experiencia en el estudio de Prins y Ranzenhofer como decisiva en la formación de Palanti. En particular, la teoría de Ranzenhofer que, en sintonía con los postulados de Boito y Viollet-le-Duc, señalaba al hormigón armado como material posibilitador de una nueva arquitectura que necesariamente requeriría la superación del código clásico para dar con nuevas formas que fuesen el producto de la racionalidad constructiva. Formas que, como gran parte de la producción arquitectónica de la época, encontraría cierta resistencia por parte de los sectores más conservadores en el ámbito disciplinar.

\section{Tensión con la Sociedad Central de Arquitectos}

Desde fines de siglo XIX, predominaba de manera hegemónica en el país el eclecticismo europeo -validado por las Academias- que había servido como vía para resolver los grandes programas metropolitanos de la nueva Capital estatal y se incrementaba, como señalamos, la búsqueda de un "estilo nacional" impulsada por parte de un sector dirigente.

En 1901, bajo la dirección de Alejandro Christophersen, se creó la Escuela de Arquitectura en el marco de la Facultad de Ingeniería y de Ciencias Exactas, lo que señaló una diferencia en la formación profesional: por un lado -como señala Cirvini-posibilitaba la formación autónoma de profesionales de grado en Buenos Aires; por otro, permitía adecuar las prácticas a la realidad local, distinta de la europea. ${ }^{127}$ Avanzando en la institucionalización de la disciplina en el contexto local, hacia 1904, por Ley nacional No 4416 se autorizó la reválida de diplomas de ingeniero provenientes de universidades europeas "y en la misma ley se autorizaba el ejercicio, por idoneidad profesional en Arquitectura, previa obtención del título de competencia en la Universidad.” En 1905 -mismo año en que egresan los primeros arquitectos de la Escuela- se diplomaron noventa arquitectos extranjeros que rindieron el examen de reválida en la Escuela de Arquitectura, Facultad de Ciencias Exactas. ${ }^{128}$

"Este modo de blanquear la situación de los títulos extranjeros suscitó grandes controversias y críticas; sin embargo era un hecho de gran importancia en la legitimación de la actividad de los practicantes de la disciplina, ya que supuso el reconocimiento por parte del Estado de la necesidad de legislar y regular las prácticas profesionales.” ${ }^{229}$ Posteriormente,

127 Cirvini, Nosotros los arquitectos, 44.

128 Cirvini, Nosotros los arquitectos, 44.

129 Cirvini, Nosotros los arquitectos, 44-45. 
la Ley $\mathrm{N}^{\circ} 4560$ impuso como condición poseer un título nacional de arquitecto o ingeniero para ocupar cargos en organismos estatales relacionados a obras públicas. "El camino de la legitimación del título profesional ya estaba iniciado; el debate entre los arquitectos se orientará en adelante, a definir el lugar que debían ocupar en la construcción del hábitat con relación a los otros actores con quienes compartían el campo." ${ }^{130}$ Esta ley pretendía saldar el problema de la dificultad para detectar la legitimidad de los títulos profesionales: en el contexto argentino de principios de siglo corroborar la autenticidad de un diploma de origen europeo. Como señala D’Amia, muchas de las referencias que se tienen sobre la titulación de los arquitectos provienen de memorias autobiográficas o publicaciones de la época frecuentemente encargadas por los propios protagonistas. ${ }^{131}$ Tal es así que en el caso de Palanti lo vemos figurar como ingeniero en ciertas publicaciones.

Esta situación -explica Cirvini- derivó en que, hacia 1906, la mayoría de los socios de la Sociedad Central de Arquitectos (SCA) fueran profesionales formados en el exterior que habían revalidado sus diplomas. Palanti, en cambio, no mostraba interés en pertenecer a la SCA o desempeñarse en cargos públicos, como tampoco de ejercer docencia; por lo tanto, no tramitó la reválida de su título durante su primer período de permanencia en la Argentina (1910-1933). Esta actitud lo diferenciaba de sus connacionales Francisco Gianotti, Virginio Colombo o Angel Valdemarca quienes, por el contrario, se establecieron en el país de manera permanente. Esta actitud alejó a Palanti del grupo profesional hegemónico, nucleado en la SCA y que operaba como "portavoz de los intereses corporativos".

Considerando lo dicho, no sorprende que los mayores logros edilicios del arquitecto sean prácticamente ignorados por las publicaciones especializadas- si lo mencionaban, era sólo para realizar comentarios negativos - como la Revista de Arquitectura, creada en 1915 por el Centro de Estudiantes de Arquitectura -que había "formulado sus propósitos en dirección a la búsqueda de una arquitectura nacional, como arte y cultura propia, inspirada en nuestra historia y apoyada en los recursos de la naturaleza y el clima"- y desde 1917 era portadora de la opinión de la SCA orientada a fines políticos, "de inserción institucional dentro de la sociedad civil y de una articulación con la modernización que imponía el modelo económico del capitalismo en expansión.”. ${ }^{132}$ Palanti, entonces, sólo pudo publicar su obra en la revista del

130 Cirvini, Nosotros los arquitectos

131 D’Amia, "Architetti lombardi a Buenos Aires: percorsi formativi e prime occasioni profesionali".

132 Cirvini, Nosotros los arquitectos, 65. "La aparición cronológica de los órganos de la prensa corporativa se 
CACYA (Centro de Arquitectos, Constructores de obras y Anexos), un organismo que reunía una amplia gama de profesionales (arquitectos sin reconocimiento de título, empresarios de la construcción, maestros y constructores). La tenaz resistencia de los círculos profesionales a su obra, evidenciada durante los años 20 , se consolidaba ante las cambiantes modas estilísticas. Alejado del Neocolonial, de la tradición Beaux Arts de la Sociedad Central de Arquitectos así como de los primeros pasos del Racionalismo, encerrado en la prisión de su poética, Palanti resultaba a los ojos del campo cultural bonaerense el hacedor de una producción cada vez más exótica que encontraba aprobación en el circulo de sus connacionales.

\section{Mario Palanti, II cortesano. El vínculo con la committenza}

Esta situación de tensión que se daba entre Palanti y la SCA no parece haber afectado al arquitecto: durante las décadas de 1920 y 1930, se desplazó entre Italia y la Argentina, y disfrutó de una situación económica holgada. El álbum de fotos conservado por la familia del arquitecto lo muestra en lujosos viajes transatlánticos, vestido con la última moda, practicando equitación, golf, natación y otros deportes, disfrutando paseos en estancias y playas rioplatenses, lejos quedaba el origen humilde milanés del cual Palanti renegaría: “(...) doveva essere buttato a mare -le preguntaba su hermano Giuseppe-come bai fatto con tutti gli altri tuoi parenti, che banno solo lo torto di essere poveri cristi senza un soldo". ${ }^{133}$

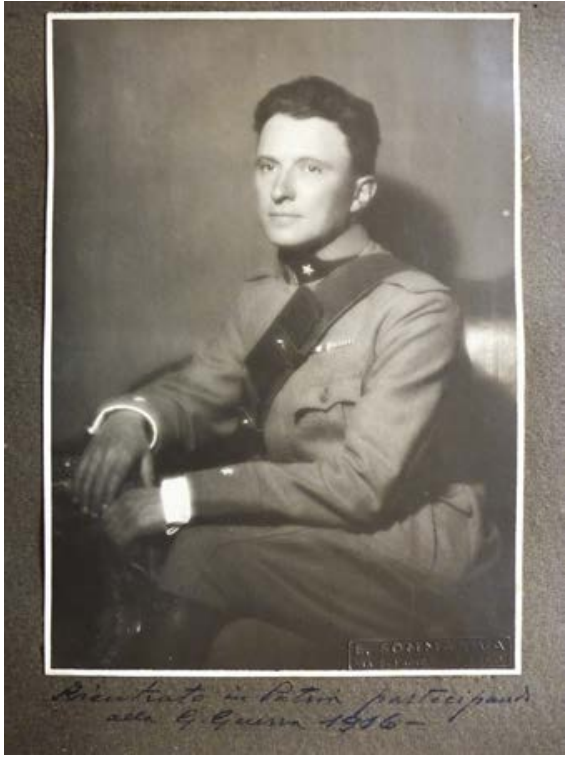

Fotografía de Mario Palanti. Rientrato in patria. Partecipando alla G.Guerra, Italia, 1916. Album personal. AGEP.

corresponde con el desarrollo habido en la delimitación de los campos disciplinares y con la modificación de las prácticas profesionales a medida que se profundiza la modernización como proceso de transformación material de la cultura. Así surgirá primero la Revista Técnica (1895), con temas de Ingeniería, Arquitectura, Minería e Industria, luego La Ingeniería (1897), órgano oficial del Centro Nacional de Ingenieros, con todas las ramas de la disciplina, más tarde Arquitectura (1904) como apartado específico dentro de la Revista Técnica. En 1910 se crea el Centro de Estudiantes de Arquitectura y al año siguiente se funda la Revista del Centro de Estudiantes de Arquitectura (1911), que tendrá la efímera vida de un año. Finalmente se crea la Revista de Arquitectura (1915), en primer lugar portavoz del Centro de Estudiantes de Arquitectura y luego, desde 1917, también de la Sociedad Central de Arquitectos. Esta última Revista que tendrá una permanencia ininterrumpida de casi cincuenta años (hasta 1962), será el órgano principal de expresión del conjunto de la corporación. Si bien coexistieron durante algunos períodos revistas técnicas que expresaron otras voces, como Nuestra Arquitectura (1929) y El Arquitecto (1919), ninguna tuvo la continuidad -dentro del período de estudio-, ni el peso, ni la pluralidad de voces y de debates que ofreció la Revista de Arquitectura." Cirvini, Nosotros los arquitectos, 52.

133 Carta de Giuseppe Palanti a Mario Palanti, 25 de octubre de 1927. Archivio Palanti (AP) “(...) tenía que 


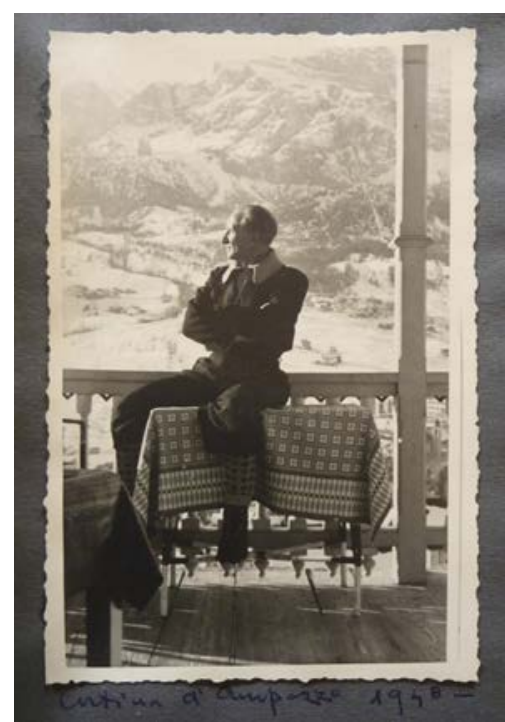

Mario Palanti en Cortina

D ampezzo antes de viajar a la Argentina. 1948. AGEP

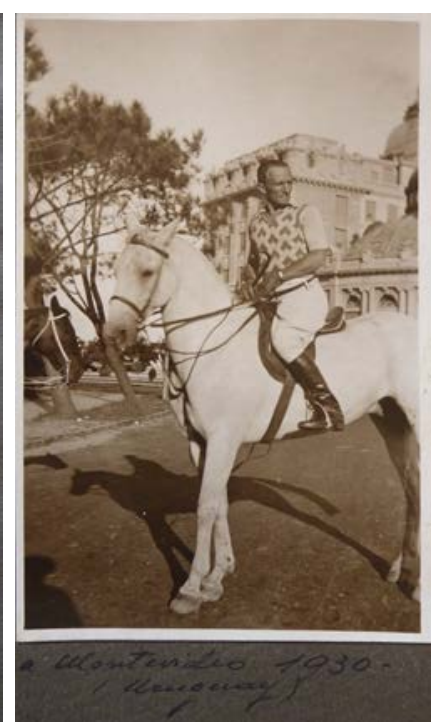

Fotografía de Palanti en Montevideo. 1930 . Album perso-
nal. AGEP

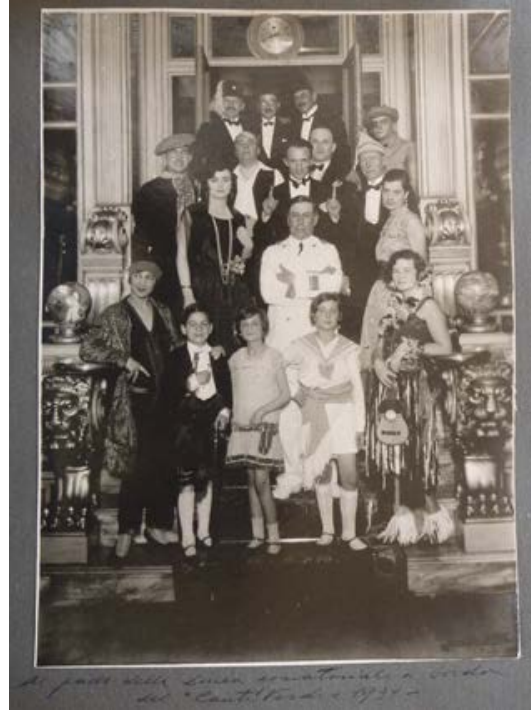

Fotografía de Mario Palanti Al paso della línea equatoriale a bordo del "Conte verde", 1931. Album personal. AGEP

Por cierto, esta figura montada por Mario Palanti requería constantemente de la ayuda

de su hermano mayor quien desde Italia acompañaba las impulsivas iniciativas del arquitecto propias de una "imaginación técnica": en la década de 1930 montó la empresa Cinematográfica "Platano Films" con sede en Buenos Aires y Milán, también junto a Giuseppe diseñó un submarino indestructible, compró automóviles, realizó viajes y publicó, con su ayuda, varios de los volúmenes que publicitaban su obra.

Luego de una discusión familiar, y considerando el esfuerzo que esta actividad requería, en una carta del 25 de octubre de 1927, Giuseppe Palanti reclamó a su hermano el ajuste de las deudas contraídas al fracasar la inversión inmobiliaria que ambos habían hecho en Berlín tras adquirir tres viviendas luego de la Primera Guerra. A través de la protesta de Giuseppe, el documento permite ver la cantidad de favores que éste había hecho por su hermano menor a fin de que mantuviera en alto el estatus de su carrera:
(...) prima che tu partissi, quando invocavo quel senso di fratellanza che doveve inspirare $i$ tuoi atti, mi hai detto che gli affari sono gli affari, e che io non sono mai stato tuo fratello e tante simili gentilesse, cosi io, da nomo d'affari, intendo che il lavoro che io ho fatto sia pagato e, se vuoi, ti darò un elenco esatto di tutti gli impegni che tu hai preso con me e promesse non mantenute, cominciando dal $40 \%$ della tua prima pubblicazione, dall'intero profitto delle 300 copie rimaste che dopo bai voluto spedire per intero, dal 10\% della casa smontabile (in una tua del 26-6-22) dalle rappresentanza della stessa per l'italia, per finire alla promessa di iscrizione a tuo carico della ipoteca di 189.000 marchi, e delle centinaia di viaggi,

ser lanzado al mar - le preguntaba su hermano Giuseppe - como has hecho con todos tus otros parientes, que cometen sólo el error de ser pobres cristianos sin dinero”. [Traducción Florencia Minatta] 
perditempi, incombense di ogni specie, per le quali sinora non avevo esposte che le spese vive senza mai far cenno al mio tempo e alla energia dei miei anni più belli spesa con le Film, coll'Italcable, con Pirelli e Carosio, con tutte le tue pratiche per avere la laurea di ingegnere, col monumentale, dove, oltre al tempo e le pratiche spese per ottenere quel posto, mi sono impegnato per due ritratti (a meno di fare col tuo sistema!) con gli eterni brevetti, viaggi a Roma al Garda a piuro e che so io per tutti $i$ tuoi castelli in aria, con le pratiche per l'automobile, presso i giornali in diverse occasioni, macchine cinematrografiche, macchine trattrichi pavesi, ecc., macchine per blocchiere con relativo concorso fra le case costruttrici, piastrelle, ecc., col tuo volume dei "Quattro anni di lavoro" (Bestetti ne sa qualche cosa), medaglia per la scuola di Architettura, ecc. Lettere a centinaia a te e agli altri, ma sempre per te. ${ }^{134}$

La carta deja ver la multiplicidad de actividades que inquietaban el espíritu ingenioso de Mario Palanti, principalmente aquellas relacionadas a los avances técnicos (submarino, Italcable, Films, automóviles) y en las cuales involucraba a Giuseppe. En efecto, gran parte del material publicitario de Mario Palanti que hoy conocemos fue gestionado por su hermano. Radicado en Buenos Aires y sin los contactos o posición social que Giuseppe tenía en Milán, la negociación de estas diversas iniciativas hubiera sido imposible para el arquitecto.

Como parte de sus estrategias propagandistas, en 1921 el arquitecto conformó la Fondazione Mario Palanti, a través de la cual financió becas para estudiantes de arquitectura. Premeditando sus pasos, las mismas eran otorgadas a través de la l’Università di Architettura di Roma, la Reale Accademia d'Italia y la Santa Sede Vaticano tejiendo una cadena de favores que involucraba instituciones del Estado y de la Iglesia. ${ }^{135}$ Citando fragmentos de los relatos de Mario, Giuseppe le recordaba a su hermano menor que las propuestas recibidas tenían como único fin el beneficio del arquitecto:

134 Carta de Giuseppe Palanti a Mario Palanti, del 25 de octubre de 1927. AP “(...) antes de que partieras, cuando invocaba aquel sentido de hermandad che debería inspirar tus actos, me has dicho que los negocios son los negocios, y que yo no he sido nunca tu hermano y tantas gentilezas similares, de esa manera yo, como hombre de negocios, entiendo que el trabajo que he realizado debe ser pagado y, si quieres, te daré un elenco exacto de todos los trabajos que has realizado conmigo y de las promesas que no has mantenido, comenzando con el $40 \%$ de tu primera publicación, de la ganancia completa de las 300 copias que sobraron y que luego has querido enviar en su totalidad, el 10\% de la casa desmontable (en una carta tuya del 26-6-22) de la representación de la misma para Italia, para finalizar con la promesa de inscripción a tu cargo de la hipoteca de 189.000 marcos, y de los cientos de viajes, pérdidas de tiempo, incumbencias de toda especie, por las cuales hasta ahora no había expuesto más que los gastos de bolsillo sin haber nunca mencionado mi tiempo y la energía de mis años más bellos gastada con los Film, con el Italcable, con Pirelli y Carosio, con todas tus pruebas para obtener tu título de ingeniero, con el monumental, donde, además del tiempo y de los gastos para obtener ese puesto, me he comprometido para realizar dos retratos (a menos que hagamos tu sistema!) con las eternas patentes, viajes a Roma al Garda a Piuro y qué se yo a cuantos otros castillos tuyos, con los papeles para el automóvil, en el diario en diversas ocasiones, máquinas cinematográficas, los automóviles Pavesi, etc., máquinas para bloques de concreto con sus competencias entre los fabricantes, baldosas, etc., con tu volumen de los "Quattro anni di lavoro" (Bestetti sabe alguna otra cosa), medalla en la escuela de Arquitectura, ecc. Cartas de a centenares a ti y a los otros, pero siempre por ti." [Traducción Florencia Minatta]

135 Ver apéndice. 

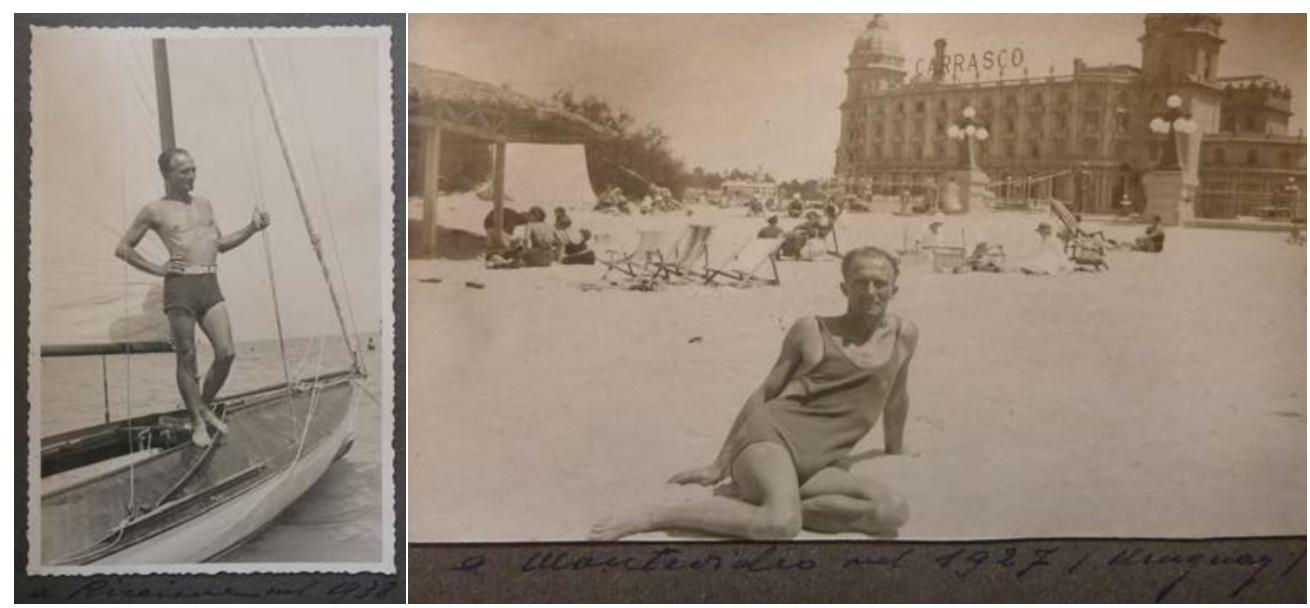

Fotografía de Palanti durante A Montevideo nel 1927, Archivo Guido y Emilio Palanti (AGEP) vacaciones en Riccione,

Italia, 1938. Album personal. AGEP

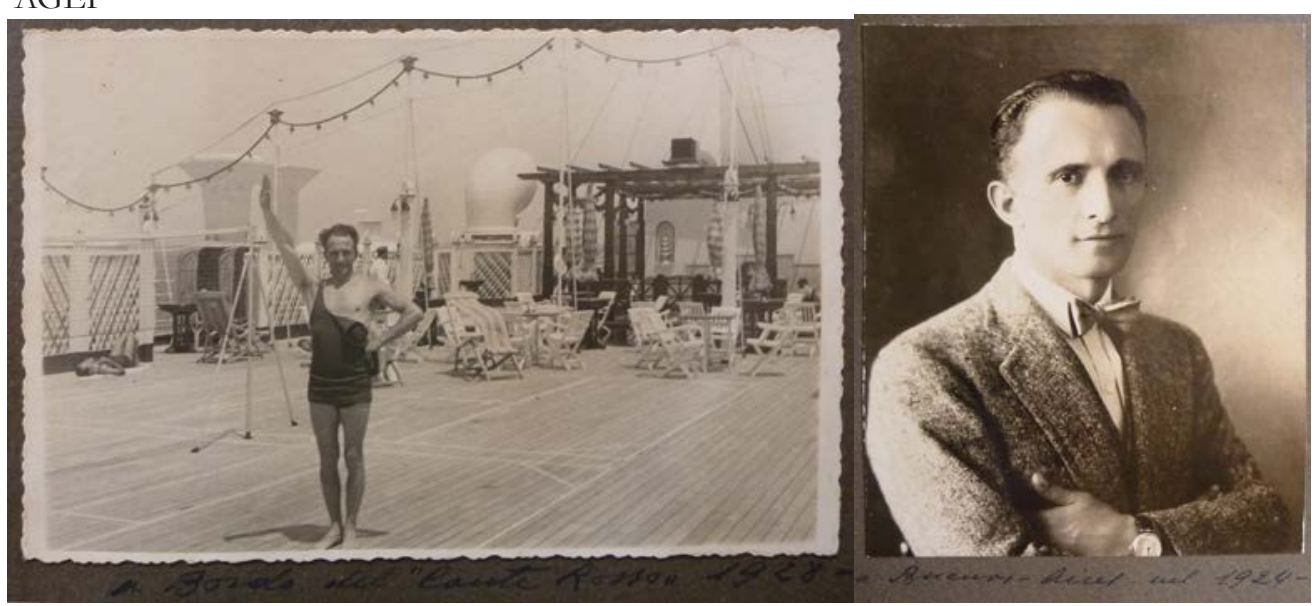

Saludo Fascista de Mario Palanti a bordo del Comte Rosso. 1928. AGEP

Fotografía de Mario Palanti en Buenos Aires, 1924. Album per-
sonal. Archivo Guido y Emilio sonal. Archivo Guido y Emilio
Palanti (AGEP)

'To istituii un'altra borsa di studio per figli di italiani nati nell'Argentina ed ivi residenti, preso il Vaticano. L'ho fatto oltre che per fine di bene anche per atto politico. Devi sapere che la salita è difficile e il mantenersi in alto ̀̀ ancora più difficile.", poi più avanti mi parli della ottenuta benedizione della torre barolo e il 20-9-925 "Questa accettazione della borsa la ritengo una mia vittoria, perchè a modo mio è senza dubbio un motivo per farmi conoscere da tutto il cervello Vaticanesco.", Ed il 21-1-924 "Ti ricorderai che io ottenni l'altissimo onore di istituire una borsa di studio presso il Vaticano e che portasse l'intestatura S.S. Papa Pio XI cosa che per gli intendenti in faccende clericali significa un gran onore anche perchè si tratta di un'istituzione all'eternità" E dire che a Berlino per poco giuravi che l'avevi fatto per me per ottenermi il ritratto! Una bella tolla! ${ }^{136}$

136 Carta de Giuseppe Palanti a Mario Palanti, del 25 de octubre de 1927. AP "Instituí otra beca de estudio para hijos de italianos nacidos en Argentina y allí residentes, en el Vaticano. Lo he hecho más que como fin benéfico, como acto político. Debes saber que la subida es difícil y el mantenerse en alto es todavía más difícil.", luego más adelante me hablas de la bendición obtenida con la torre barolo y el 29-9-925 "La aceptación de la beca la 
La pintura a la que Giuseppe hace referencia es un retrato del Papa Pio XI que en 1923 el artista accedió a realizar ad honorem por pedido de su hermano. ${ }^{137}$ (El cuadro estaba destinado a la Nunciatura porteña cuya remodelación finalizaría en 1927 y estaba a cargo del arquitecto. Como parte de su estrategia, éste decidió no cobrar

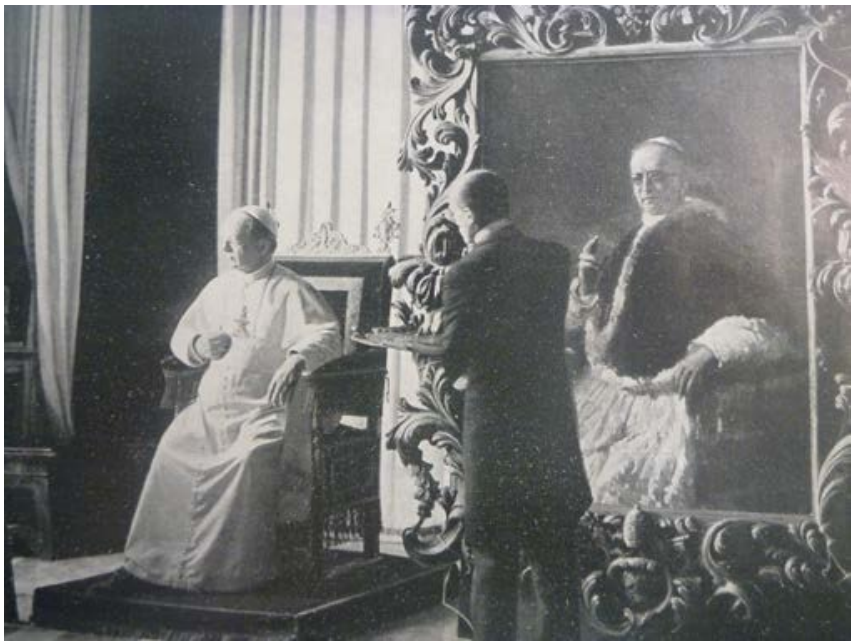
por el proyecto y por el año completo

Giuseppe Palanti pintando a Pio XI. L'Illustrazione italiana 45, noviembre 1924.

de dirección de obra, situación que utilizó en su favor, tal como lo demuestra el intercambio epistolar entre Palanti, Pietro Gasparri -nuncio en Buenos Aires- y Giovanni Beda Cardinale desde el Vaticano. ${ }^{138}$ Precisamente, en 1927, mientras Mario Palanti residía en Buenos Aires, Beda Cardinale -quien como nuncio porteño había bendecido la torre del Barolo- consiguió tras una extensa negociación el nombramiento de Mario como Commendatore de la Orden de San Gregorio Magno y de Giuseppe de la Orden de San Silvestre: las mismas representaban la gratitud, por parte del Vaticano, al trabajo sin remuneración y a las becas financiadas por el arquitecto y a la pintura realizada por Giuseppe. ${ }^{139}$

Esta capacidad de moverse como il cortesano no se limitaba a Italia sino que se extendía a los círculos sociales en la Argentina. Como resultado, Palanti logró su inclusión en los sectores más encumbrados de la colectividad italiana y establecer relación, a principios de la década de 1930, con miembros de la elite cultural rosarina. En julio de 1933, contrajo matrimonio con María Elena Castagnino, hermana de Juan B. Castagnino coleccionista de arte a quien posiblemente considero una victoria personal, porque a mi modo es sin dudas un motivo para hacerme conocido por todo el cerebro Vaticanesco.", y el 21-1-924 “Te acordarás que obtuve el altísimo honor de instituir una beca de estudio en el Vaticano y que portara la investidura su S. Papa Pio XI, cosa que para los administradores en cargos clericales significa un gran honor también porque se trata de una institución para la eternidad" Y pensar que en Berlín por poco jurabas que lo habías hecho por mí para que obtuviera el retrato! Una hermosa imprudencia!" [Traducción Florencia Minatta]

137 Carta de Mario Palanti a Monsignore Dr. Maurilio Silvani, Segretario della Nunziatura, Buenos Aires, 14 de junio de 1923. Archivio Segreto Vaticano (ASV), Archivio Nunziatura Apostolica in Argentina, Giovanni Beda Cardinale, Busta 100, Fascicolo 513, "varios”, an.1923-1925 ff. 1-306, f.281.

138 De acuerdo al contrato Palanti cobraría el monto total (no estipulado) en 4 cuotas. ASV, Archivio Nunziatura Apostolica in Argentina, 99, fasc. 510.

139 En una carta del 7 de mayo de 1923, el nuncio apostólico de Buenos Aires, P. Gasparri le explicaba a Beda Cardinale que "(...) mi faccio una gradita premura di significarle, con preghiera di rendersene interpretare presso l'Arch. Sig. Mario Palanti, che il SANTO PADRE é stato ottimamente impressionato dalle generose disposizioni di quel bravo signore e dalle sue nobili intenzioni per il progetto di una borsa di studio (...)" Carta de Gasparri a Beda Cardinale 7 de mayo de 1923. ASV, Segretaria di stato di sua Santita,1932 Rubrica 77, fasc.2. f.3. 
Palanti había conocido en Buenos Aires. Juan, junto con otros nueve hermanos, eran hijos de Lucrecia Tiscornia y José Castagnino que conformaban una de las familias más ricas e influyentes de Rosario. ${ }^{140}$ Aunque disuelto poco después debido a la precipitada partida del arquitecto hacia Italia en marzo de 1934, el casamiento muestra la facilidad de Palanti para entrar en contacto con los círculos de poder local. $^{141}$

El tipo de comitentes que el arquitecto frecuentaba se hace evidente en una carta del 30 de marzo de 1923 que Mario le envía a su hermano Giuseppe convocándolo a realizar pinturas y ganar dinero fácilmente: "Ti ripero un'altra volta che c'è da far quattrini in pochi mesi facendo unicamente ritratti a certa distinta categoria di gente. Bada che io di antura sono pessimista e se mi arrischio a parlare cosi è perchè sono certo di quel che ti dico (data la tua virtù)! ${ }^{142}$ El optimismo de Palanti no es en anda casual: para ese momento estaba terminando el Pasaje Barolo, había ganado el concurso para el Palacio Salvo y en el estudio
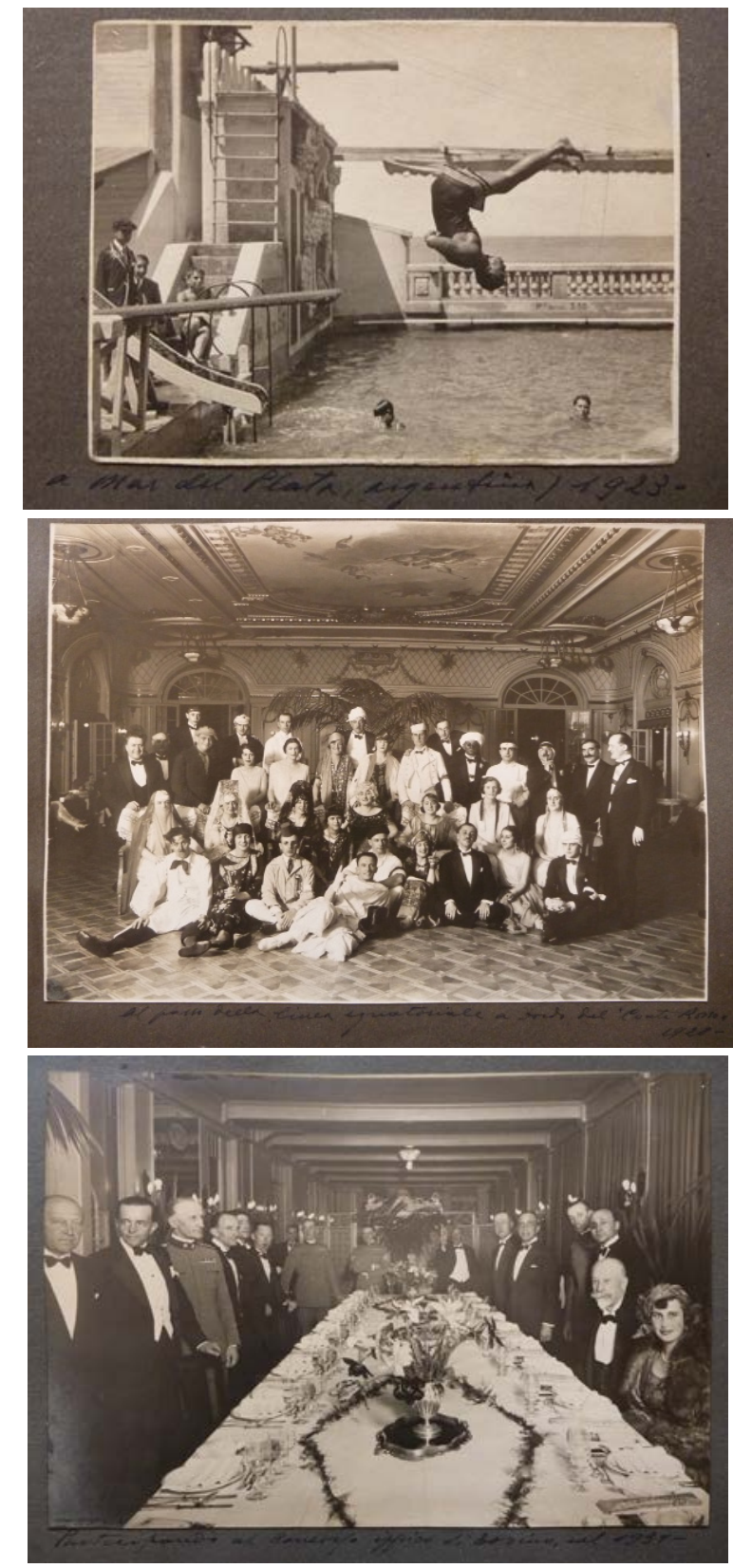

-A Mar del Plata. Argentina. 1923. AGEP -al passo della linea equatoriale a bordo del Conte
Rosso, 1928 - Participando al Campo hipico di Torino.1931. AGEP abundaban los encargos. Sin embargo su inicial fortuna profesional y social forjada en la Argentina comenzó por entonces a ensombrecerse lentamente.

Si consideramos esta capacidad de Palanti de promocionarse a sí mismo como profesional

140 Alonso, Sebastián y María Margarita Guspi Teran, Historia genealógica de las primeras familias italianas de Rosario, siglo XVIII y siglo XIX hasta 1870. (Rosario: Consolato Generale d'Italia, 2005).

141 Losada, Leandro, La alta sociedad en la Buenos Aires de la Belle Époque, Buenos Aires, Siglo XXI, 2008.

142 Carta de Giuseppe Palanti a Mario Palanti, del 25 de octubre de 1927. AP "Te repito otra vez que hay que generar dinero en pocos meses realizando únicamente retratos a cierta distinguida categoría de personas. Mira que de antemano soy pesimista y si me arriesgo a hablar de esta manera es porque estoy seguro de lo que te digo (dada tu virtud)! [Traducción Florencia Minatta] 
mediante estrategias publicitarias tales como becas, libros, postales, tarjetería o medallas, no nos sorprende la cantidad de encargos que éste recibió entre 1910 y 1933, su primera etapa de permanencia en Buenos Aires. En este lapso de cerca de veinte años Palanti recibió treinta y siete encargos principalmente por parte de connacionales dedicados al comercio y a la industria, muchos de ellos, inclusive, provenientes de la zona de la Lombardía. ${ }^{143}$ Se debe tener en cuenta que, hacia 1887, el 53\% del sector industrial de Buenos Aires (entre patrones y empleados) estaba formado por italianos. Estos estaban presentes tanto en empresas grandes como en pequeñas y predominaban en los rubros de construcción, metalurgia y alimentos. ${ }^{144}$ De acuerdo al censo de 1914, los italianos representaban el 20\% de la población porteña. ${ }^{145}$ Este particular contexto económico cultural favoreció sin duda la posibilidad para Palanti de llevar a cabo sus obras en el marco de una colectividad que crecía económicamente y exigía un lenguaje arquitectónico que la representara.

Por otra parte, muchos de los comitentes de Palanti sentían la necesidad de construir monumentos celebratorios de su suceso económico. Esta tendencia se potencia a partir de las características de la economía local que tendía por entonces a una inversión diversificada en variados rubros. Entre todos ellos sobresalía la construcción debido al alto rendimiento de la renta inmobiliaria en una metrópoli en expansión como la capital argentina. Todas estas razones constituyen las causas que explican la naturaleza y la cantidad de obras que conforman la producción rioplatense de Palanti. Ello puede verse en los encargos realizados para Luis Barolo, Andrés Roccatagliata, Alberto Grimoldi, David Costaguta, César Baragli, Pedro Vasena o los hermanos Salvo en el Uruguay. Los nombres dan cuenta del entorno en el cual se movía el arquitecto en la Argentina y las relaciones que entabló al llegar al país: los estratos más altos de la colectividad italiana. Vaya como ejemplo David Costaguta empresario textil para quien Palanti construyó un Petit Hótel y quien luego

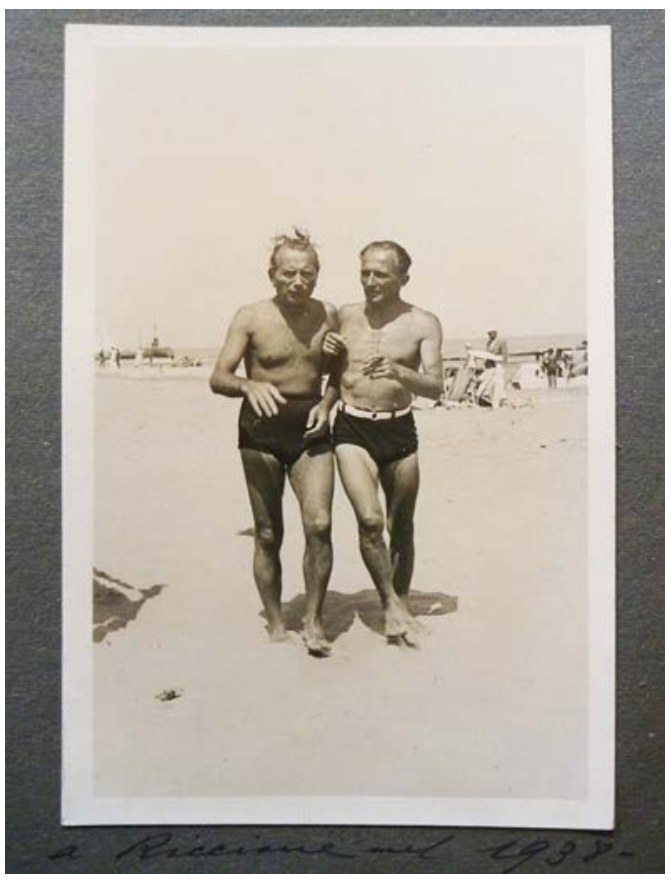

a Ricciane 1939

143 Ver apéndice.

144 Devoto, Historia de los Italianos en Argentina, 129.

145 Devoto, Historia de los Italianos en Argentina, 303. 
sería Vice Presidente de la Sociedad Anónima "Palanthome, la casa argentina". ${ }^{146}$ Otro industrial que se inclinó por la arquitectura de Palanti fue Pedro Vasena quien habiendo hecho fortuna como empresario metalúrgico, le encargó al arquitecto una Villa en San Isidro. Vasena llegó a la Argentina en 1853, trabajó como herrero, instaló su propio taller que creció con el tiempo. Luego de la Primera Guerra, el negocio metalúrgico Vasena e Hijos se había enriquecido notoriamente empleando cerca de dos mil obreros pasando a llamarse Compañía Argentina de Hierros Vasena e Hijos. En 1916, tras fallecer su propietario, la empresa pasó a manos de sus hijos y se fusionó con TAMET (Talleres Metalúrgicos San Martín). ${ }^{147}$

Interesado en la difusión del idioma y cultura italiana, David J. Spinetto fue otro de los grandes comitentes de Palanti. Spinetto padre había sido el fundador del mercado Ciudad de Buenos Aires, David fue médico pero se dedicó a la administración de los bienes paternos. Desde chico participó en la vida de instituciones italianas, apoyó la fundación del Instituto Italiano di Cultura, el Centro Latino de Estudios Dantescos como también en varias sociedades italianas de socorros mutuos. ${ }^{148}$ Opositor del fascismo, en 1924 publicó a través del Instituto Argentino de Cultura Itálica el texto Per la cultura italiana in Argentina. ${ }^{149}$ De acuerdo a su nieto, David Pini Spinetto, las diferencias ideológicas provocarían luego la ruptura entre comitente y arquitecto. Sin embargo, el nombre de la familia aparece nuevamente en un proyecto para una casa de fin de semana destinada a los hermanos Spinetto realizado durante el regreso de Palanti al país, en la década de 1950.

Entre la clientela de Palanti, encontramos también un gran grupo de inmigrantes italianos relacionados -en diferentes actividades- a la industria textil. Si bien los principales fueron Lius Barolo y los hermanos Salvo radicados en el Uruguay, se suman nombres como Andrea Roccatagliata, Francisco Piccaluga o el importador textil Davide Costaguta.

Este primer círculo de comitentes demuestra tempranamente la orientación de una trayectoria que está marcada por una constante e inquebrantable voluntad de vincularse con los círculos de poder local en el afán de gestionar encargos y financiar sus propios proyectos.

$\overline{146}$ Le Cronache italiana, 23 ene 1923.

147 Adolfo Dorfman, Historia de la industria argentina (Buenos Aires: Solar Hachette, 1970). Devoto, Historia de los Italianos en Argentina, 130.

148 Dionisio Petriella y Sara Sosa Miatello, Diccionario Biográfico italo-argentino, Dante Alighieri. Consultado julio 2013 http://www.dante.edu.ar/web/dic/m.pdf

149 David J. Spinetto, Per la cultura italiana in Argentina (Buenos Aires: Mercatali, 1924). 
Como mencionamos, uno de sus principales comitentes fue Luis Barolo. Nacido en Italia, Barolo llegó en 1890 a la Argentina para establecerse como importador textil en Buenos Aires. ${ }^{150}$ Poco después, en 1903, comenzó un emprendimiento industrial para lo cual requirió la liberación de maquinaria destinada a instalar una fábrica de tejidos de lana y fibra de algodón. El apoyo por parte del gobierno a través del proteccionismo aduanero, entre otros factores, le permitió al empresario establecer una de las primeras casas dedicadas al tejido de este producto. ${ }^{151}$ Ese mismo año, con el fin de encaminar la industria nacional, el Ministerio de Agricultura de la Nación lanzó una campaña para promover el cultivo de dicha fibra en las provincias del norte, acción que se sumaba a la aplicación de medidas proteccionistas por parte del Estado. La posibilidad de establecer una plantación en el Chaco permitiría prescindir de la importación de la materia prima.

En 1906, Luis Barolo junto a un grupo de inversionistas formado por Alfredo Demarchi, Francisco Piccaluga, Eusebio García y Enrique Menghenini fundó la firma Hilanderías Argentinas de Algodón S.A. con la intención de fabricar en el país hilados y torcidos de algodón, aunque fracasaría debido a la baja protección arancelaria y la escasa producción local de la fibra. ${ }^{152} \mathrm{El}$ mismo año de 1906, la industria recibió el diploma de Gran Premio a la iniciativa en la muestra “Gli italiani all'estero" en el marco de la Esposizione Internazionale di Milano -premio que también recibieron Pietro Vasena y Davide Costaguta-- ${ }^{153}$

Más allá de la relativa importancia que tuvo el cultivo de la fibra en la Argentina, hacia 1914, como indicó Fernando Rocchi, la industria textil producía sólo el 23\% del consumo nacional y dentro de esta industria, la textilería algodonera se mantuvo rezagada. ${ }^{154}$ De acuerdo a ciertas fuentes, Luis Barolo habría iniciado el negocio inmobiliario junto a Francisco Piccaluga y Americo Ferrando quienes luego abandonaron la empresa. ${ }^{155}$ Poco después, el primero encargó a Palanti el Hotel Castelar. ${ }^{156}$ Picacaluga, quien había llegado a la Argentina en 1890 -y luego

150 Obituario de Luis Barolo. La Prensa, 15 de junio de 1922.

151 Sobre la historia de la industria véase el ya clásico trabajo de Dorfman, Historia de la industria argentina.

152 Claudio Belini, "La Compañía General de Fósforos y los orígenes de la industria hilandera de algodón en Argentina, 1920-1935”. Am. Lat. Hist. Econ [online], No34 (2010) [citado 2015-02-20]: 93-123. Consultado el 20 de febrero de 2015. <http://www.scielo.org.mx/scielo.php?script $=$ sci arttext\&pid=S1405- 22532010000200004\&ln $\mathrm{g}=$ es\&nrm=iso $>$. ISSN 2007-3496.) 97

153 "Gli italiani all'estero. Diplomi e medaglie assegnati dalla giuria", Esposizione Internazionale di Milano. (Libreria Fratelli Bocca, Milano, 1907), 80-83; 218, 234, 242, 263.

154 Fernando Rocchi, "La armonía de los opuestos: Industria, importaciones y la construcción urbana de Buenos Aires en el período 1880-1920”, Entrepasados, año IV, n. 7 (1994): 51.

155 Vattuone, El Barolo.

156 El nombre de Francisco Piccaluga figura en el remate judicial del Pasaje Barolo "Puppo Agustín contra Piccaluga Francisco y otros por división de condominio.” Ejecutado por A. C. Taquini \& Cía. y publicado en $L a$ 
de la muerte de Barolo, en 1923, adquirió la empresa lanera Barolo \& Cía.- ${ }^{157}$, había organizado la Co. Algodonera Nacional de Hilandería y Tintura de Algodones junto con Luis Barcia y Antonio Meneghini.

En efecto, la posibilidad de realizar negocios, con o sin éxito, comúnmente se solventaba a través de la inversión en diferentes rubros. Particularmente, Barolo y Cía. dividió la producción en varios tipos de trabajos y tejidos que le permitían permanecer activo en el mercado. ${ }^{158} \mathrm{~A}$ diferencia de otros empresarios como Ernesto Tornquist, o Nicolás Mihanovich, Barolo parece no haberse vinculado al negocio inmobiliario a excepción del Pasaje Barolo y un cine sobre Avenida de mayo, también obra de Palanti.

La fábrica de Barolo, ubicada en la ciudad de Buenos Aires, en Suárez entre Patricios y Hernandarias, empleaba, en 1905, cerca de doce mil husos manejados por hilanderas y niños. Las condiciones en que se encontraban los empleados llevaron a las "fabriqueras de Barolo" a iniciar en 1906 una fuerte protesta en reclamo de mejoras laborales. Poco después, la protesta cobró forma en la Unión Gremial Femenina. ${ }^{159}$ Estos conflictos se sumaron a los vaivenes del mercado y a la laxitud de la política proteccionista de principios del siglo XX. En este marco, la multiplicidad de

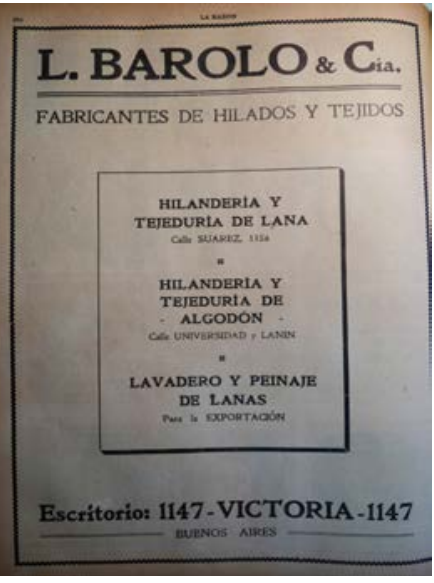

Almanaque La Razón, 1922 inversiones se presentaba como una manera segura de evitar la pérdida de grandes sumas por oscilaciones económicas, impuestos o huelgas. ${ }^{160}$

Entre 1914 y 1918, la producción textil argentina percibió una disminución en las importaciones. A pesar de los inconvenientes, las industrias textiles experimentaron cierto crecimiento: en 1917 el monto de exportaciones en Pesos Oro fue de 47.407 .902 y ascendió

Prensa, 2 de noviembre 1938. Sobre el litigio de petición de herencia de los nietos de L. Barolo véase: Miguel A. Pachecho, La verdad sobre el famoso asunto Barolo. (Buenos Aires: imprenta Lopez, ca.1932)

157 "Una época de cambios: la industria textil Argentina entre dos crisis, 1914-1933", Estudos Ibero-Americanos, PUCRS, v. XXXIV, No 2, (dezembro 2008)

158 Otros ejemplos son la empresa Campomar y Soulas -fusionada con Salvo Hnos. en Montevideo- o Dell'Acqua, Demarchi. Véase, Guido Di Tella, “La Unión obrera textil, 1930-1945”, Desarrollo Económico 33, N¹29 (abril-junio, 1993).

159 Ester Kandel, “Argentina: Acerca de la vulnerabilidad de las mujeres y los niños”, Presentado en las II Jornadas para los Departamentos de Historia de los Institutos Terciarios: Los Terciarios Hacen Historia, (Instituto Joaquín V. González. 17,18 y 19 de septiembre de 2008). Ver de Jorge Schvarzer "Conflictos laborales”, en Empresarios del pasado. La Unión Industrial Argentina, (Buenos Aires: CISEA, 1991), 53.

160 Rocchi menciona la duplicidad de actividades que se dio en la Argentina en la que un mismo individuo era importador y exportador a la vez. Fernando Rocchi, "La armonía de los opuestos: Industria, importaciones y la construcción urbana de Buenos Aires en el período 1880-1920”, Entrepasados, año IV, Nº 7 (Buenos Aires, 1994): 58. 
a 83.797.597 en 1919, momento en que la exportación de productos se vio nuevamente incrementada. ${ }^{161}$ Muy posiblemente este crecimiento económico haya impulsado la decisión de invertir en el negocio inmobiliario.

En 1926, l'Illustraz̧ione italiana dedicó una serie de números a "L'Italia e gl' italiani in Argentina" donde relataba la biografía de varios emigrantes italianos que habían hecho fortuna en Sudamérica y la revista consideraba como ejemplo -curiosamente, a pesar de haber levantado un rascacielos, Barolo no figura entre ellos-. Quien sí recibió la atención de la revista fue otro empresario textil, Andrea Roccatagliata. Nacido en Santa Margarita Ligure, Roccatagliata partió de Italia a los 14 años para radicarse en Argentina y trabajar junto a su padre en la casa comercial de la familia, dedicada al rubro textil. Con veinte años estaba al mando de la firma la cual incrementó su capital en poco tiempo. Además de haberse dedicado a la importación de tejido de algodón, Roccatagliata dedicó los últimos veinte años de su vida a la industria edilicia acumulando en su propiedad cerca de 700 departamentos entre los cuales se encuentra el palacio ubicado en Avenida Callao y Santa Fe, Buenos Aires. La revista señalaba al empresario como un hombre visionario que "de la chata Buenos Aires de su juventud vio desarrollarse la metrópolis con sus rascacielos y sus torres" y que, en vez de invertir en comercio o en la "accidentada" industria, había preferido “(...) participar en la transformación edilicia de la ciudad, invirtiendo con fe y seguridad su capital”. El resultado -señalaba la revista- era como una piedra italiana en la Argentina: una "mole imponente" que ofrecía una "impronta de verdadera italianidad" y había sido obra de Mario Palanti. ${ }^{162}$

Como fue señalado, uno de los comitentes más importantes de Palanti fue la firma Salvo Hnos. con sede en Montevideo. Así como se dio en la Argentina, entre fines de siglo XIX y principios del siglo XX, el Uruguay atravesó un proceso de desarrollo económico impulsado por una política de carácter proteccionista que apuntaba a la modernización. El período comprendido por las dos presidencias de Luis Batlle y Ordóñez (1903-1907 y 1911-1915) se caracterizó por encaminar al país en un proceso que llevaría, tiempo después, a la consolidación de la industria nacional con apoyo del Estado. Efectivamente, la industria manufacturera uruguaya se vio favorecida la aplicación de medidas proteccionistas orientadas a la sustitución del modelo

161 En 1918 las importaciones se redujeron en un 65,4\% en comparación con 1913.

pp.332-334. El Almanaque del Mensajero presenta los siguientes números: Importación en peso oro, en 1915, 51.934.567; en 1916, 65.592.071; en 1918, 54.324.83. Almanaque del Mensajero, años 1915 a 1920.

162 "L'Italia e gl'italiani in Argentina", L'illustrazione italiana, No45 (7 nov. 1926). 
ganadero exportador por un modelo de industrialización. Este proceso, acompañado por una política de inmigración, dio lugar al crecimiento urbano de manera acelerada, especialmente en Montevideo, capital del país y centro de capitales privados. Como consecuencia, se inicia un proceso de densificación del área central de la ciudad. ${ }^{163}$ En este marco, la firma Salvo Hnos. decidió invertir en un emprendimiento inmobiliario lograría gran trascendencia: el Palacio Salvo (1922-1923).

El primero de los Salvo, Lorenzo Salvo Vasallo, llegó al Uruguay desde su Liguria natal en la década de 1860; trabajó como empleado en un comercio para luego iniciar su propio emprendimiento, proceso que concretó en un lapso menor a cinco años. ${ }^{164}$ La ayuda de la familia fue crucial en el crecimiento económico: su esposa, Ángela Debenedetti, colaboró ahorrando las remesas que le llegaban desde Uruguay. ${ }^{165}$ La tienda primigenia de Lorenzo Salvo Vassallo se convirtió en manos de sus hijos Ángel, Lorenzo y José, en una fructífera empresa textil. ${ }^{166}$ No menos importante ha sido el apoyo estatal recibido por los industriales de la época; al respecto, Raúl Jacob explica que "El sector industrial se afirmó particularmente durante las dos presidencias de José Batlle y Ordóñez (1903 a 1907 y 1911 a 1915). La creación del Banco de Seguros del Estado y la nacionalización del República señalarán una nueva concepción, en la que el Estado controlará diversos resortes económicos. En ella estará también implícito el destino de la industria". ${ }^{167}$ Dentro de la política batllista de estímulo de la industria uruguaya, "el proteccionismo aduanero fue defendido como el ideal de política económica (...) y estimularía la industrialización del país, el único camino para alcanzar su verdadera independencia”. ${ }^{168}$

Este impulso industrializador benefició a la descendencia de Lorenzo Salvo Vasallo

163 Véase, Luis Bertola, La industria manufacturera uruguaya 1913-1961: un enfoque sectorial de su crecimiento, fluctuaciones y crisis. (Montevideo: CIEDUR-FCS. 1991).

164 Véase Beretta Curi, Jacob, Rodríguez Villamil y Sapriza. La industrialización del Uruguay 1870-1925. Cinco perspectivas históricas (Montevideo: Fundación de Cultura Universitaria, 1978).

165 Alcides Beretta Curi, El imperio de la voluntad. Una aproximación al rol de la inmigración europea y al espiritu de empresa en el Uruguay de la temprana industrialización, 1875/ 1930 (Montevideo: Editorial Fin de Siglo, 1996), 79. Asimismo, Magdalena Bertino, "La industria textil uruguaya: concentración de capitales y articulación regional, 1900-1960", H-Industria. Revista de historia de la Industria, los Servicios y las Empresas en América Latina, No 4-5, año III (2009); María Camou y Silvana Maubrigades, "Tejiendo una historia: la industria textil uruguaya, 1898-2000”, H-Industria. Revista de historia de la Industria, los Servicios y las Empresas en América Latina, № 4-5, año III (2009).

166 Raúl Jacob, Breve historia de la industria en el Uruguay (Montevideo: Editorial Fondo de Cultura Universitaria, 1981), 73. De acuerdo a Raúl Jacob “este empuje industrializador fue obra del esfuerzo personal, del espíritu de ahorro, de la capacidad comercial de un reducido número de empresarios que pudieron superar la condición de asalariados y fundar un pequeño taller".

167 Raúl Jacob, Breve historia de la industria en el Uruguay, 76.

168 Rodríguez Villamil, "Proteccionismo y librecambio: El programa de la Liga Industrial de 1880", en Industria uruguaya: dos perspectivas, Martín Bruxedas y Raúl Jacob (Montevideo: Editorial Fondo de Cultura Universitaria, 1989): 26. 
que fue decisiva en el devenir de la empresa. Sus hijos Ángel, Lorenzo y José expandirían los negocios más allá del "Almacén y Tienda Salvo": ampliaron sus inversiones e incorporaron en 1897 la empresa textil "La Victoria" e invirtieron en plantaciones y viñedos. En 1898 recibieron protección estatal para su industria a través de la exención de derechos de aduana sobre la materia prima necesaria para la manufacturación de los productos, como también sobre la importación de maquinaria y de piezas de repuestos; asimismo, las fábricas quedaron exentas de la Contribución Inmobiliaria y de la Patente de Giro. ${ }^{169}$

En 1899, un año después de concedidos los beneficios económicos, la textil “La Victoria” se asoció a la firma textil Campomar, con negocios también en la Argentina. La sociedad Salvo, Campomar y Cía. fundó entonces "La Nacional” destinada a hilados y tejidos. ${ }^{170}$ Los beneficios otorgados se institucionalizaron en las leyes promulgadas en 1908 y 1909 que tenían la finalidad de "aumentar la ocupación, fomentando la actividad industrial con la desgravación de aranceles a las materias primas que se importaban para elaborar en el país” y la exoneración del derecho de aduana a determinados artículos empleados para la producción industrial. ${ }^{171}$ Como resultado, ante el crecimiento de la empresa, Salvo Hnos. decidió realizar una ultima gran inversión: el rascacielos.

Ahora bien, a pesar de no haber mencionado a la totalidad de la clientela de Palanti mucha de la cual no tenemos información-, al reparar en la implantación de las obras podemos tener un panorama amplio del nivel económico de los comitentes.

Al observar el plano 1 que gran parte de la producción no es "periférica," sino que se ubica en una zona céntrica, en los barrios de Montserrat y Balvanera, a lo largo de la Avenida de Mayo -a partir de la Avenida 9 de Julio hasta Plaza Congreso- y sobre Avenida Rivadavia hasta Plaza Miserere. Le siguen San Nicolás, Recoleta y Palermo. Efectivamente, si se compara el plano de ubicación de las obras con el plano 2 que muestra el valor del suelo por metro cuadrado puede notarse que casi la totalidad de la producción palantiana se ubica en los sectores donde el precio del suelo es más elevado. Junto a los aspectos económicos, las condiciones físicas y culturales del entorno dan cuenta del tipo de committenza con el que Palanti se relacionaba.

En las diferentes escalas - desde la casa de renta al rascacielos- podemos decir que prácticamente en todos los casos el interés de los propietarios se volcaba en la creación de una

169 Beretta Curi, Jacob, Rodríguez Villamil y Sapriza. La industrialización del Uruguay 1870-1925, 211-214.

170 Raúl Jacob, Las otras dinastías 1915-1945 (Montevideo: Proyección, 1991), 243.

171 Jacob, Breve historia de la industria en el Uruguay, 83. 


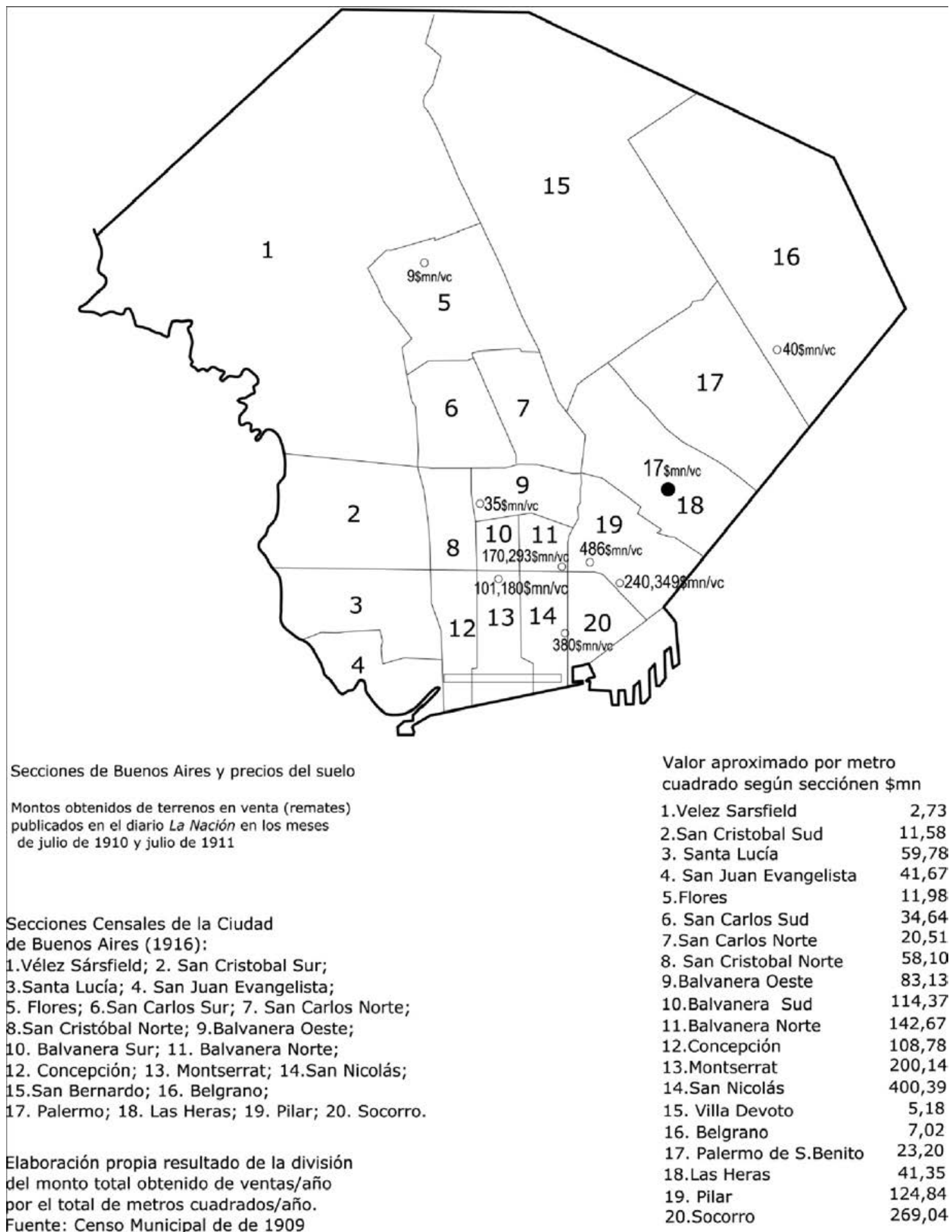

Plano 1. elavorado para mi Tesis de Maestria, Virginia Bonicatto Escribir en el cielo

imagen como símbolo identificatorio de su empresa, posición social o trayectoria. Es en ese sentido que interpretamos las lógicas de encargo provenientes de iniciativas privadas en el marco de las cuales la arquitectura se presentaba como la posibilidad de conjugar ganancia y prestigio: por un lado los encargos eran parte de una estrategia comercial de los comitentes orientada a disminuir el riesgo económico a través de la diversificación no integrada, por otro lado, permitía 


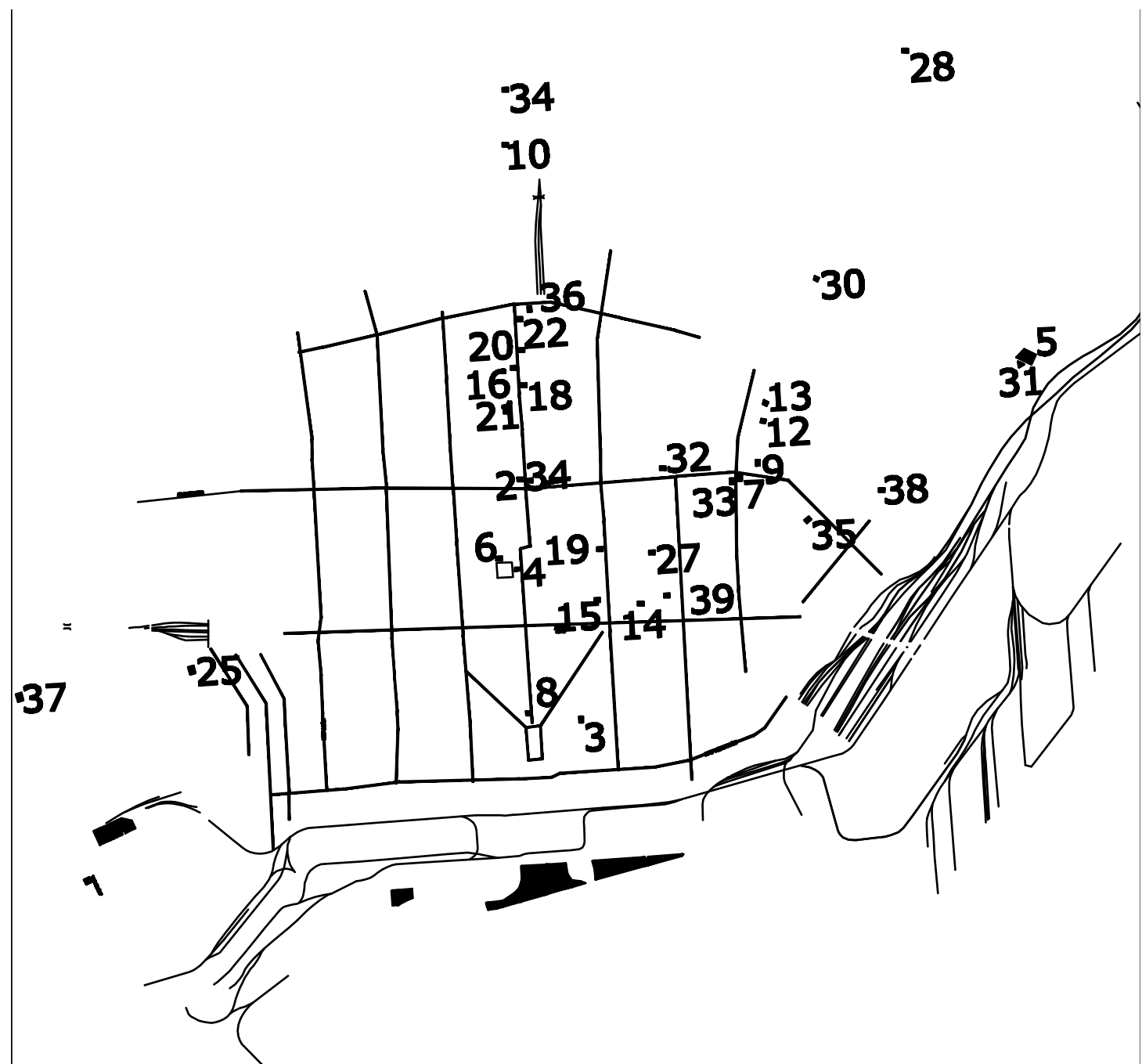

Plano 2. Ubicaciòn de las obras de Mario Palanti en la ciudad de Buenos Aires.Elaboraciòn propia

Obra en Buenos Aires

1. Pabellón italiano para la Exposición del Centenario de mayo, 1910

2. Edificio Giuseppe Peretti, Rivadavia 1916.

3. Edificio banco Francés e Italiano. Perón y San Martín

4. Palacio Barolo, Av. de Mayo 1370

5. Palacio Concesionaria Fevre y Basset, Av. Figueroa Alcorta 3301-99

6. Palacio Valsecchi, Victoria y Alsina

7. Edificio Roccatagliata, Santa Fe y Callao

8. Hotel Castelar, Av. de Mayo 1150

9. Palacio de la Nunciatura, Riobamba 1227

10. Cinema Roca, Av. Rivadavia 3742

11. Garage Peretti, B. Mitre (s/d)

12. Petit Hotel Silvio J. Merlo Azcuenaga y Arenales

13. Petit hotel Pedro Ganduglia, Arenales 2275

14. Edificio Cassottana, Tucumán 1146

15. Edificio Nicolás Bruzone e H. Libertad 145

16. Edificio G. B. Uboldi, Av. Rivadavia 2440-60

17. Edificio Cesare Baragli, Av. Rivadavia (s/d)

18. Edificio Angelo Baragli, Av. Rivadavia (s/d)

19. Edificio Mario Palanti, Av. Corrientes 1347

20. Edificio Pietro Vila, Av. Rivadavia 2625

21. Edificio Mario Palanti, Victoria y Sarandi

22. Edificio Cesare Baragli, Av. Rivadavia 2701

23. Edificio Industrial J. Manzanares e c., Barracas (s/d)
24. Edificio Odine Bazzani, Av Rivadavia(s/d)

231 Petit Hotel Carmelo Novello, Av. Montes de Oca

26. Petit Hotel Cesare Rossi, Barracas (s/d)

27. Petit hotel Davide Costaguta, Uruguay 640-6

28. Palacio Vasena, San Isidro(s/d)

29. Petit Hotel Aurelio Devoto, Juncal (s/d)

30. Petit Hotel Adrian Beccar Varela, Av. Las Heras. 2599/ Gallo2527

31. Petit Hotel Eduardo Resta, (junto a Algier) Eduardo Costa 3079-9

32. Petit Hotel Azaretto-Spato, Viamonte 1871

33. Edificio Roccatagliata, Santa Fe 1769

34. Casa Grimoldi, Av. Rivadavia 5050 DEMOLIDA

35. Petit Hotel Rodriguez Peña 1650 DEMOLIDO

36. Casa de B. Ginocchio. Bartolomé Mitre y Av. Pueyrredón

37. Arando y Zavaleta, Hornos 1248-68

38. Boveda Spinetto

\section{Obra en Uruguay e Italia}

39. Capilla funeraria Palanti, Milán.

40. Palacio Salvo, Montevideo, Uruguay

41. Tienda en Paysandú, Uruguay 
dar forma material a una carrera exitosa a través de una obra arquitectónica. Al momento de contratar un profesional, la tarea fue confiada a la firma de Mario Palanti.

\section{Avenida de Mayo 695: el estudio particular}

En 1912, finalizado el contrato con la firma Prins y Ranzanhofer y ante el incremento de trabajo, Palanti instaló su oficina particular en Avenida de Mayo 695 para realizar desde allí los encargos de manera independiente. ${ }^{172}$ Su rápida inserción social y laboral le posibilitó -como vimos- el acceso a una serie de encargos en el ámbito local que pronto se transformaron en una intensa actividad. Dada la cantidad de tareas, todo hace suponer que el arquitecto contaba con ayuda en el estudio, pero hasta el momento no hemos encontrado documentación que lo pruebe y, por lo tanto, desconocemos si Palanti empleaba o no dibujantes u otro tipo de colaboración en las tareas del estudio. Sin embargo, ciertos datos surgen del Contrato de Construcción de la Nunciatura de Buenos Aires que se conserva en el Archivo Secreto del Vaticano. El mismo explicita que las tareas en obra se realizaban "según planos confeccionados por Mario Palanti” quien, además, operaba como "Arquitecto Director" de la obra supervisando desde la estructura hasta los agregados en los diferentes tipos de revoques. ${ }^{173}$ Si bien el contrato refiere a la Nunciatura porteña (1927), podemos suponer que el arquitecto lo empleaba para todas sus obras pues está basado en un modelo genérico que permitía la incorporación de observaciones o modificaciones en sus meticulosos 186 artículos y 35 páginas que explicaban -con sumo detalle- las tareas y obligaciones de cada parte. ${ }^{174}$

Pero, además de la intensa actividad en obra, la producción desarrollada durante esta etapa se caracterizó por una serie de esquicios o soluciones utópicas o ideales que en parte se remiten a su etapa formativa y por proyectos más o menos convencionales en los cuales el arquitecto realizó sus primeras experiencias constructivas. ${ }^{175}$ Dentro de los primeros podemos consignar: una Catedral gótica para Buenos Aires y la Iglesia del Tigre, además de diversos bocetos de residencias y monumentos que recuerdan, por el dinamismo y la monumentalidad,

$\overline{172}$ Palanti, Curriculum Vitae, 1958.

173 Archivio Segreto Vaticano, Archivio Nunziatura Argentina, 99, fasc.510. Mario Palanti, Contrato de Construcción, Nunciatura.

174 Archivio Segreto Vaticano, Archivio Nunziatura Argentina, 99, fasc.510. Mario Palanti, Contrato de Construcción, Nunciatura.

175 Sobre la producción de Palanti véase Fernando Aliata y Virginia Bonicatto, Mario Palanti 
a los diseños iniciales de Sant'Elia. Tal vertiente proyectual que comienza con la ya citada colaboración en el estudio de Prins y Ranzenhofer para la gótica sede de la Facultad de Derecho se desarrolla a lo largo de todo este tiempo. Esta línea incluye también una serie de búsquedas explícitas en lenguajes neomedievales que carecen de comitente o implantación precisa y que por las fechas vemos que se inician en su etapa de estudiante: Iglesia Votiva (circa 1909), Villa Medieval (1915), Templo Votivo de la Paz Universal (1916), Convento Alpino, etcétera. Durante este período son varios de los estudios sobre detalles góticos realizados por Palanti. No se trata sólo de puras invenciones formales, muchos de ellos tienen una referencia directa a modelos existentes en el repertorio histórico: así el Mercado del Abasto (1913) reproduce los "halles" nórdicos; la catedral porteña resulta una combinación de varias catedrales góticas con sus proporciones engrandecidas. En algunos casos, como ya habíamos enunciado, dentro de esta línea experimental repropone trabajos de su etapa formativa. Ejemplo de ello es el proyecto para una Bolsa realizado en 1909 -cuyas láminas se conservan en un archivo privado- y que fue presentado luego, en 1911, bajo el lema "Pro Humanitate" en el concurso para la Escuela de Medicina y Hospital Policlínico de Rosario. ${ }^{176}$

El exitoso trabajo de Palanti se vio interrumpido por el regreso del arquitecto a Italia ante el estallido de la Primera Guerra Mundial. El 3 de noviembre de 1916, antes de partir, Palanti realizó en el Palacio de la Comisión Nacional de Bellas Artes de la ciudad de Buenos Aires una Exposición personal de arquitectura que resumió el trabajo realizado hasta el momento. ${ }^{177}$ Allí, exhibió no sólo la obra construida sino también proyectos, estudios y bocetos que fueron compilados y publicados en Milán -con ayuda de su hermano Giuseppe- en el volumen Prima Esposizione Personale di Architettura nella Republica Argentina. ${ }^{178}$ Precedido por la introducción escrita por el profesor Giulio Carotti, ${ }^{179}$ el libro -como lo harían los títulos posteriores- informaba al público italiano sobre los logros y méritos que el arquitecto había alcanzado en Argentina. Junto a la valoración artística de su obra, la introducción hacía hincapié en la firme voluntad de Palanti por retornar a la península impulsada por un apasionado nacionalismo que lo obligaba a enrolarse en el ejército una vez desatada la guerra. ${ }^{180}$ Asimismo, la publicación deja ver la dualidad entre un ansia experimental expresada en una serie de diseños ideales- algunos de ellos

176 Palanti, Prima esposizione personale d'architettura nella Repubblica Argentina

177 Diario La Prensa, Buenos Aires, 3 de noviembre de 1916.

178 Palanti, Prima esposizione personale d'architettura nella Repubblica Argentina

179 Carotti Palanti, Introducción en Prima esposiz̨ione personale d'architettura nella Repubblica Argentina

180 Palanti, Prima esposizione personale d'architettura nella Repubblica Argentina 


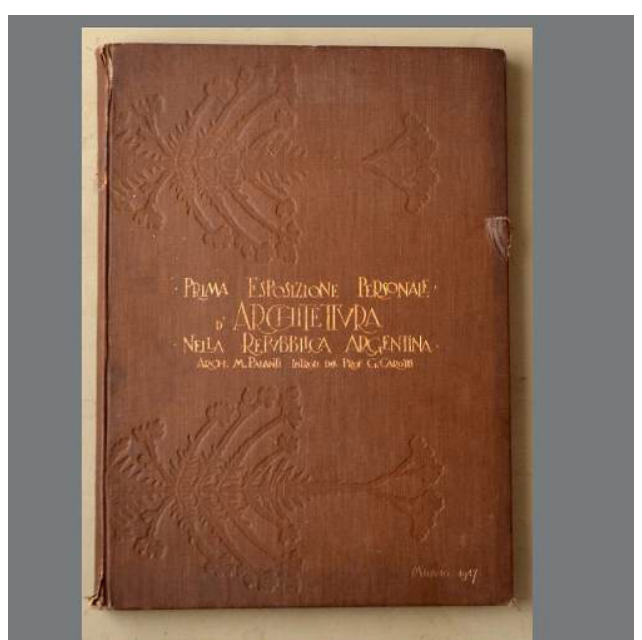

Prima esposizione personale d'architettura nella Repubblica Argentina. Milán. Stab. di arti grafiche Rizzoli e Pizzio.1917.

pueden ubicarse dentro de sus mejores

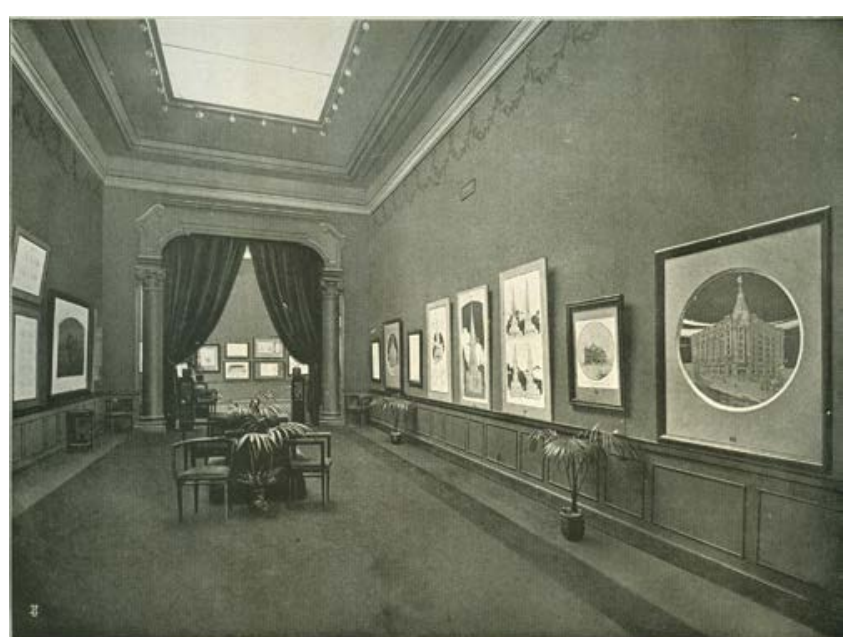

Fotografía de uno de los salones de la exposición de obras de Mario Palanti. Buenos Aires, noviembre de 1916. Prima esposizione...Tav. II

trabajos- y una amplia gama de realizaciones en las cuales todavía es bien visible un convencional eclecticismo.

Paralelamente, como veremos, en algunas de las casas de renta y en residencias particulares Palanti experimenta esta serie de estilemas de creación personal que dan, por primera vez, cierta coherencia a sus búsquedas en torno a una nueva arquitectura. La temprana casa de Av. Rivadavia 2625, así como la obra de Ocampo y Eduardo Costa (1923), muestran -como veremos- las variables de este ordenamiento. En la última sobresale el uso de los haces de semicolumnas que se habían ensayado en el Barolo, combinados con una techumbre de tejas. En otros casos, como en la casa de renta de Santa Fe y Callao (ca.1920), el resultado de la experimentación parece retrotraerse a estadios anteriores de su evolución proyectual. Una obra notable, que acompaña a la realización de las grandes casas de alquiler, es la agencia de automóviles Fevre y Basset (1928). Partiendo de una fachada más convencional, introduce en su cubierta una cita de la pista de pruebas de la Fábrica Fiat de Lingotto, Turín (1919-1923), intentando asimilar un esquema moderno a una matriz morfológica de raíz ecléctica.

A pesar de estos productos originales y de experiencias que quedan a mitad de camino, un Eclecticismo más formal que puede parangonarse a la producción de Luigi Broggi o Luca Beltrami en la zona central de Milán a fines del siglo XIX, continúa siendo en esta etapa el estilo que articula la mayoría de sus obras. Principalmente, esta arquitectura "convencional" (en la que se ve el uso de elementos del repertorio clásico, gótico o románico) responde a comitentes más conservadores, relacionados a sedes bancarias,empresas o instituciones religiosas: entre ellos, 


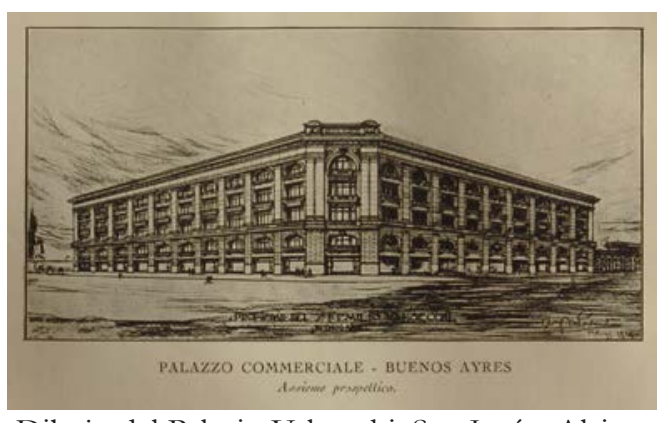

Dibujo del Palacio Valsecchi, San José y Alsina. Buenos Aires. Ca. 1919-24. Mario Palanti. Quatro anni di lavoro...

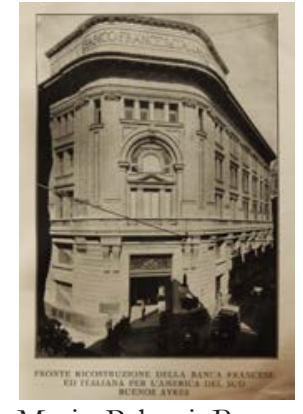

Mario Palanti. Banco francés e italiano, Buenos Aires. Quattro anni
di lavoro

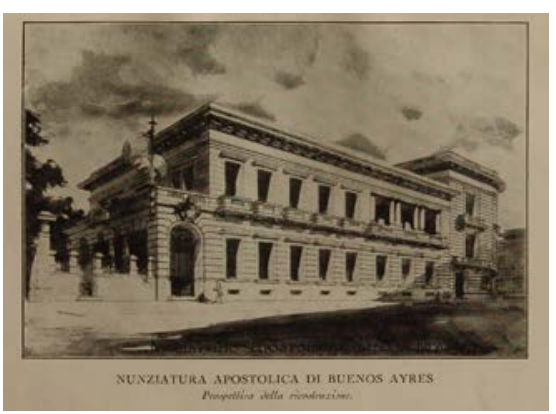

Nunciatura apostólica. Buenos Aires Mario Palanti. Quatro anni di lavoro...

el Banco Francés e Italiano, el edificio Comercial de Alsina y San José (1921), el Hotel Castelar (1928) de Avenida de Mayo 1148, la ampliación del Banco de la Provincia de Buenos Aires (1931), algunas obras para instituciones católicas como La Nunciatura Apostólica o el colegio

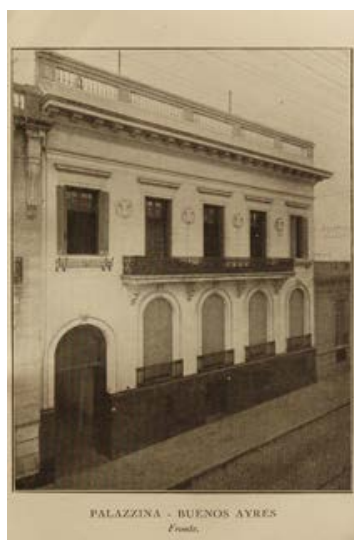

Mario Palanti, Arenales 2275 Petit Hotel para Pedro Ganduglia. Quattro anni di lavoro

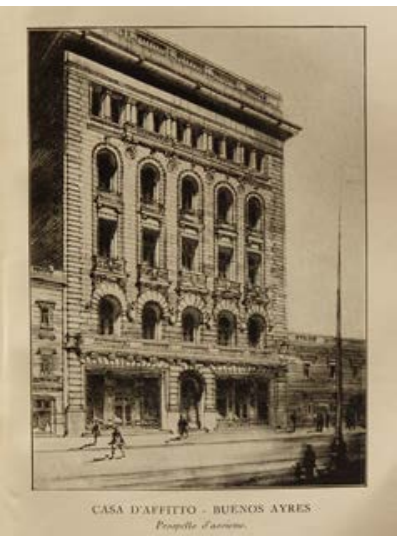

Mario Palanti. Casa de renta. Quattro anni di lavoro

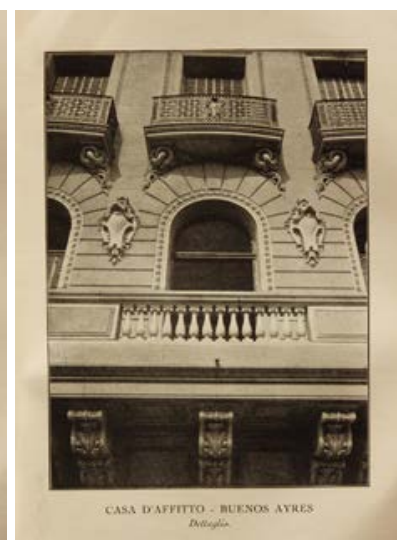

renta. Detalle, Buenos Aires. Quattro anni di lavoro

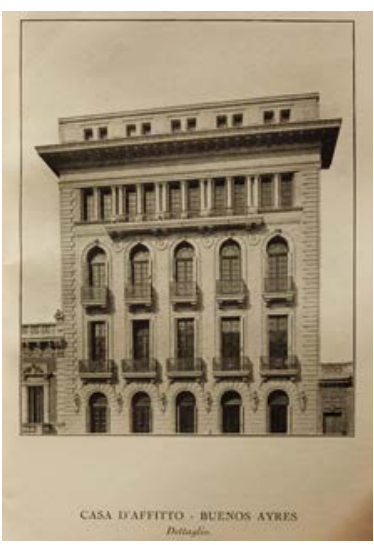

Mario Palanti. Petit Hotel Juan B. Uboldi, Buenos Aires.Quattro anni di lavoro

Santa Rosa son claros ejemplos de esta tendencia que parece contraponerse a las invenciones planteadas en los proyectos de algunas de sus casas de renta o de los dos grandes rascacielos. También ofrecen esas características convencionales un importante número de residencias y petits-hôtels construidos en la zona norte de la ciudad como, por ejemplo, la propiedad de Adián Beccar Varela, los Petits-Hôtels Azaretto-Spato, Uboldi, Novello o Costaguta, las casas de renta de su propiedad en Victoria y Sarandí o la ubicada en Castelli y Rivadavia. A todo esto debe sumársele una cantidad de proyectos no realizados como el casino-teatro-hotel "Montecarlo, ciudad de Mónaco" y el mismo programa aplicado en Mar del Plata (1920-1924), o la sala de Conciertos Augusteum.

Precisamente, durante las primeras décadas de siglo XX, la obra de Palanti está marcada por una constante oscilación entre lo convencional y lo experimental. Sin embargo, frente a 
esta explicita dualidad que muestra su arquitectura, la voluntad de cambio permanece como una constante en sus escasos escritos. Es allí, y en las obras experimentales, donde podremos ver expresadas materialmente las ideas de Palanti.

\section{Experimentación y ensayos en la obra porteña}

Entre la vasta producción que Palanti realiza como fruto de los encargos que recibe en su estudio de Avenida de Mayo, nos interesa, particularmente, centrarnos en aquellas obras en las que, como parte de su búsqueda, se registra cierta voluntad de innovación visible en la experimentación formal, lingüística o tipológica. Entre las obras tempranas en las que Palanti realiza experimentaciones podemos citar la Casa Vila (Rivadavia 2625) y la Casa Peretti (Rivadavia 1916) en las que se ve una marcada preocupación por la construcción de un lenguaje personal para resolver la arquitectura urbana de media densidad. Como era habitual en las casas de renta, mientras que la planta es un ejercicio de máxima racionalización de las posibilidades

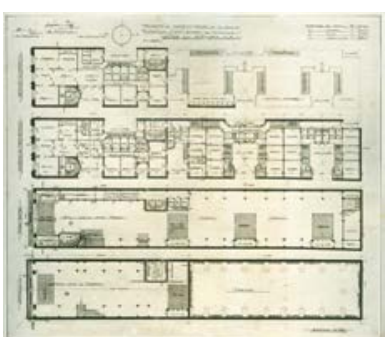

Planos y Fotografía de la Fachada de la Casa Vila Rivadavia 2526, Buenos Aires, Mario Palanti. Ca.1914. Prima esposizione..
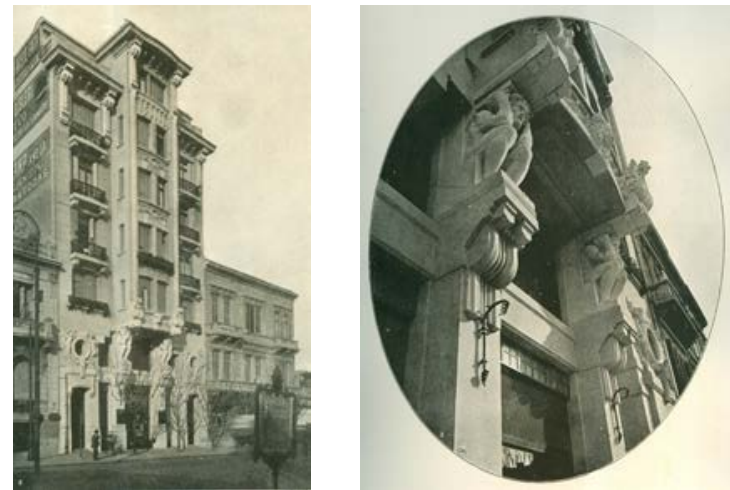

Fotografía de la Fachada y de los atlantes en su estado original, Casa Peretti, Rivadavia 1916, Buenos Aires, Ca. 1915. Mario Palanti. Prima esposizione...

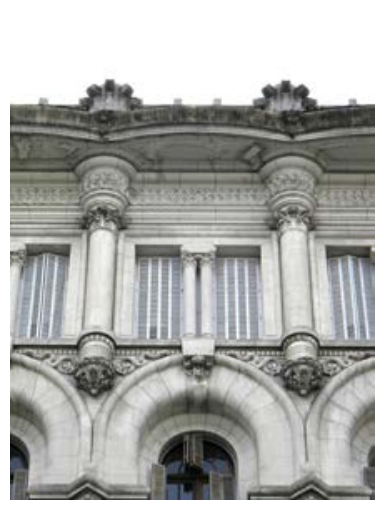

Fotografía de detalles de la Fachada, Casa Vila, Rivadavia 2526, Buenos Aires, Ca.1914. Mario Palanti. Foto Alejandro Danie Machado (ADM)

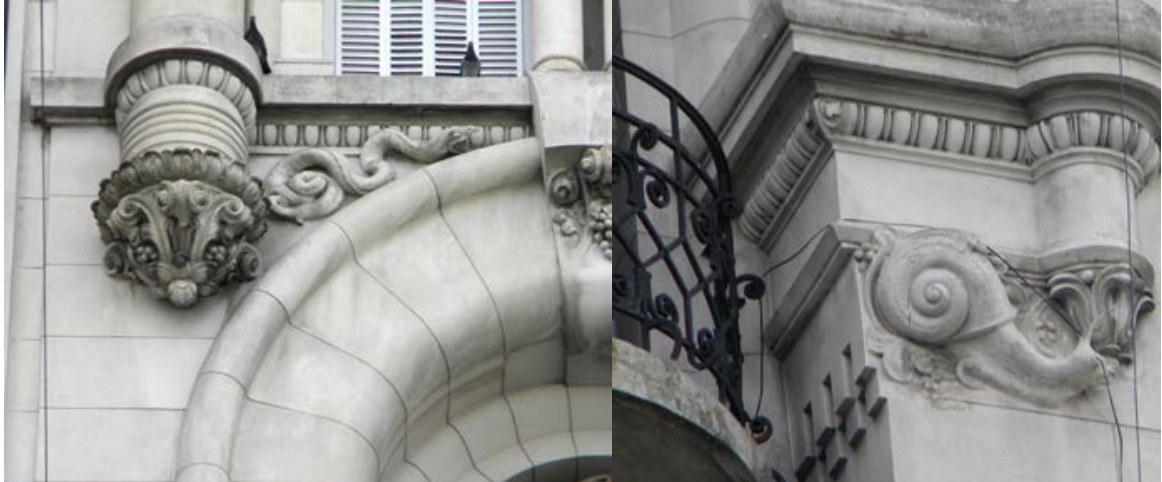

La libre interpretación de la naturaleza. Fotografía de detalles de la decoración de detalles de la Fachada Casa Vila Rivadala parte superior de la Casa Vila, Rivadavia via 2526, Ca.1914. Buenos Aires, Mario 2526, Buenos Aires,Ca.1914. Mario Palanti. Palanti. Ca.1914. Foto ADM Foto ADM 

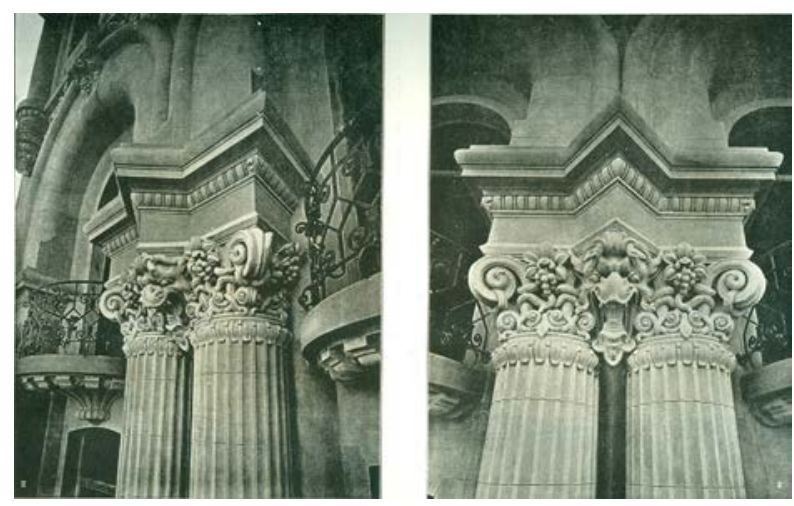

Fotografía de detalles de capiteles y cornisa del orden gigante, Casa Vila, Rivadavia 2526, Buenos Aires, Mario Palanti. Ca.1914. Prima esposizione... Tav.LXXIII

del código de edificación, ${ }^{181}$ las fachadas son el centro del diseño y muestran elementos propios del repertorio que Palanti venía elaborando desde su época en Brera. Esta situación de plantas especulativas carentes de exploración no es exclusiva de las casas de renta, sino que se verificará en otros ejemplos de la obra palantiana como los dos edificios que el arquitecto realiza para Andrea Roccatagliata (Santa Fe y Callao y Santa Fe 1769) y la vivienda ubicada en Eduardo Costa 3079.

Tanto en la Casa Vila como en la Casa Peretti el arquitecto ensaya por primera vez una composición de fachada por fuera de los cánones clásicos y se enuncian algunos temas recurrentes que luego se desarrollarán en su etapa madura, sobre todo en el Barolo y el Salvo. En ellas se detectan elementos arquitectónicos, fragmentos provenientes de diversas tradiciones, que escapan al código clásico y dan como resultado un extraño ensamble de disposición en vertical. Por ejemplo los balcones semicirculares -recurso que el arquitecto utilizará luego en muchos de sus edificios-, el uso de columnas y semicolumnas -gigantes o de a pares- capiteles de fantasía, bases de apoyo compuestas por atlantes, ménsulas con motivos geométricos, vegetales o provenientes de la fauna, ornamentación Liberty que incluye follajes, animales imaginarios, caracoles y serpientes. Entre ellos, el arquitecto tiene predilección por las serpientes y las líneas sinuosas que resultan la principal decoración aplicada: la vemos bajo los balcones, sobre los

181 En un lote cuya profundidad es cinco veces su ancho, el arquitecto crea una serie de patios de aire y luz que le permiten disponer de seis unidades por planta con escaleras cada dos departamentos y prolongados pasillos de circulación a lo largo de la fracción. Como sucede generalmente en este tipo de plantas, las unidades que dan sobre el frente son las de mejor distribución y categoría, disminuyendo la calidad de los departamentos a medida que nos acercamos al fondo del terreno. La cuestión tan particular de los lotes angostos y profundos de la ciudades en damero como Buenos Aires motivó la atención de Palanti quien en su artículo"Algunas consideraciones sobre arquitectura edilicia”, El Arquitecto Constructor. №246 (1 de agosto, 1922). subrayó la necesidad de modificar la organización morfológica del suelo urbano a partir de la modificación de la legislación a fin de lograr lotes más amplios que permitan edificios de mayor holgura. En efecto, no vamos a encontrar en las indagaciones del arquitecto una especial preocupación higiénica o ética en relación con el problema de la vivienda que caracterizará a los primeros representantes de la modernidad en la Argentina como Antonio Vilar o Wladimiro Acosta, sino más bien un meditado aprovechamiento racional de los espacios que brinda la normativa: reproducir en altura la casa de patio tradicional. 
arcos, en capiteles, artefactos de iluminación.

Si bien ciertos elementos como ménsulas desproporcionadas, columnas apareadas u óculos decorados nos recuerdan a la tradición clásica, la composición resultante es absolutamente experimental. Palanti parece recordarnos su formación en Brera y decirnos aquí que deben

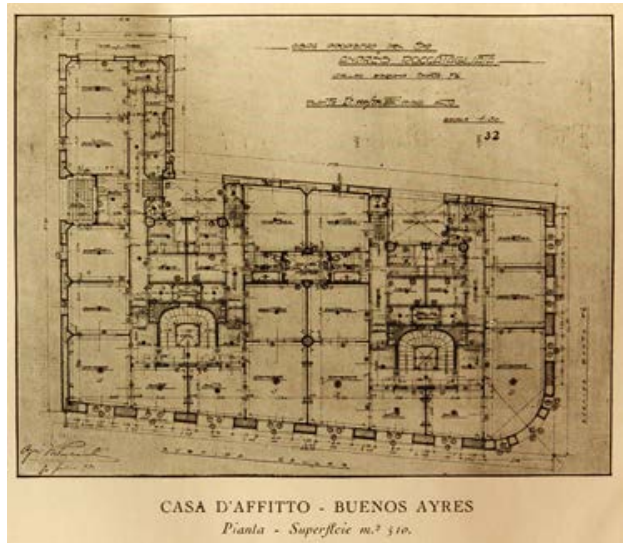

Planta tipo. Edificio Roccatagliata. Santa Fe y Callao. Buenos Aires. 1921. Mario Palanti. Quattro Anni...

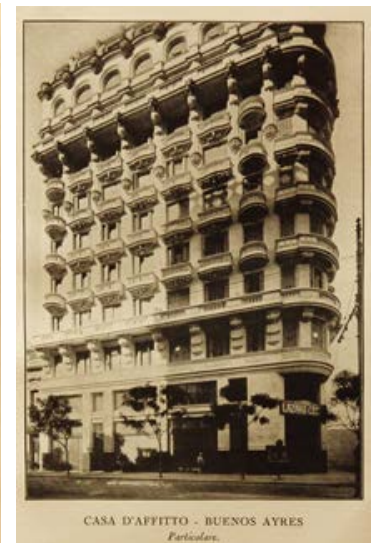

Detalle de la fachada. Edificio Roccatagliata. Santa Fe y Callao. Buenos Aires. 1920-21. Mario Palanti. Quattro Anni...

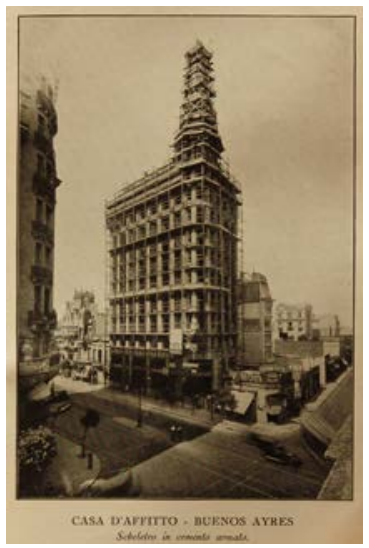

Fotografía de la construcción. Edificio Roccatagliata (1920-21). Se puede ver la casa Lazaro Costa sobre Santa Fe, aún no ensanchada. Santa Fe y Callao. Buenos Aires. Ca. 1920. Mario Palanti. Quattro Anni...

explorarse todas las posibilidades y que de esa exploración surgirá sin duda un estilo nuevo.

Ahora bien, si en estas obras podemos señalar la exploración del repertorio decorativo, otras obras se destacan por la búsqueda en el dominio vertical del objeto y en el sistema constructivo. Ejemplo de ello es el edificio Roccatagliata, una obra de $4.000 \mathrm{~m}^{2}$ y doce pisos que se acerca en magnitud vertical a los rascacielos de Palanti en un planteo que saca provecho de su ubicación en la intersección de Santa Fe (aún no transformada en avenida) y la Avenida Callao. ${ }^{182}$ El edificio muestra una disposición de un cuerpo principal con una pequeña torre en esquina. Si bien esto era común en muchos edificios de la época ubicados en esquina, nos interesa particularmente el diseño de la torre: caras facetadas, semicolumnas y cornisa ondulada la convierten en un preludio -en pequeña escala- de la resolución empleada en el Palacio Salvo. Esto transforma al edificio en una de las pruebas entre el Pasaje Barolo y el rascacielos uruguayo. En efecto, el boceto inicial del edificio Roccatagliata publicado por el arquitecto en su libro Quattro anni di lavoro muestra un diseño que se aleja del código clásico para acercarse a las líneas 


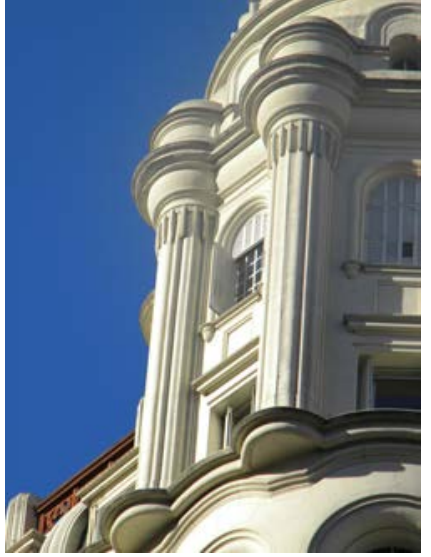

Una invención decorativa. Detalle de las columnas de la torre. Edificio Roccatagliata, Santa Fe y Callao. Buenos Aires. 1920-21. Mario Palanti. Foto ADM

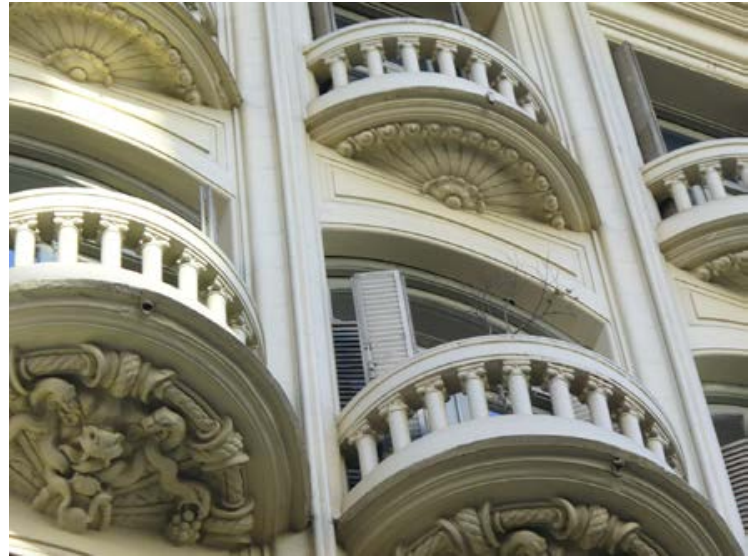

Mario Palanti. Edificio Roccatagliatta. Av. Santa Fe 1769. (1921) Detalle. Foto Alejandro Machado

góticas ensayadas por Palanti y que pueden verse en los primigenios dibujos para la Catedral metropolitana, el Pasaje Barolo o el Palacio Salvo. ${ }^{183}$ A este camino exploratorio debemos sumar los ejercicios proyectuales como el mausoleo Glorificando gli Eroi Nostri (1918), el edificio presentado al concurso para la Aduana de Montevideo -también publicado como "Edificio público para Buenos Aires"-, ${ }^{184}$ los templos votivos o los estudios góticos de su etapa formativa a los que ya hemos hecho referencia. ${ }^{185}$ Entre la producción realizada en la década de 1920, tiene singular relevancia la Concesionaria Resta Hnos. (luego Fevre y Basset) ca.1926-1928. ${ }^{186}$ Es evidente que el arquitecto conocía la Fabrica Fiat en Lingotto (1916-1927, Torino, Italia) con su pista de pruebas en la terraza. ${ }^{187}$

Por ello es que el edificio puede ser considerado como una pequeña recreación local del proyecto de Matté Trucco que con sus 250 metros de largo y sus cinco pisos llegó a ser una de las plantas fabriles de automóviles más importantes del mundo en esos años y un símbolo de la $\overline{183}$ Palanti hizo uso de dos situaciones urbanas especiales planteadas en el Reglamento General de Construcciones que permitían la edificación a mayor altura: la ubicación en esquina y sobre dos avenidas. Hacia Los proyectos planteados por el Municipio hacia 1904 disponían el ensanche de una serie de calles que corrían de Este a Oeste y transformaban al lote en un sitio estratégico: la construcción en altura sería concedida más allá de la concreción del ensanche. El planteo de Palanti saca provecho especulando con esta situación ya que en aquel momento el ensanche de Santa $\mathrm{Fe}$ era un proyecto que sería reactivado hacia fines de la década de 1920. Valeria Gruschetsky, "El espiritu de la calle Corrientes no cambiará con el ensanche" La transformación de la calle Corrientes en avenida. Debates y representaciones. Buenos Aires 1927-1936. tesis de Licenciatura inédita, defendida en Buenos Aires: Universidad de Buenos Aires, 2008), 51.

184 Mario Palanti, Proyecto para aduana de Montevideo. Los Angeles, Getty Research Institute (910002), Mario Palanti Papers, Serie I, Folder 8. (GRI). El mismo proyecto es presentado en Cinque anni di lavoro. 331

185 Palanti, Prima esposizione personale d'architettura nella Repubblica Argentina

186 La obra se realizó durante la segunda estadía del arquitecto en la Argentina. En algunas fuentes se indica que el mismo fue proyectado en coautoría con el Arq. Oscar González, aunque otras lo dan como obra singular de Palanti. Los trabajos fueron iniciados en 1927 y el edificio fue inaugurado en diciembre de 1928 durante la exposición del automóvil.

187 Amadeo Ramos Carranza, Dibujos y arquitectura: la Fiat Lingotto (1916-1927), tesis doctoral dirigida por M. trillo de Leyva y J. L. trillo de Leyva, (Escuela Técnica Superior de Arquitectura, Universidad de Sevilla. Diciembre de 2005). 

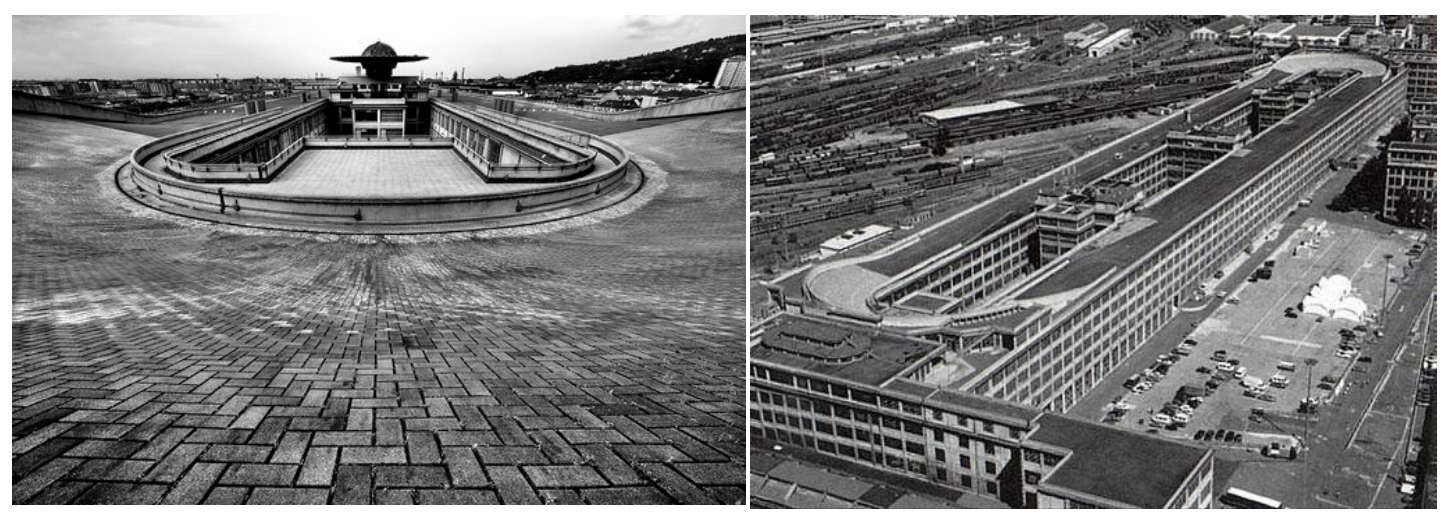

Ing. Matté Trucco, Fabrica Fiat en Lingotto (1916-1927, Torino, Italia)

productividad del Estado Fascista. ${ }^{188}$ La recreación local, tal como lo demuestra la publicidad publicada en Il Giornale d'Italia con motivo de la inauguración del edificio, suponía una llamada propagandística hacia la modernidad y a la valoración de la industria automotriz. ${ }^{189}$

En este caso podríamos hacer un paralelo con las casas de renta mencionadas más arriba. Existe una desconexión entre la planta y la fachada, pero los términos son inversos. Mientras que en las casas de renta las fachadas tienen un marcado carácter experimental y contrastan con una

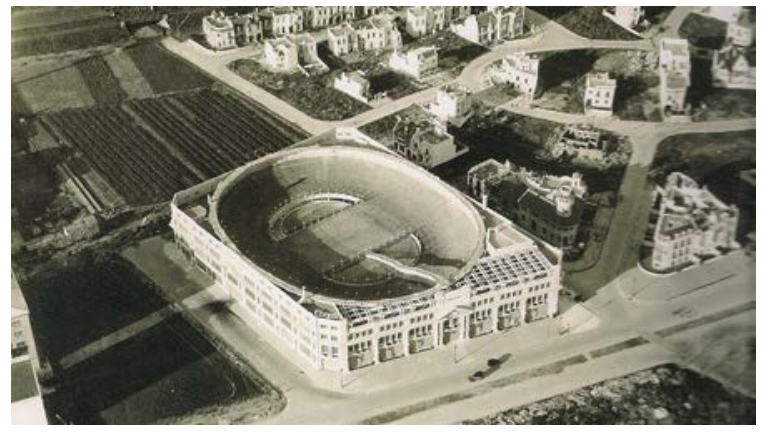

Fotografía de la concesionaria. A la derechael chalet realizado por Palanti y Algier. Puede observarse la convivencia entre el edificio comercial e industrial, el Barrio Parque, cultivos y el tren. Avenida Fi
Alcorta no 3351 , Buenos Aires.ca. 1930. s/d.

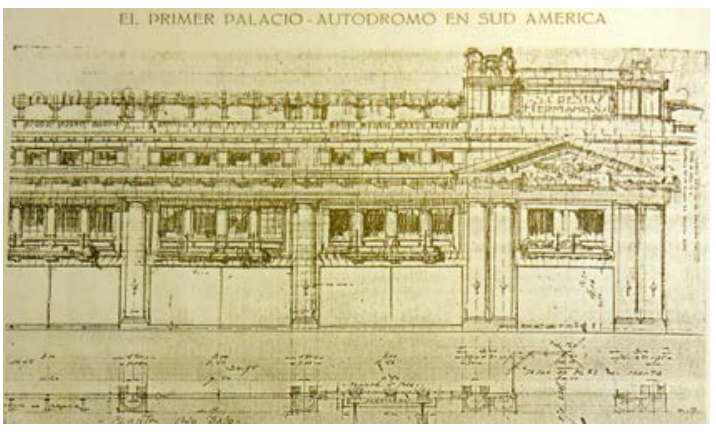

Planos de la fachada. Concesionaria Fevre y Basset. Avenida Figueroa Alcorta no 3351, Buenos Aires. 1926-28. Mario Palanti. Revista CACYA n' 1, junio,

planta especulativa; aquí la planta con su estructura de hormigón armado y su rampa de acceso a la terraza que sigue los lineamientos de la obra de Matté-Trucco aparece como una verdadera innovación basada en las nuevas premisas técnicas y espaciales de la arquitectura moderna que contrastan con el lenguaje ornamental de la portada. En efecto, la estructura en hormigón no sólo permitía el acceso de los automóviles a la terraza sino que admitía un gran salón de ventas de 80 metros de largo por 16 de ancho con una gran losa sin columnas intermedias. La obra fue 


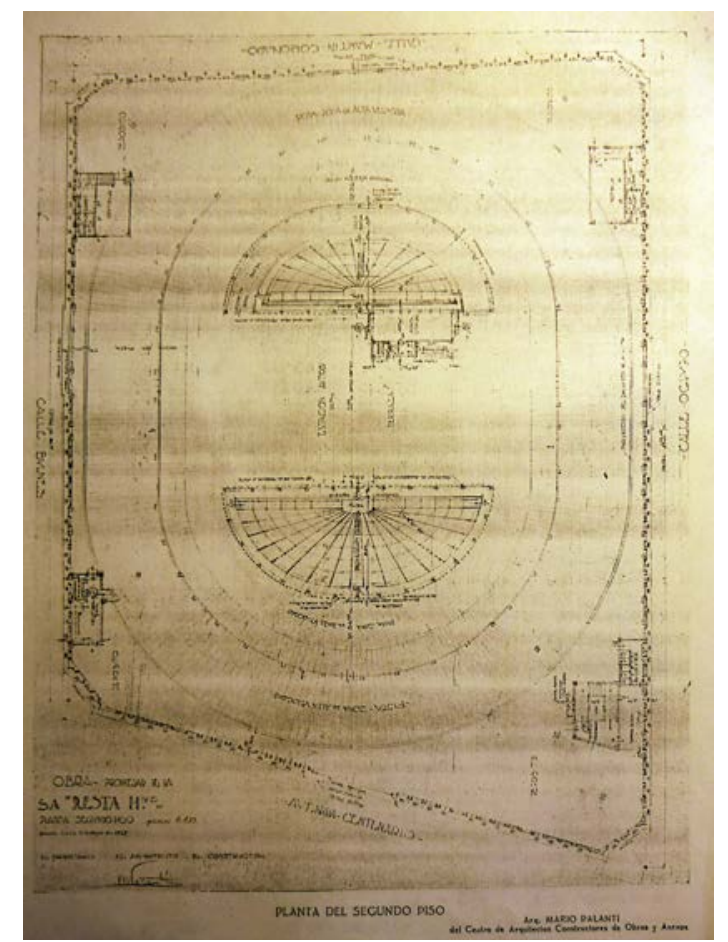

Planos del segundo piso. Concesionaria Fevre y Basset. Avenida Figueroa Alcorta no 3351 , Buenos
Aires. 1926-28. Mario Palanti. Revista CACYA n 1, junio, 1927

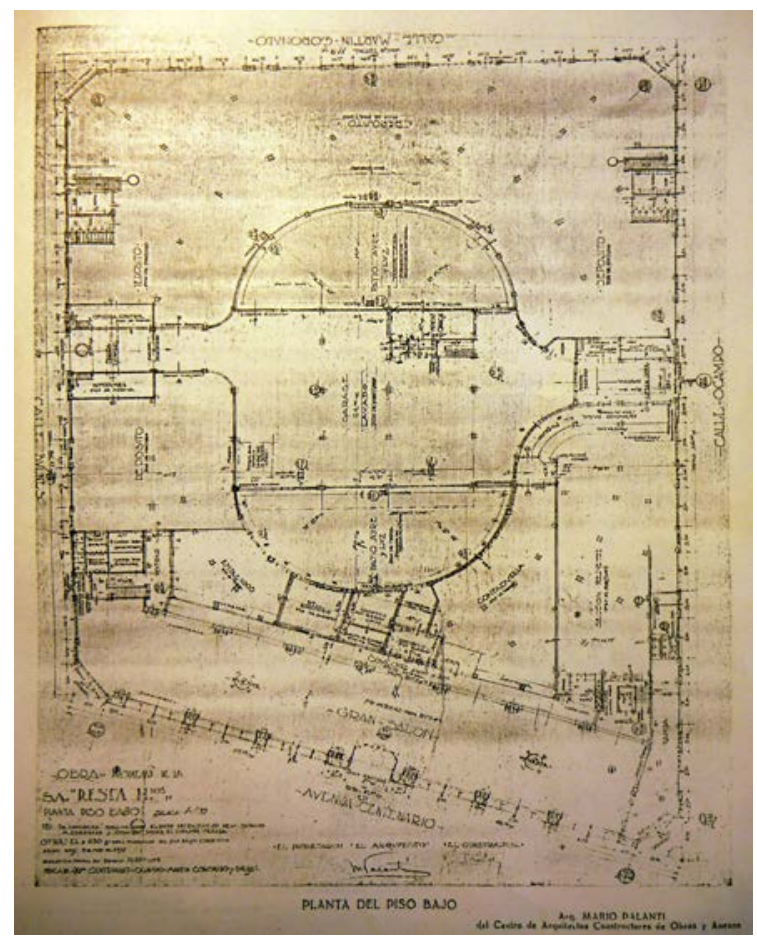

Planos del segundo piso. Concesionaria Fevre y Basset. Avenida Figueroa Alcorta n' 3351 , Buenos Aires. 1926-28. Mario Palanti. Revista $C A C Y A$ n $^{\circ} 1$, junio, 1927

dividida en cinco secciones con juntas de dilatación para evitar los movimientos térmicos de la masa de hormigón armado. La pista en principio fue revestida con ladrillos prensados de máquina y luego se le colocó una capa asfáltica. En realidad se trataba de dos pistas superpuestas. La inferior era para bajas velocidades y la superior de pruebas para altas velocidades contenía

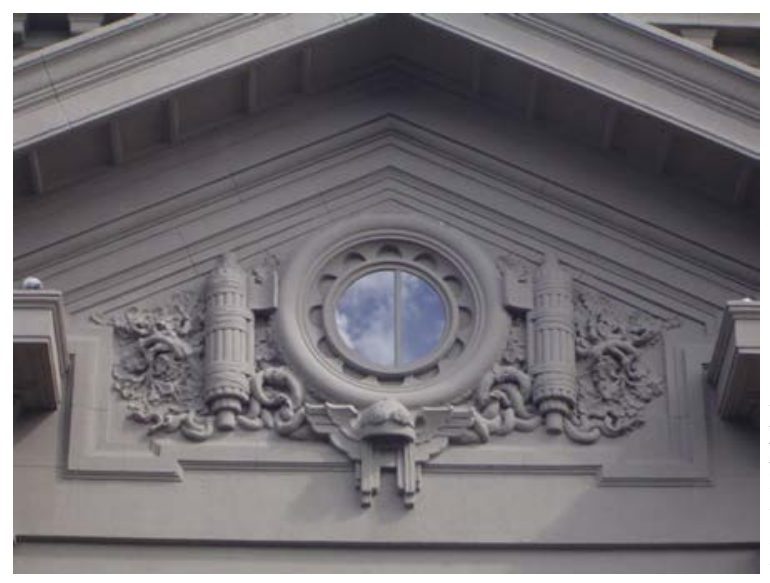

Detalle de la fachada principal. Se ve el frontis con los fasci. Avenida

Figueroa Alcorta n⿳3 3351. 1926-28. Mario Palanti. Foto Fernando Aliata

un parapeto de hormigón de seguridad en su perímetro. En uno de los laterales de la pista se dispuso un restaurante con pérgolas para observar desde allí las actividades automovilísticas. La innovación del conjunto se completó con el uso de instalaciones de montacargas y ascensores, calefacción central, servicio de incendio, telefonía y correo neumático. ${ }^{190}$ Frente a este alarde 190 Mario Palanti, "El primer palacio autódromo en Sud América, Resta SA", CACYA, N¹ (Buenos Aires, jun. 1927): $12-16$. 
de modernidad la fachada, en cambio, está compuesta de una manera tradicional con estilemas característicos del neo renacimiento italiano con elementos destinados a caracterizar al edificio: una gorra con las antiparras del piloto enmarcados por dos haces lictorios: símbolos de la autoridad republicana en la antigua Roma adoptados como emblema por el fascismo y dispuestos por Palanti en un modo de relacionar el régimen con la modernidad.

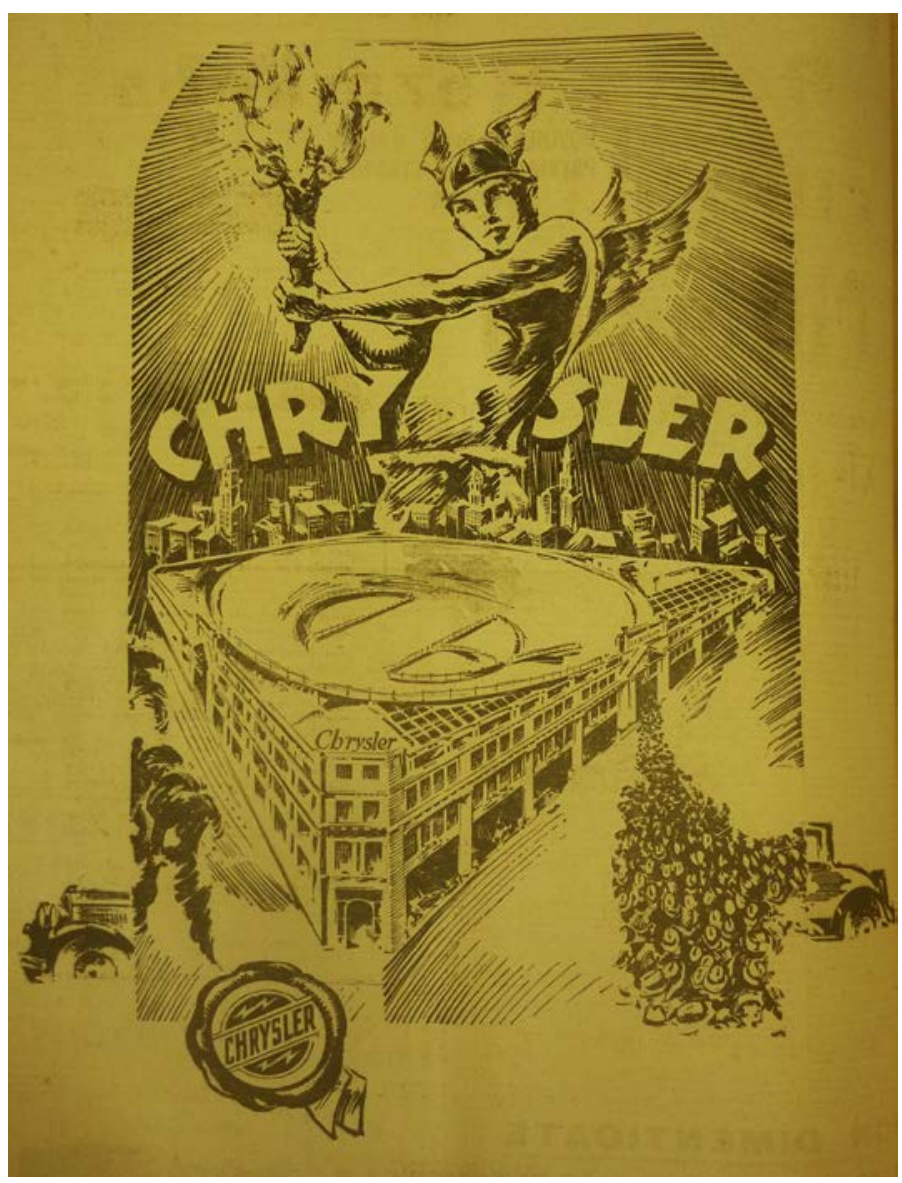

Moedrnidad y dinamismo en el corazón de la metrópolis. Un edificio que conPublicidad con motivo de la inauguración de la consecionaria Chrysler en Il Giornale D italia. Buenos Aires, 29 de noviembre de 1928.

Como vimos, mientras que parte de la producción de Palanti se mantiene en líneas convencionales en respuesta a encargos más conservadores, en aquellos en los que Palanti tuvo libertad de acción por parte de los comitentes pueden verse materializadas sus ideas: el arquitecto confía que una nueva arquitectura podrá surgir del ensayo lingüístico permanente que conjugado con las nuevas técnicas, el clima y el medio produzca una síntesis. Sin embargo, la enorme diversidad de las propuestas parece no poder provocar a la larga una integración. Debemos esperar a los grandes rascacielos para que la arquitectura experimental de Palanti adquiera una madurez definitiva. 


\title{
Capítulo III. E1 primer rascacielos. E1 Pasaje Barolo
}

\begin{abstract}
L'impressione che si riceve nell'arrivare in un paesse, che ancora non si conosce, tanto per terra, come per mare (molto piú intensa in questo caso) proporziona una visione nuova, una nuova sensazione scenografica, e láspetto del complesso di elementi che caratterizzano una apparizione, infonde quel che si potrebe chiamare la 'configurazione architettonica del luogo', da cui deriva, senza altra transazione, l'enorme importanza che riveste il complesso tema edilizio.

(Mario Palanti, Cinque anni di lavoro, 1924)
\end{abstract}

\section{Un colosal encargo}

Tengo el agrado de dirigirme al Señor Presidente, y por su intermedio a los señores miembros del H. Concejo Deliberante, de la ciudad de Buenos Aires, para pedirles, si lo tienen a bien, el alto favor de asistir al acto de la inauguración de la torre del edificio situado en la Avenida de Mayo No. 1356, 82, propiedad de los señores Barolo y Cía., y cuya construcción he proyectado y dirijo. ${ }^{2}$

Con estas palabras, el 27 de junio de 1923, Mario Palanti invitó a los miembros del Concejo Deliberante a la inauguración de la torre del Pasaje Barolo. Un mes antes, algunos detractores del emprendimiento habían elevado en el Concejo un proyecto de ordenanza que proponía, por razones de estética e higiene, demoler la torre de dicho edificio. $^{3}$

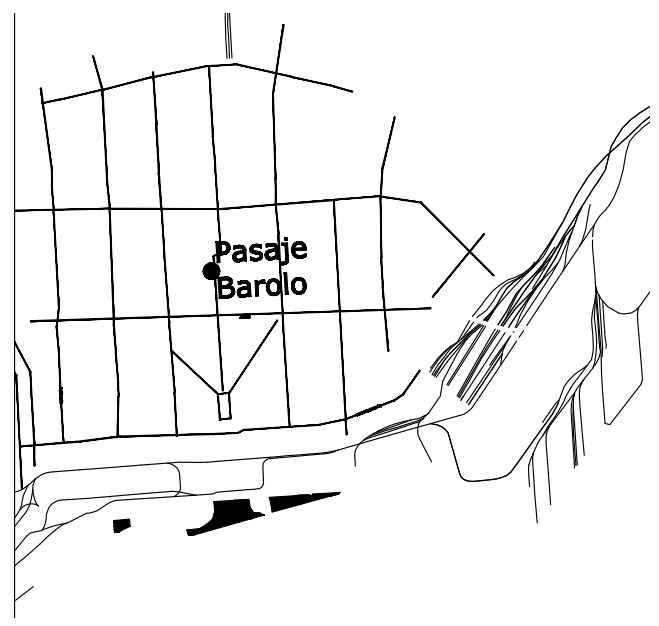
de anteproyectos. ${ }^{4} \mathrm{El}$ terreno elegido era un lote

Ubicacion del Pasaje Barolo

1 "La impresión que se recibe al llegar a un país, che aún no se conoce, tanto por tierra, como por mar (mucho más intensa en este caso) proporciona una visión nueva, una nueva sensación escenográfica, y el aspecto de la totalidad de los elementos que caracterizan una aparición, infunde aquello que se podría llamar la 'configuración arquitectónica del lugar', de la cual deriva, sin otra transacción, la enorme importancia que reviste el complejo tema edilicio." [Traducción Florencia Minatta]

2 Versiones Taquigráficas del Honorable Concejo Deliberante de Buenos Aires, junio 1923. (VT HCD)

3 VT HCD, abril 1923.

4 Rolando Schere, Concursos 1825-2006 (Buenos Aires: SCA, 2008). En la licitación de empresas constructoras para el Palacio Salvo, con fecha del 22 de mayo de 1922, Otto Gotschalk menciona la consulta para el "Pasaje Quintana", obra de 20 pisos, propiedad de Luis Barolo y Cía. en Avenida de mayo al 1388. Caja 265, carpeta 4, AGN Montevideo. 
levemente irregular de $1.393 \mathrm{~m}^{2}$ al 1366-82 sobre la conocida Avenida de Mayo, entre Santiago del Estero y Salta, a una cuadra del Congreso Nacional. ${ }^{5}$ Además de la particularidad de ser un solar pasante -el lote tenía salida a calle Victoria (hoy Hipólito Irigoyen-, el mismo se ubicaba sobre la avenida que era, además, el eje cívico porteño con la Plaza de Mayo como inicio y la Plaza del Congreso como remate. Definido el solar, quedaba entonces definir el proyecto.

En este escenario metropolitano de la Avenida de Mayo, a mitad de cuadra se destaca el gran portal diseñado por Palanti, con 7,50 metros de ancho y tres niveles de altura que funciona como galería de acceso al edificio. Frente a la Galería Güemes o las Galerías Pacífico (antes Bon marché) que vinculaban dos estrechas calles de matriz fundacional, el Barolo, al igual que el Pasaje Roverano o el Urquiza Anchorena era -y en cierto modo continúa siéndolo- un enlace entre el presente y el pasado. A pesar de ello, Palanti vinculó la avenida y la calle a través de una resolución lingüística similar en ambas fachadas: el espectador atravesaba este amplio corredor y se trasladaba del boulevard metropolitano a la herencia de "la gran aldea" o viceversa. En este sentido la intervención se relaciona, por cierto, con la operación Hausmaniana en tanto que genera la posibilidad, a través de la apertura de avenidas, de la implantación de edificios que, como grandes empresas inmobiliarias, conectan el tejido antiguo con las nuevas intervenciones.

Iniciada durante el gobierno de Torcuato de Alvear según el proyecto de J. Buschiazzo, la apertura de la Avenida de Mayo (1882-1894) dio como resultado una situación particular de cuadras angostas que ofreció una zona ideal para la construcción de pasajes comerciales. ${ }^{6}$ La Avenida se había convertido en el boulevard central de la ciudad, paseo
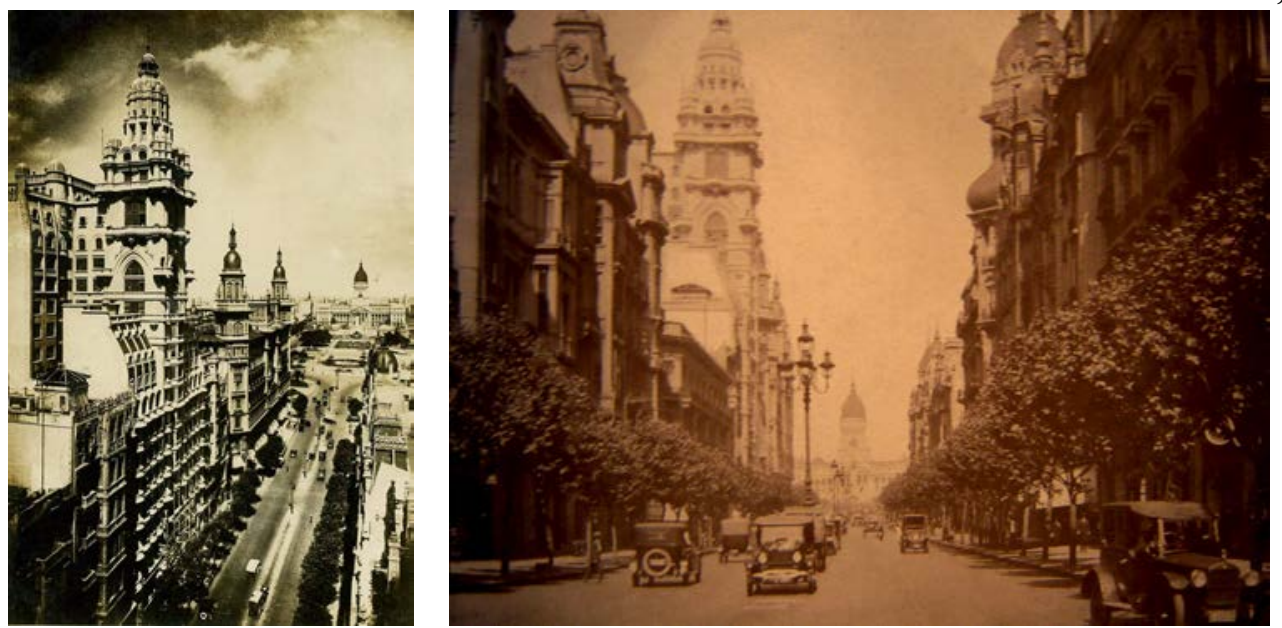

Vista de la Avenida de Mayo. A la izquierda, el Pasaje Barolo. Tarjeta postal s/d.Ca.1930

5 El lote mide 30,88m de frente sobre Avenida de Mayo y 30,78 sobre la calle Victoria al 1363-85 (hoy Hipólito Yrigoyen). Los laterales del lote miden: 44,23 s-obre la calle Santiago del Estero y 44,14 sobre Salta. Sección Catastro e inmueble, Julio 1945. Archivo CEDIAP.

6 Liernur, Arquitectura en la Argentina del siglo XX. 
obligado de un gran número de porteños que desde fines del siglo XIX circulaban por sus veredas. El primer subterráneo inaugurado en 1913 formaba junto a los cafés, las luces, los locales comerciales y las galerías la atmósfera que permitía a la pequeña burguesía local asomarse al universo de vida civilizada que las grandes urbes europeas -Viena, París, Berlín, Praga, etcétera-, exhibían.

Con el anhelo de mantener un aire europeo, la Avenida tenía su propia reglamentación condicionando la altura de las fachadas a una altura mínima de 20 metros y máxima de 25 sobre la línea municipal. ${ }^{7}$ En este contexto de pretendida uniformidad, el Pasaje Barolo irrumpe con sus 90 metros transgrediendo los límites permitidos sobre la famosa vía porteña. ${ }^{8}$

El proyecto fue controversial desde sus inicios: para conseguir la altura anhelada la obra obtuvo, por única vez, la excepción de las reglamentaciones particulares de la Avenida lo que permitió alcanzar la mencionada altura de 90 metros superando la de cualquier otro edificio de la época: recordemos que, como señalamos en el capitulo dos, existía por entonces en Buenos Aires una rápida carrera por lograr un émulo local del rascacielos, síntesis del imaginario del progreso en la cual compiten una serie de edificios. ${ }^{9} \mathrm{Al}$ iniciarse las obras del Pasaje Barolo la ciudad contaba ya con el Plaza Hotel (1907-1909) de 63 metros de altura, el Railway Building de 78 metros (1907-1910) y la Galería Güemes (1912-1916) de 77 metros. Con sus 90 metros, el Barolo consiguió el título de mayor altura en Buenos Aires, que mantendría hasta la construcción del Kavanagh en 1936.

\section{Resolver un problema: la morfología del rascacielos}

Este panorama y debate en torno a la construcción en altura no era una particularidad porteña, sino que invadía las grandes urbes en torno al globo. En efecto, uno de los grandes focos de discusión -como lo explica el trabajo de Quintana de Uña- fue la Europa de entreguerras donde, además de la existencia de cascos antiguos ya consolidados, la difícil situación económica

7 Ordenanza de Construcción de 1910, aprobada en noviembre, publicada en la revista La Ingeniería del Centro Nacional de Ingenieros, Año XIV, Números correspondientes a nov-dic., 1910. La Ordenanza sería reformada en la Ordenanza Municipal 2736 de junio de 1928. Véase María Isabel de Larrañaga, "Las normativas edilicias como marco de la arquitectura moderna en Buenos Aires (1930-1940)", en Anales del LAA n 27-28.

8 La altura de 90 metros es señalada por Palanti en L'Eternale Mole Littoria, 36. Palanti aclara que ha realizado dos rascacielos, uno de 90 metros en Buenos Aires y uno de 120 metros en Montevideo. Asimismo, la postal que muestra la torre del pasaje Barolo llamada "torre palantiana", AGEP

9 Virginia Bonicatto, Escribir en el cielo. Relatos sobre los primeros rascacielos en Buenos Aires (1907-1929) tesis de maestría inédita (Universidad Torcuato di Tella, Noviembre 2011). 
dificultaba la materialización de las propuestas. ${ }^{10}$ Ejemplo de ellos son los rascacielos de cristal de Mies van der Rohe o las propuestas realizadas por futuristas y expresionistas. Quintana de Uña descubrió alrededor de seiscientos proyectos provenientes de veintidós países que dan cuenta de la magnitud que el debate teórico sobre la construcción altura tenía en la Europa de entreguerras. Pero si bien las indagaciones proyectuales abundaban no sucedía lo mismo, por ejemplo, en Norteamérica donde los ejemplos construidos que eran fruto de una carrera especulativa desenfrenada que no daba lugar a experimentaciones. ${ }^{11}$

Sin embargo, también en sede norteamericana los problemas en torno a la morfología eran tema de debate. Desde principios de siglo XX, el crítico norteamericano Montgomery Schuyler había ya detectado la ineficiencia del academicismo decimonónico como herramienta para dar respuesta formal al rascacielos y había dedicado tiempo a dilucidar problemáticas propias de la construcción en altura, resultantes del intento por controlar dimensionalmente el objeto ante la falta de instrumentos institucionales adecuados. Sus trabajos "The Sky-scraper Up-ToDate" (1899) y "The Skyscraper Problem" (1903) dejarían a la vista el problema de dominio formal que enfrentaría el rascacielos; por ejemplo, si el Guaranty Building (1894) diseñado por Sullivan y Adler dejaba percibir su esqueleto metálico o, si en la solución que propusieron para el Wainwright Building (1890-91) el exceso de "follaje" no permitía dilucidar la función estructural del edificio. ¿Cómo dominar formalmente un nuevo objeto arquitectónico? En efecto, entender el debate del momento permitirá comprender en mayor profundidad las soluciones propuestas por Palanti al tema del rascacielos. ${ }^{12}$

De acuerdo al crítico Francisco Mujica, entre las opciones de configuración más conocidas en los rascacielos norteamericanos podemos encontrar tres categorías: a) prismas simples, b) torres aisladas, c) setback piramidal. A ellos podemos sumar el prisma con adición de la torre, categoría propuesta por Rem Koolhaas en 1978 como el "verdadero" rascacielos. ${ }^{13}$

En cuanto a los modelos de ocupación en planta, se pueden señalar formas geométricas simples como el cuadrado o el rectángulo utilizados en Chicago y otras disposiciones más complejas que pueden catalogarse tipográficamente - siguiendo la semejanza con el alfabeto

10 Quintana de Uña. Sueño y frustración.

11 Consideremos que, por ejemplo, hacia 1908 Nueva York contaba con quinientos treinta rascacielos de entre diez y cuarenta pisos. Revista Arquitectura, (Revista Técnica) No 47 (marzo 1908).

12 Montgomery Schuyler, American Architecture and other writings, Vol. I-II. Massachusetts: Harvard University Press, 1961. (publicados originalmente entre 1883-1909).

13 Mujica, Francisco. History of the Skyscraper. (París: Archaeology \& Architecture Press, 1929. Rem Koolhaas, Delirious New York: a retroactive manifesto for Manhattan, (Monacelli Press, 1994 [1978]), 87. 


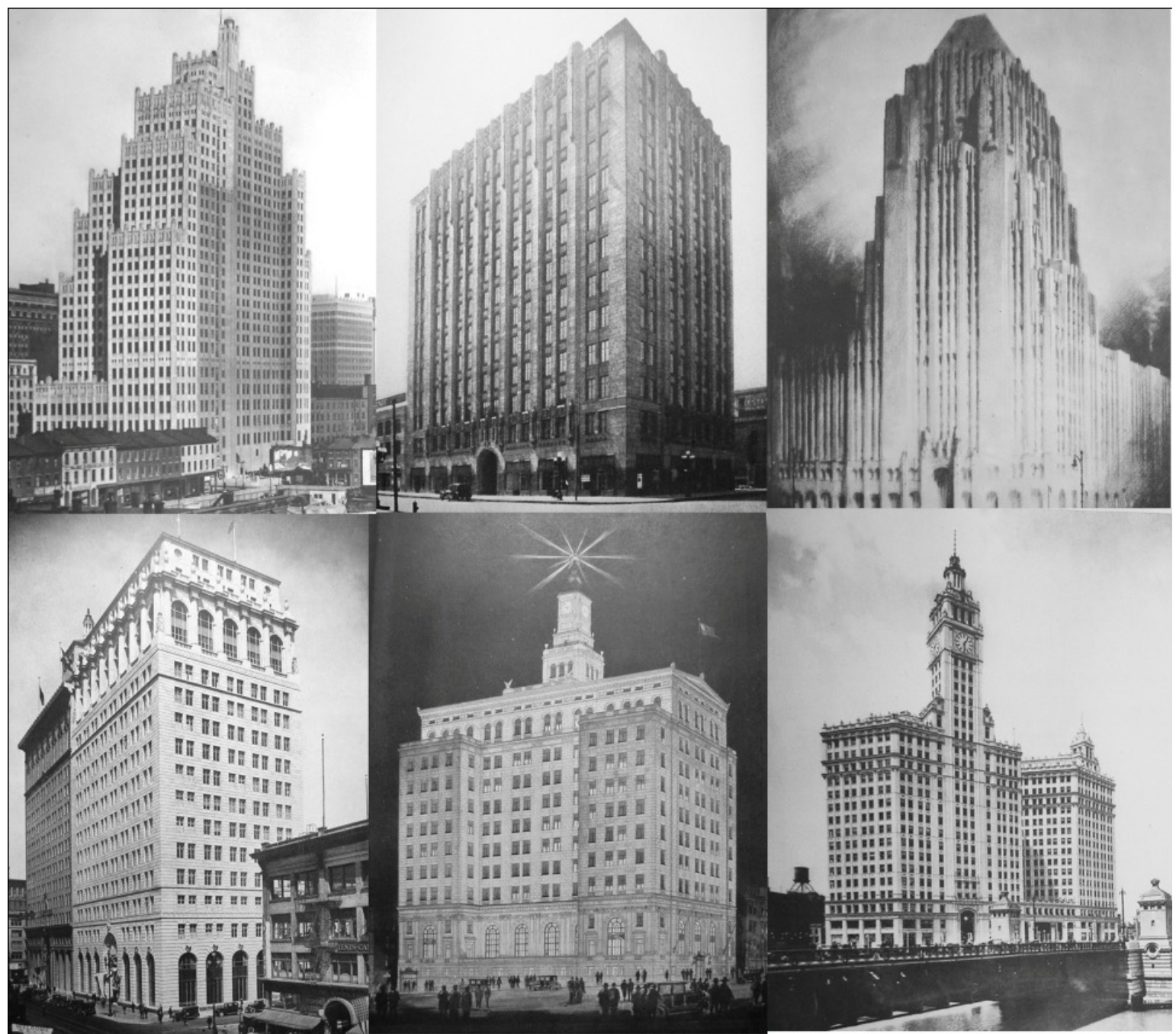

Ejemplo de categorías de rascacielos en ejemplos norteamericanos:

a , c, Setback

b, d, bloque

e, f, bloque y torre

Se suman ejemplos ya vistos como: Torre aislada en el
Singer Bld.; Bloque y torre en el Woolworth Bld.

a. St. Louis Telephone Bld.

b.Baker Building.

latino planteada por Carol Willis al estudiar el rendimiento inmobiliario de las formas- en esquemas en "H”, “T”, “O”, “U”, "E” o "L". ${ }^{14}$

Además de estos ejemplos, se dan también operaciones como la del Flatiron de D. Burnham y F. Dinkelberg (New York, 1902) que maximizan las posibilidades del espacio interior destinado a renta inmobiliaria. El resultado de ello es una operación simple que repite en altura la forma y superficie del lote. Estas múltiples variantes "tipográficas" se alejan de lograr un “tipo” (según la idea de Quatremere de Quincy) normal, estandarizado, de rascacielos tal como proponía Sullivan.

14 Carol Willis, Form follows finance: skyscrapres and skylines in new York and Chicago (New York: Pinceton Architectural Press, 1995). Véase Quintana de Uña, Sueño y frustración, 171-172. c. Dibujo, Hugh Ferris.

d.Pacific Gas \& Electric Bld.

Office Bld. Daventport

a, b, f: The History of the Skyscraper, Op.Cit.

$\mathrm{d}$, The Metropolis of Tomorrow, Op.Cit.

d, e, American Commercial Buildings, Op.Cit. 
Si bien los ejemplos podían ser diferentes, en la disposición interior eran similares: en la mayoría de los casos norteamericanos se realizaba una reproducción de plantas tipo con un remate y una planta baja diferente, en donde el hall, como espacio semipúblico, era el único lugar donde se disimulaba la lógica especulativa. ${ }^{15}$

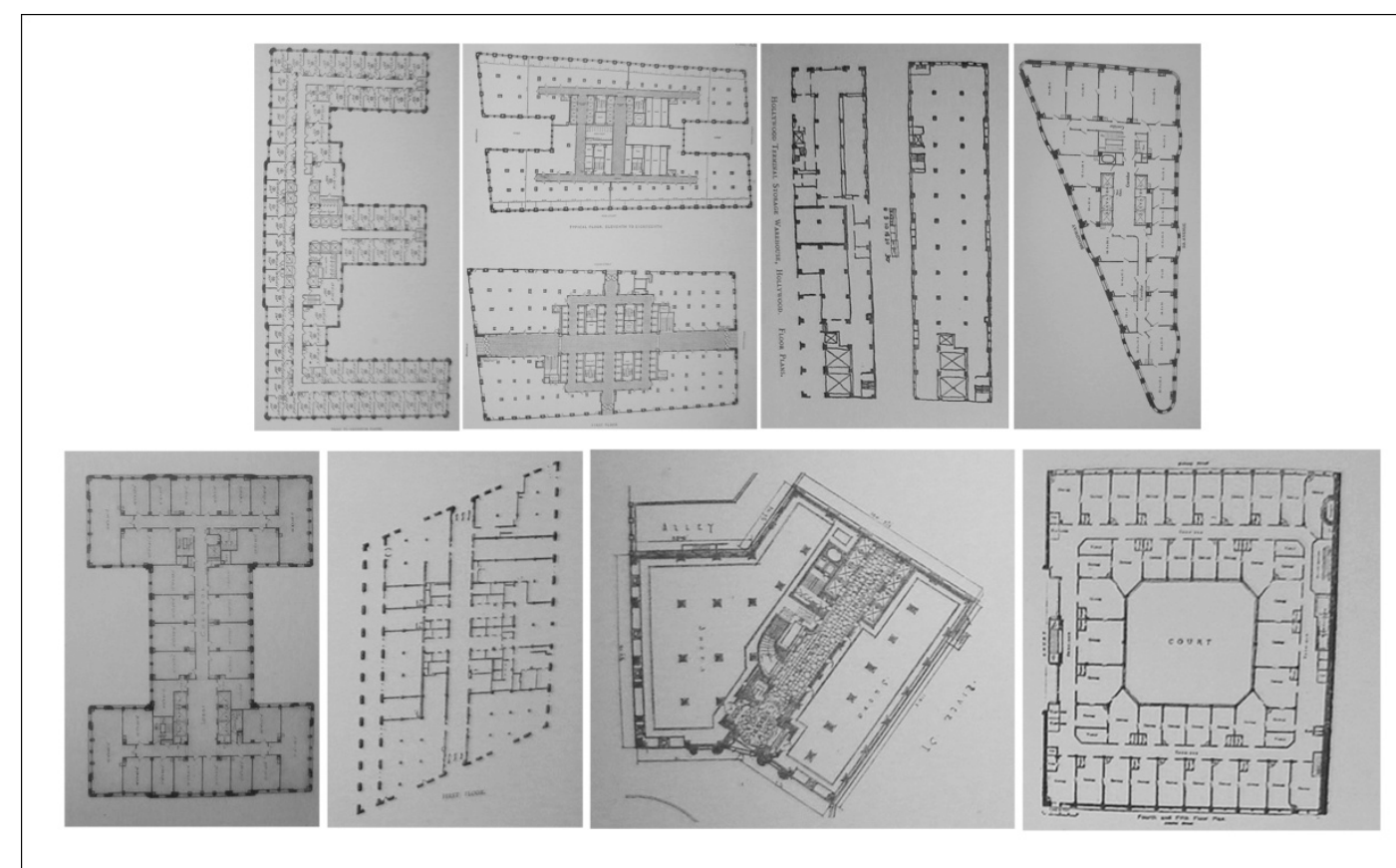

Arriba: diferentes tipos de disposición en planta de rascacielos norteamericanos. Rus Bld., Equitable Bld., Holywood Terminal, Flatiron, Macabees Bld., New York Telephone Bld., London Guaranty, Rand Mc. Nally Bld. The bistory of the Skyscraper, Op.Cit.

Derecha: Diversidad de plantas del Pasaje Barolo

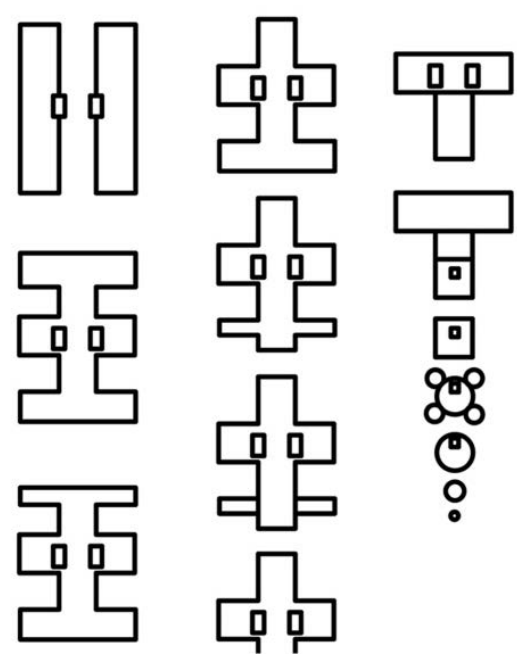

A partir de la sanción de la zoning law neoyorquina en 1916, cobró relevancia el desarrollo de edificios en setback que, debido a las prescripciones establecidas por la normativa, promovían la yuxtaposición de formas de ascenso telescópico que fueron inspiradoras de los dibujos de Hugh Ferris que sin duda Palanti conocía. ${ }^{16}$ A su vez, la reglamentacion brindaba un

15 Manfredo Tafuri y Dal Co, Arquitectura Contemporánea, 69.

16 Hugh Ferris en The Metropolis of Tomorrow (New York: Princeton Arch.Press, 1986 (1929)). 
posible recurso de dominio formal del edificio ante la ya probada dificultad del sistema clásico al momento de resolver obras de múltiples niveles.

Hacia 1890, Sullivan había declarado que el diseño de la construcción en altura era un problema que debía ser confrontado y resuelto. Para ello, proponía sistematizar un orden de composición que resolviera la expresión exterior del rascacielos. Basado en su máxima: “donde la función no varía tampoco varía la forma", planteaba una división tripartita que podía imitar la columna de la antigüedad grecorromana, el misticismo del número tres o ciertas formas de la naturaleza.

El edificio se dividía así en una planta baja y un segundo piso, que podían ser destinados a diferentes usos, y sobre estos — funcional al objetivo mercantilista del rascacielos — un número indefinido de plantas similares destinadas a oficinas hasta alcanzar el "ático": un remate cargado de simbolismo. En efecto, Sullivan planteaba el uso de decoración para simbolizar la institución que un edificio debía representar. El ornamento se dispondría allí donde la especulación parecía ceder: en planta baja y en el remate. ${ }^{17}$

Efectivamente, la arquitectura se enfrentaba resolver un tipo nuevo de construcción que no se basaba en el muro como soporte estructural, lo que generaba un problema lingüístico entre el soporte y la envolvente-decoración que en reiteradas ocasiones, por razones de estética, ocultaba la función estructural del material.

Así, de acuerdo al juicio de expertos como Francisco Mujica o Montgomery Schuyler, se pueden separar dos etapas relacionadas al problema lingüístico y de control formal planteado por el rascacielos: una primera etapa (1884-1913), donde el vocabulario del clasicismo, sus líneas rectas, la solidez y la composición tripartita en fachadas fue tomado como referente, y una segunda (1913-1926) a partir del empleo de elementos del sistema gótico afianzado por Cass Gilbert en 1913 en el Woolworth Building, caracterizada por la verticalidad, nervaduras, honestidad estructural y mayor tamaño de aventanamientos en proporción a la superficie de fachada. ${ }^{18}$ Efectivamente, el hecho de señalar estas cuestiones permitirá dar una lectura diferente a las soluciones desarrolladas por Palanti.

$\overline{17}$ Louis Sullivan, The tall building artistically considered, Lippincott's magazine (marzo 1896).Consultado noviembre 2011. http:/ /academics.triton.edu/. Wim de Wit, Louis Sullivan: The Function of Ornament (Norton, 1986).

$18 \mathrm{Al}$ respecto, Gilbert expresaba que, entre todos, el gótico era el que reunía las características apropiadas para el diseño de rascacielos, considerado como “apropiado" por Francisco Mujica, History of the Skyscraper. (París: Archaeology \& Architecture Press, 1929), 34-35. 


\section{Estrategias proyectuales}

Familiarizado con el debate en torno a la construcción en altura, y fiel a su método proyectual, los antecedentes del Pasaje Barolo pueden rastrease en la misma producción del arquitecto. En los primigenios proyectos utópicos de templos votivos, iglesias y mausoleos se ven elementos que serían retomados por Palanti en el diseño de su primer rascacielos.

Los primeros bocetos realizados para el edificio de Luis Barolo muestran características neogóticas que recuerdan a la ya mencionada Facultad de Derecho, realizada por el estudio de Prins y Ranzenhofer. ${ }^{19}$ Deudores de la formación del arquitecto en la Academia de Brera, los proyectos de Palanti muestran en plantas y en corte un sistema de composición vinculado con el método de la Ecole des BeauxArts de París: múltiples ejes de composición, ideas de partí, point, marche, poche..$^{20}$ Efectivamente, las indagaciones de Palanti no se

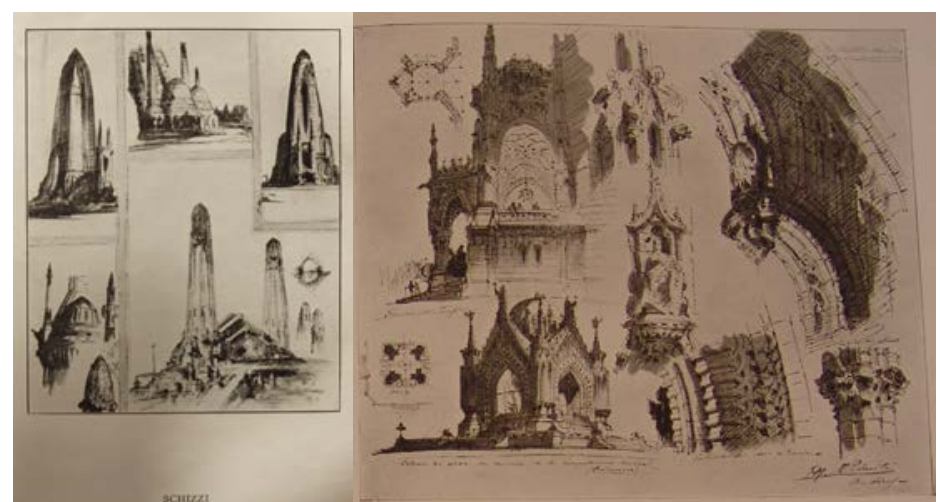

Izq. Esquicios . Mario Palanti. Quatto Anni di lavoro Der. Estudios de motivos ojivales. Ca. 1912. Mario Palanti. Prima esposizione personale di architettura...

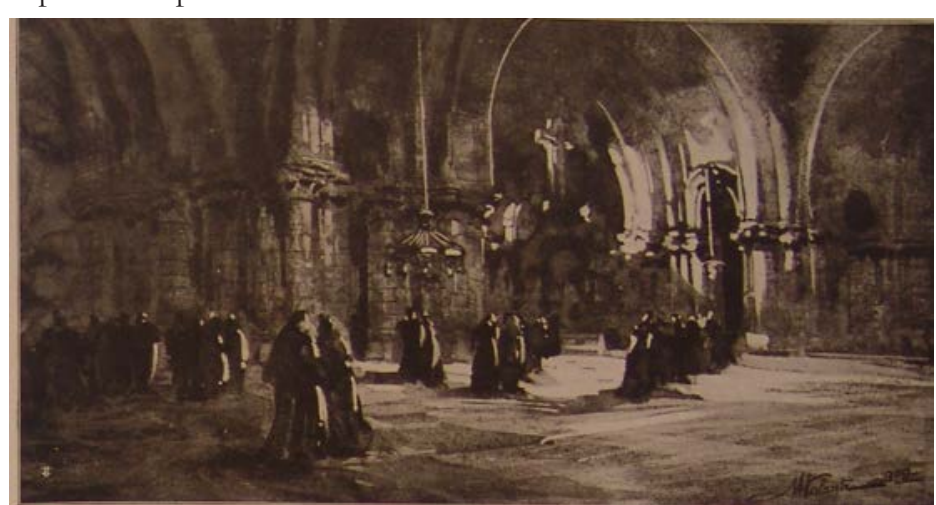

Mario palanti. Proyecto para iglesia votiva. Prima esposizione personale di architettura..

técnica de representación mediante

19 Sobre el proyecto de A. Prins véase: Diario La Prensa, 3 de mayo de 1910; Revista de Arquitectura de la SCA, (marzo/abril de 1910, No. 62, pp. 25/37 Revista de Arquitectura de la Sociedad Central de Arquitectos, No 62 (marzo/ abril 1910): 25-37; Anuario La Razón 1922, Buenos aires, p.98 Anuario La Razón (Buenos Aires, 1922): 98; Ibíd, 1923, p 183. Ibíd, (1923): 183. Asimismo, el trabajo de Julián Velazquez. "Las Heras 2214, la construcción del espíritu contradictorio", trabajo inédito presentado para el seminario "Historia de la arquitectura argentina y latinoamericana", FAU-UNLP.

20 Giuliana Ricci (a cura di), L'architettura nelle Accademie riformate: insegnamento, dibattito culturale, interventi pubblici (Milano: Guerini e Associati., 1992). De la misma autora, "Tradition and modernity in the training of italian Project designers towards the late 1800s and early 1900s", en Architectural Culture Around 1900, critical reappraisal and heritage preservation, Buenos Aires, Universidad Torcuato di Tella, 2003. Sobre la formación de la Ėcole des Beaux Arts véase: Drexler (ed.), The Architecture of the École des Beaux-Arts. 
el empleo de perspectivas a vuelo de pájaro, expresivas vistas interiores y exteriores en acuarela o detalles constructivos y ornamentales que muestran su vínculo originario con las artes plásticas y su interés en el diseño de objetos. ${ }^{21}$

Siguiendo $\operatorname{los}$ postulados boitianos, el repertorio formal del cual se nutre Palanti para dar respuesta al rascacielos

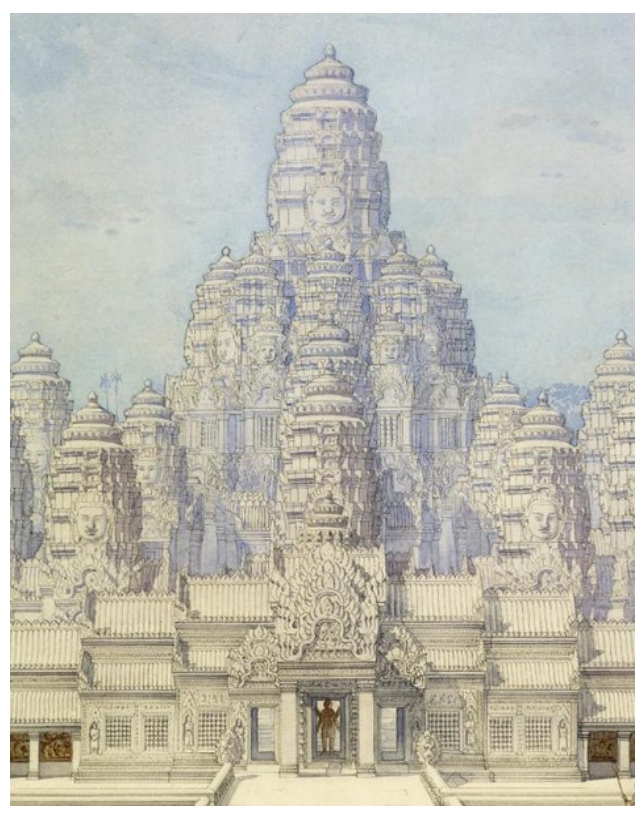
Templos de Angkor por Louis Delaporte, publicado en su texto Voyage au Cambodge. L'Architecture khmer, 1880

es amplio. En él convive la tipología en altura norteamericana con elementos del Medioevo lombardo y, según la comparación hecha por Carlos Hilger, hay en el edificio referentes de los templos hindúes de Jaipur y Amber. ${ }^{22}$ Si estos templos formaban parte del repertorio del cual Palanti se nutría es algo que desconocemos. ${ }^{23}$ Pero los motivos exóticos pueden provenir de otra fuente: el texto Voyage an Cambodge. L'Architecture khmer, de Louis Delaporte, publicado en París en $1880 .{ }^{24}$ Como señala Jean-Pierre Épron en Comprendre L'Éclecticisme, hacia fines del siglo XIX, los arquitectos se veían más atraídos por los descubrimientos arqueológicos que por la vida profesional durante sus años de estudio. Como ejemplo, cita el caso de los templos de Angkor publicados en L'Architecture en 1888 y cuyas sinuosas torres muestran líneas que se asemejan a las del Pasaje Barolo. ${ }^{25}$ En efecto, hacia principios de siglo XX, la búsqueda de inspiración en modelos exóticos era común al momento de resolver el problema que formalmente representaba el rascacielos en el cual el clasicismo había ya demostrado sus limitaciones. ${ }^{26}$

Más allá de estas fuentes, el desarrollo de la exploración en la tipología en altura, como señalamos, se encuentra también en los tempranos proyectos para la Facultad de Derecho y la Catedral para Buenos Aires, el edificio de Callao y Santa Fe (1920). Como veremos, estos

21 Palanti se inició como pintor, siguiendo a su hermano Giuseppe quien fue un destacado pintor, escenógrafo y diseñador de espacios interiores y objetos decorativos. Crespi Morbio (a cura di), Giuseppe Palanti.

22 Carlos Hilger, "Mario Palanti: su Monumento al Genio Latino", Summa +, No 3 (noviembre 1993): 42.

23 Varias imágenes habían sido publicadas en 1913 por L'Illustraz̧ione italiana: "Città e necropoli indiane. Jaipur e Amber", L'Illustrazione italiana, $\mathrm{N}^{\mathrm{o}} 32$ (10 de agosto 1913).

24 Louis Delaporte, Voyage au Cambodge. L'Architecture khmer (Paris: C. Delagrave, 1880).

25 Jean-Pierre Épron, Comprendre l'Éclecticisme (París: Norma, 1997), 290-291.

26 Francisco Mujica, History of the Skycraper. 
ejemplos serán los antecedentes de la larga secuencia de proyectos de rascacielos, temática que, junto con la experimentación técnica, interesaría a Palanti hasta los últimos años de su carrera.

Al igual que en la Galería Güemes diseñada por Francisco Gianotti, en el Pasaje Barolo se propone una tipología de rascacielos que incluye la "galería comercial", programa que se repetirá en el Palacio Salvo. Si bien en este caso -a diferencia del Salvo- no contamos con las bases del

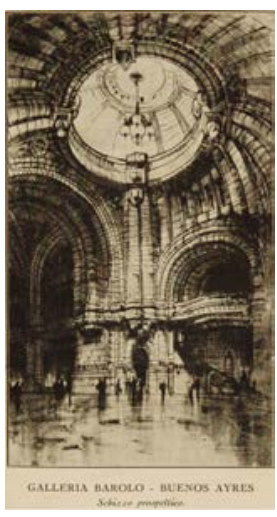

Boceto de una perspectiva interior. Pasaje Barolo (1919-22). Avenida de Mayo 1370, Buenos Aires. Ca. 1919. Mario Palanti. Quattro anni di lavoro. Milán. Casa Editrice d'arte Bestetti \& Tumminelli.1924

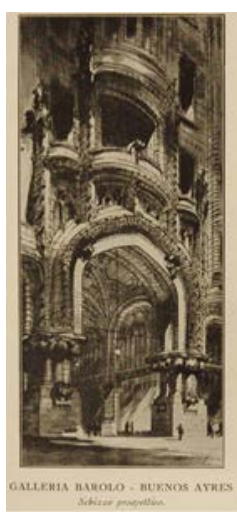

Boceto del portal de acceso. Pasaje Barolo (1919-22). Avenida de Mayo 1370, Buenos Aires. Ca. 1919. Mario Palanti. Quatto Anni...

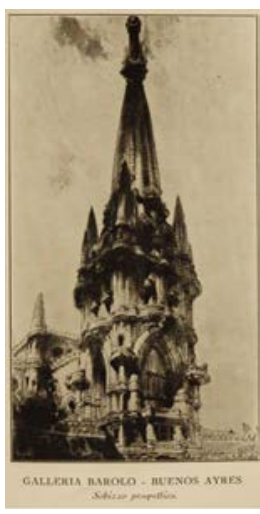

Boceto de la torre del Pasaje Barolo (1919-22). Avenida de Mavo

1370, Buenos Aires. Ca. 1919.

Mario Palanti. Quatto Anni...

concurso, muy posiblemente el requerimiento del pasaje como parte del programa de rascacielos de oficinas haya surgido por parte del comitente al considerar la implantación del edificio y la vida metropolitana.

Al momento de resolver el programa, Palanti se inclina por una disposición que se asemeja al neoyorquino Woolworth Building (1913): el volumen con anexión de la torre sobre la fachada, en una conjunción de bloque en setback, al que -en el caso porteño- suma el pasaje comercial y una planta deudora de las casas de renta que el mismo Palanti diseñaba. Como resultado formal, esta unión de galería comercial y rascacielos dio una tipología de compleja yuxtaposición volumétrica que en la búsqueda de dominar formalmente el objeto se alejó de los esquemas norteamericanos en bloque, torre, setback y sus variantes, para acercarse, en todo caso, a la experimentación teórica.

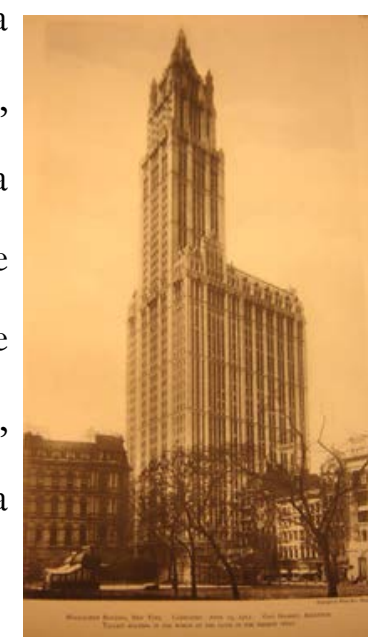

Woolworth Building, Nueva York, Estados Unidos: 1913. Cass Gilbert, en F. Mujica, History of the Skyscraper, Archaeology \& Architecture Press, Paris.New York, 1929. 
En efecto, si bien el espacio para renta es explotado al máximo en los pisos superiores, en la planta baja el hall se deja como pasaje abierto y público situación que diferencia al Pasaje Barolo de ejemplos como el Equitable Building (1915) de E. Graham en Nueva York donde el hall a modo de "pasaje de acceso" se cierra con carpinterías volviéndose privado. En el edificio de Palanti, en cambio, el pasaje opera como una calle cubierta, un espacio urbano dentro del edificio. Este recorrido lleva al baricentro del edificio donde se ubica el núcleo de circulación vertical que conduce a las oficinas. El pasaje estructura la composición del edificio en planta

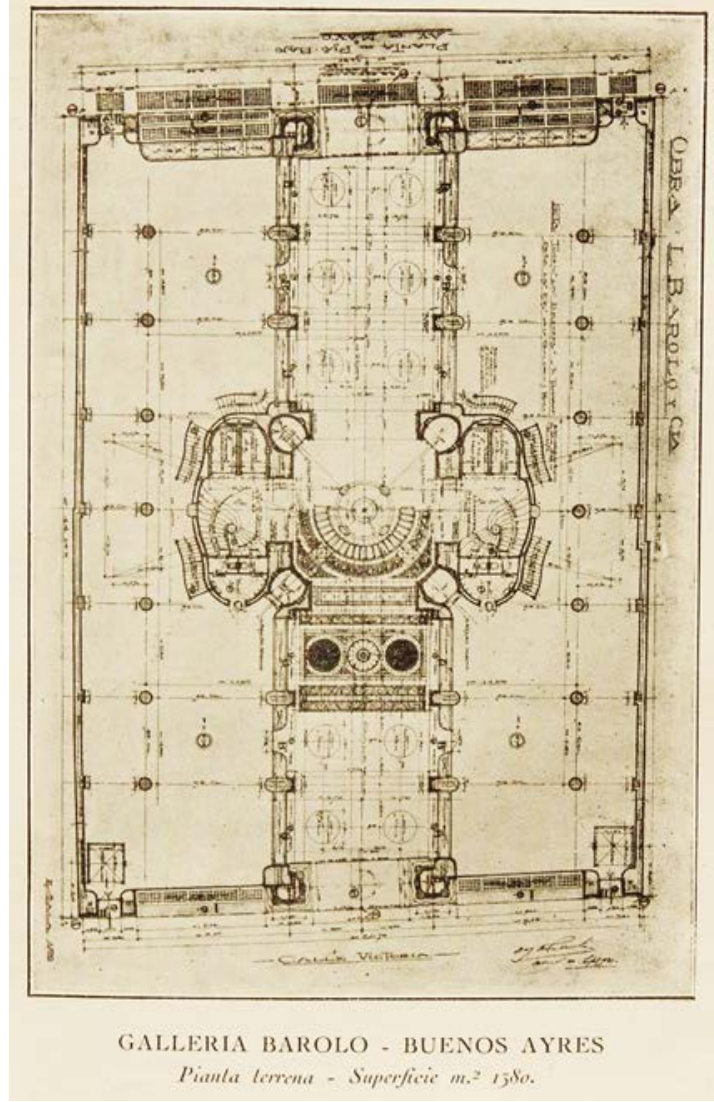

Planos nivel planta baja. Pasaje Barolo. Avenida de Mayo 1370, Buenos Aires. (1919-22). Mario Palanti. Mario Palanti. Quattro Anni...

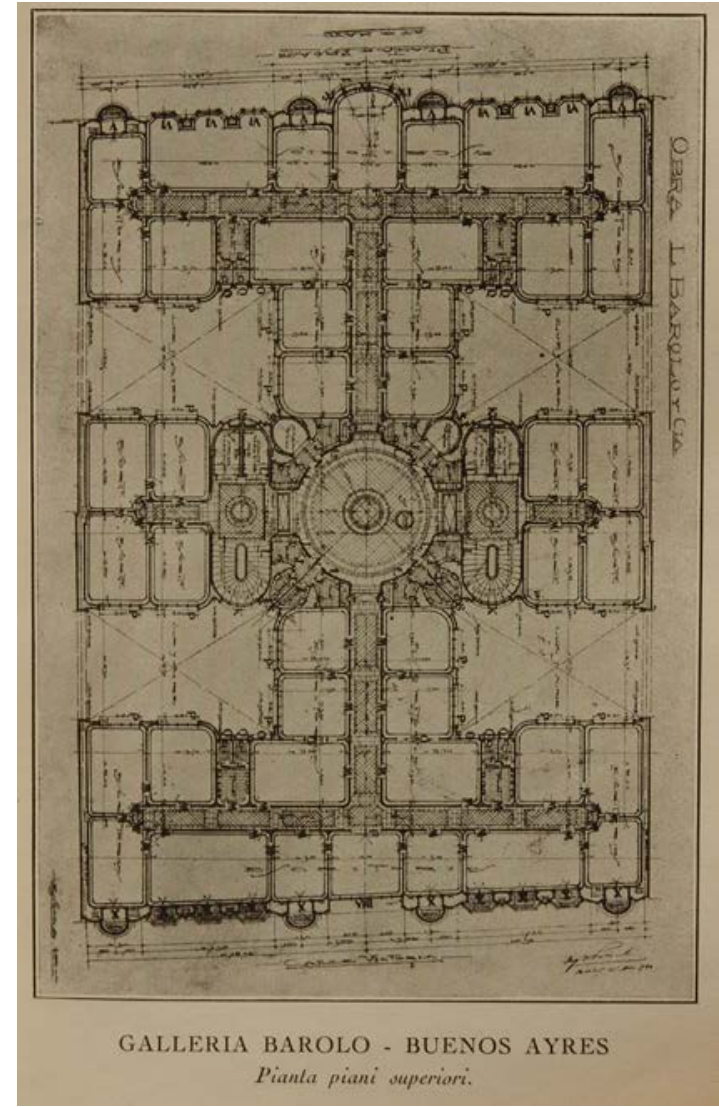

Planos $V^{\circ}$ piso. Pasaje Barolo. Avenida de Mayo 1370, Buenos Aires. (1919-22). Mario Palanti. Quattro Anni...

como un eje principal (Av. Mayo-Victoria) que es atravesado por tres ejes transversales. Este esquema que intercala bloques de habitaciones con pequeños patios de ventilación puede ser asociado, en diferente escala, a la disposición en planta de las casas de renta cuya realización era ya una constante en la obra del arquitecto.

Ahora bien, como rascacielos, el edificio presenta una particularidad al carecer, prácticamente, de plantas tipo: doce diseños diferentes componen la totalidad del edificio. Algo 
notorio en una tipología que, en su raíz norteamericana intentaba lograr el mayor rendimiento del lote mediante la repetición del mismo en altura -o de plantas tipo- lo que permitía mayor rapidez de ejecución y menor costo de obra. En nuestro caso, la especulación dejó una brecha para la experimentación formal y lingüística visible en la tipología de pasaje-rascacielos, la estructura de hormigón armado y la ornamentación. Los niveles que van de la planta baja al piso octavo mantienen los tres ejes de circulación. A partir del piso noveno se pierde el eje paralelo a la calle Victoria y a partir del piso once desaparece el eje paralelo a la Avenida de Mayo manteniendo sólo el eje central. Este mecanismo

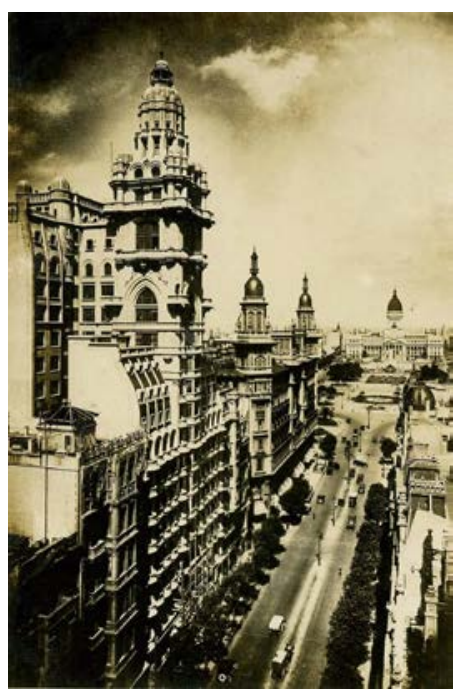

Vista aérea de la Avenida de Mayo. A la izquierda, el Pasaje Barolo. Tarjeta postal s/d. Ca. 1930 permite el retranqueo del edificio a modo de setback: menor altura a nivel de la línea municipal -excepto por la torre- y mayor altura en el bloque central, donde se recupera el espacio para renta. A partir del piso doce, la obra mantiene un esquema en cruz latina que continúa hasta el piso trece y pasa a un esquema en "T" hasta el piso diecisiete a partir del cual la torre emerge sola, separándose del cuerpo central. Con su forma sinuosa, la torre se eleva hasta el piso veintidós, alcanzando los 90 metros con un potente faro giratorio.

A diferencia del Woolworth Building, cuya fachada - con sus 240 metros- marca un vertiginoso ascenso a través de líneas verticales, el Pasaje Barolo presenta una fachada articulada en tres partes tanto en horizontal como en vertical, disminuyendo el impacto visual de la ascensionalidad: el bloque principal muestra una tripartición a-B-a (oficinas-torre-oficinas) y en horizontal se divide en basamento, desarrollo, coronamiento (locales-oficinas-mansarda). Los bloques verticales de oficinas (a) están formados por tres hileras verticales de bay windows y una hilera de balcones con balaustres que cierran la composición en los laterales. El módulo central de la torre (B) se divide a su vez en tres dando como resultado una composición de fachada -a nivel del cuarto piso- de ritmo "a-b-b-b, a-B-a, b-b-b-a" más articulada que la del Woolworth. En la planta baja, la torre da lugar al ingreso al pasaje formado por un arco nervurado de tres niveles que se funde

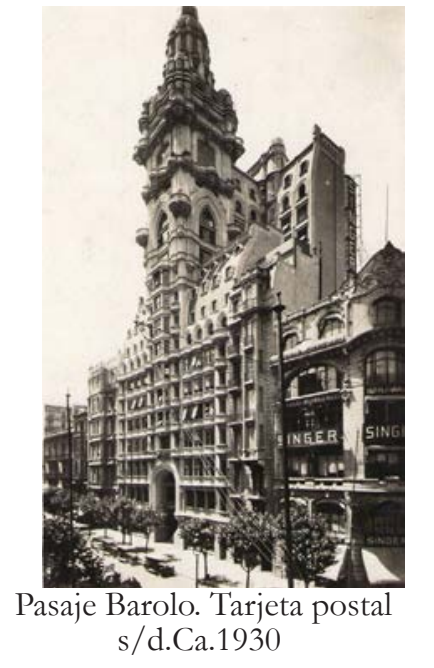
en gruesos pilares que parecen aferrarse al suelo. Los módulos 
laterales llegan al nivel de vereda con locales comerciales. La fachada sobre calle Victoria está compuesta por bay windows y balcones en los extremos que siguen el ejemplo de la fachada principal y responden prácticamente de igual manera a dos situaciones diferentes.

Como la torre medieval que emerge del castillo o el templo, la torre del Barolo emerge de la composición como un elemento que se destaca del conjunto de rasgos con una lectura diferente. Las tres caras visibles muestran distintos tipos de aberturas que, en conjunto, actúan como ornamento: en el piso trece, un arco ojival de dos pisos de altura con balcones de $3 / 4$ de círculo y $1 / 2$ círculo provoca la ilusión a quien lo observa, de estar ante una torre de planta cuadrada cuando en realidad es rectangular. En el piso quince, un arco rebajado de dos niveles es acompañado por balcones formados por medios óvalos, en las esquinas pequeños balcones circulares completan la composición. A partir del piso diecisiete, la planta de la torre toma verdadera forma cuadrada y se despega por completo del edificio. Los balcones, diferentes entre sí, están formados por tres círculos unidos que se repiten a menor escala en el piso siguiente y son la base de los pequeños cupulines. Esta operación a través de la cual se desdibujan los ángulos de la torre mediante el uso del círculo y se escalan los elementos a medida que la composición asciende se repetirá en la torre del Palacio Salvo. La torre del Barolo termina su ascensión de manera telescópica hasta

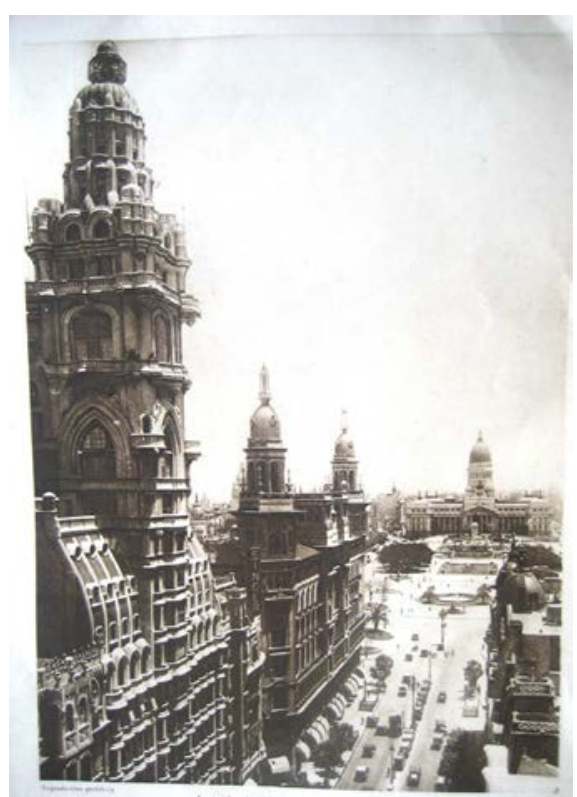

Torre del Pasaje Barolo. Antigua postal. Ca. 1930. s/d

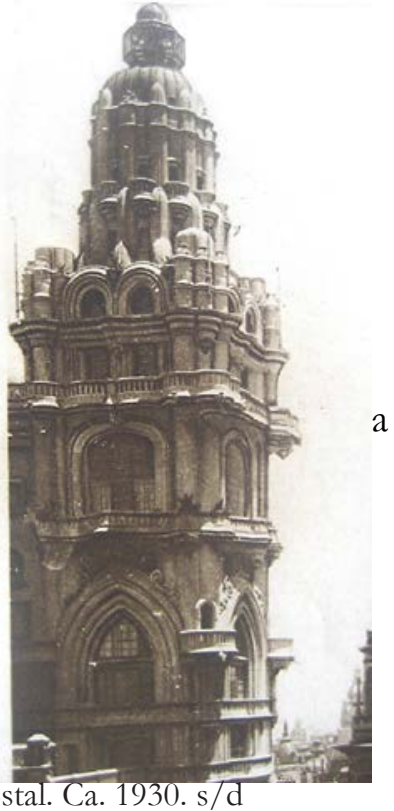

a rematar en el piso veintidós, con un faro giratorio, un elemento que era habitual encontrar en los rascacielos neoyorquinos y que Palanti retomaría, además de en el Palacio Salvo, en proyectos como la Aduana para Montevideo y la Mole Littoria, entre otros. El faro era también portador de una alta carga simbólica: iluminado con 300.000 bujías, permitía distinguir al Barolo a kilómetros de distancia y extendía, de esta manera, el dominio visual del rascacielos.

En sintonía con el pensamiento violletiano y la enseñanza de Boito, Palanti intenta conjugar una síntesis utilizando los elementos estilísticos extraídos de la historia: evocaciones de 
templos orientales, arquerías de reminiscencias románicas, arcos ojivales, haces que constituyen nervaduras buscando caracterizar la verticalidad de la torre se suman a la nave de basílica medieval que organiza el pasaje de planta baja. De acuerdo a Palanti, todo ello combinado armónicamente con elementos modernos como, entre otros, ascensores, montacargas, instalación eléctrica o, inclusive, la estructura de hormigón, daría como resultado una "nueva arquitectura" que debía "contemplarlos todos y armonizarse con todos ellos." ${ }^{27}$

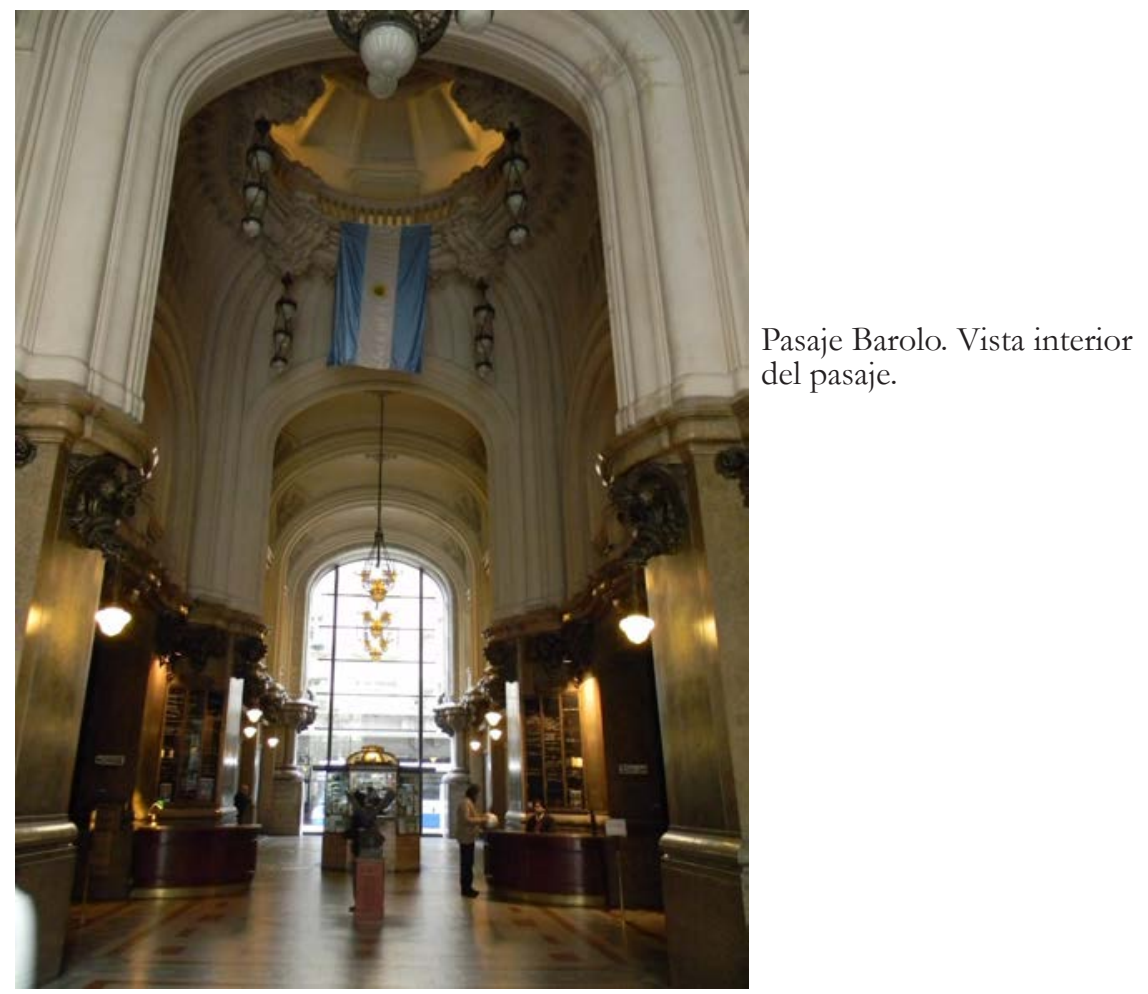

La secuencia permite ver cómo Palanti dio una respuesta al problema de la decoración a gran altura a través de la reinterpretación de fuentes del Medioevo como posible solución frente al sistema clásico. El resultado se aleja de los prismas rectangulares de Chicago para acercarse, en todo caso, al goticismo que muestra el Woolworth Building o el Chicago Tribune (1922).

En efecto, en el Barolo se ve una libre conjunción entre ornamentación y formas geométricas: gran parte de los elementos decorativos provienen de la utilización del círculo y la curva en sus más variadas combinaciones. Esto puede verse en las diferentes aberturas y balcones que se superponen en una homogeneidad pensada para ser vista desde lejos, mientras que, desde los mismos balcones, se puede observar la decoración (hoy inexistente) ubicada sobre los arcos, las ventanas o los capiteles, e inclusive la presencia de macetas con plantas.

$\overline{27}$ Palanti, "La era moderna tiene orientaciones nuevas en arquitectura?" . Véase Aliata y Bonicatto, Mario Palanti. 
Palanti no limitó la manipulación al exterior. Al ingresar al edificio, tenemos la sensación de que la torre coincide con el centro geométrico de la composición como lo hace una cúpula en una iglesia de planta en cruz latina. Este punto baricéntrico está coronado por una secuencia de anillos que disminuyen hasta terminar en una cúpula escondida en la losa del tercer piso: un trompe l'oeil que genera la ilusión de un espacio cupulado que aparenta ubicarse en correspondencia con la torre del edificio. La torre, en cambio, está en realidad desplazada del baricentro del conjunto hacia la línea municipal sobre la Avenida de Mayo (a la manera del Woolworth Building) como resultado de una estrategia de diseño que permite por un lado, mostrar la totalidad de la altura a nivel peatonal y por otro, esconder el bloque central de oficinas.

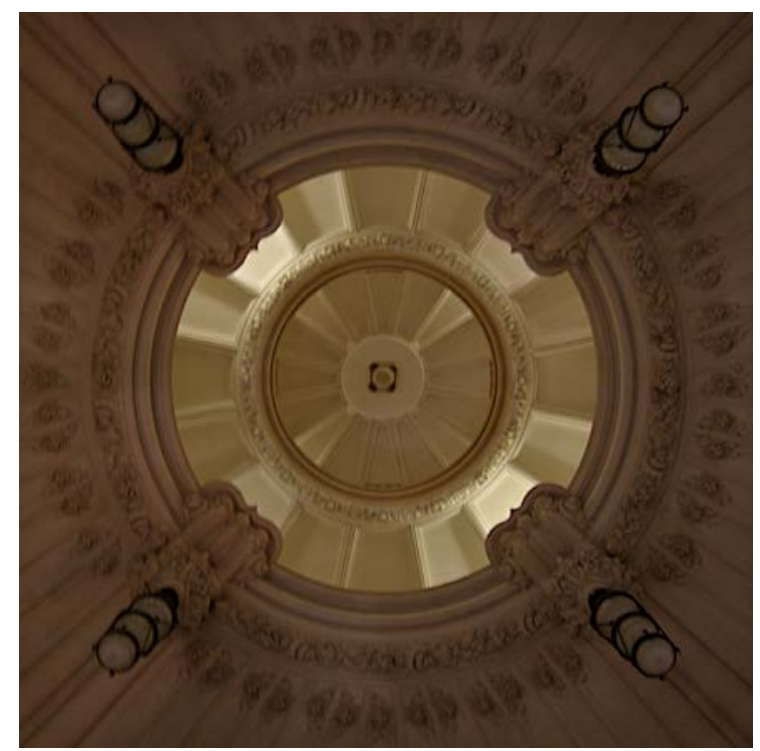

Cúpula interior

del Pasaje Barolo

En los pisos de acceso público, donde Palanti la considera necesaria, se concentra la mayor cantidad de decoración. El acceso principal está flanqueado por dos grandes columnas formadas por el descenso de los nervios del arco del portal de acceso. Los capiteles realizados en granito de diferente textura muestran un conjunto de follaje, frutos y animales exóticos. En el interior, los capiteles de los seis pares de pilastras nervuradas, que toman los arcos que estructuran el pasaje, están formados por dragones realizados en bronce que sirven para portar las lámparas y recuerdan a los detalles decorativos que realizó Giuseppe Palanti, hermano del arquitecto, para el concurso del hospital de Rosario en 1911 y a las lámparas para el Palazzo di Giustizia de Roma (1889-1911), también de G. Palanti. El solado completa la decoración a través de dibujos geométricos en verde rojo y crema, colores de la reciente unificada Italia y una serie de rosetones en bronce y vidrio que actúan como lucernas para el primer subsuelo. El solado en 
damero junto con elementos como la escuadra y el compás en los ascensores y los balaustres de la escalera a modo de "columnas de Salomón" han incrementado, como señala Mercedes Bares, la carga simbólica del edificio y su asociación con la masonería. ${ }^{28}$ No es extraño si se considera que el 11 de febrero de 1919, antes de emprender el retorno a la Argentina, Palanti fue iniciado con el grado de aprendiz a la logia masónica Fratelli Bandera de Milán..$^{29}$ Como un sello del autor que se revela en el edificio, el cielorraso del pasaje formado por seis bóvedas nervuradas -decoradas en el centro y esquinas con caracoles, serpientes y flores-, revela al visitante las inscripciones en latín seleccionadas por el arquitecto. La proliferación de citas y fragmentos de diversas arquitecturas quieren ser conjugadas por el autor para procurar un modelo de rascacielos diferente a las más abstractas construcciones de las ciudades norteamericanas, que seguramente conocía en detalle a través de las múltiples publicaciones que los mostraban por entonces como símbolo del progreso. El rascacielos latino, frente a la abstracción metropolitana, debía proponer una pausa, un llamado constante a la tradición de la disciplina.

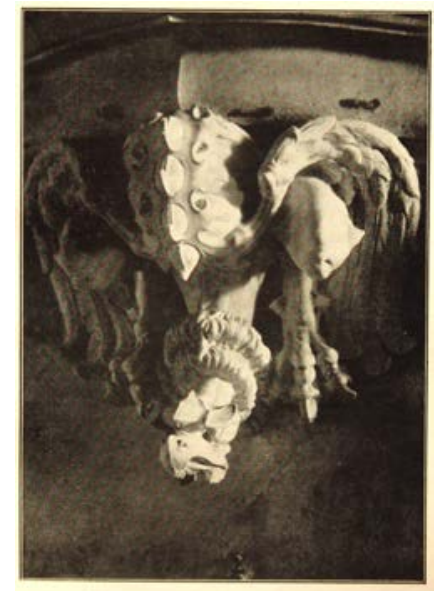

GALLERIA BAROLO - BUENOS AYRES

fotografia. esculturas en bronce.

Pasaje Barolo. Avenida de Mayo 1370, Buenos Aires. Mario Palanti. Quattro Anni...

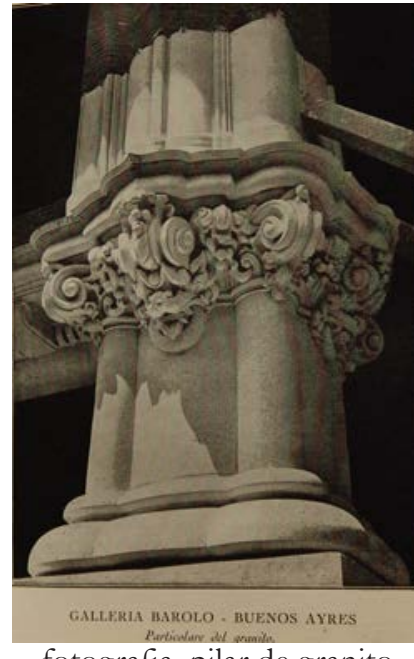

fotografia, pilar de granito del portal de acceso. Avenida de Mayo 1370, Buenos Aires. (1919-22). Mario Palanti. Quattro Anni...

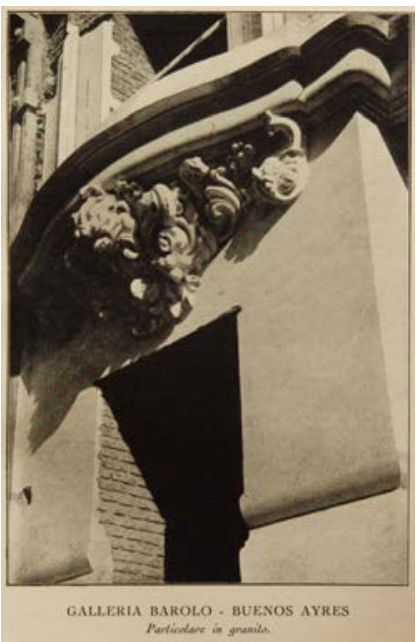

Detalle de la fachada. Avenida de Mayo 1370, Buenos Aires. (1919-22). Mario Palanti.

Quattro Anni...

28 Bares, "La galleria Barolo di Buenos Aires": 48.

29 Stefania Tuzi, "Mario Palanti architetto visionario tra italia e Argentina" en Contributi italiani all'architettura argentina. Progetti e opere tra il XIX e il XX secolo. Tuzi, Sabugo (a cura di). (Roma: DEI Tipografia del genio civile, 2014): 95. 


\section{Experimentaciones técnicas}

Pero el edificio no sólo es una invención tipológica sino que constituye una experiencia técnica excepcional. En efecto, el estudio de los avances y saberes técnicos de principios de siglo XX permitirá ubicar la obra de Palanti en su contexto de producción y detectar las innovaciones que en éstas se realizaron.

En un momento en que primaban las estructuras de acero de tipo skeleton construction -esqueleto de acero de uniones roblonadas, entrepisos de bovedillas de chapa galvanizada, una capa de hormigón liviano y una carpeta de cemento alisado-, la aparición de estructuras como la del Pasaje Barolo o Palacio Salvo sería realmente revolucionaria. Consideremos que el primer rascacielos realizado en hormigón armado en Norteamerica fue el Ingalls Building de 15 pisos, inaugurado en 1903, en Ohio y si bien en Europa se ponía a prueba este sistema constructivo, el límite de altura alcanzada no superaría los sesenta metros, hasta

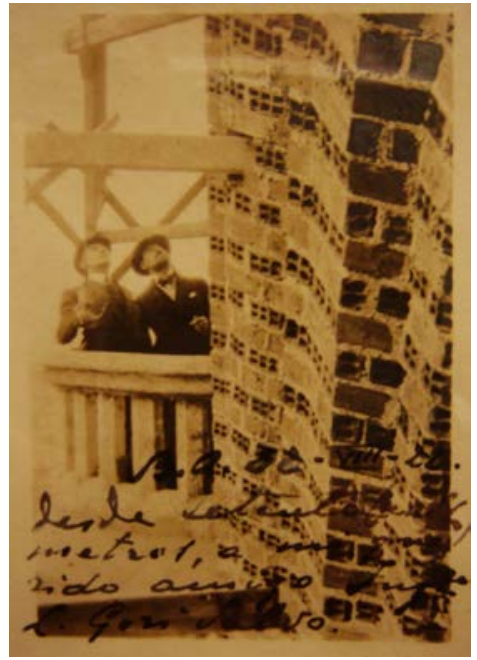

Desde la altura de setenta metros a mi querido amigo, Ing. Gori Salvo. Buenos Aires, 2 de agosto de 1922. Mario Palanti papers, GRI entrada la década de $1930 .{ }^{30}$ Por lo tanto, estos edificios rioplatenses fueron reales bancos de prueba en el uso vertical del hormigón consiguiendo que cada record local conformara, simultáneamente, un récord internacional. ${ }^{31}$

Efectivamente, hasta principios del siglo XX, la construcción en el contexto porteño se apoyó principalmente en el hierro y acero para todo tipo de obras públicas y privadas, pues el alto costo del cemento favorecía la elección del sistema metálico a pesar del estado germinal de la siderurgia local y la casi inexistencia de yacimientos de metales. ${ }^{32}$ Tanto hierro como acero provenían en su mayoría de acerías europeas a las que se sumaban empresas argentinas como Vasena, Otonello, Rezzonico y Zamboni. Las tres últimas adquiridas por Ernesto Tornquist luego de la crisis de 1890 y fusionadas luego en Talleres Metalúrgicos San Martín (TAMET). ${ }^{33}$

30 Javier Quintana de Uña, Sueño y frustración. El rascacielos en Europa.1900-1939 (Madrid: Alianza, 2006), 32.

31 Francisco Liernur, "Nuevos rascacielos en Buenos Aires: vivir en las nubes", Arquis (1994): 92.

32 Eduardo Gentile, "Materialidad del proyecto arquitectónico: acero, hormigón, acero", Revista 47 al fondo, Nº (abril 2001). El sistema constructivo era tema común en el debate internacional, Sigfried Giedion, Building in France, building in iron, building in ferroconcrete (Los Angeles: Getty Center for the History of Art and the Humanities, 1995 (1928)). O el de Francis Skillman Onderdonk, The ferro-concrete style: reinforced concrete in modern architecture, with four bundred illustrations of European and American ferro-concrete design (Stamford: Architectural Book Publishing Co. Inc., 1928).

33 Véase Petronilo Escudero (dir.), Anuario de Arquitectura e Ingeniería en la República Argentina, Revista La Construcción (Buenos Aires, 1922). Sobre la red industrial de principios del siglo XX, véase, Graciela Silvestri, El color del río: 
Esta primacía del acero cambiaría hacia la década de 1920, entre otras razones, por causas técnicas y económicas. Durante la Primera Guerra, la importación se vio reducida de manera notable. ${ }^{34} \mathrm{~A}$ esto se sumó la política de restricciones a la producción de acero establecida por el gobierno en $1917 .{ }^{35}$ Tales condiciones se dieron conjuntamente con el ascenso del cemento armado que, en versión alemana, francesa o italiana, circulaba desde principios del siglo XX en el Río de la Plata. ${ }^{36}$

Pero la preferencia del armazón metálico era común -de hecho la vemos en varias casas de renta de Palanti-, y se daba en el sector más conservador de la profesión ingenieril que se inclinaba por la rapidez de montaje y los cálculos más sencillos y ya conocidos del acero (muchas veces calculada su resistencia en catálogo) ante la heterogénea resistencia, que por diferencias de preparación, colado o curado, revelaba tener el hormigón.

En contraste con quienes optaban por lo "convencional", los espíritus inquietos como Mario Palanti -o Francisco Gianotti- se orientaban hacia el uso del hormigón. ${ }^{37}$ Además del vínculo de Palanti con Ranzanhofer, quien como vimos promocionaba el material a través de la revista La Ingeniería, seguramente el arquitecto conocía publicaciones específicas como la Revista Arquitectura que divulgaban las ventajas que el sistema ofrecía. ${ }^{38}$

historia cultural del paisaje del riachuelo (Bernal: UNQUI, 2003), 232-235 y 248-264; Fabio Grementieri y Claudia Shmidt, Alemania y Argentina, la cultura moderna de la construcción (Buenos Aires: Larivière, 2010), 143. Asimismo, sobre la condición de los empleados y el tema social véase Beatriz Seidel, Crónicas de la semana trágica enero de 1919 (Buenos Aires: Corregidor, 1999); Rocchi, Chimneys in the dessert.

34 En 1913, la importación de acero y otros era de 9 millones \$o/s (pesos oro) bajando a 3 en 1915, 0,7 en 1916 y 0,3 en 1918. Dorfman, Historia de la industria argentina.

35 Ante tal situación, las industrias metalúrgicas fabricaban alternativas locales usando el hierro viejo: maquinaria agrícola y ferrocarriles en desuso, Gentile, "Materialidad del proyecto arquitectónico": 143.

36 Como señalan Grementieri y Shmidt, los alemanes tenían capitales y conocimiento técnico para las empresas de cemento y hormigón armado. La década de 1930, fue ya una conquista del hormigón aunque el acero aún se pensaba como superior por algunos que le atribuían velocidad de montaje, liviandad, transparencia etc. El tema llegó a su fin por la escasez de importaciones de hierro durante la década de 1930 y el hormigón comenzó su ascenso hasta la actualidad. Según los autores, el triunfo del hormigón armado sobre el hierro se cristalizó definitivamente con la Segunda Guerra Mundial, pero a ello concurrieron varios factores: 1) La tradición arquitectura argentina basada en la mampostería de barro y ladrillos o piedras eventualmente. 2) Escasez de yacimientos de hierro y carbón. 3) La contribución de las empresas alemanas que pujaban por el hormigón armado. Grementieri y Shmidt, Alemania y Argentina, 144.

37 La primera experiencia del hormigón armado en rascacielos fue la construcción de la Galería Güemes (19121915), planteada originalmente en acero y realizada en hormigón con el asesoramiento del ingeniero Manuel F. Pereyra Ramírez y Nicolás Spallone, a cargo de la constructora de Phillip Holzmann \& Cía., (Geopé). Grementieri y Shmidt, Alemania y Argentina, 127.

38 Entre ellos, la revista Arquitectura:, "El hormigón armado y sus múltiples aplicaciones”, No 13/14 y 15/16 (noviembre/diciembre 1904); "El hormigón armado y el porfirolito en las construcciones militares", $N^{\circ} 7 / 8$ (agosto 1904); La Revista de Arquitectura: Joaquín Bassedoga, "El cemento armado en la arquitectura", No 111 (febrero 1917); Otto Gottschalk, "Entrepisos huecos de hormigón armado", No 16 (1918); Revista La Ingeniería del Centro Argentino de Ingenieros, números varios durante 1910. Carlos Geneau, "Losas planas de hormigón armado", No 30 (mayo 1922); "Estatuas monumentales de cemento armado", № 36 (diciembre 1923); Bartolomé Ferro, "Hormigón armado, cálculos de algunas estructuras, reglas prácticas y aplicaciones”, No 58 al 71 (1925 y 
Principalmente, los artículos señalaban la capacidad del hormigón de mantenerse estable en caso de incendios a diferencia del hierro, cuyo módulo de elasticidad cae verticalmente ante el calor extremo inutilizando las estructuras y/o colapsando la estabilidad de todo el edificio. Además de ello, garantizaba impermeabilidad y lograba un esqueleto monolítico frente al ensamblaje que representaba la armadura metálica. Este sistema estructural era calificado por Palanti como una técnica superior a la usual construcción en hierro y podía compararse con el tradicional ladrillo romano. Dada su superioridad, entre sus propuestas a realizarse en hormigón armado encontramos el proyecto para la Mole Littoria, presentado a Mussolini en 1924, el Palazzo del Littorio (1934) y el Auditorio (1935). ${ }^{39}$

Pero, mientras que el comportamiento del acero se conocía, el hormigón requería un know how que garantizara cálculos precisos para lograr resultados homogéneos que en las primeras décadas estaba ligado a patentes que formaban las grandes empresas (Monier, Hennebique, Wayss y Freitag, etcétera). ${ }^{40}$ Para ello, los calculistas, frecuentemente extranjeros, eran convocados por las mismas empresas que ofrecían la posibilidad de experimentar en estructuras de hormigón armado, como en los rascacielos, que eran prácticamente imposibles de realizar, por ejemplo, en Alemania o Francia donde la técnica se venía desarrollando aunque sin conseguir elevar los edificios a una altura mayor que cincuenta metros. ${ }^{41}$

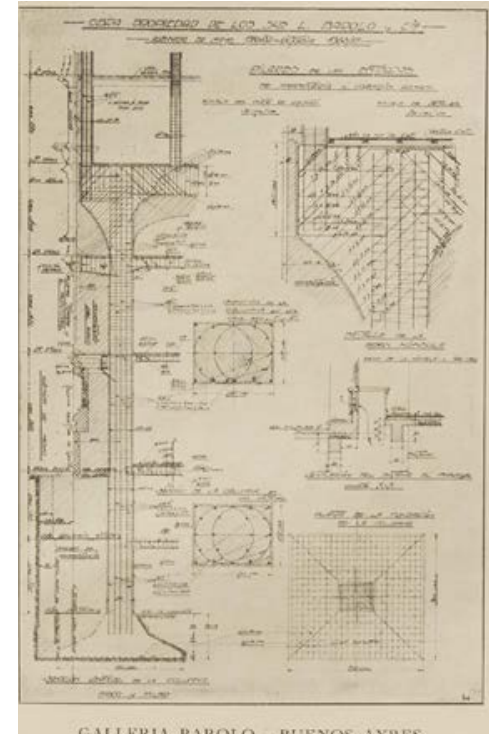

Detalle del doblado de hierros, plano estructural. Pasaje Barolo (1919-22). Avenida de Mayo 1370 , Buenos Aires. Ca. 1919. Mario Palanti. Quatto Annidi lavoro

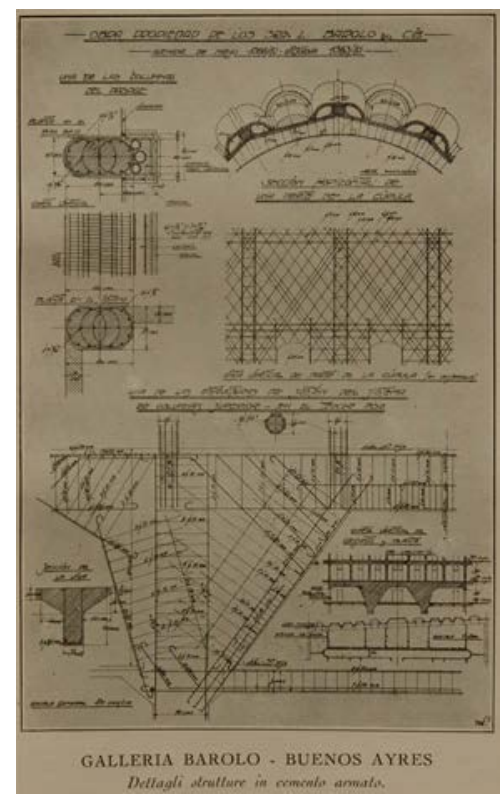

Detalle del doblado de hierros, plano estructural. Pasaje Barolo (1919-22). Avenida de Mayo 1370, Buenos Aires. Ca. 1919. Mario Palanti. Quatto Anni..

Varias empresas constructoras de origen alemán instaladas en la Argentina tendrían la oportunidad de ser pioneras en estas construcciones. Entre ellas, Wayss \& Freitag desde 1906, Dyckerhoff \& Widmann, F.H. Schmidt y, dedicada también a la producción de cemento,

1926), publicado nuevamente en $\mathrm{N}^{\circ} 86$ al 92 (febrero/agosto 1928).

39 Mario Palanti, Auditorium: progetti, Roma, anno XIII E.F. (Milano: Rizzoli, 1935).

40 Edgardo Lima/ Victorio Hernández Balat/Juan F. Bisso, "Hormigón armado: notas sobre su evolución y su teoría", Seminario sobre la resistencia de materiales, disponible web: http://www.ing.unlp.edu.ar/

41 Grementieri y Shmidt, Alemania y Argentina, 138. 
Doppel-Dyckerhoff. ${ }^{42}$ En principio, estas empresas se dedicaron a la construcción de silos, entubados, faros, construcciones fabriles, etcétera. Obras que requerían no sólo de saberes técnicos, manejo del hormigón a gran altura y mano de obra especializada, sino también de maquinaria, andamiaje, grúas y sistemas de hormigonado que llevaran el material, como en el caso del Pasaje Barolo, hasta alturas de noventa metros.

Efectivamente, la estructura del edificio estuvo a cargo de la empresa alemana Waiss \& Freitag $^{43}$ que operaba exclusivamente según las indicaciones de Palanti en su rol de "Arquitecto Director" (AD). De acuerdo al Contrato de Construcción de la Nunciatura Apostólica de Buenos Aires al que ya hemos hecho referencia, todos los planos y cálculos realizados por la empresa en base al diseño del arquitecto debían ser supervisados y aprobados por Palanti. Asimismo todo el material que fuese descargado en obra. En el caso del hormigón, la mezcla debía hacerse según las indicaciones del AD. ${ }^{44}$ Esto era válido también para los encofrados que debían construirse en maderas avaladas por el $\mathrm{AD}$ y cuando éste indicara que el material había alcanzado el grado correcto de resistencia. ${ }^{45}$

De acuerdo a las pocas imágenes y planos que muestran la estructura del Pasaje Barolo, podemos ver que la misma se compone por zapatas aisladas sobre las cuales se apoyan las columnas de los pórticos correspondientes a dos niveles de subsuelo. Sobre éstos últimos se apoyan pórticos de tres niveles de altura que forman el pasaje en planta baja. Los puntos de apoyo forman una retícula regular de nueve hileras de cuatro columnas. Por encima de estos se desarrollan las plantas de oficinas con una estructura de columnas, vigas y losas de sistema

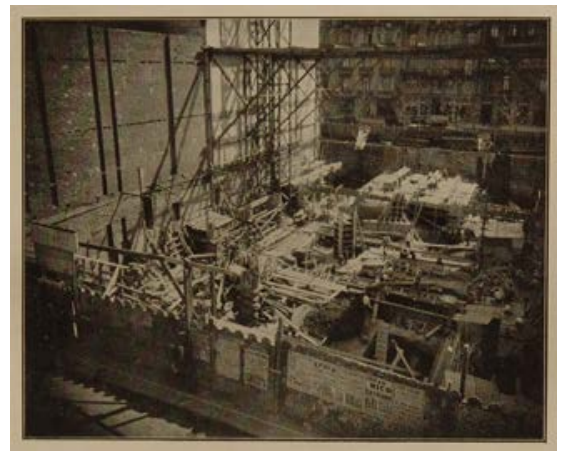

Comienzo de la obra. Pasaje Barolo Ca. 1920. Avenida de Mayo 1370, Buenos Aires. Ca. 1920. Mario Palanti. Quatto Anni..

$\overline{42}$ Otras, fueron Gruen \& Bilfinger, originalmente dedicada a infraestructura hidráulica; Geopé, originalmente propiedad de Philipp Hofmann, la constructora de Otto Gottschalk, M. Kinbaum, Bencich y la Compañía Platense de construcciones S.A. (luego Siemens-Bauunion). Grementieri y Shmidt, Alemania y Argentina, 118-119.

43 Grementieri y Shmidt, Alemania y Argentina.

44 De acuerdo al Artículo 168, (el cemento debía ser aprobado por Obras Sanitarias de la Nación, arena oriental, pedregullo canto rodado o granito en proporciones: Una parte de cemento, dos de arena y tres de piedra) Mario Palanti, Contrato de Construcción, Nunciatura. Archivio Segreto Vaticano, Archivio Nunziatura Argentina, 99, fasc.510. 45 Mario Palanti, Contrato de Construcción, Nunciatura. Archivio Segreto Vaticano, Archivio Nunziatura Argentina, 99, fasc. 510 . 
Hennebique. Principalmente en el pasaje, como veremos, este sistema estructural de hormigón armado fue cubierto con ornamentación. Es que, como afirmaba el Arquitecto Director: "El trabajo será hecho en un todo con las reglas del arte"46

\section{Símbolos y alegorías en el pasaje: El Danteum}

"Mi oficina está en el purgatorio", declara uno de los personajes de la ficción titulada El jardín de bronce que, al igual que otros relatos, toma al Barolo como escenario. ${ }^{47}$ Por cierta razón, el edificio ha despertado en el público e historiadores la búsqueda de un trasfondo esotérico.

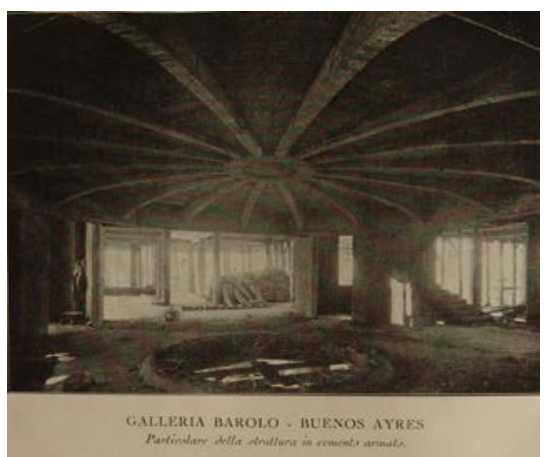

Construccion de la estructura en cemento armado, vacío sobre punto central del pasaje.Pasaje Barolo (1919-22). Avenida de Mayo 1370, Buenos Aires. Ca. 1920. Mario Palanti. Quatto Anni...

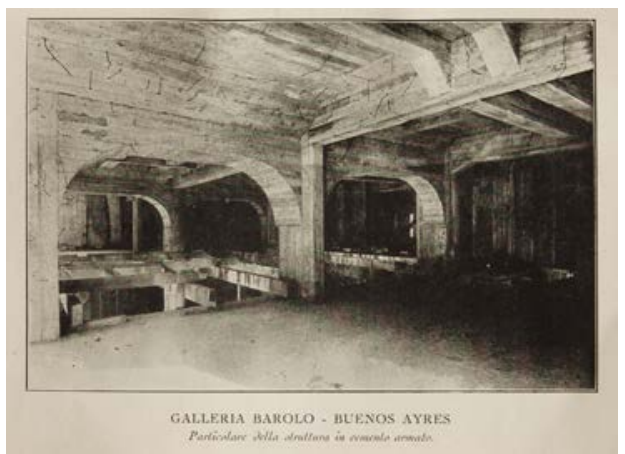

Detalle de la construcción de la estructura porticada del pasaje. Pasaje Barolo (1919-22). Avenida de Mayo 1370, Buenos Aires. Ca. 1919. Mario Palanti. Quatto Annidi lavoro

El visitante que ingresaba al pasaje pasaba ligeramente por el universo mercantil materializado por locales - en isla y a los lados de la galería- que contrastaba con las inscripciones en latín ubicadas en el cielorraso. En ellas se pueden leer frases de los poetas latinos Horacio, Virgilio o fragmentos de la Biblia que intentan hacer reflexionar al visitante o, posiblemente, se refieren a la construcción del edificio:

Sic vos, non vobis mellificatis apes (así, vosotros, abejas hacen la miel para otros)

Sic vos, non vobis nidificatis aves (así vosotros pájaros construyen nidos para otros)

Virgilio en las puestas de la casa de Augusto

Ut portet nomen eius coram géntibus (Para que se lleve su nombre ante la gente) ${ }^{48}$

46 Mario Palanti, Contrato de Construcción, Nunciatura. Artículo 21. p.5. Archivio Segreto Vaticano, Archivio Nunziatura Argentina, 99, fasc.510.

47 Gustavo Malajovich, Eljardin de bronce (Barcelona: Penguin Random House, 2012). Otro caso es Montserrat de Daniel Link (2006).

48 Missale romanum ex decreto sacrosancti concilii Tridentini restitutum, s. Pii 5. Pontificis maximi jussu editum, Clementis 8. \& Urbani 8. auctoritate recognitum 1767, p.447. 


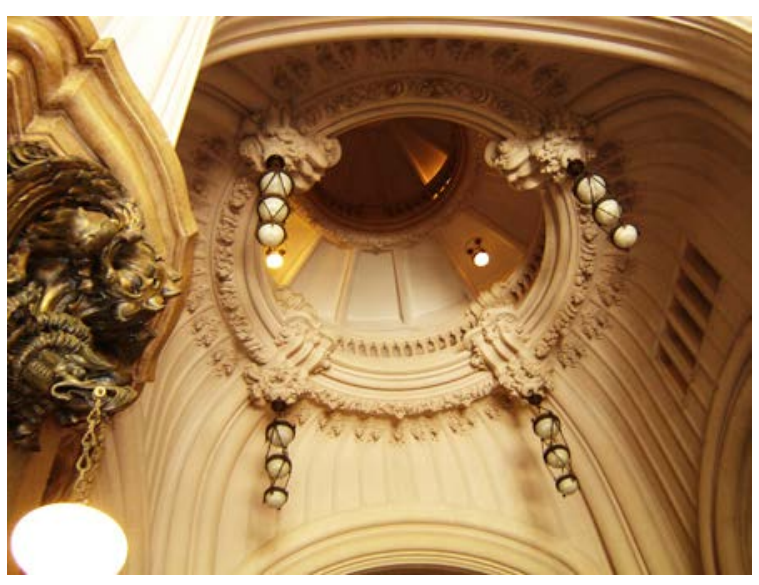

Detalles ornamentales que acompañan la secuencia de vacíos y cúpula interior sobre el punto central del pasaje. Pasaje Barolo. Avenida de Mayo 1370, Buenos Aires. (1919-22). Mario Palanti. Foto Virginia Bonicatto

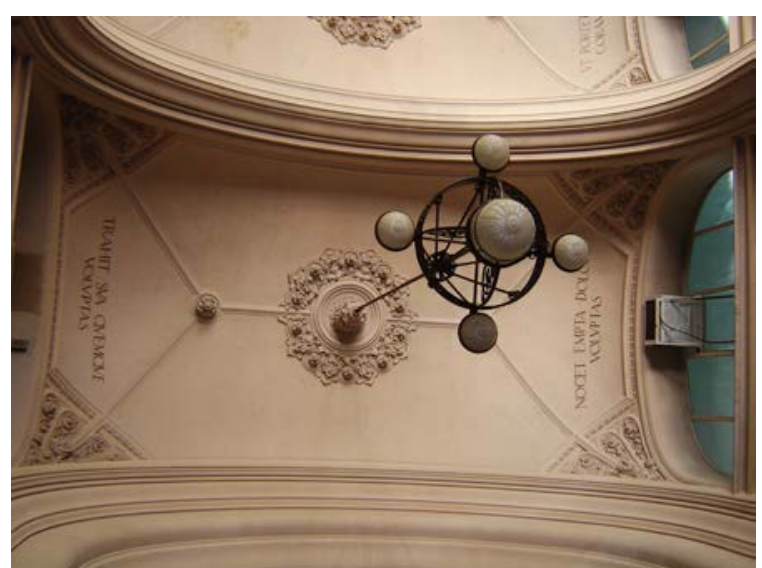

Inscripciones en latín y detalles ornamentales en una de las bóvedas del pasaje. Pasaje Barolo. Avenida de Mayo 1370, Buenos Aires. (1919-22). Mario Palanti. Foto Virginia Bonicatto

\section{Fundata est supra firmam petram (fundada sobre piedra firme) (49 $^{4}$}

Nocet empta dolors voluptas (perjudica el placer comprador con el dolor: Horacio, libro

1)

Trabit sua quemque voluptas (Cada uno se ve arrastrado por su propio placer: Virgilio

$$
\text { Églogas, II, 65) }
$$

Qui fecit opus-ut est-ut ipse mallet novit (Quien hizo la obra la conoce tal como es, así como él la preferiría)

Homines quam màxime hómines (que los seres humanos sean lo mejor posible)

Ars homo ádditus naturae (El arte es el ser humano agregado a la naturaleza)

Dittora occídit, spíritus vivificat (La letra mata, el espíritu vivifica: 2 Corintios 3,6 Nuevo testamento)

Malis tibi placere quam pópulo (prefiere agradar a ti mismo antes que al pueblo: Séneca, cartas a Lucio) Omis pulchritudins forma únitas est (La unidad es el molde de toda obra de arte) Corpus animun tegit et détegit (El cuerpo a veces oculta el alma, otras la revela)

Este recorrido lleva al baricentro del edificio donde se ubica el núcleo de circulación vertical que conduce a las oficinas y talleres y donde, según el estudio de Hilger, iban a yacer las cenizas de Dante. De acuerdo a este ensayo, el edificio fue inspirado en la Divina Comedia. Además de ello, con una erudita narración, el texto explica que Luigi Barolo y Mario Palanti planeaban trasladar los restos del poeta al edificio ante la posible amenaza de un nuevo conflicto bélico. ${ }^{50}$

49 Tomás Ramón, Conceptos extravagantes y peregrinos: sacados de las divinas y humanas letras y Santos Padres, para muchas y varias ocasiones que por discurso del año se ofrecen predicar en casa de Gabriel Graells (1619), 280.

50 Hilger, "Mario Palanti: su Monumento al Genio Latino". A partir de este texto, el trabajo de Alejandro Gangui 
Si bien por el momento no se cuenta con fuentes documentales que avalen esta hipótesis, de haber existido un vínculo con Dante éste puede, por un lado, relacionarse a la conmemoración del seiscientos aniversario de su muerte, en 1921. Ese año, muchos actos se llevaron a cabo a lo largo del país, inclusive, el Teatro Colón organizó una celebración en honor al poeta, pero no contamos con registros de intenciones similares en la documentación de Palanti..$^{51}$ Por otro lado, puede pensarse en una relación a través de la citas a poetas latinos y filósofos a quienes Dante "salva" del infierno..$^{52} \mathrm{O}$, en todo caso, el uso de círculos en el diseño en planta o la altura del edificio de 90 metros -adjudicada por Palanti- puede relacionarse con los nueve círculos del infierno. Pero, como señalamos, al carecer de documentación tales cuestiones permanecen en el plano de las hipótesis. Pero fundamentalmente, la referencia a Dante en un edificio no era algo que debía ser ocultado: recordemos el Danteum diseñado por Giuseppe Terragni en 1938. Además, en las postales publicitarias sobre el Barolo, Palanti llama al edificio "Mole Palantiana" y no Danteum.53 Sin embargo, otra cuestión nos lleva a vincular al Pasaje Barolo con el proyecto para un mausoleo, pero no dedicado a Dante, sino a los caídos en la Gran Guerra.

\section{El mausoleo metropolitano}

En 1917, llamado a combatir en la Primera Guerra, Palanti emprende el que sería el primero de los viajes de regreso a Italia. Una vez en el país se enroló en la Armada del Genio, en Trieste donde fue nombrado como subteniente en 1918. El hallazgo de nueva documentación en archivos privados dio a conocer que el proyecto que antecede al Pasaje Barolo fue realizado por Palanti en 1918, en Trieste, mientras operaba como subteniente en la Armada del Genio durante

se inspiró para realizar un estudio astronómico del cielo sobre el Barolo: Alejandro Gangui, "The Barolo palace: Medieval astronomy in the streets of Buenos Aires", en Culture and Cosmos: A journal of the bistory of astrology and cultural astronomy $15, \mathrm{~N}^{\circ}$.

51 El Almanaque del mensajero del año 1923, muestra, en la sección "Monumentos y conmemoraciones", bustos de Dante inaugurados en diciembre de 1921. Uno en Rosario, uno en Córdoba, otro en Washington y otro en el Rosedal de Palermo (éste último el 18 de diciembre). Previamente, en septiembre, se había realizado en el Teatro Colón un acto oficial en conmemoración del poeta. Almanaque del Mensajero, Buenos Aires, Vda de M. Sundt, año XIII, 1923, p. 210-211. Almanaque del Mensajero (Buenos Aires: Vda de M. Sundt, 1923), 210-211. La guía turística del Touring Club Italiano (1932) y "Artisti italiani nell'America Latina" de Saverio Kambo (ca. 1930) (gentileza del Arq. Gustavo Brandariz) no hacen mención al tema de "Dante". Argentina, Paraguay, Uruguay, Touring Club Italiano (guías azules), 1932, p. 125; Tampoco en la Guía Cultural de Buenos Aires, Municipalidad de BA, 1980, pp.8-18

52 Agradezco a Paricia Feysulaj esta observación.

53 Thomas L. Schumacher, The Danteum: architecture, poetics, and politics under Italian fascism (New York: Princeton Architectural Press, 1993 (1985)) Kambo, "Artisti italiani nell'America Latina": 96 Kambo señala: "In queste nobili competizione internazionali (del rascacielos) il Palanti aggiungeva il suo Nome a quelli di molti'altri artisti nostri che, pur così, emergono in quelle lontane terre latine." , 97 
la Primera Guerra. El diseño era el de un artefacto arquitectónico de base concéntrica y 150 metros de altura titulado Mausoleo. Glorificando gli eroi nostri di terra, del mare, del cielo. Sintetizzando la monumentomania, que el arquitecto firmaba como "Sott.te del Genio Palanti Mario addetto al Comando $3^{a}$ Armata”. El proyecto fue expuesto en Trieste en 1919 y presentado un año antes al Presidente dei Ministri, Emauele Orlando, con la intención de que la idea fuese llevada a cabo. ${ }^{54}$ Como parte del proyecto, Palanti propuso una serie de esculturas de su autoría: Anima d'eroe representada por un águila elevando el cuerpo de un caído (similar a la reproducción que se encuentra en el Pasaje Barolo que lleva el nombre "Glorificando gli Eroi Nostri” junto a la firma: "Sott.te MP, Trieste 1919”)..$^{55}$ El conjunto, de acuerdo a algunas fuentes, representaría el cuerpo de Dante siendo trasladado a los cielos. ${ }^{56}$ Romana Potenza, una escultura que muestra un centauro alado y Genio Alato representa, nuevamente, el cuerpo de un hombre elevado por un águila. La obra
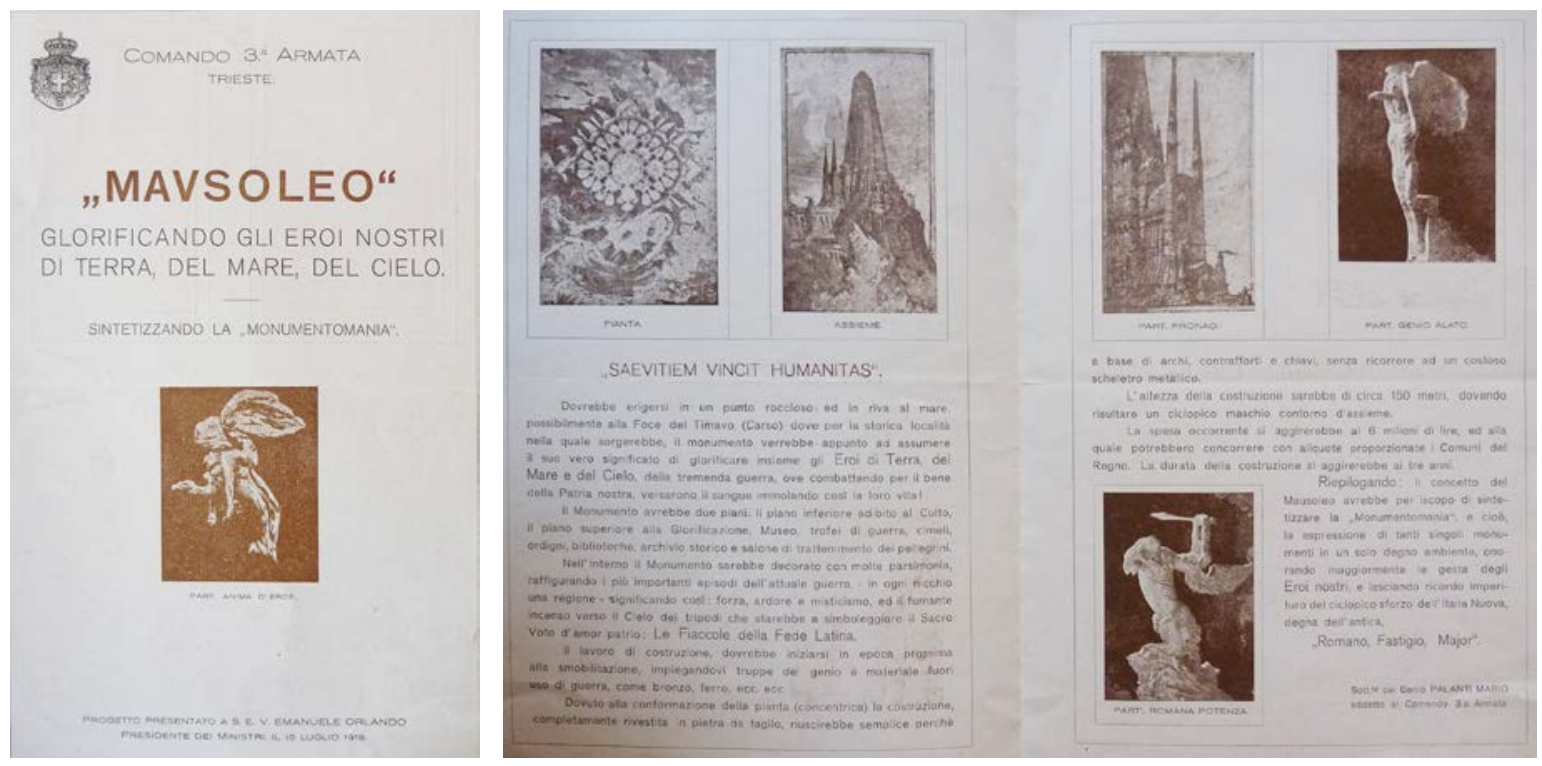

Mario Palanti. Folleto de presentación del Mausoleo Glorificando gli Eroi nostri, 1918. AGEP

completa formada por el Mausoleo y los grupos escultóricos fue presentada en formato de folleto. Posteriormente, el mismo proyecto fue publicado por Palanti en Quatro anni di lavoro (1924) - por lo que obtuvo las felicitaciones de Ottavio Dinale- ${ }^{57}$ lo que deja ver en un claro ejemplo la constante reelaboración -e inclusive repetición- de diseños como método y estrategia proyectual. $^{58}$

$\overline{54}$ Kambo, "Artisti italiani nell'America Latina".

55 Mario Palanti, folleto para "Mausoleo. Glorificando gli eroi nostri di terra, del mare, del cielo". 1919. Archivo Privado Guido y Emilio Palanti.

56 Hilger, "Mario Palanti: su Monumento al Genio Latino"-

57 "Per i fratelli innumeri che egli ha visto cadere, progetta un mausoleo che è degno della grandiosità romana, delle concezioni moderne e de la immensità del sacrificio." Otavio Dinale, Prólogo, Buenos Aires abril 1924, en Palanti, Quattro anni di lavoro. Palanti publicó el cinco láminas pertenecientes al proyecto (pp. 145-149). Una de ellas (lámina p. 147) se encuentra, por azar, en una colección privada.

58 La publicación muestra una serie de esculturas entre las cuales la figura Genio Alato es presentada bajo el título 


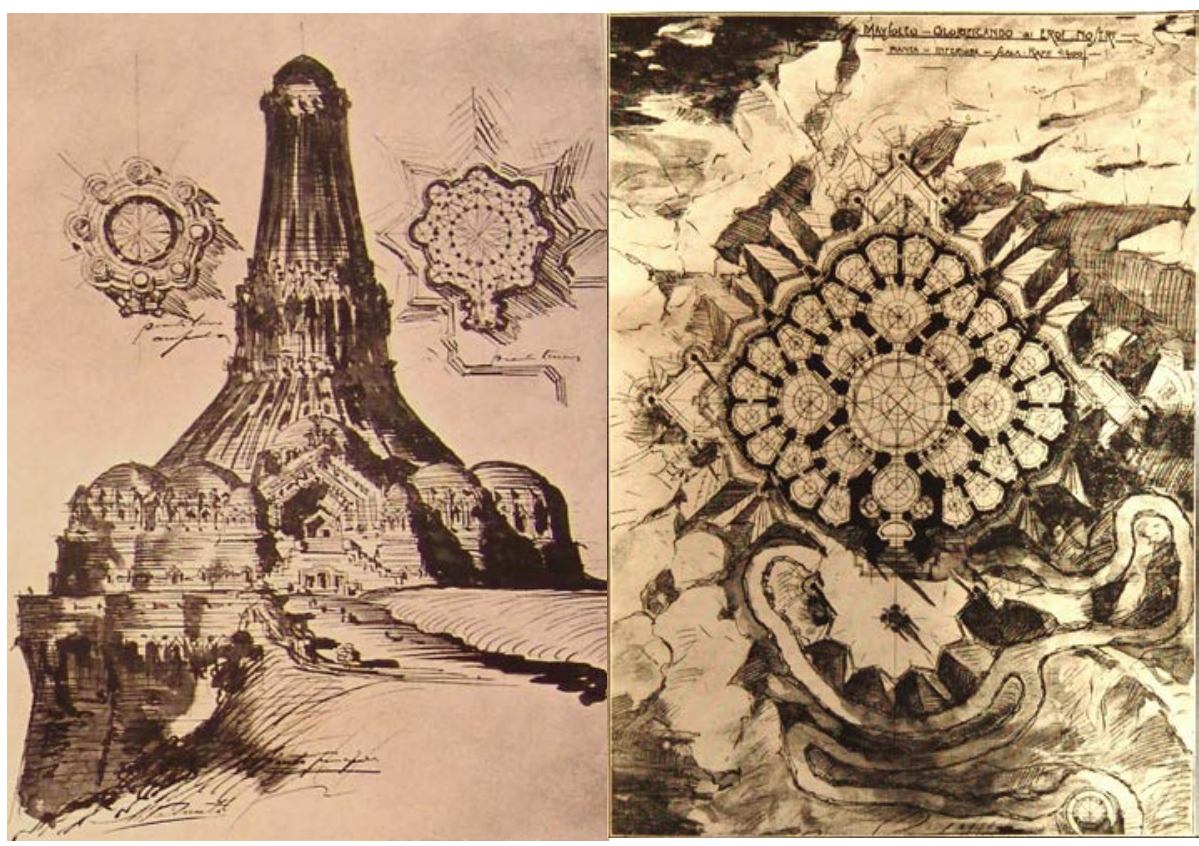

Izq. Deus Pacem Servavit. Estudio para un mausoleo (ca.1910-1914). Mario Palanti. Prima esposizione personale di architettura...

Der. Mausoleo grlorificando gli eroi nostri (1918). Planta inferior. Mario Palanti. Quatro anni di lavoro.

\section{Bajo el título "SAEVTTIEM \\ VINCIT HUMANITAS" el folleto promocionaba la} idea y explicaba brevemente el diseño y su significado. El edificio -que recuerda vagamente al Cimitero Monumentale di Monza de Sant'Elia (1915)- se ubicaría en la boca del río Timavo (Carso) y estaría destinado a honrar los caídos durante la Primera Guerra: su fin, señalaba el autor, sería "glorificare insieme

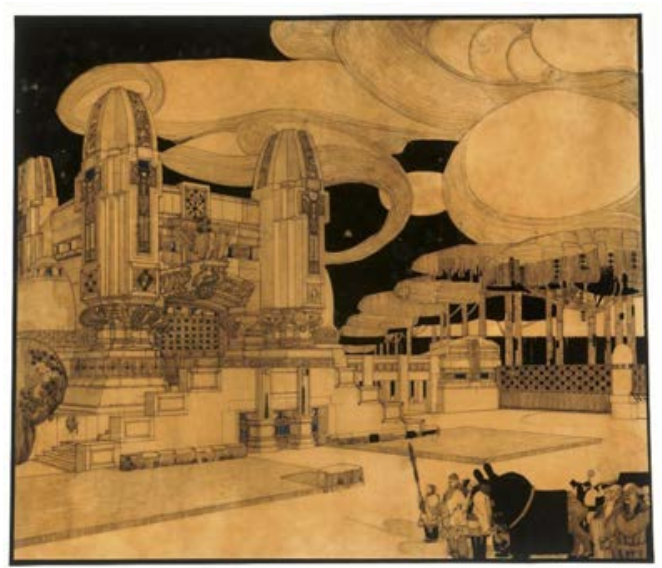

Cimitero Monumentale di Monza de Sant'Elia gli eroi di Terra, del Mare e del Cielo, della tremenda guerra, ove combattendo per il bene della Patria nostra, versarono il sangue inmolando cosi la loro vita". ${ }^{59}$

Como explica Daniele Pisani, ya en 1918 varios artículos señalaban la proliferación indiscriminada de monumentos, "invasión monumental" en palabras del crítico de la época Ettore Janni quien como solución proponía concentrarlos en "pocos y grandiosos monumentos" ${ }^{60}$ Además de ello, como alternativa, Janni señalaba la posibilidad de realizar obras

"Elevazione". Palanti, Quattro anni di lavoro,70.

59 Palanti, Mausoleo. Glorificando gli eroi nostri. “(...) glorificar juntos a los éroes de la Tierra, del Mar y del Cielo, de la tremenda guerra, donde combatiendo por el bien de nuestra Patria, dejaron su sangre, inmolando de esta manera sus propias vidas". [Traducción Florencia Minatta] 60 Daniele Pisani, "Monumentomania" en La memoria di Pietra. Consultado el 15 de febrero de 2015. http://circe.iuav.it/Venetotra2guerre/01/02.html. Véase también el texto de Massimiliano Savorra, "La monumentomania e i concorsi artistici nell'Italia unita" en F. Mangone, M. G. Tampieri (a cura di), Architettare l'Unità. Arcbitettura e istituzioni nelle città della nuova Italia, catalogo della mostra (Roma 26 aprile-28 maggio 2011), 
de utilidad pública antes que monumentos lo que brindaba una solución que, como señala Pisani, sería apropiada por el fascismo una década después. ${ }^{61}$ En esta línea, la propuesta de Palanti -que repetiría luego en la Mole Littoria- no se centraba solamente en el programa de mausoleo sino que contaba con usos múltiples y públicos como biblioteca, archivo histórico, museo, etcétera. En sintonía con los debates del momento, Palanti proponía, además, "Sintetizar la monumentomania" y planteaba una financiación adaptada a la posguerra: la construcción que demoraría tres años estaría a cargo de las tropas del Genio y se realizaría con materiales bélicos en desuso. El sistema estructural evitaría el costoso esqueleto metálico (típico de los rascacielos) al optar por un sistema de arcos, contrafuertes y claves en un "ciclopico maschio contorno d'assieme". ${ }^{62}$

La propuesta para el mausoleo deja ver ciertas ideas que Palanti sostendría a lo largo de su carrera: el monumento utilitario bajo forma de rascacielos, la planta concéntrica, el sistema estructural derivado de la construcción en piedra y el uso de la escultura como complemento de la arquitectura. Esta idea de Palanti de realizar un monumento a los caídos se inscribe en el clima cultural de la primera posguerra que favorecía la oportunidad de materializar proyectos como mausoleos, cementerios, templos o sacrarios que desde fines de siglo XIX eran programas frecuentes en la enseñanza académica. ${ }^{63}$

Como ejemplo, se puede citar el concurso público para un monumento a los caídos a erigirse sobre el Monte San Michele impulsado por el Comitato Nazionale per la Glorificazione del Fante Italiano, en enero de 1920. La propuesta había surgido del Ufficio Centrale per la Cura e le Onoranze alle Salme dei Caduti (COSCG) fundada en 1919 y tenía como fin la sistematización de sepulturas e inhumación de restos de los caídos que se encontraban diseminados por el territorio. ${ }^{64}$

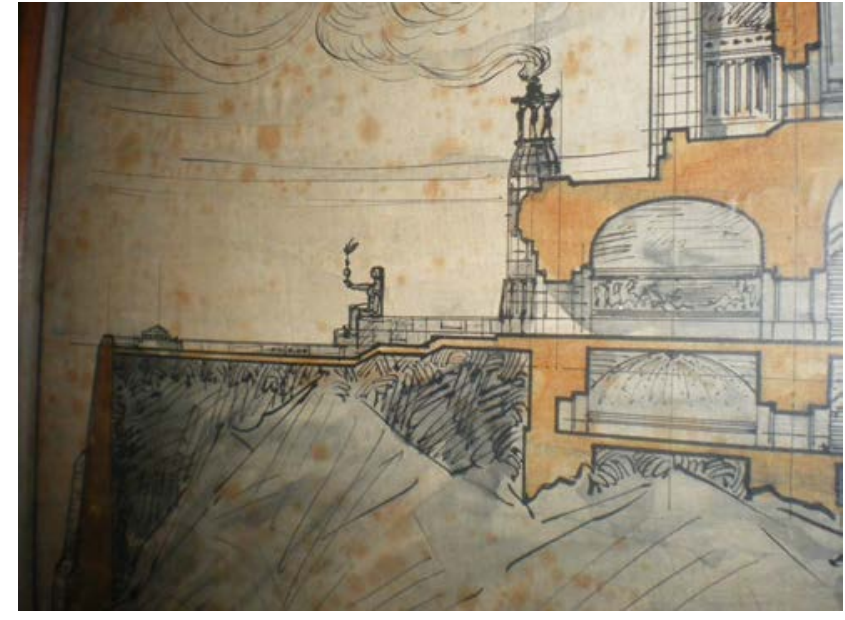

Mario Palanti. Mausoleo Glorificando gli Eroi nostri. 1919. Plano original. Colección privada

Napoli 2011, 335-347. Asimismo, el trabajo de Fabio Mangerie, "Tra architettura e scultura: caratteri della "monumentomania" fra Ottocento e Novecento" en L'architettura della memoria in Italia Cimiteri: monumenti e città 1750-1939 a cura di Maria Giuffrè, Fabio Mangone, Sergio Pace, Ornella Selvafolta (Milano: Skira, 2007), 261265.

61 Daniele Pisani, "La massa come fondamento. I sacrari fascisti della Grande Guerra", Engramma, No 117 (junio 2014). Consultad el 14 e febrero de 2015. http:/ /www.engramma.it/eOS/index.php?id_articolo=797

62 "Mausoleo. Glorificando gli eroi nostri di terra, del mare, del cielo", 1919.

63 Gaetano Palazzolo, "Sub specie aeternitatis. Architettura della memoria in forma di rotonda nel periodo tra le due guerre", Tecla, No9, (Università degli Studi di Palermo, 30 de junio 2014).

64 Daniele Pisani, "Dalle sepolture di fortuna al COSCG", La memoria di pietra. Consultado el 15 de febrero de 


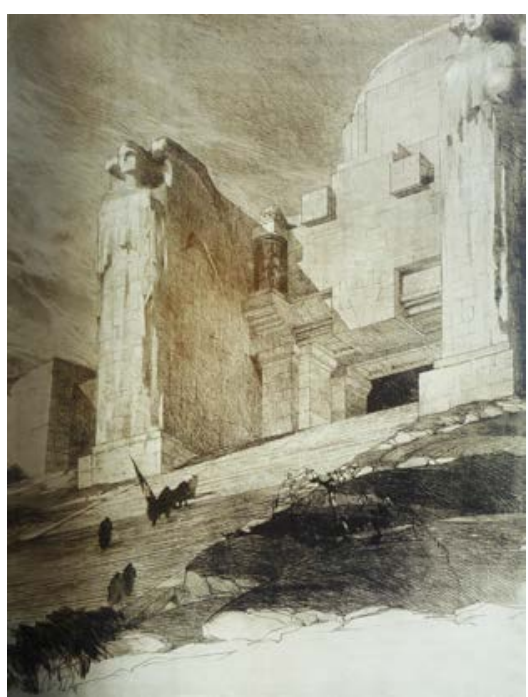

Mezzanotte y Griffini, Proyecto para el concurso Monumento al fante. 1920. L'llustrazione italiana 33, agosto 1920

La idea de erigir un gran monumento celebrativo dedicado al Fante italiano, explica Massimiliano Savorra, surgió a partir de la propuesta realizada en 1917 por el General Emanuele Filiberto di Savoia el Duca d'Aosta para honrar a los caídos de la Terza Armata que éste comandaba y de la cual Palanti formaba parte..$^{65}$ Es muy posible que Palanti haya visto una oportunidad en esta iniciativa lanzada por su General el Duca d'Aosta y que poco tiempo después le haya presentado el proyecto del Mausoleo Glorificando gli eroi nostri. En efecto, en 1919, obtuvo por parte del General una cordial salutación:

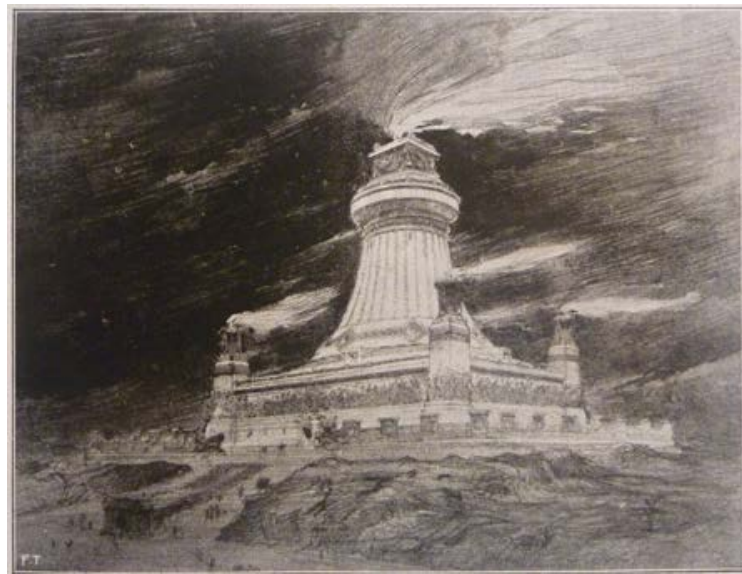

Guido Crilli. Proyecto para el concurso Monumento al fante. 1920. L'ilustrazione italiana 33, agosto 1920

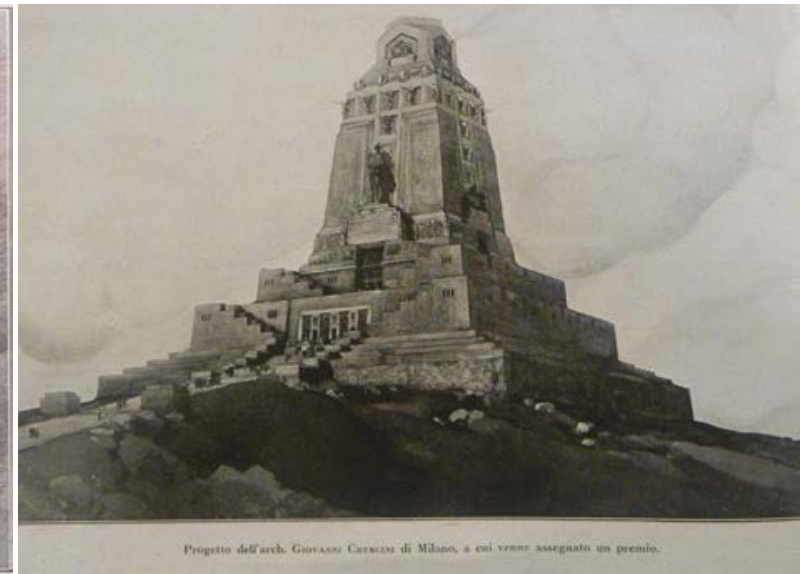

Giovanni Crescini. Proyecto para el concurso Monumento al fante. 1920. L'llustrazione italiana 33, agosto 1920

2015. http://circe.iuav.it/Venetotra2guerre/01/01.html.

65 "L'idea di erigere un monumento celebrativo era stata lanciata con grande enfasi già dopo Caporetto dal quotidiano "Grigio Verde", riprendendo peraltro una proposta del duca d'Aosta fatta per onorare i caduti della sua III armata nel 1917”. Massimiliano Savorra, "La rappresentazione del dolore e l'immagine dell'eroe: il monumento al Fante" en L'architettura della memoria in Italia Cimiteri: monumenti e città 1750-1939 a cura di Maria Giuffrè, Fabio Mangone, Sergio Pace, Ornella Selvafolta, (Milano: Skira, 2007): 365. 
Al Tenente Mario Palanti, per cordiale ricordo e come espressione del compiacimento mio, per l'opera sua nobilmente dedicata ad esaltare il valore dei miei soldati, e la memoria degli eroi caduti. Emanuele Filiberto di Savoia, Trieste 24/III/1919.6

Sin embargo, un año después (1920) cuando finalmente se llama a concurso para el Monumento al Fante italiano, Palanti no figura entre los 81 proyectos que participaron del certamen, como así tampoco entre los cinco arquitectos invitados a una segunda vuelta en 1921. ${ }^{67}$ En ese momento, Palanti se encontraba trabajando en Buenos Aires. Pese a sus esfuerzos, su multifuncional rascacielos-mausoleo no había encontrado eco en la Italia de posguerra, no obstante la idea permanecería vigente y saldría a la luz en otro proyecto: el Pasaje Barolo.

Si bien nos mantenemos en el plano de las hipótesis, ciertas líneas del proyecto para el Mausoleo Glorificando... pueden rastrearse en el diseño del Pasaje. Además de la altura, el ascenso telescópico y el programa de rascacielos multifuncional, los dibujos muestran una estrategia habitual empleada por Palanti al momento de proyectar: la continua reelaboración de formas y la adaptación de las mismas a las circunstancias. Por un lado, el mausoleo tiene sus antecedentes en la producción palantiana en varios esquicios de figuras de planta central y en construcciones utópicas en altura como el proyecto para una feria "Exposición universal de la paz Golf FCCA (1920-24)", mausoleos y templos votivos. ${ }^{68}$

Por otro lado, como fue señalado, el uso de plantas circulares en el diseño de mausoleos era habitual en las primeras décadas del siglo XX. En efecto, el uso de rotondas para lugares sagrados y la centralidad como forma "perfecta" son lugares comunes en la historia de la arquitectura. Implican una búsqueda de un modelo ideal de rotonda-mausoleo, como señaló Tafuri al hablar la planta de Catedral de Granada de Diego Siloé. ${ }^{69}$

Si se observa la disposición general del Mausoleo Glorificando... podemos ver la clásica planta central rodeada por capillas. Su matriz geométrica es repetida en la composición que da forma el núcleo central del Pasaje Barolo: en los tres primeros niveles una secuencia de círculos genera un gran espacio central con cuatro círculos menores sobre las dos diagonales. Un proyecto de Palanti conservado en un archivo privado muestra el corte del mencionado 66 Mario Palanti, Curriculum Vitae, 1932. Archivio Centrale dello Stato, Segretaria Particolare del Duce (1922-1945). (ACS SPD). Busta 1154. Al Teniente Mario Palanti, como cordial recuerdo y expresión de mi complacencia, por su obra noblemente dedicada a exaltar el valor de mis soldados, y la memoria de los éroes caídos. Emanuele Filiberto de Savoia, Trieste 24/III/1919. [Traducción Florencia Minatta]

67 Los cinco competidores eran: Enrico Griffini con Paolo Mezzanotte, Guido Cirilli, Alessandro Limongelli, Giuseppe Mancini, Eugenio Baroni.Como parte del jurado se encontraba Gaetano Moretti. Savorra, "La rappresentazione del dolore e l'immagine dell'eroe".

68 Palanti, Prima esposizione personale d'arcbitettura y Palanti, Quattro anni di lavoro.

69 Manfredo Tafuri, Sobre el renacimiento. Principios, ciudades, arquitectos (Madrid: Catedra, 1995 (1992)), 242. 
Mausoleo realizado en 1918 junto a un pequeño boceto en lápiz que deja ver el trazo del círculo con las diagonales y los círculos menores. Fiel a su método proyectual, Palanti repetiría este esquema en el diseño de la torre del Palacio Salvo. Como vimos en el primer capítulo, Boito enfatizaba el uso de la geometría como herramienta de diseño mediante la cual las más complejas formas podían sintetizarse. El uso del círculo como herramienta de diseño es recurrente en la obra palantiana. Precisamente, esta secuencia en la que el proyecto para el Mausoleo es planteado como antecedente en el diseño del Pasaje Barolo nos permite repensar la maniera en que el arquitecto elaboraba sus diseños y las estrategias proyectuales que empleaba.
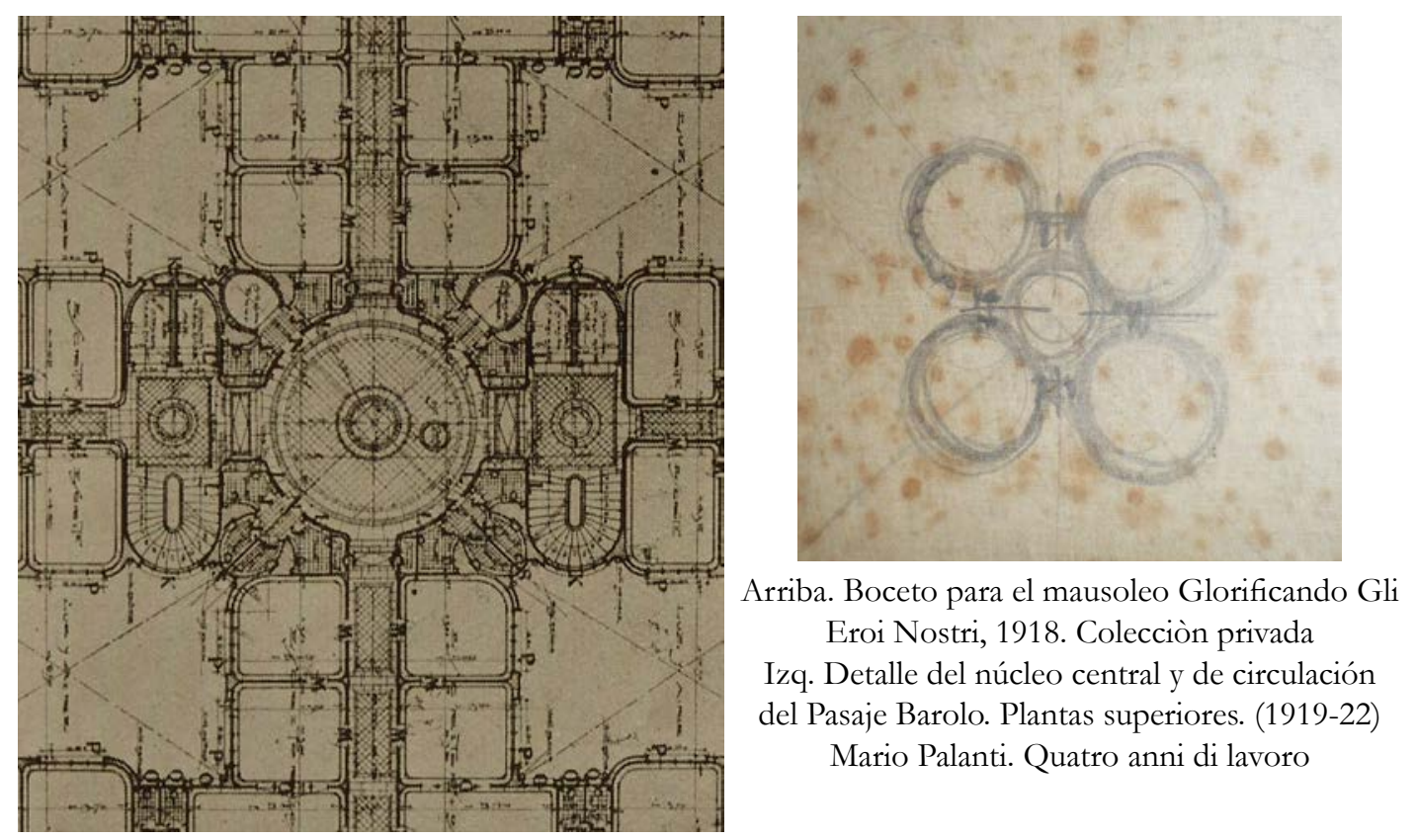

\section{La mala prensa: críticas desde el ámbito disciplinar}

En enero de 1920, la revista El Arquitecto presentó al Palacio Barolo como una obra que "haría época" en la Avenida de Mayo. ${ }^{70}$ Una década más tarde, la obra de Palanti fue motivo, por un lado, de fuertes críticas negativas por parte de un sector del ámbito disciplinar y, por otro, de un silencio provocador por parte de la prensa. Este último punto, cobra relevancia si se compara -como veremos más adelante- la repercusión que el Palacio Salvo tuvo en los medios montevideanos. A diferencia del rascacielos uruguayo, el Pasaje Barolo no fue la primera obra en altura en la metrópoli porteña, que ya contaba con edificios en altura como el Railway Building, el Plaza Hotel o la Galería Güemes y otros ejemplos menores. No obstante -y a pesar de las

$\overline{70}$ “Edificio Luis Barolo", El Arquitecto 1, No 2 (Buenos Aires, enero 1920). 
grandes transformaciones urbanas que ocupaban primeras planas en los periódicos-, llama la atención que en medios porteños como La Prensa, La Nación y La Razón, que hicieron eco de la primera exposición de arquitectura realizada por Palanti en 1916, no hayan publicado, en el mes de julio de 1923, alguna referencia a la inauguración del Pasaje. ${ }^{71}$ Esta ausencia podría atribuirse a razones ideológicas. Tal sea el caso, probablemente, del periódico L'Itaila del Popolo de postura antifascista o en Il Giornale d'Italia que mostraba cierta ambigüedad política. Tampoco hay registros en Le Cronache italiane que, sin embargo, publicó una nota sobre la Sociedad Palanthome en enero de $1923 .{ }^{72}$ Sin embargo, noticias sobre el Pasaje se ven en revistas de tirada popular como el Anuario de La Razón que en 1922 publica una imagen del proyecto primigenio o Caras y Caretas que registra con una fotografía, en la sección Sociales, la inauguración de la torre en 1923. ${ }^{73}$ Como veremos más adelante, esta situación difiere notablemente con la repercusión que el Palacio Salvo tuvo en la prensa uruguaya en la cual, como primer rascacielos en Montevideo, el edificio recibió un seguimiento continuo desde el inicio del proyecto.

Desde el ámbito disciplinar, en un contexto que intentaba construir una "arquitectura argentina" y conseguir cierto orden estético en la ciudad, las protestas por parte de profesionales

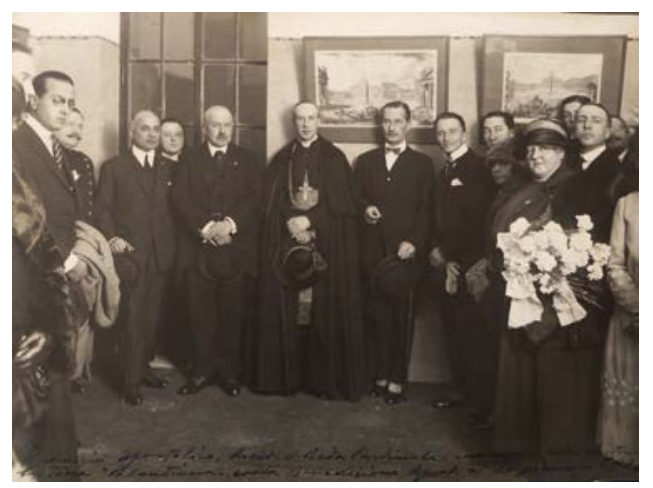

Fotografía de la inauguración de la torre del Pasaje Barolo: Il nuncio apostolico Beda Cardinale inaugura colla autorita la Torre "palantiana" colla bendizione apost. Al 20 piano, Buenos Aires, 7 de julio de 1923. Álbum personal. AGEP

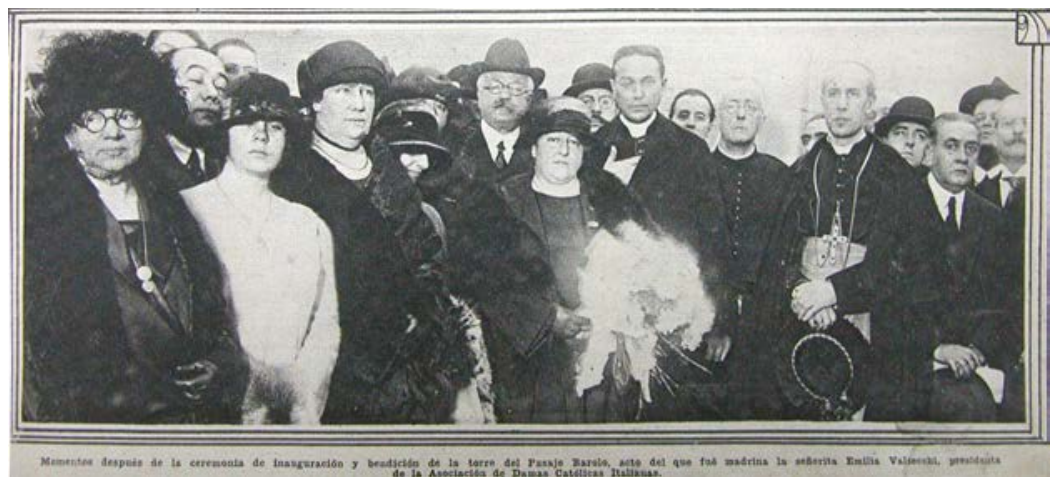

Inauguración del Pasaje Barolo. Caras y Caretas, julio 1923.

$\overline{71}$ Se relevó el mes completo de julio de 1923 de los siguientes periódicos de Buenos Aires: La Prensa, La Nación, La Razón, Il Giornale d'Italia, Le Cronache italiane, Il popolo d'Itaila.

72 Le Cronache Italiane Buenos Aires, 23 enero de 1923. María Victoria Grillo, “Creer en Mussolini. La proyección exterior del fascismo italiano:(1930-1939)", en Más allá de la historia social, Miguel Ángel Cabrera ed. Marcial Pons (Ediciones de Historia, 2006)

73 Anuario de La Razón, Buenos Aires, 1922. Caras y Caretas, julio de 1923. 
en torno a la altura de los edificios y el estilo eran parte del debate. Con su particular lenguaje el Barolo no sería la excepción. Artículos como los de Víctor Julio Jaeschke y Alejandro Christophersen en la Revista de Arquitectura reflejaban la postura de algunos miembros de la Sociedad Central de Arquitectos para quienes el mencionado edificio conjugaba diferentes factores que empobrecían la estética de la ciudad. ${ }^{74}$

En una nota titulada "El cumplimiento de la ley. El Pasaje Barolo" publicada por El Arquitecto en mayo de 1923 -antes de la inauguración de la torre-, se explicaba que el concejal García Anido había presentado ante Concejo Deliberante un proyecto para la demolición de la torre, que "las autoridades [habían] 'permitido', en abierta contradicción con las ordenanzas, que se ultrapasen los límites fijados.” ${ }^{\prime 75}$ La queja iba dirigida a la reciente creada Comisión de Estética Edilicia (CEE), a la que se acusó de, "no haber dado señales de vida." Como respuesta, José A. Hortal envió una "carta abierta" donde defendió a la CEE y señaló -en un conciso ataque hacia comitente y arquitecto- al Pasaje Barolo como "un exponente de la incultura artística de capitalistas y pretendidos arquitectos que tanto abundan en nuestro ambiente."’76

En una nota de diciembre de 1925 titulada "Las diversas influencias arquitectónicas en la edificación de Buenos Aires" el defensor del Beaux Arts Alejandro Christophersen describió el "entrevero" de la trama urbana porteña observando que entre algunas de las construcciones con

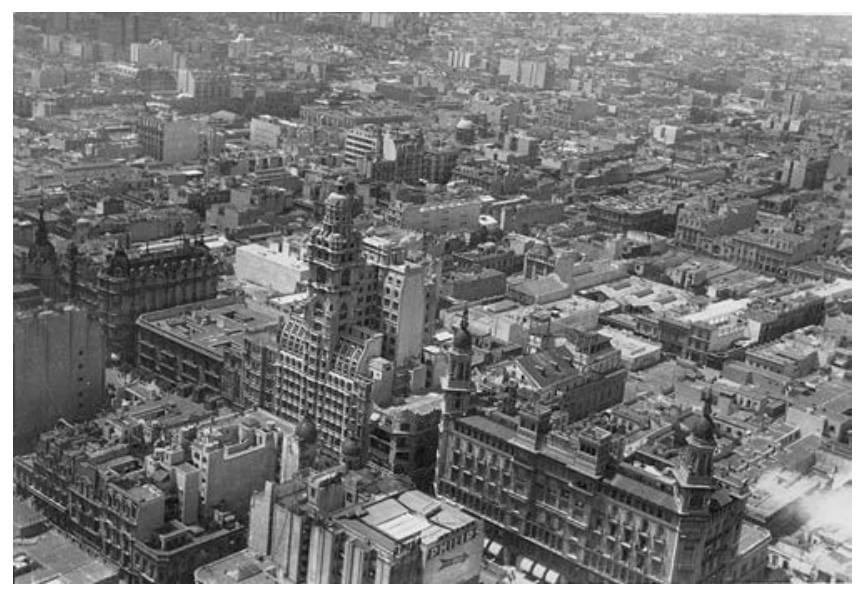

Vista aérea de Avenida de Mayo. Al centro, el Pasaje Barolo. Ca.1930

74 Alejandro Christopersen, "Los rascacielos y las construcciones gigantescas", Revista de Arquitectura, No 36 (diciembre 1923): 123-125; "Mandobles contra la lógica y la estética", Revista de la Sociedad Central de Arquitectos, No 56, año XI (Buenos Aires, agosto 1925); Víctor Jaeschke, "Prohibición de abrir pasajes", Revista de Arquitectura, No 92 (agosto 1928): 339-342.

75 "El cumplimiento de la ley. El Pasaje Barolo", El Arquitecto 3, N³4 (Buenos Aires, mayo 1923): 260-262.

76 "Carta abierta", El Arquitecto 3, N 36 (Buenos Aires, julio 1923): 328-334. 
reminiscencias del pasado aparecía “(...) algún edificio disfrazado de ‘rascacielo’ que exterioriza el brusco salto a la opulencia del inmigrante de ayer". ${ }^{77}$ En su provocador tono reclamaba:

Debemos combatir entre otras cosas, que predominan en esta ciudad de los 'minaretes', las torres fantásticas, las cúpulas inútiles y demás 'verrugas' con que algunos creen conveniente rematar un edificio, sin que nada determine semejante adorno sino el afán de exhibicionismo, culpa a veces de un cliente poco educado en arte o de un arquitecto demasiado condescendiente. ${ }^{78}$

Por otro lado, el arquitecto Alberto Prebisch, quien desde las páginas de la revista Martín Fierro luchaba por las líneas "puras y blancas" de la modernidad, señalaba que tanto estilo como reglamentación urbana habían encontrado un ejemplo de lo "incorrecto" en Pasaje Barolo. En búsqueda de "lo nacional” Prebisch consideró adecuado que la forma “(...) no sea el resultado de un trasplante caprichoso y ridículo de otras formas que pertenecen a épocas de diferente contextura que la nuestra, y que se pueden considerar definitivamente caducas.’’79

Con su particular lenguaje y carga simbólica, el Pasaje Barolo fue causa de reiterados debates que, en varias ocasiones, soslayaron la importancia del ensayo técnico, estructural o tipológico puesto a prueba en esta construcción. Un símbolo de la modernidad en la Avenida de Mayo como resultado de la audacia financiera de Luigi Barolo cuyos logros empresariales parecen haber sido enriquecidos, a lo largo del el tiempo, por la fama del edificio. ${ }^{80}$

El rascacielos porteño muestra la respuesta que Palanti propone ante la problemática que representa la construcción en altura de un programa multifuncional. Los elementos estilísticos extraídos de la historia se intentan conjugar aquí en una síntesis condicionada por la tripartición sullivaniana de fachada contemplada en la reglamentación sobre la Avenida de Mayo. Esta conjugación, a la que el propio Palanti quiere ver como la alternativa "latina" al programa

77 Alejandro Christopersen, "Las diversas influencias arquitectónicas en la edificación de Buenos Aires", Revista de Arquitectura de la Sociedad de Arquitectos del Uruguay, año XI, No XCIV (Montevideo, septiembre 1925): 195-205. Nota publicada luego en Revista de Arquitectura, N79 (julio 1927): 291-309. Sobre A. Christophersen véase, Alejandro Crispiani, "Alejandro Christophersen y el desarrollo del Eclecticismo en la Argentina" en Cuadernos de Historia IAA 6 (Bs. As.: FADU, UBA, Abril 1996).

78 Alejandro Cristophersen, "Mandobles contra la lógica y la estética" no 56 (agosto 1925): 279. En esta oportunidad señaló la actitud de ciertos arquitectos que, con la única intención de hacerse notar, rompieron con sus obras la armonía urbana. En el número de junio de 1925 Christophersen ya había escrito sobre "Algunas reflexiones sobre la reglamentación de la profesión de Arquitecto", Revista de Arquitectura de la Sociedad Central de Arquitectos, año XI, No 54 (Buenos Aires, junio 1925).

79 Alberto Prebisch, "Precisiones de Le Corbusier", Revista Sur, (Buenos Aires, verano 1931). Véase el texto de Alicia Novick, "Alberto Prebisch. La vanguardia clásica", Cuadernos de Historia IAA 9 (junio de 1998) y Alberto Prebisch, Colección "Maestros de la Arquitectura Argentina Buenos Aires: Clarín, 2014)Adrián Gorelik y Graciela Silvestri, "El pasado como futuro. Una utopía reactiva en Buenos Aires", Punto de Vista, No 42 (Buenos Aires, abril 1992).

80 Entre el público en general, el nombre "Barolo" es más conocido que Dell’Acqua, Demarchi o Campomar y Soulas, quienes tuvieron mayor relevancia en el mundo textil. 
del rascacielos moderno, serviría, de ahora en más, para organizar los mejores ejemplos de su producción urbana y volvería a reiterarse, como veremos, en el palacio Salvo de Montevideo.

En el Pasaje Barolo podemos ver la conjunción de galería comercial y rascacielos. Como resultado formal, esta unión generó una tipología de compleja yuxtaposición volumétrica que se alejó de los esquemas norteamericanos en bloque, torre, setback y sus variantes, para acercarse, en todo caso, a la experimentación teórica de las propuestas realizadas en la Europa de entreguerras. ${ }^{81}$

Además de ello, debemos considerar que, en el contexto metropolitano rioplatense, tanto en el Pasaje Barolo y, como veremos a continuación, en el Palacio Salvo, los requerimientos funcionales del encargo se despegaron del clásico destino de oficinas u hotel para inclinarse hacia la innovación: la gran galería comercial europea se fusionó con el rascacielos norteamericano.

81 Por ejemplo, los proyectos para los rascacielos de cristal de Mies van der Rohe, Taut, Mendhelson, Quintana de Uña VER. 


\section{Capítulo IV. Superar su marca: el Palacio Salvo en Montevideo}

¡Qué idea de reposo daría un rascacielos acostado en el suelo! Con casi todas las ventanas mirando cara al cielo. Y desangrándose por las tuberías del agua caliente y de la refrigeración. El rascacielos de Salvo es la jirafa de cemento que completa el zoológico edificio de Montevideo.

(Alfredo Mario Ferreiro, Poema del rascacielos Salvo, 1927)

\section{1. "La lucha por la felicidad"}

En 1922, tres años después participar en el concurso para el Pasaje Barolo, Palanti se presentó a un llamado a concurso internacional de anteproyectos para la construcción otro rascacielos: el Palacio Salvo, en Montevideo.

El concurso fue convocado dicho año por la firma Salvo Hnos. El terreno elegido era el antiguo sitio de la tradicional confitería "La Giralda", inaugurada en 1832, conocido por ser el local donde Matos Rodríguez tocó por primera vez la Cumparsita, y que ahora cedía lugar

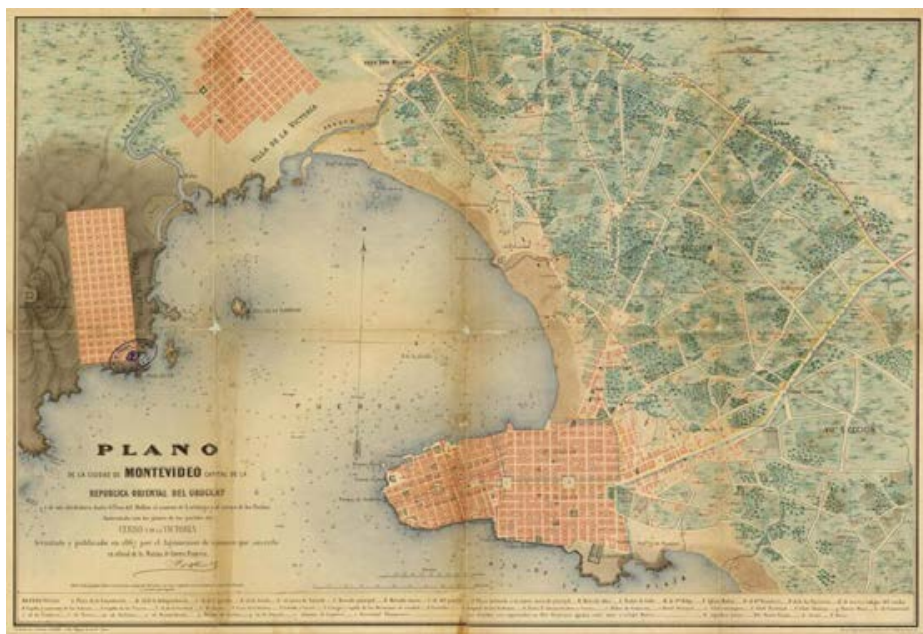

Plano de Montevideo, Uruguay, 1867. Se ve la Plaza Independencia como bisagra entre la Ciudad Vieja y la expansión urban a lo largo de la Avenida 18 de Julio.

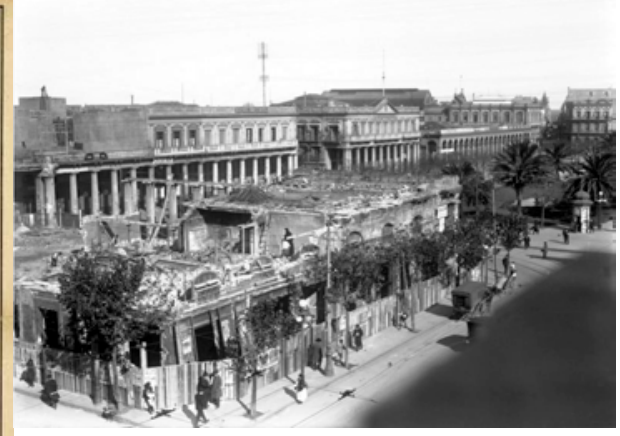

Vista de la Giralda en demolición. Ca. 1922. Montevideo, Uruguay. 
a “(...) un soberbio edificio, que será por su belleza el punto de atracción de todo el pueblo". ${ }^{1}$

El lote de 1798, $95 \mathrm{~m}^{2}$ sobre el cual se levantaría el rascacielos se ubica en la intersección de la Avenida 18 de Julio entre la Plaza Independencia y la calle Andes. Esta ubicación privilegiada se ve favorecida por su inserción urbana: se presenta como remate de la Avenida, frente a la Plaza Independencia, actuando como bisagra entre la Ciudad Vieja y la expansión de la ciudad. Pero los Salvo no fueron pioneros en tal emprendimiento inmobiliario. Seducido por la ubicación clave del lote, Marcelino

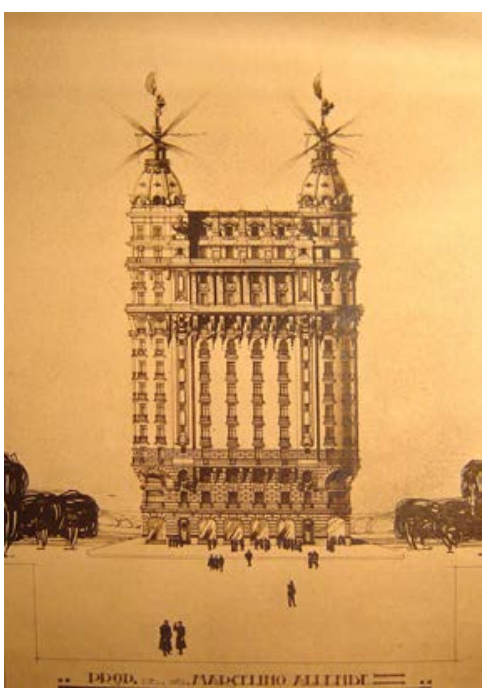

R. Tiphaine. Proyecto para Marcelino Allende. AGN Montevideo. Allende, su anterior propietario, había intentado edificar en 1918 el "Palacio Allende", un edificio destinado a oficinas de alquiler cuyos 15 pisos y 49 metros de altura le otorgaban el título (en papel) de rascacielos. Pero finalmente, luego de algunas licitaciones y proyectos presentados, el efímero sueño de Marcelino Allende quedó en la nada y el terreno pasó a manos de la sociedad de los hermanos Salvo a fines de 1919.²

Las bases del concurso impulsado por Salvo Hnos. hacían énfasis en el valor estilístico y las funciones que albergaría la obra. El interés de los propietarios se volcaba en la creación de una imagen como símbolo identificatorio de su empresa; el edificio debía contar con un programa multifuncional de hotel, restaurantes, oficinas, salones para fiestas, locales comerciales, una torre y un pasaje comercial de tipo "monumental". ${ }^{3}$ Estas características transformarían al edificio en una tipología que conjugaría -como en la Galería Güemes (19121916) o el Pasaje Barolo- el rascacielos norteamericano con la gran galería comercial europea.

Según la noticia, la torre se ubicaría, preferentemente, en el enclave de 18 de Julio y Plaza Independencia, coronando el edificio en la principal esquina del terreno. El llamado fue hecho en junio y cerrado en agosto con la participación de diecisiete proyectos provenientes de ambas orillas del Río de la Plata. Lo interesante, como en el caso del concurso para el Chicago Tribune llevado a cabo el mismo año de 1922 en Estados Unidos, es que las propuestas presentadas permiten tener un panorama de las soluciones que se planteaban en el contexto rioplatense en torno a la problemática de la construcción en altura.

1 Diario El Día, Montevideo, 22 de marzo de 1922.

2 Véase el material disponible en Archivo General de la Nación, Uruguay (AGN), Archivo del Palacio Salvo, Caja 265, carpeta 1 (1918-1919).

3 Diario El Día, Montevideo, 22 de marzo de 1922. 


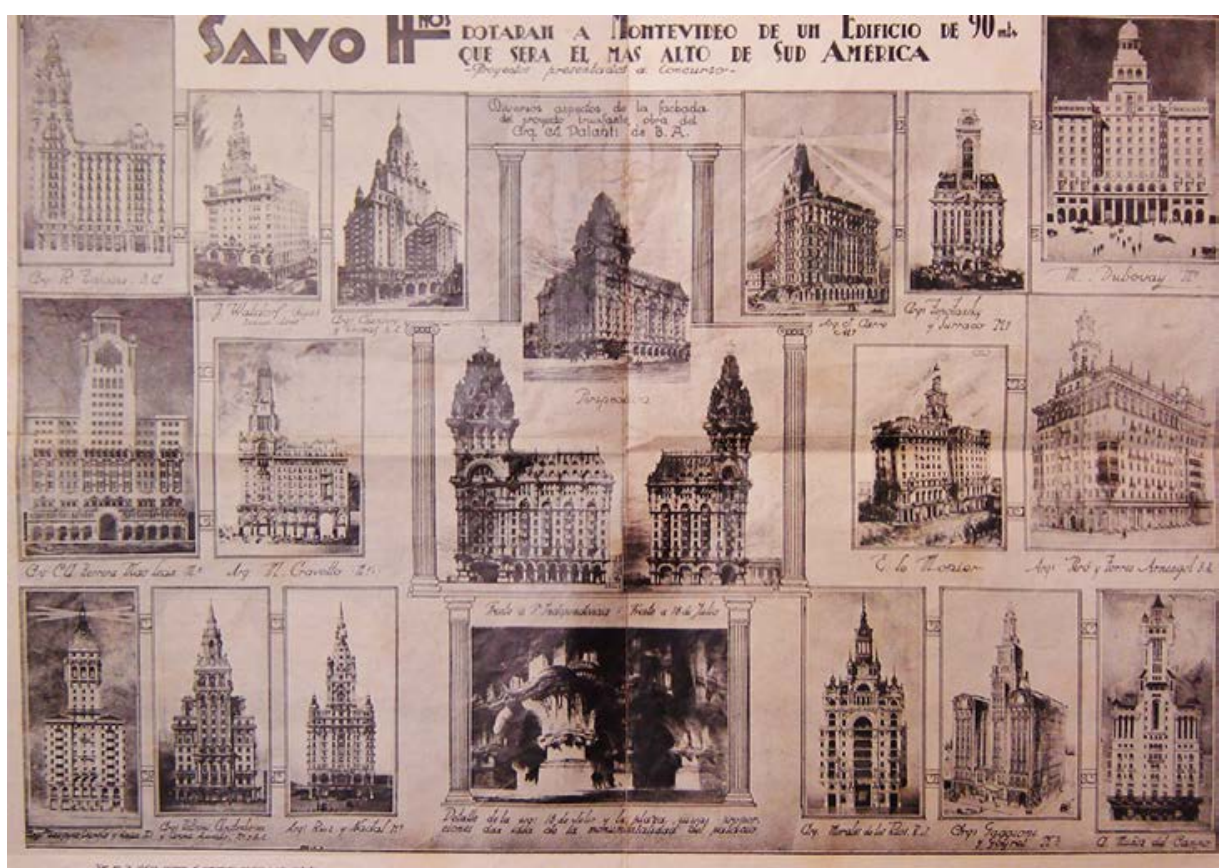

Proyectos presentados al llamado a concurso para el Palacio Salvo, Mundo Uruguayo 16 de nov. de 1922. Centro de Documentación e Información en Historia de la Arquitectura, el Urbanismo y el Territorio - Instituto de Historia de la Arquitectura - Facultad de Arquitectura - Universidad de la República - Uruguay (IHA)

Desde una lectura tipológica, los proyectos presentados pueden diferenciarse, a grandes rasgos, en cuatro grupos de acuerdo a la ubicación de la torre:

Aquellos que se componen por un gran bloque con anexión de la torre en el centro: Arqs. J. Waldorf; J. Carre; C.A. Herrera Mac Lean; Peró y Torres Armengol.

Aquellos generados a partir de un esquema de planta en U con una torre central: Arqs. Chambers y Thomas; Gaggioni y Goyret; M. Dubovay; E. Le Monier.

Aquellos compuestos por un esquema esbelto del cual surge la torre central: Arqs. Veltromi; A. Christophersen y Serena Acevedo; Morales de los Rios; Muñoz del Campo, Topolansky y Surraco; Vázquez Varela y Rocca; Ruiz y Nadal.

Aquellos formados por un bloque con la torre en esquina: Arqs. M. Cravotto; M. Palanti; R. Tiphaine.

En cuanto al lenguaje, aun habiendo probado ya su ineficacia para resolver la tipología en altura, los proyectos giraban principalmente en torno a elementos provenientes del sistema clásico en el marco de un eclecticismo derivado de la Ecole de Beaux Arts con variantes que se acercaban al neo renacimiento francés o neo renacimiento italiano. Entre ellos vemos el uso

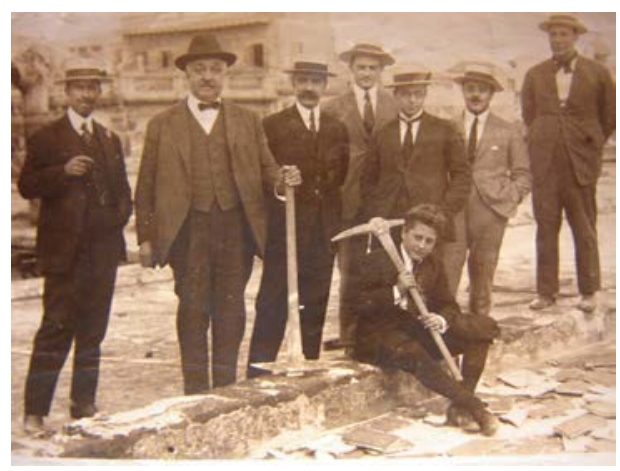

Lorenzo Salvo en el inicio de las obras del Palacio. 1923, AGN Montevideo. 
de cúpulas, templos y ordenes clásicos (Chambers y Thomas, Ruiz y Nadal), un clasicismo despojado (C.A. Herrera Mac Lean, Dubovay) o plateresco (Peró y Torres Armengol). La única excepción en la que se ve un híbrido entre neogótico y neorrománico es el diseño de Palanti cuya lúgubre torre resaltaba entre las espigadas cúpulas y mansardas derivadas de la Ecole. La variedad de alternativas no conformó a los comitentes por lo que decidieron declarar el concurso desierto. Sin embargo, posteriormente, el diseño del edificio fue encargado a uno de los participantes: el arquitecto Mario Palanti.

Posiblemente, los Salvo se inclinaron por Palanti quien tenía experiencia en edificios en altura ya que estaba finalizando, en ese momento, la construcción del Pasaje Barolo. ${ }^{4} \mathrm{Al}$ igual que sucedió en el edificio porteño, el inicio de la obra del Palacio Salvo requirió de la aprobación de pedidos de excepción ya que la torre -elemento que realzaría la monumentalidad del edificiosobrepasaba la altura permitida sobre la Avenida 18 de Julio. En esta arquitectura de la excepción, Palanti alcanzó el título de rascacielos a través de la composición del bloque principal con la anexión de una torre, un procedimiento empleado ya en Norteamérica al cual se recurría para lograr la altura anhelada: la esbeltez deseada se alcanzaba por la elevación de un porcentaje del total de la masa construida lo que permitía esquivar los límites impuestos por el municipio

En noviembre de 1922, a pocos meses de cerrar el concurso, los Salvo pidieron al Presidente del Consejo de Administración Departamental, el Ingeniero Luis P. Ponce, que “(...) se considere el pedido de aprobación de altura de la torre que alcanzará en la fachada correspondiente a la Av. 18 de Julio y Andes los 85 m". ${ }^{5}$ Las demás fachadas del edificio -se explicaba- no superarían la altura permitida de 31 metros, lo que denota la importancia de la torre en el contexto general de la obra. La situación particular de la torre, ubicada sobre la avenida y frente a la plaza, inducía, y a la vez permitía a los hermanos Salvo intentar persuadir a las autoridades para obtener la aprobación de las leyes y conseguir así la altura establecida en el proyecto. Como estrategia -y conociendo el interés del municipio-, los comitentes destacaban la «grandeza» de la obra y el «beneficio» que obtendría la ciudad con su imagen; el 14 de diciembre de 1922, ante la proximidad de la fecha de inicio de la obra, la firma de los hermanos Salvo presentó una nueva nota a la Comisión de Obras Municipales donde pedía que se tuviera en

4 Recordemos que, como señalamos en el Capítulo II, Palanti tuvo varios comitentes vinculados a la industria textil: Luigi Barolo, Francisco Piccaluga, Andrea Roccatagliata, Davide Costaguta.

5 Carta al Sr. Presidente del Consejo de Administración Departamental del 16 de noviembre de 1922, AGN, Archivo del Palacio Salvo, Caja 265, carpeta 1 (1923-1925). 
cuenta la "monumentalidad de la obra que se proyecta". En 1923, la firma intentó conseguir nuevos beneficios económicos por parte del municipio a través de una reducción en el aforo "por tratarse de un terreno en el que se está por realizar una construcción moderna" durante cuyo tiempo de obra no se percibiría renta alguna: "la ley de Contribución Inmobiliaria -explicabanexonera del impuesto a los edificios en construcción”. De no concederse el beneficio, y no pudiendo concretar las obras por cuestiones económicas, se verían "forzados a dejar ruinas sobre la avenida”. Una amenaza eficaz para un municipio que intentaba consolidar en la arquitectura una versión material de prosperidad. ${ }^{7}$

Dos años más tarde, nuevos debates pusieron en juego la continuidad de las obras. El Municipio tenía dudas sobre la factibilidad de la construcción de la torre y sobre el efecto formal al que consideraba de un "dudoso resultado para la armonía arquitectónica de la Plaza”. Vinculado por un lazo familiar a los propietarios y codirector de la obra, el ingeniero Gori Salvo, afrontó esta situación enviando una carta al director de Obras Municipales, el ingeniero Octavio Hansen, en la cual explicaba que la torre conformaría sólo $1 / 20$ del volumen total del edificio y por lo tanto no provocaría un problema estructural. ${ }^{8}$ A pesar de los trámites realizados y de los vínculos políticos de los Salvo, en abril de 1925 la Dirección de Obras Municipales envió una nota en la que se "intimaba la paralización inmediata de los trabajos de construcción de la torre". ${ }^{9}$ Pero los propietarios no eran los únicos interesados en la materialización del edificio. Finalmente, las autoridades también colaboraron facilitando la modificación de aquellas leyes y reglamentos que se interponían con la imagen proyectada para la

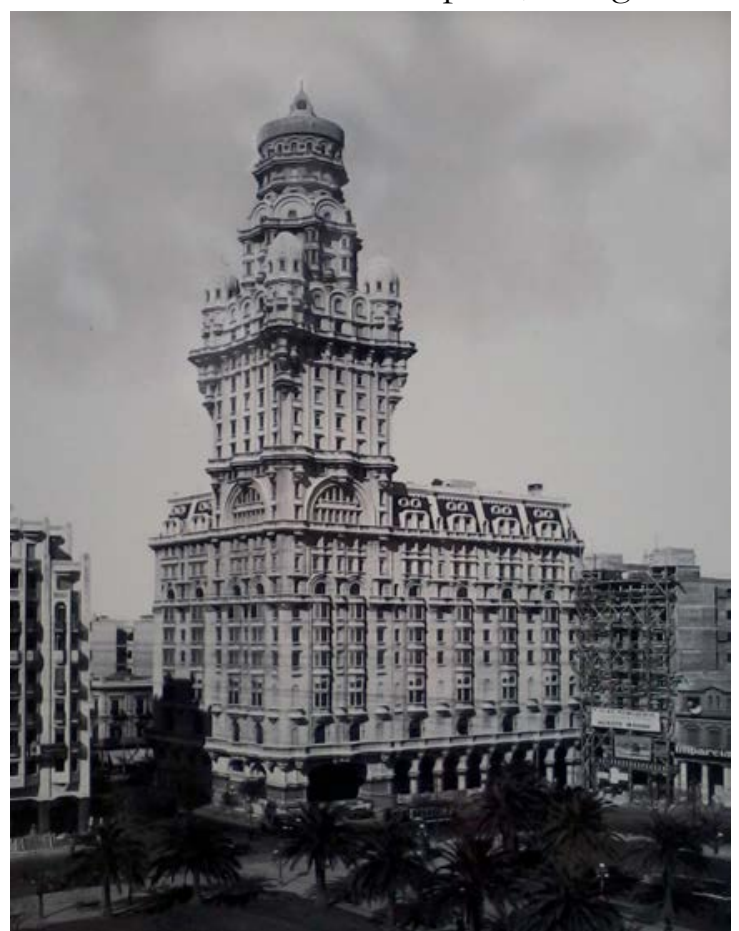

Palacio Salvo en el momento de su inauguración. Ca. 1930. Palacio Salvo, 18 de Julio entre plaza Independencia y Andes, 1922-28, Mario Palanti. Antigua postal. Palacio Salvo. Año 1929. (Foto: 576FMHA. CMDF.IMM.UY- Autor: S.d./IM)

6 Carta de los Hnos. Salvo a la Dirección de Obras Municipales, 14 de diciembre de 1922, AGN, Archivo del Palacio Salvo, Caja 265, carpeta 3, (1922-1923).

7 AGN, Archivo del Palacio Salvo, Caja 265, carpeta 3, (1922-1923).

8 Carta del Ing. G. Salvo al Dir. de Obras Municipales, Ing. Hansen. 18 de febrero de 1924. AGN, Archivo del Palacio Salvo, Caja 265, carpeta 4. (1922-1924)

9 AGN, Archivo del Palacio Salvo, Caja 265, carpeta 3 (1922-1923) 
obra: el interés por parte de las autoridades se leía en la concesión de "permisos especiales". Uno de los primeros permisos se obtuvo con el apoyo de, primero, la Municipalidad que permitió la realización del pasaje comercial en planta baja, y segundo, el Cuerpo Legislativo que dictó una ley que autorizaba la "construcción de galerías y pasajes". ${ }^{10}$

En ese sentido, podemos considerar que los pedidos especiales aprobados fueron en parte respuesta a la voluntad del municipio de conseguir beneficios a través de la inserción de una tipología con un elevado contenido simbólico: el rascacielos —es decir, el capital privado— como elemento urbanizador, símbolo de progreso y modernidad. Hacia 1927, con la obra en su etapa final, un gran cartel ubicado en el piso once, precisamente en el arranque de la torre, dejaba leer: "El Batllismo lucha por la felicidad"."

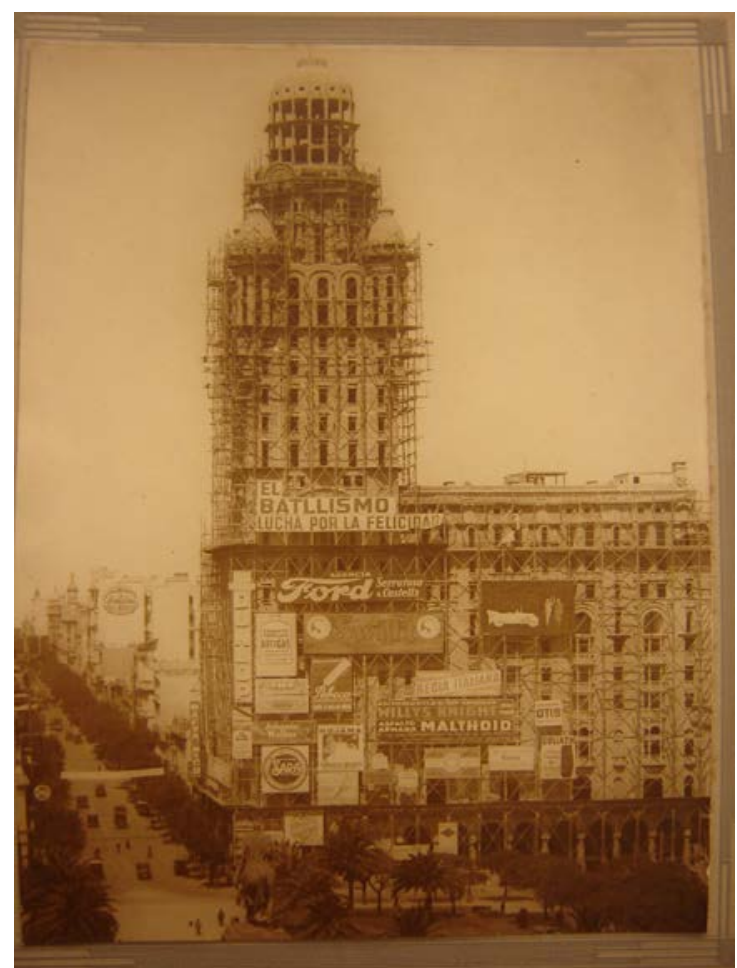

Vista del Palacio Salvo. Se puede ver el cartel que dice "El Batllismo lucha por la felicidad". Mario Palanti Papers, GRI. Los Angeles.

\section{La materialización de una trayectoria: la construcción del Palacio}

En el proyecto para el Palacio Salvo, al igual que en otros encargos realizados por industriales dedicados al rubro textil -como el ya mencionado Pasaje Barolo o el edificio Roccatagliata-,

$\overline{10}$ "Por el embellecimiento de la ciudad. La demolición de la Giralda", Diario El Día, Montevideo, 21 de marzo de 1922.

11 Los Angeles, Getty Research Institute (910002), Mario Palanti Papers, Serie I, Folder 8. (GRI) 
los primigenios bocetos neogóticos de Palanti se transformaron en líneas que se acercan al neorrománico al alcanzar la faz de proyecto. Como en los casos mencionados, esta particularidad se hace más evidente en la torre donde el arquitecto, siguiendo los planteos mencionados por Boito en el capítulo uno, emplea un método proyectual en el que priman las líneas curvas y el círculo como herramientas de diseño.

En lo referente a la distribución, el Palacio se despliega en un total de 31 plantas que se reparten en dos subsuelos, planta baja y once pisos que son dispuestos en un basamento, un desarrollo compuesto por plantas tipo y un remate formado por una pequeña mansarda del cual despegan los diecisiete pisos que componen la torre en esquina. ${ }^{12}$

El conjunto se organiza en un bloque con la anexión de la torre, elemento que otorga al edificio el título de rascacielos: efectivamente, sin ella el Salvo sería un hotel moderno en una tipología de palacio de disposición tripartita en fachada (pórtico- desarrollo-mansarda). En cuanto a la ocupación en planta, el bloque principal del edificio reproduce la forma del lote aprovechando la privilegiada implantación con tres caras libres (33.50 metros en su frente menor sobre la Avenida 18 de julio y 53,70 metros sobre la calle Andes y la Plaza Independencia) lo que permitió la ventilación directa en 204 unidades mientras que 88 ventilan hacia los dos patios de aire y luz (de 10 x 12 metros) que se intercalan en el centro del edificio junto con los núcleos de circulación.

Si bien el edificio comparte con el Barolo la disposición de bloque con anexión de la torre, en el caso del Palacio Salvo primó esta última ante el pasaje comercial. Centrada sobre la fachada principal, la torre del Pasaje Barolo -como ya observamos- se levanta sobre el eje central de la galería comercial exaltando la importancia visual ya otorgada al pasaje por el arco de ingreso de tres niveles de altura: en efecto, el Barolo es conocido como un "pasaje" y como no un "palacio".

En el caso del Palacio Salvo los elementos fueron desplazados del eje central: el pasaje resulta disimulado detrás del porticado (Pasiva ${ }^{13}$ ) sobre Plaza Independencia y la torre es desplazada hacia la esquina logrando una mayor perspectiva y realzando su condición de

12 La diversidad de funciones que contiene el Palacio Salvo lo acerca más a la Galería Güemes y no a su "gemelo" Barolo destinado a comercio y oficinas de alquiler.

13 Además del diseño de la Plaza Independencia y su ordenamiento, en 1837 el arquitecto italiano Carlo Zucchi construyó la casa de Elías Gil, ubicada en Plaza Independencia y provista de arcadas de medio punto sobre pilares de base cuadrada formando una acera techada. Este tipo de pórtico es llamado "pasiva" pues la casa Gil sirvió de cuartel al Regimiento de los Pasivos -veteranos jubilados- durante la Guerra Grande. César Loustau, Influencia de Francia en la arquitectura de Uruguay (Montevideo: Trilce, 1995) 


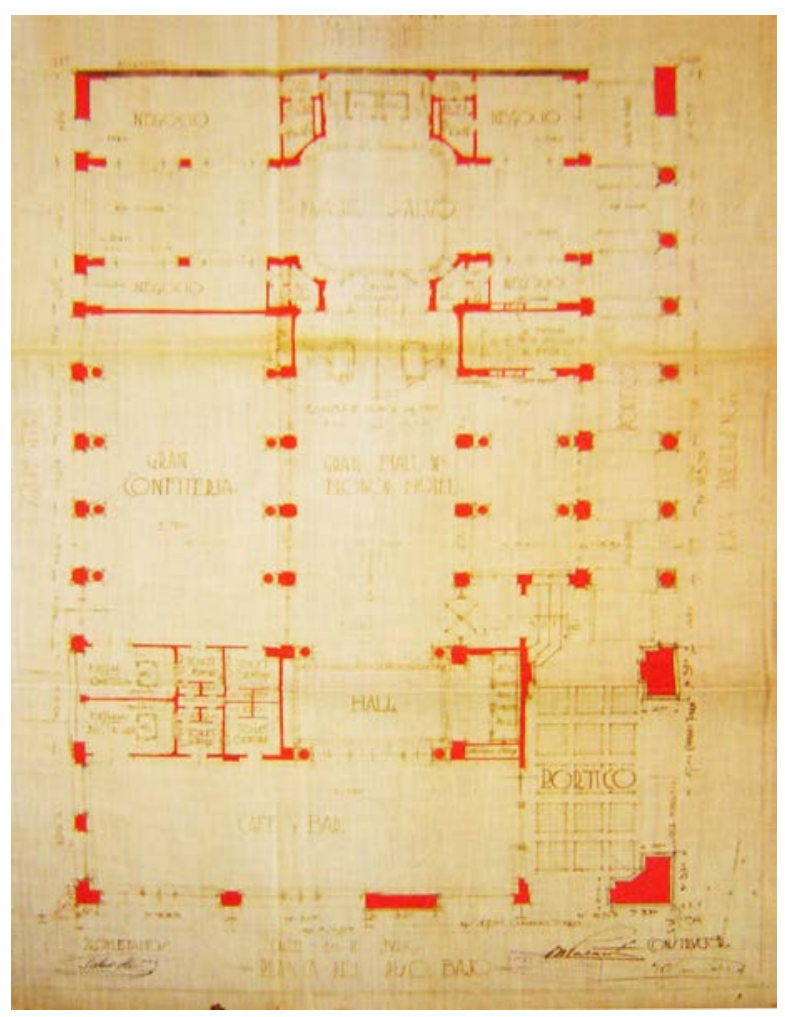

Planta baja del Palacio Salvo. 18 de Julio entre plaza Independencia y Andes, Montevideo. 1922-28, Mario Palanti. Permiso de Construcción Nº3.965. Colección de Permisos de Construcción Municipales (1907-1931). IHA

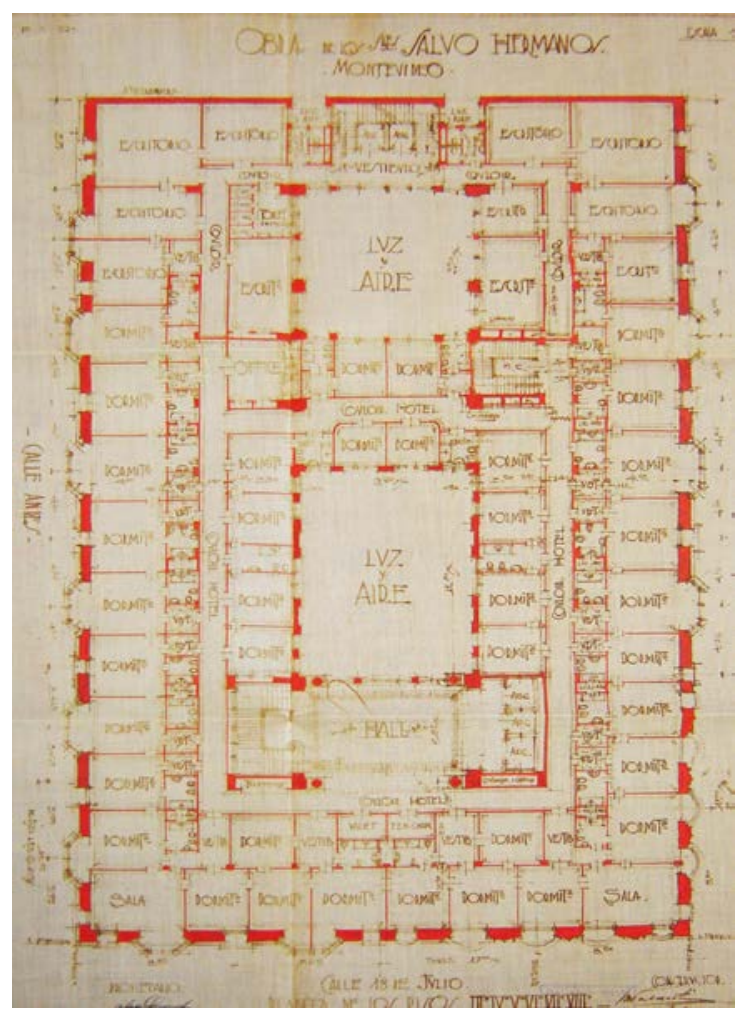

Planta pisos III al VIII. Palacio Salvo, 18 de Julio entre plaza Independencia y Andes, Montevideo. 192228, Mario Palanti.Permiso de Construcción No83.965. Colección de Permisos de Construcción Municipales (1907-1931). IHA

excepción urbana, un hito que marca el ingreso a la avenida más importante de la ciudad.

Esta galería comercial, cuyo protagonismo queda sometido a los arcos de la Pasiva, cuenta con cuatro locales comerciales convertibles en seis y una altura que toma la planta baja y entrepiso. Su presencia es prácticamente anecdótica si se compara con la impronta metropolitana, por ejemplo, de la gran arcada del Pasaje Barolo o la Galería Güemes en Buenos Aires. Pero este dispositivo conformado por el pasaje tenía un fin práctico: comunicar, a mitad de cuadra, la calle Andes con la Plaza Independencia asegurando el tránsito de peatones en una calle interior dentro del edificio. Además de ello, el pasaje permitía nuclear el acceso independiente a las oficinas de alquiler ubicadas en la zona próxima a la medianera entre los pisos tercero a noveno y separadas del hotel sólo por un tabique divisorio cuya demolición permitiría la eventual incorporación de las unidades al hotel. En efecto, -a excepción del primero y segundo piso donde funcionaba la cocina- este sector del Palacio Salvo se comportaba como un edificio autónomo.

El subsuelo del edificio -como en la Galería Güemes porteña- albergaba actividades abiertas al público que satisfacían las demandas de la incipiente vida metropolitana: 
un bar (utilizado como teatro) ubicado sobre los 33,5 de la Avenida 18 de Julio, un comedor, un salón de té y peluquerías todos ellos con entrada independiente sobre la calle Andes y sobre el pasaje..$^{14}$

Entre la planta baja y el tercer piso se ubican-además del pasaje comercial- aquellas actividades públicas relacionadas al hotel: una confitería (sobre Avenida 18 de Julio), un bar y el acceso principal del hotel que se esconde tras la Pasiva sobre Plaza Independencia. Al ingresar al hotel se encuentra el vestíbulo principal con la escalera de honor y la batería de ascensores que opera como principal distribuidor de circulación.

En el entrepiso se ubicaban las dependencias del hotel, salones de belleza y peluquerías para hombres y mujeres, comedor para niños y jardín de invierno. El primero y segundo piso albergaban los grandes salones de recepción, banquetes y fiestas con sus respectivas dependencias de servicios. Estos dos pisos funcionan estructuralmente como plantas libres con dos núcleos de circulación principal y uno de servicio como únicos elementos fijos junto con el sistema estructural de apoyos puntuales.

A partir del tercer piso se ubican las habitaciones del hotel y las oficinas en un sistema de $\begin{aligned} & \text { Plano de la torre. Palacio Salvo, } 18 \text { de Julio en- } \\ & \text { tre plaza Independencia y Andes, Montevideo. }\end{aligned}$ plantas repetibles que continúa hasta el piso nueve y se 1922-28, Mario Palanti.Permiso de Construcplantas repetibles que continúa hasta el piso nueve y se ción No83.965. Colección de Permisos de interrumpe por la mansarda (décimo nivel) que alberga

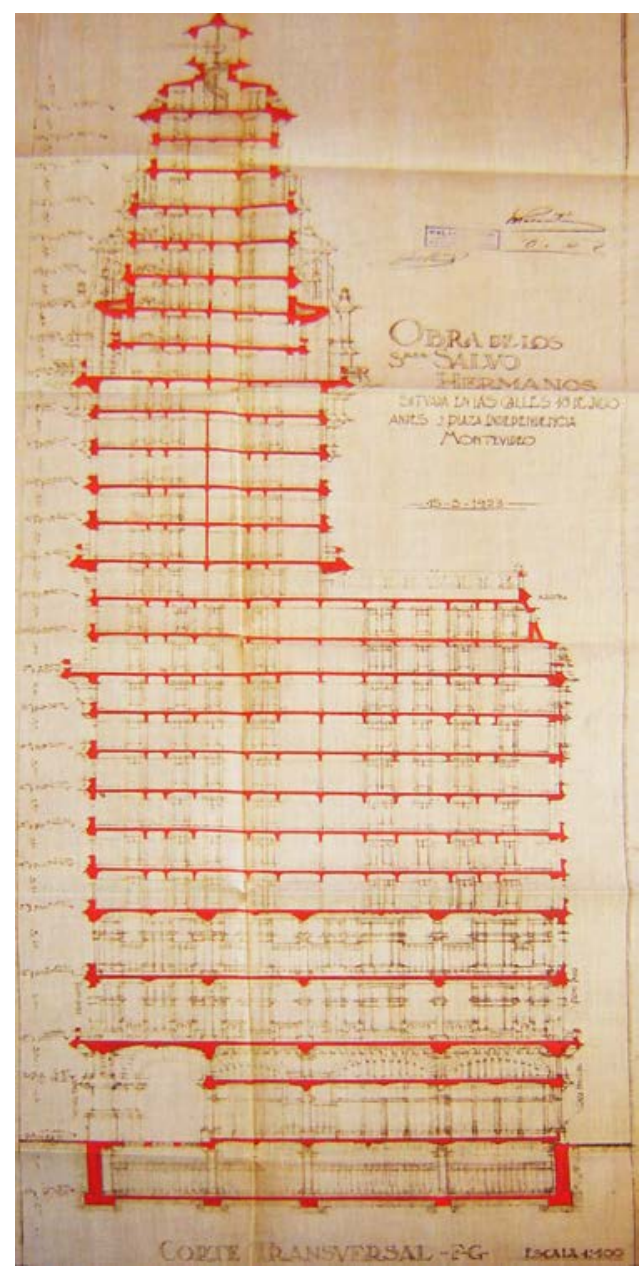

Corte transversal. Palacio Salvo, 18 de Julio entre plaza Independencia y Andes, 1922-28, Mario Palanti. Montevideo. Permiso de Construcción No83.965. Colección de Permisos de Construcción Municipales (1907-1931). IHA

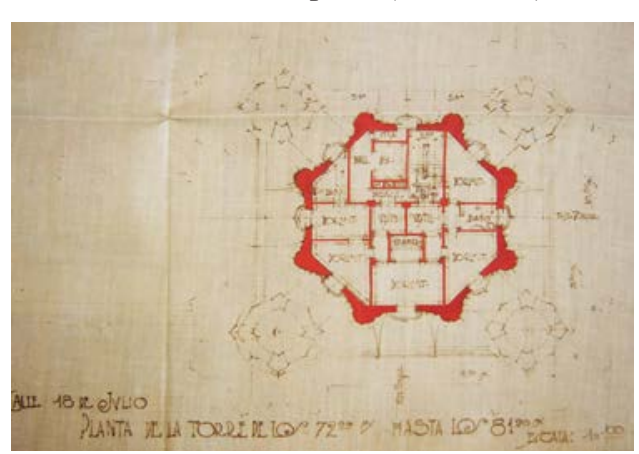
Construcción Municipales (1907-1931). IHA las habitaciones del personal y dependencias del hotel.

En el piso onceavo tiene lugar el despegue de la torre y la terraza. Los pisos once a dieciséis repiten

$\overline{14}$ Permiso de Construcción No83.965. Colección de Permisos de Construcción Municipales (1907-1931). Centro de Documentación e Información en Historia de la Arquitectura, el Urbanismo y el Territorio - Instituto de Historia de la Arquitectura - Facultad de Arquitectura - Universidad de la República - Uruguay (IHA). 
su disposición con habitaciones de uno, dos y tres dormitorios. Esta situación de plantas repetibles diferencia la solución desarrollada en el Pasaje Barolo donde por un lado, la búsqueda de ventilación e iluminación de las unidades para el lote entre medianeras y el intento de ocultar el gran bloque de oficinas por otro, derivó en una ausencia de plantas tipo. Por el contrario, las tres caras libres del Palacio Salvo permitieron dar una solución mediante la repetición de plantas que surgen como extrusión del lote en altura.

A partir del piso diecisiete, las unidades se van adaptando al ascenso decreciente de la torre que se interrumpe en el piso veinticuatro con un belvedere. Los pisos siguientes están destinados a servicios de electricidad y agua y, finalmente, el piso veintisiete es la plataforma del faro.

\section{El esqueleto}

Siguiendo con la experimentación planteada en el Pasaje Barolo, la estructura del Palacio

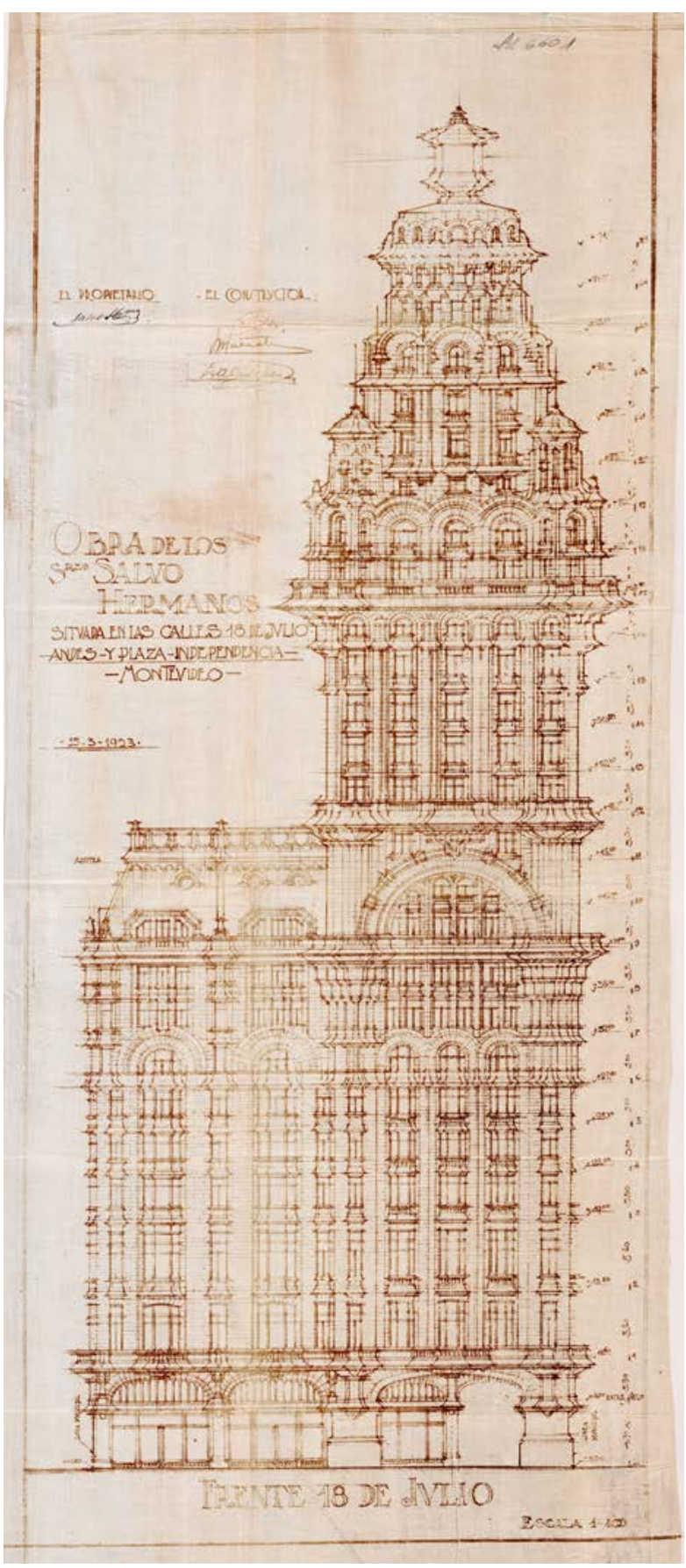

Vista sobre av. 18 de Julio. Colección de Permisos de Construcción Municipales (1907-1931). IHA Salvo fue hecha totalmente en hormigón armado y requirió para su concreción de los conocimientos desarrollados por entonces en Alemania sobre esa tecnología. La licitación fue ganada por Dickerhoff \& Widmann empresa de origen alemán que convocó al ingeniero Adolf Hartschuh para el cálculo estructural. Por pedido de los comitentes se sumó al equipo el ingeniero Gori Salvo con quien luego Palanti entablaría una buena amistad. La poca variación entre el proyecto realizado por Palanti y los planos de cálculo estructural a cargo de la empresa dan cuenta de los saberes del arquitecto en torno al 
manejo del hormigón. Ejemplo de ello son los machones que sostienen la torre, principales puntos de apoyo en planta baja, junto con la estructura de los núcleos de circulación, y el gran arco de medio punto ubicado en el piso once que desvía las cargas de la torre a estos puntos de apoyo en esquina formados por dos pilares en " $L$ " de $0,75 \mathrm{~m}$ de espesor y 1,26m y 1,76m en las caras exteriores.

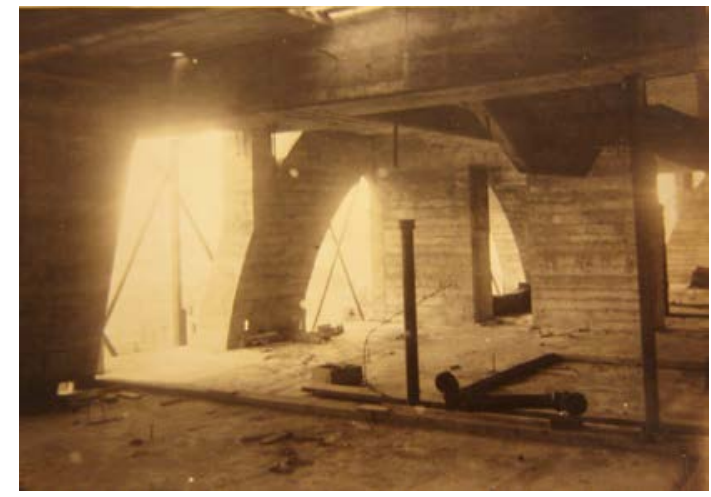

Arco sobre Plaza Ind. y 18 de Julio, Montevideo. Arq. Mario Palanti, Ing. Gory Salvo, Empresa Constructora Dickerhoff \& Widmann. Mario Palanti Papers, GRI. Los Angeles.

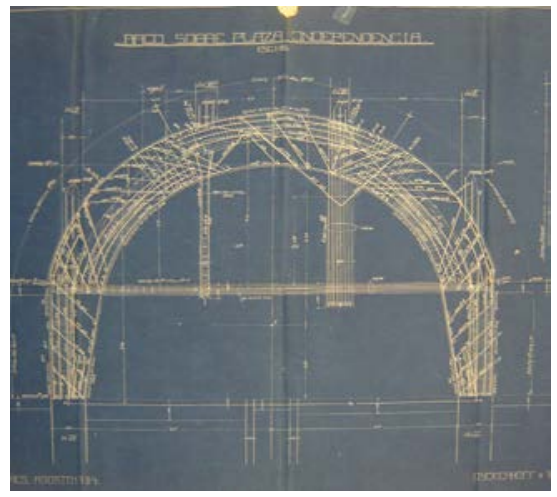

Dykerhoff \& Widmann. Palacio Salvo. Plano de doblado de hierros del arco sobre Plaza Independencia. Agosto 1924.IHA Montevideo.

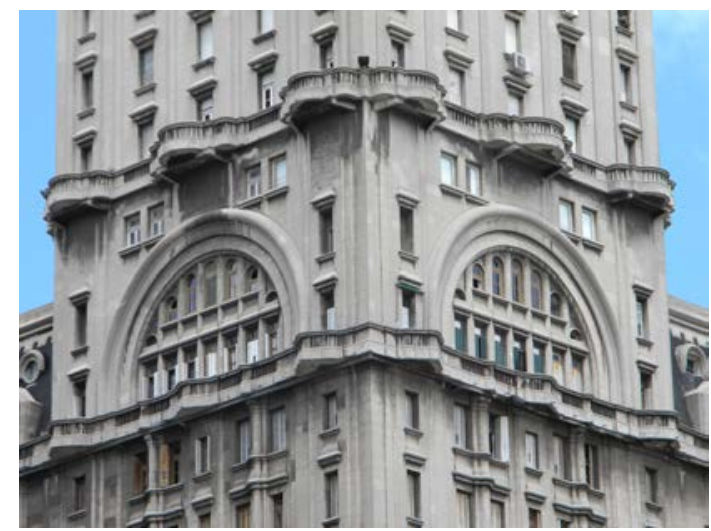

Detalle de la torre, ángulo 18 de Julio y Plaza Independencia. Se puede ver la ausencia de ornamentos. Palacio Salvo. Fotografía ADM

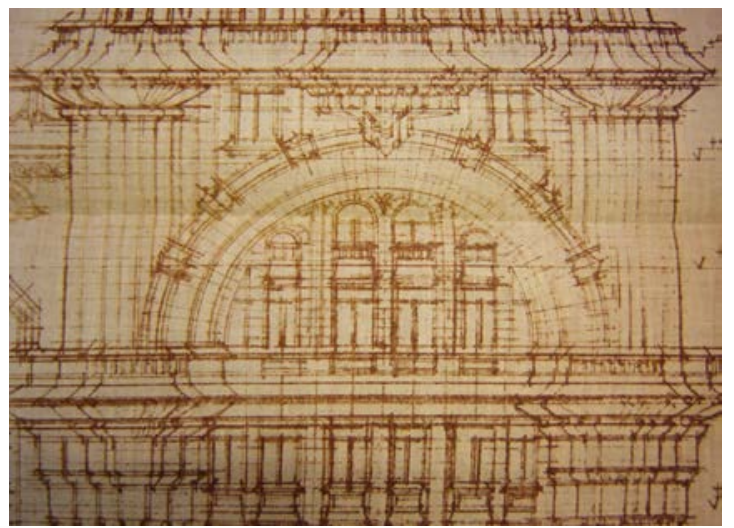

Detalles de uno de los planos originales. Se ven las ventanas termales en el nacimiento de la torre, ángulo 18 de Julio y Plaza Independencia. Palacio Salvo, 1922-28. Mario Palanti. Permiso de Construcción No83.965. Colección de Permisos de Construcción Municipales (1907-1931). IHA

La estructura de los subsuelos está formada por tres hileras de columnas en sentido longitudinal, con una luz de $12,50 \mathrm{~m}$ en los lados y $9.50 \mathrm{~m}$ en la faja del centro. ${ }^{15}$ Transversalmente, la estructura se divide en nueve hileras de columnas y losas cuya luz oscila entre $1,30 \mathrm{~m}$ a $2,78 \mathrm{~m}$. Como apoyos estructurales se suman los núcleos de circulación en el 

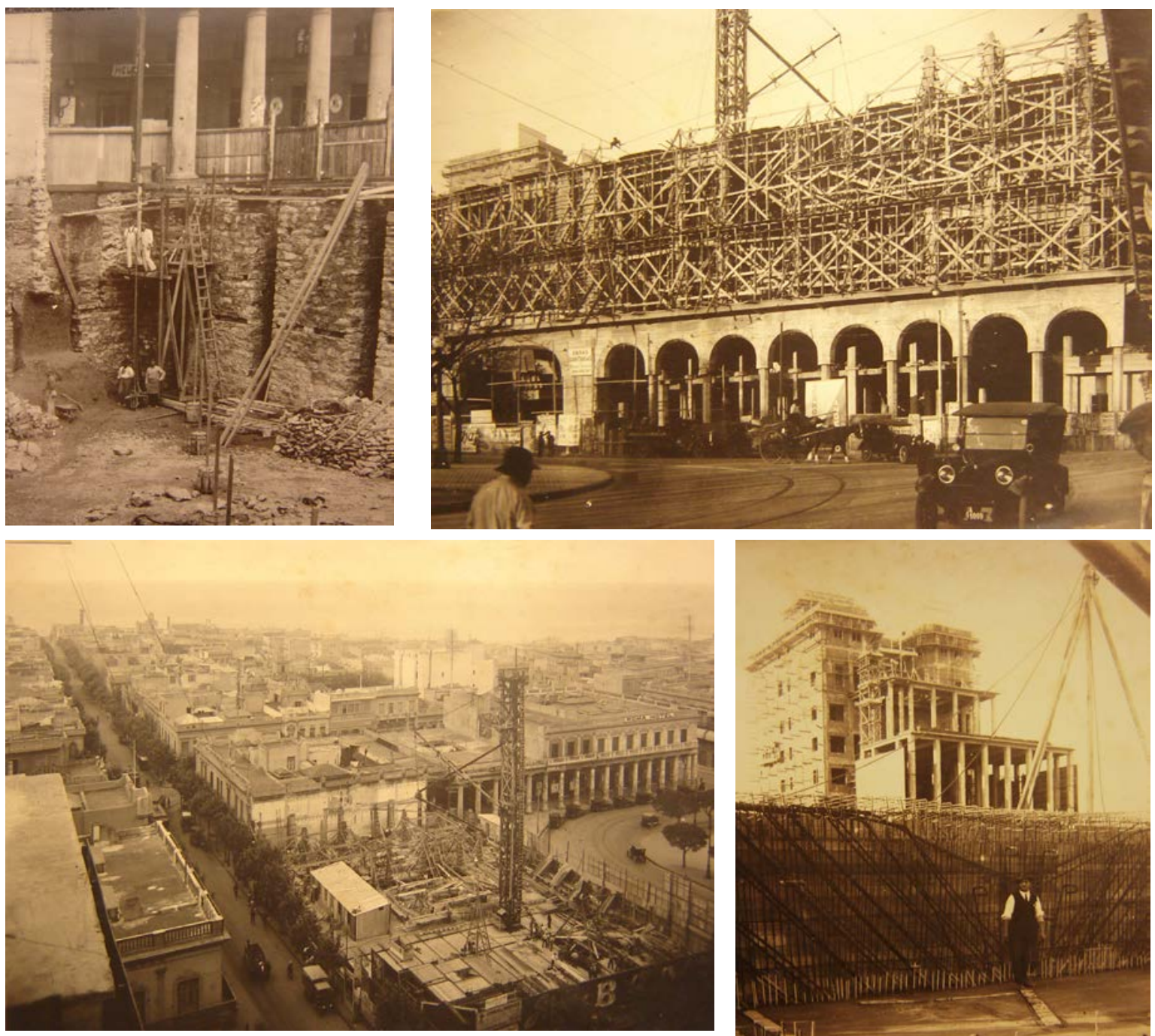

Secuencia de la construcción de la estructura de hormigón armado del Palacio Salvo (1923-1928), Montevideo. Arq. Mario Palanti, Ing. Gori

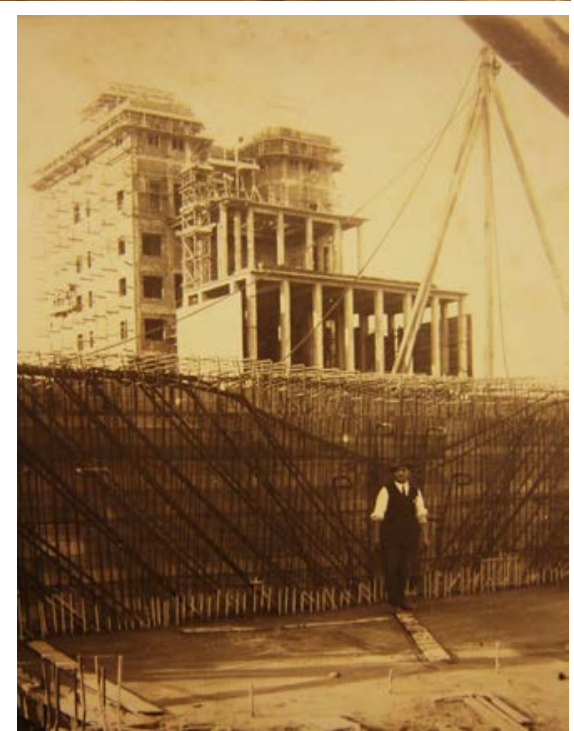

Salvo, Empresa Constructora Dickerhoff \& Widmann. Mario Palanti Papers, GRI. Los Angeles.
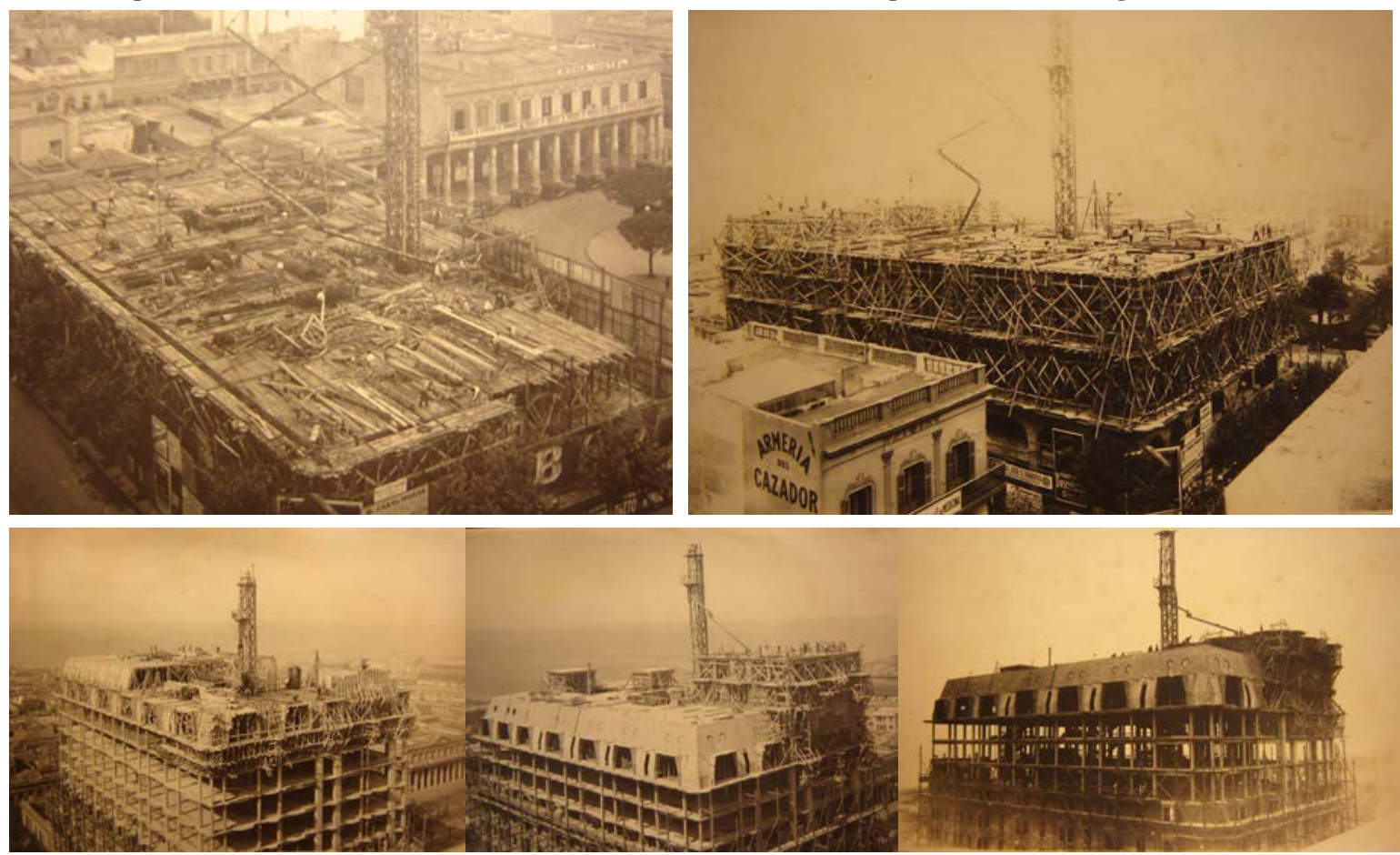

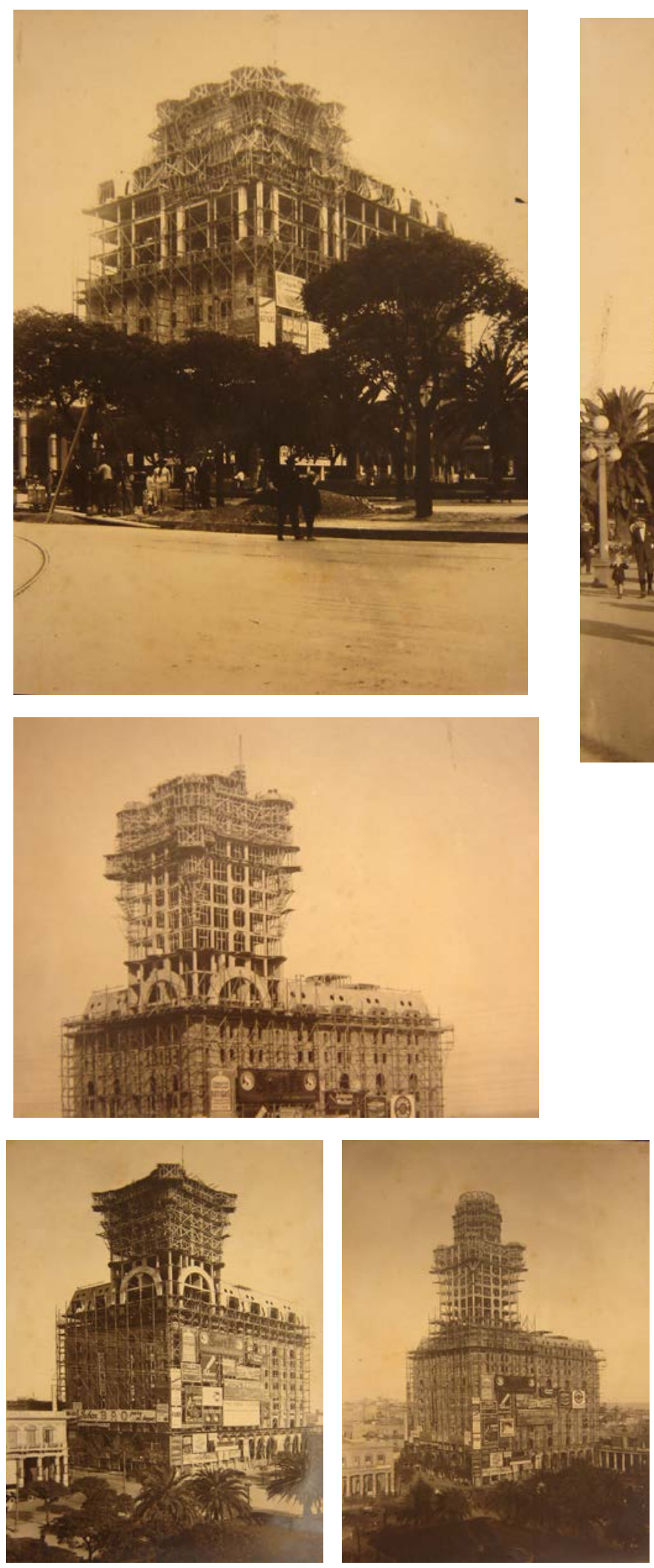

Secuencia de la construcción de la estructura de hormigón armado del Palacio Salvo (1923-1928), Montevideo. Arq. Mario Palanti, Ing. Gori Salvo, Empresa Constructora Dickerhoff \& Widmann. Mario Palanti Papers, GRI. Los Angeles.

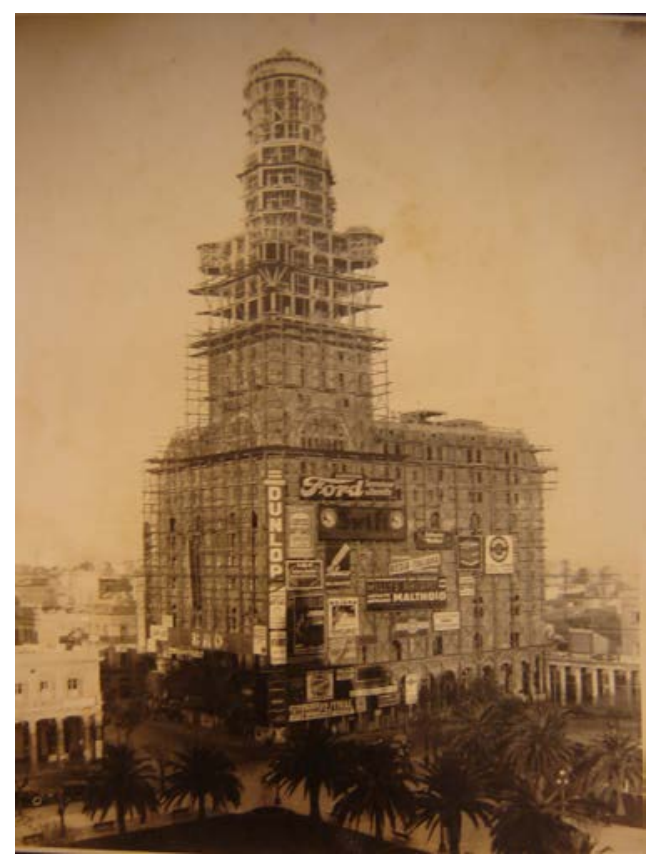


centro del lote. Este sistema se mantiene hasta el primer piso. En el segundo y tercer nivel los apoyos en sentido longitudinal se reducen a siete hileras de columnas dando como resultado plantas libres. Si bien a partir del tercer nivel y hasta el décimo los planos estructurales muestran pequeñas columnas y múltiples apeos correspondientes a las habitaciones, los mismos no son parte de la estructura portante sino de un sistema secundario.

Durante esta etapa de construcción el Salvo fue marquesina de un despliegue de cartelería publicitaria que, colgada y cambiante, operaba como un "montaje escénico" en medio de la ciudad. El esqueleto de hormigón fue cubierto por un "exoesqueleto" hecho de andamios que ya evocaba los signos del consumo de la sociedad montevideana de principios de siglo XX. ${ }^{16}$ Una vez removido el exoesqueleto, el edificio recibió la "vestimenta" exterior que, junto a la boiserie aplicada en los interiores cubrieron la impúdica desnudez del material y desdibujaron, hasta hoy, la esquelética estructura de hormigón armado posible de ser descubierta sólo en los planos.

\section{La continuidad de un método}

Al igual que en el caso porteño, el repertorio estilístico que vemos en el Palacio Salvo es resultado de un proceso proyectual realizado por el arquitecto cuya evolución se ve en obras ya mencionadas como el edificio Roccatagliata, las casas de renta en Av. Rivadavia 2625 y 1916, la vivienda en Ortiz de Ocampo y Costa o el Pasaje Barolo. Los elementos decorativos se alejan del repertorio clásico y se componen por las formas sinuosas de las salientes del edificio y elementos de líneas románicas que acercan la obra a las búsquedas de Richardson o Sullivan: ${ }^{17}$ balcones y salientes sostenidos (visualmente) por ménsulas cortas, pilares compuestos con capiteles naturalistas, columnas adosadas, arcos rebajados (esquina Av. 18 de julio y Plaza Independencia), arcos de herradura (pasiva) y arcos de medio punto con arquivoltas (fachadas).

Aquí el lenguaje cobró un valor especial; el esqueleto de cemento armado es recubierto por la que aparenta ser una densa masa manipulada con plasticidad. En el revoque Palanti no recurre a un simple buñado. Los planos que se conservan en el Getty Research

16 Alonso, Craciun, de Souza y Nisivoccia, 5 narrativas, 5 edificios, Catálogo de la $12^{\circ}$ Mostra Internazionale di Architettura de la Bienale di Venezia. (Montevideo, 2010), 14-54.

17 Wim de Wit, Louis Sullivan: The Function of Ornament (New York: Norton, 1986). 
Institute y en el archivo del Instituto de Historia de la Arquitectura (Farq UdelaR) permiten ver el meticuloso trabajo de estereotomía dibujada que Palanti realiza para cubrir arcos y bóvedas

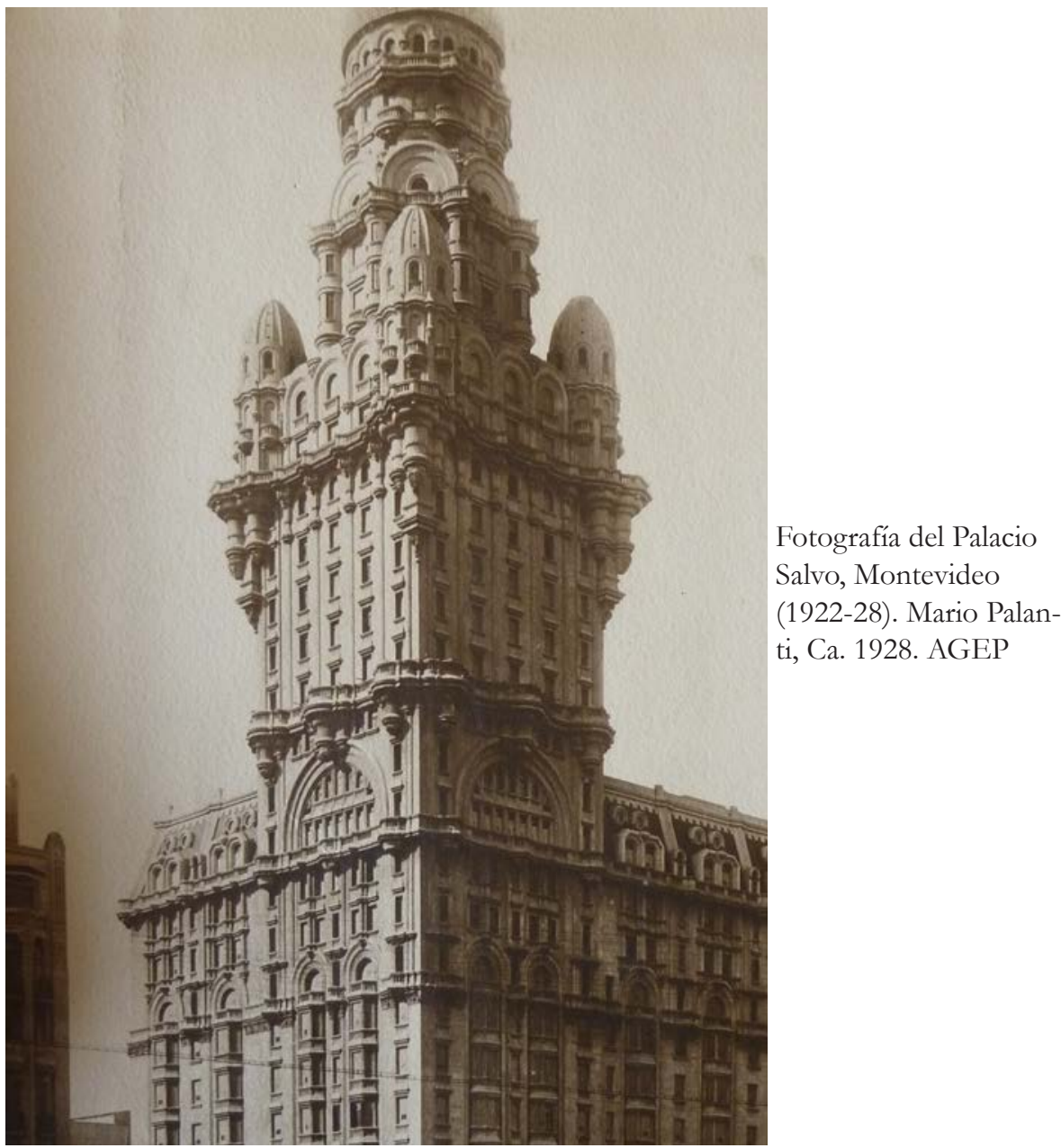

de crucería en el afán de dar carácter a la obra.

En el exterior las tres caras del edificio se arman de manera similar. La fachada principal, sobre Plaza Independencia, se compone en planta baja por ocho arcos de herradura sostenidos por ocho columnas y un gran arco rebajado que apoya sobre los machones en la esquina de Avenida 18 de Julio. Estos elementos están revestidos en granito, mientras que el resto del edificio simula una mampostería de sillares. En el primer nivel un balcón de formas sinuosas y aberturas de medio punto marcan el comienzo de lo que sería el "desarrollo" del edificio. Del segundo al quinto piso la fachada se organiza en seis fajas verticales - dos de las cuales corresponden a la base de la torre- que alternan aberturas de tipo bay-windows (A) -que evocan las empleadas en rascacielos norteamericanos como el Reliance Biulding (1891-95) de Daniel Burnham- con hileras de pequeñas ventanas rectangulares (b) sobre paños de muro ciego (b-A-b-A-b+b-A-b-A-b-A-b-A-b), repitiendo una estrategia ya empleada por Burnham 
y por Sullivan a fines de siglo XIX. La diferencia de funciones en el primero y segundo piso se detecta en la fachada sólo en los paños de muro (b), donde el vano de las ventanas es ciego, y en el tipo de aberturas (A): arcos de medio punto en el primer piso y bay-windows de altura y media en el segundo para cubrir la cota de 5 metros dispuesta en los niveles de funciones públicas. En el Sexto nivel los bay-windows (ya de un nivel de altura correspondiente a las habitaciones de hotel) rematan en balcones apuntados y aberturas formadas por arcos de medio punto y tres arquivoltas, recurso ya utilizado en las casas de renta.

En los dos niveles superiores (séptimo y octavo piso) los arcos se desmaterializan y el número de aberturas crece para revelar vagamente la estructura puntual que se esconde tras la envolvente. Siguiendo el ejemplo de la Escuela de Chicago en el Auditorium, los arcos se transforman en dos aberturas enmarcadas por tres semicolumnas. Estos dan lugar, en el piso nueve, a un balcón corrido con formas sinuosas y ménsulas lobuladas, característicos de la obra de Palanti. El balcón genera una cornisa que corta la verticalidad de la fachada y da continuidad horizontal a la composición para anunciar el despegue de la mansarda y del gran arco de medio punto que utiliza dos niveles de altura para conducir las cargas de la torre a los dos machones esquineros. La fachada sobre calle Andes se arma de manera similar. A excepción de la faja correspondiente a la torre, la fachada sobre la Avenida 18 de Julio se compone por el módulo b-A-b-A-b correspondiente a la torre más un módulo similar b-A-b-A-b. En estas dos fachadas, la Pasiva es remplazada por un sistema de arcos que enmarca las vitrinas de los comercios en planta baja.

Hasta el nivel de la mansarda el edificio parece "calmo". Pero la imagen del Salvo cobra fuerza a partir del piso once. En efecto, si pensamos que el

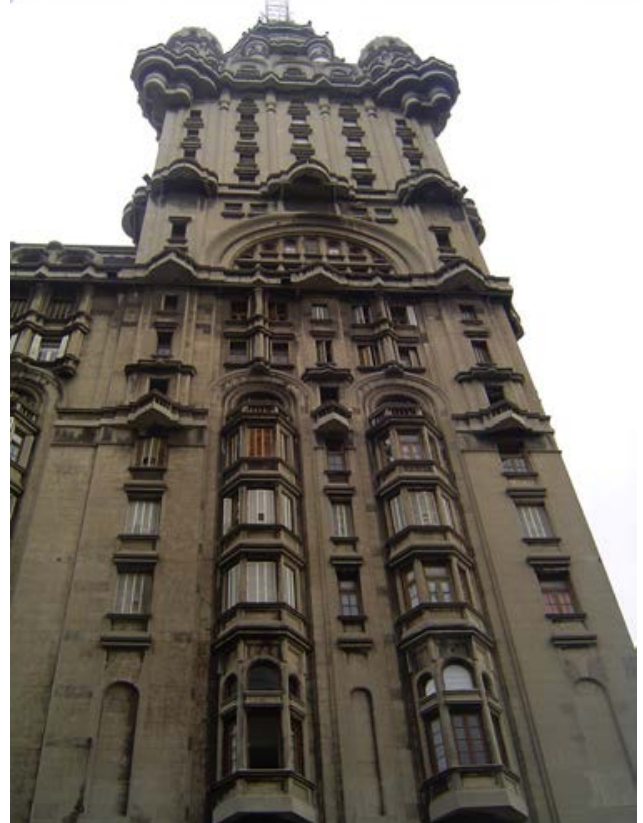

Las formas sinuosas en la torre del palacio. Se puede notar al ausencia de ornamentación en los balcones. Palacio Salvo, 18 de Julio entre plaza Independencia y Andes, 1922-28, Mario Palanti. Foto ADM

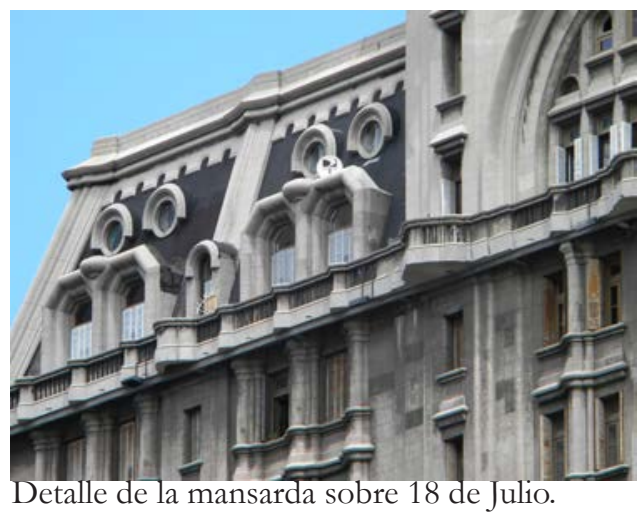

Palacio Salvo, 18 de Julio entre plaza Inde-

pendencia y Andes, 1922-28, Mario Palanti. Fotografía ADM 
carácter del Barolo está dado por el pasaje, el Salvo se debe a sí mismo a la presencia de la torre. A partir del piso once el edificio parece contradecir las pocas leyes que, de acuerdo al crítico Montgomery Schuyler, pretendían dominar formalmente al rascacielos: lejos de la vista del peatón, la ornamentación se multiplica; por su parte, la torre crece en volumen mostrando una perturbadora atectonicidad: la superficie de $289 \mathrm{~m}^{2}$ (17 x 17 metros) en el nivel once pasa a $342 \mathrm{~m}^{2}$ en el piso diecisiete $(18,5 \mathrm{x}$ $18,5 \mathrm{~m}) \cdot{ }^{18}$

En su disposición, entre el piso once y quince, la torre muestra muros lisos y ventanas regulares.

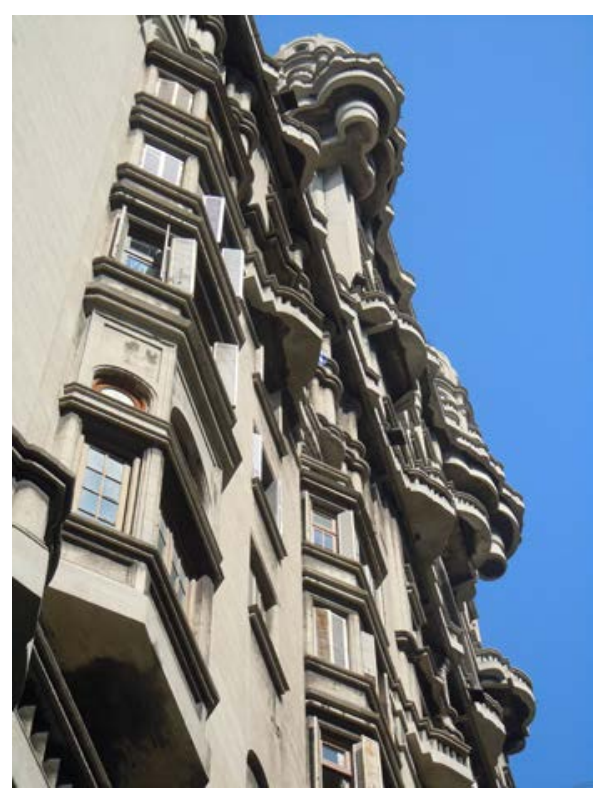

Detalle de Bay windows sobre 18 de Julio. Palacio Salvo, 18 de Julio entre plaza Independencia y Andes, 1922-28, Mario Palanti. Fotografía Fernando Aliata

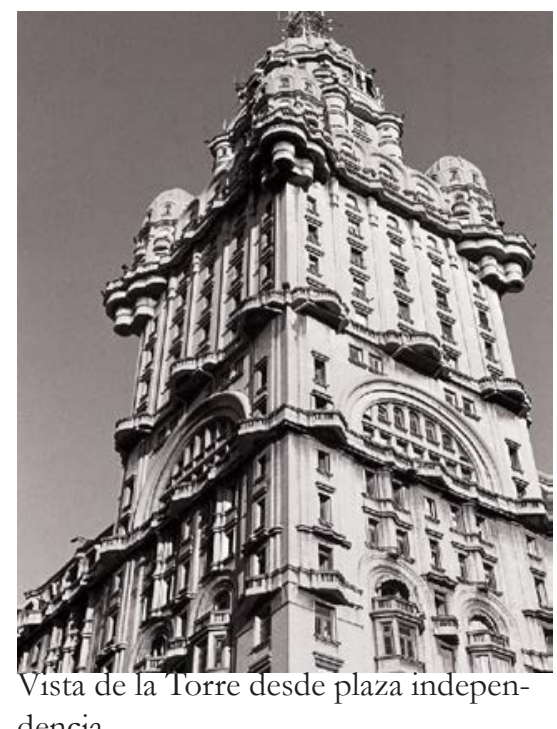

Mario Palanti. Palacio Salvo. Planta de la torre al nivel 11.Mario Palanti Papers, GRI. Los Angeles.

En el piso dieciséis se inicia un juego geométrico a base de círculos, similar al desarrollado en el Pasaje Barolo: las cuatro esquinas de la torre se descomponen en cuatro pequeñas torres de base circular de las cuales se desprenden, como en un ejercicio de escala, balcones formados por círculos menores que comienzan a desdibujar la morfología cuadrada de la torre. Esta forma se mantiene en los dos niveles superiores acompañada en fachada por aberturas y arcos de medio punto. A partir de aquí, nacen las cúpulas de las cuatro pequeñas torres; éstas abandonan la planta cuya geometría de base "cuadrada" se transforma en octogonal manteniendo el juego

18 Véase Schuyler, American Architecture and other writings. 

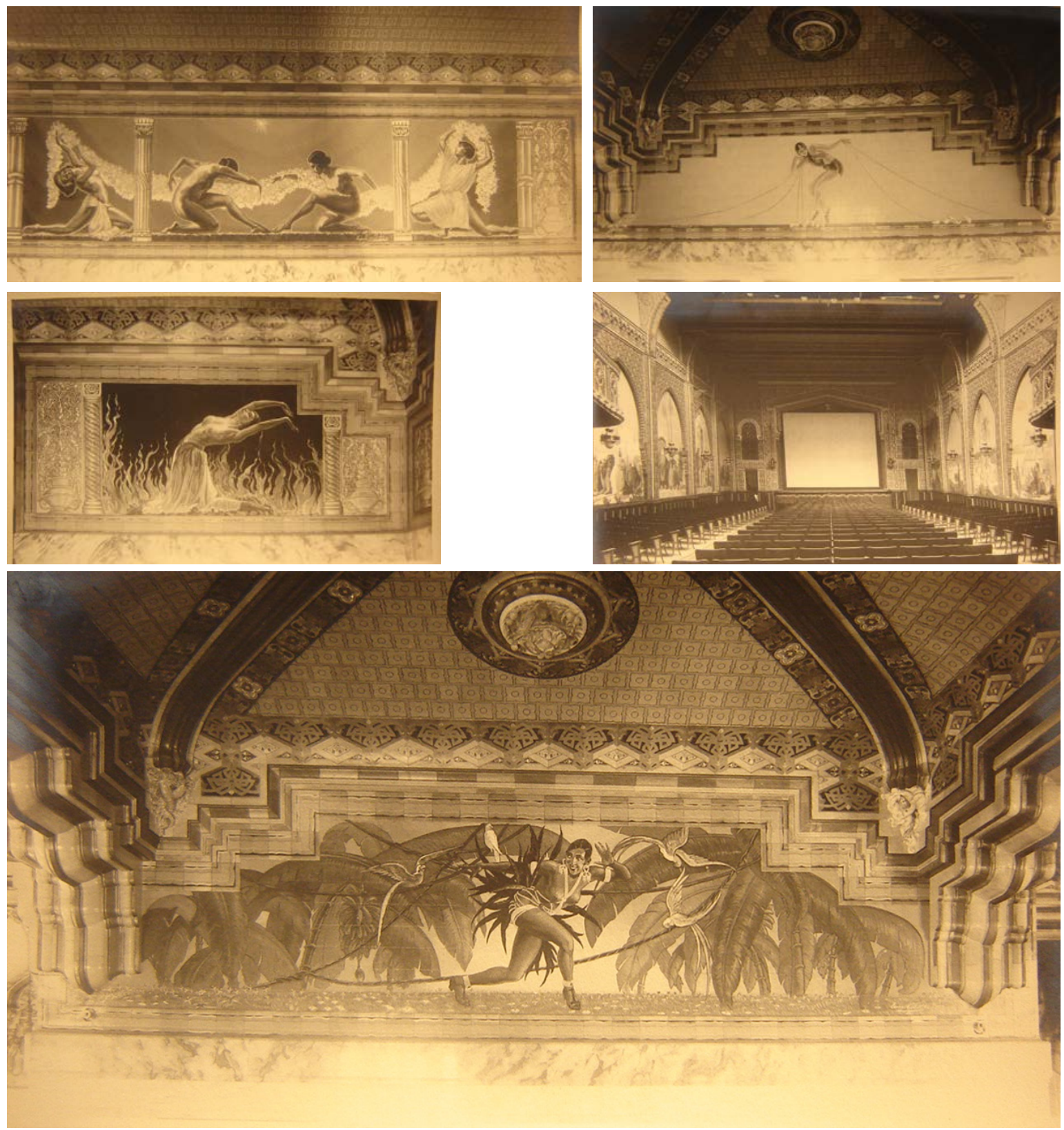

Decoracion en salones y teatro. Mario Palanti Papers, GRI. Los Angeles.

de elementos de base circular en los ángulos. Dos niveles más arriba, el juego se repite a menor escala, y vuelve a repetirse en el anteúltimo nivel. Allí, los arcos de medio punto en fachada acompañan las ocho pequeñas salientes que se despegan del cuerpo central dejando un tambor circular que, finalmente, da lugar a la cúpula con su linterna del siglo XX: el faro. Para el interior del edificio, Palanti realizó lo que podríamos llamar un diseño integral. Los planos detallan, inclusive, el tipo de pinturas que debería ir en cada salón: festivas en los salones de baile, de tipo humorístico para el comedor de niños, etcétera. ${ }^{19}$ Si bien están hoy prácticamente desaparecidas, la colección del Getty Research Institute (GRI) guarda un juego de 52 fotografías que muestran $\overline{19}$ GRI (910002), Mario Palanti Papers, Serie II, Tube 3. 
en detalle las pinturas realizadas por Enrique Albertazzi y que decoraban el primer piso: motivos náuticos antiguos, escenas de la industria portuaria moderna, bailarines exóticos danzando entre humo y llamas o Josephine Baker bailando entre plumas, pájaros y hojas de bananos. Albertazzi fue también el autor del gran vitral que representa la industria y se encuentra detrás de la escalera de honor en el primer piso. Dos de las fotografías muestran el interior del teatro ubicado en el subsuelo (hoy desaparecido) donde las paredes se ven recubiertas con elementos de la arquitectura nazarí que recuerdan diferentes escenas de la vida islámica y al Cine Alcazar de Montevideo (1928) obra de Miguel Angel Gori Salvo -hermano del ingeniero- y Juan M. Muracciole donde también trabajaron Enrique Albertazzi en los panneaux y Miguel Richieri en las esculturas. ${ }^{20}$

La decoración de los solados cambia en cada nivel variando entre tonos ocres, negros y marrones con pájaros y arabescos o tonos rojizos, verdes y crema de la bandera italiana. Estos motivos van acompañados por las iniciales «PS» en el vestíbulo de los diferentes pisos y en el acceso principal como también en los trabajos de herrería.

En la planta baja, las pilastras y columnas, revestidas en granito muestran capiteles en bronce -a los que haremos referencia- que, con minucioso detalle, dejan ver motivos de la flora y fauna de la zona: lagartos, peces, caracoles, erizos, pulpos, pasionarias, uvas, vegetales,

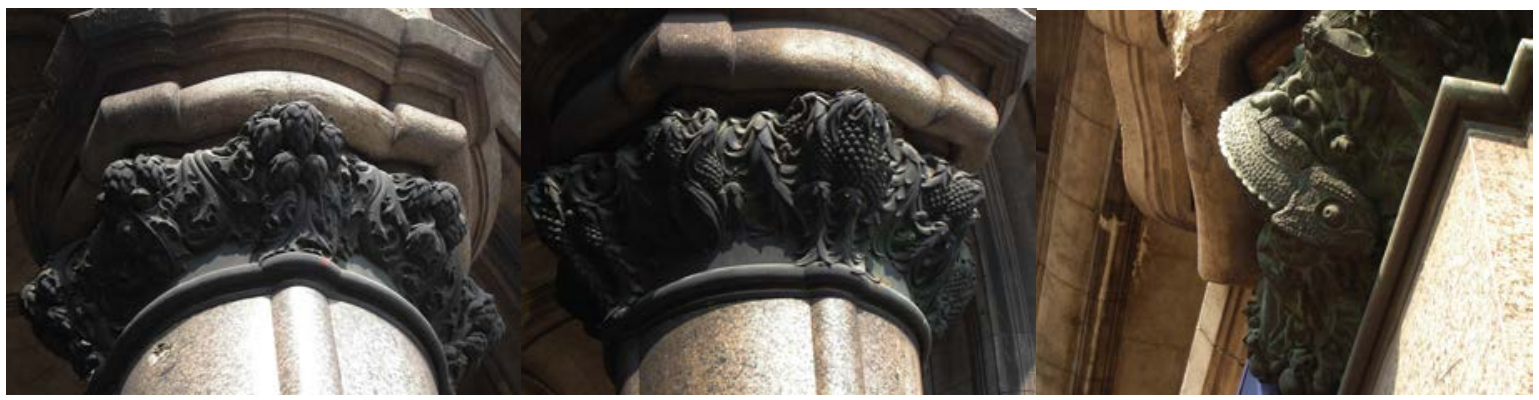

Frutos y follaje. Detalle de capiteles y frisos en bronce. Columnata sobre plaza Independencia. Palacio Salvo, 18 de Julio entre plaza Independencia y Andes, 1922-28, Mario Palanti. Foto Virginia Bonicatto

centenares de motivos diferentes que se agolpan en el despegue del edificio.

Los muros de cada nivel fueron revestidos en boiserie de madera, para la cual Palanti diseñó cada placa indicando su destino en el plano. El detalle alcanza también el diseño de cajas de ascensores, trabajos de herrería, el sistema de ventilación en los zócalos de las vidrieras,

20 GRI (910002), Mario Palanti Papers, folder 13. Véase Osvaldo Saratsola, Función completa, por favor: un siglo de cine en Montevideo (Montevideo: Ediciones Trilce, 2005), 139-140. 


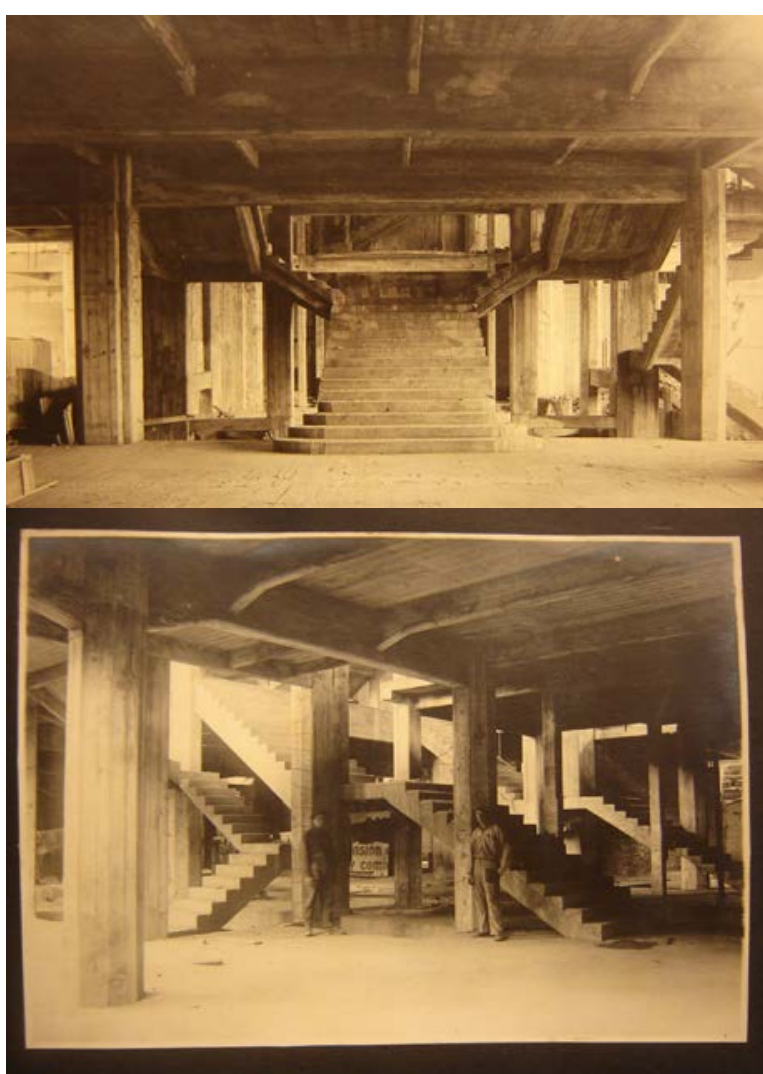

Mario Palanti.Palacio Salvo. Detalle de escalera principal en hormigon armado. Mario Palanti Papers, GRI. Los Angeles

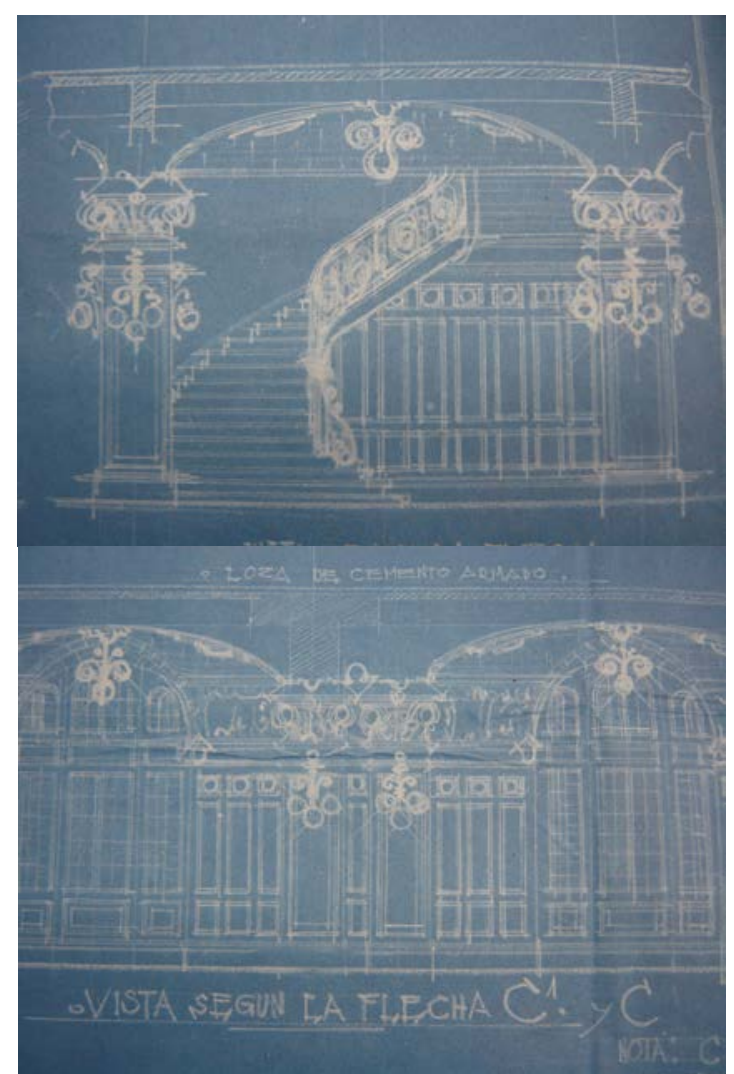

Mario Palanti.Palacio Salvo. Detalle de revestimientos y decoracion interior. Se puede ver claramente la estructura de cemento armado. Mario Palanti Papers, GRI. Los Angeles

las proyecciones de los cielorrasos, el mobiliario de las habitaciones, los artefactos eléctricos, etcétera. Los planos dejan ver cómo las losas de hormigón del cielorraso son cubiertas por el sistema de placas de encastre diseñado por Palanti y las columnas y escaleras revestidas en maderas o mármoles, dependiendo del carácter requerido. ${ }^{21}$

La colección de planos conservada en el GRI nos permite indagar en el proceso de diseño de varios detalles ornamentales. Entre ellos, los planos en ferroprusiato con fecha del 30 de septiembre de 1925 muestran el relevamiento en escala 1:5 del pilar del ángulo de 18 de Julio y Plaza Independencia y sugieren una nueva hipótesis sobre el origen de los motivos decorativos en bronce de los capiteles. ${ }^{22}$ Los dibujos exponen en detalle las impostas, apoyos y nervaduras de los grandes arcos sobre Plaza Independencia. ${ }^{23}$

El corte en planta deja ver el corazón estructural del pilar en cemento armado, la capa de $15 \mathrm{~cm}$ de granito que lo recubre y los $35 \mathrm{~cm}$ de vuelo de la cornisa de los cuales 22 cm corresponden a los típicos motivos palantianos formados por ondulantes y puntiagudas

21 GRI (910002), Mario Palanti Papers, serie II, Tubes 4, 5 y 6.

22 GRI (910002), Mario Palanti Papers, serie II Tube 7.

23 GRI (910002), Mario Palanti Papers (GRI Tube 6. 

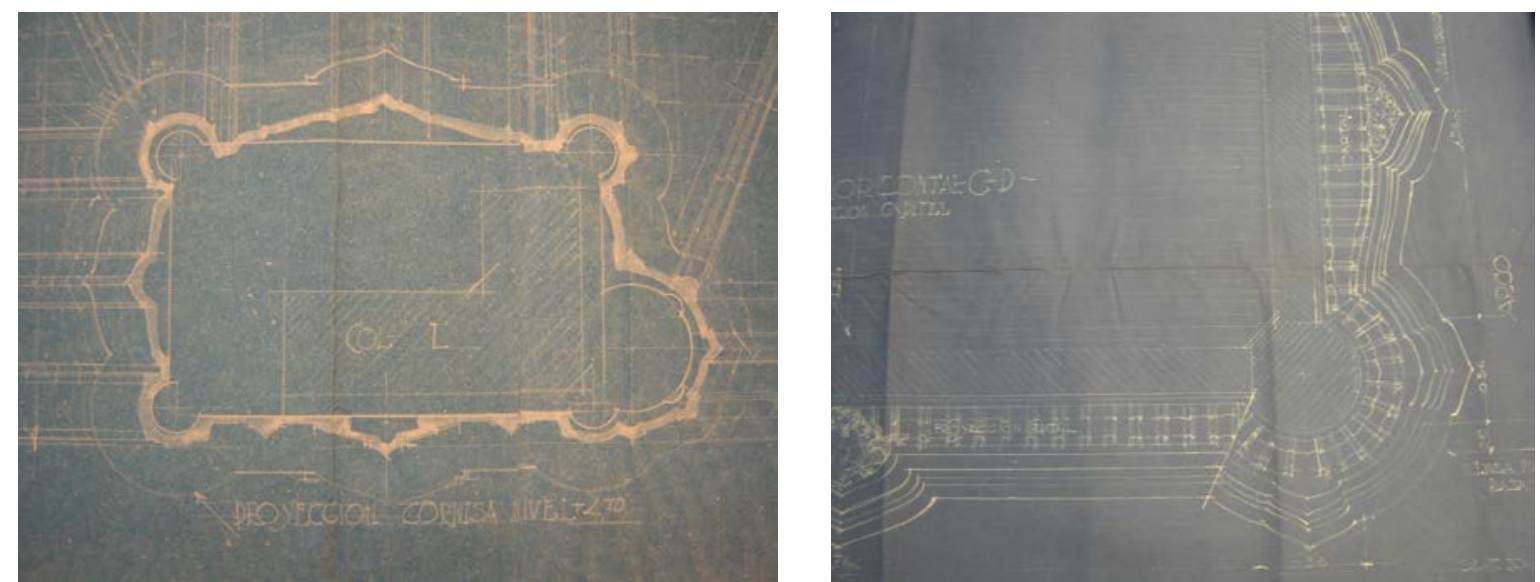

Detalle de pilar en esquina de 18 de Julio y Plaza Independencia. Mario Palanti Papers, GRI. Los Angeles.

salientes al estilo gótico.

La única referencia a la decoración que figura en el plano es un grupo decorativo central compuesto por lo que aparentan ser hojas que, con cierta torpeza en su trazado, difieren notablemente de otros diseños de Palanti. Otros motivos menores muestran dentículos y sinuosas formas naturales que se asemejan a los capiteles del Pasaje Barolo, a los de la casa de renta en Libertad 145 o, inclusive, a los diseños de la casa en Rivadavia 2526, en Buenos Aires.

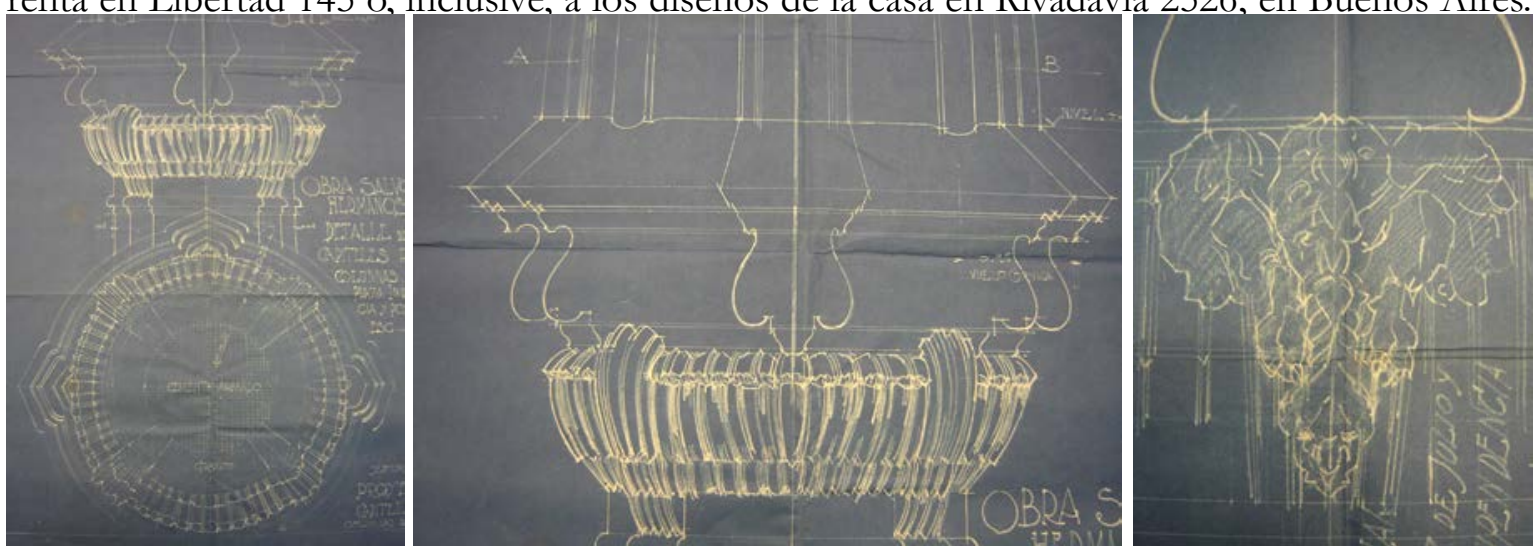

Detalle de capiteles de las columnas sobre Plaza Independencia. Mario Palanti Papers, GRI. Los Angeles.

La situación se repite en el replanteo de las columnas del pórtico sobre Plaza Independencia y en las pilastras del pasaje y el hall. ${ }^{24} \mathrm{El}$ detalle del dibujo se desvanece en el sector del capitel donde en los planos una nota aclara: "para los capiteles ver detalle al natural". ${ }^{25}$

Si se tiene en cuenta el detalle en el diseño para los trabajos de herrería, trabajos en madera, mosaicos y solados o los veintiocho modelos diferentes de artefactos de luz diseñados para el palacio, llama la atención que, entre las noventa y nueve fotografías y los doscientos

24 GRI (910002), Mario Palanti Papers, serieI, folder 10 y serie II, Tube 8. fecha 30-9-25.

25 Los Angeles, Getty Research Institute (910002), Mario Palanti Papers, serie II Tube 7. 


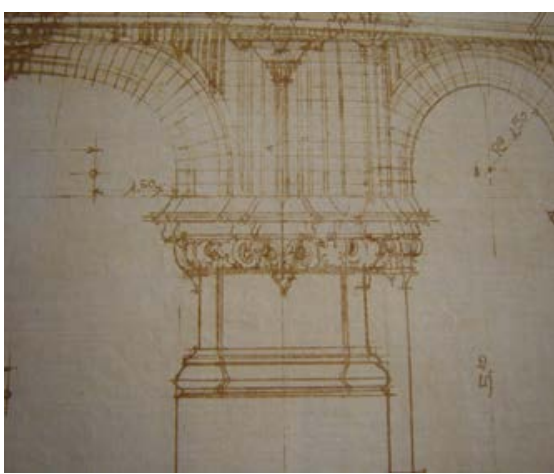

Detalle de capiteles de las columnas sobre Plaza Independencia. Mario Palanti Papers, GRI. Los Angeles.

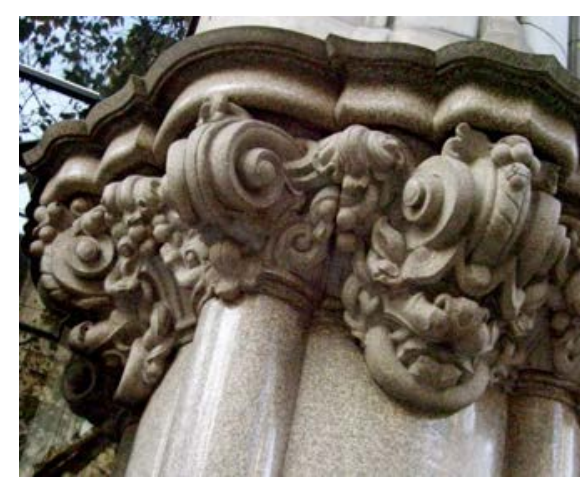

Capitel del Pilar de entrada, Palacio Barolo,

Mario Palanti Papers, GRI. Los Angeles.

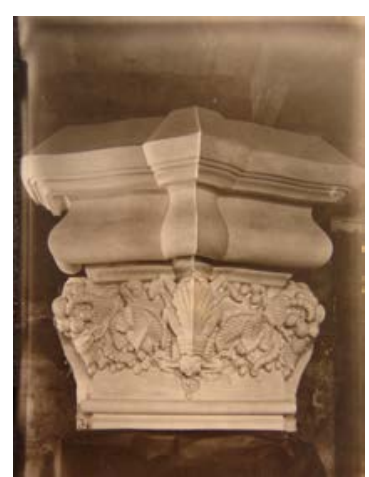

Molde en yeso. Capitel sobre Plaza Independencia.Mario Palanti Papers,

GRI. Los Angeles.

planos en ferroprusiato pertenecientes a la colección del Getty Rersearch Institute, sólo dos fotografías muestren la versión en yeso de los capiteles del Palacio Salvo tal como hoy los conocemos: una de ellas pertenece a una de las pilastras sobre 18 de Julio y la otra a una de las columnas sobre Plaza Independencia. En el Archivo General de la Nación de Montevideo (AGN) una carta hace referencia a los capiteles: el 31 de agosto de 1928, poco después de la inauguración no oficial del edificio, la firma Salvo Hnos. expidió el siguiente documento:

Certificamos por la presente que el portador Señor Luis Lippi trabajó en nuestro Palacio de encargado de los trabajos en la fundición bronce es decir todos los capiteles de este Palacio son hechos bajo la dirección del Señor L. Lippi habiendo trabajado por nuestra cuenta durante tres años, cumpliendo con las diligencias (...) A nuestra entera satisfacción expedímosle este para su gobierno (sic), por Salvo Hnos. ${ }^{26}$

De acuerdo a Eduardo Luciani, allegado a Luigi Lippi, ${ }^{27}$ los diseños para los capiteles del Palacio Salvo fueron encargados a un escultor milanés quien envió a Montevideo los modelos en yeso: Lippi fue quien estuvo a cargo de la dirección de los trabajos de fundición que llevaron al bronce dichos modelos, tarea que se realizó en los subsuelos del mismo Palacio. ${ }^{28}$

26 AGN, Archivo del Palacio Salvo, Caja 265, carpeta 10.

27 Experimentado fundidor de bronce, Luis (Luigi) Lippi era hijo de Pietro Lippi, dueño de la "Fonderia Pietro Lippi" en Pistoia, Italia, y hermano de Andrea Lippi quien también desarrolló una corta y prolífica carrera en fundición y escultura.

28 Entrevista a Acevedo Lippi, nieto de Luis Lippi, Montevideo 25 de octubre de 2014. Además de ello, la libreta de notas correspondiente a la Compañía de Créditos y Obras Públicas que se conserva en el AGN señala como escultor a Federico Ballesteros, Julio Valle Bornacelli y Miguel Richieri entre 1925 y 1927. Agradezco a William Rey esta información. (AGN Montevideo, Libreta 220, Palacio Salvo, Compañia de Créditos y Obras Públicas) 
Si se comparan los bronces del Palacio Salvo con los únicos bocetos de capiteles diseñados por Palanti la diferencia se hace evidente. La ausencia de detalles de mano de Palanti en lo referente a los capiteles, la decisión de resolverlos "al natural" y la carta a Luis Lippi que se conserva en el AGN de Montevideo llevan a poner en duda la autoría de Palanti en el diseño final de los bronces.

En primer lugar, durante la construcción del Palacio Salvo, Palanti estaba radicado en Buenos Aires -tal como lo indica la fecha de los planos y los recibos de honorarios- y viajaba a Montevideo de manera esporádica. La dirección técnica del Palacio Salvo caía principalmente en manos del ingeniero Gori Salvo y del ingeniero Hartchou representante de la firma alemana Dickerhoff \& Widmann radicada Buenos Aires y con sede en Montevideo. Tal situación convertía al Salvo en un edificio que se construía en papel en una orilla al tiempo que se levantaba materialmente en la otra.

En segundo lugar, la etapa 1922-1928, durante la cual se construyó el Palacio, fue una de las más productivas en la vida de Palanti: durante este período realizó obras como la concesionaria Fevre y Basset o el Hotel Castelar. En 1923, Palanti comenzó la refacción, ampliación y dirección técnica de la Nunciatura Apostólica en Buenos Aires, trabajo que -como ya vimos en el capítulo dos- realizaría gratuitamente con el propósito de acercarse al Vaticano. ${ }^{29}$ Entre 1924 y 1926, Palanti viajó dos veces a Italia. Además de acercarse al Vaticano su interés estaba centrado en tocar las más altas esferas del fascismo a través del proyecto para L'Eternale Mole Littoria, un rascacielos polifuncional de 350 metros de altura que, deudor del Barolo y del Salvo, era propuesto por Palanti para albergar las oficinas del Partido Nacional Fascista. La Mole fue presentada a Mussolini en 1924 y en 1926, luego de ser modificada.

Si se presta atención a las fechas, podemos ver que la Mole Littoria fue diseñada y presentada en 1924, las variantes del proyecto realizadas en 1925 y presentadas en Roma en 1926, mismo año en que publica el libro L’Eternale Mole Littoria en Milán. Si consideramos lo dicho, no resulta extraño pensar que el arquitecto estuviera dispuesto a derivar el trabajo de los capiteles del Palacio Salvo y centrar su atención en los nuevos proyectos.

29 Archivio Segreto Vaticano, Archivio Nunziatura Argentina, 99, fasc.510. Mario Palanti, Contrato de Construcción, Nunciatura. 


\title{
5. E1 rascacielos en los medios
}

Desde su inicio, el Palacio Salvo encontró un aliado en la prensa escrita: precisamente, en el diario El Día de Montevideo. Fundado en 1886 por José Batlle y Ordóñez, El Día encontró en el Palacio un dispositivo eficaz para construir la imagen de modernidad y progreso impulsada por el batllismo.

Hacia marzo de 1922, la expectativa por la construcción del edificio comenzó a ser reflejada en el periódico: "Después de esperar tanto, ese sitio, eje de Montevideo, tendrá una construcción digna de las nuevas cosas", aseveraba el diario del 21 marzo de 1922.30 Luego del fallido intento de Marcelino Allende, el emprendimiento inmobiliario de los hermanos Salvo parecía entonces realizable. El 3 de abril, el diario declaraba:

\begin{abstract}
(...) tendremos al fin, después de tantos fracasos, (...) un soberbio edificio, que será por su belleza el punto de atracción de todo el pueblo, como hasta hoy lo ha sido por tradición. Los señores Salvo merecen pues, las mejores palmas. Su nombre sustituirá con toda justicia al que hasta hoy ha servido para designar el edificio de 18 y Andes. ${ }^{31}$
\end{abstract}

La nota de la cual proviene la cita iba acompañada de una foto de los hermanos Salvo como portadores de la piqueta del progreso: con picos y palas en sus manos y parados sobre los escombros de La Giralda.

Como ha sido señalado por Manfredo Tafuri, el papel de los medios de comunicación puede ser trascendental durante el proceso de un emprendimiento edilicio de alto contenido simbólico. Tafuri hace referencia al proceso de proyecto y construcción del Rockefeller Center (Nueva York, 1931) que fue seguido:
(...) por la prensa especializada, por las revistas de actualidad, por los periódicos, como una operación de la que sentirse orgullosos: de esta manera, se reflejan en ella las esperanzas de América en la capacidad de superar la crisis, por parte de un capitalismo emprendedor y preocupado por los destinos de la comunidad. ${ }^{32}$

30 "Por el embellecimiento de la ciudad. La demolición de la Giralda", Diario El Día, Montevideo, 21 de marzo de $1922,5$.

31 "El Palacio Salvo. En el eje de Montevideo se levantará un edificio digno de nuestro progreso", Diario El Día, Montevideo, 3 de abril de 1922, 5.

32 Manfredo Tafuri, “La montaña desencantada. El rascacielos y la ciudad” en Ciucci, Dal Co, Manieri-Elia, 


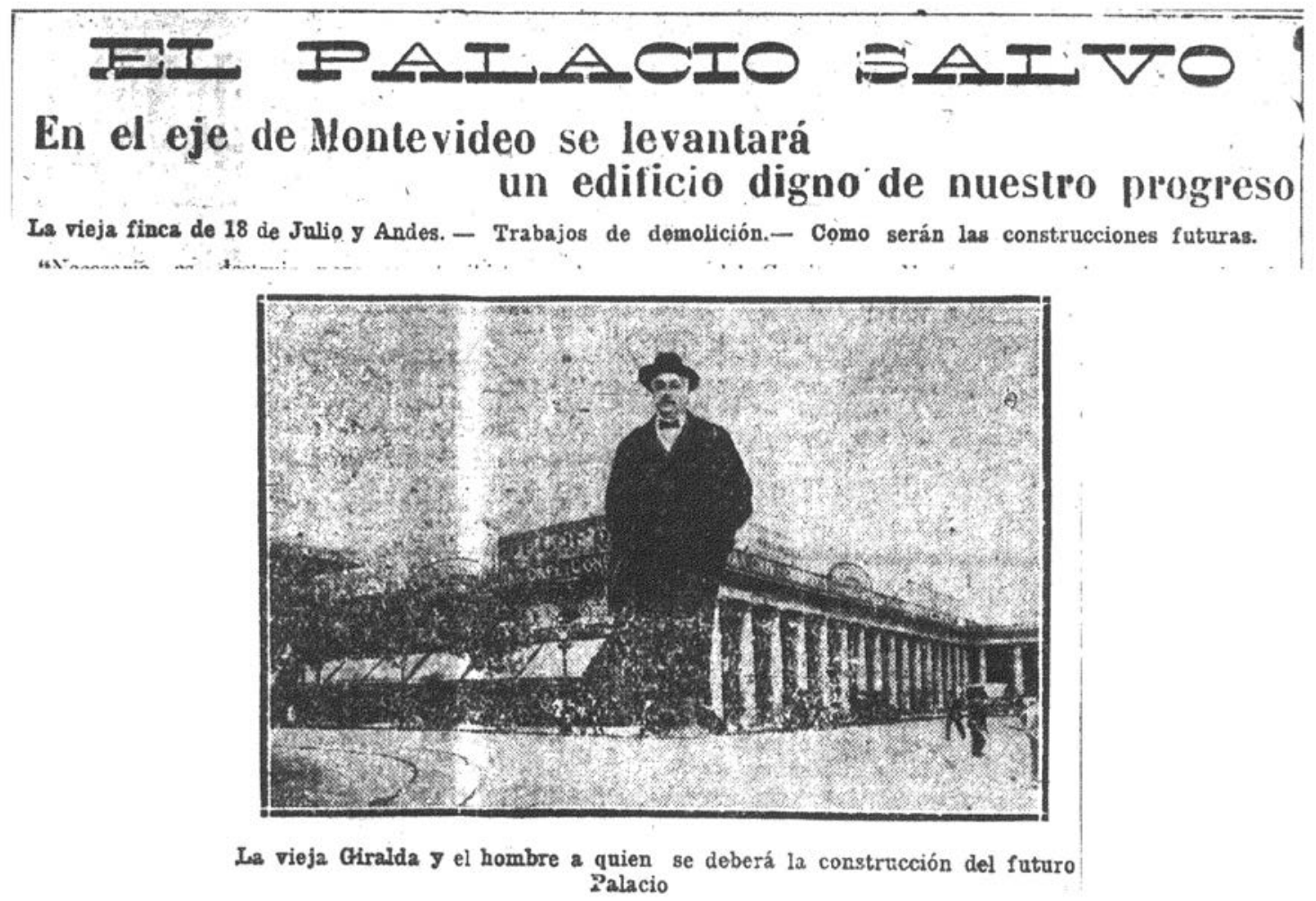

Diario El Día, Montevideo. Marzo de 1922

En el caso del Palacio Salvo, el hecho de presentar periódicamente la evolución de la obra fue determinante en cuanto a la construcción de una imagen de prosperidad asociada al edificio. En marzo de 1922, la revista de actualidad Mundo Uruguayo dejó leer en sus líneas su interés por transmitir la confianza en estos industriales:

Cuando los señores Salvo Hnos. adquirieron el solar (...) las esperanzas populares recibieron un nuevo y poderoso aliento. Los señores Salvo Hnos., emprendedores y progresistas, eran los únicos capaces de sacar partido de aquel solar y de realizar allí la admirable solución de nuestro problema edilicio. Y el pueblo que tiene sus intuiciones providenciales, no se equivocaba al juzgar a estos industriales poderosos e inteligentes, en su actitud realizadora. El palacio se haría, y se haría en forma tal que Montevideo podía sentirse en el futuro orgulloso de su transformación edilicia moderna. $^{33}$

Tafuri, La ciudad americana: de la guerra civil al New Deal (Barcelona: GG, 1973), 480.

33 "Por el embellecimiento de Montevideo", Mundo Uruguayo 201, (Montevideo: 16 de noviembre de 1922) 
La transformación edilicia implicaba la destrucción de construcciones antiguas para dar lugar a nuevos emprendimientos; por lo tanto, el vacío urbano era visto como una oportunidad y cuando la construcción se interponía entre la oportunidad y el negocio, ésta cedía su lugar en nombre del progreso. De manera casi paradójica, el diario El Día del 3 de abril de 1922 relataba a página completa la historia del tradicional café "La Giralda", para luego dar a conocer que el edificio sería "por fin" tirado abajo para dar lugar a la modernidad. La nota explicaba que

\begin{abstract}
(...) cuando la destrucción se hace por quienes sobrada fuerza poseen para realizar obra nueva, algo impone categóricamente el ahorro de vocablos (...). Así lo han dispuesto sus nuevos propietarios, los señores Lorenzo, Ángel y José Salvo, de fuerte arraigo en el ambiente, vinculados a obras nacionales que significan un positivo progreso, quienes han tomado con justo entusiasmo la idea de la nueva construcción, la cual será un elevado exponente de la belleza. ${ }^{34}$
\end{abstract}

El progreso implicaba dejar atrás lo antiguo para materializar aquello que atestiguaba el dominio de las innovaciones tecnológicas y la potencia económica de una nación. La tradición cedía entonces su lugar a la modernidad: "La Giralda" fue víctima de la tabula rasa que intentaba lograr una "ciudad nueva" construida por "hombres nuevos". 35

La inauguración del Palacio Salvo fue signada por la construcción de la historia uruguaya. En 1923 se debatió en el parlamento acerca de la fecha que debía ser considerada como apropiada para la celebración del Centenario de la Independencia del Uruguay. ${ }^{36}$ Se plantearon dos fechas: “el 25 de agosto de 1925 (Declaratoria de la Independencia) -la fecha 'blanca'- y el 18 de julio de 1930, elegida por el batllismo conmemorando la firma de la primera Constitución y la asunción del primer presidente de la República, Fructuoso Rivera". ${ }^{37}$ A las dos primeras propuestas se sumó una tercera: el año de 1928. En este año, Uruguay conquistó su independencia con la Convención Preliminar de Paz entre las Provincias Unidas del Río de la

34 "Por el embellecimiento de Montevideo"

35 Ver "La ideología de la tabula rasa", en Benedetto Gravagnuolo, Historia del urbanismo en Europa, 1750-1960 (Madrid: Akal Arquitectura, 1998), 333-339.

36 Véase Ana María Rodríguez Aycaguer, "La República del compromiso. 1919-1933", AA.VV, Historia del Uruguay en el siglo XX (1890-2005) (Montevideo, Ediciones de la Banda Oriental, 2007): 67.

37 Rodríguez Aycaguer, "La República del compromiso. 1919-1933”, 71. 
Plata y el Imperio de Brasil, y fue este, finalmente el año en que se inauguró el edificio.

La ceremonia inaugural del Palacio Salvo se realizó primero de manera privada y meses después de manera pública. La inauguración privada se llevó a cabo el 18 de julio de 1928, con la presencia de unos pocos invitados y en esta ocasión la atención iba dirigida por entero al edificio.

La inauguración oficial se llevó a cabo el 12 de octubre de 1928 con la celebración de la Primera Exposición de la Industria Nacional. El edificio, que había sido foco de atención durante varios años, se transformaba entonces en escenario para la actividad industrial. Surgía así -de acuerdo a la prensa de la época- un nuevo valor y una nueva oportunidad para la industria uruguaya. Para recibir el evento, la fachada lateral del edificio fue decorada con una instalación eléctrica realizada por la Usina Eléctrica del Estado: se colocó en el exterior una espiral con un sistema de lámparas que prendían y apagaban sobre la Avenida 18 de Julio. ${ }^{38}$ Los stands para exhibición se ubicaron en los pisos públicos del Palacio Salvo lo que permitía a los

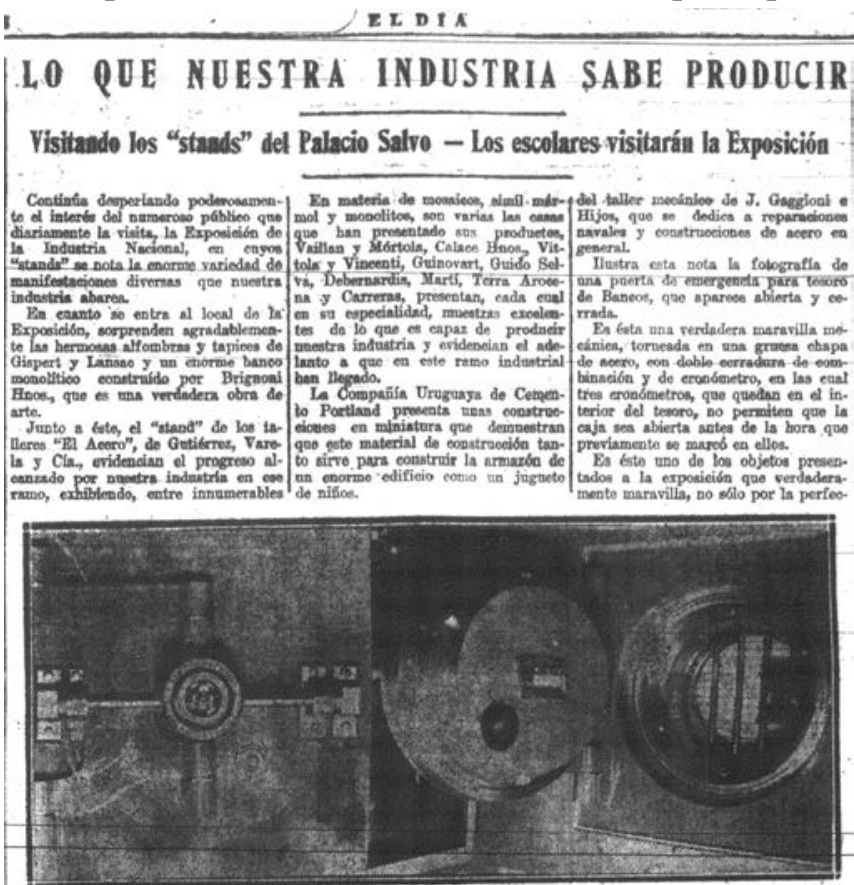

Diario El Día, Montevideo. 22 de octubre de 1928

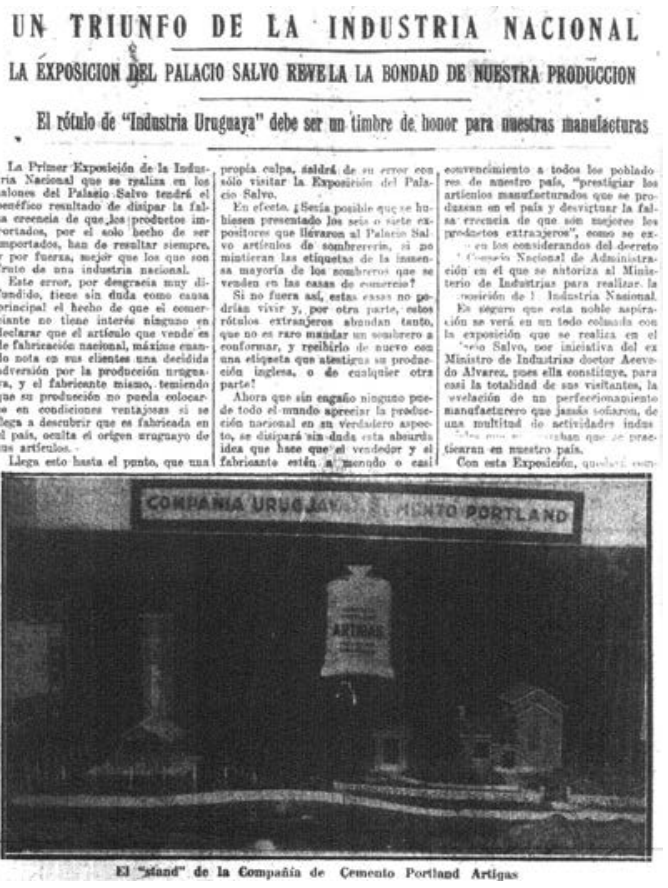

Diario El Día, Montevideo. 17 de octubre de 1928

visitantes recorrer varios niveles y conocer el edificio.

El acto inaugural contó con la presencia de varias familias de renombre, representantes de los poderes públicos y la prensa. Entre ellos, Octavio Morató, vicepresidente

$\overline{38}$ "Se inauguró la primera exposición de la Industria Nacional. El magnífico espectáculo de una era de trabajo y progreso", Diario El Día, Montevideo, 12 de octubre de 1928: 6-7. 
de la Comisión Nacional de la Industria y del Comercio expresó que la exposición "llenaba uno de los fines primordiales de su creación: propender al fomento de la producción nacional como medio de contribuir al enriquecimiento económico de la República (...)” y agregó que “(...) se trataba de una espléndida demostración de las industrias nacionales, que se podría catalogar entre los grandes acontecimientos de la historia de nuestros progresos". ${ }^{39}$ Un ejemplo claro de la repercusión que tuvo para la industria la Exposición realizada en el Palacio Salvo, fue que su organizador, José Pedro Rodríguez, quien debía cesar en sus funciones como miembro de la Comisión Nacional de la Industria y el Comercio, continuó en su cargo por decreto del Consejo Nacional de Administración para asistir oficialmente a la Exposición Ibero-Americana de Sevilla, llevada a cabo entre 1929 y 1930 y de la cual participaba el Uruguay. ${ }^{40}$

\section{Una catedral para la industria uruguaya}

En línea con la ideología batllista, el diario El Día se ocupó de seguir día a día los acontecimientos, e intentando construir, a través de sus líneas, una imagen de "vida moderna". ${ }^{41}$ Bajo el título "Primera Exposición de la Industria Nacional", la publicación del 12 de octubre anunciaba con entusiasmo lo que entendía como un "magnífico espectáculo" que concebía como resultado de una era de trabajo y progreso. Los productos exhibidos en los stands y kioscos eran, a criterio del periodista, una evidencia del "enorme esfuerzo industrial que el país ha realizado en los últimos años". ${ }^{42}$ En un fuerte tono nacionalista el periódico declaraba:

\footnotetext{
Nuestro pueblo no ha tenido hasta ahora una idea, siquiera aproximada, del estado industrial del país, de su capacidad y de su energía. Es enorgullecedora, porque nos revela la fuerza nueva en poderosa acción de desenvolvimiento. Es patriótica, porque lleva a nuestro espíritu la confianza en nosotros mismos; nos afirma el optimismo como orientación eficaz y prolífica (..... ${ }^{43}$
}

39 "Se inauguró la primera exposición de la Industria Nacional."

40 Diario Oficial de la república Oriental del Uruguay, 20 de noviembre de 1928. Centro de Documentación, Instituto de Historia de la Arquitectura, Facultad de Arquitectura, Universidad de la República, Montevideo, Uruguay.

41 Peter Frietzche, Berlín 1900, prensa, lectores y vida moderna.

42 "Se inauguró la primera exposición de la Industria Nacional".

43 "Se inauguró la primera exposición de la Industria Nacional". 
Y afirmaba que:

(...) La Primera Exposición de la Industria Nacional que se realiza en los salones del Palacio Salvo tendrá el benéfico resultado de disipar la falsa creencia de que los productos importados, por el solo hecho de ser importados, han de resultar siempre, y por fuerza, mejor que los que son fruto de la industria nacional. ${ }^{44}$

Un día después de inaugurada la Exposición, el diario El Día titulaba una nota como "El triunfo de nuestra industria, 10.000 personas apreciaron ayer la perfección de nuestras manufacturas". ${ }^{45}$ La multitud señalada por el periódico intentaba representar el éxito de la muestra así como el movimiento de masas de una metrópoli. Como señala Peter Fritzsche, parte de los cambios acontecidos en la ciudad de principios del siglo XX se pueden leer en la prensa popular que se ocupaba de "educar" a los lectores como habitantes de una ciudad moderna. ${ }^{46}$

El diario El Día no sólo informaba sobre las "aglomeraciones” que visitaban el Palacio sino que promovía la Exposición con un pormenorizado relato de la puesta en escena. Las notas, publicadas a doble página y por varias semanas, incluían fotografías de los diferentes stands acompañadas por avisos publicitarios relacionados al tema. El periódico explicaba: "Desde ahora, después del triunfo que esta magnífica exposición significa, nuestra industria no se verá más en la situación ridícula de tener que ocultarse vergonzosamente debajo de una etiqueta extranjera (...)". ${ }^{47}$ "Magnifico exponente de la industria uruguaya. Cada stand significa la existencia de una fábrica". ${ }^{48}$ En una descripción entusiasta del panorama, el periódico concentró su atención en la similitud entre los productos nacionales e importados como sinónimo de calidad. Efectivamente, la el público se inclinaba por aquellos de origen extranjero, quedando la producción nacional relegada por la desconfianza. Esta situación había sido advertida por Luis Batlle Berres quien había propuesto la sanción de una ley que obligara a los industriales a poner la etiqueta nacional en sus productos. ${ }^{49}$ Ante tal situación, los comerciantes -señalaba la prensa-

44 "Se inauguró la primera exposición de la Industria Nacional".

45 "El triunfo de nuestra industria.10.000 personas apreciaron ayer el triunfo de nuestras manufacturas" Diario El Día, Montevideo, 13 de octubre de 1928.

46 Peter Frietzche, Berlin 1900, prensa, lectores y vida moderna

47 Peter Frietzche, Berlín 1900, prensa, lectores y vida moderna

48 "Magnifico exponente de la industria uruguaya. Cada stand significa la existencia de una fábrica" Diario El Día, Montevideo, 14 de octubre de 1928.

49 Raúl Jacob, Breve historia de la industria en el Uruguay (Montevideo: Editorial Fondo de Cultura Universitaria, 1981), 85. 
se habían visto "simplemente obligados a engañar al consumidor" diciendo que sus productos eran importados: de origen francés, norteamericano, o inglés, porque así lo demandaban los compradores. ${ }^{50}$ De acuerdo al periódico se esperaba un cambio radical en las preferencias de consumo:

\begin{abstract}
Ahora que la magna exposición del Palacio Salvo brinda a todos la ocasión de saber lo que nuestra industria puede producir es de esperar una lógica reacción, es de esperar que un noble y justo orgullo reemplace la desconfianza con que hasta ahora se ha mirado la manufactura nacional y que todo el pueblo al ver de lo que es capaz nuestra industria, vaya más bien a defenderla que a perjudicarla. ${ }^{51}$
\end{abstract}

A través de sus notas el diario El Día prácticamente aseveraba que se produciría un quiebre en las costumbres de la gente y señalaba a las personas que asistieron a la exposición realizada en el Palacio Salvo como propagandistas convencidos de la excelencia de la producción nacional. ${ }^{52}$ Siguiendo las notas sobre la Exposición se percibía que la industrialización no sólo transmitía optimismo, sino que permitía ampliar los horizontes del mercado.

A cinco días de inaugurada la muestra, el diario El Día del 17 de octubre dejaba leer títulos como: "Un triunfo de la industria nacional. La exposición del Palacio Salvo revela la bondad de nuestra producción". O, por ejemplo: "El rótulo de "Industria Uruguaya" debe ser un timbre de honor para nuestras manufacturas" ${ }^{3}$. Y dos días después señalaba: "Nuestra industria se revela tan perfecta como la de los grandes productos extranjeros". El periódico se ocupó también de enfatizar las características del edificio y el despliegue de los productos

(...) amplios salones admirando la riqueza productiva de nuestro país, la enorme variedad de los artículos expuestos y la perfección de su trabajo. Muchos la inmensa mayoría de los que visitaron la exposición desconocían el grado de perfeccionamiento que han alcanzado nuestras industrias. La infinita variedad de

50 "El triunfo de la industria nacional. La exposición del Salvo revela la bondad de nuestra producción", Diario El Día, Montevideo, 17 de octubre de 1928.

51 "Magnifico exponente de la industria uruguaya".

52 "Magnifico exponente de la industria uruguaya. Cada stand significa la existencia de una fábrica", Diario El Día, Montevideo, 14 de octubre de 1928.

53 "El triunfo de la industria nacional. La exposición del Salvo revela la bondad de nuestra producción", Diario El Día, Montevideo, 17 de octubre de 1928. 
artículos elaborados en el país, perfectos y bien terminados, se acogió con asombro y frases de ponderación..$^{54}$

Como parte de la campaña política del batllismo, el periódico alentó la industria nacional y se presentó como testigo del despliegue realizado en el Palacio Salvo. El diario marcó una diferencia, un "antes y después", donde "antes" se refería a un momento en el que -de acuerdo a la prensa- "se creía que no éramos capaces de nada sino de exportar los productos agrícolas y ganaderos de nuestro suelo, y que debíamos traer del extranjero todo artículo de buena calidad." ${ }_{55}$ Se verificaba entonces, a través del periódico, que el país no debía resignarse solamente a la explotación de la tierra. "Los efectos benéficos de la campaña proteccionista del Batllismo, que defendió siempre a nuestra industria y logró así su actual desarrollo, no aparecían a la luz del día" ${ }^{56}$ La Exposición se llevaba a cabo, precisamente, en una versión material de la campaña proteccionista del batllismo que encontraba una manera eficaz de sacar provecho de los beneficios otorgados a la firma Salvo Hnos. Sin lugar a dudas, sin el relato del diario El Día la repercusión de la Primera Exposición de la Industria albergada en el Palacio Salvo hubiera sido mucho menos "espectacular".

En este marco, el Palacio Salvo puede ser visto como parte del proceso de modernización del Uruguay entre los siglos XIX y XX. Su imagen representa la voluntad del inmigrante llevada a la realidad y el resultado de una política proteccionista volcada al desarrollo de la industria nacional.

El 12 de octubre de 1928, al momento de su inauguración, el Palacio Salvo, con sus 120 metros de altura, se convirtió el rascacielos más alto de Sudamérica y el más alto del mundo en hormigón armado. A pesar de la altura y el sistema constructivo, su particular ornamentación privó a Le Corbusier de ver delante de él un rascacielos en hormigón armado y lo inspiró a llamarlo patisserie italien durante su visita a Montevideo en 1929. Del mismo modo, en sintonía con esta crítica, Werner Hegemann lo llamaría -junto con el Barolo- "monstruosidades superhumanas": "los dos más extravagantes rascacielos construidos por el Arq. italiano Mario

54 “La exposición de la industria nacional. Próxima visita de las escuelas y el asilo de huérfanos", Diario El Día, Montevideo, 19 de octubre de 1928.

55 "Magnifico exponente de la industria uruguaya."

56 "Se inauguró la primera exposición de la Industria Nacional. El magnífico espectáculo de una era de trabajo y progreso", Diario El Día, Montevideo, 12 de octubre de 1928. 
Palanti (...) una de estas fantásticas prominencias parece un gigantesco campanario en el borde de la plaza central de Montevideo." ${ }^{57}$ Más allá de su forma, la torre, como elemento simbólico, podría ser considerada no como un tradicional campanario, sino, en el sentido que señala Tafuri, a la manera de una "catedral de negocios". 58

Ganador de los dos concursos, Palanti buscó, tanto en el Palacio Salvo como en el Pasaje Barolo, conseguir una respuesta a los problemas de la metrópoli moderna conjugando la experimentación técnica, formal y funcional. En efecto, ambos casos muestran cómo el arquitecto formulo una solución al programa del rascacielos metropolitano siguiendo su preocupación por construir lo nuevo.

En este camino, su experiencia, si bien reconsidera las formas históricas, no es ajena al pasado, pero tampoco está en directa continuidad.

Podemos pensar, entonces, a Mario Palanti como un retoño tardío de la generación pos Viollet-le-Duc que, como señala Solá- Morales para el caso de Louis Sullivan, Hendrik Petrus Berlage y Antoni Gaudí, centra su preocupación en cómo sustentar estructuralmente estas grandes moles y al mismo tiempo, cómo disponer de una ornamentación adecuada que acompañe el sentido de ascensión del rascacielos, evitando así la pesada articulación del repertorio clásico ${ }^{59}$.

En efecto, Palanti reconocía las limitaciones del sistema clásico para encontrar una solución al problema formal del rascacielos, evidente en los intentos fallidos de generar una verticalidad grácil y articulada. Entonces, ¿por qué no nutrirse del sentido ascensional del gótico, de la capacidad de exhibir la robustez del románico o de la filigrana decorativa de la arquitectura oriental? La cantera de la historia es la que posee las claves para generar una arquitectura de la modernidad. ${ }^{60}$

$\overline{57}$ Guillot Muñoz, Gervasio y Álvaro, "Le Corbusier en Montevideo", La Cruz del Sur 27 (Montevideo, enerofebrero 1930): 11. Werner Hegemann, "El espíritu de Schinkel en Sudamérica", C.E.D.A. revista del Centro de Estudiantes de Arquitectura, No2 (Montevideo, octubre 1932): 15.

58 Tafuri, "La montaña desencantada. El rascacielos y la ciudad".

59 Solá Morales, Inscripciones

60 Aliata, "La cantera de la historia". 


\section{Capítulo V. Regresos a Italia}

Esos movimientos de masas exigían un nuevo estilo político que transformara a la multitud en una fuerza política coherente, y el nacionalismo, en su utilización de la nueva política, proporcionó un culto y una liturgia que podrían alcanzar ese propósito.

(George Mosse, La nacionalización de las masas, 1975)

Così, come l'intento ideale del monumento che debe testimoniare la grandeza del secolo Fascista, non poteva a meno di far vibrare la mia anima di vecchia data e predisporre tutte le forze dello spirito alla tensione della volontà, per rendermi degno dell'impresa.

(Mario Palanti, Torre Littoria, 1935)

\section{Un rascacielos para el Duce}

El momento de mayor auge de la producción de Palanti en el Río de la Plata coincidió con el ascenso del fascismo al poder. ${ }^{2}$ El 29 de octubre de 1922, guiando miles de escuadristas, Mussolini ingresó a Roma para tomar el poder como líder del partido fascista. ${ }^{3}$ Desde entonces, la Marcha sobre Roma pasaría a ser una pieza fundamental en la mitología fascista como ratificación del poder del Partito Nazionale Fascista (PNF) que había sido iniciado en 1919. A partir de la Marcha sobre Roma y posterior asunción del mando político, el régimen buscó expandir sus intereses e ideología no sólo en Italia sino también en aquellos países con una fuerte presencia de inmigración italiana. ${ }^{4}$ Poco antes de 1923, Mussolini fundó los Fasci italiani

1 Así, como el intento ideal del monumento que debe testimoniar la grandeza del siglo Fascista, no podía menos que hacer vibrar mi alma de vieja data y predisponer todas las fuerzas del espíritu a la tensión de la voluntad, para considerarme digno de la empresa. [Traducción Florencia Minatta]

2 La bibliografía sobre fascismo es sumamente amplia. Sobre el origen del movimiento y su ideología véase: Renzo De Felice, Breve storia del fascismo: con i due saggi "Il problema della identità nazionale" e "Dall'eredità di Adua all'intervento" (Milano: Mondadori, 2001); Zeev Sternhell, Mario Sznajder, Maia Asheri, El nacimiento de la ideología fascista (España: Siglo XXI, 1994); Angelo Tasca, El nacimiento del fascismo, (Barcelona: Ariel, 1983); Robert O. Paxton, Anatomía del fascismo (Barcelona: Península, 2005). Emilio Gentile, The Origins of Fascist Ideology 1918-1925 (New York: Enigma books, 2005); Costa Pinto y Aristotle Kallis, Rethinking fascism and dictatorship in Europe (Palgrave Macmillan, 2014). 3 Emilio Gentile, E fu subito regime. Il fascismo e la marcia su Roma (Roma: Laterza, 2012).

4 David Aliano, Identity in Transatlantic Play: Il Duce's National Project in Argentina, Ph.D. Theses submitted to the Graduate Faculty in History, Doctor in Philosophy, The City University of New York. ProQuest, 2008. 
all'estero que se encargarían de llevar al extranjero la ideología del partido aunque sin interferir en las relaciones internacionales. Ese mismo año, Ottavio Dinale -político fascista y cercano a Mussolini-, fue enviado para fundar el Fascio en Buenos Aires subsidiado por el PNF al igual que Il Littore, el efímero periódico del partido. ${ }^{5}$ En medio de debates internos, los Fasci locales (ocho hacia 1924) encontraron gran oposición no sólo en anarquistas y socialistas sino también en la masonería. Además de ello, como señala Davide Aliano, a diferencia de otros países como Perú o México, la comunidad italiana en la Argentina mantenía una red de asociaciones ya consolidada y organizada en la que a los Fasci les fue difícil penetrar. ${ }^{6}$ Hacia 1925 el fascio inicial lograría cierta estabilidad bajo la presidencia del industrial Vittorio Valdani -presidente del Circolo Italiano y directivo de la Compañía General de Fosforos- quien renunció en 1928 y fundó el periódico fascista Il matino d'Italia.?

Interesado en el PNF, en 1924 Palanti se inscribió en el Fasci italiani all'estero. Allí conoció a Dinale a quien pidió que entregara al Duce una copia de su primer libro a modo de obsequio y que escribiera la introducción a su último libro Quatro anni di lavoro que, al igual que los volúmenes siguientes, estaba dirigido a una audiencia italiana y fascista. ${ }^{8}$

Entusiasmado por la nueva realidad política de su patria, en 1923, Palanti había realizado los primeros bocetos para L'Eternale Mole Littoria, un proyecto de iniciativa personal que era a su vez un golpe propagandístico unido a sus deseos de retornar a Italia de una manera triunfal presentándose como el arquitecto de la nueva revolución fascista.

Después de las experiencias de los rascacielos-símbolo de Buenos Aires y Montevideo, Roma-suponía el arquitecto- podía tener su obra representativa de un estilo nuevo. Conformando una trilogía con San Pedro — símbolo del Catolicismo— y el monumento a Vittorio Emannuele —emblema del "Risorgimento"-, en su tipología de rascacielos la Mole Littoria debía ser la imagen material del fascismo, leit motiv cultural del régimen. ${ }^{9}$ Sin alejarse de la tradición histórica, su arquitectura, reinterpretaba sus elementos para adaptarlos a las nuevas tecnologías de servicios, al hormigón armado y a los programas institucionales masivos.

En agosto de 1923, Palanti realizó varios bocetos que fueron expuestos en septiembre

5 Aliano, Identity in Transatlantic Play. 94

6 Aliano, Identity in Transatlantic Play, 95

7 Hernán M. Capizzano, Presencia fascista en Argentina. Relatos y apuntes 1930-1945 (Buenos Aires: Memoria y Archivo, 2013). Véase el capítulo V, “Todos los caminos conducen a Roma: Vittorio Valdani”, pp.45-53. Devoto, Historia de los Italianos en Argentina, 347.

8 Dietrich Neumann, “A skyscraper for Mussolini”, A A Files 68 (Spring 2014).

9 Palanti, L'Eternale Mole Littoria. 


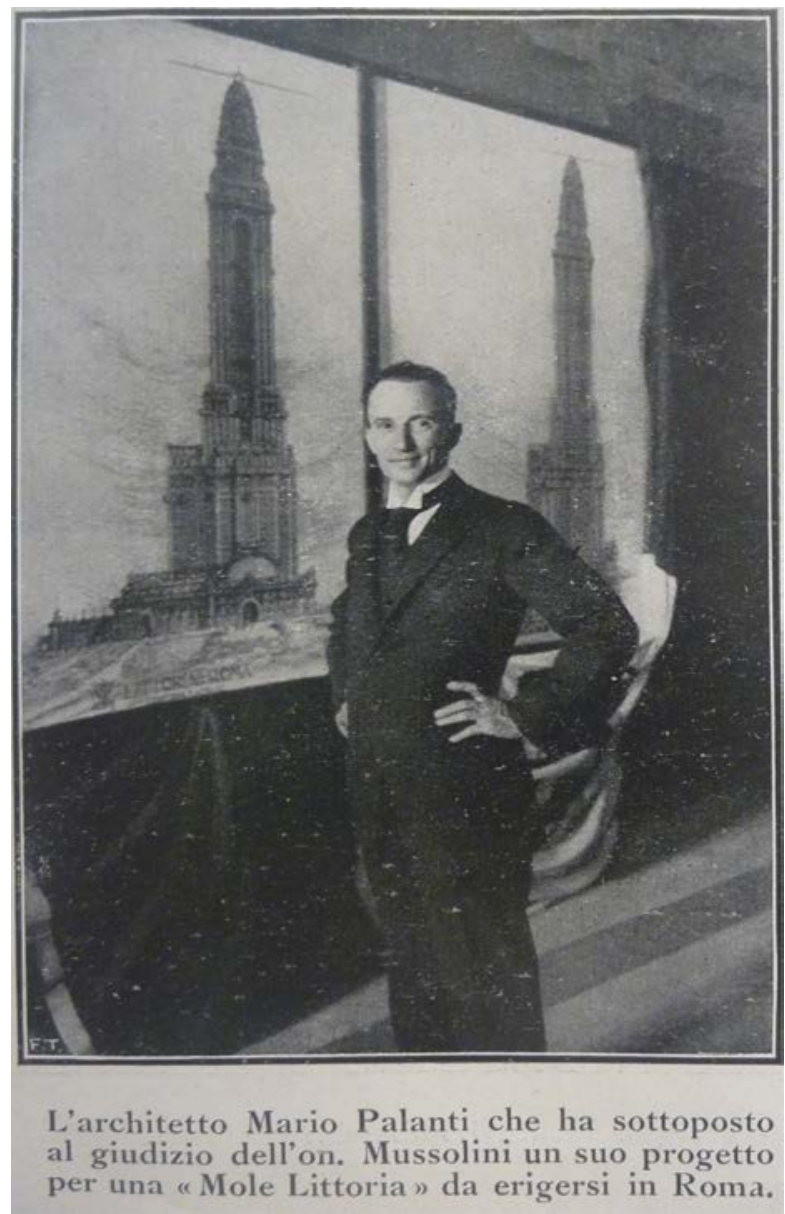

Fotografía de Mario Palanti durante la presentación de La Mole Littoria, Roma publicada en

L'Illustrazione Italiana, 26 octubre 1924, $\mathrm{n}^{\circ} 43$.

de 1924, en Roma en la Biblioteca del Palazzo Chigi con la ayuda de Dinale. ${ }^{10}$ El Duce visitó la muestra y se mostró entusiasmado por el rascacielos dedicándole una frase alentadora: "Per la Mole Littoria, Alala". ${ }^{11}$ Si bien, como señalamos en el capítulo anterior, varios monumentos conmemorativos fueron planteados durante la primera posguerra, la propuesta de Palanti fue en todo novedosa: el proyecto proponía ubicar en la que hasta entonces era considerada la "porca Roma" ${ }^{12}$ un gran rascacielos dedicado a representar el "fascismo, la renovación del espíritu y la reconstrucción de la patria”. ${ }^{13}$ Efectivamente, en 1922, con la marcha sobre Roma, Mussolini aceptaba la ciudad como cabecera del "imperio" fascista. El proyecto de Palanti se plantea sagazmente en esta coyuntura adelantándose a la Mole Littoria de Marcello Piacentini (1925) de no más de seis niveles y propuesta para la zona detrás de Roma Termini o al megalómano “modelo della Mole Littoria, più grande di S. Pietro" de Armando Brasini (1937). ${ }^{14}$

10 Palanti, L'Eternale Mole Littoria, 29. Neumann, "A skyscraper for Mussolini”: 4.

11 Palanti, L'Eternale Mole Littoria.

12 Emilio Gentile, El culto del littorio. La sacralizacion de la politica en la Italia fascista (Buenos Aires: Siglo XXI, 2010); Aristotle Kallis, The Third Rome, 1922-43: The Making of the Fascist Capital Palgrave Macmillan, 2014). Particularmente el capítulo 1, "The Fascist Conquest of Rome".

13 Palanti, L'Eternale Mole Littoria,32.

14 Antonio Nezi, "Artisti contemporanei Accademici d'Italia. Marcello Piacentini”, en Emporium Vol. LXXI, N 422: 89. Armando Brasini, "Modello della Mole Littoria, più grande di S. Pietro". ACS, Segret. Part. Duce, Cart. 
Como señala el

minucioso e innovador estudio realizadoporDietrich Neumann, el impacto que la propuesta tuvo en la prensa internacional y el debate que esta iniciativa generó tuvo como resultado una serie de intervenciones urbanas y arquitectónicas que dieron lugar a la Roma Mussolineana. Entre otros, Neumann señala la correspondencia entre Cass Gilbert y Mussolini en la que el arquitecto norteamericano intenta disuadir al Duce de realizar un rascacielos en el centro histórico de Roma y le sugiere, en cambio, que considere algún tipo de intervención como, por ejemplo, el completamiento de la vía hacia San Pedro desde el puente Sant'Angelo. ${ }^{15}$

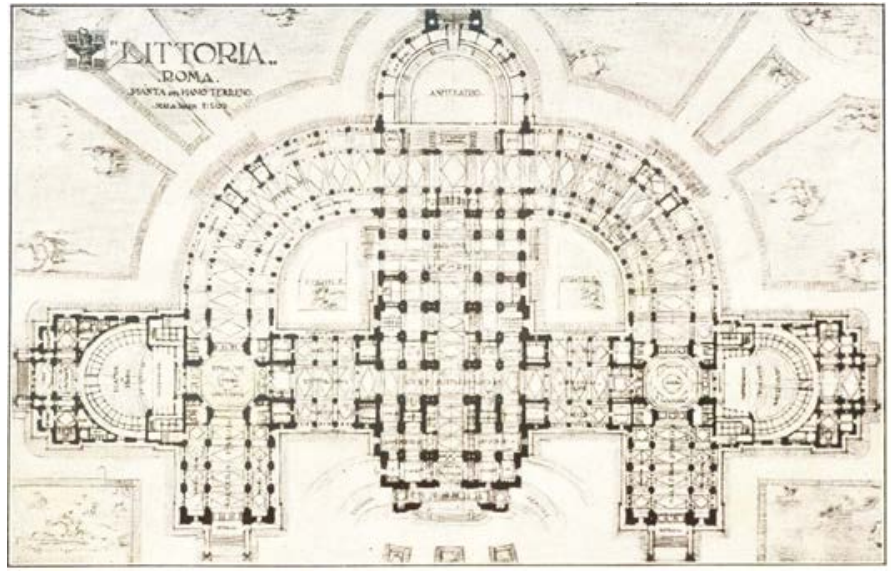

Planta de la Mole Littoria. Primera versión con una altura de 350 metros. Proyecto. Roma, 1924. Mario Palanti. L’Eternale Mole Littoria,Milán. Rizzoli \& C.1926

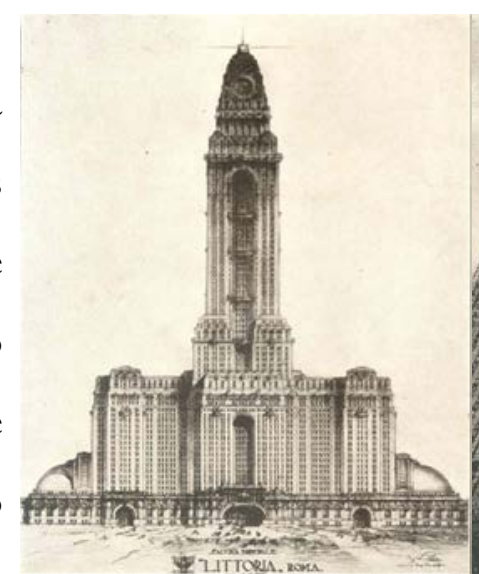

Dibujo de la Mole Littoria. Primera versión. Proyecto. Roma, 1924. Mario Palanti. L'Eternale Mole Littoria,Milán. Rizzoli \&

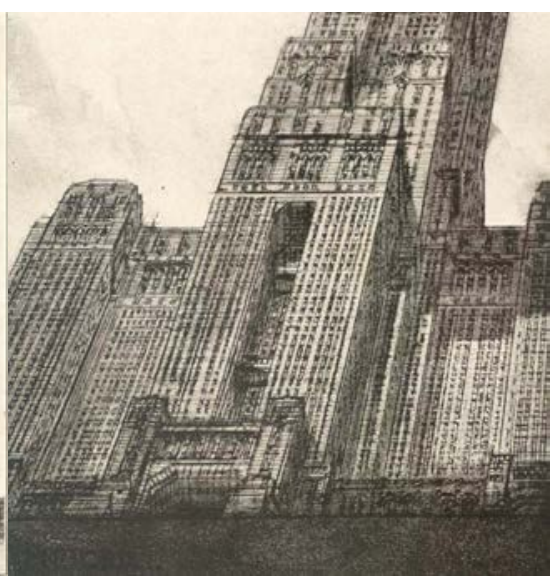

Detalle del acceso de la Mole Littoria. Primera versión. Proyecto. Roma, 1924. Mario Palanti. L'Eternale Mole Littoria,Milán. Rizzoli \& C.1926

En efecto, la propuesta de Palanti sugería un vago emplazamiento. Cercana al Palazzo Chigi, en un principio, y luego en el área del Castro Pretorio o los jardines de la Villa Borghese. ${ }^{16}$

De acuerdo a Neumann, el entusiasmo inicial de Mussolini era legítimo; Palanti no sólo era fascista sino que tenía experiencia en la construcción de rascacielos, una tipología que -como mencionamos- despertaba cierto interés en la Italia de principios de siglo XX, particularmente en el norte. ${ }^{17}$ Recordemos que en 1909 Achile Manfredini proyectó un rascacielos para Milán, se suman las propuestas futuristas de Antonio Sant'Elia y Mario Chiattone, los estudios de Renzo

Ord., b.229, f. 174.093.

15 Neumann, "A skyscraper for Mussolini?".

16 Neumann, "A skyscraper for Mussolini?".

17 Neumann, "A skyscraper for Mussolini”. En su artículo, Neumann señala que, si bien Piacentini estaba a favor del rascacielos, no consideraba que la tipología fuese apropiada para Italia. 


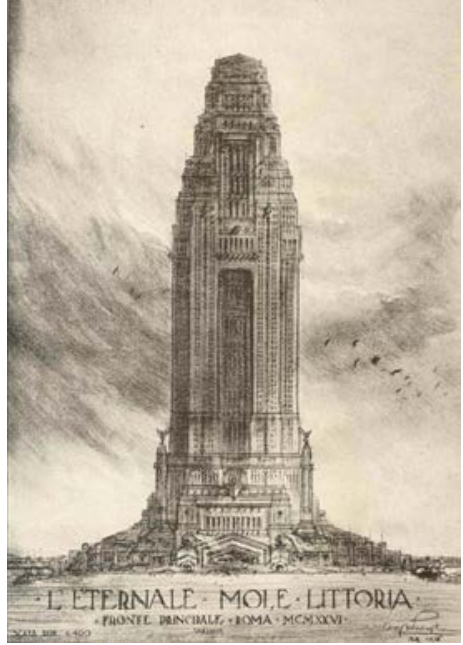

Dibujo de la segunda versión de la Mole Littoria con una altura de 300 metros. Proyecto. Roma, 1926. Mario Palanti. L’Eternale Mole Littoria,Milán. Rizzoli \& C.1926

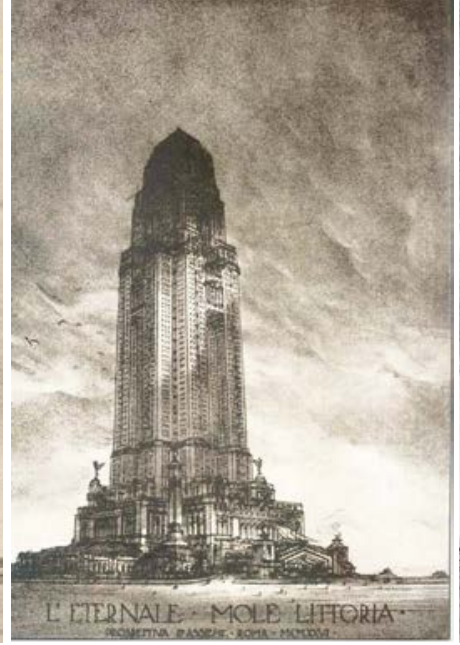

Perspectiva. Mole Littoria.

Variante del proyecto original.

Roma, 1926. Proyecto. Mario

Palanti. L'Eternale Mole Littoria, Milán. Rizzoli \& C. 1926

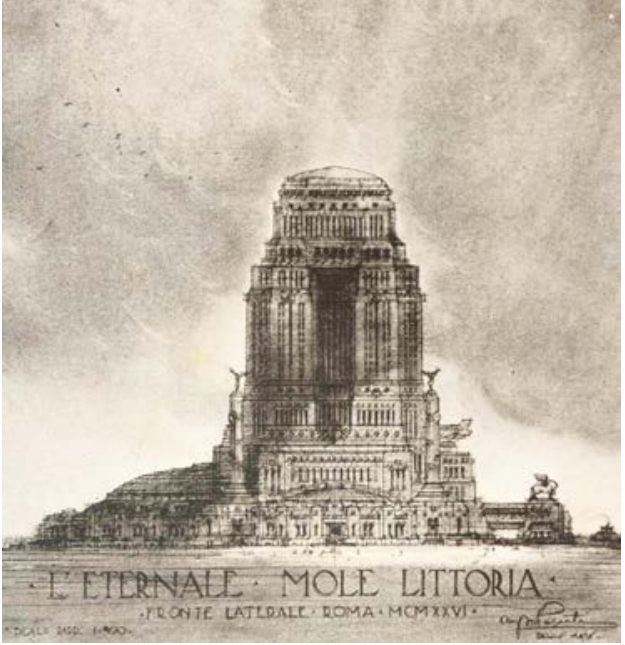

Dibujo de la tercera versión ed la Mole Littoria. Con la altura reducida a 130 metros. Proyecto. Roma, 1925. Mario Palanti. L’Eternale Mole Littoria,Milán. Rizzoli \& C.1926.

Picasso para Genova y las propuestas italianas para el concurso del Chicago Tribune en 1922 entre las cuales se encontraba el proyecto de Piacentini. ${ }^{18}$

En su eufórico fanatismo por el régimen, según Palanti, no era una exageración afirmar que:

\begin{abstract}
Perché l'Eternale sará la espressione violentamente superba Della luce di Roma fascista, irradiantesi da una massa colossale statica e dinamica, in tutto il mondo; la elevazione esplodente dellárdore fascista, come battaglia, come creazione, come dominio, come filosofia, come progresso e superiore civilitá, che sa incarnare la gloria del presente, rinnovare, con possente giovanile innesto, quelle del passato, con una noriginalità nażionale ricca di poteri di espansione e di forze di suggestione nell'Universo civile (..... ${ }^{19}$
\end{abstract}

El diseño contaba con un programa polifuncional y estaría destinado, principalmente, a hospedar las oficinas de la jerarquía fascista. Con 350 metros de altura y $70.000 \mathrm{~m}^{2}$, el megalómano proyecto planteaba, además, albergar en su interior un hotel de 4.500 habitaciones,

18 Ettore Sessa, La nuova immagine della città italiana nel ventennio fascista (Palermo: Flaccovio, 2014), 19-20. Sobre los rascacielos en Italia (y en Europa) véase Renzo Picasso, I grattacieli ed $i$ loro alleati in terra, in mare ed in cielo (Genova: Arti grafiche Caimo \& C., ca. 1935); Quintana de Uña, Sueño y frustración; Ezio Godoli y Alessandra Pelosi, Il Manifesto dell'architettura futurista di Sant'Elia e la sua eredità (Mantova: Universitas Studiorum, 2014); Katherine Solomonson, The Chicago Tribune Tower Competition: Skyscraper Design and Cultural Change in the 1920s (Chicago: University of Chicago Press, 2003).

19 Palanti, L'Eternale Mole Littoria, 28. Porque la Eternale será la expresión violentamente magnífica de la luz de la Roma fascista, que se irradiará de una estática y dinámica masa colosal en todo el mundo; la explosiva elevación del ardor fascista, como batalla, como creación, como dominio, como filosofía, como progreso y civilización superior, que sabe encarnar la gloria del presente, renovar, con poderoso compromiso juvenil, aquellas del pasado, con una originalidad nacional rica de poder de expansión y de fuerza de sugestión en el Universo civil (...)[Traducción Florencia Minatta] 
una galería de 450 metros de largo, comercios, salas de teatro, conferencias y conciertos, salas de baño, equipamiento deportivo -centro de equitación, tiro, piscina, patinaje-, biblioteca y galería de arte. ${ }^{20}$ La planta del edificio estaba formada por un basamento semicircular de 150 por 250 metros al que se le anexaba en cada extremo del diámetro un auditorio, también en forma de semicírculo. Desde este "basamento" se levantaba el rascacielos cuya decoración suprimiría -según Palanti- todo rastro de rascacielos americano. ${ }^{21}$ Además de las diferentes actividades albergadas en el interior de la Mole y en respuesta a las críticas sobre la proliferación indiscriminada de monumentos inútiles -mencionadas en el capítulo anterior-, Palanti planteaba el edificio como un centro de actividad cívica que cautivaría a los ciudadanos. Estos podrían concurrir y manifestar en masa su entusiasmo fascista: el programa podría adaptarse a cualquier superficie, siempre y cuando ésta fuese amplia y permitiera la reunión de la masa litúrgica situación que, tomando la definición de Mosse, transformaba a La Mole en un "monumento vivo" que incorporaba la vida pública. ${ }^{22}$

Al igual que en el Pasaje Barolo y el Palacio Salvo, la estructura del edificio estaba pensada en cemento armado y emplearía mano de obra local. Además de la mano de obra, la financiación también sería italiana: en él invertirían connacionales radicados en el exterior (Palanti posiblemente pensaba en sus comitentes radicados en la Argentina y el Uruguay). Una vez concluida la obra el edificio se sustentaría económicamente al funcionar como una atracción turística de significado histórico y simbólico que, además, operaría como un medio de “irradiación del el valor y la potencia de Italia". ${ }^{23}$

La figura del rascacielos se presentaba como elemento clave de una gran metrópolis que permitiría sumar a Roma en el concierto de las más grandes capitales modernas. Ante una nueva coyuntura, Palanti probaba suerte con una versión diferente de un proyecto que permanecía en su mente: construir el rascacielos más alto del mundo. Si en la construcción de sus rascacielos rioplatenses Palanti pudo poner a prueba ciertos principios planteados para el Mausoleo Glorificando gli Eroi Nostri como la multiplicidad de funciones, la planta de base concéntrica e, inclusive, el sistema de financiamiento, en la L'Eternale puede leerse la conjugación del monumento utilitario y la tipología de rascacielos.

20 Palanti, Cinque anni di lavoro, 23-24.

21 Palanti, Cinque anni di lavoro, 23

22 George L. Mosse, La nacionalización de las masas (Buenos Aires: Siglo XXI, 2007), 32

23 Palanti, L'Eternale Mole Littoria, 37-34. 
A pesar de la aprobación del mismo Mussolini, la Mole Littoria no pudo superar la faz de proyecto. La idea de construir un rascacielos con capital privado, generada a partir de su experiencia en América, no encontró eco en Italia. ${ }^{24}$ En efecto, ni la tercera versión de la Mole comprimida y "económica" de 80 metros de altura, ni las cartas de presentación y los obsequios que Palanti entregó al Duce sirvieron para concretar su megalómana propuesta. ${ }^{25}$ La Mole Littoria pretendía ser una versión superadora de sus exitosos rascacielos rioplatenses, pero fue presentada en un contexto de retracción económica. Lejos del circuito de capitalismo globalizado en el cual se movían los países del Plata durante la década de 1920, una inversión de esas características era por entonces en la península poco menos que irrealizable. ${ }^{26}$

De regreso en la Argentina y habiendo estado nueve meses en contacto con la realidad italiana, Palanti reelaboró el proyecto manteniendo la monumentalidad pero reduciendo la altura de 350 a 330 metros, luego a 190 metros para terminar en una altura de 90 y luego 80 metros. ${ }^{27}$ En junio de 1926, el arquitecto regresó a Roma y presentó el nuevo proyecto en el Salone della Vittoria donde fue visto y aprobado por el Duce. ${ }^{28}$ Sin embargo, a pesar de los cambios realizados, la propuesta no llegaría a materializarse y el difícil vínculo de Palanti con el fascismo se limitaría a los concursos llevados a cabo durante la década de 1930.

Si todas las energías de Palanti se volcaron por entonces hacia el retorno a su patria, el episodio de la Mole Littoria resultó en ese contexto un antecedente negativo y aglutinó seguramente en contra de su figura a la nueva cerchia de arquitectos del partido. Orientados hacia otras corrientes arquitectónicas éstos no podían ver con agrado la inclusión de este advenedizo y desconocido arquitecto que intenta convencer al Duce de construir un rascacielos que produciría un desequilibrio notable en el paisaje urbano del centro histórico de Roma..$^{29}$ Este inicial rechazo generó en principio su incomprensión de los cambios que estaban aconteciendo en la disciplina

$\overline{24}$ Giuseppe Pagano, "Mussolini salva l'architettura italiana", Casabella, № 78 (junio 2-3 1934); Cesare De Seta, La cultura architettonica in Italia tra le due guerre (Roma: Laterza, 1983); Paolo Nicoloso, Mussolini architetto. Propaganda e paesaggio urbano nell'Ttalia fascista (Torino: Einaudi, 2011).

25 Además de los libros, Palanti obsequió al Duce un perro traído desde la Argentina. Neumann, "A skyscraper for Mussolini": 4.

26 Nicoloso, Mussolini architetto, véase de Aristotle Kallis, “'in miglior tempo...' What Fascism did not Build in Rome", Journal of Modern Italian Studies 16, (2011): 59-83.

27 Palanti menciona los 90 metros en la página 23. La versión de 80 metros de altura aparece en las primeras páginas 16 y 18 del ibro. L'Eternale Mole Littoria, 23.

28 Palanti, L'Eternale Mole Littoria, 31.

29 Neumann, "A skyscraper for Mussolini”". 
en Italia que él mismo atribuía a "la influencia funesta de la era moderna". ${ }^{0}$ Su defensa de un eclecticismo monumentalista lo posicionaba entonces, paradojalmente, prácticamente fuera del círculo profesional del partido fascista del cual se consideraba un apasionado militante.

A partir del fallido episodio de la Mole, comenzó una etapa en la que Palanti intentó, sin suerte, adaptar su arquitectura a las líneas del Racionalismo o de cierto Monumentalismo despojado de ornamentación en el afán de aproximarse -sin abandonar sus ideales- a los postulados estéticos por los que se inclinaba la jerarquía fascista. Ejemplo de ello son los proyectos que imaginó para los grandes concursos destinados a los edificios públicos de la era mussoliniana. Todos ellos edificios monumentales en los que Palanti, manteniendo las líneas de composición académica, eliminó el repertorio decorativo desarrollado en el período anterior. Pero este giro en su arquitectura no lo salvaría del fracaso en todas las competencias llevadas a cabo por el régimen. En una carta del 10 de diciembre de 1936, dirigida a la Secretaría Particular del Duce decía estar:

\section{(...) convinto piú che mai, di non aver fatto altro che il suo dovere di italiano; ad un tempo si permette di far presente il dolore che lo opprime, per non poter continuare simile sua opera modesta di Fascista di fede, ma pure di non poter contribuiré umilmente, coll'arte sua, colla sua esperienza, per la nuova Italia} Mussoliniana (......31

Por otra parte, las continuas estrategias del arquitecto por acercarse a los círculos de poder resultaron erróneas, puesto que recibieron duras críticas por parte de los allegados al Duce que rápidamente lo alejaron del contacto con el líder. ${ }^{32}$ Pero principalmente, si bien el

30 Carta de Mario Palanti a Giuseppe Palanti del 25 de octubre de 1938.AP

31 Carta de mario Palanti a la Secretaría particular del Duce del 10 de diciembre de 1936. ACS SPD, Busta 1154. La presencia de Marcello Piacentini como miembro del jurado y el intento de obsequiar a Mussolini el libro Palazzo Littorio (1934) con su propuesta para el concurso se sumaron a ciertas actitudes que desde hacía tiempo disgustaban a la Secretaría Particolare del Duce. (...) convencido más que nunca, de no haber hecho otra cosa que su deber de italiano; en un momento se permite hacer presente el dolor que lo oprime, por no poder continuar su modesta obra de fe Fascista, pero también de no poder contribuir humildemente, con su arte, con su experiencia, para la nueva Italia Mussoliniana (...).[Traducción Florencia Minatta]

32 En 1933, Palanti intentó acercarse a Mussolini nuevamente, esta vez con un caballo que traía desde Argentina como obsequio. Pero el Duce rechazó el presente al ser advertido de que el animal pertenecía a la mujer del arquitecto, de la cual se había separado en malos términos. Nota informando sobre MP del 23 de abril de 1934 (ACS-SPD, Busta 1154). .En agosto de 1934, Mario Palanti -por intermedio de Ottavio Dinale- quiso homenajear al Duce con el primer volumen del libro Palazzo Littorio. (Carta de Ottavio Dinale a Sebsatiani, agosto de 1934, ACS-SPD, Busta 1154). En septiembre del mismo año, Sebastiani, secretario particular del Duce, le hizo saber a Dinale lo inapropiada que había sido la oferta del arquitecto (Carta de Sebastiani, 16 de diciembre de 1934, ACSSPD, Busta 1154). Sebastiani señalaba que "Per l'Architetto Palanti vi sono due punti non belli nel fascicolo, quello d'avere tentato di donare al DUCE un cavallo avuto dalla moglie con la quale era in lite, l'altro di avere pure tentato 
fascismo produjo una serie de oportunidades laborales que partían de las políticas ligadas a la edilicia y a las obras públicas, para un arquitecto que había permanecido fuera de Italia por más de dos décadas y carecía de los contactos adecuados no debe haber sido fácil encontrar un lugar: la dinámica de la competencia o la asignación de tareas a través de los arquitectos del sindicato fueron en muchos casos vinculadas a las relaciones de poder y a favores específicos. ${ }^{33}$

Al fracaso de la Mole Littoria se sumaría entonces la frustración generada por sus presentaciones para el del concurso para el Palacio del Littorio (1934 y 1937), el Auditorium en Roma (1935) y la Torre Littoria en Milán (1935). ${ }^{34}$ Si bien su arquitectura fue modificada, en los proyectos elaborados para cada uno de estos programas Palanti permanecería fuera del debate arquitectónico que se estaba desarrollando en Italia en ese momento. ${ }^{35}$

\section{Los concursos para el PNF}

Asentado el fascismo el poder, la búsqueda de una "arquitectura como arte de Estado" se dio a la par del debate arquitectónico en torno a cuál sería el "estilo" de la arquitectura fascista que buscaba, en su ambigüedad, una síntesis espiritual de lo clásico y lo moderno. ${ }^{36}$

Durante la década de 1930, varias eran las ofertas laborales para los arquitectos: durante este período el Estado impulsó numerosos concursos de arquitectura para los nuevos edificios públicos, pabellones de exposición, planos reguladores, muestras o edilicia pública. Posiblemente a través de los concursos Palanti percibió una potencial posibilidad de trabajo e inserción en el contexto profesional italiano. Con la idea de hacer permanente la Mostra della Rivoluzione Fascista (realizada entre octubre de 1932 y 1934 con motivo de los diez años de la Marcha sobre Roma), el 27 de diciembre de 1933 se realizó el llamado a concurso para el Palazzo Littorio cuyo cierre se pautaría para el 31 de julio de $1934 .{ }^{37}$

di sottoporGli il suo progetto per il Palazzo Littorio, mentre era in esplicazione il concorso relativo." Nota de Sebastiani s/f, ACS-APD, Busta 1154.

33 Nicoloso, Mussolini architetto.

34 Palanti, Palazzo Littorio.; Mario Palanti, Auditorium: progetti, (Milán: Rizzoli \& C, 1935) y Torre Littoria: progetti (Milán: Rizzoli \& C.,1935)

35 Otelo Iolita, "Da Boito a Palanti. Ricerca di identittá nelle architetture di Buenos Aires e necessitá della loro conservazione", Metamorfosi, quaderni di architettura 25/26 (Roma: "La Sapienza", 1995)

36 Giorgio Ciucci, Gli architetti e il fascismo. Architettura e cittá 1922-1944 (Torino: Einaudi, 1989)

37 Ciucci, Gli architetti e il fascismo,141-143. Véase Architettura, rivista del Sindacato naziionale fascista architetti, fascicolo especiale Palazzo Littorio. 1934 
En marzo de 1934, probablemente tentado por la propuesta, Palanti emprendió un repentino viaje a Italia. En ese momento, el arquitecto se encontraba descansando a 400 kilómetros de Buenos Aires, en la ciudad balnearia de Mar del Plata junto a su mujer María Helena Castagnino. Sin previo aviso Palanti abandonó a su esposa para dirigirse hacia Buenos Aires y tomar un vapor hacia Génova llevándose consigo una suma de dinero y un caballo llamado ‘Campeón' que presentaría como obsequio a Mussolini. ${ }^{38}$

Una vez en Italia, Palanti entró en contacto con el nuevo escenario romano en el cual se instalaría el Palazzo Littorio. Como parte de las reformas urbanísticas impulsadas por el fascismo, en 1932 se inauguró en Roma la vía del Imperio que unió la Plaza Venecia con el Anfiteatro Flavio. Una polémica acción que sepultó parte de los restos de los foros imperiales. En esos mismos años se concibió la idea de construir sobre ese nuevo eje un edificio destinado a albergar la sede nacional del PNF, una muestra permanente de la revolución fascista y el Sacrario dei Martiri Fascisti destinado a los mártires del partido. Como señala Ciucci, el Palazzo debía, ya sea por el momento del debate arquitectónico o por el tema de la celebración del PNF, convertirse en un "punto crucial para consolidar la idea de que la arquitectura 'moderna' era la única posibilidad para el 'moderno' estado fascista." ${ }^{9}$

El sitio elegido era una fracción de terreno irregular en el Foro Imperial enclavado entre el Palacio Venecia, la Basílica de Majencio y el Coliseo. A partir del momento en que se tomó la decisión de implantar el edificio en ese lugar, estalló una discusión entre quienes apoyaban su ubicación en esta área arqueológica de profunda significación en la historia de Italia y quienes opinaban que debería ser ubicado en un sector fuera del área central de

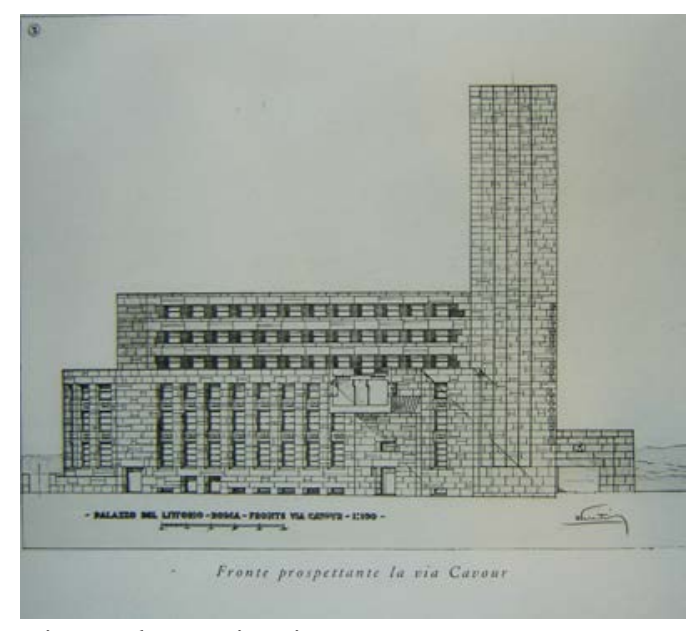

Vista. Palazzo Littorio. Roma, 1934. Proeycto. Mario Palanti. Palazzo Littorio, progetto. Milano. Rizzoli. 1934

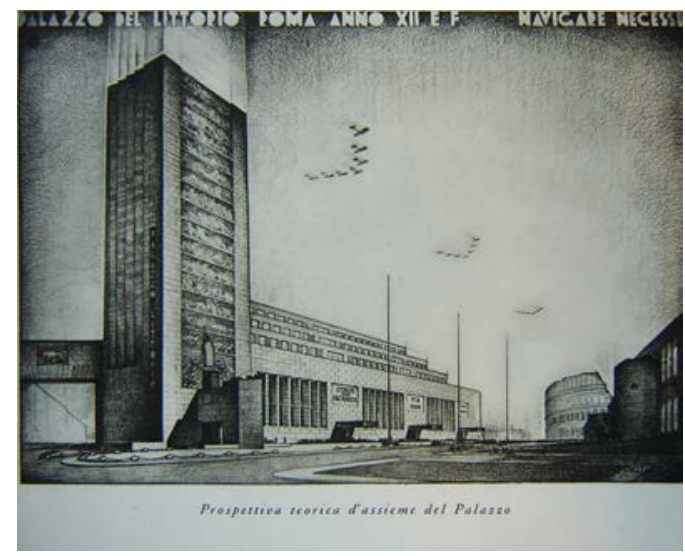

Perspectiva sobre Via del Imperio. Palazzo Littorio. 1934. Mario Palanti. Palazzo Littorio, progetto. Milano. Rizzoli. 1934

38 El Duce rechazó el presente al ser advertido de que el animal pertenecía a la mujer del arquitecto, de la cual se había separado en malos términos (SPD 1934b).

39 Ciucci, Gli architetti e il fascismo,141. 
Roma. ${ }^{40} \mathrm{Al}$ concurso se presentaron más de cien trabajos de los cuales en una primera instancia fueron seleccionados setenta y dos que fueron expuestos en 1934 sin adjudicarse un premio. Dada su magnitud, el evento de 1933 brinda un panorama del debate arquitectónico en la Italia de entreguerras, entre racionalistas y anti racionalistas, y contó con la participación de arquitectos como Giuseppi Terragni, Gino Pollini, el grupo BBPR, Adalberto Libera y Pietro Lingeri, entre otros.

Catorce de los cien proyectos fueron seleccionados para una segunda vuelta; entre ellos figuraba el de Palanti. ${ }^{41}$ El jurado estuvo presidido por Piacentini y contó con la participación de arquitectos como Brasini y Bazzani y la presencia de Giuseppe Pagano como jurado externo. A ellos se sumaban arqueólogos e ingenieros, así como algunas personalidades políticas. La exposición hizo que arreciaran las críticas a la implantación en un área tan sensible, por lo que se decidió anular el concurso y, en 1937, llamar a un nuevo concurso en un área más alejada.

La propuesta de Palanti muestra un edificio casi totalmente despojado de ornamento, revestido de lajas de granito, sin diferenciaciones o articulaciones entre las partes, con un gran basamento sobre la Vía del Imperio y una serie de niveles superiores retranqueados para dar más jerarquía al cuerpo principal con sus grandes aberturas divididas por pilastras. La propuesta evidencia entonces una volumetría longitudinal que plantea una torre en una de las esquinas en

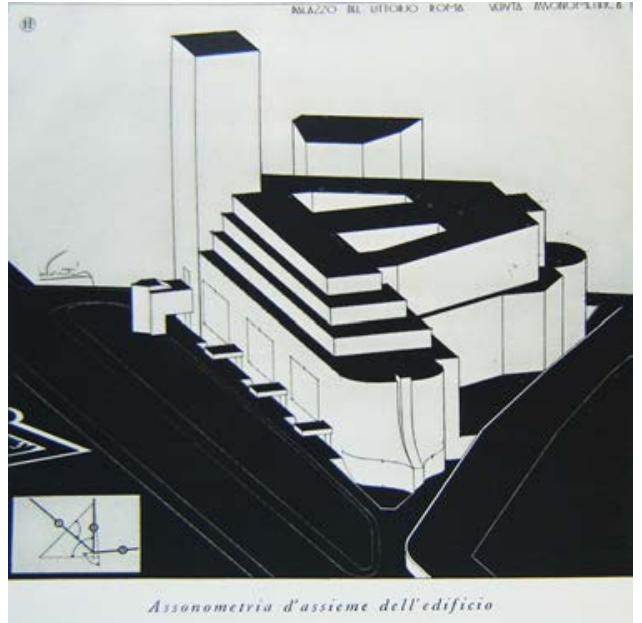

volumetría en la cual se ve la "nave" sobre Via del Imperio y el volumen adosado detrás. Palazzo Littorio. Roma, 1934. Proyecto. Mario Palanti. Palazzo Littorio, progetto. Milano. Rizzoli. 1934

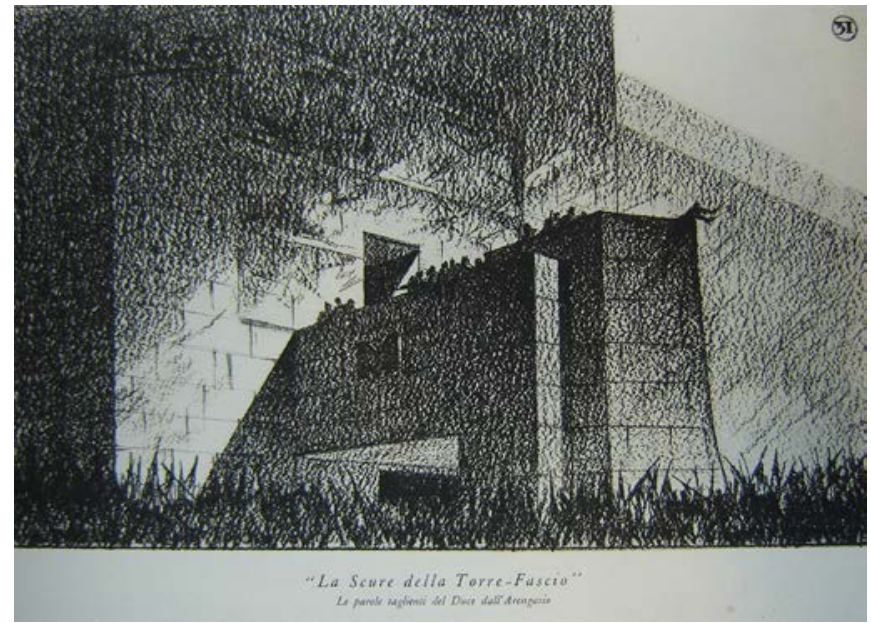

El Duce habla a la multitud. Arengario. Palazzo Littorio. Roma, 1934. Proyecto. Mario Palanti. Palazzo Littorio, progetto. Milano. Rizzoli. 1934

$\overline{40}$ Flavia Marcello, “The Politics of Place: Citing and Re-siting the Palazzo Littorio, Mussolini’s New Fascist Party Headquarters in Rome” en Architectural Theory Review (1 dicember).

41 Los premiados fueron: Carminati, Lingueri, Saliva, Terragni, Vietti (dos propuestas); Del Debbbio, Foschini, Morpurgo (dos propuestas); Del Giudice, Errera, Folin; De Renzi; Fasolo; Frezzoti; Libera; L. Moretti (dos propuestas); Palanti; Rapisardi; Ridolfi, Cafiero, La Padula, E. Rossi; Samonà; D. Torres; Vaccaro. Ciucci, Gli architetti e il fascismo,142 
dirección de Plaza Venecia y una estructura en forma de proa de barco en la otra, con la letra 'M' a modo de mascarón. La alusión náutica se completaba con el moto elegido por Palanti: "Navigare Necesse", haciendo alusión a la frase "Navigare necesse est" (Italia debe navegar) pronunciada por Mussolini en referencia al imperialismo y publicada en Il Popolo d'Italia el 1 de enero de 1920.42

Como fue señalado por Gentile, la seducción ejercida por el Duce y el culto alrededor del mismo fue uno de los pilares básicos del fascismo. Según el autor, el fascismo fue el primer movimiento político del siglo XX en llevar el mito al poder:

La instauración de una liturgia de estado fue consecuencia de la concepción (...) de que en las masas predomina el sentimiento, no la razón y que sólo apelando a los sentimientos, generando emociones y entusiasmo, por medio de mitos que dan forma a los deseos de las masas y las incitan a la acción, es posible que un movimiento político organice y utilice su energía para la consecución de sus fines. ${ }^{43}$

En este marco, le correspondía a la estética de masas diseñar la vida y la regeneración moral del nuevo hombre fascista. El arte y la arquitectura se vieron involucrados por el fascismo como herramientas para la atracción del individuo: ejercieron un tipo de seducción "irresistible" y practicaron un tipo de hechizo o hipnotismo sobre los ciudadanos para concretar una religión que representara sus mitos, sus símbolos y sus cultos. Es así como el símbolo del haz lictorio, empleado por los fascistas como insignia del partido que resumía el emblema del fuego -fuerza destructiva y purificadora- y el garrote -santo protector de los fascistas- es utilizado como parte del repertorio estilístico para caracterizar, en el sentido de Quatremere, los edificios del régimen. ${ }^{44}$ La majestuosidad de los eventos y ritos dependía en gran medida de la presentación y representación de los mismos, cosa que se llevaba a cabo con sumo cuidado; el saludo romano, las peregrinaciones en masa de miles de Camisas Negras, el culto a la bandera o al

42 Gentile, The Origins of Fascist Ideology 1918-1925, 124.

43 Emilio Gentile, El culto del Littorio (Buenos Aires: Siglo XXI, 2007), 133. El fascismo, desde este punto de vista, se representa supeditado la fidelidad de sus seguidores, por lo tanto el estado cumplía con el rol de educador, convirtiendo a multitudes en masas litúrgicas organizadas. "El fascismo, explicaba un pedagogo del régimen, precisamente por su índole de movimiento religioso, había devuelto lustre y vigor a los mitos, a los símbolos, a los ritos, llevando de nuevo estilo a la política de masas. El estilo, como expresión de orden y disciplina animados por una fe, era una señal de victoria sobre el caos y la incertidumbre, en un mundo que había salido de la tragedia de la guerra profundamente convulsionado, suspendido entre una época en crisis y una nueva época (...).’Gentile, El culto del Littorio, 153.

44 Gentile, El culto del Littorio,78-81. 
soldado desconocido son sólo algunas de las ceremonias empleadas en la realización de los ritos fascistas. Como en un teatro, las celebraciones debían deslumbrar y fascinar al público. El rito del Juramento y la Bendición cobraron cada vez más importancia, asimismo las Confesiones de fe y el Sacrificio de la Vida. La muerte, por sobre todas las cosas, era un símbolo de fe en el futuro. Los funerales no se realizaban con lamentos sino con devoción por la patria, ya que aquellos que entregaban la vida por una causa tan noble vivirían por siempre en el recuerdo del pueblo. $^{45}$

Con estas ideas en mente, y conociendo la importancia que el mito tenía en la "religión" fascista ${ }^{46}$ Palanti procuró que su diseño -aún con su escasa decoración- estuviera cargado de simbología. La idea de movimiento, de impulso revolucionario del fascismo es representada por la forma náutica del edificio. La torre es el elemento vertical que Palanti incorpora al conjunto sobrepasando la altura de la Basilica de Majencio permitida como límite en el bando. En la base de la torre ubica un arengario, una saliente, que debía servir de palco para los discursos del Duce en reemplazo del tradicional balcón de plaza Venecia.

Para el interior el arquitecto diseñó un monumental espacio abovedado como museo de las reliquias del fascismo, la "Capilla de los caídos fascistas" con el "Sarcofago dei martir" iluminado por luz cenital. El teatral Sacrario -que recuerda al Sacrario dei Martiri de la Mostra della Rivoluzione Fascista- incrementaba el dramatismo mediante una cúpula circular concéntrica

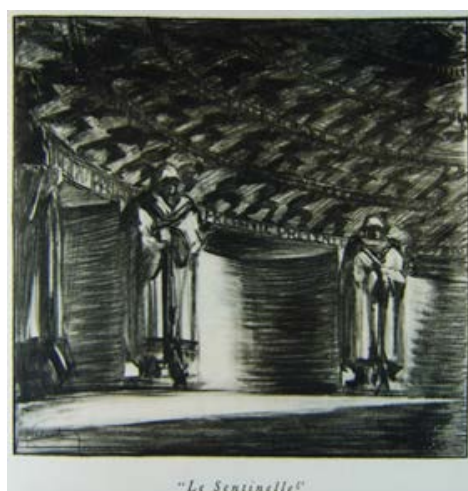

Centinelas. Sacrario. Palazzo Littorio. 1934. Mario Palanti. Palazzo Littorio, 1934

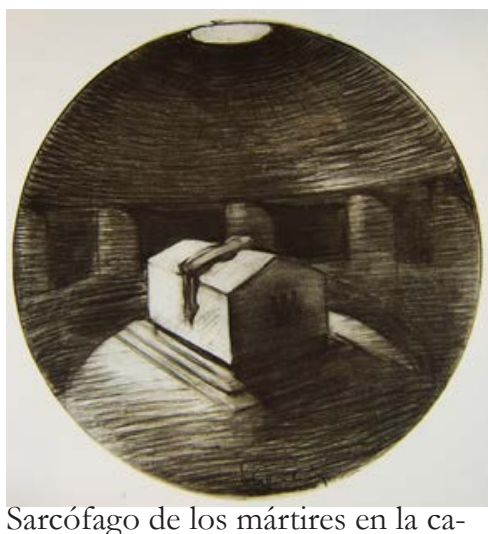

pilla de los caidos fascistas. Palazzo Littorio. Roma, 1934. Proyecto. Mario Palanti. Palazzo Littorio, progetto. Milano. Rizzoli. 1934

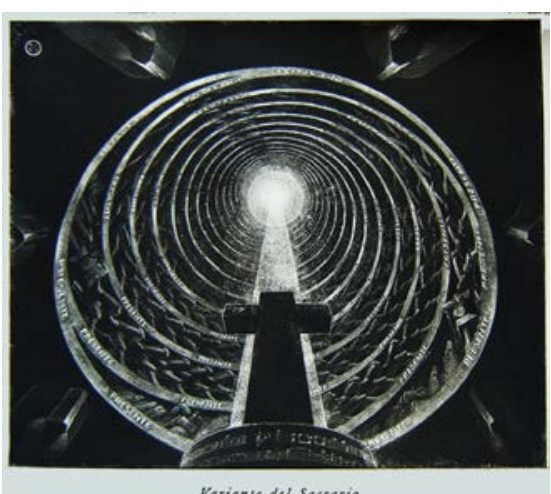

Sacrario. Palazzo Littorio. Roma, 1934. Proyecto. Mario Palanti. Palazzo Littorio, progetto. Milano. Rizzoli. 1934

45 Gentile, El culto del Littorio,78-81.

46 El mito, de acuerdo a Emilio Gentile, es "a set of beliefs and ideas, ideals, and values which are condensed in a symbolic image that is capable of mobilizing the individuals as well as the masses because it stirs up faith, enthusiasm, and action." The Struggle for Modernity: Nationalism, Futurism, and Fascism, (Praeger: Westport, 2003$), 2$. 
iluminada con luces de neón y con la repetición constante de la palabra "presente" que refería al rito del escuadrismo, se elevaba sobre un haz de cruces de mármol negro que representan a los mártires del partido rodeado enormes estatuas de "centinelas". ${ }^{47}$

Si bien el propio Duce se mostró entusiasmado con el proyecto, vio y promovió la "nave" de Palanti a segunda vuelta, las críticas del jurado no se hicieron esperar. Usando un adjetivo gentilicio como calificativo despectivo, el explícito lenguaje fue calificado por Pagano como "snob tiburonezco y sudamericano". A su crítica, Pagano sumaba la publicada en el periódico Il Popolo di Roma que dejaba ver cierto descrédito en el uso término "sudamericano" con el cual, además, identificaba a Palanti excluyéndolo del contexto italiano: “(...) abbiamo letto nel Popolo di Roma inni sviscerati a quella torta carnavalesca che Mario Palanti non riuscirebbe oggi a far digerire neanche a un sudamericano (...)" ${ }^{48}$ Conjuntamente, debemos tener en cuenta lo señalado por Fernando Devoto al explicar que los ambientes católicos hostiles a la emigración decían que en

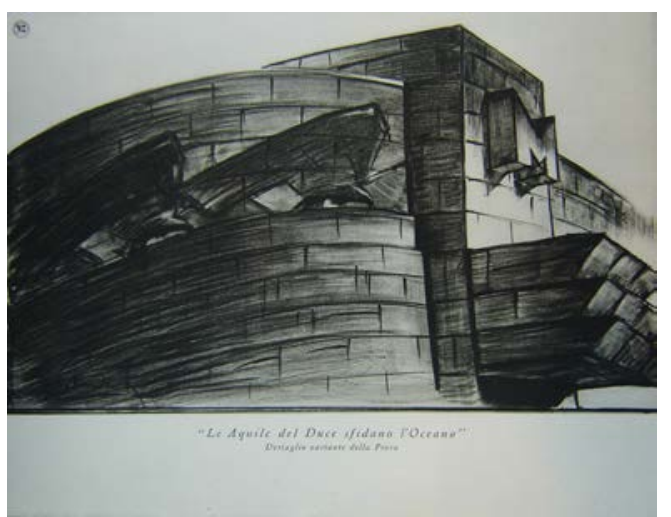

Detalle de la "proa", aguilas y la letra M representando al Duce. Palazzo Littorio. Roma, 1934. Proyecto. Mario Palanti. Palazzo Littorio, progetto. Milano. Rizzoli. 1934

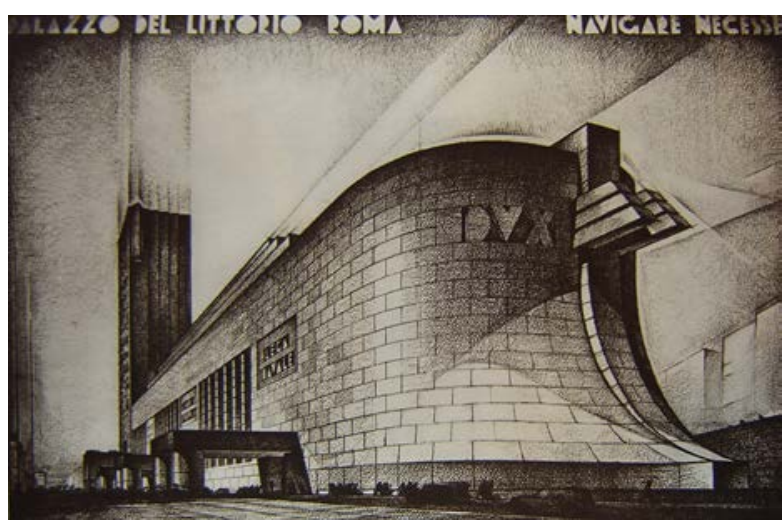

Perspectiva de "la nave". Palazzo Littorio. Roma, 1934. Proyecto. Mario Palanti. Palazzo Littorio, progetto. Milano. Rizzoli. 1934

47 Palanti, Palazzo Littorio. La repetición de la palabra "Presente" hace referencia al rito del escuadrismo cuando "il capo delle squadre" gritaba el nombre del difunto los camaradas respondían con el grito de "Presente!". Emilio Gentile, Fascismo: storia e interpretazione (Roma-Bari: Laterza, 2002), 225.

Para entender la importancia de la estética y el fascismo como religión véase: Gentile, El culto del Littorio. Mosse, La nacionalización de las masas. Mosse explica que el tema relacionado a la estética no es algo nuevo, sino que el estilo fascista es una idea del siglo XVIII que se mantiene en ascenso, en la concepción de la nueva política los actos populares, en los que mitos y cultos forman parte de una voluntad general que lleva a la religión secular.

48 “(...) hemos leído en el Poppolo di Roma himnos eviscerados a aquella torta carnavalezca que Mario Palanti no logrará hoy hacer digerir ni siquiera a un sudamericano (...). [Traducción Florencia Minatta]Pagano criticaba el "virus" de la monumentalidad del cual pocos se habían salvado, y veía en esta "ossessione della monumentalitá" interpretaciones "enfatica o infantile del valore puramente estetico insito nella qualifica di monumentale. (...) molti si sono abbandonati ad urli incompostu, realizando plásticamente veri disordini mentali: Su questo piano psicopático stanno le orge floreali di Coppedé, di Cro e di Gerace, di Massone, lo snob pescecagnesco e sudamericano di Mario Palanti; (...).". Giuseppe Pagano, Architettura e cittá durante il fascismo (Milano: Jaca Book, 2008), 24. Véase también, Giuseppe Pagano, "Mussolini salva l'architettura italiana", Casabella, No 78 (giugno 1934): 2-3 y Architettura XIII fascicolo speciale dedicato al concorso per il palazzo Littorio, 1934. Sobre el concurso del Palacio Littorio ver Marco Lecis, "Roma 1934, Il Concorso per il Palazzo del Littorio", Arte/ Architettura/ Ambiente, N 48 (giugnio 2002), Consultado 10 de diciembre 2014. www.ca.archiworld.it. Sobre G. Terragni en particular ver Manfredo Tafuri, "Il soggetto e la maschera. Una introduzione a Terragni”, Lotus, No 20 (settembre 1978): 5-28. 
América se perdía la fe, "a lo que los fascistas podían agregar que en la Argentina se perdía antes y más rápido la 'italianidad'..' ${ }^{49}$ Considerando lo dicho, Palanti, quien desde hacía años estaba obsesionado en demostrar su fe en la iglesia católica y en el régimen, recibió por parte de Pagano una crítica dura tanto hacia su arquitectura como hacia su rol de italiano y de fascista.

Pero Pagano no era una voz aislada. Consejero de Mussolini, Piacentini -olvidando su propagandístico Monumento alla Vitroria en Bolzano- veía en las manifestaciones explícitas y sin mediaciones realizadas por Palanti una arquitectura parlante cuya seducción demagógica era totalmente comprensible por las masas pero degradaba la especificidad del lenguaje arquitectónico. ${ }^{50}$ En efecto, la arquitectura palantiana abandona aquí todo decorativismo y se concentra en gestos retóricos grandilocuentes como la proa de la nave o la sala del mausoleo. Una perspectiva que lo aleja tanto del sobrio clasicismo monumentalista de Piacentini como del racionalismo vanguardista del M.I.A.R. (Movimiento Italiano para la Arquitectura Racional). Se trata como ha señalado John Beldon Scott (2011) de un ejercicio de modernidad fallida que se coloca por fuera de las líneas centrales del debate arquitectónico.

Mientras que en las propuestas para el Palazzo Littorio y, como veremos, la Torre Littoria primaba la idea fuerza y la forma, en el proyecto presentado para el concurso Auditorium, llevado a cabo en 1934, Palanti jugó una carta diferente: en esta oportunidad, la atención fue puesta en la técnica constructiva y, principalmente, en la aislación acústica. Bajo esta premisa, y en el intento de lograr una arquitectura que fuese una “(...) fusione estética della monumentalità antica con le audacie durature dell'arte del tempo di Mussolini.", ${ }_{51}$ las ocho propuestas presentadas carecían de ornamentación a fin de no afectar el sonido en el interior del auditorio. "Il mio sforzo señalaba Palanti- è diretto ad ottenere che il razionalismo interno si rispecchi all'esterno e cioè la statica rispetto all'estetica." ${ }^{52}$ Sin embargo, a pesar de haber logrado cierto racionalismo que no tenía precedentes en su obra, el proyecto no tuvo diferente suerte.

El sitio propuesto para el Auditorium se ubicaba entre Viale Aventino y Viale Baccelli con el Circo Massimo a un lado y las termas de Caracalla al otro, como parte de las estrategias urbanas desarrolladas por el fascismo que intentaban enlazar la Roma Imperial y la Roma mussolineana mediante elementos arquitectónicos.

49 Devoto, Historia de los italianos en la Argentina, 348.

50 Nicoloso, Mussolini architetto, 166.

51 Palanti, Auditorium, 7

52 Palanti, Auditorium, 31 


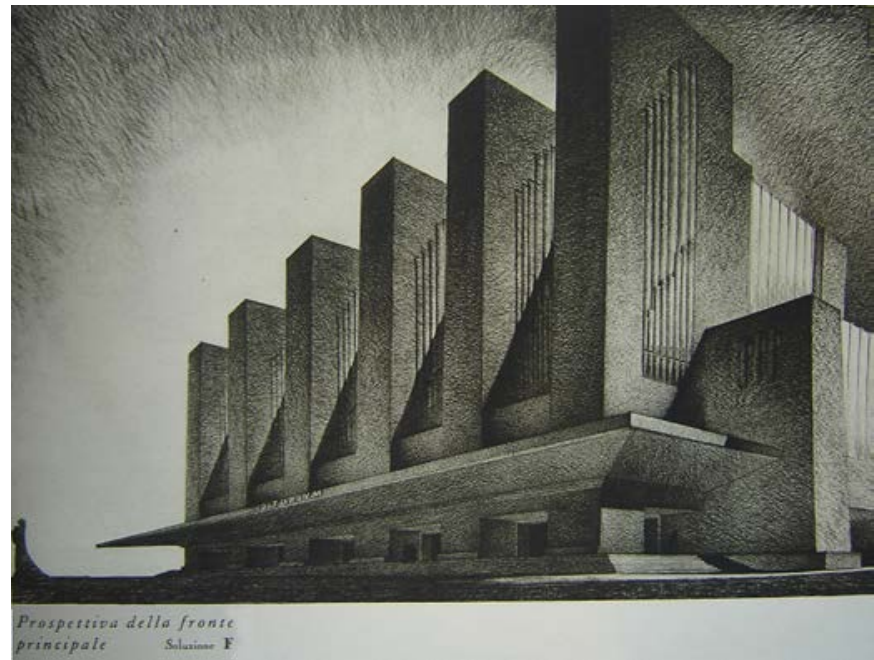

Proyecto para el Auditotium (solución "F”). Roma, 1934. Mario Palanti. Auditorium

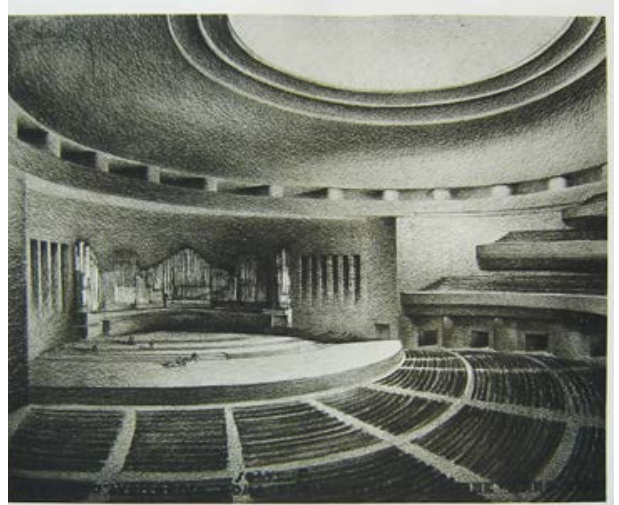

Perspectiva interiore. Proyecto para el Auditotium (solución "F"). Roma, 1934. Mario Palanti. Auditorium

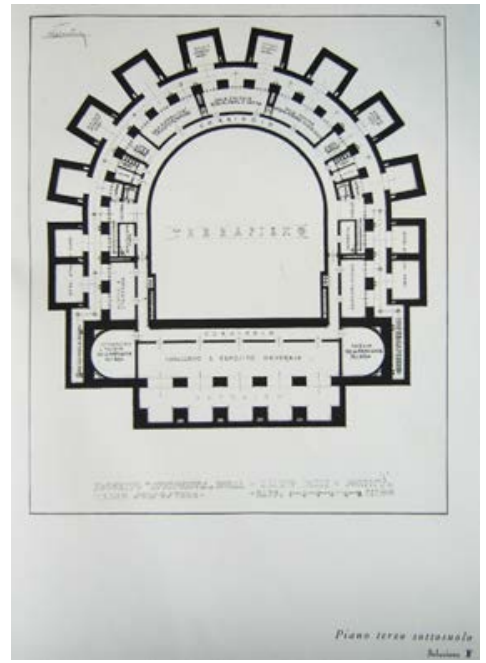

Proyecto para el Auditotium (solución "F"). Roma, 1934. Mario Palanti. Auditorium

De las ocho soluciones para la sala de conciertos presentadas por Palanti solo una cumplía de manera rigurosa las pautas del concurso. Seis soluciones no sobrepasaban los 7.000 $\mathrm{m}^{2}$ establecidos por el bando, pero dos de ellas, una de forma circular y otra elíptica, se basaban en un concepto derivado del anfiteatro cubierto y duplicaban la superficie permitiendo ubicar 15.000 personas en vez de las 5.000 requeridas. No obstante, Palanti no presentó en detalle estos ejemplos sino que se inclinó por dos soluciones que, si bien no las consideraba las mejores opciones, cumplían los requisitos pautados. La solución F, estaba planteada en forma de herradura con tres subsuelos y tres niveles de altura y un esqueleto en hormigón armado cuyos problemas acústicos solucionaba mediante cámaras aislantes. Interesado en la industria del cine -recordemos su inversión en Platano Films-, ${ }^{53}$ Palanti propuso una cabina cinematográfica 
como un elemento extra no pautado en el bando del concurso: en 1932 el cinegiornale LUCE había incorporado el sonido lo que volvía al cine en un instrumento de propaganda política masiva por excelencia. ${ }^{54}$

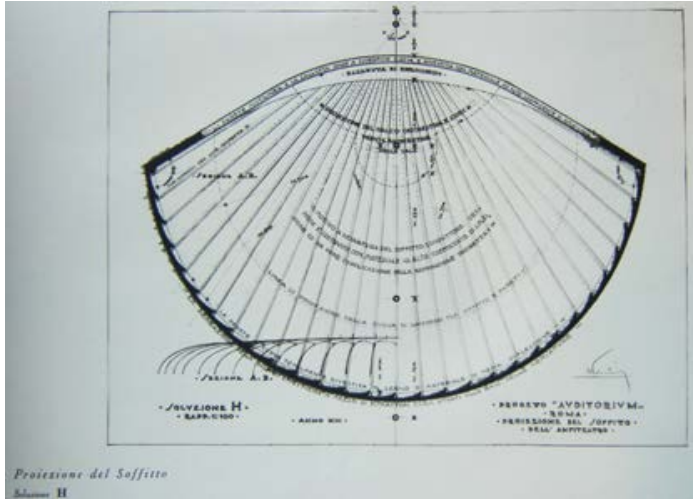

Proyecto para el Auditotium (solución "H").

Roma, 1934. Mario Palanti. Auditorium

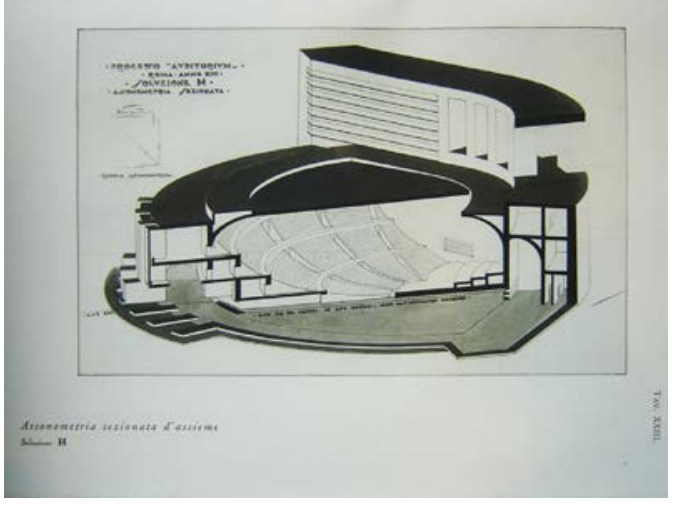

Sección en axonométrica. Proyecto para el Auditotium (solución "H"). Roma, 1934. Mario Palanti. Auditorium

El edificio estaría revestido en travertino y ladrillo. La fachada principal estaría formada por seis pilares de cuatro niveles de altura que se intercalaban con planos vidriados que dejaban lugar en planta baja a un gran semicubierto de acceso. La única decoración estaba formada por seis fasci, tres en cada una de las alas laterales. Ante la ausencia de elementos que dieran carácter al edificio, frente al acceso principal se ubicaba una escultura que simbolizaba la música y que veremos repetirse en proyectos posteriores, aunque con otro significado.

La otra solución $(\mathrm{H})$, presentada en detalle, era un edificio de poca altura y capacidad para 8.000 espectadores en forma de concha marina cuyas líneas derivaban de los requerimientos acústicos. Además del estudio de la acústica, el énfasis -señalaba el autor- estaba puesto en lograr un edificio de máxima simplicidad expresiva en su masa, con detalles que indicaran su destino y que armonizaran estéticamente con la "tensione spirituale che caratterizza la vita e le aspirazioni nazionali nell'epoca en ella civilità delle Camice Nere". ${ }^{55}$ El edificio estaba compuesto por

sede en Milán y Buenos Aires. (Archivio Palanti)

54 Lutz Becker, "Black shirt and White telephones" en Art and power. Europe under the dictators 1930-45. Dawn Ades, Tim Benton, David Eliott, Ian B. Whyte comps., (Hyward Gallery, 1995), 137. Como señaló Benjamin, "La radio y el cine no sólo modifican la función del actor profesional, sino que cambian también la de quienes, como los gobernantes, se presentan ante sus mecanismos. Sin perjuicio de los diversos cometidos específicos de ambos, la dirección de dicho cambio es la misma en lo que respecta al actor de cine y al gobernante. Aspira, bajo determinadas condiciones sociales, a exhibir sus actuaciones de manera más comprobable e incluso más asumible. De lo cual resulta una nueva selección, una selección ante esos aparatos, y de ella salen vencedores el dictador y la estrella de cine." Walter Benjamin, "La obra de arte en la época de su reproductibilidad técnica". Publicado en Walter Benjamin. Discursos Interrumpidos (Buenos Aires: Buenos Aires, 1989).

55 Palanti, Auditorium, 33 
dos partes, una horizontal y una vertical: el auditorio en forma de concha marina y una faja de cinco niveles en forma curva que acompañaba la forma del auditorio y contenía servicios y demás dependencias. El ingreso, al igual que en la solución F se daba por un amplio semicubierto atravesado por seis grandes pilares. El resultado debía ser una fusión del arte, de la técnica y de la ciencia. ${ }^{56}$

Sin embargo, en las variantes presentadas al concurso para la Torre Littoria en Piazza Duomo, impulsado por la Comuna di Milano en 1934, Palanti volvería a soluciones de un simbolismo exacerbado.

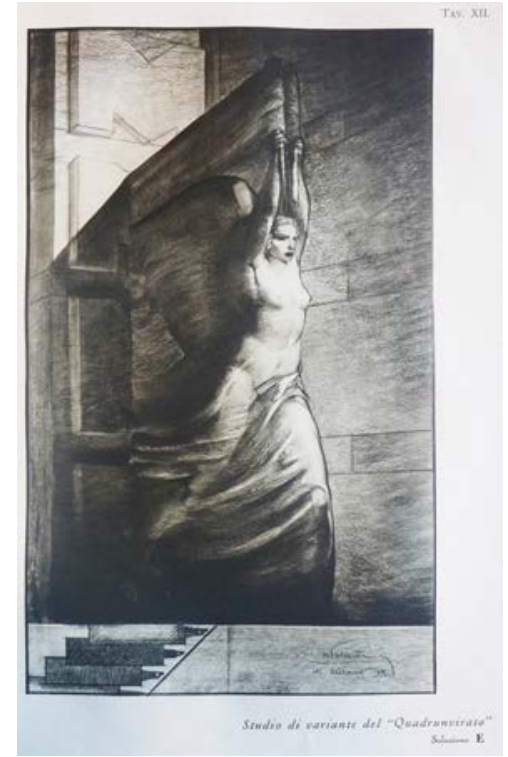

Detalle Torre Littoria Milán, 1934

Según el arquitecto, la torre estaba planteada con una función similar a la del Campanile de la Piazza de San Marcos de Venecia: debía “completar la armónica belleza de la plaza” y en su forma debía reflejar la nueva "armonía estética y fascista de Piazza del Duomo." ${ }^{57}$ De acuerdo a

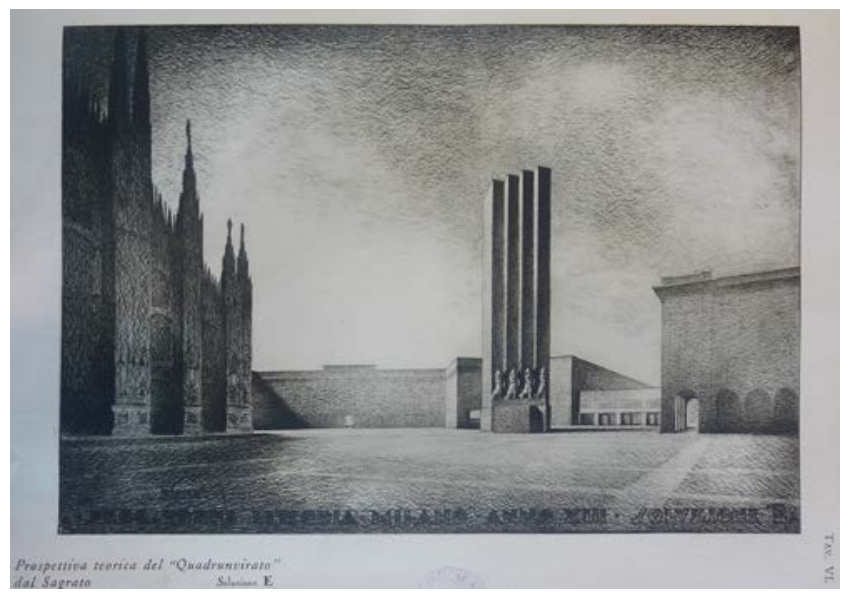

Propuesta para la Torre Littoria, Milán. 1934. Mario Palanti. Torre Littoria, progetti.1935

Palanti, el estilo de sus propuestas era "moderno por estar constituido por líneas esenciales, sin extravagancias absurdas o fuera de tono con la idea generadora." ${ }^{58} \mathrm{Si}$ en el caso del Auditorium Palanti suprimiría prácticamente toda decoración, en el caso de la Torre Littoria el edificio se tornaba un ornamento en sí mismo. Las soluciones mostraban directamente una arquitectura parlante dedicada a la propaganda política. Los ejemplos variaban entre una torre de 60 metros

56 Palanti, Auditorium, 33

57 Palanti, Torre littoria 13

58 Palanti, Torre littoria, 23 


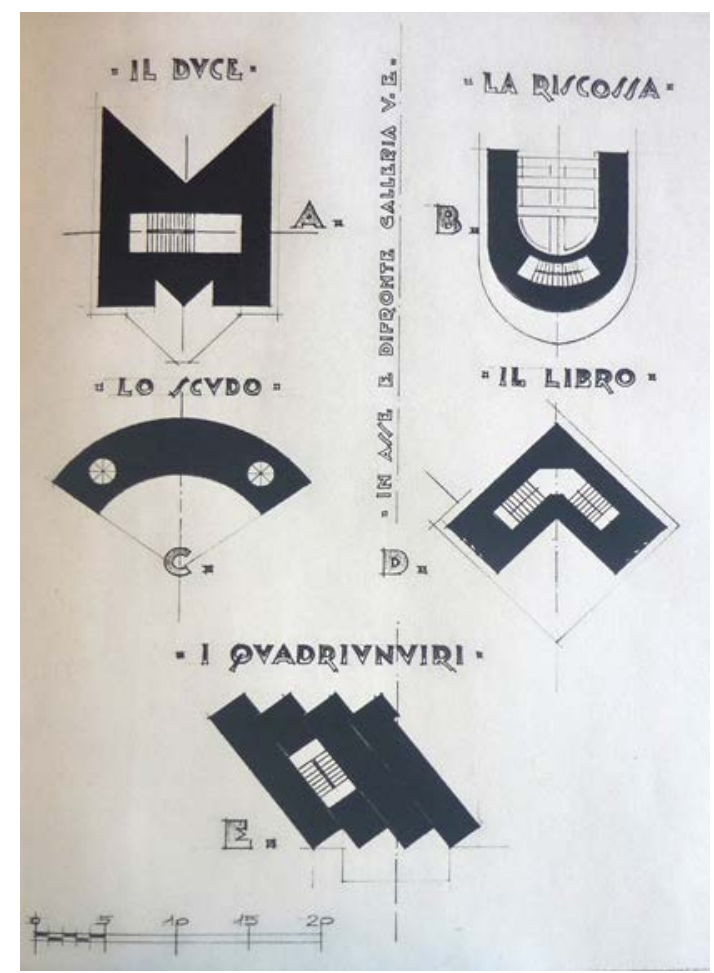

Variantes de partido para la Torre Littoria, Milán, 1934, Mario Palanti, Torre Littoria, progetti. Milán, Rizzoli \& C. 1935.

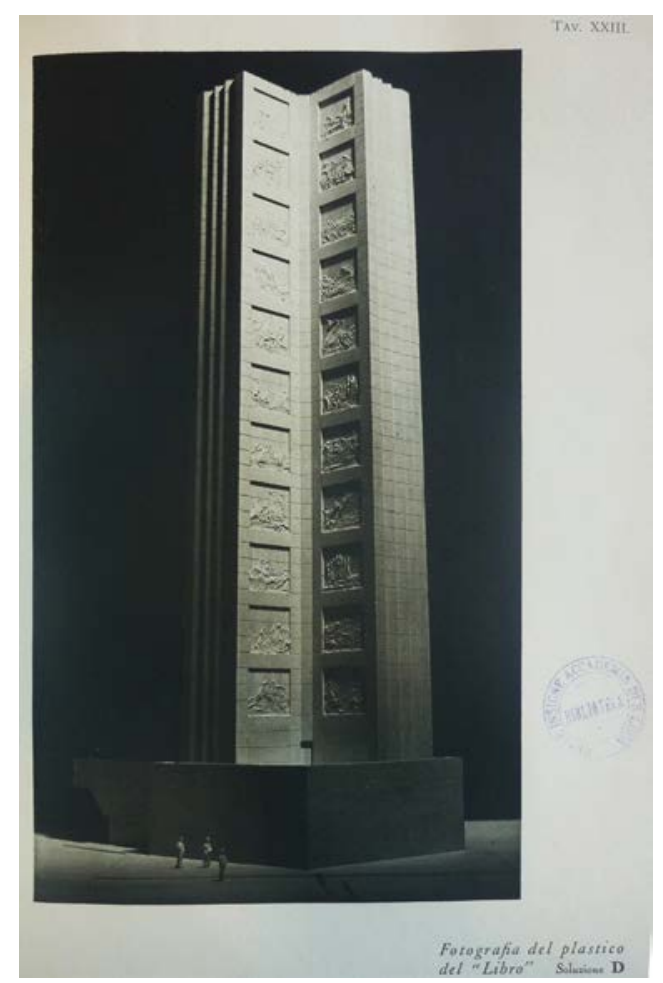

Maqueta para la Torre Littoria, en forma de "Libro". (Solucion D). 1934. Mario Palanti. Torre Littoria, progetti.1935

de altura en forma de 'M', un gran Fascio Littorio, un escudo romano, un libro semi abierto que simbolizaba la Revolución fascista escrita en la historia o un edificio formado por cuatro elementos rectangulares en forma de fascio que representaban, a su vez, el "quadriunvirato in marcia”.

Como señala Ciucci, a partir del concurso para el Palazzo Littorio el debate arquitectónico se da entre un "estilo para un Estado moderno y una imagen para un régimen espiritual. La arquitectura como forma moral se enfrenta a la arquitectura como forma ideal". ${ }^{59}$ Debate en el cual el tipo de arquitectura parlante desarrollado por Palanti quedaría fuera de juego. En efecto, el simbolismo explícito de la obra palantiana de entreguerras

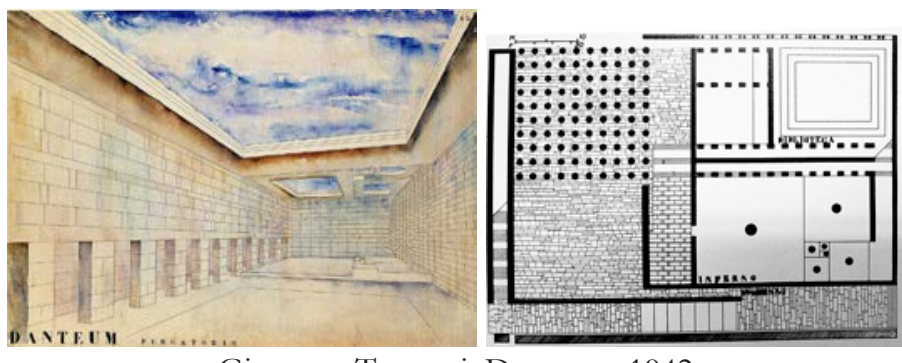

Giuseppe Terragni, Danteum, 1942

contrasta con la racionalidad invocada por el grupo de Giuseppe Terragni en las propuestas para el Palazzo del Littorio y más aún con el proyecto de Terragni y Lingeri, de 1938, para el 
Danteum que se ubicaría en el mismo sitio. La idea de una obra que glorificara al poeta fue impulsada por Rino Valdameri, director de la Accademia di Brera y cultor de Dante. ${ }^{60}$

El edificio, como muestra en su exhaustivo análisis de Schumacher, toma como símbolo de la aspiración política de Dante que era utilizada por el fascismo como alegoría política. ${ }^{61} \mathrm{La}$ relación del edificio con la obra literaria y el vínculo con la Antigüedad no se dan en una relación directa sino mediante metáforas. ${ }^{62}$ Mediante una disposición de elementos que representan el viaje de Dante, Terragni crea un escenario para el poema y una interpretación del "nuevo imperio romano de Mussolini”' ${ }^{63}$ Como estrategia, en el proyecto Terragni realiza un reinterpretación de múltiples fuentes (griegas, egipcias, romanas) que se funden en una composición abstracta que liga arquitectura y literatura con trazados que contienen el mundo clásico en el moderno. ${ }^{64}$

En su poética, el clasicismo no es una repuesta literal sino una rarefacción de las leyes intrínsecas de la arquitectura respecto de las proporciones, el espíritu clásico o del orden antiguo: la arquitectura de Terragni presume un orden ya dado, "no lo invoca sino lo evoca". ${ }^{65}$ En ella, señala Giorgio Ciucci, "La abstracción es total y el mito que el edificio debe transmitir (la fuerza en la figura de Mussolini, la transparencia de la idea fascista, el orden reconstruido por el fascismo) existe en cuanto el artificio habla de valores reales: líneas de fuerza isostáticas, paredes transparentes, rectángulos áureos, son artificios que asumen aquellos valores en el momento en el que comunican aquellos mitos.” ${ }_{66}$

\section{Sobrellevar las críticas}

A fines de la década de 1930, en una carta a su hermano, el arquitecto explicaba la perplejidad que le provocan los cambios producidos en el ambiente arquitectónico italiano y la esperanza de que se produzca, en un futuro no tan lejano, un retorno al "buen sentido". Comparando el suceso de su exposición de 1916 llevada a cabo en Buenos Aires con el ambiente de la década de 1930 en Italia decía:

60 Thomas L. Schumacher, The Danteum: architecture, poetics, and politics under Italian fascism (New York: Princeton Architectural Press, 1993 (1985)).

61 Schumacher, The Danteum, 22.

62 Schumacher, The Danteum, 24.

63 Schumacher, The Danteum, 29.

64 Schumacher, The Danteum, 107-114.

65 Ciucci, Gli architetti e il fascismo, 147.

66 Ciucci, Gli architetti e il fascismo, 148. Es, como explica Ciucci, una correspondencia formal y espiritual con las ruinas que existe en una racionalidad áurea de orden invisible y de relaciones que pueden sólo intuirse. 146. 
Io mi permetto di farti observare che in primo luogo, il frutto dal mio lavoro di quel tempo, fu oggetto di ammirazione (modestia aparte) e non vedo il perché di vergognarsi, pero recordare l'evoluzione dell 'arte mia odierna, che attraverso i grafici; poiché ancora nulla mi é stato possibile di portare a compimento. Ma comunque, la mia coscienza di artista galantuomo, non si lascerá portare verso gli sceni orribili, che purtroppo infestano tutta l'Italia, e che sembra, per Nostra fortuna subentri un pantimento, e cioé un retorno al buon senso. ${ }^{67}$

Pese a las críticas recibidas en un contexto que le era desfavorable, en esos años Palanti intentó, obsesivamente, difundir su arquitectura. Cada uno de los diseños presentados a concurso fue publicado por el autor en volúmenes que él mismo financiaba compuestos por una memoria descriptiva e imágenes de los proyectos. Los textos L'Eternale Mole Littoria (1926), Palazzo Littorio (1934), Auditorium (1935) y Torre Littoria (1935), fueron seguidos por la publicación, en 1935, de Tre progetti. Mole Littoria Roma, Auditorium Roma, Torre Littoria Milano: adesioni e giudizi, una edición formada por una introducción a cargo de Ottavio Dinale y unas 150 notas que -provenientes desde el Vaticano a la Universidad de Buenos Aires- agradecían al arquitecto el envío de alguno de sus libros. ${ }^{68}$ En una carta del 10 de diciembre de 1936, en un acto de propaganda a su trayectoria, Palanti señalaba la cantidad de donaciones para becas (Universitá di Architetura di Roma, Santa Sede Vaticano, Reale Accademia d'Itaila) que había realizado mientras vivía en el exterior (por un total de 582.000 Liras). ${ }^{69}$

Si bien los escritos no son extensos, a partir de los textos publicados por Palanti con motivo de los concursos para el régimen fascista podemos tener una idea sobre las lógicas proyectuales empleadas por el autor para construir un lenguaje que según sus ideas, ${ }^{70}$ debía ser representativo del fascismo y plantearse - con ciertas características de la nueva modernidadcomo una alternativa a las “despojadas” líneas del Racionalismo. Con respecto a esta modalidad preponderante en el contexto italiano opinaba críticamente con palabras que dejan ver la impronta boitiana:

$\overline{67}$ Carta de Mario Palanti a Giuseppe Palanti del 25 de octubre de 1938.AP. "Me permito hacerte notar que, en primer lugar, el fruto de mi trabajo de aquel momento fue motivo de admiración (modestia aparte) y no veo por qué avergonzarse al recordar la evolución de mi arte hoy en día que, a causa de las críticas, no logro poder llevarla a cabo. Pero mi conciencia de educado artista está tranquila y no se dejará llevar por las escenas horribles que lamentablemente infestan toda la Italia y que pareciera, para nuestra fortuna, haber un arrepentimiento y un retorno al buen sentido." [Traducción del autor]

68 Mario palanti, Tre progetti; Mole Littoria Roma, "Auditorium” Roma, Torre Littoria Milano. Adesioni e giudisi. (Milán: Rizzoli \& C., 1935)

69 Carta del 10 de diciembre de 1936, ACS-SPD, Busta 1154. En febrero de ese mismo año había enviado a Mussolini cinco publicaciones y se ofrecía para "qualsiasi incarico nel campo dell'Architettura o dell'Arte." Nota 26 de febrero 1936, ACS-SPD, Busta 1154.

70 Fernando Aliata, Estrategias proyectuales. Los géneros del proyecto moderno (Buenos Aires: SCA, 2014), 45 
Vi é ormai una necesità che domina, quella di esprimere un concetto architettonico con poche linee, sopprimendo archi, colonne, capitelli, timpani, trabeazioni, cornici, decoración. Ottenere il nuovo, l'originalitá e la potenza expresiva, sulla base alle esigenze razionali e funzionali, senza ricorrere alle risorse di tutti gli artificio tradicionali, sotto ai quali veniva sepolta l'ossatura, sino a sopprimere perfino il valore Della logica costruttiva. ${ }^{71}$

Sin embargo, sus intentos por adaptarse al contexto de entreguerras y lograr una vía alternativa al Racionalismo se centraron más en una narración retórica y propagandística del programa que en la concepción de los espacios y del organismo edilicio. Varios de sus diseños -como el proyecto para el Palacio Littorio en forma de nave o la Torre Littoria en sus variantes en forma de "M" o de libro muestran cómo Palanti se aleja del territorio de la arquitectura para acercarse al de la propaganda política. ${ }^{72}$ En búsqueda de amoldarse al debate arquitectónico pero intentando constituirse como una voz original, Palanti señalaba:

"Futurismo è più una parola che una realtà, più una tendenz̧a che una manifestazione. Il cubismo non è caratteristica di un tempo, ma può balzar fuori dall'anarchia del pensiero di qualsiasi eopca, e non solo mei periodi di decadenza, ma anche in quelli di gloria. ${ }^{{ }^{3} 3}$ Como respuesta, el arquitecto se proponía realizar un equilibrio entre modernidad y tradición que a su entender daría como resultado un "racionalismo espressivo". ${ }^{74}$ Esta combinación llevada al máximo de su potencialidad y manteniéndose dentro de las líneas de la tradición tenía, según Palanti, "la fuerza congénita para afrontar todos los problemas del arte. Y de los del arte fascista." ${ }^{75}$ Pero, principalmente, este maridaje entre modernidad y tradición le permitía aceptar las líneas de la llamada "arquitectura moderna” con la condición de mantener cierta expresividad.

Por otra parte, al entender a la revolución fascista como "una obra de arte" Palanti la transformaba en un elemento más dentro del repertorio estilístico disponible: "L’arte debe seguire il volo delle aquile. Da questo imperativo categorico può nascere la possibilità per gli artisti del secolo fascista, di adeguarsi, nello spirito e nelle realizzazioni, a quella insuperabile opera d'arte che è la Rivoluzione Fascista."76

71 Palanti, Palazzo Littorio, 11. Existe hoy una necesidad dominante y es la de expresar un concepto arquitectónico con pocas líneas, suprimiendo los arcos, columnas, capiteles, tímpanos, entablamentos, cornisas, decoración. Obtener lo nuevo, la originalidad y la potencia expresiva en base a las exigencias racionales y funcionales sin apelar a recursos y artificios tradicionales bajo los cuales se esconde la estructura hasta suprimir el valor de la lógica constructiva. [Traducción del autor]

72 Nicoloso, Mussolini architetto, 116. Véase Aliata y Bonicatto, Mario Palanti

73 Palanti, Palaz:o Littorio, 9.

74 Palanti, Palazzo Littorio, 9.

75 Palanti, Palazzo Littorio, 9.

76 Palanti, Palazzo Littorio, 9.” El arte debe seguir el vuelo del águila. De este imperativo categórico puede surgir la posibilidad para los artistas del siglo fascista de adecuarse, en el espíritu y en las realizaciones, a esa obra de arte 
De esta manera el arquitecto mantenía su método proyectual y sumaba a la cantera de la historia la "tensión del espíritu fascista". El nuevo orden debía ser expresado en la arquitectura para diferenciarse del clasicismo estático, incoloro y mudo que se manifestaba en la expresión fatal del superado decadentismo político y moral del antiguo régimen. ${ }^{77}$ Pero su teoría -que persiste en la idea del carácter en la arquitectura- resultaba ya anacrónica en la década del treinta. En efecto, Si bien sus propuestas incorporaban nuevas tecnologías y realizaban un detallado análisis funcional del programa, la forma resultante no era reflejo de tales operaciones sino que era la consecuencia de una "idea fuerza": no se lograba separar de la praxis académica transformándose en muchos casos en una "arquitectura parlante" contenedora del programa. Efectivamente, en la búsqueda de una arquitectura como arte de Estado, la nueva conciencia artística del Estado Fascista se había inclinado oportunamente hacia los diferentes grupos arquitectónicos que, si bien diversos, recorrían un camino diferente a los sombríos espacios propuestos por Palanti.

Este diverso y complejo contexto disciplinar daba cuenta del amplio marco de opciones en el cual se inscribían las preferencias arquitectónicas del régimen. Como señala Diane Ghirardo, durante el período de entreguerras existía diversidad no sólo entre los grupos sino dentro de los mismos. Por un lado estaban los académicos Armando Brasini, Cesare Bazzani, Carlo Broggi o el editor de Dedalo, Ugo Ojetti quien impulsaba desde el eclecticismo decimonónico un estilo neoclásico. Por otro lado, los "moderados" se dividían en dos grupos: uno en Milán

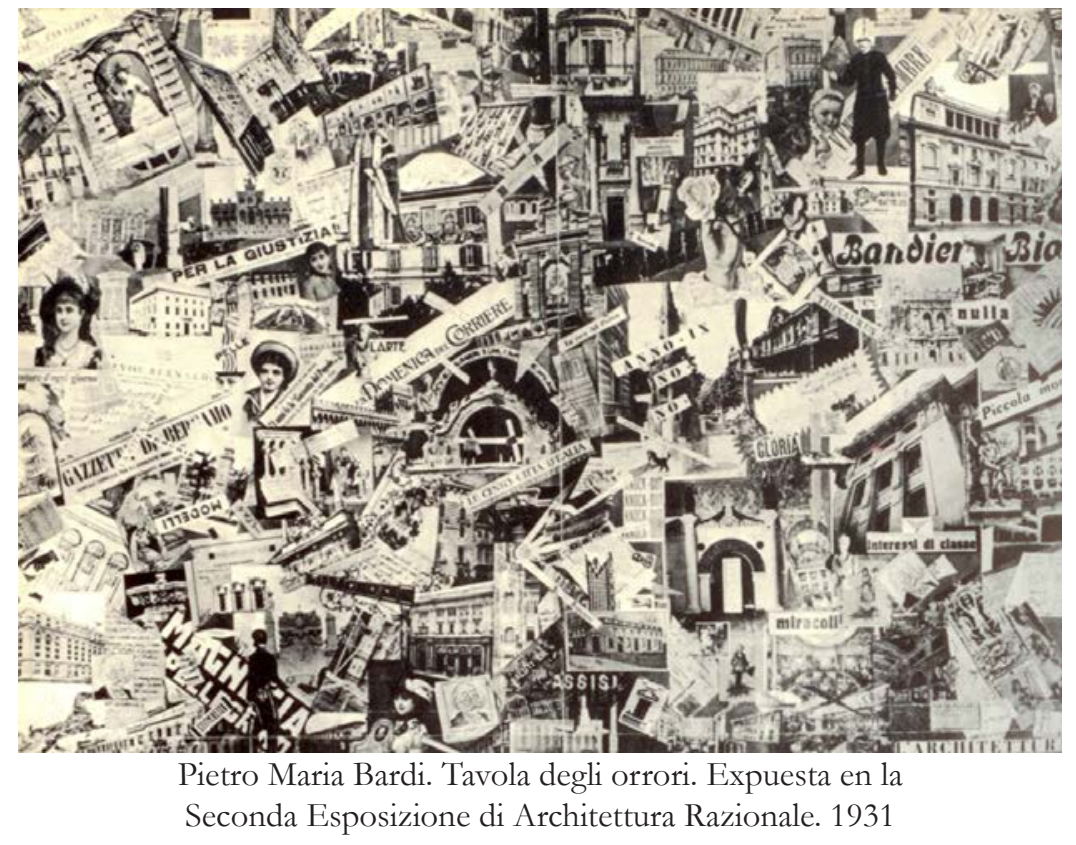

insuperable que es la Revolución Fascista." [Traducción del autor]

77 Palanti, Palazzo Littorio, 11 “(...) classicismo statico, incolore e muto, degenerato spesso in forme di estemporaneità guasta ed ibrida, la quale si manifestava come il corrispettivo fatale del superato decadentismo político morale del l'antico regime" 
(el grupo Novecento) con Piero Portaluppi, Gio Ponti, Giovanni Muzio y otro en Roma liderado por Piacentini quien, habiendo abandonado el eclecticismo decimonónico, se inclinaba hacia un academicismo racionalizado que intentaba conjugar una síntesis italiana de lo moderno y lo tradicional. Los racionalistas, por su parte, influenciados por la vanguardia europea y quienes representaban el ala italiana en general, se nucleaban en el Gruppo Sette que luego daría lugar al M.I.A.R. en 1928 entre cuyos miembros encontramos a Gino Pollini, Giuseppe Terragni, Giusepe Pagano, Adalberto Libera y Pietro María Bardi director de la revista Quadrante y autor la Tavola degli orrori presentada en 1931 en la Seconda Esposizione di Architettura Razionale. ${ }^{78}$

Este variado panorama se ve reflejado en los debates y en las publicaciones promovidos por los defensores de la arquitectura moderna. A las reiteradas críticas lanzadas por Giuseppe Pagano desde las páginas de Casabella ${ }^{79}$ Palanti respondía con protestas que tenían origen en el rechazo de su proyecto por parte del jurado del concurso del Palazo Littorio. Su queja dejaba ver, por un lado, su idea sobre la arquitectura "moderna" como representación del estado fascista y, por otro, el enfado que tenía con Marcelo Piacentini el principal operador arquitectónico del régimen que se había convertido en su persistente enemigo. En una carta de octubre de 1935, Palanti explicaba su desazón frente a un contexto que no comprendía y desaprobaba:

Mi riesce oltremodo doloroso ricorrere a questo procedimiento, spinto come da un Sacro dovere, da Italiano e Fascista fervente, per il bene colletivo, per l'arte nostra e per collaborare all'idea, se possibile, di arginare tale prepotente invadenza Piacentiniana, infiltratasi ovunque nel Regno.

Conosciamo il nostro valore professionale e conosciamo quelle dell'Arch. Marcello Piacentini, il quale ha contribuito a commercializzare l'architettura nostra, col pretesto di creare del Razionalismo Fascista. ${ }^{80}$

Piacentini y su círculo eran, según su parecer, quienes habían conspirado para que: “(...) cosí dopo sei anni dal mio ritorno in patria io non ho potuto costruire un decimetro quadrato di muro." Y continuaba

78 Diane Ghirardo "Italian Architects and Fascist Politics: An Evaluation of the Rationalist's Role in Regime Building", Journal of the Society of Architectural Historians 39, No. 2 (May, 1980), 109-127 y Tafuri y Dal Co, Arquitectura contemporánea.

79 Pagano, "Mussolini salva l'architettura italiana"; Pagano, "Il Concorso per il Palazzo del Littorio".

80 Carta de Mario Palanti al Ing. Radice Fossati del 14 ottobre 1935. ACS-SPD, Busta 1154. "Me resulta muy doloroso recurrir a este procedimiento, impulsado como por un deber sagrado de italiano y de ferviente fascista, para el bien colectivo, para nuestro arte y para colaborar con la idea, si es posible, de frenar la prepotente invasión piacentiniana que se infiltra en el Reino.Conocemos nuestro valor profesional y conocemos el del arquitecto Marcello Piacentini, quien ha contribuido a comercializar nuestra arquitectura con el pretexto de crear el Racionalismo fascista" [Traducción del autor] 
"L'Italia Fascisa sotto la guida del Duce si trasforma Imperialmente e si costruisce da pertutti. L'Arch. Palanti é escluso, e non Riesco a comprenderne le ragioni, in modo assoluto da questa immesa opera di trasformazione."

Efectivamente, como bien lo expresa Giorgio Ciucci "La transparenza di un edificio in struttura di cemento racchiuso da superfici vetrate deviene così non solo immagine della modernità, ma anche maniera di illustrare la "transparenta" stessa dell'idea fascista: il fascismo, aveva affermato Mussolini, è una "casa di vetro". ${ }^{82}$

El "estilo" fue definido por el lenguaje de la "modernidad" y el mensaje político y la representación de la "idea fascista" se vieron de esta manera expresados en la obra de arquitectos como Piacentini, Pagano, Terragni, Ponti, Muzio, Libera, Sironi entre otros. ${ }^{83}$

\section{E'42. un nuevo material para una nueva arquitectura}

El lenguaje clásico con que se identificó el fascismo encontraría su auge en la Exposición Universal de Roma (E’42) planeada para el año 1942. Como señala Ciucci, después de la Roma Imperial, la Roma papal y Roma mussolineana, con la conquista de Addis Abeba en 1936 se planteaba al E'42 como modelo para la capital y símbolo de una cuarta Roma, fascista e imperial. La iniciativa, originada en 1935, proponía llevar a cabo una celebración a la altura de exposiciones precedentes como la de Chicago, A Century of Progress (1933) o la de París, Arts et Techniques (1937), y conmemorar, a su vez, los veinte años de la Marcha sobre Roma con el propósito de afirmar -y demostrar- el rol internacional del régimen. ${ }^{84}$ En 1936, se eligió un sitio de 400 hectáreas para el emplazamiento, en la zona de Tre Fontane, cercana a Roma y al mar. A cargo del emprendimiento, Mussolini nombró a Vittorio Cini como Comisario General del Ente E’42 y a Cipriano Efisio Oppo -quien fue director artístico de la Mostra della Rivoluzione Fascista- como Vicepresidente del Ente. ${ }^{85}$ Ese mismo año de 1936 Cini presentó una lista de

81 Carta de Mario Palanti a Farinata del 23 de enero de 1940. ACS-SPD, Busta 1154. “(...) así luego de seis años de mi regreso a la patria no he podido construir un decímetro cuadrado de muro." Y continuaba "la Italia Fascista bajo la guía del Duce se transforma Imperialmente y se construye por todos lados. El Arq. Palanti es excluido, y no logro comprender las razones, de modo alguno de esta inmensa obra de transformaciones." [Traducción Florencia Minatta]

82 Ciucci, Gli architetti e il fascismo, 110. Efectivamente, como bien lo expresa Giorgio Ciucci "La transparencia de un edificio con estructura de cemento encerrado por superficies vidriadas se transforma de esta manera no sólo en la imagen de la modernidad, sino también en una manera de ilustrar la "transparencia" misma de la idea fascista: el fascismo, había afirmado Mussolini, es una "caja de vidrio". [Traducción Florencia Minatta]

83 Véase "Architettura, arte di stato" en Ciucci, Gli architetti e il fascismo.

84 Ciucci, Gli architetti e il fascismo, 177-180.

85 Ciucci, Gli architetti e il fascismo, 177-180. Nicoloso, Mussolini architetto, 196-197. Véase Archietttura, rivista del sindicato nazionale fascista di architetti, 1938 - XVII, dicembre, fascicolo speciale L’Esposizione Universale di Roma 
trece arquitectos de los cuales Mussolini eligió cinco para estar a cargo del plano regulador: Piacentini -primero de la lista-, Pagano, Piccinato, Vietti y Ettore Rossi. ${ }^{86}$

En efecto, el E’42 debía ser la imagen representativa del régimen, una ciudad cuyo centro monumental fuera caracterizado por el "estilo" de la época fascista. Para ello, se llevó a cabo un concurso organizado por el Ente para la elección de los arquitectos que estarían a cargo de los edificios permanentes, mientras que para la realización de los pabellones provisorios no había limitaciones explícitas. ${ }^{87}$

Como parte del programa se destinaba un espacio para la innovación y los avances técnicos, entre los cuales se privilegiaba la experimentación en sistemas constructivos para viviendas. En efecto, la investigación relacionada a la vivienda y al uso de nuevas tecnologías en el ámbito de la construcción se había visto incrementada en Europa desde la primera posguerra. ${ }^{88}$ Tal como lo muestran estudios como los de Enrico A. Griffini, Giuseppe Samonà o Gaetano Minucci, durante la década de 1930, el tema tomó protagonismo en el debate disciplinar italiano. ${ }^{89}$ Así lo muestran las páginas de Domus y Casabella, las dos principales revistas italianas de la década de 1930 en las que la búsqueda de una nueva arquitectura se relaciona principalmente con el tema de la "casa para todos". Durante el período, Casabella dedicó una serie de artículos a la tipología de casa popular, entre ellos el trabajo de Giancarlo Palanti-sobrino de Mario Palanti-, quien señalaba que el tema de la casa "è un problema sociale e un tempo costruttivo, economico, igienico ed estetico." ${ }_{90}$

1942. P.749 Véase Archietttura, rivista del sindicato nazionale fascista di architetti, XVII (dicembre 1938, fascicolo speciale L'Esposizione Universale di Roma 1942): 749.

86 Los restantes eran Vaccaro, Libera, Del Debbio, Terragni, Muchelucci, Montuori, muratori y Muzio. Nicoloso, Mussolini architetto, 198.

87 Ciucci, Gli architetti e il fascismo, 183.

88 El tema de la habitación colectiva encuentra en la exposición Weissenhofsiedlung de Stuttgart (1927) y en el CIAM de 1929 dedicado al tema vivienda (existenzminimum) dos de las principales expresiones de esta búsqueda. Véase de Auke van der Woude y Rafael García, "La vivienda popular en el Movimiento Moderno", Cuaderno de notas No7 (diciembre 1999): 3-54. Consultado 13 de febrero 2015. http://polired.upm.es/index.php/cuadernodenotas/ index $(13 / 2 / 15)$

89 Alberto Sartoris, Gli elementi dell'architettura funzionale. Sintesi panoramicadell'architettura moderna (Milano: Hoepli, 1932); Enrico A. Griffini, Costruzione raz̧ionale della casa (Milano: Hoepli, 1933); y Giuseppe Samonà, La casa popolare

(Napoli: Politecnica, 1935).

90 Giancarlo Palanti, "Nota sulle case popolari”, Casabella, No78 (giugno 1934): 6-7; Véase la tesis doctoral de Claudia Cagneschi. La costruqione razionale della casa. Scritti e progetti di Giuseppe Pagano, Alma Mater Studiorum Università di Bologna, Dottorato di Ricerca in Composizione Architettonica, Scuola di Dottorato in Ingegneria Civile ed Architettura XXI Ciclo di Dottorato 2009. Consultado 12 de febrero 2015. http://amsdottorato.unibo. it/1440/1/Cagneschi Claudia tesi.pdf (12/2/15) particularmente el capítulo 1 "La costruzionde della casa". La autora realiza un pormenorizado trabajo sobre las publicaciones de Pagano en Cassabella. Véase: Giuseppe Pagano, "La tecnica e i materiali dell'edilizia moderna", Edilizia moderna, No5 (aprile 1932): 35; "Le case «popolarissime», Casabella, No 112 (aprile 1937): 2-5; "Elemento di abitazione minima", Casabella, No113 (maggio 1937): 14-37; "Il fascismo e la casa", Casabella-Costruqioni, No122 (febbraio 1938): 2-4. 
En 1933 la V Triennale de Milán dedicó un considerable espacio a la habitación moderna, a la estandarización y aplicación de nuevas tecnologías y materiales. La VI Triennale realizada en 1936 y curada, entre otros, por Franco Albini, Renato Camus, Ignazio Gardella y Giancarlo Palanti se focalizó, principalmente, en la muestra de sistemas constructivos y materiales edilicios, elementos decorativos y la muestra de la habitación en la que se trató el tema de la casa para tres categorías: el operario, el empleado y el profesional. En 1940, con la intervención de Pagano, la VII Triennale centró la atención en la Mostra Internazionale della Produzione in Serie. La ausencia de Palanti y del sistema constructivo que venía desarrollando se debe, posiblemente, a la presencia de Pagano.

Entre abril y mayo de 1937, probablemente vislumbrando una oportunidad, Palanti envió al Ente Organizador del E'42 los planos de unas pequeñas viviendas agrupadas a realizarse con el sistema de construcción en seco llamado "Palandomus" sobre el cual trabajaba desde
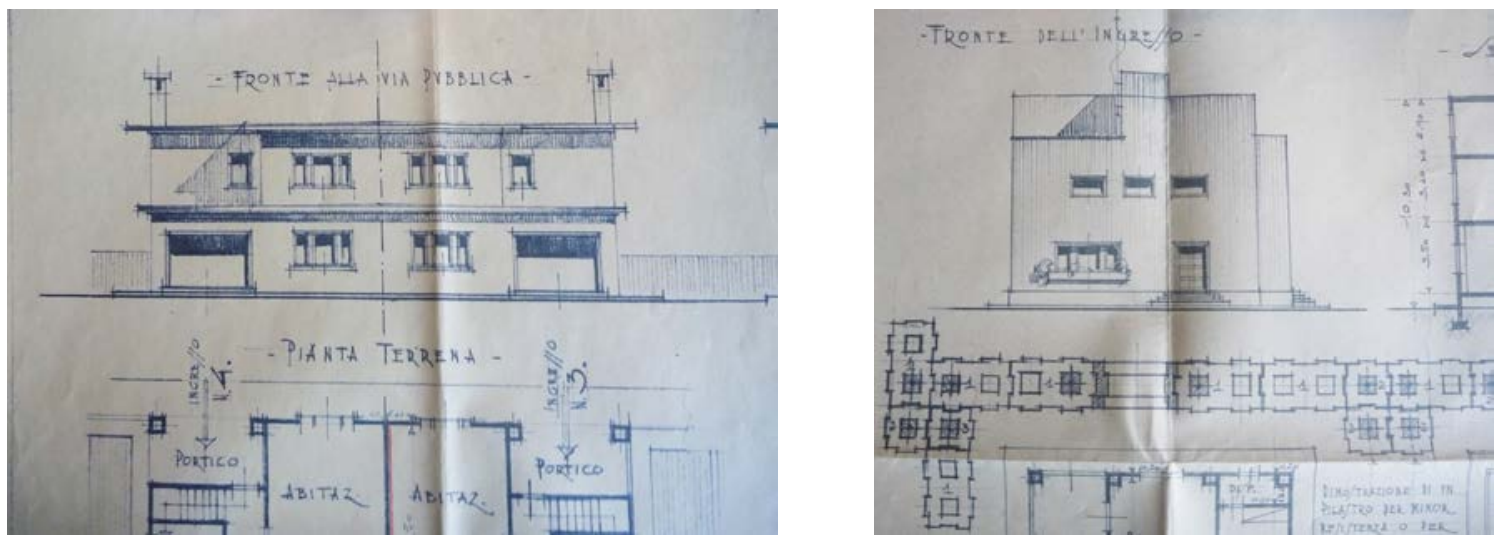

proyecto de viviendaa realizarse con sistema Palandomus, presentado para el E'42. ACS-ENR

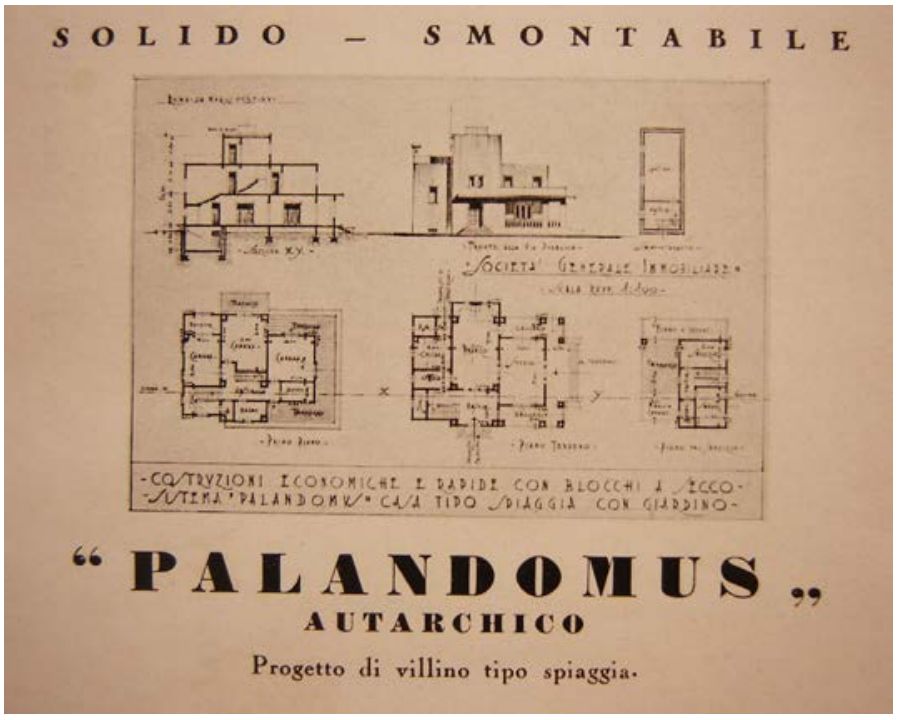

Proyecto de vivienda (la misma propuesta presentada al E'42)

Palandomus.Milan.ca. 1938. GRI 
hacía tiempo. Conociendo el interés que el Ente tenía en la demostración de los avances de la industria y de nuevas técnicas constructivas, el 2 de noviembre de ese año le envió una carta a Vittorio Cini sobre la iniciativa del Ente de obtener construcciones de rápida realización, económicas y desmontables con la "esperanza de que le concediera el favor" de darle un lugar en la muestra..$^{91}$

De acuerdo a la carta que se conserva en el Archivio Centrale dello Stato, Palanti recibió la aprobación para enviar un presupuesto para la construcción de una piccola baracca a realizarse con el sistema "Palandomus" en la cual se construirían las maquetas, dentro del recinto de la exposición: el 2 de diciembre Palanti se contactó con el ingeniero Cesare Palazzo, a cargo de la Direzione dei Servizi Tecnici, para agradecer su recomendación y comunicarle el próximo envío del presupuesto de la construcción. ${ }^{92}$ Poco después, el 7 de diciembre, Palanti le envió una carta al Vicepresidente del Ente, Cipriano Efisio Oppo, para notificar el envío del presupuesto y dejar en claro que no pretendía obtener remuneración alguna por el trabajo pues su único anhelo era poder poner a prueba el sistema y demostrar así su superioridad. ${ }^{93}$ Precisamente, luego de los fallidos episodios acaecidos en los concursos para el régimen fascista, el E'42 se presentaba ante Palanti como una nueva oportunidad que le permitiría dar a conocer su invento.

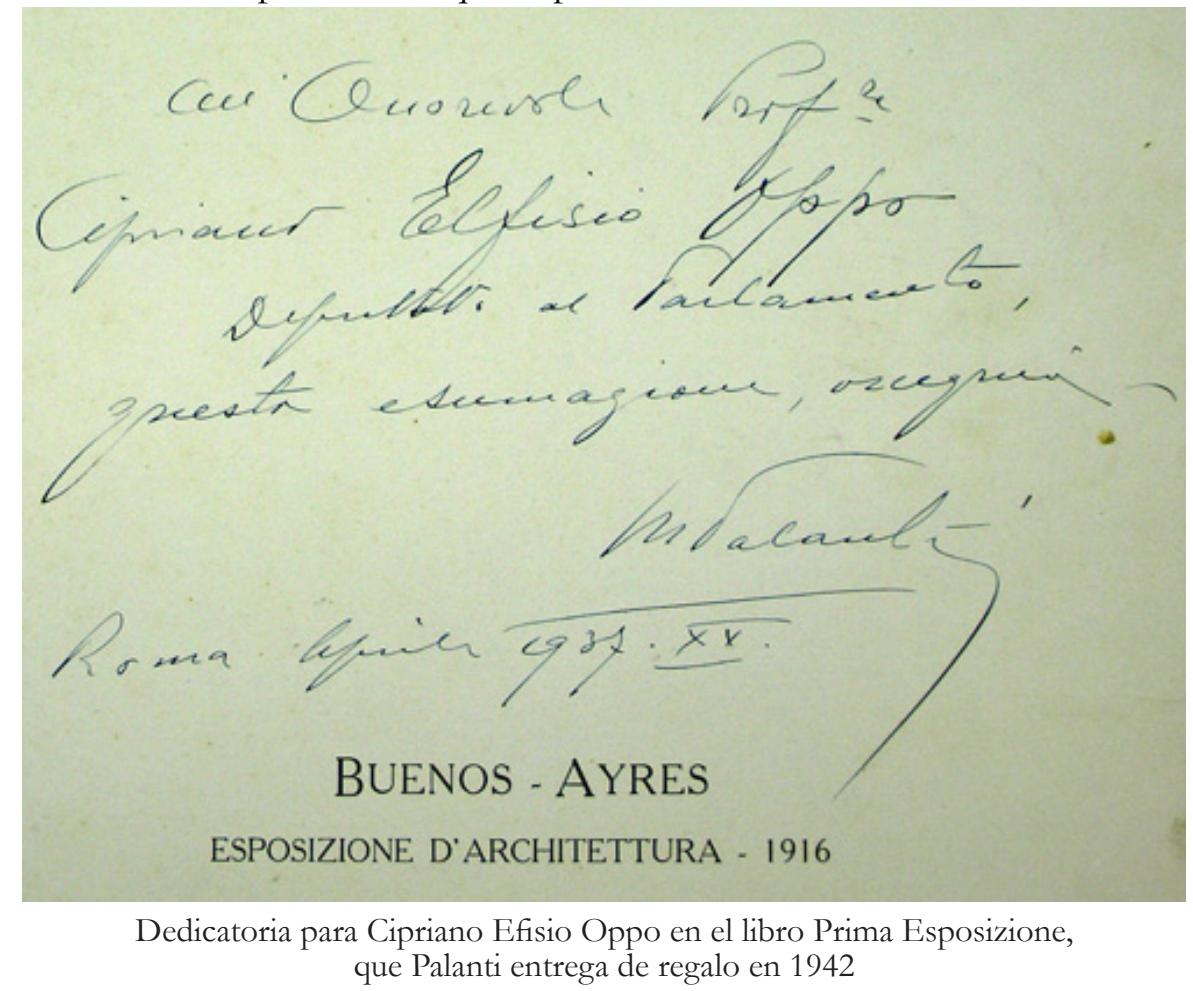

91 Carta de Mario Palanti a Vittorio Cini, 2 de noviembre de 1937. Archivio Centrale dello Stato, Esposizione Nazionale Roma E42 (ACS ENR), Busta 322.

92 Carta de Mario Palanti a Vittorio Cini, 2 de diciembre de 1937. ACS ENR, Busta 322.

93 Carta de Mario Palanti a Cipriano Efesio Oppo, 7 de diciembre de 1937. ACS ENR, Busta 322. 
En 1940, el convulsionado ambiente bélico llegó al E’42. El ingreso de Italia a la Segunda Guerra marcó el abandono del inmenso cantiere de la Exposición: el año de 1942 no recibió la inauguración sino el abandono de las tareas y los esfuerzos y recursos fueron destinados a la guerra. ${ }^{94}$ Si desde hacía ya seis años los constantes pedidos y súplicas por trabajo ante la jerarquía fascista que Palanti realizaba no encontró respuesta, con la energía del régimen volcada en la Segunda Guerra las posibilidades para Palanti de convertirse en un arquitecto del fascismo se veían agotadas..$^{95}$

Sin embargo, si algo caracterizó la trayectoria del arquitecto fue la perseverancia. A partir de 1938, en sintonía con la problemática del momento, el arquitecto concentró su atención en el sistema "Palandomus", el bloque modular sobre el que experimentaba desde inicios de su carrera y en el cual el arquitecto volcaría sus expectativas profesionales. ${ }^{96}$

\section{Antiguas invensiones técnicas}

El primer sistema desarrollado por Palanti, llamado Palanthome, databa de la década de 1920 y estaba compuesto por diferentes piezas que se encastraban para armar una vivienda básica y económica que éste había llamado "Casa Universal Palanti” y cuyo sistema había patentado en la Argentina y otros países. ${ }^{97}$

El 2 de enero de 1923 se había conformado la "Sociedad Anónima PALANTHOME. La casa argentina. Construcción económica” con fabrica ubicada en Vélez Sarsfield entre Zepita y Luzuriaga del barrio de Barracas, Buenos Aires, y un capital de $1.500 .00 \$ \mathrm{~m} / \mathrm{n}$ y cuyo funcionamiento fue autorizado por decreto en abril de ese mismo año. ${ }^{98}$ Como muestra el estatuto

$\overline{94}$ Véase H. James Burgwyn, Mussolini Warlord: Failed Dreams of Empire, 1940-1943, (Enigma Books: 2013)

95 Carta de Mario Palanti a Farinata, 24 de enero de 1940. ACS SPD, Busta 1154. (Ver apéndice)

96 Palanti, Palandomus autarchico; Palandomus laterizio ermafrodita; ca.1948. Palanti, Mario. Palandomus Ca. 1956, borrador del libro, AGEP

97 Como parte de sus propuestas Palanti había diseñado viviendas "económicas” para la Unión Popular Católica Argentina. En 1923, el sistema fue patentado en Uruguay, Brasil, España, Inglaterra y Francia. El año siguiente en Canadá y en 1925 el sistema fue patentado en Argentina y en Estados Unidos (AGEP) . En 1938, ya como Palandomus, fue patentado en Italia, en 1939 en Estados Unidos mismo año que intentó patentarlo en Argentina, Brasil y Uruguay. (ver apéndice)

98 Boletin Oficial de la República Argentina, año XXXV no 10.001 del 18 de agosto de 1927. Actas del 25-7-1927, 691. Palanti había vendido al que sería el primer directorio de la Sociedad Anonima "Palanthome la casa argentina": “(...) la patente y marca de su invento "PALANTHOME", la patente "CASA UNIVERSAL PALANTI" los útiles y demás existencias de propiedad del mismo (...). La concesión por cinco años de una fracción de terreno aislada en el local de la Exposición Rural de Palermo (Capital) con una casita construida según el sistema "Casa Universal Palanti”. El contrato de arrendamiento por cinco años de una manzana de terreno (...) con frente a la Avenida Vélez Sársfield y calles Zepita y Luzuriaga con sus galpones y existencias y una serie de modelos del sistema PALANTHOME" (...)", Archivio Segreto Vaticano, Archivio Nunziatura Apostolica in Argentina, Giovanni Beda Cardinale. Busta 97, Fascicolo 500, “varias”, an.1921-1923, ff. 1-102. 


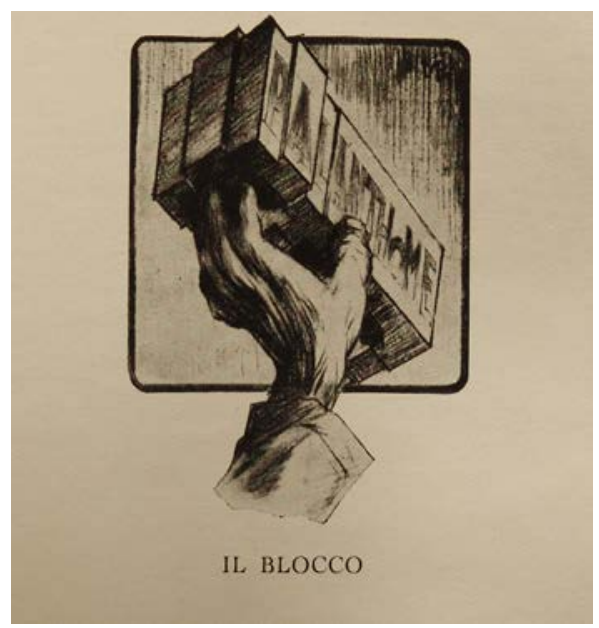

Palandomus.Milan.ca. 1938. GRI

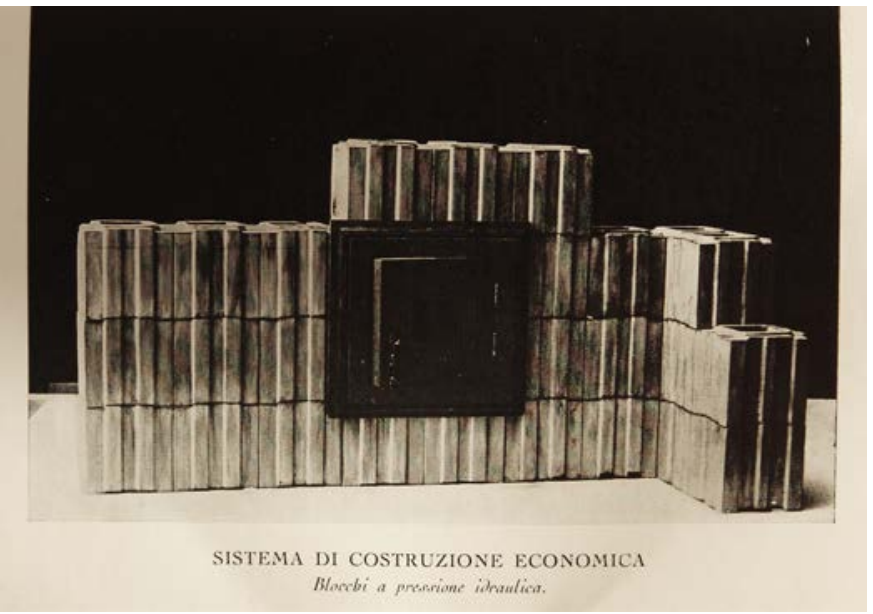

Prueba del sistema.Palandomus.Milan.ca. 1938. GRI

de la Sociedad, el directorio estaba formado, entre otros, por el Presidente. Dr. Eliseo Segura, Vice presidente Sr. David Costaguta, Secretario. Dr. Miguel Ángel Carcano y Mario Palanti que permanecía como Director Técnico Ad Honorem.99 Sin embargo, la Sociedad no permanecería activa por mucho tiempo. En noviembre de 1925 se llamó a asamblea extraordinaria para discutir la reducción del capital social en un 50\% y se pidió autorización para la venta de las instalaciones y maquinarias. ${ }^{100}$ En agosto de 1927, la Sociedad quedaba disuelta y el decreto que autorizaba su funcionamiento quedaba derogado. ${ }^{101}$

A pesar de la disolución de la Sociedad, Palanti continuó sus investigaciones. Este sistema de bloques Palanthome, que podía estar compuesto por arcilla -cruda o cocida- cemento, terracota u otros, y en el cual primaba la "forma" por sobre el material, derivó en la década de 1930 en el sistema "Palandomus autarchico" y luego, en la década de 1940, en el ermafrodita que estaba compuesto por un ladrillo cerámico "tipo", de formato ondulado, que abandonaba el encastre macho-hembra para simplificarse en un único bloque hermafrodita. Esta simplicidad absoluta otorgada por el monomaterial era, según Palanti, la virtud que lo diferenciaba de otros sistemas con características similares. ${ }^{102}$

En efecto, el primigenio sistema "Palanthome" se componía por un bloque cuyas

99 Presidente. Dr. Eliseo Segura, Vice presidente Sr. David Costaguta, Secretario. Dr. Miguel Ángel Carcano, Tesorero. Dr. Alberto Costabel, los vocales: Dr. Felipe Gottheil de Luca, Sr. Alejandro Saoli, Ing. Antonio Poy Costa, Síndico Dr. Fernando Cremonesi, Sindico Suplente, Dr. Carlos A. Pueyrredón. Archivio Segreto Vaticano, Archivio Nunziatura Apostolica in Argentina, Giovanni Beda Cardinale. Busta 97, Fascicolo 500, "varias", an.19211923, ff. 1-102.

100 Boletin Oficial de la República Argentina, año XXXIIL no 9487 del 13 de noviembre de 1925. Actas del 10-111923, 393.

101 Boletín Oficial de la República Argentina, año XXXV no 10.001 del 18 de agosto de 1927. Actas del 25-7-1927, 691.

102 Biblioteca de la Reale Accademia, Roma (BRA). Carta de Mario Palanti al Dir. De la Enciclopedia Treccani. 20 de octubre de 1947. Sobre la técnica edilicia en Italia y sobre el Palandomus véase el texto de Eleonora Trivellin Storia della tecnica edilizia in Italia: Dall'unita ad oggi. Alinea Ed. 1998. pp. 92-95. 


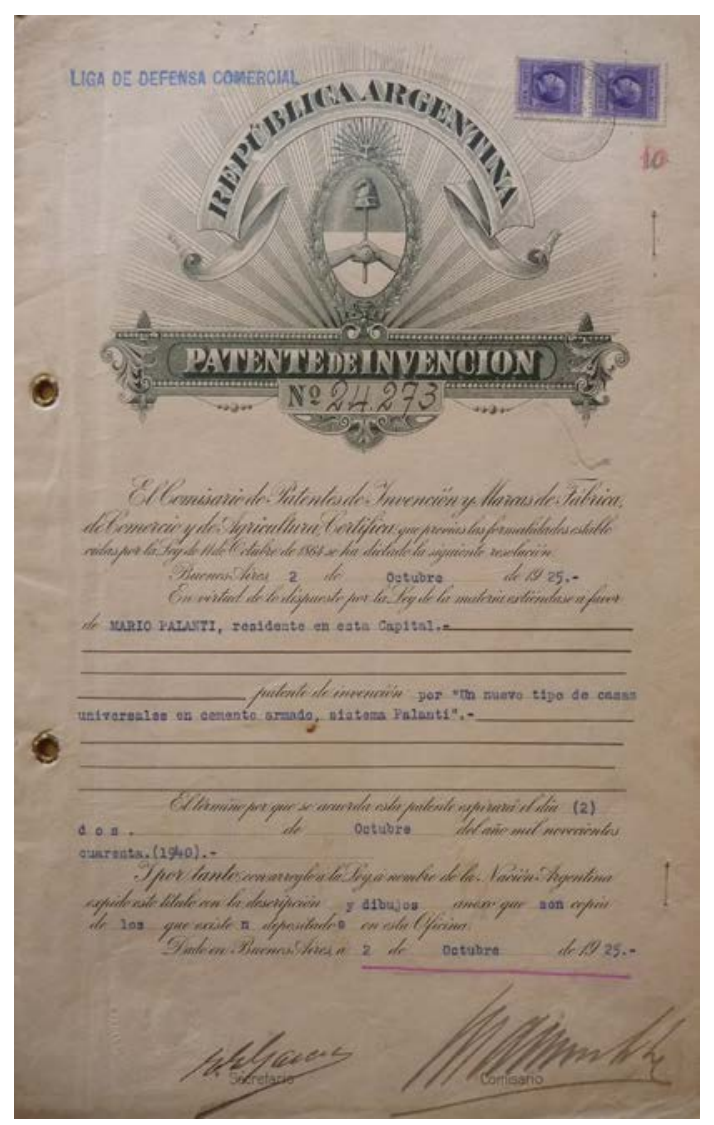

Patente de invención el sistema Palanthome en la República Argentina. 1925. AGEP

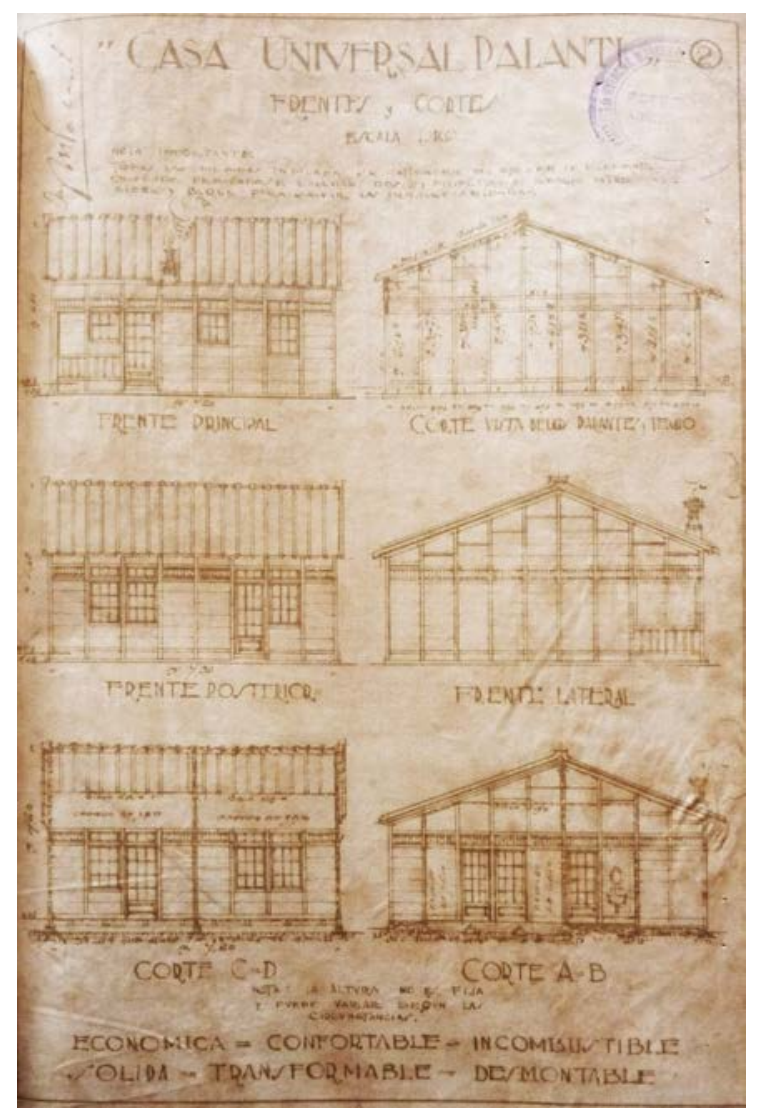

Vistas y cortes de vivienda tipo realizada con el sistema Palanthome. Patente de invención en la Argentina. 1925. AGEP

medidas podían variar en ancho, largo y alto dependiendo de las necesidades y que se dividía en dos partes (cabeza y cuerpo) con un centro hueco donde pasaban las instalaciones o se vertía hormigón armado. El sistema para la Casa Universal prefabricada aseguraba un ahorro del 30 al 50\% respecto de otros sistemas ya que todo - desde los cimientos a la cubierta- se construía con un único material. ${ }^{103}$ Si bien era prefabricado, el sistema se alejaba notoriamente de la estandarización. La casa se armaba con un sinfín de piezas diferentes: catorce variantes de bloques chatos, tres variantes de bloques largueros, bloques de pared, de cubierta, curvos, bloques destinados a instalaciones, a bases, etcétera. Precisamente, este sería uno de los factores que Palanti evitaría en el futuro en el intento de lograr la máxima estandarización y economía en los elementos constructivos.

Durante años Palanti intentó insertar su sistema constructivo en el mercado. Como ya fue mencionado, durante la década de 1920 la difusión se dio mediante patentes en diferentes países, mientras que en la década siguiente comenzó a publicitar el sistema con el nombre

$\overline{103}$ Desde principios de siglo XX -e incrementado durante el período de la primera posguerra- se desarrollan varios sistemas. Junto a la patente del Palanthome, sólo en los Estados Unidos, por ejemplo, encontramos cuatro sistemas diferentes de bloques para construcción: Faulkner, 1905; Diamond, 1911; Gronert et al, 1916; Poth et al, 1922. US Patent Office. https://www.google.com/patents/US1552077 Consultado agosto 2014. 
"Palandomus" o "Palandomus autarchico" con ciertas modificaciones: el mismo había sido simplificado reduciendo notablemente la variedad de bloques y eliminando el encastre machohembra. El formato mantenía los lados rectos con hendiduras y, de acuerdo a Palanti, superaba en economía al ladrillo común en un 40\% y permitía alcanzar alturas de hasta 70 metros. Además de esta simplificación en los elementos constructivos, el sistema permitía mayor economía al posibilitar la recuperación y reutilización del material como también su producción in situ mediante una máquina a vibración posible de ser trasladada, por ejemplo, a sitios de emergencia. ${ }^{104}$

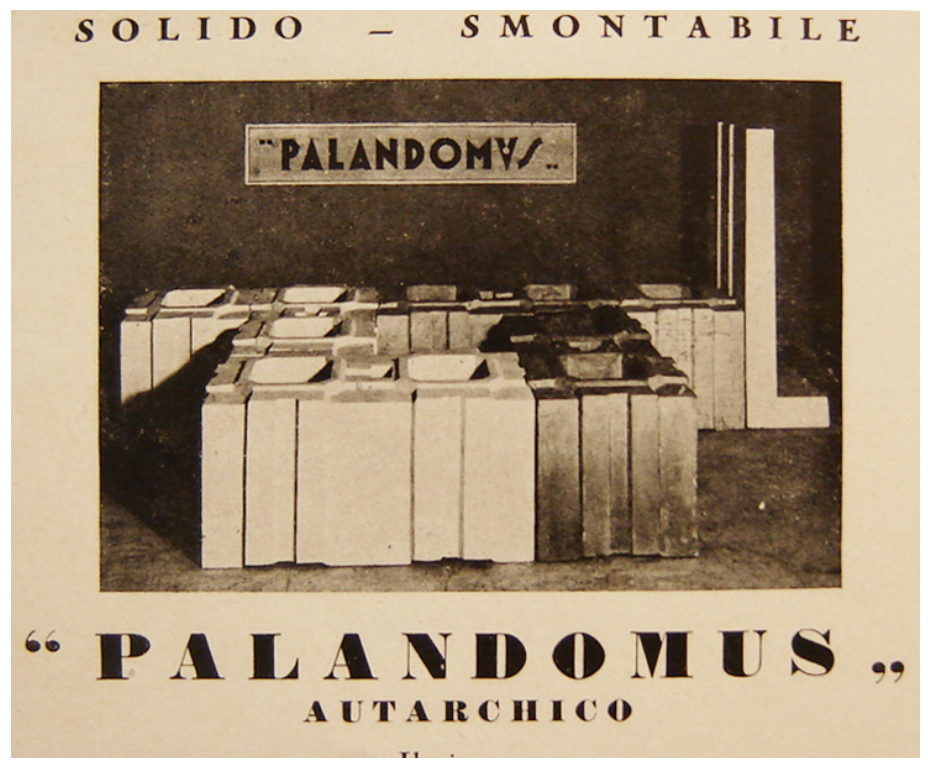

Prueba del sistema.Palandomus.Milan.ca. 1938. GRI

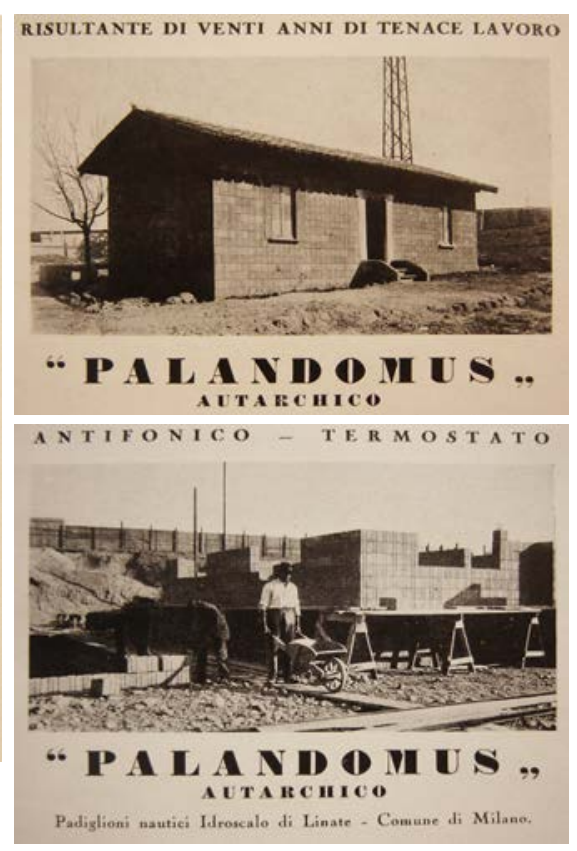

Fue esta versión del sistema, "Palandomus autarchico", que Palanti presentó en 1937 al ente autónomo de la Exposición del E’42 para participar con la construcción de un pabellón y de una vivienda modelo que luego, en 1939, publicó junto a otros proyectos en el libro Palandomus Autarchico. ${ }^{105}$ Allí, Palanti explicaba que su sistema permitía:

Ottenere costruzioni positivamente economiche, é problema Sociale, latente secolare di ogni popolo civile; il tormento degli Architetti ed Ingegneri studiosi. Il Palandomus', comunque, segna un principio técnico nettamente nuovo e di possibili ulteriori sviluppi. Per le sue caratteristiche, può vincere la competenza di qualunque altro sistema conosciuto; e di ragione nel campo edile e Sociale, responde perfettamente all appello 'Autarchico' del Capo del Governo. ${ }^{106}$

$\overline{104}$ Mario Palanti mayo 1939. GRI, 910002, Mario Palanti Papers, Serie I. De acuerdo a una carta del 14-6-1938 que Palanti escribe a Mario Salvatore, la blocchiera con un uso de 10 días, en dos días se implanta para trabajar, produce cerca de 400 bloques al día con la asistencia de 3 hombres uno a cargo y dos ayudantes. Los bloques se hacen con cualquier tipo de arena (fina o gruesa), los bloques deben estacionarse por aproximadamente 10 días. A pie de obra, rápido y económico, 60 cent c/u. AGEP

105 Casas tipo para operarios con el sistema de construcción en seco Palandomus. 3 de mayo 1937. En una carta, Palanti explica que en Roma no tiene gente de confianza para llevar a cabo el trabajo. ACS-ENR. Busta 322

106 Mario Palanti, Palandomus Autarchico (ca. 1939), GRI, 910002, Mario Palanti Papers, Serie I. Obtener 
El libro contenía documentación demostrativa como detalles de las pruebas de materiales realizadas en el Politecnico di Milano, la patente del invento en la Associazione Nazionale Fascista di Inventori y varias fotografías que muestran pequeñas puestas a prueba del material como una torre realizada en la Fiera Campionaria di Milano (1938), ${ }^{107}$ la construcción de un pabellón náutico en el Idroscalo di Linate, una cabaña y una vivienda tipo para operarios de la Società Generale Immobiliare, Roma, aunque también incluye la Concesionaria Resta Hnos. (Av. Figueroa Alcorta, Buenos Aires) como realizada con este sistema. ${ }^{108}$ Como parte de sus estrategias publicitarias no podemos dejar de mencionar dos tarjetas

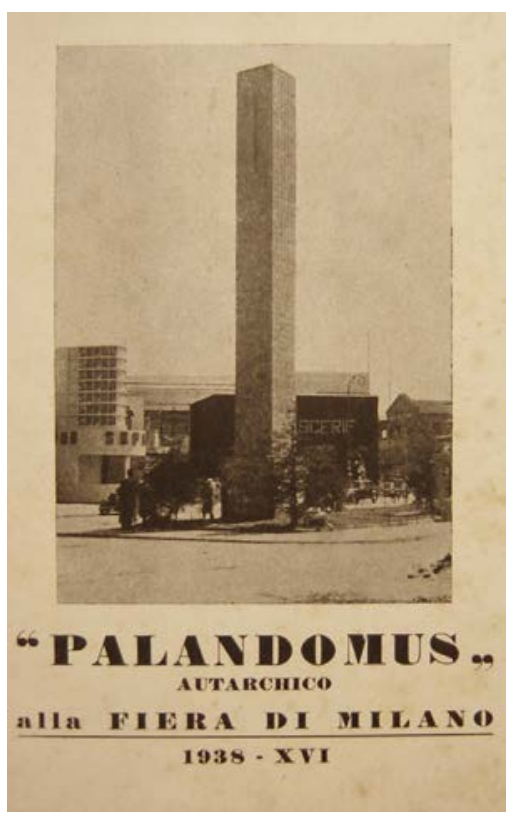

Mario Palanti. Torre realizada con Palandomus en el Feria e Milàn. 1938. Palandomus.Milan.ca. 1938. GRI postales que estimamos datan de 1939 y se conservan en Roma, en el Archivo de la Accademia Nazionale dei Lincei. La primera postal titulada "La victoria del sistema", fue enviada desde Buenos Aires junto con un artículo de "orden tecnico-sociale" -al que nos referiremos más adelante- escrito por Mario Palanti y publicado en el periódico Terra

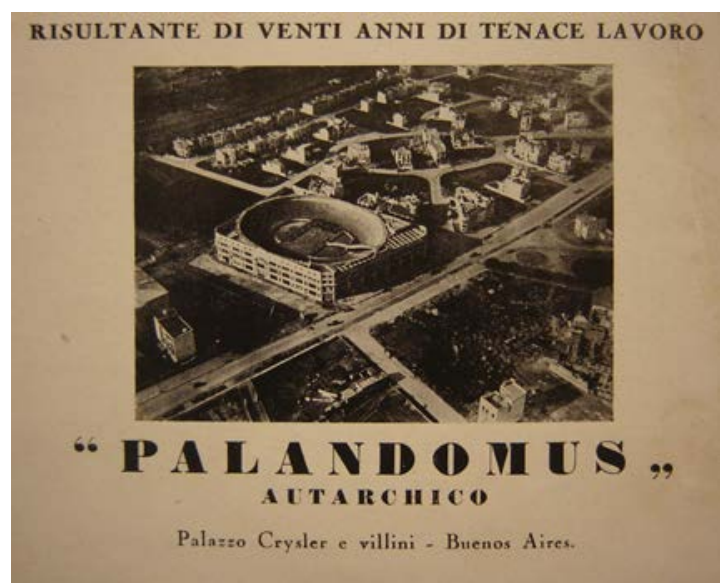

Fotografía dela consecionaria Fevre y Basset (192628) publicada como parte de los proyectos realizados con el sistema Palandomus. Mario Palanti. Palandomus.Milan.ca. 1938

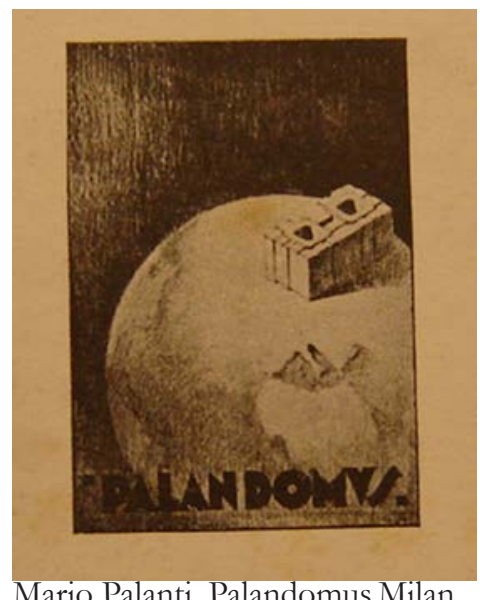

Mario Palanti. Palandomus.Milan. ca. 1938. GRI

construcciones positivamente económicas, es un problema social, secular latente de cada pueblo civil; el tormento de los Arquitectos e Ingenieros estudiosos. El 'Palandomus', sin embargo, marca un principio técnico netamente nuevo y de posibles ulteriores desarrollos. Por sus características, puede vencer a la capacidad de cualquier otro sistema conocido; y de acuerdo al campo edilicio y Social, responde perfectamente al apodo 'Autárquico' del Jefe de Gobierno. [Traducción Florencia Minatta]

107 Archivio Storico Fondazione Fiera di Milano. Folleto. 1938.

108 Palanti, Palandomus Autarchico. 
d'oltremare el 15 de mayo de $1953 .{ }^{109}$ La tarjeta muestra una victoria alada sosteniendo laureles con los brazos en alto, sobre un podio con la leyenda "Palandomus Argentina". Detrás, el mundo de la construcción representado por altos edificios cubiertos de andaminos. La segunda postal deja leer al reverso: "Palandomus Uruguay - construcciones - ultraeconomicas". La imagen que
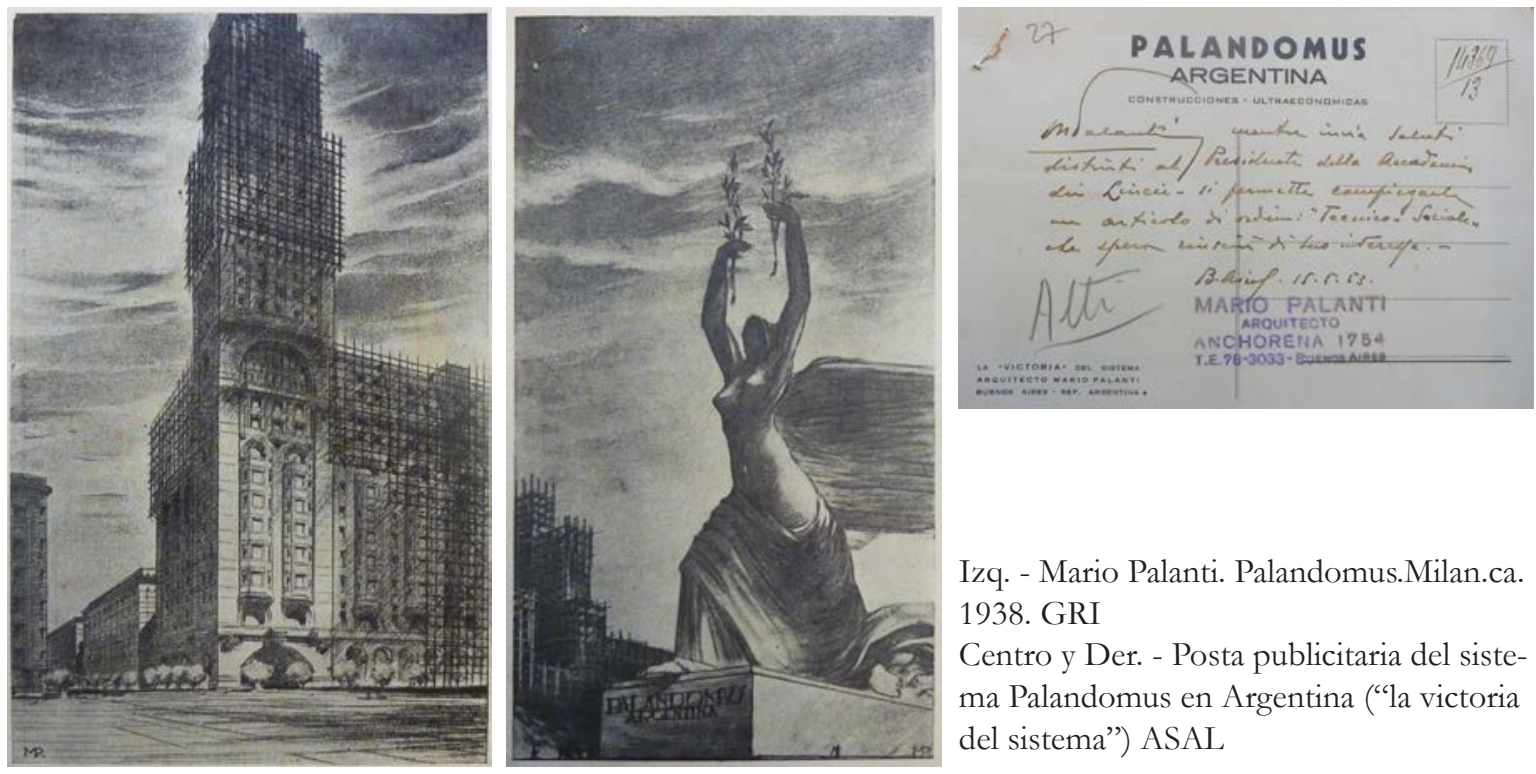

presenta en el frente es nada menos que el Palacio Salvo, cubierto de andamios y despojado de ornamentación y del cual señala: “en construcción - 30 pisos- Plaza independencia Montevideo -Rep. O. del Uruguay - ingeniero arquitecto Palanti-Gori”."110 Además de las publicaciones (y la impresión de tarjetas postales, papelería y tarjetería), en 1938 presentó el sistema al Istituto Case Popolari -que dedicaba esfuerzos a la investigación en temas de vivienda- y entre esta fecha y hasta 1948, promovió el "Concorso Palandomus" a través de la Fondazione Mario Palanti en la Reale Academia di Architettura de Roma. ${ }^{111}$

Durante 1939 Palanti dedicó los esfuerzos a difundir la nueva versión del sistema Palandomus autarchico -ermafrodita- en el extranjero. Con esta finalidad, y con la única condición de que mantuviera el nombre "Palandomus", el arquitecto ofreció el bloque en la Argentina a Carlos Nobile -quien no pudo aceptar la oferta-, al arq. Giovanni Bianchi en Brasil, en Uruguay

109 La postal fue escrita el mismo día de la publicación de la nota, el 15 de mayo de 1953, e iba dirigida a la Accademia. El artículo, titulado "Il nuovo stadio al foro-itálico di Roma. Perche rettangoloide e non rotondo?" presentaba los argumentos de Palanti en defensa de la forma circular, geometría que, como veremos, lo obsesionaría los últimos años de su carrera. Publicado en Terra d'oltremare el 15 de mayo de 1953. Archivio Storico Accademia dei Lincei (ASAL), Busta 47, titolo VII, foglio 58.

110 ASAL, Busta 47, titolo VII, foglio 58.

111 Carta de Cav. Carlo Chiarle a Mario Palanti sobre case popolari, 12 de junio de 1938 y Carta del $1^{\circ}$ de junio de 1938. (ASAL). Titolo 8, Busta 57 fasc.57. Roma. 
al ingeniero Lorenzo Gori Salvo -con quien estuvo, como ya vimos, a cargo de la construcción del Palacio Salvo- y a "otros amigos para otros países de Sud-America". ${ }^{112}$

La correspondencia entre Palanti y Gori Salvo que se conserva en el archivo del GRI permite ver el entusiasmo que el arquitecto depositaba en el bloque. En una carta del 2 de abril de 1939 explicaba el sistema al ingeniero y lo ofrecía junto con la máquina blochiera para que éste lo fabricara en el Uruguay. ${ }^{113}$

(...) yo deseo hacerte en regalo, definitivo de el 'Palandomus ermafrodita', sin compensociones [sic] de ninguna especie, presente ó futuro, como hago para lo demas mis amigos, porque el campo de assion [sic] que voy a tener aqui en Europa y Africa de el 'Palandomus', va a cer muy grande immeso [sic], porque elemento militar de primer plano, ó orden. Y para eso estoy en el justo momento de constituir una Sociedad. ${ }^{114}$

De acuerdo a Palanti, el éxito del sistema dependía -más allá de las cuestiones técnicas a su cargo- de la maquinaria y, principalmente, de la conformación de un grupo financiero para su explotación, de no ser así, señalaba el arquitecto, el proyecto "se muere antes de nacer" ${ }^{115}$ En una actitud que nos recuerda a Erdosain, aquel personaje arltiano que casi en la misma década intentaba dar el "batacazo""116, Palanti le explicaba a Gori Salvo:

(...) el aber inventado un exellente producto, no es suficiente, necesita crear la maquina que dea vida al mismo producto; y esta vez despuez de casi 20 años he conseguido lo positivo. [sic] (...) al día ocho del mes entrante (...) se realizará en Milan; una muestra de Leonardo y de las invenciones Italianas, a la cual pienso participar con el 'Palandomus'; es decir estrenar el nuevo sistema publicamente (...) En su sencillez vos comprendara el alto significado, de la construccion a seco, revolucionar en gran parte el criterio tecnico construttivo. [sic] ${ }^{117}$

112 Carta de Carlos Nobile a Gori Salvo 6 de julio de 1939, Carta de Mario Palanti a Gori Salvo, 5 de junio de 1939. GRI, 910002, Mario Palanti Papers, Serie I. Documentación relacionada al sistema Palandomus.

113 Carta de Mario Palanti a Gori Salvo, 5 de junio de 1939. GRI, 910002, Mario Palanti Papers, Serie I.

114 Carta de M. Palanti a Gori Salvo, 2 de abril de 1939. GRI, 910002, Mario Palanti Papers, Serie I. Documentación relacionada al sistema Palandomus.

115 Carta de M. Palanti a Gori Salvo, 2 de abril de 1939. GRI, 910002, Mario Palanti Papers, Serie I.

116 Erdosain es el personaje principal de la novela de Roberto Arlt, Los siete locos (1929) que culmina en Los lanzallamas (1931). Como explica Beatriz Sarlo, "El batacazo, exaltación final que obsesiona a Erdosain, puede alcanzarse a través de un descubrimiento afortunado, la construcción de una máquina o la obtención de una fórmula química: el triunfo del inventor proporciona, de un solo golpe, fama, mujeres y dinero". Beatriz Sarlo, "Guerra y conspiración de saberes" en Una modernidad periférica: Buenos Aires 1920 y 1930, Buenos Aires, Nueva Visión, 1988, p. 57.

117 Carta de M. Palanti a Gori Salvo, 2 de abril de 1939. GRI, 910002, Mario Palanti Papers, Serie I. 
En un penoso intento de aparentar una prospera actividad profesional - que en realidad se desdibujaba cada día con más intensidad - confesaba a su amigo Gori Salvo su obsesión por el "Palandomus" tal vez por representar este último la única esperanza posible de triunfo:

Yo actualmente tengo al estudio mucho trabajos importantes (no de concursos) pero todo te debo confesar, de que mi espiritu esta todo dirijido en el 'Palandomus', diría una verdadera mania, un espiritu que me domina diria en todo momento. [sic]

Es inutil de que te diga mi evolucion tecica-artistica, diría casi una revolución tal es el cambio racional y sustancial de todo mi espiritu dinamico, y se me permite siempre juvenil, de querer siempre luchar pare el mejor. [sic] ${ }^{118}$

En la post data le comentaba:

No me has dicho si el palacio Salvo esto todavía en pie! Ademas te dire, de que el Podestá de Milan, me ha llamado a formar parte de la Comicion de el Plano Regulador de la Ciudad; [sic] encargo muy importante, y que me ofrece la posibilidad de tener muchos contactos de personalidades. ${ }^{119}$

Incansable, casi una década más tarde, Palanti produjo una nueva versión del sistema. El bloque se había transformado en un ladrillo cerámico con el nombre "Palandomus lateriz̧io ermafrodita" que ahora se presentaba como el resultado de 30 años de estudio. A diferencia de las versiones anteriores, el ladrillo "Palandomus ermafrodita" presentaba una composición química definida que optimizaba el rendimiento en un $25 \%$ respecto del ladrillo cerámico común de $18 \mathrm{~cm}$ y había sido probado en los hornos de la S. A Palli e Figli (Voghera) construyendo unos pocos prototipos de viviendas. ${ }^{120}$

Prácticamente aislado del contexto disciplinar, Palanti dedicó los años siguientes al estudio de su sistema constructivo y a ciertos prototipos de vivienda y edificios en altura. Como declaraba en una conferencia radial realizada en Milan en octubre de 1945 para promocionar su libro Architettura per tutti: "Tema fondamentale del mio lavoro é la casa di abitazione, la casa del popolo

118 Carta de M. Palanti a Gori Salvo, 2 de abril de 1939. GRI, 910002, Mario Palanti Papers, Serie I.

119 Carta de M. Palanti a Gori Salvo, 2 de abril de 1939. GRI, 910002, Mario Palanti Papers, Serie I.

120 Mario Palanti, Palandomus Laterizio ermafrodita (ca. 1948). BRA 


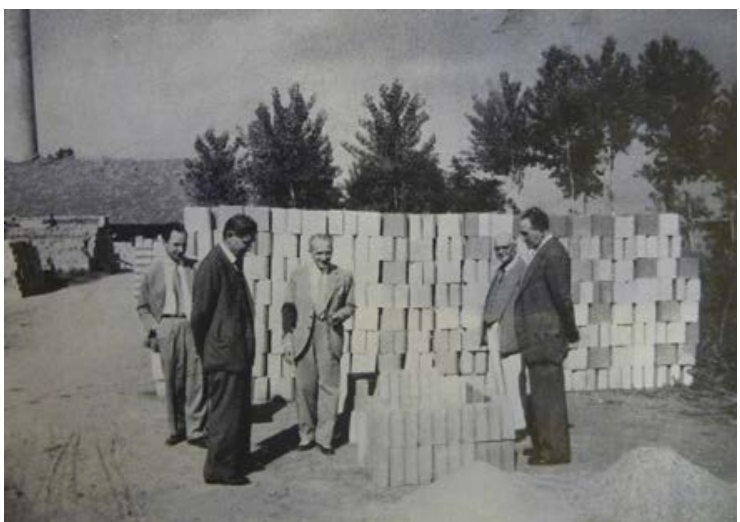

Prueba experimental del ladrillo Palandomus en los Hornos de la S.A. Palli e Figli, Voghera. Ca. 1939. Mario Palanti Palandomus, case per il popolo, ca. 1948

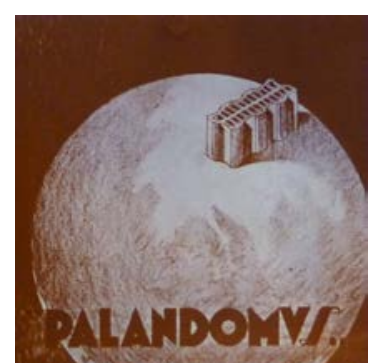

Mario Palanti Palandomus, case per il popolo, ca. 1948

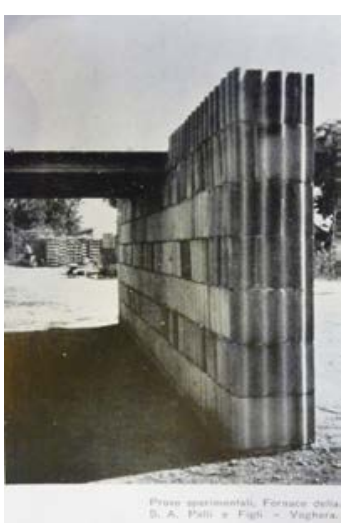

Prueba experimental del ladrillo Palandomus en los Hornos de la S.A. Palli e Figli, Voghera. Ca. 1939. Mario Palanti Palandomus, case per il popolo, ca. 1948

argomento umano di supremo interesse in ogni tempo, am particularmente oggi che una aberrante politica ha privato milioni di itailani di questo dirito inalienabile dell'individuo." 121 Además de ello señalaba que su trabajo obedecía a la razón, a la economía y a la técnica: "Sono convinto associandomi ad altri valenti -señalaba-che l'opera architettonica debba essere organismo, vita. Non riesumazione anacronistica di moduli stilistici di accatto, non vanitosa esibiz̨ione di grandezze illusive." ${ }^{122}$ Con el fin de la guerra y la caída del fascismo, Palanti volvía a su favor su ausencia en el campo disciplinar durante el régimen:

La critica ad alcune realizzazioni costruttive e soluzioni urbanistiche in patria non è mossa da risentimenti personali, solo dalla convinzione che si commisero degli errori cui la coscienza comanda la riparazione ove sia posibile o per lo meno la condanna al fine di non commetterne piu in avvenire. ${ }^{123}$

121 Mario Palanti, conferencia radial en Milán, Octubre de 1945. ASAL, Titolo 8, Busta 57 fasc.58. Además de presentar el sistema Palandomus, el arquitecto criticaba ciertos proyectos que se inclinaban por la expansión horizontal frente al crecimiento en altura y, entre otros, las intervenciones que tomaban espacios públicos como la de Piazza San Babila, el monumento a los caídos en Piazza Sant’Ambrogio, el Palazzo dell’Arte realizado por Muzio. Ante este ataque aclaraba: "nessun risentimento personale mi muove contro gli autori delle opere o dei progetti (...), solamente la persuasione di adempiere un dovere civico, un dovere sociale che oggi le mutate condizioni politiche consentono di soddisfare con tutta libertá e senza reticenze."

122 Mario Palanti, conferencia radial en Milán, Octubre de 1945. ASAL, Titolo 8, Busta 57 fasc.58.

123 Palanti, conferencia radial en Milán, Octubre de 1945. La crítica a algunas realizaciones constructivas y soluciones urbanísticas en la patria no es motivada por resentimientos personales, sólo por la convicción de haberse cometido errores en donde la consciencia demanda la reparación donde sea posible o por lo menos la condena al fin de no cometer más en el futuro. [Traducción Florencia Minatta] 
Convencido de que nuevas oportunidades se presentaban, cerraba su conferencia con una declaración que -al igual que el discurso- abundaba en neutralidad política y obviaba toda referencia al fascismo:

Sia dunque accolto di buona grazia il mio lavoro frutto di fatica e di sincerità, oggi che il Paese pur fra travagli e dolori, ha cominciato a riprendere il suo cammino.

Oso sperare che venga a me, precluso in questi ultimi anni da ogni attività costruttiva, dopo il molto lavoro speso all'Estero, la comprensione del pubblico, e l'accoglimento di qualcuna delle mie idee da parte di persone più disposte e sensibili a favorire la rinascita della Nazione. ${ }^{124}$

Sin embargo, y pese a las expectativas que el arquitecto depositaba en el sistema "Palandomus" como medio para la reconstrucción de las ciudades, el contexto italiano de la segunda posguerra no ofreció nuevas oportunidades. Como hemos expuesto, la serie de fracasos en su relación con el Estado Fascista llevó al arquitecto a centrar su atención en el sistema constructivo "Palandomus" que, junto con las prácticas en el manejo del hormigón armado, dan cuenta de su experiencia técnica y parecen conjugar en él la mezcla ideal entre arquitecto e ingeniero que para Camillo Boito debía ser la nueva figura emergente del binomio BreraPolitécnico, un profesional capaz de proyectar autónoma e integralmente sin tener que someterse a los dictados del ingeniero civil. ${ }^{125}$

Sería precisamente el constante fracaso en el intento de insertarse en el contexto disciplinar italiano lo que daría impulso a Palanti para probar suerte donde la había encontrado anteriormente. Pero, en su búsqueda constante por acercarse al poder para promocionar su arquitectura, la figura de Palanti pareciera acercarse, como señalan Ballent y Gorelik a “(...) la historia de Dinócrates y Alejandro relatada por Vitruvio: el arquitecto que pone en juego toda su osadía intelectual para ganarse el favor del poder y desarrollar así su voluntad fáustica.’126 En efecto, esta constante preocupación por llevar a cabo su obra y materializar su sistema constructivo encontraría respuesta en la Argentina de los años 50’.

124 Palanti, conferencia radial en Milán, Octubre de 1945. Sea entonces bienvenido de buena manera mi trabajo fruto de fatiga y de sinceridad, hoy que el País aún en medio de dificultades y dolores, ha comenzado a retomar su camino. Me atrevo a esperar que venga a mí, impedido en estos últimos años de cualquier actividad constructiva, luego de muchos trabajos realizados en el Exterior, la comprensión del público, y la aceptación de cualquiera de mis ideas de parte de personas más dispuestas y sensibles a beneficiar el renacimiento de la Nación. [Traducción Florencia Minatta]

125 En una carta del 7 de octubre de 1925, en el marco de una discusión, entre otros reclamos Giuseppe señala a su hermano el haberlo ayudado a intentar graduarse como ingeniero. AP (véase capítulo dos)

126 Anahí Ballent y Adrián Gorelik, "El Principe” en Block 5 (diciembre, 2000):6. 


\section{Capítulo VI. Buenos Aires 1948. El viaje de la esperanza}

E cosi dopo sei anni dal mio ritorno in patria io non ho potuto costruire un decimetro quadrato di muro.

L'Italia Fascisa sotto la guida del Duce si trasforma Imperialmente e si costruisce dapertutti. L'Arch. Palanti è escluso, e non riesco a comprenderne le ragioni, in modo assoluto da questa immensa opera di trasformazione.

(Mario Palanti, Roma, enero de 1940) ${ }^{1}$

\section{Arquitectura para todos}

En agosto de 1948, a bordo del buque "Italia" junto a su esposa, Mario Palanti llega, una vez más -y por última vez-, al puerto de Buenos Aires. Habían transcurrido quince años desde que el arquitecto había abandonado la Argentina para radicarse en Italia de manera permanente.

El retorno al Río de la Plata, evidentemente, mostraba que su experiencia en Italia había fracasado. Como hemos observado, desde 1933, con el fascismo ya consolidado en el poder, Palanti, a pesar de sus esfuerzos, no encontraría lugar para su arquitectura. Aun el autopropagandismo sin límites y las súplicas por trabajo realizadas por el arquitecto ante la Secretaría Particular del Duce tuvieron como resultado el fracaso en los concursos llevados a cabo por el régimen fascista. Sus estrategias resultaron incorrectas puesto que recibieron duras críticas por parte de los allegados a Mussolini y dejaron a Palanti fuera de juego. Paralelamente, como fue explicado, su obra fue blanco de ataque por parte de la prensa y la crítica profesional. ${ }^{2}$ En este marco, en un contexto en el cual su arquitectura no tenía lugar y tras la destrucción de su vivienda durante el bombardeo a Milán en el mes de agosto de 1943, Palanti decidió refugiarse en Stresa Borromeo, en una propiedad que pertenecía a la familia de su segunda mujer, Nahir

$\overline{1}$ "Y así luego de seis años de mi regreso a la patria no he podido construir un decímetro cuadrado de muro.

La Italia Fascista bajo la guía del Duce se transforma Imperialmente y se construye por todos lados. El Arq. Palanti es excluido, y no logro comprender las razones, de ningún modo de esta inmensa obra de transformaciones." [Traducción Florencia Minatta]

2 Recordemos lo señalado en el capítulo anterior. 
Marazzi Castiglioni. ${ }^{3}$ La pareja permanecería allí hasta finalizada la Segunda Guerra. ${ }^{4}$ Durante su estadía en Stresa, Palanti utilizó su “desaparición” de escena para dedicarse a la exploración proyectual. En un clima bélico y de recesión económica, sus esfuerzos se alejaron de la indagación en torno al rascacielos y fueron dirigidos a la investigación tipológica en viviendas y al perfeccionamiento del sistema constructivo "Palandomus". Su estratégico regreso fue de la mano de su libro Architettura per tutti, publicado en edición bilingüe (italiano e inglés) en 1945. Precisamente, el volumen iba dirigido a promocionar el sistema constructivo que, dadas sus características según Palanti, resolvería de manera eficaz la reconstrucción de las ciudades destruidas durante la guerra. ${ }^{5}$ Pero no sería la devastada Europa de entreguerras donde Mario Palanti encontraría una nueva oportunidad. En julio de 1947, la pareja se traslada nuevamente a Milán para, en 1948, emprender el viaje hacia la Argentina. ¿Qué expectativas laborales tenía Palanti para decidir regresar a la nuestro país?

Hacia 1945, si bien en el contexto de posguerra se podía apreciar cierto rechazo por aquellas formas arquitectónicas asociadas al fascismo, la estética manejada por Palanti había sido excluida del centro de escena una década antes. ${ }^{7}$ Es que, precisamente, como señala Schumacher, la manera del fascismo de vincular el clasicismo con el nuevo lenguaje fue indirecta y la unión con la gloria del pasado romano se realizó mediante métodos de diseño que no se verificaron en la obra de Palanti, la cual planteaba una relación inmediata con un pasado con el cual el fascismo no se mostró interesado. ${ }^{8}$

Podemos pensar que, ante el contexto que le era esquivo y la perspectiva de no conseguir encargos en Italia, tres cuestiones pueden haber influido en la decisión del arquitecto para probar suerte en la Argentina.

3 Con 57 años, Palanti contrajo matrimonio el 7 de enero de 1943, en Milán, con Nahir Marazzi Castiglioni, de 40 años. Acta Comune di Milano, Ufficio Stato Civile. 5 de julio de 1948, AGEP. En 1952 Nahir abandonó a Palanti en Buenos Aires. La correspondencia de 1954 muestra la intención de Nahir de conseguir el divorcio. Palanti se ocupa del tema y aclara que no regresa a Italia por estar "ocupadísimo". En 1957, habiendo Palanti regresado a Italia, piden la anulación del matrimonio ante el tribunal de Milán, AGEP.

4 En una nota Palanti explicaba que había cambiado de domicilio: "A motivo del crollo dell'edificio dove abitavo in Via A. Mussolini N/4 - aseguito offesa nemica (...)." Nota de MP a la Fondazione Mario Palanti, Stresa Borromeo, 15 agosto 1943. ASAL, Titolo 8 Busta 47, foglio 58.

5 Mario Palanti, Architettura per tutti (Milano: Casa Editrice d'arte Bestetti, 1946).

6 Acta de separación entre Mario Palanti y Nahir Marazzi Castiglioni, Milán, 1957, AGEP.

7 Sobre el contexto italiano véase Julian Jackson, (coord.) Europa 1900-1945 (Barcelona: Crítica, 2003). Ruth BenGhiat, "Fascism, Writing, and Memory: The Realist Aesthetic in Italy, (1930-1950)", The Journal of Modern History, Vol. 67, No 3 (The University of Chicago Press, Sep. 1995): 627-665.

8 Véase Schumacher, Terragni e il Damteum. Cesare De Seta, La cultura architettonica in Italia tra le due guerre (Roma: Laterza, 1983). Ciucci, Gli architetti e il fascismo. 
En primer lugar, en 1947, en rol de primera dama, Eva Perón visitó Europa realizando un viaje en el cual la "Nueva Argentina" era presentada ante la Europa de posguerra como un lugar lleno de oportunidades. ${ }^{9}$ Como señaló Liernur, varios hechos justificaban el optimismo con el cual Eva Perón exhibió el país durante su viaje a Europa. Entre 1945 y 1948 el mercado interno había aumentado un 29\%. La población del Gran Buenos Aires aumentó de 3.400.000 habitantes en 1936 a 4.700 .000 en 1947 y junto con ésta los bienes de consumo. Aumentó la inmigración y se incrementó el desarrollo edilicio mediante el otorgamiento de créditos financieros. ${ }^{10}$ Un dato no menor fueron las políticas de vivienda pública desarrolladas por el peronismo en el marco de las cuales el crédito edilicio financió la realización de cerca de 500.000 viviendas. ${ }^{11}$ Es muy probable que Palanti, radicado ya en Milán, haya percibido esta situación como una nueva oportunidad. Precisamente, frente a una Italia devastada por la Segunda Guerra, la (Nueva) Argentina se presentaba, otra vez, ante el arquitecto como un lugar colmado de esperanza.

En segundo lugar, como señala Rigotti, durante la década de 1940 se produjo un gradual desplazamiento de los ingenieros por parte de los arquitectos que pasaron a ocupar puestos claves en el aparato estatal junto con la valorización del ejercicio de la función pública. Además de ello, como explica Mark Healey, no se puede dejar de lado el lugar de privilegio que se le dio a los arquitectos durante la reconstrucción de San Juan tras el terremoto de 1944, cuando el Estado se inclinó por aquellos profesionales relacionados a líneas vanguardistas en la arquitectura. ${ }^{12}$ En efecto, la necesidad de reclutar personal cualificado primaba por sobre las afiliaciones políticas: "La ausencia de un prejuicio antifascista -señala Federica Bertagna- se explicaba no sólo por una afinidad de tipo ideológico sino también por la necesidad de reclutar personal donde estaba disponible, o sea, evidentemente en los países derrotados y entre aquellos

9 Jorge Francisco Liernur, "Architetti italiani nel secondo dopoguerra nel dibattito architettonico nella "nuova Argentina” (1947-1951)", Metamorfosi, No 25/26 (Roma: La Sapienza, 1995). Navarro, Evita.

10 Marcelo Rougier, La economía del peronismo. Una perspectiva histórica (Buenos Aires: Sudamericana, 2012). Para un panorama general, véase la introducción de Juan Carlos Torre a Los años peronistas : 1943-1955. (Buenos Aires : Sudamericana, 2002)

11 Liernur, "Architetti italiani nel secondo dopoguerra nel dibattito architettonico nella "nuova Argentina".

12 Sobre el accionar del Estado y la relación de éste con los profesionales y técnicos en la reconstrucción de San Juan véase Ana María Rigotti, "Piedra de toque, manzana de la discordia. San Juan: terremoto y fragmentación". Asimsimo, el texto de Mark Healey, Elperonismo entre las ruinas el terremoto y la reconstrucción de San Juan (Buenos Aires: Siglo XXI, 2012). Sobre la relación entre ámbito disciplinar y el ámbito político durante el peronismo véase: Silvia Augusta Cirvini, "El ejercicio profesional de la arquitectura en el primer peronismo (1943-1955). Una relación comprometida entre el conflicto y la negociación", Estudios interdisciplinarios de América Latina y el Caribe vol.23.1, (ene-jun 2012): 119. 
que se habían alineado con los nazifascistas." ${ }^{13}$

En tercer lugar, el desarrollo del país impulsaba una fuerte política inmigratoria, ${ }^{14}$ en este contexto, como señala el estudio de Liernur, el flujo inmigratorio proveniente de Italia ascendió notablemente: 1945, 697; 1946, 4.158; 1947, 38.370; 1948, 116.115; 1949, 148.372; 1950, 1.331.208. ${ }^{15}$ De acuerdo a Bertagna, “La Argentina de Perón apuntaba a desarrollar sectores hasta entonces poco avanzados en el campo industrial, y por lo tanto debía importar personal con alto nivel de preparación científica y mano de obra calificada (...)". ${ }^{16}$ En febrero 1947, la Delegación Argentina Inmigración Europea (DAIE) establecida en Roma firmó un acuerdo entre Argentina e Italia sobre la base del cual se instalaron en Nápoles y Génova con el encargo de seleccionar mano de obra para satisfacer las necesidades del mercado de trabajo argentino. ${ }^{17}$ La DAIE debía “(...) enrolar técnicos, operarios y personal calificado, para desarrollar los proyectos en el campo industrial previstos en el plan quinquenal aprobado para el período 1946.-1951". ${ }^{18}$ Liernur señala que durante el período 1947-1951 varios profesionales italianos fueron contratados para realizar tareas en diferentes ámbitos. En el lapso comprendido entre 1947 y 1957 el número de profesores, técnicos y afines provenientes de Italia fue de 8.713. ${ }^{19}$ Entre los que visitaron el país podemos nombrar, entre otros, a Cino Calcaprina, Alberto La Padula, Ernesto N. Rogers, Bruno Zevi, Enrico Tedeschi, Luiggi Piccinato y Pier Luiggi Nervi. ${ }^{20}$ Son estas las razones que se consideran determinantes en la decisión de Mario Palanti de regresar a la Argentina en 1948 con la intención de retomar los brillantes éxitos de su juventud. ${ }^{21}$

13 Federica Bertagna, La inmigración fascista en la Argentina (Buenos Aires: Siglo XXI, 2007), 158. Véase en el "Epílogo" el apartado "Nacionalismo, fascismo y peronismo" en el libro de Federico Finchelstein, Fascismo trasatlántico. Ideología, violencia y sacralidad en Argenitna y en Italia, 1919-1945 (Buenos Aires: FCE, 2010). Finchelstein señala que "El peronismo no fue en sí mismo una forma de fascismo, sino el sorprendente surgimiento de una forma mentis fascista que Perón con cautela pero sin pausa trató de llevar a la práctica.” p., 308.

14 El promedio anual pasó de 42.780 entre 1930 y 1939 a 61.693 entre 1945 y 1960. María Inés barbero y María cristina Cacopardo, "la inmigración europea en la Argentina; viejos mitos y nuevas condiciones", en Estudios migratorios latinoamericanos $\mathrm{n}^{\circ}$ 19, (Buenos Aires: dic. 1991).

15 Liernur, "Architetti italiani nel secondo dopoguerra nel dibattito architettonico nella "nuova Argentina" (1947-1951)":71.

16 Liernur, "Architetti italiani nel secondo dopoguerra nel dibattito architettonico nella "nuova Argentina" (19471951)": 133. Bertagna señala que esta era una "Estrategia de gestión de las migraciones características de la segunda posguerra, fase en la cual, sobre la base de acuerdos, los gobiernos de los países de partida y de llegada se ocupaban de regular las corrientes y seleccionar a los trabajadores en el plano profesional." Bertagna, La inmigración fascista en la Argentina, 132.

17 Bertagna, La inmigración fascista en la Argentina, 145

18 Bertagna, La inmigración fascista en la Argentina, 148. En febrero de 1948 se creó la Comisión Nacional de Radicación de industrias (CNRI) cuyas ventajas fueron aprovechadas por varios italianos, entre ellos empresas como Agostino Rocca y Techint. Véase "Técnicos y empresas en la argentina”, Bertagna, La inmigración fascista en la Argentina.

19 Liernur, "Architetti italiani nel secondo dopoguerra nel dibattito architettonico nella "nuova Argentina".

20 Liernur, "Architetti italiani nel secondo dopoguerra nel dibattito architettonico nella "nuova Argentina".

21 Acta de separación entre Mario Palanti y Nahir Marazzi Castiglioni, Milán, 1957, AGEP. 


\section{De la casa al rascacielos. El Estado como comitente}

Si algo caracterizó el accionar de Palanti a lo largo de su carrera fue el intento, constante, por vincularse con los círculos de poder en el afán de concretar sus proyectos. En este sentido, su actitud durante esta última estadía en Argentina dista mucho de la "apoliticidad" que durante el período caracterizó a la mayoría de los socios de la Sociedad Central de Arquitectos. ${ }^{22}$ Recién llegado al país Palanti intento probar suerte en la esfera privada para luego de unos años se inclinarse hacia el Estado. Efectivamente, la producción proyectual que Palanti realizó entre 1948 y 1955 se centró principalmente en viviendas y monumentos, todos ellos vinculados al peronismo y el diseño de un megarascacielos que lo obsesionaría hasta el fin de su carrera. Es que, probablemente, Palanti veía en el Estado un posible comitente para el cual retomar el monumentalismo académico de los años fascistas. Tal como lo había hecho en otras oportunidades,

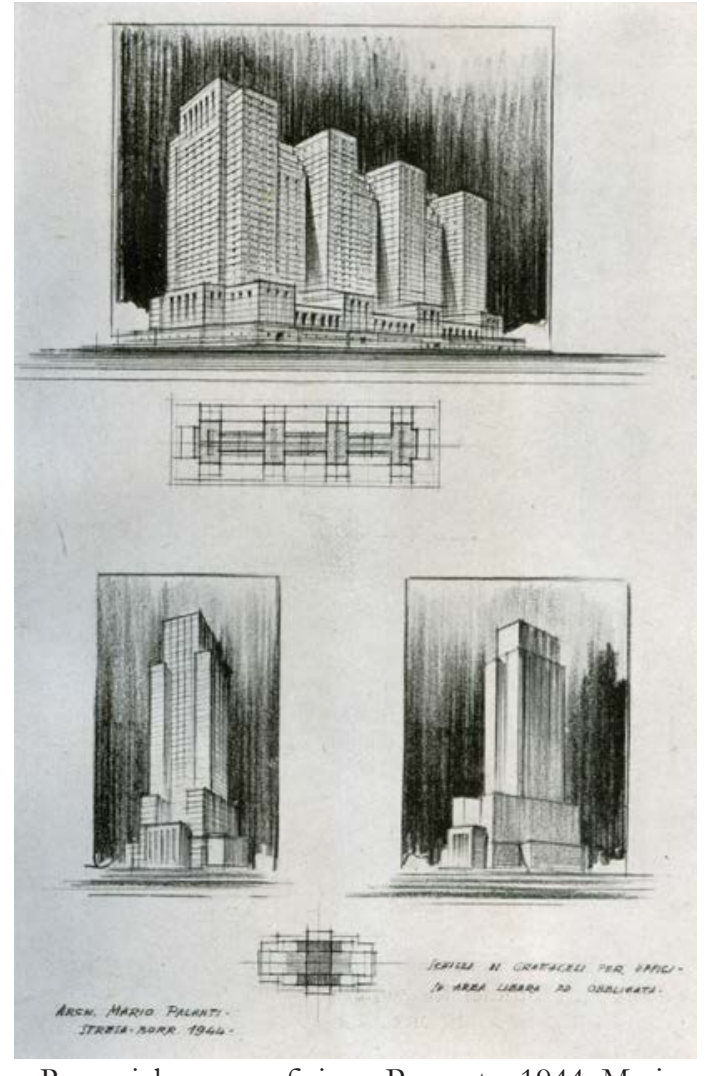

Rascacielos para oficinas. Proyecto, 1944. Mario Palanti. Architettura per tutti. Milán. Casa Editrice d'arte Bestetti.1946. intentaría establecer lazos con el poder que, según pensaba, llevaría a cabo sus propuestas.

La carta que Palanti jugó fue de la mano del ladrillo cerámico "Palandomus" ermafrodita que, en sus diferentes versiones, y como vimos anteriormente, acompañaba al arquitecto desde los inicios de su carrera. Con este sistema Palanti aseguraba que podría construirse "Desde la humilde casa al rascacielos", todo con un único elemento. ${ }^{23}$ Probablemente, el contexto en torno a la crisis de 1949 presentó a ojos del arquitecto una posibilidad para dar el "batacazo" con este sistema constructivo que desde hacía décadas le inquietaba. Es muy posible que con esta idea en mente haya obsequiado a Juan Domingo Perón el ejemplar de Architettura per tutti que forma parte de su biblioteca personal. ${ }^{24} \mathrm{~A}$ pesar de carecer de título habilitante en el país y

22 Cirvini, "El ejercicio profesional de la arquitectura en el primer peronismo".

23 Mario Palanti, Palandomus, ca. 1938. Folletos. AGEP.

24 Graciela Swiderski (dir.), Biblioteca de Juan Domingo Perón, Bibliografía sobre el peronismo (Buenos Aires, Archivo General de la Nación, 1997). 
de los problemas legales que esto significaba, Palanti encontró en el Estado peronista y no en un comitente privado la posibilidad de aproximarse a materializar sus sueños: saltar a la fama con el rascacielos más alto del mundo y llevar a cabo su ladrillo con el que pretendía conquistar el mundo de la construcción.

Entre 1947 y 1951 tuvo lugar el Primer Plan Quinquenal planteado por el gobierno de Perón para la organización del Estado. Con una marcada impronta industrialista de fuerte presencia Estatal, el Plan condensaba los principales lineamientos de la acción de gobierno para el lapso de cinco años como

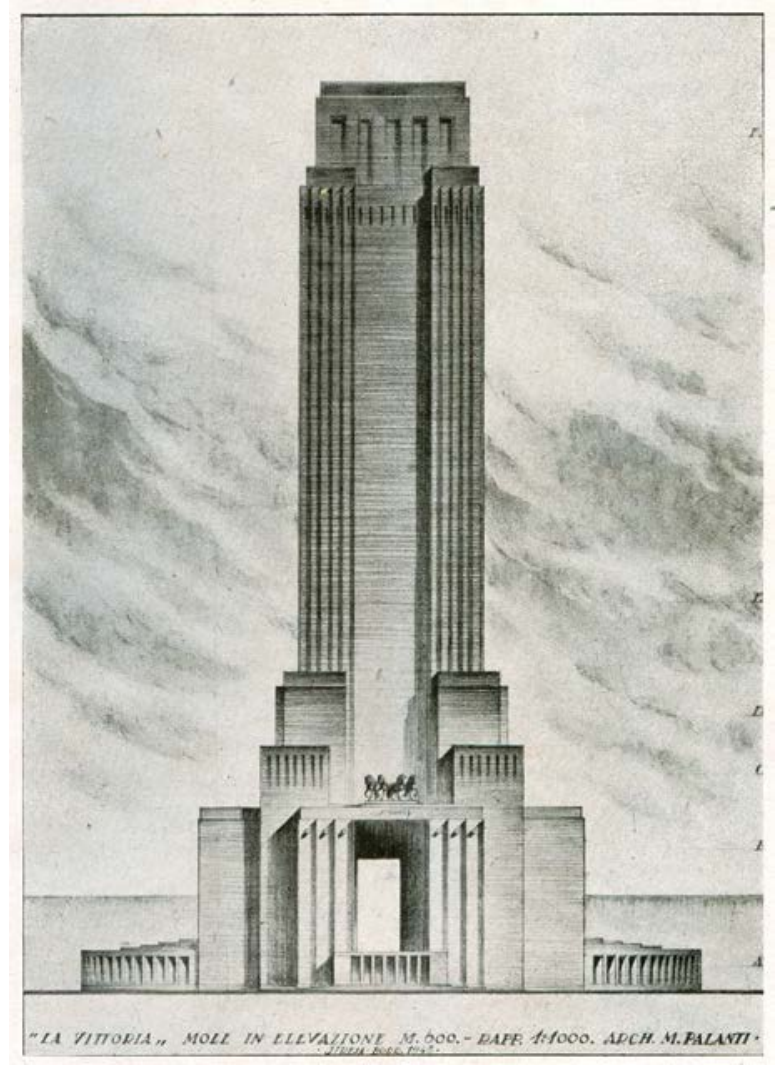
Perspectiva. Mole Vittoria, 1945. Proyecto. Mario Palanti. Architettura per tutti, 1946 también los proyectos de ley sobre distintas materias que el Ejecutivo planteaba como parte de su plan de realizaciones e inversiones. El Plan proponía, entre otros, la necesidad de rever y codificar en un solo cuerpo el conjunto de medidas que afectaban la exportación y la importación, y la modificación de leyes entre las cuales se encontraban la ley de organización de los ministerios, la ley de organización de la sanidad pública, la ley de organización del Servicio Exterior de la Nación, la ley de fomento de la industria nacional como también el fomento del consumo de materia prima nacional.

Una vez finalizado el Primer Plan Quinquenal, el gobierno lanzó el que sería el Segundo Plan Quinquenal cuyo inicio se vio retrasado hasta 1953 debido a los ajustes necesarios surgidos a partir de la crisis de 1949. Como señala Marcelo Rougier, a diferencia del primero, el programa no planteaba evitar la crisis de la industria que se daría por la recuperación del comercio internacional, sino “(...) resolver la crisis estructural del sector externo de manera compatible con el sostenimiento de una política de redistribución de ingresos y la 'justicia social'.” ${ }^{25}$

En efecto, entre sus principales lineamientos se planteaba, como objetivo fundamental de las relaciones económicas externas del país, el asegurar el desarrollo progresivo de la economía 
social mediante la promoción de las actividades que contribuyeran a consolidar la independencia económica de la Nación.

En este marco, en 1952 tuvieron comienzo los préstamos del Plan Eva Perón con el fin de financiar viviendas individuales, económicas y de no más de $70 \mathrm{~m}^{2}$ destinadas a obreros y empleados “comprendidos en las leyes de previsión social y que no superaran los $2.000 \$$ mensuales.”26 Para regular esto, el Banco Hipotecario Nacional (BHN) -responsable del otorgamiento de créditos- creó la Dirección Técnica Plan Eva Perón que se ocupaba de entregar en mano una carpeta con un legajo que, junto al asesoramiento técnico, posibilitaban la gestión y ejecución de la obra por parte del potencial propietario. Así, además de tener el Estado control sobre las características tipológicas de las viviendas, los costos se veían notoriamente reducidos. ${ }^{27}$

Pero si bien la reducción de costos era un tema importante las políticas del peronismo, como explica Anahí Ballent, no centraron su accionar en la prefabricación de viviendas optando por métodos y formas de construcción tradicionales. No obstante, a fin de impulsar la construcción de bajo costo y gran escala, la intendencia metropolitana creó, en 1952, el Instituto Experimental de la Construcción a partir de la existente División Laboratorio de Ensayo de Materiales de la Dirección General de Obras Municipales. ${ }^{28} \mathrm{Al}$ respecto, Ballent señala que, si bien los resultados de esta acción no son conocidos, muy probablemente hayan existido iniciativas de este tipo en el marco del Segundo Plan Quinquenal ya que el mismo incluía "algunas propuestas, no demasiado definidas, sobre la necesidad de industrializar la construcción. ${ }^{29}$ Efectivamente, uno de los resultados de esta acción fue el estudio y aceptación por parte del Ministerio de Obras Públicas (MOP) del ladrillo cerámico "Palandomus" para la construcción de viviendas financiadas por el BHN.

En 1952, Palanti presentó en el Instituto Experimental de la Construcción sus ladrillos cerámicos Palandomus para ser testeados en compresión, aislación térmica y absorción de agua a fin de corroborar si estos podían o no reemplazar al ladrillo común en la construcción masiva de viviendas. ${ }^{30}$ Pero Palanti no sería el único interesado. Durante este período fueron varias las propuestas realizadas por particulares ante la Secretaría Legal y Técnica para colaborar con sus

\footnotetext{
26 Anahí Ballent, Las huellas de la politica: vivienda, ciudad, peronismo en Buenos Aires, 1943-1955 (Bernal: UNQUI,2005), 88.

27 Ballent, Las huellas de la política, 88

28 Ballent, Las huellas de la politica, 94

29 Ballent, Las buellas de la politica, 94

30 Ballent, Las huellas de la política, 94
} 
“invenciones” en el Segundo Plan Quinquenal: en julio de ese mismo año, el mendocino Jakobo Welkerling solicitó -señalando lo ocurrido en San Juan tras el terremoto de 1944- que "se le otorgue patente a ladrillos para construcción de viviendas antisísmicas". ${ }^{31}$ En noviembre de 1953, Primo Prottante aseguraba "haber descubierto un sistema nuevo en materia de fabricación de ladrillo" que presentaba para que fuera empleado por el Estado. ${ }^{32}$ Ambas peticiones fueron denegadas. En 1952, Erwin Alberto Klipstein presentó un "sistema de construcción de casas de material, económicas, marca Klip”, que consistía en planchas de hormigón armado prefabricadas. El "invento" fue evaluado como "una variante más de sistemas conocidos" sin "características especiales que merezcan interés preferencial por parte del estado." ${ }_{33}$ Por su parte, Nestor Jeandet había presentado, en abril de 1953, un sistema constructivo para viviendas económicas basado en placas y bloques de "hormigón-fibra". Al igual que en el caso anterior, se explicó que "el material propuesto no reúne características que le permitan remplazar con ventaja a los comunes en uso, y por lo tanto no se estima justificado el apoyo que solicita." ${ }_{34}$

En septiembre de 1953, Palanti recibió la noticia de que los ladrillos "Palandomus" ermafrodita eran "aptos para sustituir en obras a los ladrillos llenos comunes de máquinas que se fabrican en el país." ${ }^{55}$ A partir del estudio se dedujo que "(...) un tabique construido con el tipo de ladrillos "Palandomus" de $9 \mathrm{~cm}$ de espesor equivale a una pared ejecutada con ladrillos comunes macizos de $21 \mathrm{~cm}$ de espesor." ${ }^{36}$ De acuerdo a los ensayos realizados se calculó que el costo por $\mathrm{m}^{3}$ de mampostería ejecutado con "Palandomus" de 6x18x23cm era de 177.90 pesos mientras que el $\mathrm{m}^{3}$ realizado en ladrillos comunes llenos ascendía a 282.60 pesos. ${ }^{37} \mathrm{El} 13$ de septiembre de 1954, le fue comunicado a Palanti que los ladrillos cerámicos “"'Palandomus”” serían aceptados "en la construcción de edificios financiados con préstamos otorgados por este Banco (Hipotecario Nacional)". ${ }^{38}$ El ladrillo cerámico sería aplicado por Palanti en diversos

31 Archivo General de la Nación (AGN). Secretaría Legal y Técnica, Presidencia Juan Domingo Perón (SLT JDP), caja 669, exp. n 55.186/52. Julio 1952.

32 AGN (SLT -JDP) caja 669, exp. n 4281 y 4281/53 CDE 1. Noviembre 1953.

33 AGN (SLT -JDP) caja 669, exp. n. 55.367/52. Diciembre 1952.

34 AGN (SLT -JDP) caja 474, exp. n 1803/53. Abril de 1953. Los casos no pretenden ser ilustrativos de la cantidad de presentaciones realizadas durante el período - de las nueve cajas relevadas el porcentaje mayor fue de peticiones desaprobadas-, pero sí dan cuenta de la inquietud en torno a la experimentación en materiales y sistemas constructivos.

35 Certificado de prueba del ladrillo cerámico Palandomus. Obras Sanitarias de la Nación. Dirección Principal de Investigaciones Técnicas. Exp. 23.1313-P-53. 29 de septiembre de 1953. AGEP.

36 Planilla de ensayos correspondiente al expediente referencia ladrillos cerámicos Palandomus. exp. 112.816-P52. Dirección General de Obras Particulares. Buenos Aires 30 de julio de 1954.

37 Comparación de costo de mampostería ejecutada con elementos Palandomus y ladrillos comunes. Agosto de 1955, AGEP.

38 Se aclaraba: "Los muros deberían tener un espesor no menor a $18 \mathrm{~cm}$ (dos ladrillos) y se permitirán muros 


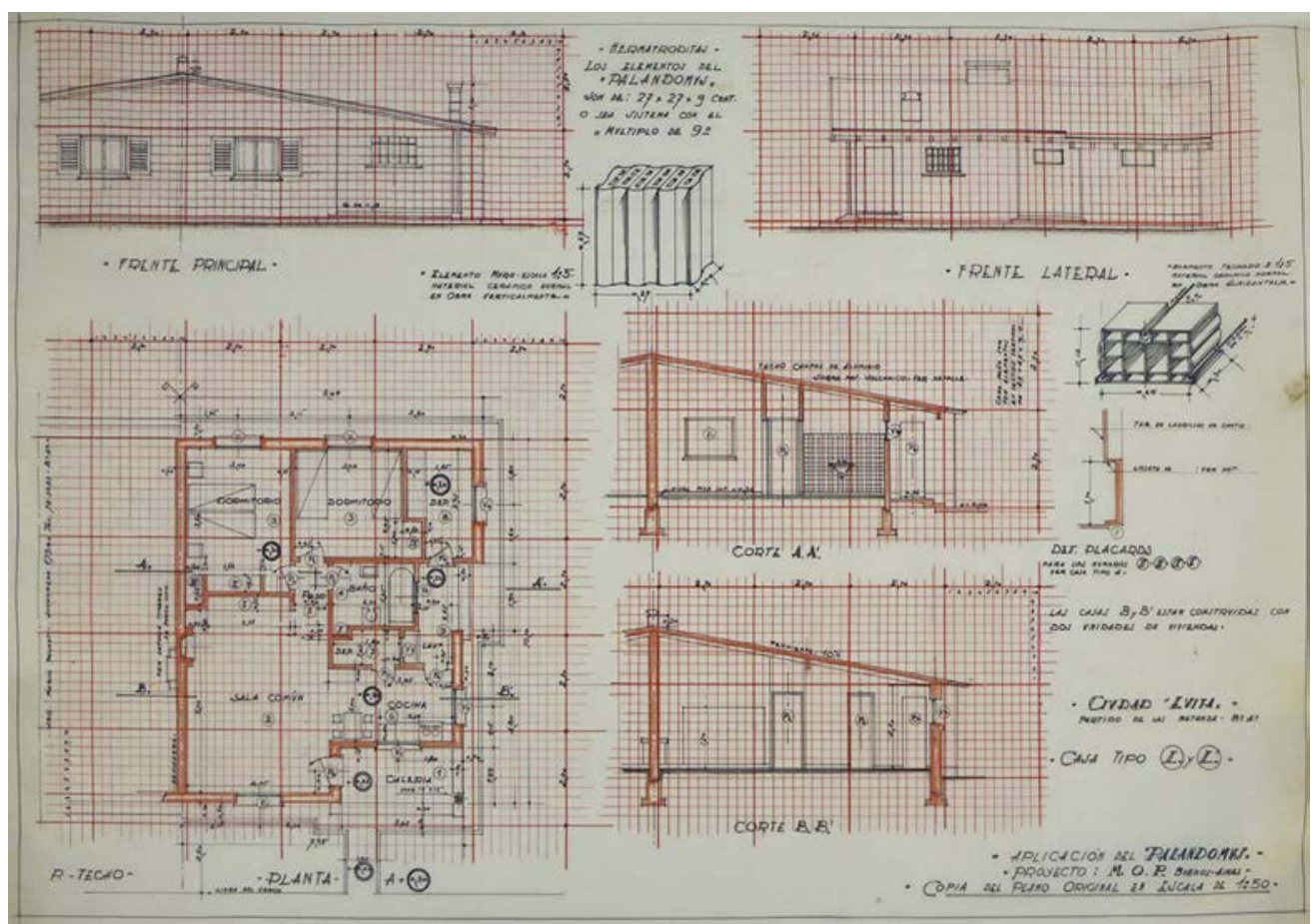

Proyecto para viviendas en Ciudad Evita. La matanza, Buenos Aires.

Mario Palanti ca. 1952. AGEP

proyectos para el Estado, entre ellos viviendas para Ciudad Evita, partido de la Matanza.

Emprendida entre 1947 y 1957, Ciudad Evita sería la primera ciudad obrera de la Argentina y contaría con 15.000 viviendas, de las cuales se entregaron 5.000 entre 1953 y 1957, algo sin precedentes en el país. El proyecto de vivienda para esta ciudad realizado por Palanti es de una casa para una familia "tipo" de cuatro integrantes. La unidad es un chalet de tipo casa cajón de aproximadamente $65 \mathrm{~m}^{2}$, con techo a dos aguas de "chapa de aluminio" y sistema constructivo "Palandomus" con un módulo de 27 × 27 × $9 \mathrm{~cm}$. La casa, a la cual se ingresa mediante un porche, tiene una organización concéntrica y compacta en torno a un paso desde el cual se accede a las diferentes habitaciones: dormitorios, baño, cocina y sala. Se suman a estos ambientes el lavadero, un depósito interior y uno exterior. ${ }^{39}$

Antes de trabajar en el diseño para Ciudad Evita, Palanti había realizado varios proyectos de casas tipo cajón cuyo antecedente puede ser rastreado en las viviendas proyectadas en 1919 para la Unión Católica Argentina. Posteriormente, en 1948, realizó el proyecto de viviendas

portantes sólo para edificios de planta baja y un piso alto. Los agujeros siempre deben quedar verticales.” Aprobación de material de construcción. Banco Hipotecario nacional. Ministerio de Finanzas de la nación. 13 de septiembre de 1954. AGEP.

39 Mario Palanti, Proyecto de vivienda para Ciudad Evita, ca. 1950. AGEP. Sobre la vivienda en Argentina véase: Jorge Francisco Liernur, “Casas y jardines. La construcción del dispositivo doméstico moderno (18701930)" y Anahí Ballent, "La casa para todos: grandeza y miseria de la vivienda masiva", Historia de la vida privada en la Argentina, Fernando Devoto y Marta madero Dirs. Tomo 3 (Buenos Aires: Taurus, 1999). Asimismo, Jorge Francisco Liernur, "El nido en la tempestad. La formación de la casa moderna en la Argentina a través de manuales y artículos sobre economía doméstica 81870-1910”, Entrepasados, Revista de Historia, año VI, No 13 (fines de 1997). 


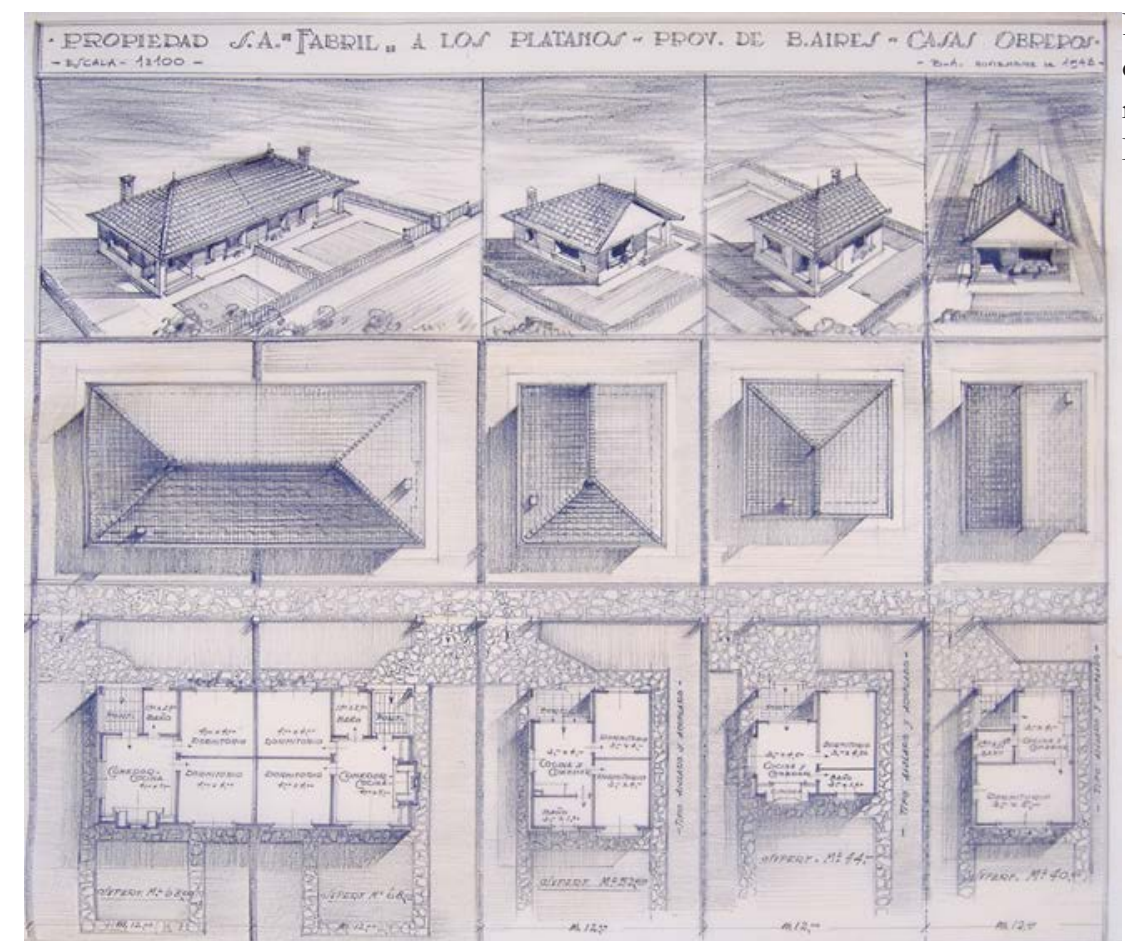

Proyecto para viviendas para obreros de la fabril Los Platanos, Provincia de Buenos Aires. Mario Palanti, 1948 AGEP

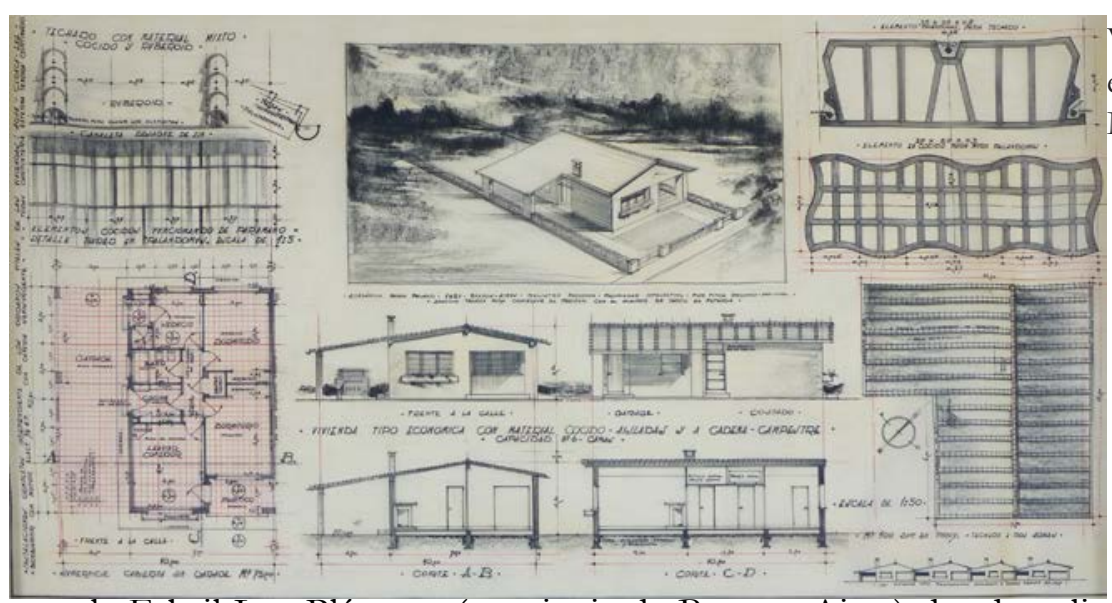

Vivienda campestre tipo economica, aislada y en cadena Mario Palanti 1951. AGEP

para la Fabril Los Plátanos (provincia de Buenos Aires) donde aplicó, al igual que en 1919, un lenguaje pintoresco. Con mayor o menor éxito en sus soluciones, esta producción proyectual de viviendas suburbanas de planta compacta basadas en el sistema constructivo "Palandomus", continuaría durante los años siguientes. Entre los proyectos realizados pueden diferenciarse aquellos en los que se ve una mayor dedicación: la vivienda para los hermanos Spinetto (s/f); viviendas de tipo campestre, aisladas y en cadena (1951); vivienda de fin de semana (s/f). Además de realizar una planta compacta con dos dormitorios, estar comedor y agrupar el baño y cocina con la habitación de servicio, las viviendas cuentan con elementos asociados al ocio y a la vida al aire libre alejada de la ciudad: lenguaje pintoresco, un garaje para el automóvil, jardín, un porche o galería de ingreso. El diseño de estos proyectos se intercala con el diseño de viviendas en las que, utilizando el sistema "Palandomus" y los postulados del existenæminimum, Palanti intentó 
dar una solución ultra económica al problema habitacional mediante una "humilde confortable vivienda" ${ }^{40}$ Con estas ideas diseñó viviendas "económicas suburbanas" para la empresa "La Funcional" (1951), una "vivienda de fin de semana de tipo mínimo" de $30 \mathrm{~m}^{2}$ con capacidad para cinco camas y con la posibilidad -como era común en la tipología de casa cajón- de elegir cubierta plana o a dos aguas (1951). Se suman a la producción los proyectos de una vivienda con la misma superficie y capacidad para ocho camas (cuatro camas marineras); otra vivienda que contaba con una gran sala común y dos dormitorios, uno de hombres y otro de mujeres (1951) y varios prototipos de viviendas rurales de 63.5 a $73.5 \mathrm{~m}^{2}$ de dos y tres dormitorios con capacidad

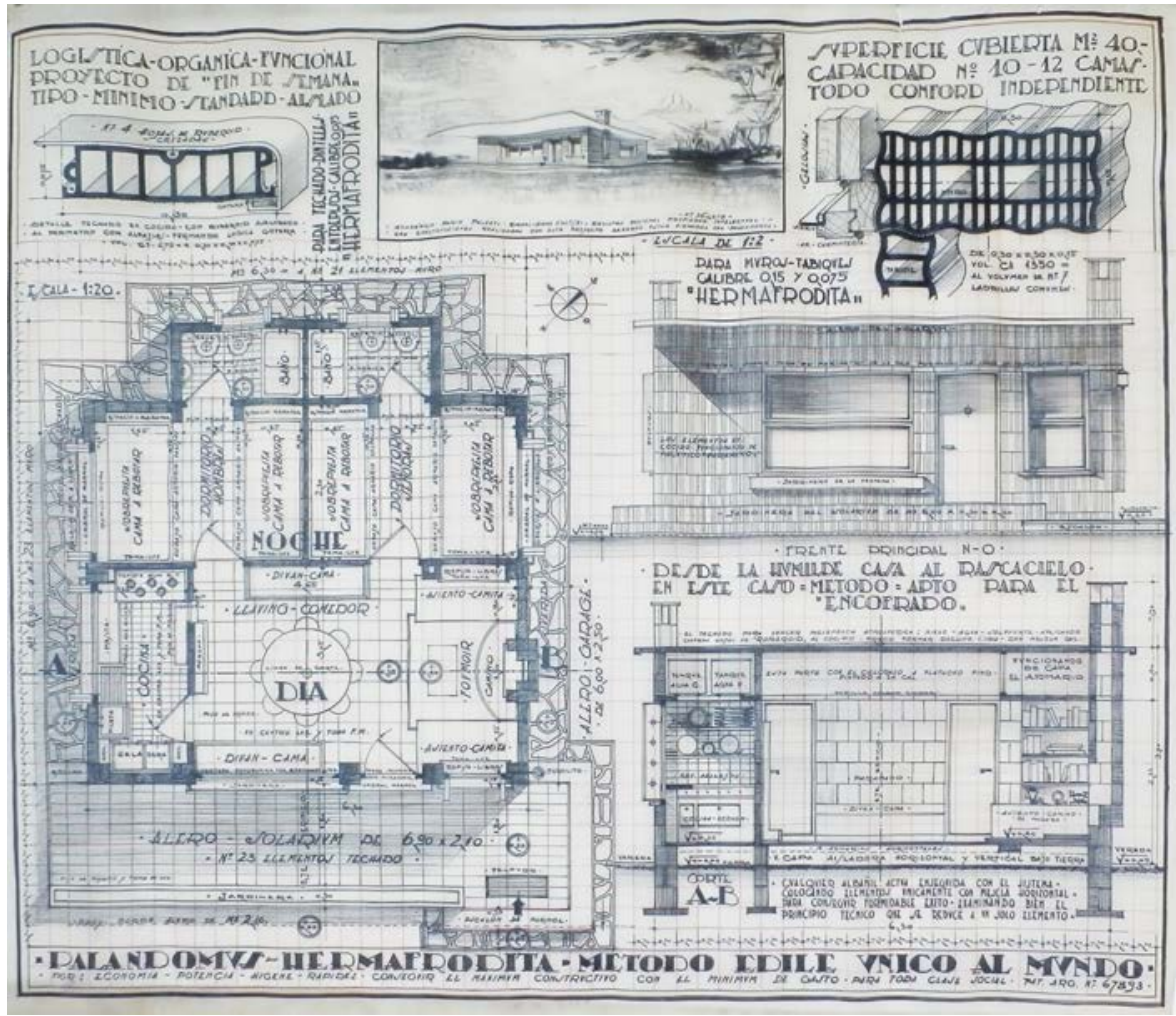

Vivienda campestre tipo economica, aislada y en cadena Mario Palanti 1951. AGEP

hasta doce camas (1950 y 1953 para la constructora D.F.P.). Estas viviendas, a diferencia de los proyectos anteriores, muestran una distribución más simple y menos elaborada. Las unidades se arman en una planta cuadrada con un espacio dominante de precaria flexibilidad cuyo uso variaba de día y de noche (living-comedor y fumuar a dormitorio con camas rebatibles o camitas diván) ${ }^{41}$

En sintonía con las propuestas que surgían del Estado por intermedio del Plan Eva Perón (que planteaba la posibilidad de prescindir del profesional), en todos los casos Palanti parecía inquietarse más por las indicaciones técnicas y el sistema

$\overline{40}$ Mario Palanti, Plano de vivienda, Buenos Aires, 29 de octubre de 1951. AGEP.

41 Planos de viviendas. Buenos Aires, 1950 y junio, agosto y octubre de 1951. AGEP. 


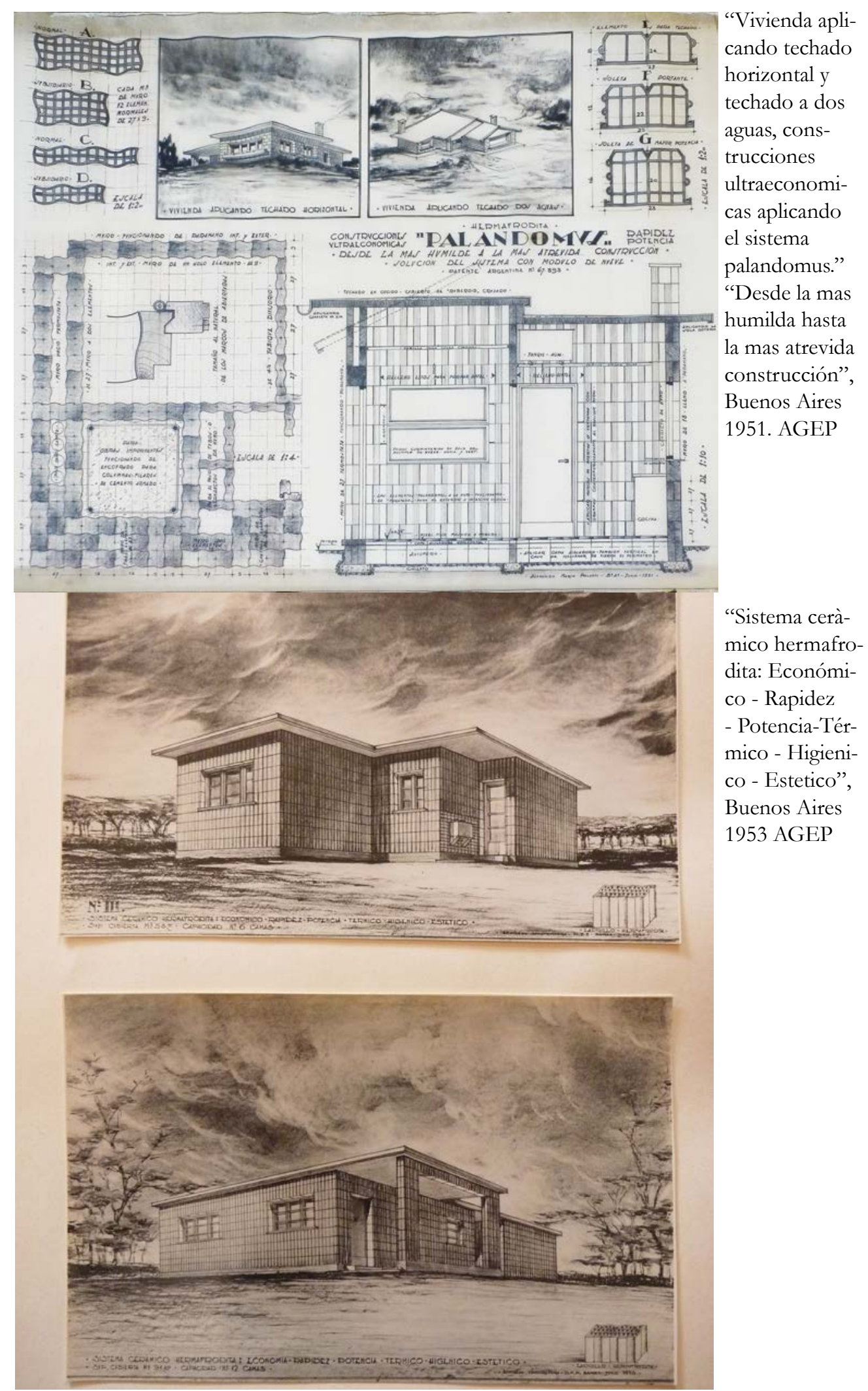

constructivo que por la resolución de la planta. Además, los planos de sus viviendas iban acompañados de detalles constructivos e indicaciones técnicas que permitían al propietario prescindir del arquitecto. Leyendas como: "cualquier albañil actúa enseguida con el sistema", "un solo hombre puede hacerlo" o "para conseguir formidable éxito examinar bien este plano" 
publicitaban el "Palandomus" como sistema de autoconstrucción..$^{42}$ Esta operación, en la que el arquitecto, en su rol tradicional, parecía correrse de escena cediendo lugar a la producción masiva de vivienda, da un giro al descubrir que las casas realizadas con "Palandomus", como explicitan varios planos, deberían estar "firmadas al frente con el nombre Palandomus".

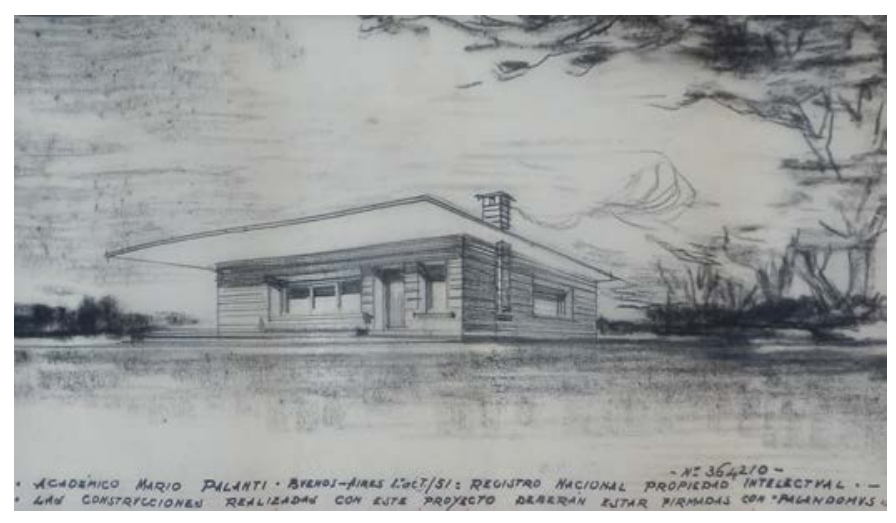

"Las construcciones realizadas con este proyecto deberan estar firmadas con palandomus", Buenos Aires oct. 1951. AGEP

En 1954, Palanti propuso al Estado dos últimos proyectos de grandes dimensiones: un plan de "Viviendas justicialistas" que se organizaban en diferentes ideas de partido -circular, cuadrado, rectangular- sobre una base de $10.000 \mathrm{~m}^{2}$ y el rascacielos más alto del mundo. La Torre Babele que, con ciento veinte pisos y 400 metros de altura, proponía construir en Buenos Aires como había intentado levantar en Roma, en 1924, la Mole Littoria dedicada al fascismo. ${ }^{43}$ Pero estos, como veremos, fueron sólo dos de varios proyectos de tipo colosal con los que el arquitecto intentó seducir al gobierno peronista.

\section{Una regresión oportunista. Monumentos metropolitanos}

Haciendo uso de la fuerza icónica que tenía la imagen del Jefe de Gobierno y su esposa, Palanti propuso, en 1950, un proyecto para un monumento dedicado a Perón y Eva. El arquitecto utilizó su oficio profesional para llegar a los círculos de poder repitiendo una actitud que ya había empleado sin éxito con el papado y con el fascismo. Con una sola leyenda valoraba el trabajo de Perón, su vinculación con la iglesia y señalaba la labor de Eva como trabajadora compañera. El esquicio -posiblemente a ubicarse en la costanera sur- deja leer la inscripción: "Dios bendice la labor del Jefe de Estado y de su colaboradora esposa". El monumento retoma un esquema realizado por Palanti anteriormente: una base rectangular que se adentra en el agua

$\overline{42}$ Vivienda mínima (de techos planos) aislada o en cadena (10/8/51). AGEP.

43 Giornale d'Italia, Buenos Aires 22 de noviembre de 1954. 


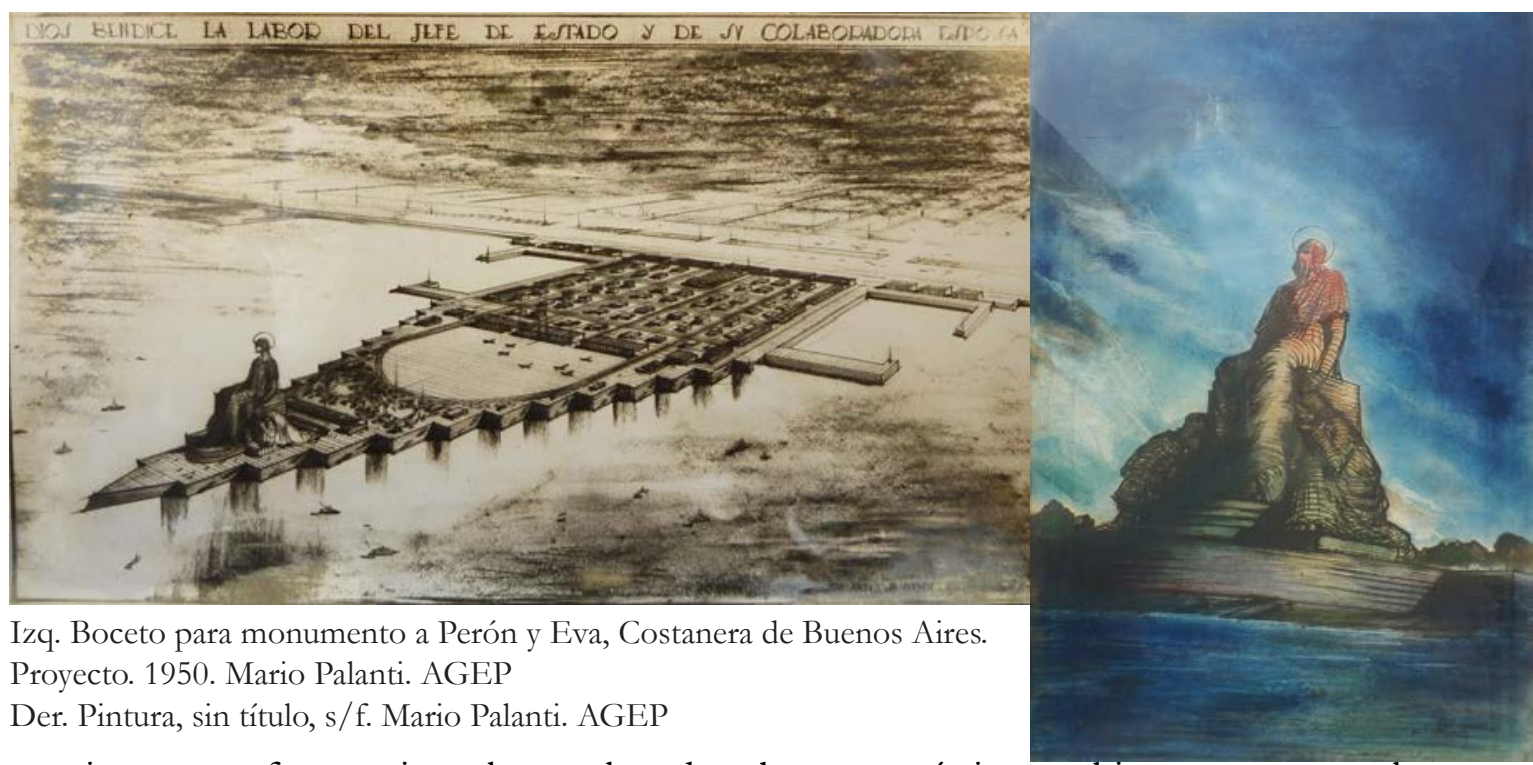

termina en una forma triangular escalonada sobre cuyo vértice se ubica una gran escultura que representa a Dios acompañado a sus lados por Perón y Eva arrodillados. La gran base opera como plataforma sobre la cual se implanta un barrio (obrero?), una aparente pista de aterrizaje y un parque recreativo.

El monumento encuentra antecedentes en la misma producción de Palanti: el mismo "partido" había sido desarrollado en la década de 1930 como monumento dedicado a "La Storia” y reaparecería luego, en 1968, en el libro Centuplicare Nostri valori Potenziare nostra economie, un volumen donde, como veremos, retomó el tema del rascacielos. ${ }^{44}$

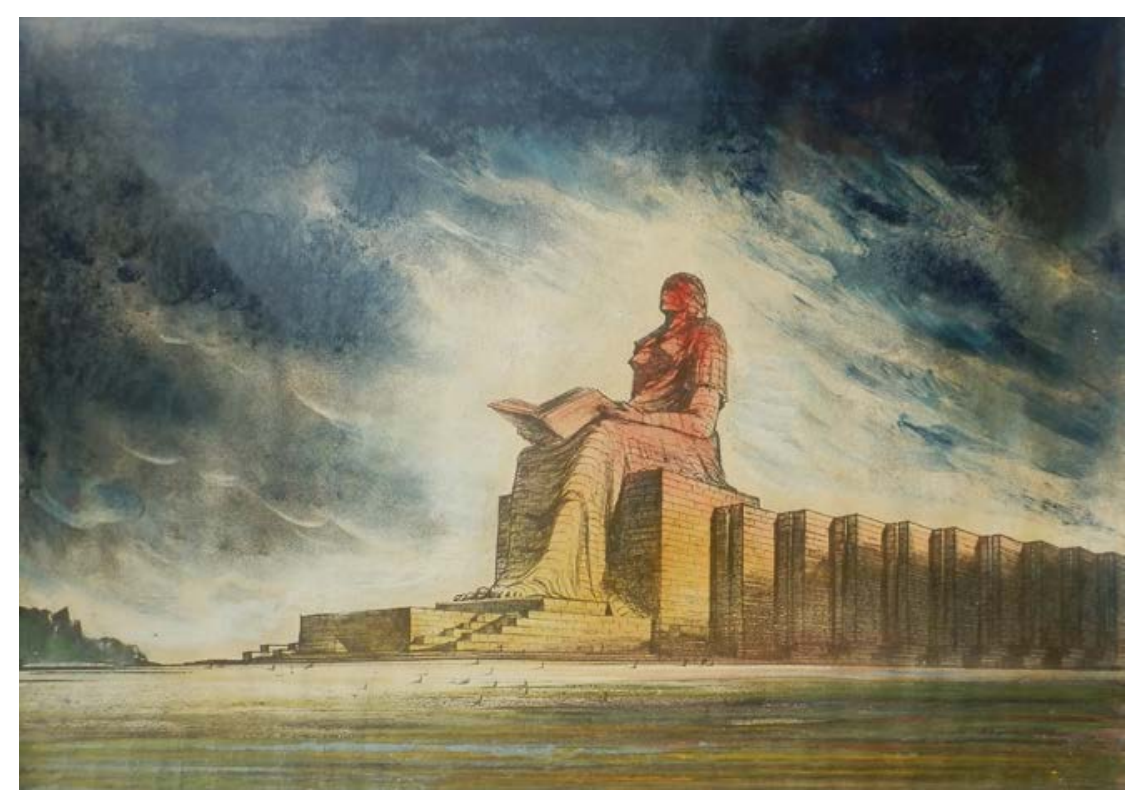

Pintura publicada luego como monumento a "La Storia" en Centuplicare nostri valori.... Mario Palanti, s/f. AGEP

$\overline{44}$ Mario Palanti, Centuplicare nostri valore potenziare nostra economia (Milano: Esperia, 1968), 18-19. Biblioteca dell’Accademia dei Lincei, Roma. 
Muy probablemente motivado por las intervenciones urbanas realizadas en su ausencia y la nueva escala metropolitana que había adoptado Buenos Aires, entre 1949 y 1950, Palanti proyectó dos arcos de triunfo monumentales que se ubicarían en la Avenida 9 de Julio y cuyos antecedentes pueden distinguirse en el proyecto presentado en el concurso para el Monumento alla Vittoria en la Piazza Fiume de Milán, llevado a cabo en 1937, en el cual, según la crítica de E. Tedeschi, el proyecto de ganador - de Carminati, Mazzoleni y Martini- había entendido la modernidad del tema "en modo serio y constructivo". ${ }^{45}$ Si bien Palanti obtuvo el cuarto puesto en este concurso, se debe, en parte,

a que los proyectos de Gardella, Albini, Romano y Giancarlo Palanti -sobrino del arquitecto- y Banfi, Belgioioso, Peressutti, Rogers (BBPR) - "de calidad digna de ser señalada"- habían quedado fuera por no respetar las pautas del llamado. ${ }^{46}$

El primer arco diseñado por Palanti fue el "Arco de la Victoria", realizado en 1949 y que se ubicaría en la Avenida 9 de Julio y Moreno. ${ }^{47} \mathrm{El}$ arco, de 35 metros de frente por 75 de lado, tendría una de sus bases en el centro de la Avenida y la otra estaría conformada por el edificio del MOP, que actuaría como un "contrafuerte". La propuesta incluía un reordenamiento del

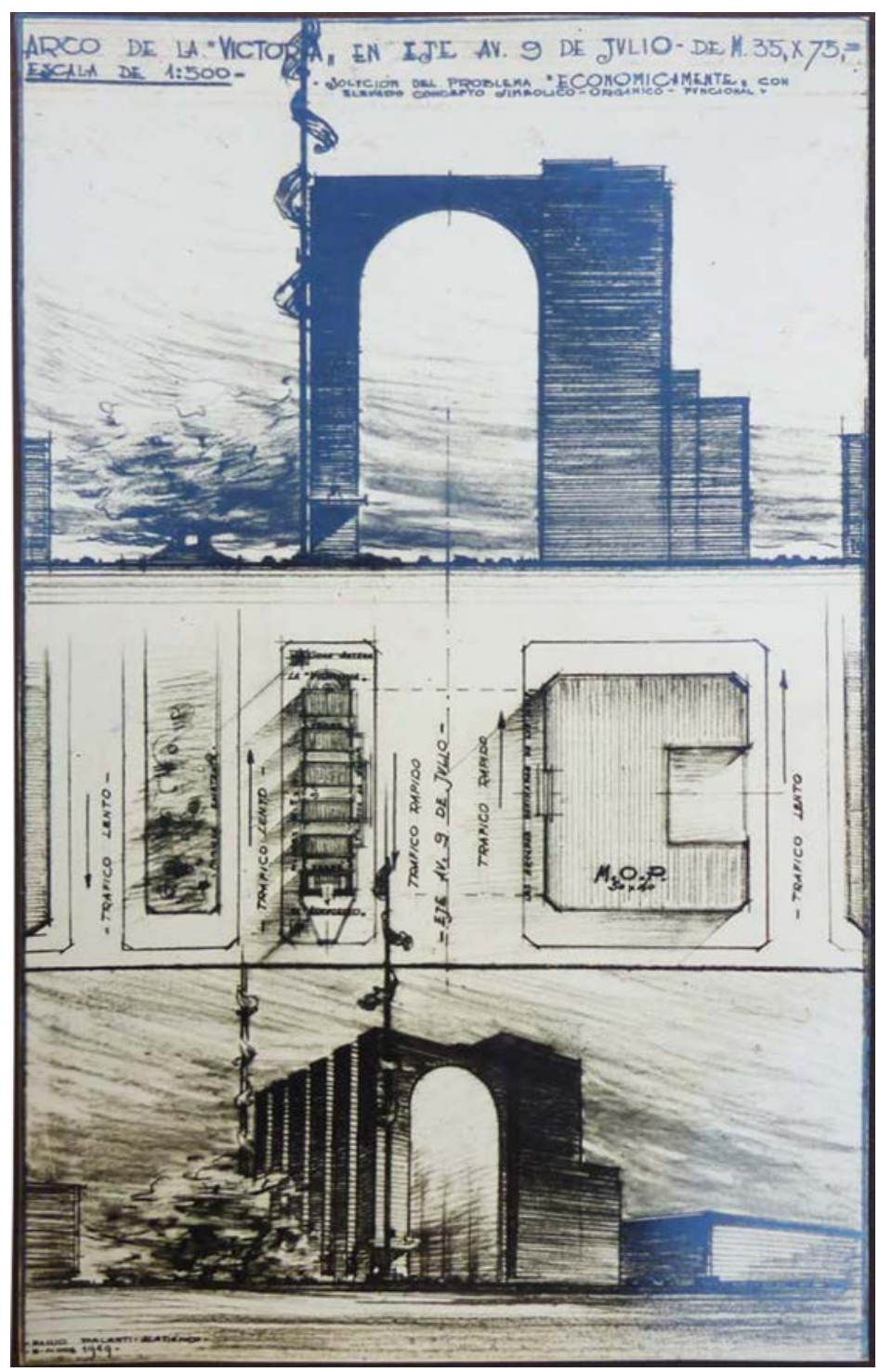

Boceto para Arco de la Victoria, Avenida 9 de Julio y Moreno, Buenos Aires, 1949. Proyecto. Mario Palanti. AGEP.

$\overline{45}$ Enrico Tedeschi, "Concorso per il Monumento alla Vittoria in Milano", Architettura. Rivista del sindicato nazionale fascita architetti, XVI (nov. 1937, fasc.XI): 645.

46 Tedeschi, "Concorso per il Monumento alla Vittoria in Milano": 645.

47 El 14 de abril de 1955, el diario La Prensa publicó una nota titulada "Estará terminado en 1957 el arco de triunfo que honrará a Perón”. La obra, señalaba el MOP de la Provincia de Buenos Aires, se emplazaría en la Plaza Olazábal, Avenida 7 y 38 de la ciudad de La Plata. 
tráfico: el tránsito rápido circularía por debajo del arco y el lento por los laterales. La base del arco ubicada frente al MOP estaba formada por seis pilares de 5 x 10 metros, con tres metros de distancia entre sí. El remate del conjunto se daba hacia el sur con una escultura de la Victoria y una "Gran Antena" y hacia el norte con un arengario a modo de proa que recuerda la propuesta de Palanti para el Palazzo Littorio. En uno de los bocetos pueden verse banderas argentinas y una figura que desde el arengario saluda a una multitud que, como una tropa, escucha perfectamente ordenada en hileras las palabras del líder. La incorporación del arengario era común en los programas promovidos por el régimen fascista. Además de los diseños para el Palazzo Littorio y la Torre Littoria, podemos citar el proyecto de Plinio Marconi para el Municipio de Addis Abeba (1939), el de Giuseppe Pagano, Marcello Piacentini y Cesare Valle para el Pabellón italiano (1936-37) para la Exposición Internacional de París. De la misma fecha es la Piazza di Aprilia obra de Concezio Petrucci, Mario Tufaroli, Filiberto Paolini y Ricardo Silenzi donde se ve la torre municipal con la incorporación del arengario. ${ }^{48}$ Este dispositivo sería retomado por Palanti en el proyecto para conmemorar la muerte de San Martín.

El segundo arco fue diseñado un año después. En 1950, con motivo del aniversario de los cien años de la muerte del Libertador, bocetó un monumento que honraría al prócer argentino y se ubicaría en la intersección de Avenida 9 de Julio y Avenida de Mayo una "Monumental obra para eternar el heroísmo del libertador del pueblo argentino, General José de San Martín". ${ }^{49}$ Al igual que el caso anterior, su ubicación en la principal avenida de la ciudad no

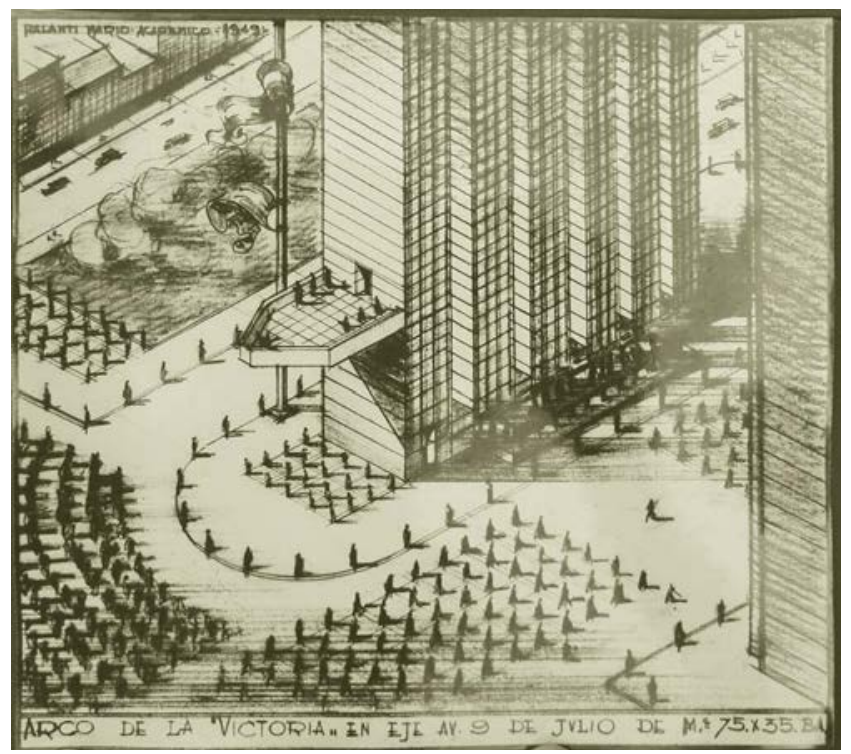

Detalle del proyecto para un Arco de la Victoria, Avenida 9 de Julio y Moreno, Buenos Aires, 1949. Proyecto. Mario Palanti. AGEP era en nada inocente. En efecto, Palanti había elegido emplazar este dispositivo propagandístico en una zona de alta visibilidad pública: se trata de un arco de triunfo sobre una base elíptica de 100 metros de longitud en un cruce de avenidas de alto contenido político social y cultural.

$\overline{48}$ Nicoloso, Mussolini architetto.

49 Mario Palanti, bocetos para Monumento al general San Martín. Ese mismo año, bajo el lema "Funcional" Palanti participó del concurso de anteproyectos para el Club Atlético Newell’s Old Boys de Rosario. AGEP. 


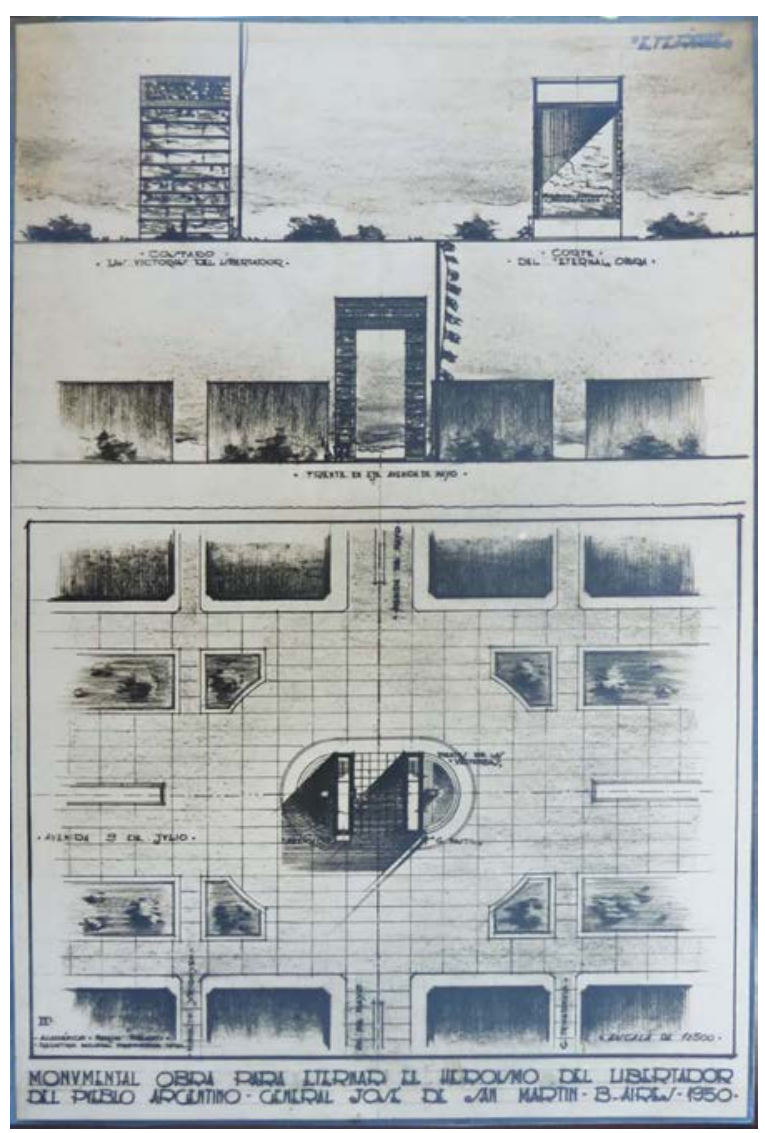

Detalle del proyecto para un Arco de la Victoria, Avenida 9 de Julio y Moreno, Buenos Aires, 1949. Proyecto. Mario Palanti. AGEP

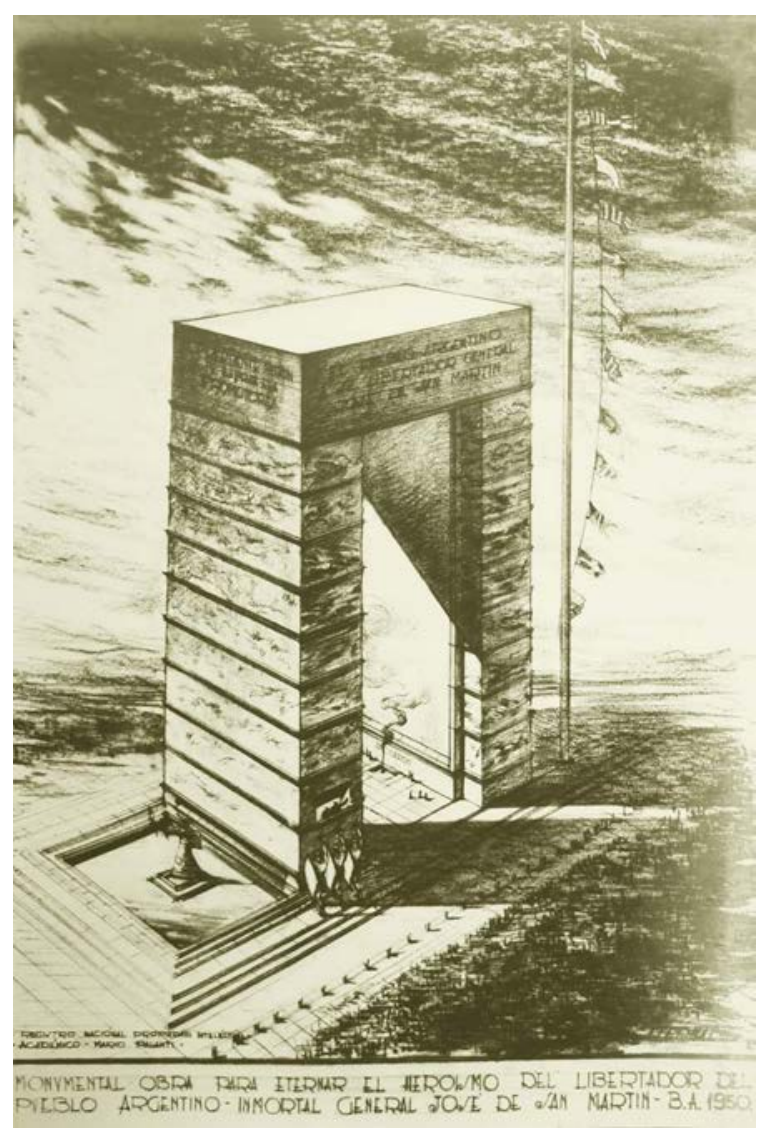

Proyecto para un arco en honor al General San Martín. Avenida 9 de Julio y Avenida de Mayo, Buenos Aires, 1950. Proyecto. Mario Palanti. AGEP

En respuesta a su emplazamiento, el frente de arco, hacia Avenida de Mayo, permitía la continuidad del eje cívico que une la Plaza de Mayo con la Plaza Congreso mientras que los laterales, con bajorrelieves, relataban los logros del General San Martín, se ubicaban de manera transversal a la Avenida 9 de Julio permitiendo la gran concentración de masas. Precisamente, el arco operaba, además de como monumento, como "altar de la patria de los argentinos": en uno de los lados se ubicaba un arengario custodiado por las esculturas de tres luchadores. Desde el balcón, dos siluetas saludan a una multitud que los vitorea: “el Jefe de estado Gen. Perón y su esposa arengando el pueblo. La apoteosis del General San Martín desde el eternal altar de la patria de los argentinos". ${ }^{50}$

Además de la incorporación del arengario, el grupo escultórico proviene de la propia obra de Palanti: el grupo de luchadores fue diseñado para el Palazzo Littorio en 1934, retomado para el Monumento alla Vittoria en 1937 y luego reelaborado en un dibujo titulado "Guarimento bíblico. Guarimento del popolo de Roma" con fecha de $1957 . .^{11}$ El relato inscripto en la

$\overline{50}$ Bocetos para Monumento al general San Martín, AGEP.

51 Mario Palanti, Guarimento bíblico, AGEP. 


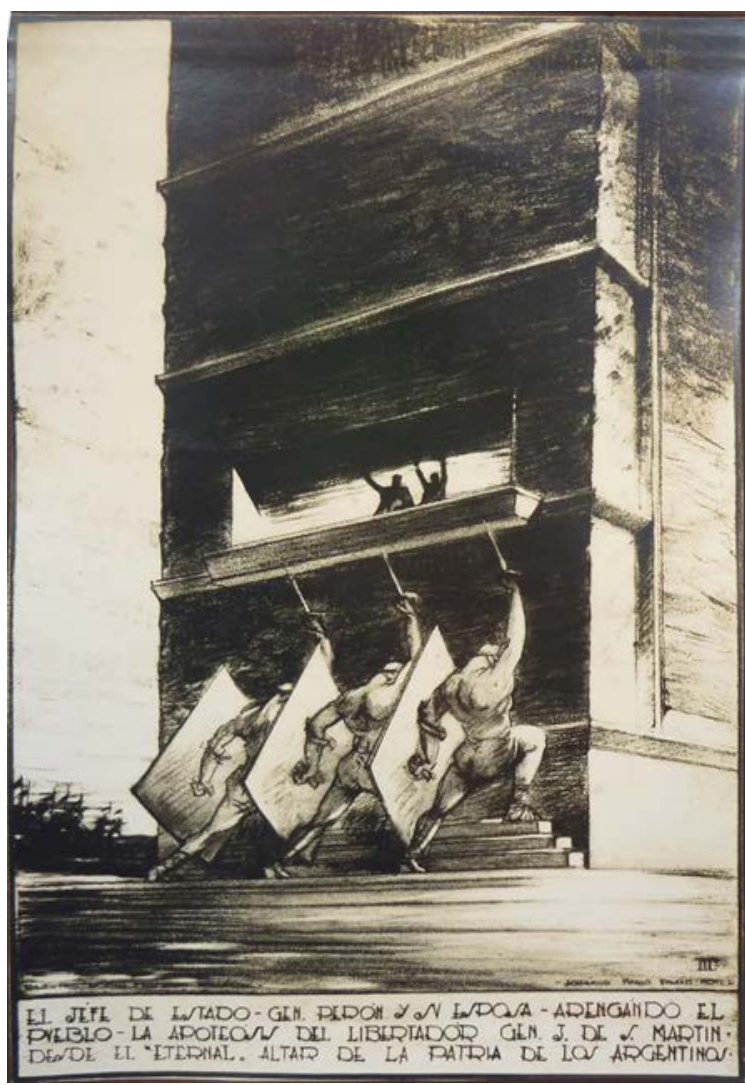

Detalle de grupo escultorico para el arco en honor a San Martín. Avenida 9 de Julio y Avenida de Mayo, Buenos Aires, 1950. Proyecto. Mario Palanti. AGEP

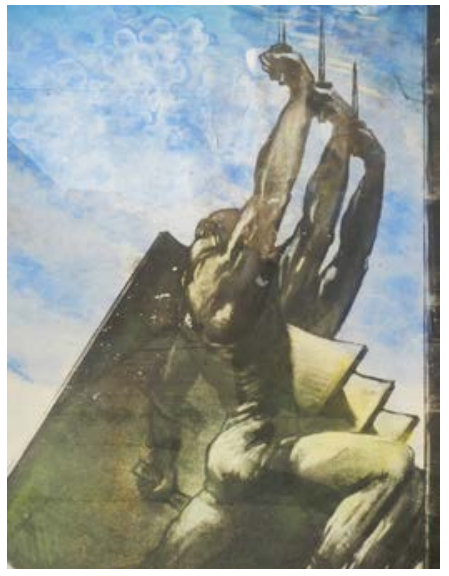

Pintura, sin título, s/f. Mario Palanti. AGEP

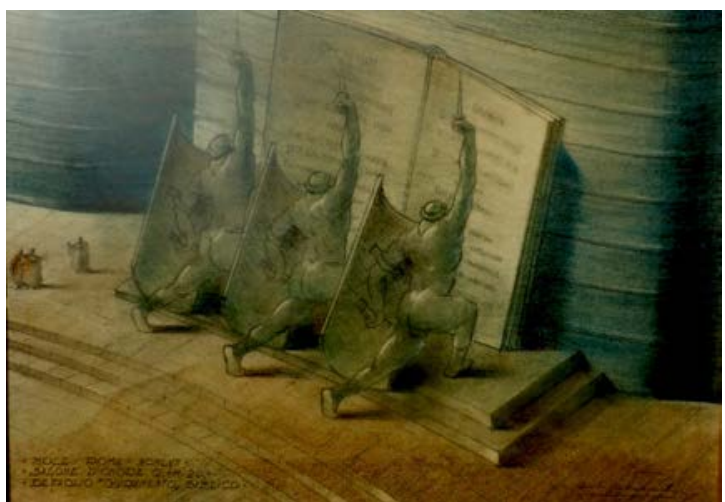

Pintura, "guarimento biblico" para la Mole Universale, Roma, 1957. Mario Palanti. AGEP

arquitectura había sido utilizado en proyectos anteriores donde empleó bajorrelieves para contar los éxitos del fascismo. Pero, principalmente, este recurso -común en varios de los proyectos presentados a concursos como el Palazzo Littorio, Auditorium y Casa Littoria- puede vincularse con el bajorrelieve "La storia di Roma attraverso le opere edilizie" (1939) que Publio Morbiducci realizó en el Palazzo degli Uffici para la Exposición del E’42.52

La muerte de Eva en 1952 había incrementado la carga simbólica en torno a su imagen convirtiéndola en un ícono y había impulsado, notoriamente, la reproducción de su figura. Ese mismo año de 1952 se fundó la Comisión Pro-Monumento a Eva Perón. ${ }^{53}$ En este contexto, Palanti dibujó el que sería su primer proyecto dedicado a Evita, prescindiendo de la figura de Juan Domingo Perón. La pintura muestra un "monumento utilitario": un edificio de cuarenta pisos, dividido en varios cuerpos y de líneas modernistas dedicado al honor de Eva Perón "La justiciera". El epígrafe deja leer: "Mole en honor a Eva Perón. Palacio de las provincias y territorios. Monumento utilitario." ${ }^{54}$

52 Gentile, El culto del Littorio. Y Ades, Benton, Eliott, Whyte comps., Art and power. Europe under the dictators 1930-

54 Mario Palanti, Mole en honor a Eva Perón. Pintura 50 x 70 cm. Buenos Aires, 1952. AGEP. 


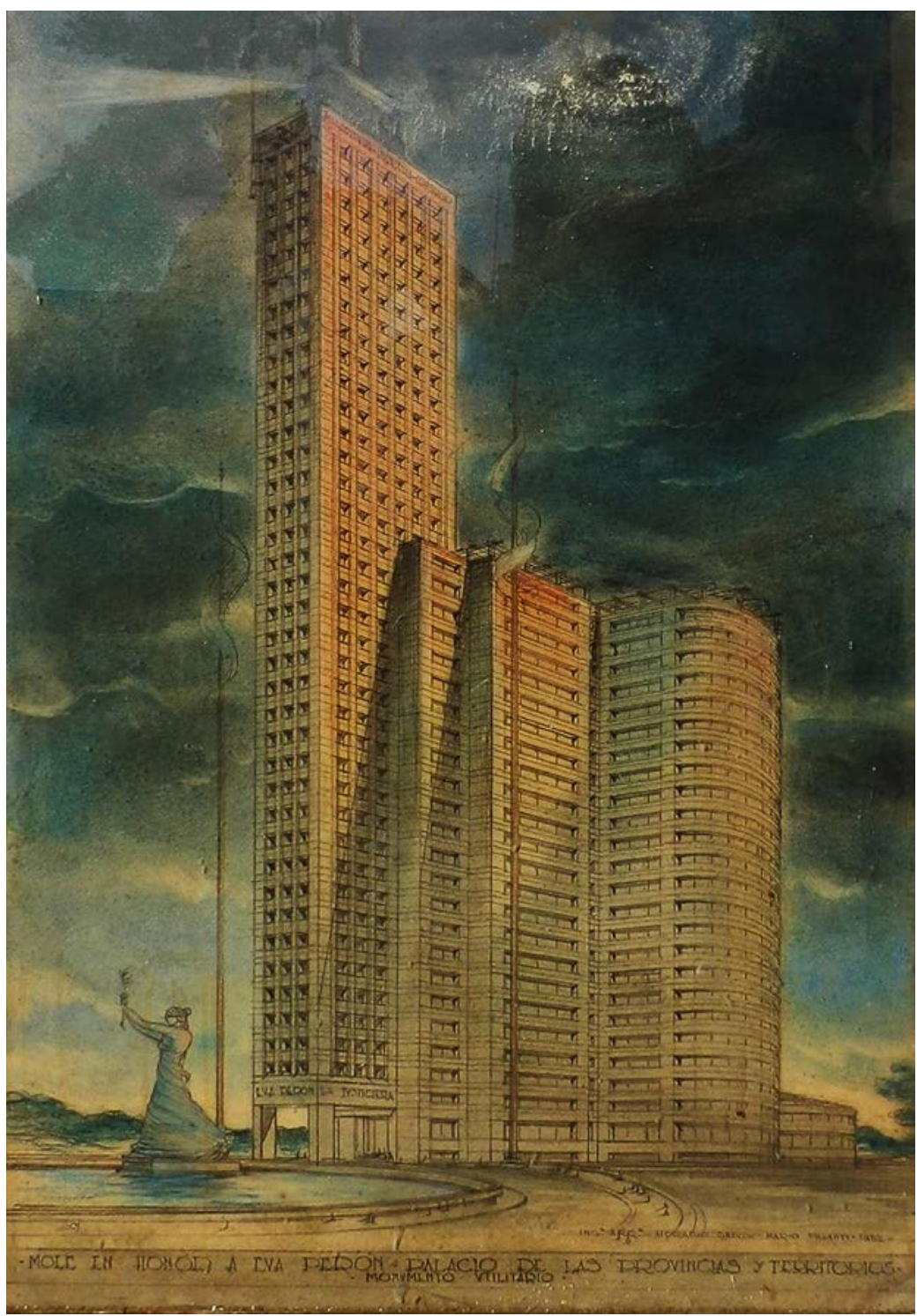

Pintura, proyecto para monumento a Evita. Buenos Aires 1952,

Proyecto.

Mario palanti. AGEP.

En agosto de 1953, Palanti realizó el que sería, quizá, el más curioso de sus proyectos: el monumento al Descamisado en honor a Evita. Como explica Ballent, el monumento a Eva Perón había tenido la iniciativa en el monumento al Descamisado surgido como una propuesta del peronismo lanzada en 1946 y que proponía ubicarlo en Avenida de Mayo y 9 de Julio (mismo sitio donde Palanti propuso el monumento a San Martín). ${ }^{55}$ Al morir Eva Perón, el Monumento al Descamisado fue dedicado al culto de Evita. En 1952, el encargo había sido hecho al escultor León Tomassi quien previamente había realizado las esculturas de la Fundación Eva Perón. El coloso se ubicaría sobre Avenida del Libertador frente al Palacio Unzué, en ese momento residencia presidencial y última morada de Eva Perón -y sitio sobre el que luego se realizaría, durante el último gobierno peronista, el también inacabado Altar de la Patria-. ${ }^{56}$ El proyecto

55 Ballent, Las huellas de la política, 179.

56 Mariana Santangelo, "Un mundial a colores: arqueología de un predio" en Registros (Mar del Plata, año 10 (n.11): 134-149. Julio 2014) 


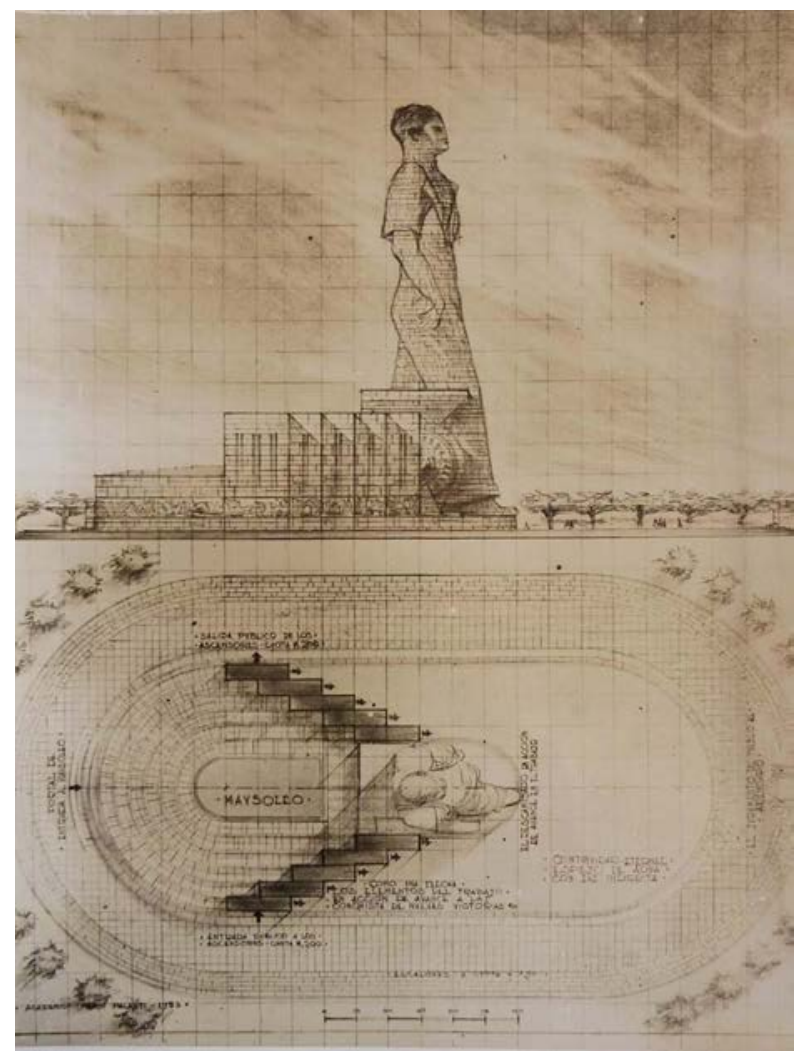

Planta y vista del propyecto para Descamisado en honor a Eva Perón. Buenos Aires 1953, Mario Palanti. Proyecto. AGEP

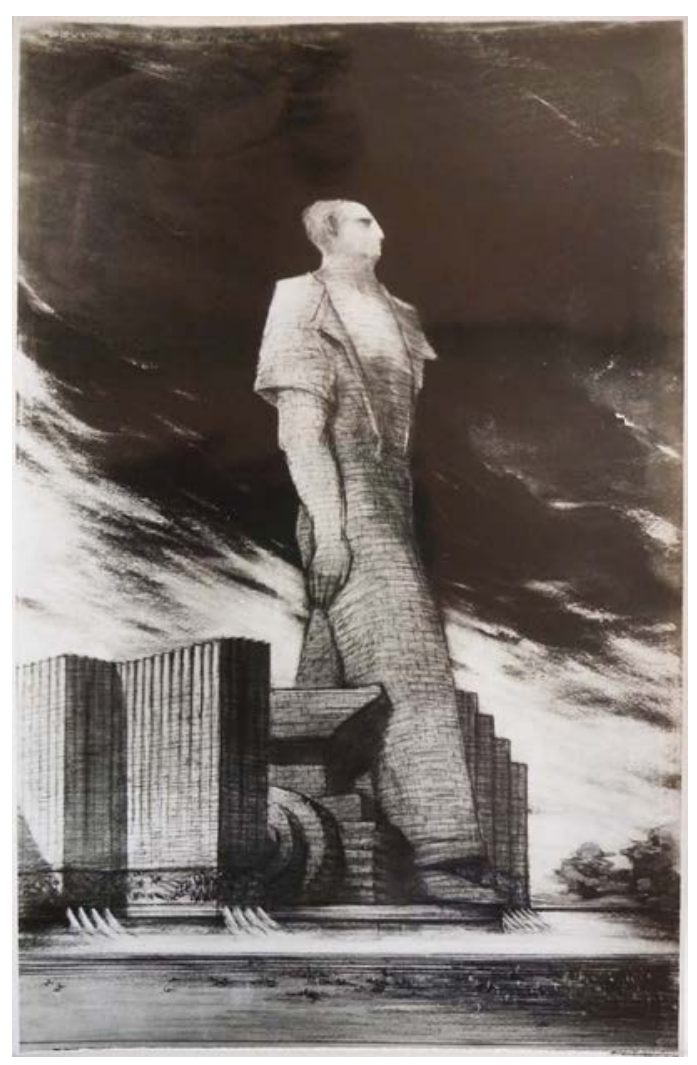

Perspectiva del propyecto para el Descamisado en honor a Eva Perón. Buenos Aires, 1953, Proyecto. Mario Palanti. AGEP

estaba compuesto por una columna sobre la cual se posaba la estatua de un colosal descamisado.

La altura total del monumento sería de 137 metros, la estatua de 60 metros y el diámetro de la escalera de acceso de 100 metros. En la base de la columna se ubicaba el mausoleo de Eva..$^{57}$ Con su altura, el descamisado operaría como un mojón urbano, un símbolo que dominaría el perfil de la ciudad y actuaría como un faro sobre el río.

Como señala Marysa Navarro, Eva Perón había encargado el monumento al descamisado a Tomassi en 1951 y la maqueta había sido presentada oficialmente en julio de 1953. A pesar de ello, menos de un mes después Palanti intentó, de todas maneras, probar suerte..$^{58}$ Probablemente el tipo de encargo de escala urbana en el cual la arquitectura se ponía al servicio de un líder político motivó a Palanti a desarrollar su proyecto.

Si como señala Ballent, el proyecto de Tomassi puede ser asociado desde el punto de vista plástico con el proyecto de Boris Iofan para el Palacio de los Soviets en Moscú (1931-1933) donde se ve el monumento como columna colosal dominada por la escultura del líder político,

$\overline{57}$ Ballent, Las huellas de la politica, 177-180.

58 Diario La Nación, Buenos Aires, 26 de julio de 1953, 1-2; Diario La Prensa, Buenos Aires, 26 y 27 de julio de 1953. Diario Democracia, 27 de julio de 1953, 3 y 8; Diario Los Andes, 10 de enero de 1954, 4-7; Diaro La Nación, 20 de abril de 1955, 2; Diario La Prensa, 1 de mayo de 1955; La Prensa, 20 de abril y 5 de agosto de 1955. 
el Descamisado de Palanti puede ser vinculado con otro proyecto de Iofan, esta vez, materializado. Nos referimos al Pabellón de la URSS para la Expo "Arts et Techniques dans la vie Moderne" llevada a cabo en París, en 1937.59 El pabellón se organizaba en una planta rectangular que se escalonaba de manera dinámica decreciendo en ancho y creciendo en altura para culminar en una "proa" sobre la cual se alzaba una colosal escultura de un hombre y una mujer que elevaban en sus manos la hoz y el martillo. El Descamisado de Palanti retoma el dinamismo de este esquema junto con elementos provenientes de la propia producción del arquitecto. El coloso se ubica en el vértice de una composición en forma de $\mathrm{V}$ escalonada cuyo dinamismo, como recurso, había sido empleado

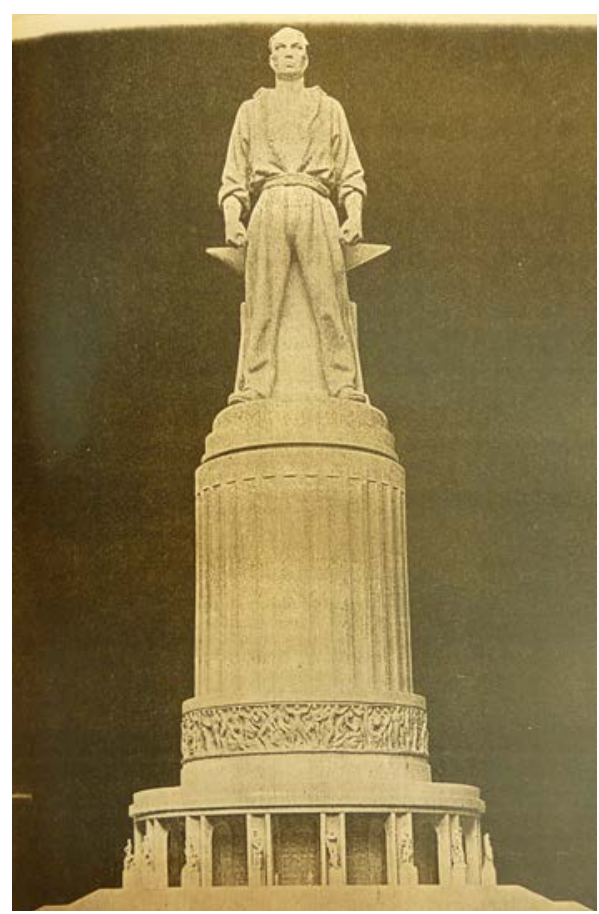
Leon Tomassi, Maqueta del monumento a Eva Perón en la propuesta para el monumento a Perón y Eva y previamente en la solución "E" presentada al concurso para la Torre Littoria de Milán (1937). En esta solución, Palanti planteó un edificio de base escalonada formada por cuatro rectángulos en forma de fasci que se elevan 60 metros como pilastras de iguales dimensiones y en cuya base se ubican las esculturas del Quadrunvirato in Marcia. Esta idea de avance se ve también representada del Palazzo Littorio con su forma náutica. Como traducción directa de la ideología en la arquitectura, el descamisado de Palanti se encuentra en marcha, "en acción de avance hacia el trabajo", simboliza el progreso "como una flecha los elementos del trabajo en acción de avance a la

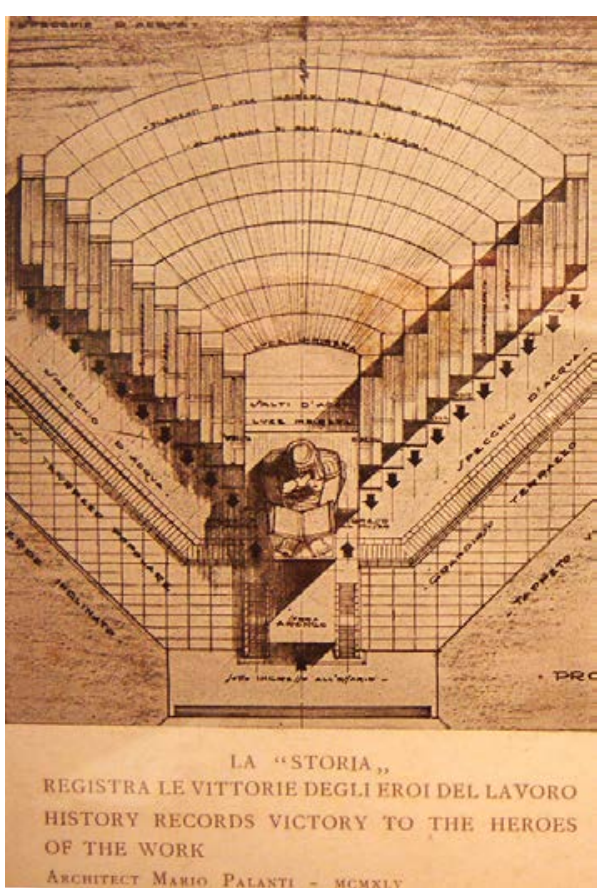

Planta de monumento dedicado a "La Storia". 1945. Se ve la idea de avance planteada en el Descamisado. Mario Palanti. AGEP conquista de nuevas victorias".

59 Alberto Samona (a cura di), Il Palazzo dei soviet 1931-1933 (Roma: Officina ed., 1976). Es interesante lo señalado por Dietrich Neumann al marcar la similitud de la base de implantación de la Mole Littoria con el proyecto de Iofan para el Palacio de los Soviets. Iofan, quien estudió en Roma, se encontraba en la ciudad en el momento en que Palanti presentó el proyecto de la Mole al Duce, y probablemente, haya estado al tanto el diseño. Asimismo, Neumann señala el vínculo con Armando Brasini y su posible relación con los proyectos de Palanti. Neumann, "A Skyscraper for Mussolini”". 
Este "avance" del proyecto de Palanti se diferencia de la figura estática representada por la escultura de Tomassi, pero se asemeja (llamativamente) a "El conductor" - una figura de un hombre que se muestra arremangado, con los puños cerrados y en actitud de avance- que era parte del grupo escultórico propuesto por Tomassi para la base del monumento. ${ }^{60}$

El coloso de Palanti medía 200 metros de altura con un total de 60 metros de longitud. La plataforma elíptica sobre la cual se implantaría el conjunto medía cerca de 360 metros en su eje mayor. El mausoleo se ubicaría detrás del Descamisado y frente a él un espejo de agua actuaba como fuelle para enfatizar la perspectiva que remataba en un arengario.

Si la propuesta de monumento realizada por Palanti fue presentada oficialmente, o no, permanece aún como incógnita. El $1^{\circ}$ de mayo de 1955 se iniciaron los trabajos de obra para la construcción del monumento diseñado por León Tomassi. Ese mismo año, meses después, Palanti emprendería el regreso a Italia sin haber conseguido concretar sus monumentales proyectos que pasarían a ser los últimos realizados para un comitente concreto. Sin embargo, el regreso no se debía sólo al fracaso en su acercamiento al gobierno peronista, también el campo privado le fue esquivo al arquitecto.

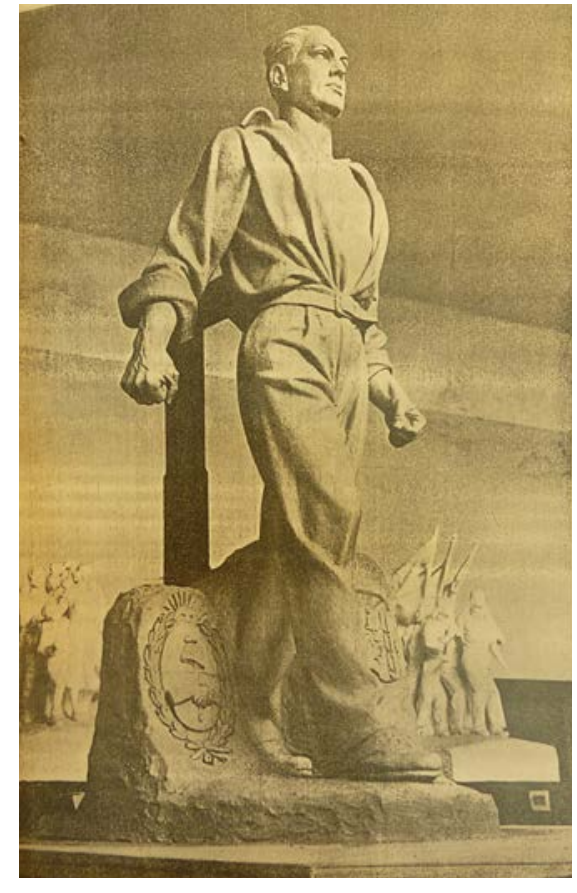

Leon Tomassi "El conductor", parte del grupo escultórico propuesto por para la base del monumento a Eva

\section{E1 desencanto. Problemas legales en torno a la profesión de arquitecto}

En 1948, Palanti regresó a la Argentina para encontrar, según explica en su currículum, “(...) un difficile ambiente nuovo, per aprirsi una breccia professionale, in un regime sociale dittatoriale." "1 A ello se sumaba -de acuerdo a este documento- la imposición de revalidar el título profesional extranjero y la exigencia, para obtener la reválida en la Universidad de Buenos Aires, de adoptar la ciudadanía argentina sin tener en cuenta -señalaba Palanti- a aquellos quienes habían “(...) realizæato opere nel

60 Presidencia de la Nación, Secretaría de Prensa y Difusión, Monumento a Eva Perón, Buenos Aires, 1955.

61 Palanti, Currículum Vitae, 1958. “(...) un difícil ambiente para abrirse una brecha profesional en un régimen social dictatorial." 
Paese a migliaia, dalle più umili ai grattacieli, quali quelle del Palanti, degne per la intensa vita di tre nomini." ${ }^{2}$. A fin de conseguir el título habilitante, Palanti se dirigió a la Universidad de Buenos Aires para realizar la tramitación correspondiente. Luego de dos años de espera, un reclamo ante la justicia y un nuevo pedido a la Universidad, el trámite quedó derogado informándosele al arquitecto que no se darían reválidas a títulos extranjeros en todo el país.

En noviembre de 1955, envuelto en problemas legales por carecer de título habilitante “(...) profondamente addolorato per la tragica sua situazione creatasi, nel novembre 1955 decide di far ritorno definitivo in Italia, dopo di aver dato anima e corpo a quel Paese, rimasto sordo ad ogni suo supremo sforzo, di studioso e di animatore tenace ed onesto nel suo compito professionale." ${ }_{63}^{3}$ (ver apéndice)

Efectivamente, el ambiente disciplinar había cambiado durante la ausencia del arquitecto. En julio de 1944, durante un gobierno de facto y por decreto del General Farrel, se regularon, bajo jurisdicción nacional, las profesiones de arquitecto, ingeniero y agrimensor, se crearon los Consejos correspondientes y se designaron los consejeros que comenzarían la labor de definir los límites y alcances de la profesión de arquitecto. ${ }^{64}$ Dentro del Consejo se discutieron, entre otras, las normas en lo referente a inscripción y matriculación quedando establecido que nadie podía dirigir o proyectar obras sin poseer título habilitante. Esto dejaba en claro el reconocimiento a las leyes vigentes y a la importancia de la formación universitaria. ${ }^{65}$ Pero en marzo de 1946, y con el fin de agilizar los trámites ante la gran cantidad de solicitudes recibidas, se creó por decreto-ley el "Registro Especial” de la Matrícula (de carácter transitorio) que se ocupó de las reválidas de títulos extranjeros y de aquellos quienes ejercían la arquitectura, agrimensura o ingeniería y carecían de título legal. ${ }^{66}$ Así, quedaba en manos del Consejo y no de la Universidad la evaluación académica de los aspirantes a la matrícula. Durante seis meses, el Registro abrió las puertas de los Consejos para todos aquellos que:

(...) al 7 de julio de 1944 se encontraban en el país desempeñando alguna de las actividades propias de los profesionales universitarios matriculados en los tres primeros Consejos [arquitectura, ingeniería, agrimensura], siempre que ellas demostrasen haber ejercido esas actividades durante un período no inferior a los diez años anteriores a la fecha de este Decreto-ley. ${ }^{67}$

$\overline{62}$ Palanti, Currículum Vitae, 1958. “(...) realizado obras a millones en el país, desde las más humildes hasta rascacielos.".

63 Palanti, Currículum Vitae, 1958.

64 Gustavo Brandariz, Consejo Profesional de Arquitectura y Urbanismo. Su trayectoria en cincuenta años (Buenos Aires, 1994, inédito), 2.

65 Brandariz, Consejo Profesional de Arquitectura y Urbanismo, 6.

66 Brandariz, Consejo Profesional de Arquitectura y Urbanismo,16.

67 Manual del ejercicio profesional de arquitecto. Documento CPAU. C-3, Bs. As. CPAU, junio de 1989, cit. en Brandariz, Consejo Profesional de Arquitectura y Urbanismo, 17. 
Durante el plazo estipulado de seis meses se presentaron 354 solicitudes para inscribirse en la matrícula, entre ellos Francisco T. Gianotti, Sydney G. Follet, Jorge y Andrés Kálnay, Caludio José Caveri y Wladimiro Acosta. Durante los años siguientes, el Consejo se dedicó a evaluar los antecedentes de los postulantes. Si bien se aprobaron la mayor parte de las solicitudes otras no tuvieron la misma suerte, entre ellas la de Mario Palanti quien presentó su solicitud fuera de fecha, en 1948, dos años después del vencimiento del plazo pautado por la ley. Además, Palanti señalaba en su currículum haber estado en Italia por los últimos diez años y no en el país, como lo requería el Decreto-ley $8036 .^{68}$ A ello debe sumarse la creación, en 1948, de la Facultad de Arquitectura y Urbanismo a partir de la vieja Escuela de Arquitectura que dependía de la Facultad de Ciencias Exactas, Físicas y naturales de la Universidad de Buenos Aires. ${ }^{69}$

Desoyendo la reglamentación vigente, Palanti había comenzado a realizar tareas profesionales. En 1950, el juzgado en lo Civil n8 de la Capital Federal solicitó al CPAU un informe sobre la situación de Palanti ya que estaba en juicio con Ángel Roncoroni por realizar tareas profesionales sin tener título habilitante. ${ }^{70}$

En 1952, Ricardo Algier informó al Consejo sobre la existencia de un letrero de obra en la refacción de la confitería París (Libertad esq. Charcas, Buenos Aires) en el cual figuraba el nombre de Mario Palanti como proyectista y catedrático. El Consejo resolvió intimar a Palanti a retirar el cartel de obra “(...) o en su defecto a encuadrarlo dentro de las disposiciones legales vigentes por carecer de título habilitante." ${ }^{71}$

Esta situación fue muy diferente a la de aquellos profesionales y técnicos italianos convocados para desarrollar tareas en el país para quienes tramitar la reválida del título habilitante no era un requisito: “(...) las leyes argentinas reconocen a los Profesores contratados por las Universidades Nacionales del país, la idoneidad para el ejercicio de la profesión (Ley Nacional $\mathrm{n}^{\circ} 4416$ art.3) ${ }^{\prime 72} \mathrm{~A}$ diferencia de quienes habían sido invitados oficialmente, Palanti había venido a probar suerte por cuenta propia sin una institución o gobierno que amparase la "ilegalidad" de su condición de arquitecto en la Argentina. Pero el monumentalismo académico de Palanti

68 Acta CPAU n¹54 del 20/01/1948, cit. en Brandariz, Consejo Profesional de Arquitectura y Urbanismo, 19.

69 Sociedad Central de Arquitectos, 100 años de compromiso con el país 1886/1986 (Buenos Aires: SCA, 1993).

70 Acta n $^{\circ} 250$ del 17/09/1950. Actas del Consejo Profesional de Arquitectura y Urbanismo (CPAU). Libro II (n`147 al 266 del 17/11/47 al 26/04/51), Biblioteca CPAU, Buenos Aires.

71 Acta n$^{\circ} 306$ del 19/06/1952. Actas del CPAU. Libro III (n²66 al 427 del 26/04/51 al 02/05/57), Biblioteca CPAU, Buenos Aires.

72 Documento sobre la "Revalida del título del Arq. Ernesto La Padula". s/d. Archivo privado. Agradezco a Sebastián Malecki esta información. 
estaba lejos de interesar al Estado cuya convocatoria se relacionaba con un interés vinculado a la “arquitectura moderna”, más allá de que sus autores fueran opositores o adscriptos al fascismo.

Efectivamente, no es casual que varios de los profesionales hayan sido contactados mientras participaban de los CIAM. Ernesto N. Rogers fue invitado por Jorge Vivanco y Jorge Ferrary Hardoy -integrantes de la delegación argentina del CIAM de 1947, llevado a cabo en Bridgwater- para dictar una serie de cursos en el Instituto de Arquitectura y Urbanismo (IAU) de la renovada Universidad de Tucumán, que intentaba consolidarse como polo de referencia a nivel regional. Asimismo, se los requería para trabajar en el Estudio del Plan para Buenos Aires (EPBA) basado en el Plan General para Buenos Aires que Ferrary Hardoy y Juan Kurchan desarrollaron junto a Le Corbusier con base en los bocetos realizados por este último durante su visita a la Argentina en 1929.

A la experiencia de la Ciudad Universitaria de Tucumán se sumó la colaboración de Lodovico Belgioioso, Enrico Peressutti y luego Nervi, Oberti, Piccinato, Tedeschi y Calcaprina junto a los locales Hilario Zalba, Rafael Onetto, José Le Pera y más tarde Sacriste, Catalano y Caminos. En 1949, Luigi Piccinato fue contactado por Vivanco y Bonet en el CIAM de Bergamo para trabajar en el EPBA. Urbanista de la ciudad de Sabaudia, Piccinato junto a Morelli, ganó el concurso para el barrio 17 de Octubre auspiciado por el Banco Hipotecario Nacional (BHN). Además de esto, Piccinato había recibido el encargo de diseñar el plan de conjunto para Ezeiza dentro del cual se encuentra Ciudad Evita. ${ }^{73}$ Por su parte, Pier Luiggi Nervi -quien había realizado un proyecto para hangares del aeropuerto de Ezeiza- colaboró con el dictado de cursos en el IAU de Tucumán y en 1950 en la Facultad de Arquitectura de la Universidad de Buenos Aires. A ello se sumaría, en 1951, el significativo aporte de Bruno Zevi a través de las conferencias dictadas sobre historia de la arquitectura y el intenso trabajo de Enrico Tedeschi en el IAU y en la Facultad de Arquitectura de Córdoba. ${ }^{74}$ En Córdoba también encontró lugar Alberto La Padula quien, como señala Malecki, "tuvo una rápida inserción en el Estado provincial desde donde fue convocado para participar de distintos emprendimientos urbanísticos.” y para quien la condición de técnico y extranjero le permitió “(...) asegurar la continuidad de los trabajos del Plan Regulador al mantenerse al margen de las virulentas disputas políticas entre peronistas y antiperonistas $(\ldots) "{ }^{75}$

$\overline{73}$ Ballent, Las huellas de la política, 146-148. "Luigi Piccinato" voz, en Jorge Francisco Liernur y Fernando Aliata, Diccionario de Arquitectura en la Argentina (Buenos Aires: Clarín Arquitectura, 2004). Anahí Ballent, "La Caja de Pandora: Los arquitectos y el peronismo" mimeo.

74 Sebastián Malecki, "Historia y crítica. Enrico Tedeschi en la renovación de la cultura arquitectónica argentina, 1950-1970", Eadem Utraque Europa, No 14 (agosto 2013).

75 Sebastián Malecki, La ciudad dislocada: Córdoba 1947-1975. Modernización y radicalización en la cultura urbana y 
Palanti, además de encontrar rivalidad por actuar con marcada inclinación en el afán de atraer al gobierno de Perón, no contaba -como fue mencionado- con una invitación oficial que le permitiera practicar la disciplina.

En abril de 1953, hizo traducir -ante traductora pública- su certificado de inscripción en el Registro Profesional de Ingenieros y Arquitectos de la Provincia de Milán realizado en octubre de 1928, ni este documento, ni haber adquirido la ciudadanía argentina, ni inclusive su listado con treinta y dos edificios construidos en Buenos Aires ayudaron para legalizar su situación..$^{76}$

\section{Un nuevo rascacielos para Buenos Aires}

Los problemas legales en el contexto profesional y, por consecuente, la ausencia de encargos, generaron el campo propicio para que el arquitecto dedicara sus esfuerzos a la divulgación del ladrillo -ahora cerámico- "Palandomus" y a otro tema que lo acompañaba, como una obsesión, desde inicios de su carrera: el rascacielos.

Especulando con la ciudad que décadas antes le posibilitó la construcción de esta tipología, en 1954, en Buenos Aires y con casi setenta años, Palanti diseñó la Torre Babele: un rascacielos polifuncional de base circular y 400 metros de altura con 120 pisos, tres subsuelos y una superficie de $100.000 \mathrm{~m}^{2}$ cuya ubicación, por “pedido de los interesados en su construcción” se mantenía como reservada. ${ }^{77}$

El proyecto retomaba el programa que Palanti planteaba en sus rascacielos -como el Mausoleo Glorificando gli Eroi Nostri(1918) o las diferentes versiones de la Mole Littoria (1924-26)-: el sistema constructivo en cemento armado, el simbolismo religioso, la multiplicidad de actividades o la monumentalidad. La leyenda que acompaña los planos deja leer: "PALANDOMUS": gran torre utilitaria y de la fe. Centro científico-cultural-artístico. $\mathrm{n}^{\circ} 130$ pisos altos y $\mathrm{n}^{\circ} 5$ subsuelo.

arquitectónica, Tesis de Doctorado en Historia, FFyH, UNC, Córdoba, 2015, mimeo. Como explica Malecki: "Lo Celso -de buenos vínculos con diversos grupos peronistas y de una clara afinidad con sectores católicos conservadores de Córdoba que apoyaban al peronismo en ese entonces-, viajó en julio de 1948 a Suiza al primer congreso de la Unión Internacional de Arquitectos. Allí, Marcello Piacentini le recomendó a La Padula como, según sus palabras, "uno de los mejores arquitectos de Roma". Motivo suficiente para que Lo Celso lo contratara para el proyecto "Ciudad Universitaria Presidente Perón”.

76 Legalización de inscripción en el Registro de Ingenieros y Arquitectos de la Pcia. de Milán, AGEP; Palanti, Currículum Vitae de Mario. En una carta Palanti le explica a su mujer que para realizar el trámite de divorcio (vía Mexico) él contaba, además con la ventaja de tener ciudadanía argentina. APC, carta de Mario Palanti a Nahir Marazzi Castiglioni, 9 de octubre de 1954.

77 "gli interessati per la sua realizzazione costruttiva, desiderano mantenere riservato il punto destinato, per il prescelto privilegio; comunque probabilmente adottando un criterio operativo enfiteusi dell'opera magna”. Mario Palanti, “Torre Babele Novus”, Giornale d'Italia, Buenos Aires, 22 de noviembre de 1954. 


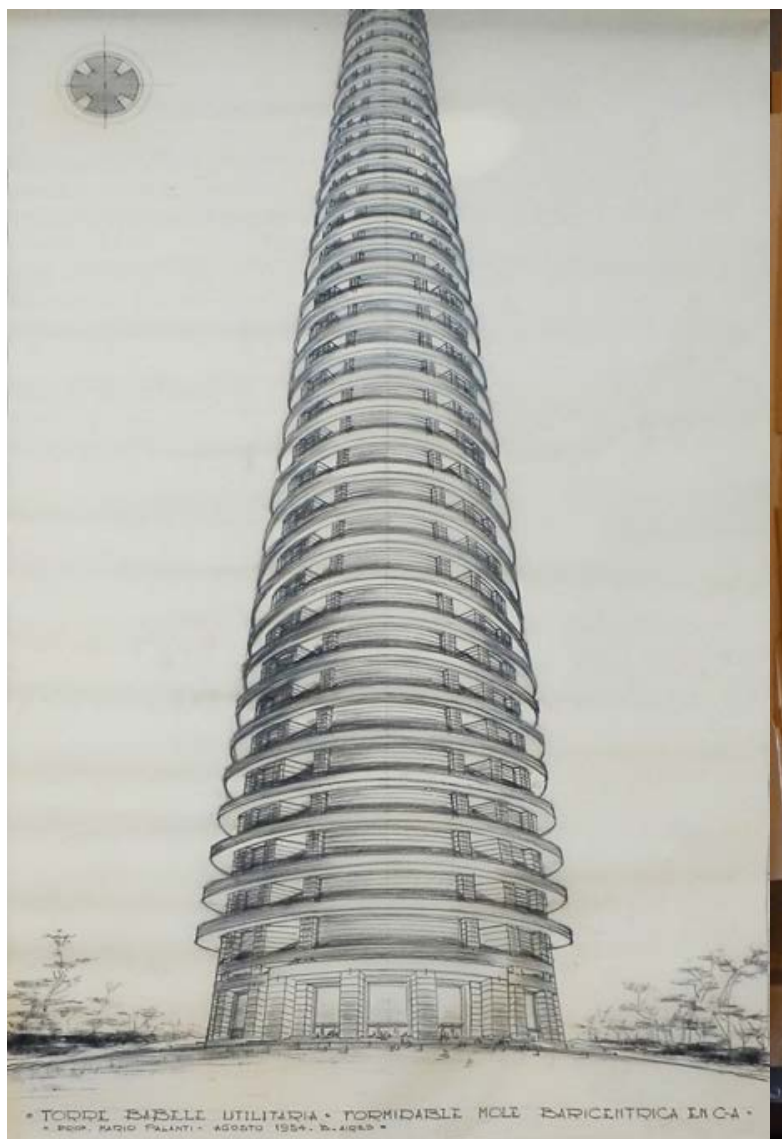

Perspectiva.Torre Babele. Buenos Aires, 1954. Proyecto. Mario Palanti. AGEP

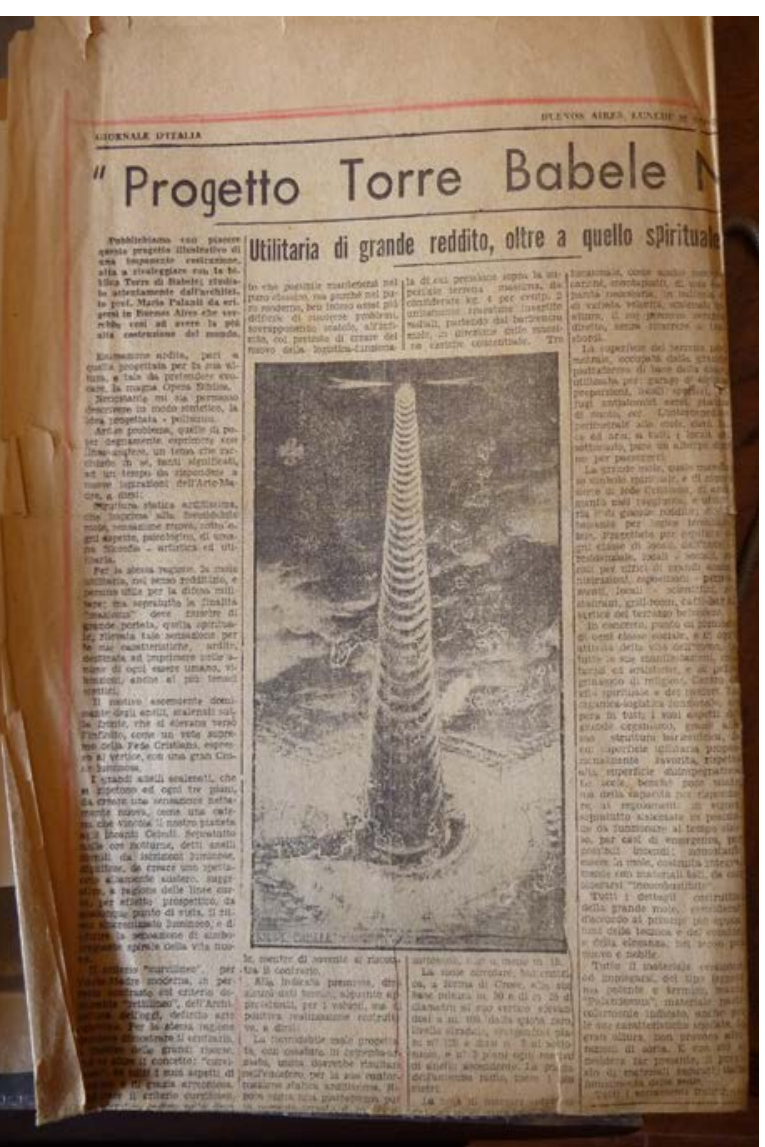

Mario Palanti, "Torre Babele Novus", Giornale d'Italia, Buenos Aires, 22 de noviembre de 1954.

No4.500 habitaciones y 4.500 baños. Gran galería exposiciones permanentes. Salones progreso técnico-social.”78

$\mathrm{Al}$ igual que en las propuestas de principios de siglo XX, la Torre, señalaba Palanti, sería "utilitaria. Elevando valores espirituales y económicos", pero a diferencia de estos proyectos,

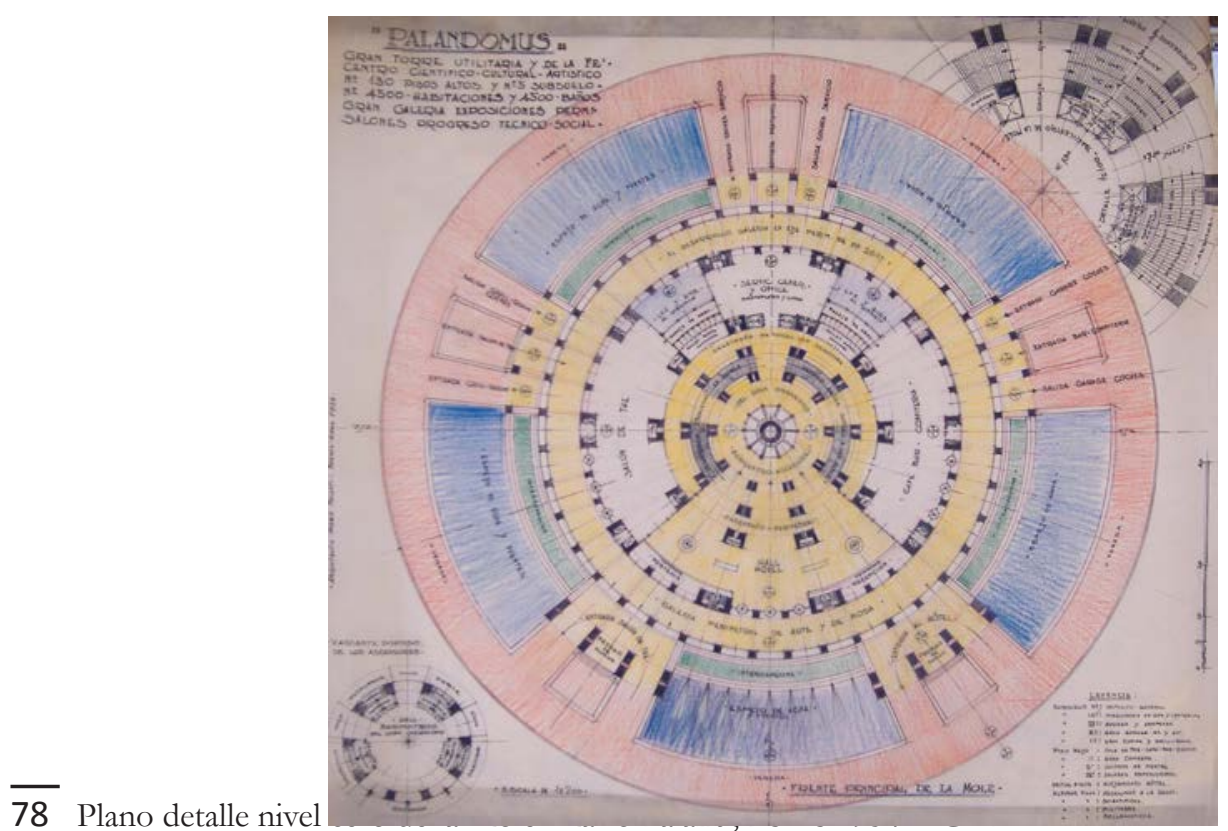

Planta. Torre

Babele."Gran torre utilitaria y de la fe". Buenos Aires 1954, Proyecto. Mario Palanti. AGEP 
en la Torre Babele el arquitecto aplicaba dos cuestiones que repetiría hasta el fin de su carrera y diferenciaban este ejemplo de sus producciones anteriores: el lenguaje y el círculo como idea base de partido.

La forma circular, como vimos, es una figura geométrica constantemente utilizada por Palanti en su método proyectual. En efecto, en diversos proyectos señalaba la primacía de lo circular como moderno, frente a lo lineal. En un artículo al que hemos hecho referencia, publicado el 15 de mayo de 1953, Palanti atacaba la conformación "rectangoloide" del Estadio Olímpico del Foro itálico en Roma diseñado por Luigi Moretti y Enrico del Debbio en la década de 1930 y finalizado, entre otros, por A. Vitellozzi ese mismo año de 1953.79 Palanti acusaba al proyecto de no responder al "concepto ultramoderno del gran estadio polideportivo" al haberse adoptado el mismo criterio que antes de la Guerra. Los estadios modernos -explicaba- debían ser de forma circular, semienterrada y semicubierta. El único proyecto que consideraba adecuado era el estadio de Río de Janeiro, de forma "circolare", "polisportivo, la cui costruzione ispiratasi da un mio progeto publicatto nel 1944" que fue difundido en 1945 en Architettura per tutti y es el mismo diseño que acompaña la nota del periódico. De acuerdo a la fecha y a la forma circular del diseño, probablemente Palanti se refiera al estadio carioca Maracaná inaugurado en 1950 como el ejemplo basado en su proyecto. ${ }^{80}$

En el caso del rascacielos Babele, de acuerdo a Palanti, la forma circular presentaba ventajas funcionales y estructurales como un mejor comportamiento ante la fuerza del viento, la ausencia de juntas de dilatación, permitir desarrollar el "dominante concepto de luz en todos los pisos" o la posibilidad de construir el edificio en un lapso de tres años. ${ }^{81}$

La estructura en hormigón armado "baricéntrica" partía de un anillo exterior de grandes pilares de $3.00 \times 4.50$ metros en el nivel cero y tres anillos interiores en los cuales se iban intercalando los servicios mientras que el cerramiento estaba planteado en ladrillos cerámicos marca "Palandomus". El diámetro de la mole disminuía en su ascenso, con 50 metros en la base y 25 en la cota del último piso. ${ }^{82}$

Como mencionamos, el programa polifuncional repite lo planteado para ejemplos

$\overline{79}$ Palanti, "Il nuovo stadio al foro italico." Diario Terra d'oltremare, 15 de mayo de 1953.

80 Palanti, "Il nuovo stadio al foro italico" Palanti probablemente se refiere al Maracaná, inaugurado en 1950 y a al proyecto para un estadio circular que publicó en 1945, en Palanti, Architettura per tutti, 232-38

81 El volumen total de hormigón armado era de aproximadamente.: $100.000 \mathrm{~m} 3$ y el volumen total de hierro aproximado de 20.000tn. "Torre Babele Novus", Giornale d'Italia, Buenos Aires, 22 de noviembre de 1954.

82 “Torre Babele Novus", Giornale d'Italia, Buenos Aires, 22 de noviembre de 1954. 


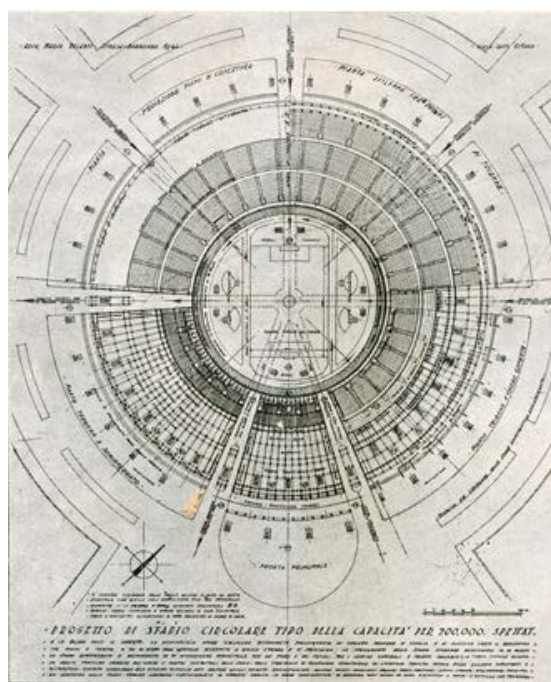

Planta. Proyecto para estadio circular, 1944. Puede verse la recurrente idea de partido circular. Mario Palanti. Publicado en Architettura per tutti, 1946

anteriores: subsuelos destinados a servicios (garaje, locales deportivos y -el siempre presentegran refugio antiaéreo). Los niveles de planta baja al tercer piso eran de índole social. El nivel de acceso contaba con cinco espejos de agua y un pronaos de honor que marcaba la entrada,

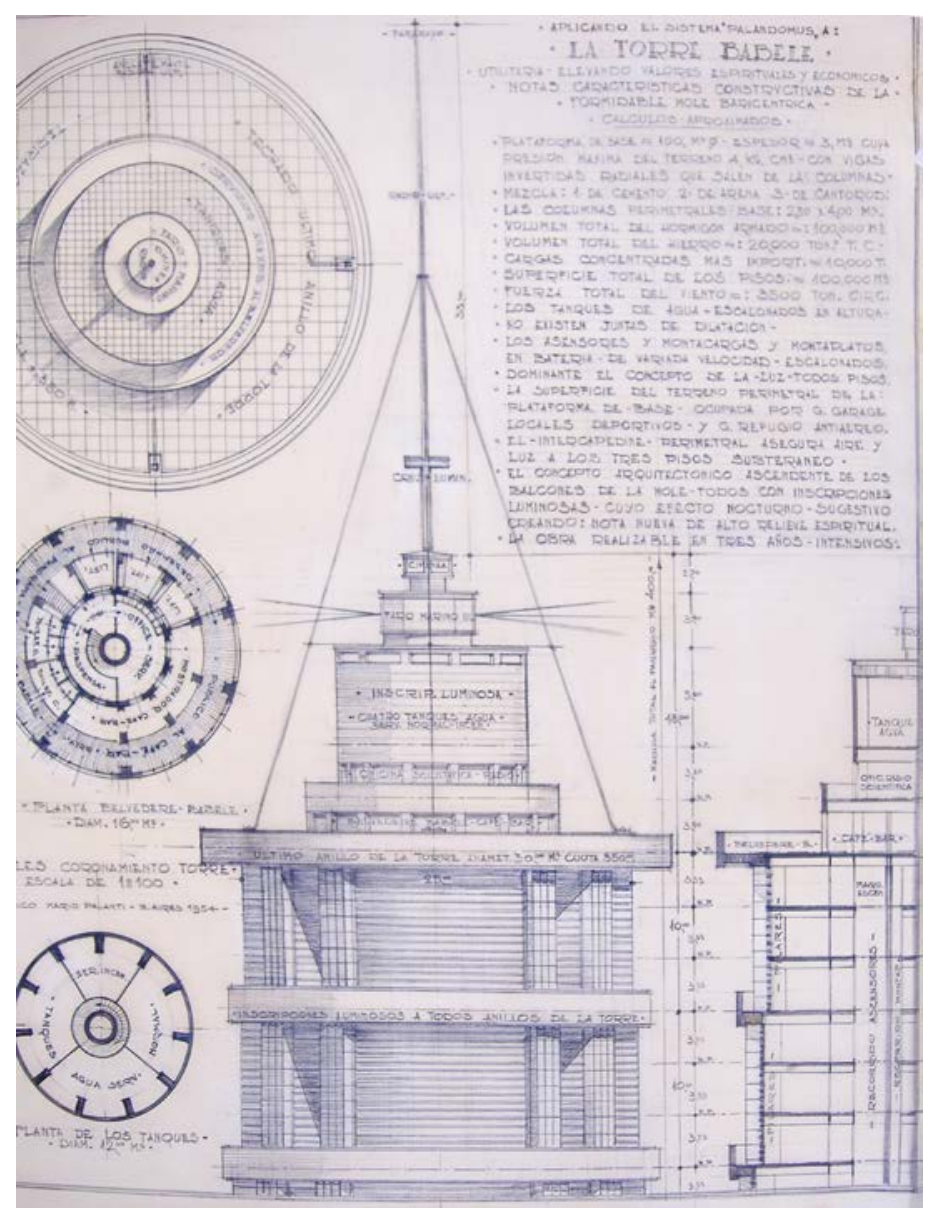

Detalle de la linterna. Torre Babele. Buenos Aires, 1954. Proyecto. Mario Palanti. AGEP 
de un lado hacia el hotel y, del otro, al gran salón de té. En el interior siete anillos dividían las actividades, comenzando por una gran galería perimetral destinada al arte y la moda que con sus 260 metros de desarrollo recuerda a la galería de los trofeos planteada para la Mole Littoria y el Palazzo Littorio.

Al igual que la Mole Littoria, la Torre Babele contaba con un hotel de 4.500 habitaciones que se ubicaban entre el cuarto piso y el último nivel. El coronamiento, a 350 metros de altura, estaba reservado para un Belvedere, un café bar y la instalación de actividades militares y científicas, si bien no incluye la pista de aterrizaje para vehículos aéreos, la intención de coronar con tecnología el rascacielos persiste. El remate estaba dado por un "faro marino", una chimenea desde la cual despegaba una cruz luminosa cuyo brazo mayor se transformaba en una antena de radio y un pararrayos con un total de 33 metros. ${ }^{83}$

Frente al clásico prisma rectangular típico de la tipología de rascacielos norteamericano al cual veía como agotado, el proyecto de Palanti se presentaba como un manifiesto; una mole que pretendía demostrar que el "criterio curvilíneo" empleado superaba y contrastaba el criterio "rectilíneo dominante" de la arquitectura del momento a la que definía como arte "cubística". ${ }^{84}$ En efecto, el edificio planteaba la primacía y los grandes recursos de la línea curva y permitía, de acuerdo al autor, crear desde lo nuevo conjugando lo clásico y lo moderno. ${ }^{85} \mathrm{Al}$ respecto señalaba:

Arduo problema, quello di poter degnamente esprimere con linee austere, un tema che racbiude in sè, tanti significati, ed un tempo da rispondere a nuove ispirazioni dell'ArteMadre, a dirsi: Struttura stetica arditissima, che imprima alla formidabile mole, sensazione nuova, sotto ogni aspetto, psicologico, si umana filosofia -artistica ed utilitaria. ${ }^{86}$

La Torre Babele (cuyo nombre figura como Babele Novus en algunos de los planos) pretendía por su masa y su altura, evocar la Torre de Babel, la "magna Opera Bíblica”. ${ }^{87}$ En efecto, construir su propia Torre de Babel, es decir el rascacielos más alto del mundo, era un

83 Mario Palanti, Plano, detalle nivel cero de la Mole, Buenos Aires, 1954. AGEP.

84 "Progetto Torre Babele Novus" Il Giornale d'italia.

85 "Progetto Torre Babele Novus" Il Giornale d'italia

86 "Progetto Torre Babele Novus" Il Giornale d'italia. "Arduo problema, aquel de poder exprimir dignamente con líneas austeras, un tema que encierra en sí, tantos significados, y un tiempo para responder a nuevas inspiraciones del Arte-Madre, es decir: Estructura estética muy audaz, che imprima a la formidable mole, nuevas sensaciones, bajo cada aspecto, psicológico, sea humana filosofía-artística y utilitaria." [Traducción Florencia Minatta]

87 "Progetto Torre Babele Novus" Il Giornale d'italia. 
interés que Palanti traía consigo desde inicios de su carrera. La relación entre este ambicioso proyecto y la histórica Torre de Babel puede verse en el ascenso telescópico formado por la sucesión de anillos en el proyecto de Palanti: de acuerdo al autor, el motivo ascendente de treinta y tres anillos escalonados que se repite cada tres pisos se "eleva al infinito" y simboliza el "voto supremo de la fe cristiana", como una "cadena que vincula nuestro planeta con los encantos celestiales" y genera un "espiral de la vida nueva”. Una situación que, por la atmosfera que intentaba crear, recuerda a la planteada para el Sacrario del Palazzo Littorio. Cargadas de misticismo, la gran cruz de coronamiento y las líneas curvas de la Torre Babele estaban pensadas para crear un efecto perspectívico, sobre todo al iluminarse por la noche. ${ }^{88}$ Ciertamente el diseño presenta una fuerte carga mística, además de la referencia a la bíblica Babel y a la fe cristiana, la simbología es visible en la constante presencia del número tres y los treinta y tres anillos posibles de ser asociados con Cristo.

El plano que muestra en detalle el coronamiento explica en una leyenda que: "El

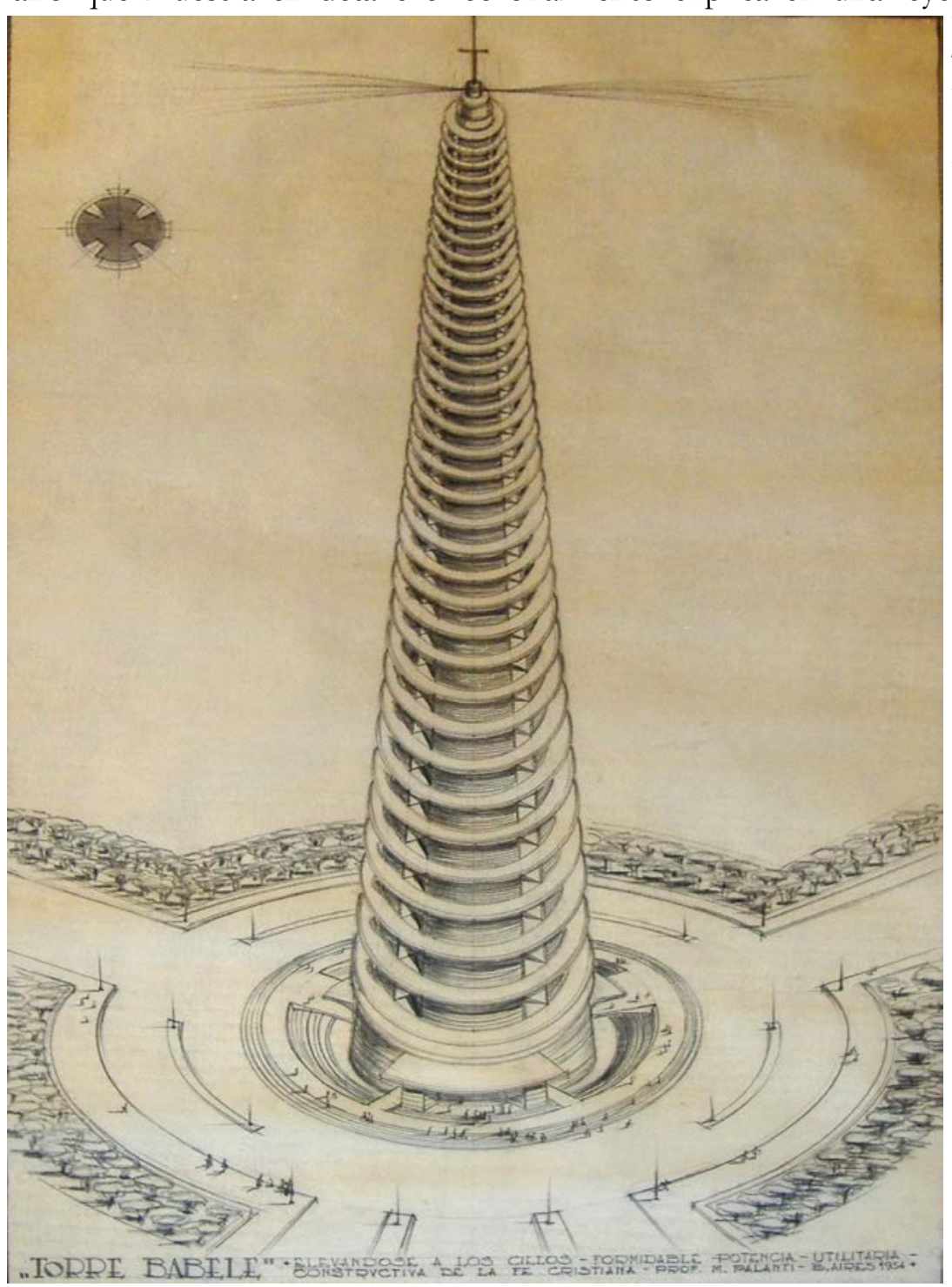

Perspectiva.

Torre Babele.

Buenos Aires,

1954. Mario

Palanti. AGEP 
concepto arquitectónico ascendente de los balcones de la mole. Todos con inscripciones luminosas cuyo efecto nocturno-sugestivo creando: nota nueva de alto relieve espiritual." ${ }^{89}$ Sin embargo, en varios planos realizados entre 1954 y 1955, el proyecto cambia su nombre al de "Mástil de la Patria. Torre Babele Novus" manteniendo la forma pero con una base de 60 metros de diámetro, un remate de 30 metros y una altura de 685 metros. El programa incluía un refugio antiaéreo mientras que la cruz luminosa de coronamiento había sido eliminada. ${ }^{90}$

Muy probablemente, Palanti haya modificado la estrategia de venta de su proyecto ante la situación que atravesaba el país. En 1955, como resultado de las varias tensiones, se anunció una reforma constitucional que establecería la futura separación entre la Iglesia y el Estado. En efecto, como señala Lila Caimari, la relación entre el Estado y la Iglesia -que años antes había hecho suya la causa peronista- había comenzado a desmejorar desde 1950 y alcanzó un punto álgido de conflicto entre 1954 y 1955. En noviembre de 1954, Perón había acusado a "ciertos sacerdotes de actividades antiperonistas". ${ }^{11}$ En junio de 1955, la situación se desbordó. Una multitudinaria procesión participó de la celebración del Corpus Christi cuando la caminata se transformó en una -aunque inofensiva- manifestación opositora. Poco después, el 16 de junio, teniendo como objetivo la Casa Rosada, sede del gobierno, aviones con la insignia "Cristo vence" participaron del trágico bombardeo a la Plaza de Mayo a lo que siguió la quema de iglesias perpetrada por ciertos grupos como represalia. ${ }^{92}$

En un clima político sumamente complejo, el rascacielos que Palanti proponía para Buenos Aires no llegó a materializarse, permaneciendo en proyecto como tantos otros de sus diseños. Pero lejos de abandonar la idea de realizar el rascacielos más alto del mundo, sería esta obsesión, junto al sistema constructivo "Palandomus", la que consumiría al arquitecto hasta sus últimos días.

89 Mario Palanti, Plano detalle de coronamiento de la Mole. Buenos Aires, 1954. AGEP.

90 Mario Palanti, Plano de planta baja "Mástil de la Patria", 1954/55. APC. Como fue mencionado, el diseño es presentado con variantes en los nombres, algo frecuente en la obra de Palanti. La Torre Babele se presenta también en 1954 como "Palandomus. Gran torre utilitaria y de la fe". Plano de planta baja, Mario Palanti, Buenos Aires, 1954, AGEP.

91 Véase Lila Caimari, "El peronismo y la iglesia católica", Nueva historia argentina, T.8 Los años peronistas (19431955), (Dir. Tomo, Juan Carlos Torre) (Buenos Aires: Sudamericana, 2002): 441-480.

92 Son muchas las preguntas y debates que se formulan en torno al tema y que escapan al contenido de esta tesis. Un breve panorama puede ser visto en el recorrido historiográfico que realiza Miranda Lida, "Catolicismo y peronismo: debates, problemas, preguntas", en Boletin del Instituto de Historia Argentina y Americana Dr. Emilio Ravignani, No27 (Buenos Aires, ene./jun. 2005). Online: http://www.scielo.org.ar/ (19-2-2015) 


\section{Arquitectura de papel}

Si algo caracterizó la última etapa de producción de Palanti fue una serie de desaciertos. Como mencionados anteriormente, a diferencia de los profesionales italianos que fueron invitados para desarrollar actividades concretas en el país, Palanti vino por cuenta propia sin un contrato específico ni trabajo garantizado. ${ }^{93}$ Efectivamente, esta situación de "desamparo" resultó ser un inconveniente para Palanti cuyo título de arquitecto carecía de validez en el país, mientras que, en su carácter de invitados, los profesionales extranjeros contaban con la validación otorgada por la convocatoria "oficial".

Probablemente Palanti haya visto una oportunidad de trabajo al amparo del Estado para alejarse de los problemas legales que afectaron su actividad profesional en la esfera privada. Además, mientras que muchos profesionales intentaban mantenerse al margen de disputas entre peronistas y antiperonistas, Palanti mostró a través de sus megalómanos proyectos una clara afinidad con el poder político oficial cimentada en el solo interés de conseguir un comitente.

Sin embargo, si bien un sistema abierto como el primer peronismo había convocado tanto a adscriptos como a detractores del fascismo y había permitido el desarrollo de diversos lenguajes arquitectónicos, ${ }^{94}$ Palanti no encontró lugar para materializar sus proyectos y permaneció en los márgenes de la disciplina, tal como le había sucedido en la Italia de entreguerras. Nuevamente, las formas del racionalismo se impusieron ante su monumentalismo académico y a su arquitectura parlante. Es que, como fue señalado por Liernur y Pschepiurca -y estudiado el caso de Tedeschi y La Padula por Malecki- "el proyecto para la Ciudad Universitaria de Tucumán fue una de las experiencias de avanzada de la cultura arquitectónica argentina más importantes y, junto con el EPBA y el grupo Austral, una de las instancias más significativas en el desarrollo de la "arquitectura moderna" en el medio local." "95 En este marco, ni el modernismo fallido desarrollado por Palanti en las décadas de 1930 y 1940 -resumido en Architettura per tutti- ni el monumentalismo totalitario que retomó a inicios de 1950, ni su último intento con el megalómano rascacielos Torre Babele encontrarían lugar en la agenda del gobierno peronista. ${ }^{96}$

93 Acta de separación entre Mario Palanti y Nahir Marazzi Castiglioni, Milán, 1957. AGEP.

94 Anahí Ballent, "Las estéticas de la política: arquitectura y ciudad. El peronismo en Buenos Aires 1946-1955" 5", Arte y Poder; V Jornadas de teoría e historia de las artes (Buenos Aires: CAIA-Facultad de Filosofía y Letras-UBA,1993). 95 El punto es señalado por Jorge Francisco Liernur y Pablo Pschepiurca en La red austral. Obras y proyectos de Le Corbusiery sus discipulos en la Argentina (1924-1965) (Bernal: UNQUI, 2008), 347 y Retomado para el caso de Tedeschi por Malecki en "Historia y crítica."

96 En una carta del 13 de octubre de 1954, hablando sobre el divorcio, Palanti le escribe a su mujer, Nahir Marazzi Castiglioni: "E mentre in questo ultimo tempo, di mia vita, tra le tante amarezze, la maggiore procura da 
En noviembre de 1955, Palanti emprendió su regreso definitivo a Italia. Llevaba en mano varios proyectos realizados entre 1948 y 1955 y un documento que certificaba la efectividad del ladrillo "Palandomus". ${ }^{97}$ En agosto de ese mismo año, el arquitecto recibió en mano un documento que demostraba la efectividad del bloque "Palandomus". Posiblemente alertado ante los bombardeos de junio y previendo una posible caída del gobierno de Perón, Palanti pidió al Director General de Industria Manufacturera del Ministerio de Industria de la Nación que emitiera una constancia en la cual se establecía que su sistema constructivo "Palandomus" había sido, efectivamente, aceptado por el Estado para la construcción de vivienda pública y masiva: "De ajustarse estrictamente la elaboración de los ladrillos marca "Palandomus" a las especificaciones antes aludidas, podrían ser empleados los mismos en sustitución de los ladrillos comunes de cal con todas las ventajas deducibles del mejor comportamiento físico y la lógica reducción de los costos por $\mathrm{m}^{3}$ de mampostería, situación esta que podría resultar de sumo interés para los futuros planes de Obras Públicas y de viviendas populares." ${ }^{98}$ Así, con setenta y un años y sin trabajo fijo, Palanti abandonaba la "Nueva Argentina" y emprendía el regresó a Italia con dos pliegos: en primer lugar, el documento que dio pie al último libro Palandomus -que nunca llegó a publicarse- y que demostraba que había podido desarrollar un sistema que, de haberse dado las condiciones, hubiera funcionado. Segundo: la idea del mega rascacielos. Nuevamente, Palanti

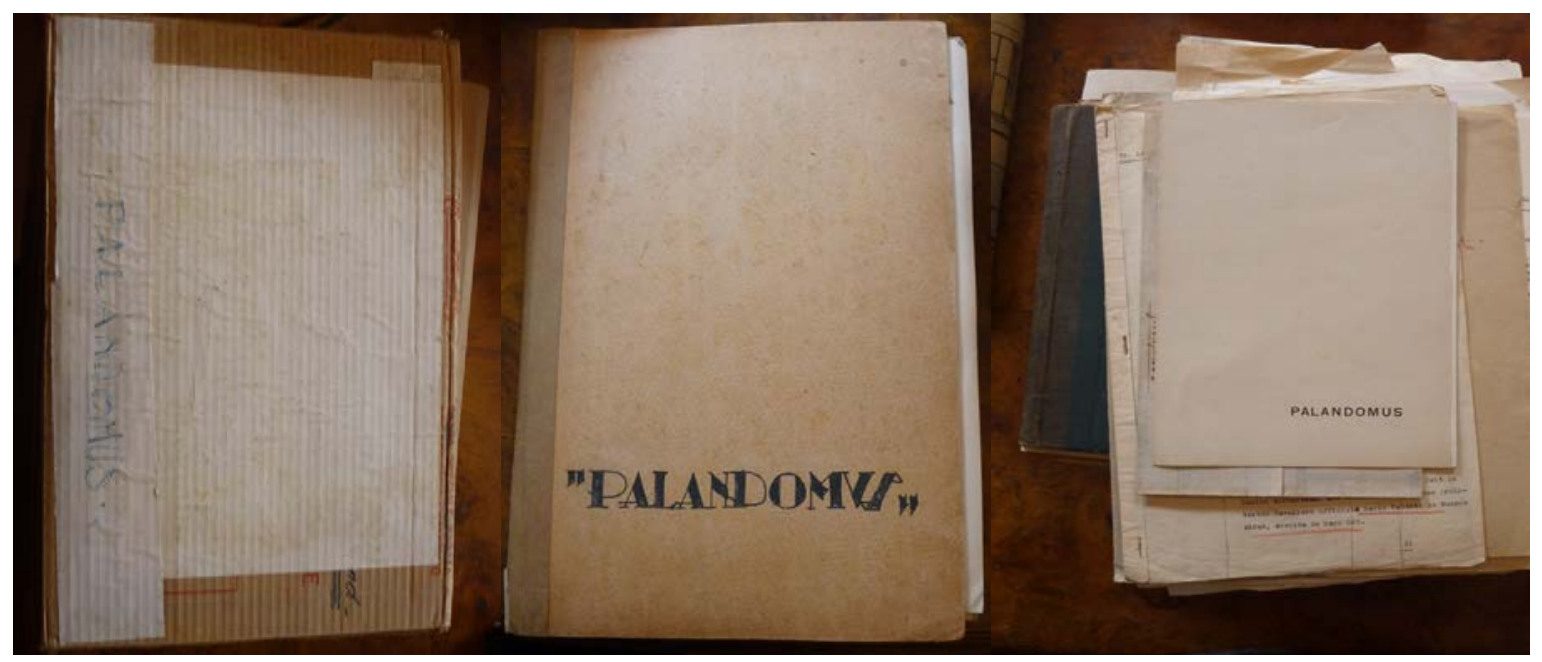

Borradores del libro Palandomus. Ca.1956/1970.AGEP

mia moglie, che doveva essermi il mio vero sostengo spirituale nella dura lotta, mi ha lasciato solo senza motivi di sorta, come un rifiuto, in premio di tanto nobile lavoro, tante fatiche in fin di bene e senza riposo, procurandomi il più grande dolore; mi è confortevole ad un tempo, la gioia di aver vinto la mia più grande battaglia professionale, $\mathrm{e}$ di tale portata che avrà risonanza nell'emisfero." AGEP.

97 Mario Palanti, Palandomus, borrador del libro con proyectos realizados en Argentina. ca. 1955. AGEP.

98 Constancia, $N^{\circ}$ 218.117/55, Ministerio de Industria de la Nación, Poder Ejecutivo Nacional, 5 de agosto de 1955. AGEP. 


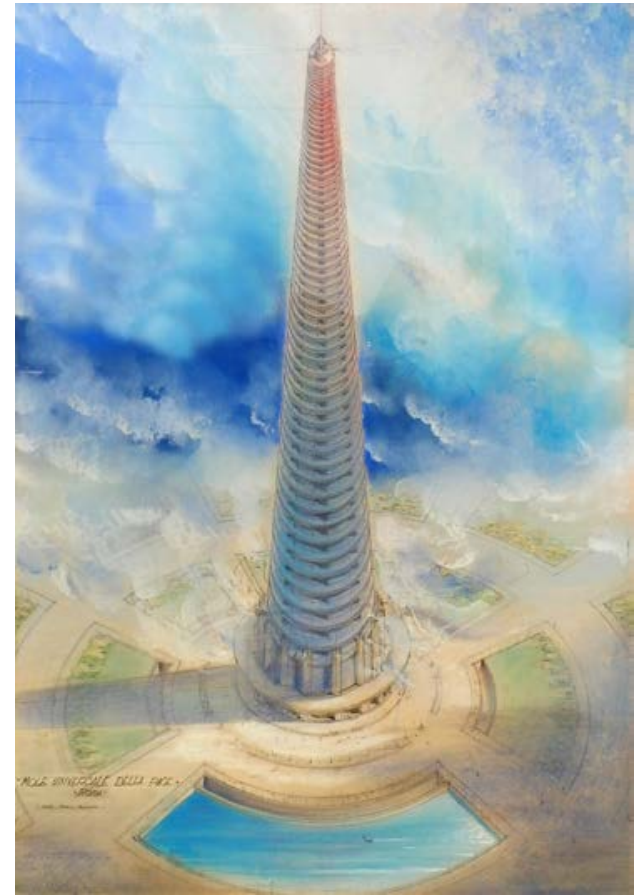

Perspectiva. Mole Universale della Pace, La acuarela muestra la reelaboración del diseño planteado para Buenos Aires. Roma, ca. 1956. Proyecto.Mario Palanti. AGEP

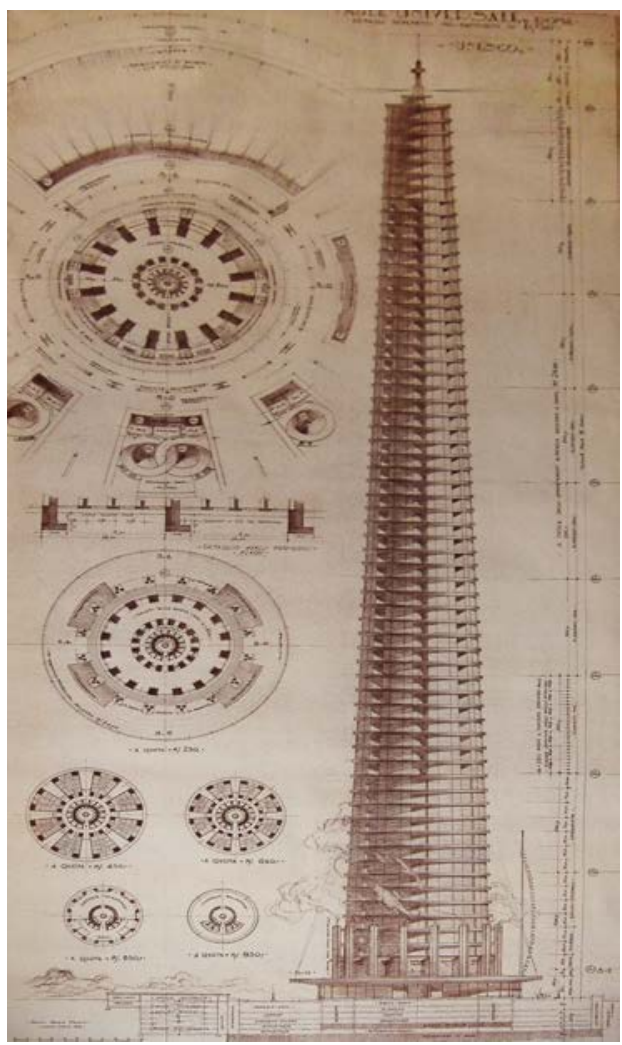

Variante de la Mole Universale della Pace, Roma, 1956-68. Proyecto. Mario Palanti. AGEP

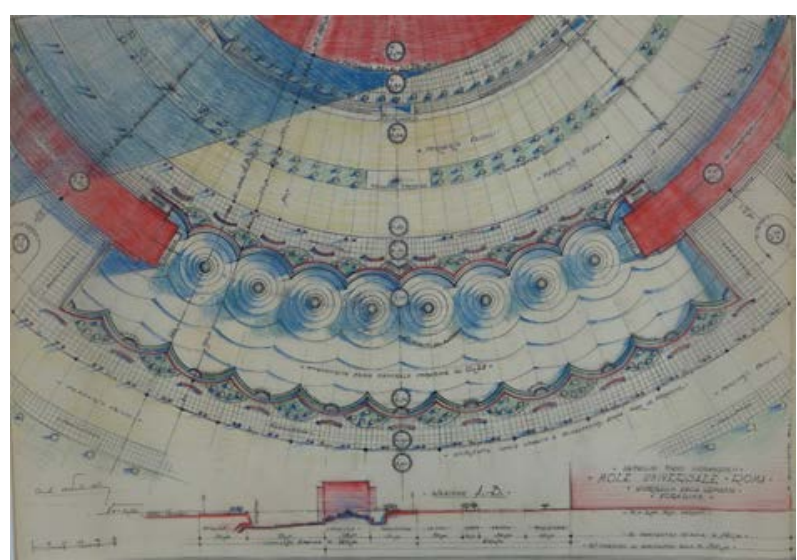

Dibujo de un detalle de planta de acceso a la Mole. Mole Universale della Pace, Roma, ca. 1956. Proyecto. Mario Palanti. AGEP

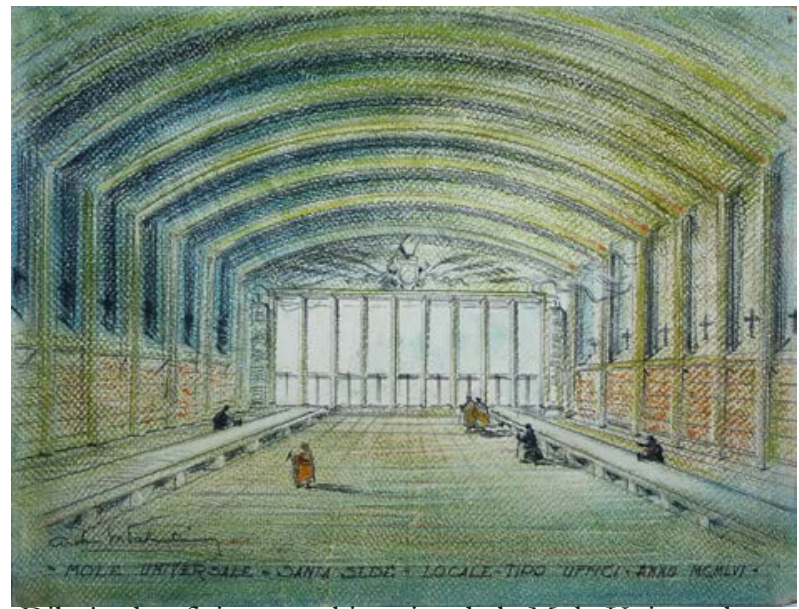

Dibujo de oficinas en el interior de la Mole Universale.

Mole Universale della Pace, Roma, ca. 1956. Proyecto.

Mario Palanti. AGEP

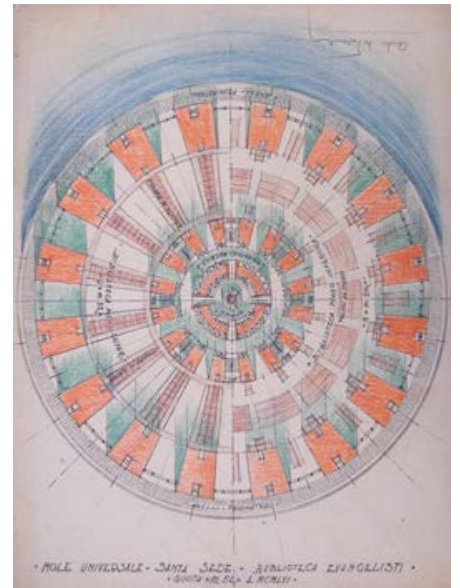

Biblioteca Evangelista, Mole Universale della Pace, Roma, ca. Universale della Pace, Roma, ca. 1956. Proyecto. Mario Palanti. AGEP

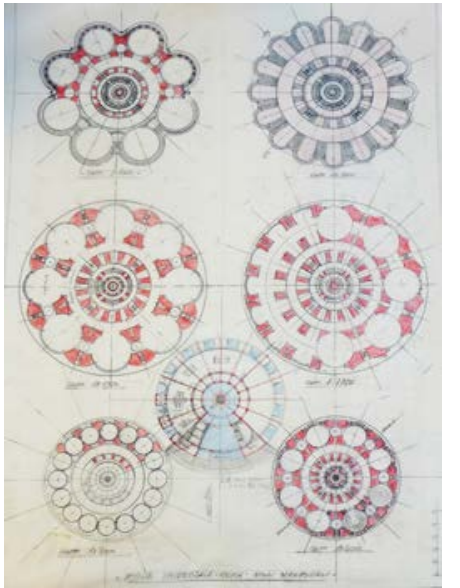

1956. Proyecto. Mario Palanti. AGEP 
abandonaba la escala americana de Buenos Aires y partía hacia Roma en busca de fondos para levantar allí el edificio más alto del mundo.

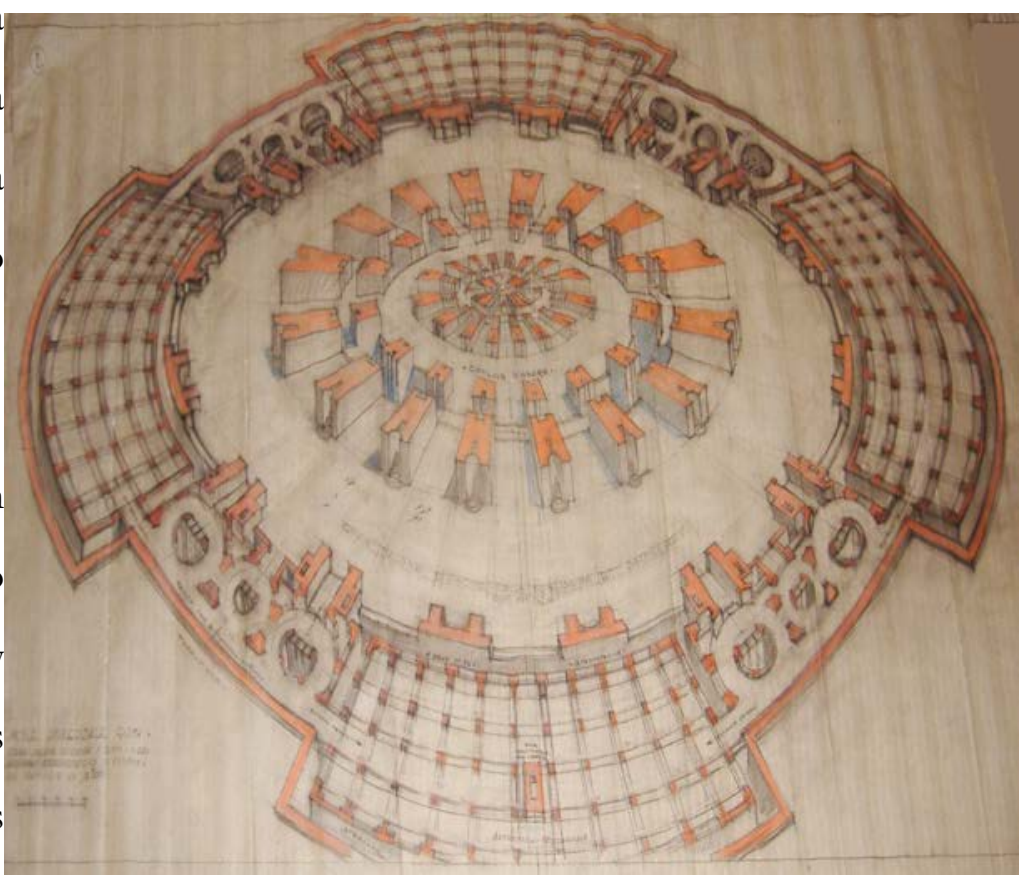

Una vez de regreso en Italia, hacia 1956, Palanti intentó llevar a cabo su idea. Noventa y cuatro planos correspondientes a las versiones del rascacielos que se conservan en un archivo privado dan cuenta de la obsesión, incansable, por construir una nueva tipología en altura. Durante casi dos décadas bajo el título de "Mole Universale U.N.E.S.C.O” y "Mole Universale,

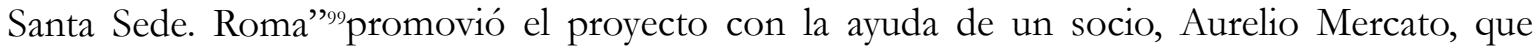

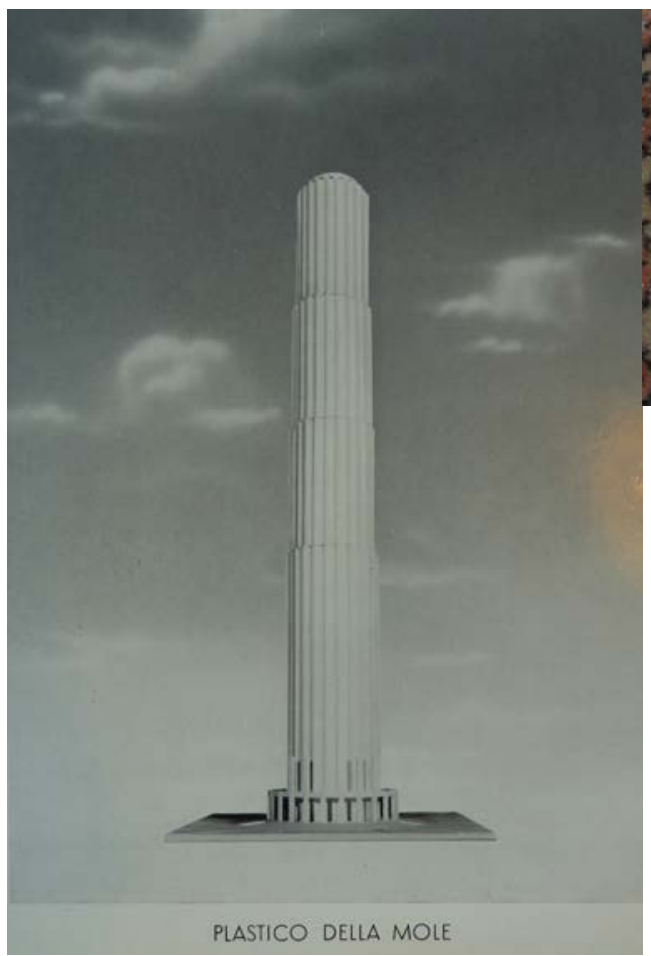

Roma, ca. 1956. Proyecto. Mario Palanti. AGEP

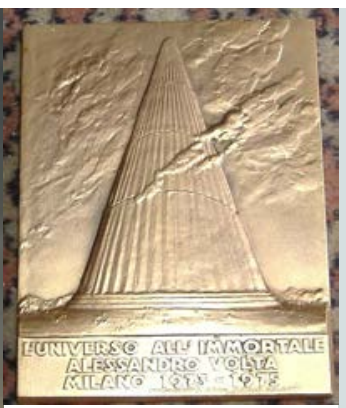

L'universo All'immortale Alessandro Volta, Milano 1973-1975

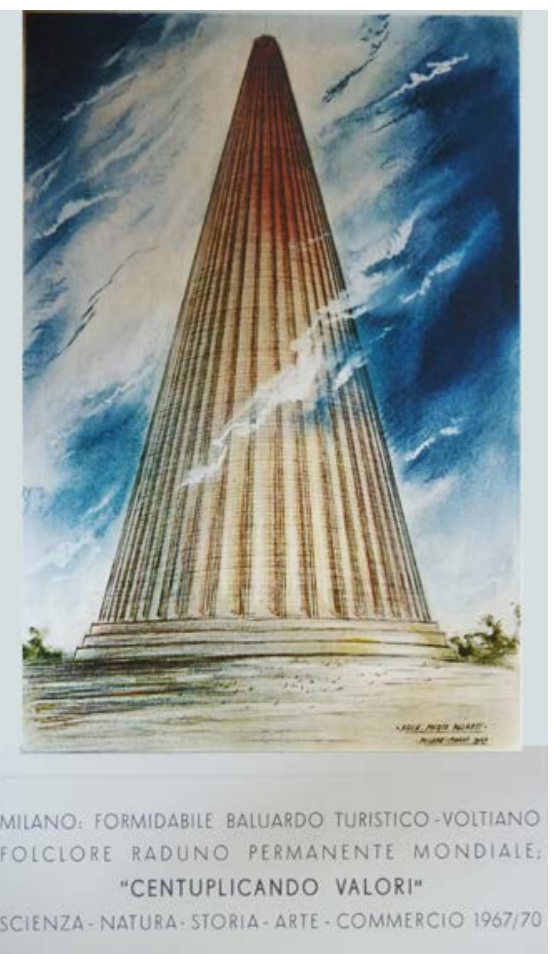

Perspectiva de la Mole Voltiana. 1967. Proyecto. Mario Palanti. Publicada en Centuplicare nostri valori...1969

99 Correspondencia entre Mario Palanti y Aurelio Mercato sobre la construcción de la Mole. 1956-1968. AGEP. 
terminó estafando al arquitecto con la excusa de promocionar el edificio.

Como se ve en los planos, la propuesta de este rascacielos era similar a la realizada para Buenos Aires aunque algunos de los diseños revelan leves variantes para adaptarse al nuevo emplazamiento. Los dibujos preservados muestran la repetición del programa multifuncional con restaurants, salones de exposiciones y, entre otros, una biblioteca en la que se lee "Mole Universale. Santa Sede. Biblioteca evangelista" y oficinas cuya espacialidad recuerda al proyecto de Boullée para la Biblioteca Real en 1785.

La anteúltima versión del proyecto fue la Mole Turistica Voltiana realizada en 1968 y publicado en 1969 en el volumen Centuplicare nostri valori potenziare nostre economía. ${ }^{100}$ El libro se inicia con una cita del Diario La Prensa que había sido publicada en 1916 con motivo de la Exposición personal de arquitectura realizada por Palanti. Con cincuenta años, la cita daba cuenta de que los logros del arquitecto pertenecían a otra época.

El resultado nos demuestra que en la medida en que Palanti se alejaba de la práctica profesional y de una realidad que ya no lo incluía las proporciones de sus sueños aumentaban. En efecto, la altura de la mole era ahora de 510 metros con una estructura de acero que le permitiría suprimir el soporte baricéntrico. El programa estaba destinado al turismo y al trabajo. Los 100 pisos de plantas libres albergarían diferentes actividades y serían un lugar permanente de encuentros internacionales. El proyecto contaba con espacios verdes, restaurants, miradores e incluía esculturas que habían sido empleadas en proyectos anteriores como La Storia, la Vittoria a la Nobilitá del lavoro que se presentaban ahora destinadas a promover valores como “scienza-natura-storia-arte-commercio". La mole mantenía la base circular que en el ascenso se escalonaba cada cien metros para disminuir el diámetro. Su exterior estaba cubierto con bloques -muy posiblemente "Palandomus"- y un sistema de iluminación. Si bien la idea de ascenso telescópico se mantenía, la Mole Voltiana había perdido aquella innovación "curvilínea" del proyecto de 1954: los anillos fueron remplazados por líneas rectas verticales que culminaban en un mirador apenas perceptible transformando al edificio en una versión de columna dórica, como una versión desideologizada -y tardía- de la columna de Adolf Loos para el Chicago Tribune.

$\overline{100}$ Palanti, Mario. Centuplicare nostri valori potenziare nostra economia. Milán. Esperia. 1968. 


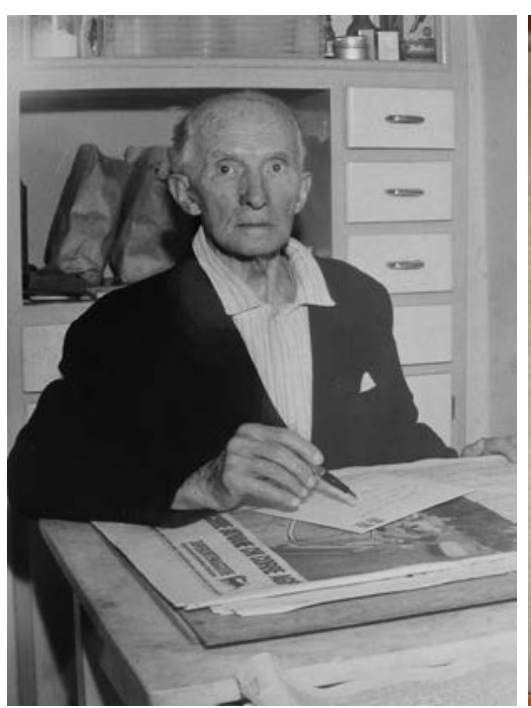

Mario Palanti ca. 1975. AGEP

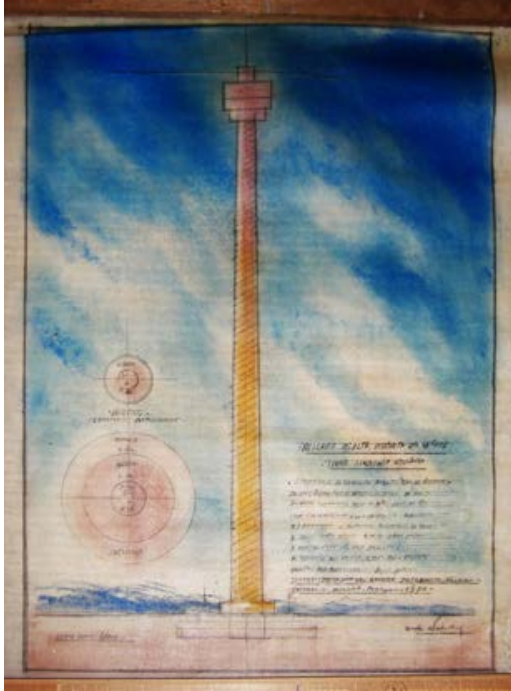

Milano esalta nobilita del lavoro 1970 (Antena en honor al Trabajo)

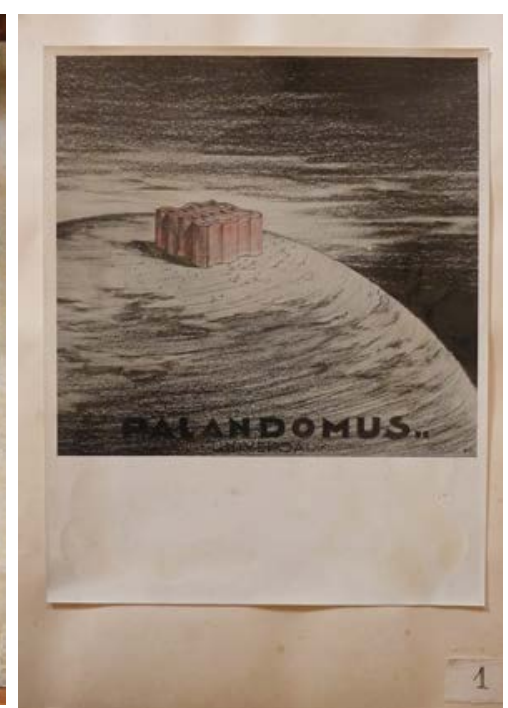

Borrador del libro Palandomus. Ca.1956/1970.AGEP

Si bien tiempo y espacio lo distanciaban de los logros de su juventud, el arquitecto mantuvo su búsqueda en torno al sistema "Palandomus" y a la tipología en altura. En 1970, con 85 años y un trazo que denota su mano anciana, Palanti continuó su saga de rascacielos en el diseño de una antena de 600 metros de altura, dedicada al trabajo y coronada por un faro. Una vez más intentaba, como lo había logrado en la década de 1920, que su arquitectura alcanzara el cielo. ${ }^{101}$ 


\section{Palabras finales. Las torres de Babel}

Los puertos de Buenos Aires, y los barrios que los
rodean: la Boca, el Dock Sur, el Paseo de Julio, son
las puertas de Babel. Por ellos se entra en la ciudad
mostruosa (sic) e inquietante donde todos los
idiomas del mundo y todas las razas se confunden
y mezclan.
(Hector Pedro Blomberg, Las puertas de Babel,
1920)

Todos los nuevos elementos de la vida moderna, vendrán a imponer sus características e imprimir su huella en el derrotero de la nueva arquitectura, ya que ésta ha de contemplarlos todos y armonizarse con todos ellos.

(Mario Palanti, "La era moderna tiene orientaciones nuevas en arquitectura”, 1922)

La hipótesis principal de este trabajo postula que la producción arquitectónica de Mario Palanti surge de la preocupación por construir un discurso innovador a partir de una búsqueda personal hacia aquello que el arquitecto concibe como una nueva arquitectura.

Una segunda hipótesis considera su obra como resultado de una unión entre su formación académica italiana y una poética abierta a un espectro mayor de opciones, que incorporan el carácter monumental de la metrópoli: como vimos a lo largo de este trabajo, la experiencia metropolitana en Buenos Aires fue decisiva en la búsqueda del arquitecto.

En esta-búsqueda, Palanti emplea un método proyectual que, como ya señalamos, se inicia con el aprendizaje del experimentalismo neogótico de Viollet-le-Duc y las adaptaciones que del mismo realiza Camillo Boito y persiste hasta la construcción de su propio repertorio. Su camino está signado por la creencia de poder convertirse en el artífice de una nueva arquitectura que, conjugando armónicamente arte y ciencia, responda a los problemas y a las necesidades de la metrópoli moderna.

Pero, como pudimos advertir a lo largo de este estudio, no toda su producción arquitectónica será parte de esta búsqueda. Efectivamente, podemos encontrar, por un lado, obras en las que mantiene líneas convencionales que no escapan al repertorio de estilemas provenientes de la historia. Sin embargo, por otro lado, encontramos casos en los que se verifica 
una búsqueda hacia la innovación.

Entre los primeros casos, encontramos obras que responden a comitentes más conservadores, relacionados a sedes bancarias, empresas o instituciones religiosas: entre ellos, el Banco Francés e Italiano (Ca. 1924), el edificio Comercial de Alsina y San José (1921), el Hotel Castelar (1928) de Avenida de Mayo 1148, la ampliación del Banco de la Provincia de Buenos Aires (1931). También éstas características convencionales se aprecian en un importante número de residencias como, por ejemplo, la vivienda Beccar Varela o los Petits-Hôtels Azaretto-Spato, Uboldi, Novello o Costaguta.

Como pudimos ver a lo largo de la tesis, esta tendencia parece contraponerse a las invenciones planteadas en los proyectos de algunas de sus casas de renta como la Casa Vila (Rivadavia 2625), la Casa Peretti (Rivadavia 1916), los edificios para Andrea Roccatagliata o sus dos grandes rascacielos: el Pasaje Barolo y el Palacio Salvo.

Efectivamente, puede leerse a los rascacielos palantianos como el resultado de una larga búsqueda que, como señalaba Palanti, plantea una nueva arquitectura, a partir de la combinación de los avances técnicos de la vida moderna, el arte, la historia y las condiciones del sitio.

En estos ejemplos, la tipología de la gran galería comercial europea se fusionó con el tipo de rascacielos norteamericano: el uso público del espacio atraviesa el edificio como una calle más de la ciudad, situación que los diferencia del típico gran hall de acceso de los rascacielos norteamericanos.

Los casos de rascacielos analizados conjugan una multiplicidad de factores del pensamiento palantiano: su creación refleja el impacto de las modalidades locales, la escala americana y los programas metropolitanos que no están directamente vinculados con el período formativo italiano de Palanti, pero que encuentran campo de desarrollo para la experimentación.

En este contexto, el Barolo y el Salvo se consideran una manifestación que aúna la producción concreta de las ideas del arquitecto. Las moles resultantes tendrían todas las condicionantes que el mismo Palanti exigía en su prédica teórica llevando la invención a sus extremos: la monumentalidad, el rascacielos, el programa multifuncional, la tecnología y un repertorio de ornamentación original que diera carácter al edificio.

Efectivamente, estos nuevos programas metropolitanos le dieron a Palanti un espacio para el desarrollo de nuevas soluciones técnicas, funcionales y tipológicas. En este sentido, cobra relevancia la libertad de acción otorgada por esta committenæa que permitió al arquitecto realizar caminos de exploraciones de nuevas formas a escala monumental. Y el osado desafío que Palanti 
se planteó fue realizarlo desde de su tipología más característica: el rascacielos.

A partir de estas experiencias, Palanti buscaría constantemente la manera de financiar sus proyectos. De ello da cuenta el derrotero del arquitecto en su intento constante de promocionar sus ideas y conseguir encargos, una incansable voluntad que lo llevó a intentar acercarse al poder: al fascismo, al papado y al peronismo.

Ciertamente, en el intento de adaptarse a las demandas del poder de turno, su oscilante búsqueda derivo en una arquitectura camaleónica. Ello puede verse en su intento de racionalismo expresado en Architettura per tutti o su arquitectura parlante en las propuestas para los concursos del Partido Nacional Fascista de la Italia de entreguerras o el monumentalismo propagandista de su Descamisado, Mole en Honor a Eva o arcos conmemorativos que propone en el último período en Argentina.

Sin embargo, en este vaivén continuo de su carrera que lo traslada a ambos lados del Atlántico, permanecerá constante, por un lado, la búsqueda por innovar en el sistema constructivo "Palandomus" y, por otro, la experimentación en la construcción en altura.

Como pudimos ver, esta invención técnica visible en la multiplicidad de publicaciones, patentes y modelos guiaría la trayectoria del arquitecto, desde la década de 1920 hasta el final de su carrera. Otra de las persistencias de Palanti será la incansablemente búsqueda de reproducir la experiencia americana en cada retorno a Italia. El arquitecto intentará reproducir el prototipo del rascacielos multifuncional en sus diferentes versiones de monumento: en 1918 el Mausoleo Glorificando gli eroi nostri, en 1924 la Mole Littoria y, entre 1956 y 1971, las múltiples versiones de la Mole Universale. Lejos quedaban las innovadoras experiencias rioplatenses.

Pero si la búsqueda y la aspiración a ser el forjador de la nueva arquitectura se mantienen inalterables en Palanti a lo largo de su extensa obra, la idea de torre de Babel que domina su última producción parece evocar la confusión de las lenguas en que dramáticamente se desarrolla hacia finales de su carrera. Las propuestas propagandísticas desarrolladas en la Italia de entreguerras o la regresión monumentalista de los proyectos para el gobierno peronista parecen desvanecerse en la obsesión por lograr una nueva tipología de rascacielos. Este experimentalismo que abona múltiples caminos y que incluyen las alternativas más abstractas de su última etapa, queda trunco frente a lógica racionalidad cartesiana de las catedrales de los negocios de la modernidad que prevalecen como dogma casi inalterable en la arquitectura del siglo XX. 


\section{Apéndice}

\section{Cronología}

1885. Septiembre 20: nace en Milán Mario Vittorio Pietro Palanti en el seno de una familia humilde de origen Cremonés (Casalbuttano ed Uniti). Hijo del carpintero Giovanni Palanti y la costurera Virginia de Gasperi.

1903. Realiza un proyecto conmemorativo de Giuseppe Verdi.

1904. Con 19 años, ingresa a la Academia di Belle Arti di Brera, Milán. Previamente, en 1898, se había inscripto en la misma institución su hermano Giuseppe (1881-1946) quien se dedicó a las artes plásticas. Mario Palanti decide inclinarse hacia la arquitectura. Toma clases con Mentessi, Moretti, Ferrari y luego con Camillo Boito.

1905. Dibujo del templo Atenea Nike.

1907-1908. Estudios para un Museo de Historia Natural.

1908. Estudios para un edificio para una Bolsa y una Estación ferroviaria.

1909. Se gradúa como arquitecto en la Academia di Brera, Milán. Obtiene el premio de la fundación Clericetti con un proyecto de edícola para la casa di Risparmio delle Provincie Lombarde in Milano. Proyectos: una iglesia votiva (justus ut palma florebit), un convento alpestre. Estudio de un portal.

1910. $1^{\circ}$ de Mayo. Llega a la Argentina para participar en la construcción del Pabellón Italiano para la Exposición del Centenario junto al ingeniero Luigi Luiggi entre otros. - Obtiene la medalla de oro en la Exposición Internacional de Bruxelles donde había enviado su trabajo. Decide permanecer en la Argentina debido a las ofertas laborales.

1910-12. Trabaja en el estudio de Arturo Prins y Oskar Ranzenhoffer. Allí tiene contacto con Francisco Gianotti y Alejandro Virasoro. Como miembro del estudio colabora en la construcción de la Facultad de Derecho sede Las Heras, Buenos Aires. Proyectos: Petit Hotel privé. Estudios: motivos ojivales, arco de triunfo, monumento expiatorio.

1911. Participa del Concurso para la Facultad de Medicina de Rosario, Santa Fe, bajo el lema "pro Humanitate" donde obtiene una mención (con el mismo proyecto presentado en Brera, en 1908, para un Bolsa). Proyecto para el traslado de la Pirámide de Mayo en Buenos Aires.

1912. Ante el número de encargos, decide independizarse e instala su estudio de arquitectura en la ciudad de Buenos Aires en la Avenida de Mayo 695. Realiza bocetos que incluyen detalles de catedrales neogóticas reutilizados luego para su proyecto de un nuevo edificio para la catedral de Buenos Aires; puerta de bronce para la bóveda David Spinetto, Recoleta. Otros proyectos en Buenos Aires: una iglesia en el Tigre, un Museo Nacional de Historia Natural y un Petit Hotel en Rodriguez Peña 1650. Realiza estudios para un gran portal.

1913. Intensa actividad en Buenos Aires que se prolonga en los años sucesivos: Casa de F. Cassotana. Tucumán 1146; Petit Hótel Costaguta, Uruguay 640-6; Casa de renta en Rivadavia 1916. Proyectos: Mercado de Abasto de Buenos Aires, Villa en San Isidro, Buenos Aires, para la familia Vasena; Ampliación del Banco de la Provincia de Buenos Aires chalet pintoresco; Chalet Bancalari, Rioja y Corrientes, Olivos, Prov. de Buenos Aires; Chalet en Avellaneda, Prov. De Buenos Aires; Casa Comercial. S/d.; Villa Medieval. 
1914. Obra construida en Buenos Aires: Casa de Bernardo Vila. Av. Rivadavia 2625; Cine Presidente Roca. Av. Rivadavia 3736. Proyectos: mausoleo para la familia Vasena en el Cementerio del Norte (Recoleta) Sección n ${ }^{\circ}$, Buenos Aires. Realiza un proyecto de catedral (neogótica) para la ciudad de Buenos Aires; Sucursal Bancaria tipo para el Nuevo Banco Italiano; Club del Orden. Sede social, San Martín y Juan de Garay, Santa Fe, Prov. de Santa Fe; casa comercial en esquina.

1915. Obra construida en Buenos Aires: Casa de A. Grimoldi, Av. Corrientes 3400; Hotel B. Ginocchio, Av. Pueyrredón y Bartolomé Mitre; Chalet de Alberto Grimoldi, Av. Rivadavia 5050. Proyectos: Casa de alquiler y sucursal bancaria del Nuevo Banco Italiano, S/d. Kiosco despacho de leche. Hipódromo de Palermo, Buenos Aires; Villino campestre, s/d.; Studio di Mausoleo, $\mathrm{s} / \mathrm{d}$.

1916. Obra construida en Buenos Aires: Casa de B. Ginocchio, Bartolomé Mitre y Av. Pueyrredón. Proyectos: Templo Votivo a la Pace Universale (Ad maiorem Dei gloriam); casas populares en Avellaneda, Prov. De Buenos Aires; Chalet A. Grimoldi; Castillo medieval. El 3de noviembre, en Buenos Aires: se inaugura la primera exposición personal de arquitectura en el Palacio de Bellas Artes donde expone sus obras, dibujos y proyectos. Luego de la muestra, regresa a Italia para enrolarse en la Armada del Genio en Trieste y participar en la Primera Guerra Mundial.

1917. Publica en Milán Prima esposiżione personale d'architettura nella Repubblica Argentina. Es nombrado Subteniente, Armada del Genio.

1918. Combate en Trieste. Es nombrado Cavalliere della Corona d'Italia. Julio: presenta a S.E.V. Emauele Orlando Presidente dei Ministri, un proyecto para honrar a los caídos durante la Guerra: "Mausoleo glorificando gli eroi nostri di terra, del mare, del cielo"-sintetizzando la "monumentomania".

1919. Enero: presenta en la exposición de Trieste el proyecto para el Mausoleo realizado en 1918. Escultura de adolescente a caballo luego titulada "trionfatore". Se afilia a la logia masónica Fratelli Bandera de Milan con el grado de aprendiz. Regresa a la Argentina para continuar con la tarea profesional.

1919-1924. Realiza en Buenos Aires una intensa actividad profesional. Edificios construidos durante esta etapa: Casa de Juan B. Uboldi, Av. Rivadavia 2460; Casa de departamentos de lujo de Lorenzo Raggio, Libertad y Viamonte; Petit Hotel Ganduglia, Arenales 2275; Palazzina Merlo, Palazzina de lujo, s/d.; Palazzina, s/d.; Palazzina Merlo y Peluffo, Arenales y Junín; Petit Hótel de Carmelo Noveno, Av. Montes de Oca 141; Sede Social Sociedad de Mutuo Socorro "Unión de la Boca", Olavarría y Palos; Banco Francés e Italiano, Perón y San Martín; Palacio Comercial de Emilio Valsechi, Alsina y San José; Fábrica Aranda y Zavaleta. Gral. Hornos y Av. Manuel Montes de Oca; Casa entre medianeras, Av. Corrientes s/n; Casa de renta y locales, Rivadavia y Castelli; Petit Hotel para la familia Azaretto-Spato, Viamonte 1871.

Proyectos: Iglesia "Mater Dolorosa" Av. Gaona y Campichuelo y "colegio Santa Rosa" de los Padres Misionarios del Sagrado Corazón, Buenos Aires. Palacio en esquina s/d; Grand Hótel Casino Teatro de Augusto Linati, Mar del Plata, Prov. de Buenos Aires. Con el sistema Palanthome: Casas económicas de la Acción Popular Católica Argentina; Casas populares Unión Popular Católica Argentina. Barracas; Anfiteatro para conciertos clásicos (con el ing. A. Israel) para Faustino da Rosa; Estudios de casas de renta en Buenos Aires; sede bancaria; Edificio público en Buenos Aires (mismo presentado a concurso para Aduana de Montevideo); Mausoleo Círculo de la Prensa.

Templo votivo y mausoleo glorificando gli eroi nostri, estudio de templo votivo, mausoleo y ara degli eroi. Estudio de reforma, bocetos para un salón, una galería. 
1920. Comienza la construcción del Pasaje Barolo, Buenos Aires. Casa de Andrés Roccatagliata, Av.Callao y Av. Santa Fe, Buenos Aires. Proyectos: de Casa de renta y cine, Luis Barolo, Av. De Mayo; Exposición Universal de la Paz, Bosques de Palermo.

1921. Casa de Andrés Rocatagliata, Av. Santa Fe 1769-71, Buenos Aires. Funda una beca para estudiantes de arquitectura (Reale Scuola di Architettura, Roma). Es nombrado Académico ordinario de la Academia de Brera. Patenta uno de sus primeros sistemas de construcción en seco "Maison Universelle Palanti” y luego “Casa Universale Palanti”. Diploma de Gran Premio en la Exposición Sudamericana de Bellas Artes (según CV).

1921-22. Crea la Fondazione Palanti y dona 371.000 Liras para el estudio de la arquitectura a la Universitá di Architettura di Roma.

1922. Acepta la propuesta realizada por su hermano Giuseppe e invierte en cinco casas de renta en Berlín. Marzo, participa del concurso para el Palacio Salvo, Montevideo. Es anunciado como vencedor en agosto. Obra construida en Buenos Aires: Residencia particular, Ortiz de Ocampo y Emilio Costa (en colaboración con Algier). Proyectos: Balneario Montecarlo y Villa Mónaco con Teatro Hotel y casino "Monte Carlo", General Madariaga, Prov. De Buenos Aires.

1923. Funda un premio anual para estudiantes de arquitectura titulado S. E. Benito Mussolini. Se inscribe en Buenos Aires en el Partido Nazionale Fascista all'Estero. Comienza la obra para la Nunciatura Apostólica de Buenos Aires, Riobamba y Arenales (realiza proyecto y dirección de obra gratuitamente). Consigue que su hermano Giuseppe pinte un retrato del Santo Padre para la Nunciatura porteña. Casa de Nicolás Bruzzone, Libertad 145, Buenos Aires. Se inician las obras del Palacio Salvo, Av. 18 de julio y Andes, Montevideo y en julio se inaugura la torre del Pasaje Barolo. Establece la Sociedad Anónima "Palanthome. La casa argentina S.A." con una fábrica ubicada en Zepita y Vélez Sarsfield, Barracas, Buenos Aires. Patenta el bloque Palanthome en Francia, Uruguay e Inglaterra. Participa de la Exposición Rural Argentina donde construye una casa con el sistema Palanthome (demolida en los 50'). Es nombrado Commendatore della Corona d'Italia. Es nombrado Académico di San Luca al merito in clase.

1923-24. Fondazione Palanti dona 91.000 Liras para el estudio de la arquitectura, Santa Sede, Vaticano.

1923-1932. Funda un premio para el estudio de la arquitectura en Roma en homenaje a S.S. Papa Pio XI destinada a hijos de italianos nacidos en Argentina y Uruguay (Reale Scuola di Architettura, Roma y la Santa Sede); Casas de renta y local propiedad de Mario Palanti, Av. Corrientes 1463-9 y Victoria y Sarandí esta última sería rematados en noviembre de 1933.

1924. Noviembre. Viaja a Italia para presentar la Mole Littoria $(330 \mathrm{~m}$. de altura) a Mussolini. Expone el proyecto en el Palazzo Chigi, Roma. Patenta el sistema de construcción en seco Palandomus en Canadá. Publica Quatro anni di lavoro y Cinque anni di lavoro con La Mole Littoria. Mayo, compra mausoleo en el Cimitero Monumentale di Milano. Proyecto de Colegio de la Congregación de Santa Rosa de las monjas misionarias del Sagrado Corazón, Buenos Aires. Conjuntamente con De Pretis, Gianotti y Locati, participa del Consejo de redacción de la Revista Arquitectura y Arte Decorativo. Publicación ilustrada, que se edita, al menos, hasta 1926.

1925. 5 oct. Se inscribe en Italia al Partito Nazionale Fascista. Retorna a la Argentina. Patenta el sistema de construcción en seco en Estados Unidos. Patenta en Argentina el "sistema Palanti", un "sistema universal de casas en hormigón armado". Publica Cinque anni di lavoro. Esculturas, bronces fundidos: "Il sacro voto", "anima d'eroe", "freccia in potenza", "elevazione", "votis viribusque", "centauro in lotta". Dibujos: "La fiaccola della Fede Latina", Il dinamismo fascista", "Hodie crast et semper". 
1926. Viaja a Italia por unos meses. Reelabora el proyecto de la Mole Littoria (130 m. y luego 80 m. de altura) y lo publica nuevamente. Envía una copia a Mussolini.

1927. Obra construida: Agencia de autos y taller Resta Hnos. Av. del Libertador, Buenos Aires; Hotel Castelar Av. de Mayo 1142, Buenos Aires; Local París-Londres, 18 de Julio y Plata, Paysandú, Uruguay. Tras la gestión realizada por Beda Cardinale es nombrado Commendatore della Ordine di San Gregorio Magno.

1928. 23 de octubre. Se inscribe en el Registro Profesional de Ingenieros y Arquitectos de la Provincia de Milán.

1930. Mausoleo en el Cimiterio Centrale di Milano. Publicado en Rassegna di Architettura. Pide una audiencia con Mussolini.

1931. Regresa a Italia a bordo del Conte Verde. Establece en Roma un "Premio trienale" por la suma de 120.000 Liras para alentar la arquitectura en Reale Accademia d'Italia. Pide una audiencia con Mussolini.

1932. Vuelve a solicitar una audiencia con Mussolini para hablar sobre la Mole Littoria.

1933. 17 de febrero: es nombrado Academico de la Pontificia Insigne Accademia dei Virtuosi al Pantheòn. Regresa a Argentina. El 31 de julio, en la ciudad de Rosario, se casa con María Elena Castagnino proveniente de una familia de origen genovés de la alta sociedad rosarina.

1934. Febrero, envía un caballo a Italia para obsequiarlo a Mussolini. Marzo, se separa de su esposa. El Duce rechaza el regalo de Palanti. Palanti se presenta al concurso del Palazzo Littorio, Roma. El diario "Il Popolo di Roma" critica su proyecto y lo asimila a "una torta carnavalesca que hoy no se la puede hacer digerir ni a un sudamericano".

1935. Participa del consurso Auditorium, Roma. Junio, regresa a la Argentina a bordo del dirigible Graf Zeppelin_(vía Rio de janeiro). Regresa a Italia en octubre a bordo del Neptunia. Publica Torre Littoria, Auditorium y Tre progetti Mole Littoria Roma, "Auditorium" Roma, Torre Littoria Milano. Envía un ejemplar a Mussolini. Octubre, envía nota a la presidencia del concurso señalando la "prepotente invasión piacentiniana". Acusa a M. Piacentini de comercializar la arquitectura con el pretexto de crear un "Racionalismo fascista".

1936. Reclama por qué no se le permite colaborar con su arte en la Italia fascista, señala su triunfo en el exterior como italiano y fascista.

1937. Concurso para la Casa Littoria, Roma; Monumento a la Victoria, Milán publicados en Architettura. Rivista del sindicato fascista di arch. Ascendido a Capitán de la Armada del Genio. Envía el sistema Palandomus al EUR41

1938. Discute con su hermano Giuseppe y se distancia de la familia. Patenta un "bloque para construcción en seco" en Milán. Se presenta con los bloques en la "Fiera Campionaria di Milano". Se remata en Buenos Aires el Pasaje Barolo.

1939. Patenta el sistema constructivo Palandomus. Realiza pruebas en el laboratorio de materiales del Politecnico di Milano, octubre 1939.

1940. Pide audiencia con Mussolini. La secretaría particular le sugiere realizar una exposición escrita. En enero envía una carta a Farinata reclamando mayor consideración del gobierno fascista. 
1942. Discute fuertemente con su hermano Giuseppe. Escribe a la Reale Accademia d'Italia para señalar que tanto el premio como la fundación que lo otorga deben llamarse "Mario Palanti" y no simplemente "Palanti".

1943. 7 de enero a los 57 años Se casa en Milán con Nahir Marazzi Castiglione de 40 años. Agosto, cambia el domicilio a Stresa Borromeo luego de que su edificio (Via Mussolini 4, Milán) es afectado durante un bombardeo.

1944. se refugia en Stresa Borromeo a causa de la guerra. Se dedica a realizar proyectos, esquicios, dibujos. Proyecta con el sistema "Palandomus hermafrodita" diseños que abarcan desde casas agrupadas, viviendas en cadena, en altura, adosadas, en bloque para operarios, edificios en "colmena" metropolitana (al estilo Hilberseimer), mausoleos, hospitales, colegios hasta un campo de golf y hoteles en altura.

1944-45. Stresa Borromeo: Estudio del problema ferroviario y proyecto de estación ferroviaria, tribuna náutica.

1945. Publica The temple of the Universal Peace, y otra versión de Auditorium. Proyectos: (en Stresa Borromeo) Auditorium, Sucursal bancaria, casino-teatro-cine-hotel, central eléctrica, colegio, convento, estación ferroviaria, fuente de los héroes del trabajo, piscina cubierta, teatro lirico, Mole Vittoria (600 m.la más alta del mundo).

1946. Publica Architettura per tutti con los proyectos "racionalistas" diseñados en esos años. Muere Giuseppe Palanti, Mario Palanti no permite que sea sepultado en la bóveda familiar.

1946-47. Ca. Pruebas experimentales con ladrillos Palandomus en los hornos de la S. A. Palli e Figli, Voghera, Lombardía.

1947. ca. Se instala con Nahir en Milán. Publica Caseperilpopolo Palandomus. Laterizio ermafrodita. El volumen cuenta con proyectos para un edificio de oficinas de $300 \mathrm{~m}$ de altura, un "Monumental templo votivo" para Brasil, edificio de viviendas en bloque "case per il popolo", la Sede de la Camara del Lavoro di Milano, un edificio de departamentos y construcciones portuarias con el sistema Palandomus.

1948. Ante la falta de trabajo en Italia, viaja a Argentina para probar suerte junto a su mujer Nahir. Proyecta viviendas para la Fabril Los Plátanos.

1949. Realiza un proyecto para un Arco de la Victoria sobre la Av. 9 de julio, Buenos Aires.

1950. Realiza un proyecto para un Monumento en honor a San Martín, Buenos Aires.- 17 de septiembre. Por iniciativa de Angel Roncoroni el juzgado en lo Civil n ${ }^{\circ} 2$ de Capital Federal pide al CPAU información sobre Mario Palanti a fin de conocer si éste tenía o no título habilitante. Se comunica que MP no estaba habilitado para ejercer la profesión ya que no se hallaba inscripto bajo ningún carácter en ese organismo.

1951. Realiza diversos proyectos para viviendas económicas Palandomus Argentina. Proyecta viviendas para Ciudad Evita con el sistema. Realiza un proyecto para un Monumento a Perón y Eva, Buenos Aires.

1950-1955. realiza diversos proyectos con el sistema palandomus: viviendas en serie, viviendas rurales y viviendas para obreros. Participa del concurso para el estadio del club Newell's Old Boys de Rosario.

1952. El M.O.P. aprueba el sistema Palandomus para la construcción de viviendas del $2^{\circ}$ Plan 
Quinquenal. Nahir parte hacia Italia y abandona a Palanti. 16 de junio: Actas del CPAU. Arq. Ricardo Algier informa sobre un cartel de obra con el nombre de Mario Palanti en la Confitería París (Libertad esquina Charcas). Desde el CAPU le piden que lo retire o legalice su situación pues no posee título habilitante.

1953. Proyecto para el monumento al descamisado, Buenos Aires. Intenta sin éxito legalizar el título de arquitecto. La CPAU le pide que retire cartel de obra. Proyecto de estadio circular para el Foro Itálico de Roma.

1954. Proyecto para Puente Pueyrredón (publicado antes en Arch. Per tutti). Proyecto Torre Babele Utilitaria, Buenos Aires. 400 m. de altura.

1955. Sin título habilitante y luego de la caída de Perón, emprende en noviembre su regreso definitivo a Italia.

1956. Comienza a trabajar en el proyecto para la "Mole Universale, Santa sede, Roma". Conoce en marzo a Aurelio Marcato quien se demuestra interesado en el proyecto. Financiado por Palanti, Marcato ofrece buscar fondos para materializar la Mole a cambio de un porcentaje.

1957. Palanti se separa legalmente de Nahir por mutuo acuerdo. Envía un ejemplar de Architettura per tutti al presidente provisional argenitno.

1959. Envía un ejemplar de Architecture for all a A. Frondizi y al Ministerio del Interior, Buenos Aires.

1965. 25-9, denuncia haber sido estafado por Aurelio Marcato a través de la hipnosis.

1966. Pide a Nahir una mensualidad (4.200.000 Liras anuales) para la compra de alimentos. Declara estar necesitado por haber sufrido "una serie de desventuras" y por haber sido víctima de una gran estafa. Envía medallas y tarjetas al Vaticano, Academia de Ciencias Sueca, Secretaría de Estado, Madrid.

1967. Realiza el proyecto para la "Mole Alessandro Volta", Milán, de 600 m. de altura.

1968. Publica Centuplicare nostri valori moltriplicare nostra economía. Allí muestra la Mole Voltiana dedicada al turismo.

1969. Con 84 años, reclama la mensualidad a su ex mujer. Acusa a Nahir de abandonar el techo conyugal "sin reconocimiento de gratitud".

1970. Proyecto de antena dedicado a la "Novilità del lavoro".

1971. (ca.) Envía medallas conmemorativas de la paz universal. Imprime tarjetas postales con dibujos de su autoría. Reporta a la Academia de San Luca su abandono de la práctica profesional desde 1960.

1975. Recibe cartas de la embajada de Canadá, Japón, Estados Unidos, China, Alemania, Austria, Francia y la Corte Internacional de Justicia en agradecimiento por el envío de una medalla por la Paz Universal. Deja dinero para aquellos proyectos de arquitectura destinados a conmemorar la paz universal.

1977-1981. Premio di laurea Mario Palanti, Universita degli Studi di Milano.

1978. 6 de septiembre. Muere en Milán. 


\section{CURRICULUM VITAE DI MARIO PALANTI \\ Attività Professionale}

Il primo maggio dell'anno 1910 l'Arch. Mario Palanti, nato a Milano il XX Settembre 1885 da fu Giovanni e fu De Gaspari Virginia, sbarca in suolo Argentino per la prima volta, formando parte di una Commissione Ufficiale del suo paese, Italia, in occasione dei festeggiamenti del Centenario dell'indipendenza Argentina coi membri: Senatore Ing. Luiggi, Senatore Silvestri, Arch. Moretti, Conte Dr. De Visart, Dott. Piccinini, Ing. Ragnoli, Ing. Ravà. Il giorno seguente ricevuti, dall'Eccellentissimo Presidente della Repubblica Argentina.

La finalità del Comitato, di realizare la costruzione del Palazzo d'Italia all'Esposizione Internazionale di Buenos-Aires, progettato dal Palanti vinto in concorsi, e di allestirne la relativa mostra italiana. Detto palazzo realizzato in un periodo di tre mesi, sotto la direzione tecnica dell'autore, viene premiato con Diploma di Gran Premio da parte dal Governo Argentino.

Nel contempo il Palanti espone suoi studi tecnici, all'Esposizione internazionale di Bruxelles (Belgio) 1910 e viene premiato con Diploma di medaglia d'oro.

Subito dopo terminato il loro compito, l'On. Commissione Presieduta dal Sen. Luiggi, fa ritorno in Italia, al Palanti gli pervengono molte offerte di lavoro, e fra queste: la Direzione dello Studio dell'Ing. A. Prins, con oltre sessanta costruzioni in via di esecuzione e con elevati emolumenti; pertanto decide di rimanere a Buenos-Aires. Terminato il suo contratto di due anni, il Palanti apre uno studio per dare mano allo svolgimento di sue progettazioni, opere che via via, vengono realizzate fino all'anno 1916, epoca che abbandona l'Argentina per recarsi nella sua Patria, pero compiere il suo dovere alla chiamata alle armi, solamente dopo di aver realizzato una sua mostra delle sue opere e studi, nei locali della "Comision Nacional de Bellas Artes (Ministero della Pubblica Istruzione) risultando detta mostra la "Prima esposizione personale di architettura nella Repubblica Argentina” premiata con medaglia d'oro - e pubblicata dall'editore Rizzoli 1916.

Congedato il Palanti Tenente dell'Arma del Genio a Trieste, nell'anno 1920, fa ritorno in Argentina, per riprendere il cammino professionale e nonostante la sorpresa di una grave crisi economica, il Palanti dopo due anni di lotta non comune, riesce emergere, vincendo concorsi per opere di elevata portata, fra queste il Palazzo Galleria Barolo, per volume e per altimetria, riuscendo il primo edificio verso i cento metri a Buenos Aires, con ossatura incemento armato.

Nel contempo il Palanti vince pure un importante concorso per Montevideo (Uruguay) Palazzo Galleria Salvo, ancor più ardito del precedente, realizzandone la costruzione in unione dell' Ing. Gori-Salvo. Tale opera, dichiarato l'edificio più alto del mondo per molti anni di carattere civile, in cemento armato.

Ma pure il Palanti, svolge molta attività nell'interno della Repubblica Argentina, Uruguay ed altri Paesi Sud-Americani, per corrispondenza. 
Il Palanti mentre realizza opere ardite, vuole dimostrare essere utile alla classe umile del popolo lavoratore, e con un suo sistema costruttivo prefabbricato, realizza una piccola casa dal nudo terreno, in 5 giorni, all'Esposizione Rural Argentina" 1923, conferendogli diploma di Gran Premio. La cassetta di tre locali più servizi, abitata per oltre 20 anni intatta, e successivamente demolita per urbanistica.

Con l'attività e col risparmio del suo tenace lavoro professionale, il Palanti istituisce Borse di Studio e Premi "Ente morale perpetuo" per lo studio dell'Architettura Superiore a Roma potendovi concorrere Argentini ed Uruguayani. Altra Borsa di Studio presso la S. Sede, che porta il nome di "Papa Pio XI".

Nell'anno 1934 dopo aver realizzato a Buenos Aires edifici per suo conto: Calle Corrientes 1347, e Calle Sarandì angolo Victoria, fa ritorno in Italia per un meritato riposo. Ma successivamente 1935 ritorna a Buenos Aires a mezzo del dirigibile Zepelin, per una sistemazione di carattere familiare e per un periodo di pochi mesi.

In Italia il Palanti nel frattempo, sorpreso dalla seconda grande Guerra Mondiale, si dedica attivamente per determinati lavori di ricostruzione e formando parte di Commissioni Comunali per lo svolgimento urbanistico della Milano seriamente colpita dai bombardamenti.

Nell'anno 1948 fa ritorno in Argentina e trova un difficile ambiente nuovo, per aprirsi una breccia professionale, in un regime sociale dittatoriale. Fra l'altro viene imposta la rivalida di ogni titolo professionale per immigrati. Ma per ottenere tale rivalida presso le Università locali, primo requisito, ottenere la cittadinanza Argentina; e ciò senza tener conto di chi in passato ha realizzato opere nel Paese a migliaia, dalle più umili ai grattacieli, quali quelle del Palanti, degne per la intensa vita di tre uomini.

Comunque il Palanti non si perde di animo inoltra regolare domanda all'Università di Buenos Aires, ma dopo lunga e paziente attesa di oltre un anno, la sua pratica smarrita !! Il Palanti terribilmente colpito, avrebbe dovuto ricorrere alla Giustizia ma dopo ponderata riflessione, rinnova la sua domanda all'Università e purtroppo rinnovandosi altra paziente attesa per altro anno e più. Un bel giorno, un decreto, sorpresa governativo, sospende ogni rivalida di titoli stranieri in tutto il Paese e per ogni attività professionale.

Il Palanti profondamente addolorato per la tragica sua situazione creatasi, nel novembre 1955 decide di far ritorno definitivo in Italia, dopo di aver dato anima e corpo a quel Paese, rimasto sordo ad ogni suo supremo sforzo, di studioso e di animatore tenace ed onesto nel suo compito professionale.

Il Palanti, ha realizzato parecchie pubblicazioni tecniche dei suoi progetti e studi in diversi periodi di tempo.

\section{MARIO PALANTI}

- Accademico della Insigne di San Luca

- Accademico della Pontificia dei Virtuosi al Pantheòn

- Commendatore dell'ordine di San Gregorio Magno

- Commendatore della Corona d'Italia

- Capitano del Genio $1^{\circ}$ Gran Guerra Mondiale - decorato in campo.

- Medaglia d'oro dell'Università di Milano, quale benemerito.

Mario Palanti, Curriculum Vitae, 1958- AGP

ELENCO DELLE PRINCIPALI OPERE REALIZZATE 
Palazzo d'Italia all'Esposizione Inter. di B. Aires 1910 - che ha motivato il suo primo viaggio in Argentina per conto del Governo Italiano Edificio Giuseppe Peretti e C. Av. Rivadavia 1916 - B. Aires

Palazzo del Banco Francese ed Italiano per il Sud America. - B. Aires -

Palazzo-Galleria Barolo (22 piani in elevazione) Av. di Mayo - B. Aires. Il primo edificio in quel paese di tanta altura, che ha motivato la leggenda che dovrebbe precipitarsi. - Per contro la sua struttura statica è tanto potente, da poter raggiungere il doppio in altura.

Palazzo-Galleria Salvo (30 piani in elevazione) Piazza Indipendenza - Montevideo, Uruguay. Altro edificio con struttura in cemento armato, che pure ha dovuto subire certa maldicenza, per deficenza statica, e risulta in potenza da oltre trent'anni, a lo soffiar dé venti.-

Palazzo-Auto Crysler, a Palermo Chico, B. Aires, munito di pista di prova al piano di copertura, con cinque piani in elevazione.

Palazzo-Emilio Valsecchi, sup. M2 6.000.- Calle Vittoria angolo Alsina. B. Aires.

Palazzo Andrea Roccatagliata. Av. Santa Fé, angolo Av. Callao - B. Aires.-

Grand Hotel, Castellar, Av. de Mayo - B. Aires. (N.300 - Camere e N.300 bagni)

Palazzo della Nunziatura Apostolica di B. Aires - B. Aires.

Grand-Cinema, Rosa; Av. Rivadavia B. Aires -

Garage Peretti e C. - Calle B. Mitre - B. Aires -

Petit-Hotel, Silvio J. Merlo - Calle Azeuenaga - Esq. Arenales - B. Aires.

Petit-Hotel, Pedro Canduglia - Calle Arenales - B. Aires -

Edificio Francesco Cassottana - Calle Tusuman - B. Aires -

Edificio Nicolas Bruzone e H. - Calle Libertad - B. Aires.

Edificio Giovan Battista Uboldi Av. Rivadavia - B. Aires.

Edificio - Cesare Baragli - Av. Rivadavia - B. Aires

Edificio Angelo Baragli - Av Rivadavia - B. Aires

Edificio Mario Palanti - Av. Corrientes - B. Aires

Edificio Pietro Vila - Av. Rivadavia - B. Aires -

Edificio Mario Palanti (5 corpo indip.) Calle Vittoria ang. Sarandì. B. Aires

Palazzo-Cesare Baragli (M2. 3.000.-) Av. Rivadavia - B. Aires.-

Edificio-Industriale-J. Manzanares-e C. in Barracas - B. Aires

Petit-Hotel Carmelo Novello - Av. Monte de Oca -. B. Aires.

Petit-Hotel - Cesare Rossi - In Barracas - B. Aires -

Edificio Odine Bazzani - Av. Rivadavia - B. Aires.

Petit Hotel, Davide Costaguta - Calle Uruguay - B. Aires

Palazzo - Alfredo Vasena - San Isidro - Prov. di B. Aires

Petit-Hotel, Aurelio Devoto, Calle Juncal - B. Aires.

Petit-Hotel, Adrian Bescar Varela - Av. Las Seras - B. Aires

Petit-Hotel, Eduardo Resta, Palermo Chico - B. Aires -

Inoltre ha realizzato un numero molto notevole di progettazioni e costruzioni, nell'interno dell'Argentina e del Sud-America: Brasile, Uruguay, Chile, Venezuela, Columbia.- In Europa il Palanti ha svolto attività professionale, per la ricostruzione del post-Guerra (seconda Guerra mondiale).

Particolarmente in questi ultimi anni, si è dedicato per lo studio dell'abitasione economica delle masse, all'oggetto di ottenere: economia di costo, potenza stativa, igiene, in opposizione del così detto "prefabbricato", sistemi che non hanno prosperato ovunque, per geniali che siano, nell'universo. Egli ottenne per mezzo di "UN SOLO ELEMENTO COSTRUTTIVO” risolto il problema "verticale, e cioè il muro, con un mattone-perfezionato; comprovata la economia di mano di opera e di materiale malta, a due terzi in meno.-

Mario Palanti, Curriculum Vitae, 1958- AGP

Roma, 24 settembre 1934 / XII 
Illustre Collega,

Entro il corrente mese, l'Accademia debe bandire, per la prima volta, il concorso Mario Palanti per un progetto architettonico di soggetto religioso, cristiano-cattolico, su un determinato tema e per un determinato luogo. Il premio è di lire 20.000.

La Comissione, presieduta da S.E. Bazzani e della quale anche V.E. fa parte, non ha avuto l'opportunità di riunirsi negli scorsi mesi, per determinare il tema del concorso. Data la strettezza del tempo, ho dovuto fare ricorso direttamente a S.E. Bazzani il quale propone il seguente tema:

Su di un aspra montagna dei sacri confini della nostra Patria deve sorgere un Santuario dedicato al Santo Paolo, monito di forza, di sacrificio, di saggezza cristiana.

La costruzione da progettare dovrà ricoprire complessivamente una area di mq. 2500, dei quali circa la metà per il Tempio e l'altra metà circa per gli annessi al tempio, (per necessità de il culto, e per ricovero). L'opera che sorgerà ai confini d'Italia, terrà presenti le mirabili tradizioni d'arte della chiesa Cattolica Apostolica Romana e dovrà pure essere espressione del nostro tempo.

Il progetto sarà redatto:

con alzati (prospetti e sezioni) nella scala $1=100$

con planimetria (nella scala $1=100)$

con particolari decorativi (esterni ed interni) nella scala $1=20$ e sarà illustrato con due vedute prospettiche (una esterna, l'altra interna). Ed ai concorrenti è lasciata libera di redigere e presentare, ove credano, un plastico dell'Opera, nella scala $1=100$.

Prego V.E. di volersi comunicare se approvi la proposta Bazzani o quali modificazioni crede di dever indicare o eventualmente quale altra proposta ritenga di dover fare.

Ad ogni modo, è necessario concludere al più presto, perchè ripeto, a norma dello Statuto, il concorso deve essere bandito entro questo mese.

Faccio quindi affidamento sulle Sue cortesi sollecitudini

Con i più cordiali saluti

\author{
p. Il Presidente \\ C.FORMICHI
}

\author{
ALLE LL.EE. \\ BRASINI $=$ PIACENTINI \\ OJET'TI $=$ PARIBENI
}

Carta de C.FORMICHI, Roma, 24 settembre 1934, ASAL. T8.B47.F.57 


\section{A S.E. CARLO FORMICHI \\ V. PRESIDENTE DELLA R.ACCADEMIA D'ITALIA \\ ROMA}

A riscontro della Sua lettera in data 24 correlativa al bando di concorso "Mario Palanti", sono lieto di comunicarLe che il tema suggerito da S.E. Bazzani non solo è di mio completo gradimento, ma mi sembra anche molto ben scelto e opportuno.

Devo solo osservare che mi sembra superfluo specificare che l'opera, sorgendo ai confini d'Italia, dovrà tenere presenti le mirabili tradizioni d'arte della Chiesa Cattolica, Apostolica, Romana, pure essendo espressione del nostro tempo.

Le tradizioni d'arte della Chiesa sono troppo vaste per servire come punto di riferimento, perchè vanno dal primitivo Cristiano al gotico, dal romanico al barocco: essendo poi la costruzione ai confini d'Italia e quindi presumibilmente anche in una zona montana, l'architettura potrebbe anche avere i tipici caratteri delle costruzioni alpestri.

Mi sembra quindi che si potrebbe rinunciare a questa specificazione (tradizioni della Chiesa Cattolica, Apostolica, Romana) e per lasciare più liberi i concorrenti, togliere anche, se si vuole, l'altra specificazione che, cioè la costruzione debba essere espressione del nostro tempo.

Gradisca i miei più distinti ossequi

Marcello Piacentini

Carta de Marcello Piacentini a Formichi, Milano, Roma 26 Settembre 1934, ASAL. T8.B47.F.57

Roma 29 Settembre 1934. XII 
Carissimo Formichi,

Tu mi conosci bene, e sai che non sono così piccolo da voler tener duro per solo capriccio: ho anzi il principio di cercare vie di conciliazione ogni volta che è possibile. Ma come vuoi approvare un bando di Concorso di Architettura che pretende che "su di un'aspra montagna dei sacri confini della nostra Patria" debba sorgere una Chiesa che "tenga presenti le mirabili tradizioni d'arte della Chiesa Cattolica Apostolica Romana"?! Ma non pensi quanti potranno ridere di questa enfatica e assurda pretesa?

Io non voglio far perdere tempo: ma perchè il Collega Bazzani, invece di dettar lui il tema, non ci ha convocati come era suo elementare dovere?

Queste cose le avremmo discusse tra di noi, e risolte in tempo.

Per vedere di conciliare mi contento si tolga almeno la "Cattolica Apostolica Romana": si potrebbe dire: "terrà presenti le mirabili tradizioni dell'arte religiosa italiana".

In tutti i modi, se questa mia formula non andasse, niente male. Io posso benissimo astenermi dalla Comissione: gli altri tre colleghi, che hanno accettato integralmente il bando, possono perfettamente giudicare.

Ti dico questo per non metter bastoni tra le ruote. Credo sarà il miglior sistema.

Scusami se non ho aderito in pieno alla tua richiesta, come sarebbe stato mio vivissimo desiderio, ma proprio non me la sento.

Ti saluto caramente

Marcello Piacentini

\author{
A S.E. CARLO FORMICHI \\ V. PRESIDENTE DELLA \\ R. Accademia d'Italia
}

Carta de Marcello Piacentini a Formichi, Milano, Roma 29 Settembre 1934, ASAL.

T8.B47.F.57

Milano, 18 dicembre 1934 - XIII E. F. 


\section{CARO COMM. SEBASTIANI,}

Sono stato informato dello scrupolo insorto, a proposito del desiderio dell'Architetto Palanti, dal richiamo di un increscioso incidente di un'offerta giudicata inoportuna, già superata. Siccome io penso che vi dìa equivoco d'interpretazione, mi permetto di chiarire: l'Architetto Palanti non ha a suo tempo presentato il bozzetto al Concorso, per speciali considerazioni riguardanti specialmente il volume e il relativo ingombro. Intendiamoci bene, egli non pensava, chè sarebbe stato irrispettoso e inopportuno, offrire il bozzetto al Duce, ma soltanto, data anche l'importanza estetica ed organica del bozzetto stesso, che è di grande dimensioni e accuratissimo, mettere il Duce nella possibilità di vederlo, collocandolo e montandolo, dove il Duce ordinasse e magari anche al Palazzo degli esami, dove potrebbe essere visitato dalla Commissione.

Se dopo questi opportuni chiarimenti, la questione può essere ripresa in esame, la metto nelle sue mani e l'affido alla sua sagace oculatezza.

Grazie e cordiali saluti,

\section{OTTAVIO DINALE}

Carta de Ottavio Dinale a Sebastiani, Milano, 18 dicembre 1934, ACS.SPD.B1154 


\section{Copia}

Milano, 14 Ottobre 1935. XIII

Lettera aperta al Conte Ing. Radice Possati

Vice Podestà di Milano e Vice Presidente

Dell'On. Comm. Giudicatrice del Concorso

Pubblico, per la "Terre Littoria" Milano.

Palazzo Marino - Città.

Illustre Ingegnere,

Non ricevetti a tutt'oggi alcuna Sua risposta, alla mia lettera nerea con allegato, da Buenos Ayres, del 7 Agosto 1935. XIII․

Mi permetto insistere, benchè il momento non sia propizio per discutere questioni d'arte (ma per ben altre battaglie) comunque, si impone la necessità di segnalare per il futuro, di ricordare, di precisare verità schiaccianti, contro supremi interessi minacciati, non personali, regionali, ma bensì nazionali.

Mi riesce oltremodo doloroso ricorrera a questo procedimento, spinto come da un Sacro dovere, da Italiano e Fascista fervente, per il bene collettivo, per l'arte nostra e per collaborare all'idea, se possibile, di arginare tale prepotente invadenza Piacentiniana, infiltratasi ovunque nel Regno.

Conosciamo il nostro valore professionale e conosciamo quelle del' Arch. Marcello Piacentini, il quale ha contribuito a commercializzare l'architettura nostra, col pretesto di creare del razionalismo Fascista. Ma è pure doveroso ricordare che mentre il sottoscritto attraversa l'Oceano nell'anno 1924 e 1926, per presentare al Duce un grandioso progetto, che Egli onorava con la dedica "PER LA MOLE LITTORIA ALALA'" un collega che oggi pretende dominare l'architettura e l'arte fascista in Italia e di imporre ovunque le sue volontà come un credo (ostacolando la via a chi pure ne aveva Sacrosanto diritto) veniva severamente castigato per antifascismo!

E precisamente, per quanto concerne il caso specifico, il sottoscritto intende significare ancora una volta, colla presente, la sua formale protesta alla S.V.Ill.ma e fare tutte le riserve del caso.

Con perfetta osservanza Fascista.

Arch. Mario Palanti, Via Vincenzo Monti, 25

Milano

P.S. Compiego un opusculo di Adesioni e Giudizi a me diretti, con prefazione di S.E. Prof.

Dinale.Carta de Mario Palanti al Ing. Radice Possati, Milano, 14 Ottobre 1935, ACS.SP.B1154

Milano 10 Dicembre, 1936.E.F.XV . 


\title{
FONDAZIONI A PERPETUITÀ DI MARIO PALANTI
}

\author{
presso lo STATO ITALIANO. \\ presso la SANTA SEDE. VATICANO. \\ presso la REALE ACCADEMIA D'ITALIA. \\ per lo studio dell'Architettura a Roma.
}
Estratto conti dall'anno 1931 - 32, come risulta
dalle documentazioni allegati.

presso l'Università di Architettura di Roma

istituito dall'anno 1921-22 ………………………... £. 371,000.-

presso la Santa Sede, Vaticano

istituito dall'ano 1923-24

$£ .91,000 .-$

presso la Reale Accademia d'Italia

istituito dall'anno 1931-32

$£ \cdot 120,000$

totale $£ .582,000$.-

Le donazioni compiute con fede Fascista, fin dal 1922, mentre il sottoscritto risiedeva all'Estero, ebbero inizio all'età sua di 35 anni, ispirate, per aver il medesimo, realizzato in origine, i suoi studii, grazie una modesta Borsa di Studio, istituita presso la Cassa di Risparmio di Milano.

Ricorda, di aver realizzato anni or sono, un Mausoleo, per onorare la memoria de' suoi carii Genitori (ove figurano emblemi del Littorio) al Monumentale di Milano, e di aver invertito, per tale opera, oltre un milione di lire, come il resto guadagnato all'Estero.

Il sottoscritto, si è permesso di ricordare quanto sopra esposto, perchè gentilmente richiestogli da persona amica, convinto più che mai, di non aver fatto altro che il suo dovere di italiano; ad un tempo si permette di far presente il dolore che lo opprime, per non poter continuare simile sua opera modesta di Fascista di fede, ma pure di non poter contribuire umilmente, coll'arte sua, colla sua esperienza, per la nuova Italia Mussoliniana, inquantochè ad ogni suo tentativo di lavoro presentato, venne recisamente stroncato ogni via, da tre anni che risiede in Patria, dopo aver trionfato coll'Arte sua all'Estero, e si domanda il perchè dell'ingiusta situazione che si trova, e di tal natura, da cambiare di professione.

Ma con fede Fascista, l'agricoltore,

allegati $\mathrm{N}^{\circ} .3-$

Arch. Comm. Mario Palanti Accademico di S.Luca e dei Virtuosi Ufficiale del Genio della G. Guerra decorato

Fascista della prima ora.

Carta de Mario Palanti, Milano 10 Dicembre, 1936, ACS.SPD.B1154 
Illmo. comm. Ing. Palazzo

dell'Ente Autonomo Esposizione

del 1941 Roma.

\section{Oggetto: "Palandomus".}

Illustre Ingegnere,

In merito al preventivo, per la piccola baracca, a realizzarsi entro il recinto della progettata Esposizione 1941, che Ella tanto gentilmente, mi ha chiamato a dare prezzo; non potrò consegnare a Lei il preventivo, prima di lunedì o martedì p. La causa, per essere assente da Roma, la persona alla quale dovrei affidare con fiducia, tale incarico.

Mi sono affrettato avvisarLa, per l'imprevisto indicato, e ne approfitto per inviarLe il mio sentito ringraziamento, per avermi ricordato.

Con distinzione, ossequi fascisti,

\section{MARIO PALANTI}

Carta de Mario Palanti al Ing. Palazzo , Roma 2 Dic. 1937, ACS.ENR.B322.F.5219 


\title{
Roma 7 Dic. 1937. XVI%
}

\author{
All'On. Dr. Prof. \\ CIPRIANO EFISIO OPPO \\ Deputato al Parlamento \\ V. Pres. Ente Autonomo Esposiz. \\ Universale 1941. Roma
}

\section{Gentile Onorevole,}

Giorni or sono, il comm. Ing. Palazzo, mi ha consegnato un piccolo disegno di baracca (dove si progetta di eseguire i plastici, entro il recinto della futura Esposizione) per dare prezzo di costruzione, col sistema "Palandomus".

Ho digià consegnato il preventivo corrispondente; ed io spero che l'On. Ente Autonomo, vorrà benevolmente considerarlo. In questa circostanza, non intendo in assoluto di guadagnare somma alcuna, animato dal desiderio di poter dimostrare, il mio sistema e la sua superiorità.

Ho infinitamente apprezzato l'atto cortese dell'Ing. Palazzo, pel quale penso, deva a Lei la mia riconoscenza, di avermi raccomandato; e La ringrazio pertanto sentitamente.-.

Lieta occazione, per inviarLe il mio migliore saluto,

Suo obbligamo,

\section{MARIO PALANTI}

Carta de Mario Palanti a Cipriano Efisio Oppo, Roma 7 Dic. 1937, ACS.ENR.B322.F.5219 
Caro fratello,

La Ghin mi fa leggere la tua lettera che io la avrei spedita almeno dopo le nozze, perchè è peggio di niente, e spero che non le sia di cattivo augurio.

E' il solito frutto del tuo sistema nervoso.

Però devo confessare che in mezzo a delle falsità c'è nella

lettera una qualità ed è la chiarezza e la fermezza nel confermare che tu non vuoi più avere a che fare nè con me nè con i miei.

Sta bene, padronissimo, ma prima di salutarci è bene chiarire due cose: la prima, che ho apprezzato il tuo riavvicinamento cell'anno scorso, ma che il cadere di tutto nel silenzio non è stato affatto colpa mia; la seconda, che, contrariamente a quanto ebbe a dirmi l'Avv. De Marchi che io jo messo lo zampino in una certa critica sulla tua arte, non so in quale rivista moderna, io ti dichiaro esplicitamente e per iscritto che non solo non mi sono occupato affatto di tale faccenda, ma cge venni a conoscenza di detta critica solo dopo stampata.

Io non ho mai, dico mai, avuti rapporti qualsiasi coi direttori de tali Riviste, che conosco di sfuggita, e non mi vergogno di difendere, quando mi si presenta l'occasione, la tua opera d'architetto specie in rapporto ai tempi nei quali si è svolta.

Questo è quanto volevo dirti prima di salutarti.

Giuseppe PALANTI

Carta de Giuseppe Palanti a Mario Palanti, Milano 22 Ottobre 1938, Archivo Giuseppe Palanti. 
Caro fratello,

Milano 25 Ott. 1938.XVI /

$22 / 10 / 38$

$\mathrm{I}^{\circ} /$ "che il silenzio a seguito del tuo tentativo di riavvicinamento, non è stato per colpa mia! - Ed allora per colpa di chi!

$\mathrm{II}^{\circ}$ / "che tu non avevi messe lo zampino nella pubblicazione in qualche rivista cittadina, in merito ad una severa, quanto volgarissima critica sull'arte tua".-

E sta bene, ammettendo il caso specifico, ci viene e suona in perfetta discordanza, cella tua stessa dichiarazione, in calco alla tua lettera, nella quale mi dici:

"non mi vergogno di difendere la tua opera di architetto, in raporto ai tempi nei quali si è svolta".

Io mi permetto di farti osservare che in primo luogo, il frutto del mio lavoro di quel tempo, fu oggetto di ammirazione (modestia a parte) e non vedo il perchè di vergognarsi, per ricordare tale mio passato di lavoro. In secondo tempo, non è possibile giudicare l'evoluzione dell'arte mia odierna, che attraverso i grafici; poichè ancora nulla mi è stato possibile di portare a compimento. Ma comunque, la mia coscienza di artista galantuomo, non si lascerà portare verso gli sconci orribili, che purtroppo infestano tutta l'Italia, e che sembra, per nostra fortuna subentri un pentimento, e cioè un ritorno al buon senso.

Ciò premesso, ne approfitto col dirti, che quando mi si presenta l'occasione (le quali molto di sovente e senza cercarle perchè interpellate) di parlare dell'arte tua, come loro dicono di passatista; io malgrado i nostri tesi rapporti antagonici, esalto il tuo operato artistico, la qual arte per fortuna ancora non ha subito l'influenza funesta dell'era moderna. $\mathrm{E}$ con ciò intendo dire, che quando si entra nella sincera convinzione; si esalta e non si deve vergognarsi.

In merito all'avvenimento della Ghin, alla quale intendo essere di buon augurio, per ogni bene e felicità, non deve essere interpretato il mio gesto erroneamente. Il male augurio, l'ebbi io da te, che mi hai amareggiato l'esistenza sotto ogni profilo ingiustamente, dopo di avermi dilapidato ciò che era mio, e non contento ti sei divertito successivamente alla turlupinatura.- Ma di quello tu non hai colpa se nato coll'ironia cinica in viso. Comunque il tuo fratello non conserva rancori di sorta, unicamente desidera vivere in pace a di vivere del suo lavoro, che tanto ne ha di bisogno, e senza fare del male ma se possibile di fare del bene, come del resto in suo passato.

Chiude e con viva preghiera di non ritornarvi sopra all'argomento per alcuna ragione, ma ho voluto portare la chiara luce alla verità; e ciò tutto.

MARIO PALANTI

Carta de Giuseppe Palanti a Mario Palanti, Milano 25 Ott. 1938, Archivo Giuseppe Palanti. 
a.S.E. Gran Collare Maurisiano Luigi Federzoni Presidente della Reale Accademia d'Italia

Oggetto: "Palandomus"

Eccellenza,

mi sia concesso l'onore di mettere a conoscenza della E.V.il sistema di costruzioni economiche a secco "Palandomus;" rispondente alle necessità autarchiche, nel campo edilizia e dimostrato arditamente all'attuale "Fiera di Milano".

$\mathrm{Ma}$ in considerazione del principio, che ogni iniziativa nuove per buona che risulti, deve essere incoraggiata sotto ogni profilo, dalle Autorità Competenti o Culturali (quale la Reale Accademia d'Italia), per poter ottenere l'esito desiderato, specialmente per la natura del ritrovato, di ordine tecnico - scentifico; mi sia permesso di:

fare richiesta alla Eccellenza Vostra affinchè tale sistema "Palandomus" (frutto e risultante di vent'anni di tenace lavoro) sia considerato nella Classe di competenza, quale ritrovato autarchico, materiali di costruzioni e per concorrere ai premi relativi, istituiti annualmente a titulo incoraggimento, presso la Reale Accademia d'Italia.

Il sistema di costruzione "Palandomus", a secco, ha la prerogativa della smontabilità, e per conseguenza ricupero della materia impiegata; ma di eterna funzione e potenza nei casi voluti. - Si ottiene con qualunque sostanza o composto di sabbia - cemento, argilla cotta o cruda o chimica.

Fiducioso che la E.V. vorrà degnarsi di considerare benevolmente la mia domanda, rispettosamente mi professo fin d'ora obbligatissimo,

Arch. MARIO PALANTI

Accademico di S. Luca e dei Virtuosi.

$\mathrm{R}$ o $\mathrm{m} \mathrm{a}$

Carta de Mario Palanti a Gran Collare Maurisiano Luigi Federzoni, Milano 19 Aprile 1938, ASAL. T8.B47.F.57 
Caro Farinata,

Vi ricordate quando tre anni fa, io Vi pregai di segnalare il mio caso al Duce.

Appresi da Voi a suo tempo che il Duce s’interessò attraverso la sua Segreteria particolare; ma purtroppo, nulla ne è venuto.

E così sopo sei anni sal mio ritorno in patria io non ho potuto costruire un decimetro quadrato di muro.

Lasciamo andare il danno che pur pesa, poichè, Voi sapete bene che ho deto un milione e mezzo per fondazioni, per lo studio dell'architettura; e ne ho gettato almeno un altro per spese di progetti i Italia; cioè quasi tutto quello che ho guadagnato all'Estero dopo lunga e dura vita di lavoro, è sfumato.

Ma la questione più grave, è quella dello spirito; sono ancora giovane e sono intatte e perfezionate le mie capacità di lavoro; ho vinto all'Estero un infinità di concorsi, ho avuto per primo l'idea del Littoriale a Roma che è tanto piaciuta al Duce ed in seguito sono stato fra i quattordici vincitori del concorso di secondo grado per l'erigendo Palazzo del Littorio a Roma.

L'Italia Fascista sotto la guida del Duce si trasforma Imperialmente e si costruisce da pertutto. L'Arch. Palanti è escluso, e non riesce a comprenderne le ragioni, in modo assoluto da questa immensa opera di trasformazione.

Voi Farinata, sino dal 1922, a BUENOS AIRES mi conoscete, nella mia figura professionale, di combattente di fascista.

Una sola cosa Vi dico, il mio spirito è assetatissimo; ha sete, sete, sete. Invocate dal Duce che mi sia fatta giustizia e che sia calmata questa violenta febbre del mio spirito.

La nostra antica amicizia, mi autorizza a formulare questa intima e profonda preghiera.

Sono un forte, le avversit $\}$ a non mi abbattono, ma mi danno forza per chiedere non dei privilegi o dei favoritismi; ma soltanto un umano e positivo riconoscimento.

Vi saluto cordialmente, nella comune fede e nella comune passione Fascista, e Vi ringrazio,

\section{MARIO PALANTI}

Carta de Mario Palanti a Farinata, Roma 24 Gennaio 1940, ACS-SPD. BUSTA 1154 
Io ti ho steso la mano e ci hai sputato sopra! Ti chiedo dei fatti, dei nomi, dei confronti, delle precisazioni perchè il pallone della tua colossale montatura si sgonfi, e tu salti tutto a piè pari a concludi solo con delle volgari invettive che non mi sfiorano nemmeno perchè so di non meritarmele, (cosa che tu chiami coll'abusato nome di cinismo), e mi fanno pensare che tu sei realmente malato.-

Pazienza! Chi ha il giudizio l'adoperi!

Vuoi essere lasciato tranquillo? E' giusto; è quello che agogno anch'io. Però se ci tieni veramente a questo, non devi, prima di tutto, occuparti dei fatti miei personali e particolari dove tu non c'entri per nulla. Io conosco i fatti miei come sono realmente - ho passati già troppi dispiaceri - e so come devo comportarmi senza che il fratello faccia de "Paladino" - cosa che io ho sempre osservato nei tuoi riguardi.

In secondo luogo deve cessare la denigrazione e la calunnia verso di me perchè questa è veramente una viltà e mi difenderei certamente in tutti i modi. Io non ti ho denigrato e calunniato ripeto, e pretendo di essere trattato ugualmente.-

Infine, e chiudo: siccome tiri sempre in bello mio figlio; non so cose possa averti fatto e detto; in ogni modo io gli ho sempre dato dei buoni consigli nei tuoi riguardi e spero li abbia seguiti. E' ormai un uomo e non un ragazzo e può rispondere lui delle proprie azioni perchè ha abbastanza senno per ragionare e distinguere il bene dal male.-

Giuseppe PALANTI

Carta de Giuseppe Palanti a Mario Palanti, Milano 9 Aprile 1942, Archivo Giuseppe Palanti. 


\title{
Bibliotecas y archivos
}

\section{Argentina}

La Plata: Biblioteca Dardo Rocha-Universidad nacional de La Plata; Biblioteca de la Facultad de Arquitectura y Urbanismo (FAU-UNLP); Biblioteca de la Facultad de Humanidades-UNLP.

Rosario: Biblioteca de la Mujer; Biblioteca Juan Alvarez; Archivo Palacio de Tribunales; Biblioteca y Archivo del Museo Histórico Provincial de Rosario "Julio Marc".

Buenos Aires: biblioteca Universidad Torcuato Di Tella; Biblioteca Alejandro Christophersen de la Sociedad Central de Arquitectos (SCA); Instituto de Arte e Investigaciones Estéticas(IAA-FADU-UBA); Biblioteca del Instituto Italiano di Cultura; Biblioteca del Centro Argentino de Ingenieros; Biblioteca de la Academia Nacional de Historia, Biblioteca Esteban Echeverría (Palacio Legislativo de la Ciudad de Buenos Aires); Instituto Histórico de la Ciudad de Buenos Aires (IHCBA); Centro de documentación e Investigación de la Arquitectura Pública- Centro de Documentación e Información -Ministerio de Economía (CeDIAP); Archivo General de la Nación, Centro de Estudios Migratorios latinoamericanos (CEMLA); Biblioteca Tornquist (Banco Central de la República Argentina); archivo de planos históricos y domiciliarios AySA (Aguas y Saneamientos Argentinos S.A.).

\section{Uruguay:}

Montevideo: Biblioteca Facultad de Arquitectura y Biblioteca de la Facultad de Humanidades UdelaR; Archivo del Instituto de Historia de la Arquitectura, FArq-UdelaR; Biblioteca Nacional; Instituto Italiano di Cultura; Biblioteca de la Sociedad de Arquitectos del Uruguay; Biblioteca universidad ORT, archivo del Palacio Legislativo; Archivo General de la Nación; Archivo del Centro de Fotografía de Montevideo.

Italia:

Milán: Archivo privado Giuseppe Palanti; Archivo privado Guido y Emilio Palanti; Colección privada Angela y Cristina Palanti; biblioteca de la Academia di Belle Arti di Brera.

Roma: Archivio Segreto Vaticano, Archivio Storico nel Archivio Lincei; Biblioteca e Archivio dell'Accademia di San Luca; Fondo della Reale Accademia d'Italia; Archivio Centrale Dello Stato; Archivio della Società Geografica; Biblioteca Centrale.

\section{Estados Unidos:}

Getty Research Library, Getty Research Institute-Sepcial Collections

\section{Fuentes primarias}

\subsection{Diarios, revistas y almanaques}

\author{
Argentina \\ Almanaque del Mensajero (1910-1932) \\ Almanaque La Razón (1919-1930) \\ Diario La Prensa \\ Diario La Nación \\ Revista Caras y Caretas \\ PBT
}


Suplemento Arquitectura, Revista Técnica, Sociedad Central de Arquitectos (SCA)

Revista de Arquitectura, SCA

La Ingeniería, Centro de Ingenieros

Revista CACyA (Centro de Arquitectos Constructores y Afines)

Cronache italiane

Giornale d'Italia

La patria degli italiani

\section{Uruguay}

Mundo uruguayo

Diario El Día

Revista de Arquitecturas, SAU

Almanaque del banco de Seguros del Estado

\section{Italia}

Il popolo d'Italia

L'Illustrazione italiane

La vie d'Italia

Architettua

Casabella

Rasegna d'architettura

\subsection{Publicaciones oficiales}

Versiones Taquigráfica de las Sesiones del Honorable Concejo Deliberante de la Ciudad de Buenos Aires, 1905-1930

Intendencia Municipal, Comisión Estética Edilicia, Proyecto orgánico para la urbanización del Municipio. El Plano Regulador y de Reforma de la Capital Federal, Talleres Peuser, Buenos Aires, 1925

Censo General de población, Edificación, Comercio e Industrias de la Ciudad de Buenos Aires, Buenos Aires, Compañia Sud-americana de Billetes de Banco, 1910. (levantado en octubre 1909),

Censo General de población, Edificación, Comercio e Industrias de la Ciudad de Buenos Aires, Buenos Aires, Compañia Sud-americana de Billetes de Banco, 1905. (levantado entre el 11 y 28 de septiembre de 1904).

AA.VV., La República Argentina en 1910. Estudio bistórico, físico, político, social y económico, Tomo I., H. Comisión del Centenario de la Independencia Argentina y Junta de Historia y Numismática Americana, Buenos Aires, Maucci Hnos., 1910.

\subsection{Fuentes Primarias Editas}

Christophersen, Alejandro. 1923. Los rascacielos y las construcciones gigantescas. Revista de Arquitectura n ${ }^{\circ}$ 36. Buenos Aires: SCA. dic. 
56, ago.

Blomberg, Héctor Pedro. 1920. Las puertas de Babel. Buenos Aires: Cooperativa Editorial Ltda Boito, Camillo. 1887. I principii del disegno e gli stili dell'ornamento. Milano: Ulrico Hoelpi editore. 1893. Questioni pratiche di Belle Arti. Restauri, concorsi, legislazione, professione, insegnamento. Milano: Ulrico Hoelpi editore. 1880. Architettura del medio evo in Italia con una introdũione sullo stile futuro dell'architettura italiana. Milano: Ulrico Hoelpi editore.

Boletin Oficial de la República Argentina, año XXXV no 10.001 del 18 de agosto de 1927. Actas del 25-7-1927.

Carotti, Giulio. 1917. Prefazione. Prima esposizione personale d'arcbitettura nella Repubblica Argentina. Palanti,M. Milano. Stab. di arti grafiche Rizzoli e Pizzio.

Chantecler, E.. 1910. Concurso de la facultad de derecho. Revista de Arquitectura No 62, marzo y abril.

Christophersen, Alejandro.1918. Correspondencia entre AC y Marcelino Allende. (Caja 265. AGN. Montevideo).

Comisión de Estética Edilicia MCBA, Proyecto orgánico para la urbanización del Municipio, Buenos Aires, Talleres Peuser, 1925. También de gran influencia durante el period fue el texto de Werner Hegemann/Elbert Peets/ Alan J. Plattus. 1996(1922). The American Vitruvius: an architect's handbook of Civic Art, Princeton Architectural Press.

Cousin, Victor. 1947 (1829). Necesidad de la filosofía: introducción a la historia de la filosofía. Buenos Aires: Espasa-Calpe

De Fabris, Emilio . 1864. Del Sistema Tricuspidale per il coronamento della facciata di Santa Maria del Fiore. Seguito alle considerazione pubblicate nel 1864. Firenze: Tipografia di Barbera.

Delaporte, Louis. 1880. Voyage an Cambodge. L'Architecture khmer. Paris: C. Delagrave.

Escudero, Petronilo (dir.). 1922. Anuario de Arquitectura e Ingeniería en la República Argentina. Revista La Construcción. Buenos Aires.

Esposizione Internazionale di Milano. Libreria Fratelli Bocca, Milano, 1907

Ferreiro, Alfredo Mario. 1927. El hombre que se comió un autobús (Poemas con olor a nafta). Montevideo,LaCruz del Sur.

Ferris, Hugh. 1986 (1929).en The Metropolis of Tomorrow New York: Princeton Arch.Press.

Guillot Muñoz, Gervasio y Álvaro. 1930. Le Corbusier en Montevideo. La Cruz del Sur 27, ene. feb. Montevideo.

Hegemann, Werner. 1932. El espíritu de Schinkel en Sudamérica. C.E.D.A. revista del Centro de Estudiantes de Arquitectura, no 2 octubre. Montevideo. 
Hortal, José. 1923. Carta abierta. El Arquitecto. Vol. III. Nª 36. Buenos Aires. Julio. Jaeschke, Víctor. 1928. Prohibición de abrir pasajes. Revista de Arquitectura. no 92, ago. Martel, Julián. 2008 (1891). La Bolsa. El Aleph.

Mujica, Francisco. 1929. History of the Skyscraper. París: Archaeology \& Architecture Press.

Oskar Ranzenhofer, "El cemento armado en la arquitectura. Expresión de sus fuerzas internas" en La Ingeniería 1 (Enero 1910): 9-11.

Pachecho, Miguel A. ca.1932. La verdad sobre el famoso asunto Barolo. Buenos Aires: imprenta Lopez.

Pagano, Giuseppe. 1934a. Mussolini salva l'architettura italiana. Casabella. nº 78. giug. 2-3. 1934b. Il Concorso per il Palazzo del Littorio. Casabella XII-XIII. Oct. 6- 41.

Prebisch, Alberto. "Precisiones de Le Corbusier", Revista Sur, (Buenos Aires, verano 1931).

Ramon, Tomás. 1619. Conceptos extravagantes y peregrinos: sacados de las divinas y humanas letras y Santos Padres, para muchas y varias ocasiones que por discurso del año se ofrecen predicar en casa de Gabriel Graells.

Schuyler, Montgomery. 1961. American Architecture and other writings, Vol. I-II. Massachusetts: Harvard University Press, (publicados originalmente entre 1883-1909).

Skillman Onderdonk, Francis. 1928. The ferro-concrete style: reinforced concrete in modern architecture, with four hundred illustrations of European and American ferro-concrete design. Stamford: Architectural Book Publishing Co. Inc.

Spinetto, David J. 1924. Per la cultura italiana in Argentina. Buenos Aires: Mercatali.

Sullivan, Louis. 1896. The tall building artistically considered, Lippincott's. Magazine, marzo: http:// academics.triton.edu/.

Viollet-le-Duc, Eugène-Emmanuel. 1863. Entretiens sur L'Architecture. Paris: A. Morel et Co. 1867. Dictionaire raisonné de l'architecture française du XIe au XVIe siècle. Paris: A. Morel et Co.

Voti e pareri diversi sulla facciata del duomo di Firenze pubblicati per cura della deputazione promotrice (Firenze, M. Celini:1865)

\subsubsection{Material publicado por Mario Palanti}

1917. Prima esposiz̨one personale d'architettura nella Repubblica Argentina. Milán. Stab. di arti grafiche Rizzoli e Pizzio.

1919. Mausoleo. Glorificando gli eroi nostri di terra, del mare, del cielo.

1922. Algunas consideraciones sobre arquitectura edilicia. El Arquitecto Constructor. N²46. 1 de agosto.

1924. Quattro anni di lavoro. Milán. Casa Editrice d’arte Bestetti \& Tumminelli. Palanti. 
1924. Cinque anni di lavoro. Milán. Casa Editrice d'arte Bestetti \& Tumminelli. Palanti, Mario. 1924b.

Palanti, Mario. 1926. L’Eternale Mole Littoria. Milano: Rizzoli \&C.

1934. Palazzo del Littorio, progetto. Milano: Rizzoli \& C.

1935. Auditorium: progetti, Milano: Rizzoli \& C.

1935.Torre Littoria: progetti, Milano: Rizzoli \& C.

1935. Tre progetti; Mole Littoria Roma, "Auditorium" Roma, Torre Littoria Milano. Adesioni e giudisi. Milano: Rizzoli \& C.

ca. 1939.Palandomus autarchico, Milano.

1945. Auditorium. Milano: Esperia.

1945. Temple of the Universal Peace. Milán: Emilio Bestetti.

1946. Architettura per tutti. Milano: Casa Editrice d'arte Bestetti.

ca. 1948.Palandomus laterizio hermafrodita, Milano.

1969. Centuplicare nostri valori potenziare nostra economia. Milano: Esperia.

\section{Publicaciones de Palanti en diarios, anuarios y revistas}

1908/9, Mausoleo Commemorativo, Svolgimento perpetico, Scuola del Prof.G. Mentessi. Studi di Architettura, corso Academia di Belle Arti, en Studi di architettura della scuola superiore nella $\mathrm{R}$. accademia di b. arti e nel R. Politecnico di Milano, vol 1. Milano: Bestetti e Tuminelli.

1917. "Arquitectura religiosa. Proyecto de catedral" en Revista de Arquitectura. Órgano del Centro de Estudiantes de Arquitectura. Nº. Buenos Aires. 22-23.

1920. "Edificio Luis Barolo" en El Arquitecto N³. Buenos Aires. Feb. 47-49. Palanti, Mario. 1920. Edificio Luis Barolo. El Arquitecto N³. Buenos Aires. Feb.

1923. "La era moderna tiene orientaciones nuevas en arquitectura?" en El Arquitecto Constructor. $\mathrm{N}^{\circ} 258.1$ feb.

1927. "El primer palacio autódromo en Sud América, Resta SA" en CACYA Nº1. Buenos Aires. jun. 12-16.

1954. Torre Babele Novus. Giornale d'Italia. Buenos Aires, 22 de noviembre.

\subsubsection{Traducciones $\mathrm{y}$ reediciones de fuentes primarias}


Ruskin, John. 1955 (1849). Las siete lámparas de la arquitectura. Buenos Aires: Safian.

Ruskin, John. 2000 (1851-1853). Las piedras de Venecia. Valencia: Consejo general de la arquitectura técnica de España.

Quatremere de Quincy, Antoine-Chrysostome. (1832) 2007. Diæionario storico di architettura. Le voci teoriche. A cura di Valeria Farinati e Georges Teyssot. Venezia: Marsilio Editori, 1985 (Traducción: Fernando Aliata y Claudia Shmidt, Diccionario de Arquitectura: voces teóricas, Buenos Aires, Nobuko, 2007).

Simmel, Georg. 1998 (1903). Las grandes urbes y la vida del espiritu. El individuo y la libertad. Ensayos de crítica de la cultura. Barcelona: Península.

\section{Fuentes secundarias}

\subsection{Bibliografía sobre Mario Palanti}

Aliata, Fernando. 1997. La cantera de la historia. Mario Palanti y la construcción de una poética ecléctica en Argentina. En: Cuadernos de Historia del Instituto de Arte Americano. No 8. Buenos Aires: IAAIA-FADU-UBA. Junio.

Aliata, Fernando y Bonicatto, Virginia. 2014. Mario Palanti, Colección Maestros de la Arquitectura argentina. Buenos Aires: Clarín Arquitectura.

Bares, María Mercedes. 2006. Progetti di Mario Palanti in America Latina. En: Il Disegno di Architettura, n³2. Roma: Ronca Editore.

2007. La galleria Barolo di Buenos Aires. En: Il tesoro delle città. Roma: Strenna dell'Associazione Storia della città. Anno V.

Bonicatto, Virginia. 2010. Textos e ideas. Repercusiones e historiografía. Arquitextos año 11. Ago. http://www.vitruvius.com.br/revistas/read/arquitextos/11.123/3523. (consulta 28 de mayo de 2014).

2011. Escribir en el cielo. Relatos sobre los primeros rascacielos en Buenos Aires (1909-1927). Tesis de maestría en Historia y Cultura de la Arquitectura y la Ciudad, UTDT. Buenos Aires, inédita.

2013. Mario Palanti and the Palacio Salvo. The art of constructing skyscrapers. The Getty Research Journal n ${ }^{\circ}$. Los Angeles: The Getty Research Institute. Febrero.

Cacciatore, Jorge. 1985. Mario Palanti. Sección "tapa homenaje" de Revista Summa, no 210, marzo.

1989. Edificio Barolo, Buenos Aires. Sección "Patrimonio" de Revista summa. $n^{\circ} 261$, mayo.

Coen, Sara. 2012. Mario Palanti, architetto e artista multiforme. Le sue tracce nell'Archivio storico del Gruppo Intesa Sanpaolo. Intessa Sanpaolo, Archivio storico news N. 15, Archivio Storico 
Intesa Sanpaolo. Milano.

--------. 2013. Opere e progetti di Mario Palanti. En Contributi italiani all'architettura argentina. Progetti e opere tra il XIX e il XX secolo, Tuzi, Sabugo (a cura di). Roma: DEI Tipografia del genio civile.

Daguerre, Mercedes. 1995. Milano- Buenos Aires: la perdita del centro. Metamorfosi, quaderni di architettura. "La Sapienza". No 25/26.

Gangui, Alejandro. 2014. The Barolo palace: Medieval astronomy in the streets of Buenos Aires. Culture and Cosmos: A journal of the bistory of astrology and cultural astronomy, Vol. 15. N.1.

Gatti, Pablo. 1995. Nacimiento y opacidad de un símbolo. Almanaque del Banco de Seguros del Estado. Montevideo.

Hilger, Carlos. 1993. Mario Palanti: su Monumento al Genio Latino. Summa + no 3, nov. 1996. Capriccio italiano. Arquitectos europeos y Buenos Aires, 1860-1930. Buenos

Aires: Fundación TIAU.

Hilger, Carlos y Sánchez, Sandra. 2008. Macrocosmos y microcosmos en la obra de Mario Palanti. Summa no95, Buenos Aires. sept.

Iolita, Otelo. 1995. Da Boito a Palanti. Ricerca di identittá nelle architetture di Buenos Aires e necessitá della loro conservazione. Metamorfosi, quaderni di architettura, "La Sapienza", No 25/26.

Neumann, Dietrich. 2014. A skyscraper for Mussolini. A A Files 68 (Spring 2014).

2.2. Bibliografía general

Adorno, Theodor. 2001. The Culture Industry. Selected essays on mass culture. London: Routledge classics.

Ballent, Anahí y Gorelik, Adrián. 2000. El Príncipe. En: Revista Block N 5. Buenos Aires: UTDT. Diciembre, pp 6-11.

Aliata, Fernando. 2006. La ciudad regular. Arquitectura, programas e instituciones en el Buenos Aires posrevolucionario, 1821-1835. Bernal: UNQUI-Prometeo.

2014. Estrategias proyectuales. Los géneros del proyecto moderno. Buenos Aires: SCA.

Alonso, Craciun, de Souza y Nisivoccia. 2010. 5 narrativas, 5 edificios, Catálogo de la $12^{\circ}$ Mostra Internazionale di Architettura de la Bienale di Venezia. Montevideo. 
Alonso, Sebastián y Guspi Teran, María Margarita. 2005. Historia genealógica de las primeras familias italianas de Rosario, siglo XVIII y siglo XIX hasta 1870. Rosario: Consolato Generale d'Italia.

Antola, Susana y Ponte, Cecilia. 1997. El edificio de renta como tipo arquitectónico generador de ciudad. Montevideo: Instituto de Historia de la Arquitectura. Facultad de Arquitectura. Universidad de la República.

2000. La nación en bronce, mármol y hormigón armado. En: Los uruguayos del centenario. Nación, ciudadanía, religión y educación (1910-1930), (dir) Caetano Gerardo. Montevideo: Taurus.

Arana, Mariano y Garabelli, Lorenzo. 1995. Arquitectura renovadora en Montevideo 1915-1940. Reflexiones sobre un periodo fecundo de la arquitectura en el Uruguay. Montevideo: Fundación de cultura universitaria.

Ballent, Anahí. 2005. Las huellas de la politica: vivienda, ciudad, peronismo en Buenos Aires, 1943-1955. Bernal: UNQUI.

Banham, Reyner. 1965 (1960). Teoría y diseño en la era de la máquina. Buenos Aires: Nueva Visión.

Banti, Alberto Mario. 2004. Il Risorgimento italiano. Roma-Bari: Laterza.

Barbero, María Inés y Rocchi, Fernando. 2002. Empresarios, empresas y organizaciones empresarias. Nueva bistoria de la Nación Argentina, tomo IX. Buenos Aires: Planeta.

Belini, Claudio. 2010. La Compañía General de Fósforos y los orígenes de la industria hilandera de algodón en Argentina, 1920-1935. Am. Lat. Hist. Econ [online], No34 [citado 2015-0220] Recuperado de <http://www.scielo.org.mx/scielo.php?script=sci_arttext\&pid=S140522532010000200004\&lng=es\&nrm=iso >. ISSN 2007-3496.)

Benevolo, Leonardo. 1978. Historia de la Arquitectura Moderna. Barcelona: Gustavo Gili. 1986 (1960). Historia de la arquitectura moderna. Barcelona: Gustavo Gili.

Ben-Ghiat, Ruth. 1995. Fascism, Writing, and Memory: The Realist Aesthetic in Italy, (19301950). The Journal of Modern History. Vol. 67. No 3. Sep. Chicago: The University of Chicago Press.

Beretta Curi, Alcides. 1966. El imperio de la voluntad. Una aproximación al rol de la inmigración europea y al espiritu de empresa en el Uruguay de la temprana industrialización, 1875/ 1930. Montevideo: Editorial Fin de Siglo.

1978. De nuestras industrias (1900-1915) aspectos técnicos, crecimiento, legislación proteccionista. En: La industrialización del Uruguay 1870-1925, Cinco perspectivas históricas. Montevideo: Fundación de Cultura Universitaria.

Beretta Curi, Jacob, Rodríguez Villamil y Sapriza. 1978. La industrialización del Uruguay 1870-1925. Cinco perspectivas históricas. Montevideo: Fundación de Cultura Universitaria. 
Bergdoll, Barry. 2000. European architecture 1750-1890. Oxford: Oxford University Press.

Berger, John. 2005. Modos de ver. Barcelona: Gustavo Gili.

Berjman, Sonia. 1995. Proyectos de Bouvard para la Buenos Aires del Centenario: Barrio, plazas, hospital y exposición. $D A N A, N^{\circ} 37 / 38$.

Berman, Marshall. 1989 (1982). Todo lo sólido se desvanece en el aire. La experiencia de la modernidad. Madrid: Siglo XXI.

Bertino, Magdalena. 2009. La industria textil uruguaya: concentración de capitales y articulación regional, 1900-1960. En: H-Industria. Revista de historia de la Industria, los Servicios y las Empresas en América Latina, n 4-5, año III.

Bertola, Luis. 1991. La industria manufacturera uruguaya 1913-1961: un enfoque sectorial de su crecimiento, fluctuaciones y crisis. Montevideo: CIEDUR-FCS.

Bosaglia, Rosana. 1972. Giuseppe Palanti saggio critico, La Rete.

Bronislaw, Baczko. 1991. Los imaginarios sociales. Memorias y esperanzas colectivas. Buenos Aires: Nueva Visión.

Bullrich, Francisco, 1963. Arquitectura argentina contemporánea: panorama de la arquitectura argentina 1950-1963. Buenos Aires: Ediciones Nueva Visión.

Buschiazzo, Mario J. 1967. La Arquitectura en la República Argentina 1810-1930, Buenos Aires, 1966 y Art Nouveau en Buenos Aires. Documentos de Arte Argentino, Cuaderno no 27, Academia Nacional de Bellas Artes, Buenos Aires.

Camou, María y Maubrigades, Silvana. 2009. Tejiendo una historia: la industria textil uruguaya, 1898-2000. H-Industria. Revista de historia de la Industria, los Servicios y las Empresas en América Latina, n ${ }^{\circ} 4-5$, año III.

Caride, Horacio. 1997. Francisco Gianotti: la vanguardia en la mansarda. Cuadernos de Historia, IAA, $n^{\circ} .8$.

Cibotti, Ema. 1994. Periodismo político y politica periodística, la construcción pública de una opinión italiana en el Buenos Aires finisecular. Entrepasados, nº 7. Buenos Aires.

Cibotti, Ema. 2000. Del habitante al ciudadano: la condición del inmigrante. Nueva Historia Argentina Tomo V. Dir. Tomo, Mirta Zaida Lobato. Buenos Aires: Sudamericana.

Cirvini, Silvia Augusta. 2004. Nosotros los arquitectos: campo disciplinar y profesión en la Argentina moderna. Buenos Aires: Zeta.

Ciucci, Giorgio. 1989. Gli architetti e il fascismo. Architettura e città 1922-1944. Torino: Einaudi. 
Contreras, Leonel. 2005. Rascacielos porteños. Historia de la Edificación en altura en Buenos Aires (15802005). Buenos Aires: Secretaría de cultura de la Nación, Comisión para la preservación del patrimonio histórico cultural.

Crespi Morbio, Vittoria (a cura di). 2001. Giuseppe Palanti: pintura, teatro, publicita, disegno. Torino: Umberto Alemandi \& C.

Cripa, María Antonieta. 2002. L'architettura ragionata. Milano: Editoriale Jaca Book.

D’Amia, Giovanna. 2013. Architetti lombardi a Buenos Aires: percorsi formativi e prime occasioni profesionali. En Contributi italiani all'architettura argentina. Progetti e opere tra il XIX e il XX secolo, (a cura di) Tuzi, Sabugo. Roma: DEI Tipografia del genio civile.

Daguerre, Mercedes. 1998. La construzione di un mito. Ticinesi in Argentina. Commitenza e architettura (1850 1914). Suiza: Accademia di Architettura di Mendrisio.

De Felice, Renzo. 1979. Entrevista sobre el fascismo. Buenos Aires: Sudamericana.

de Larrañaga, María Isabel. Las normativas edilicias como marco de la arquitectura moderna en Buenos Aires (1930-1940). Anales del IAA n²7-28.

De Seta, Cesare. 1983. La cultura architettonica in Italia tra le due guerre. Roma: Laterza.

De Solà-Morales, Ignasi. 2003. Inscripciones. Barcelona: GG.

de Wit, Wim y Van Zanten, David. 1986. Louis Sullivan: The Function of Ornament. New York: Norton.

Dellapiana, Ellena. 2005. Il mito del medioevo. En Storia dell' Architettura italiana, l'ottocento, (a cura di) Amerigo Restucci, vol. II. Milano: Electa.

Dellapiana, Ellena. 2005. Camillo Boito. En Storia dell' Architettura italiana, l'ottocento, (a cura di) Amerigo Restucci, vol. II. Milano: Electa.

Devoto, Fernando y Barbero, María Inés. 1983. Los Nacionalistas: 1910-1932. Buenos Aires: CEAL.

Devoto, Fernando y Rosoli, Gianfausto. 1985. La Inmigración Italiana en la Argentina. Buenos Aires: Biblos.

Devoto, Fernando. 2003. Historia de la Inmigración en la Argentina. Buenos Aires: Sudamericana.

2006. Historia de los Italianos en Argentina. Buenos Aires: Sudamericana.

Di Tella, Guido. 1993. La Unión obrera textil, 1930-1945. Desarrollo Económico 33, n¹29, abriljunio.

Dorfman, Adolfo. 1970. Historia de la industria argentina. Buenos Aires: Solar Hachette. 
Drexler, Arthur (ed.). 1977. The Architecture of the École des Beaux-Arts. New York: MoMA.

Dulitsky y Ulanovsky. 2013. Divino Barolo. Buenos Aires: Ideame.

Épron, Jean-Pierre. 1997. Comprendre l'Éclecticisme. París: Norma.

Frampton, Kenneth. 1995. Studies in Tectonic Culture: The Poetics of Construction in Nineteenth and Twentieth Century Architecture. Graham Foundation for Advanced Studies in the Fine Arts.

Frietzche, Peter. 2008. Berlin 1900, prensa, lectoresy vida moderna. Buenos Aires: Siglo XXI.

Frisby, David. 2007. Paisajes urbanos de la modernidad. Exploraciones críticas. Bernal: UNQUI.

Gatti, Pablo. 1995. Nacimiento y opacidad de un símbolo. Almanaque del Banco de Seguros del Estado. Montevideo: s/d

Gandolfi, Fernando y Gentile, Eduardo. 2006. El rascacielito. La Central Defensa. Buenos Aires: Fundación Telefónica.

Gentile, Eduardo. 2001. Materialidad del proyecto arquitectónico: acero, hormigón, acero. Revista 47 al fondo, $\mathrm{N}^{\circ} 6$, abril.

Gentile, Emilio. 2007. El culto del Littorio: La sacralización de la política en la Italia fascista. Buenos Aires: Siglo XXI.

2005. La vía italiana al totalitarismo. Partido y estado en el régimen fascista. Buenos Aires: Siglo XXI.

2007. El culto del Littorio. Buenos Aires: Siglo XXI.

Gentile, Emilio. 2003. The Struggle for Modernity: Nationalism, Futurism, and Fascism, Praeger: Westport.

Ghirardo, Diane. 1980. Italian Architects and Fascist Politics: An Evaluation of the Rationalist's Role in Regime Building. Journal of the Society of Architectural Historians 39, No. 2 (May,)

Giedion, Sigfried. 1978 (1941). Espacio, tiempo y arquitectura. (El futuro de una nueva tradición), Madrid: Dossat, S.A.

1995 (1928). Building in France, building in iron, building in ferroconcrete. Los Angeles: Getty Center for the History of Art and the Humanities.

Goldemberg, Jorge. (comp.). 1985. Eclecticismo y Modernidad en Buenos Aires. Buenos Aires: FAUUBA.

Gorelik, Adrián.1998. La grilla y el parque. Espacio público y cultura urbana en Buenos Aires, 1887-1936. Bernal: UNQUI.

2003. Lo moderno en el debate: ciudad, modernidad, modernización. Universitas Humanística 56, junio. Colombia: Pontificia Universidad Javeriana. 
2004. Buenos Aires en la encrucijada: modernización y política urbana. En Miradas sobre Buenos Aires: modernización y politica urbana. Buenos Aires: Siglo XXI.

Gorelik, Adrián y Silvestri, Graciela "El pasado como futuro. Una utopía reactiva en Buenos Aires", Punto de Vista, No 42 (Buenos Aires, abril 1992).

Grandi, Maurizio (a cura di). 2012. Architettura a Milano negli anni dell'unità. La trasformazione della città il restauro dei monumenti. Milano: Libraccio Editore.

Gravagnuolo, Benedetto. 1998. Historia del urbanismo en Europa, 1750-1960. Madrid: Akal Arquitectura.

Grementieri, Fabio. 2005. Buenos Aires Art Nowveau. Buenos Aires: Ediciones Verstraeten.

Grementieri, Fabio, y Shmidt, Claudia. 2010. Alemania y Argentina: la cultura moderna de la construcción. Buenos Aires: Ediciones Larivière.

Grillo, María Victoria. Creer en Mussolini. La proyección exterior del fascismo italiano: (1930-1939), Programa de Estudios de Historia Europea Contemporánea. Facultad de Filosofía y Letras (UBA). Instituto Dr. Emilio Ravignani. Proyecto UBACYT FI 061. 2004-2007. Dirigido por Luis Alberto Romero y Lilia Ana Bertoni.

Gruschetsky, Valeria. 2008. "Elespiritu de la calle Corrientes no cambiará con el ensanche" La transformación de la calle Corrientes en avenida. Debates y representaciones. Buenos Aires 1927-1936. Buenos Aires: Universidad de Buenos Aires, tesis de Licenciatura inédita.

Gutierrez, Ramón et. al. 2004. Italianos en la Arquitectura Argentina. Buenos Aires: CEDODAL.

Gutman, Margarita. 1999. Buenos Aires 1910: memoria del porvenir. IIED- América Latina, FADUUBA, The Getty Research Institute.

Gutman, Margarita y Reese, Thomas (Eds.). 1999. Buenos Aires 1910: el imaginario para una gran capital (Buenos Aires, Eudeba).

Hobsbawm, Eric. 2007. Historia del siglo XX. Buenos Aires: Paidós/Crítica.

Hunter, Carlos y Solsona, Jorge. 1990. La Avenida de Mayo, un proyecto inconcluso. Buenos Aires: FAU-UBA.

Iglesia Rafael y Sabugo, Mario. 2006. La cindady sus sitios. Buenos Aires: Nobuko.

Jackson, Julian (coord.) 2003. Europa 1900-1945. Barcelona: Crítica.

Jacob, Raúl. 1981. Breve historia de la industria en el Uruguay. Montevideo: Editorial Fondo de Cultura Universitaria.

Jacob, Raul. 1991. Las otras dinastías 1915-1945. Montevideo: Proyección. 
Kandel, Ester. 2008. Argentina: Acerca de la vulnerabilidad de las mujeres y los niños. Presentado en las II Jornadas para los Departamentos de Historia de los Institutos Terciarios: Los Terciarios Hacen Historia, Instituto Joaquín V. González - 17,18 y 19 de septiembre.

Koolhaas, Rem. 1994 (1978), Delirious New York: a retroactive manifesto for Manhattan, Monacelli Press.

Lanciotti, Norma. 2009. De rentistas a empresarios: inversión inmobiliaria y urbanización en la pampa argentina, Rosario, 1880-114. Santa Fe: Editorial UNL.

Lecis, Marco. Roma 1934, "Il Concorso per il Palazzo del Littorio". En Arte/Architettural Ambiente: www.ca.archiworld.it

Liernur, Jorge Francisco. 1980. Rascacielos de Buenos Aires. Nuestra Arquitectura no 511-512, Buenos Aires.

1982. Área central norte. Reflexiones para una crítica. Summa $\mathrm{N}^{\circ}$ $171 / 172(\mathrm{feb} / \mathrm{mar})$.

1993. La ciudad efímera. En El umbral de la metrópolis: transformaciones técnicas y cultura en la modernización de Buenos Aires (1870-1930), Liernur y Silvestri. Buenos Aires: Sudamericana.

Liernur, Jorge Francisco. 1994. Nuevos rascacielos en Buenos Aires: vivir en las nubes. Arquis.

1995. Architetti italiani nel secondo dopoguerra nel dibattito architettonico nella "nuova Argentina” (1947-1951). Metamorfosi, 25/26. Roma: La Sapienza.

2001. Arquitectura en la Argentina del siglo XX. La construcción de la modernidad. Buenos Aires: Fondo Nacional de las Artes.

Liernur, Jorge Francisco. 2003. Acerca de la actualidad del concepto simmeliano de metrópoli. Estudios Sociológicos, enero-abril, año/vol. XXI no 001, el Colegio de México, DF. Disponible web: http://redalyc.uaemex.mx/pdf/598/59806102.pdf.

Lima, Edgardo; Hernández Balat, Victorio; Bisso, Juan F. FALTA AÑO. "Hormigón armado: notas sobre su evolución y su teoría", Seminario sobre la resistencia de materiales, disponible web: http://www.ing.unlp.edu.ar/

Lousteau, Cesar J. 1998. Influencia de Italia en la arquitectura del Uruguay. Montevideo: Instituto Italiano di Cultura.

Machado, Alejandro. http://mariopalanti.blogspot.com.ar/

Malajovich, Gustavo. 2012. El jardin e bronce:: Penguin Random House.

Malecki, J. S.: La ciudad dislocada: Córdoba 1947-1975. Modernización y radicalización en la cultura urbana y arquitectónica, Tesis de Doctorado en Historia, FFyH, UNC, Córdoba, 2015, mimeo. 
Mangerie, Fabio. 2007. Tra architettura e scultura: caratteri della "monumentomania" fra Ottocento e Novecento, en Giuffrè, Mangone, Pace, Selvafolta (a cura di). Skira.

Marcello, Flavia. 2007. The Politics of Place: Citing and Re-siting the Palazzo Littorio, Mussolini’s New Fascist Party Headquarters in Rome. Architectural Theory Review. 1 dic.

Morachiello, Paolo y Teyssot, Georges (eds). 1980. Le macchime imperfette Architettura, programma, istitustoni nel XIX secólo. Roma: FALTA EDITORIAL.

Morgan, Philip. 1995. Italian Fascism, 1919-1945. New York: St. Martin’s Press.

Mosse, George L. 1995. Estetica fascista e società alcune considerazioni. En Il regime fascista, (a cura di) A. del Boca, M. Legnani, M.G. Rossi. Roma-Bari: Laterza.

2007. La nacionalización de las masas. Buenos Aires: Siglo XXI.

Navarro, Marysa. 2005. Evita. Buenos Aires: Edhasa.

Nicoloso, Paolo. 2011. Mussolini architetto. Propaganda e paesaggio urbano nell'Italia fascista, Torino: Einaudi.

Novick, Alicia. 2000. Planes versus proyectos. Algunos problemas constitutivos del Urbanismo Moderno. Buenos Aires (1910-1936). Revista de Urbanismo, No 3. Universidad de Chile: FAU, Ago. Disponible en: http://revistaurbanismo.uchile.cl/n3/index.html;

Occhipinti, Chiara. 2012. Milano nei progetti dei giovani architetti civili. En Architettura a Milano negli anni dell'unità. La trasformażione della città il restauro dei monumenti, (a cura di) Maurizio Grandi . Libraccio.

Ortiz, Gutiérrez, De Paula, Mantero. 1968. La arquitectura del liberalismo en la Argentina. Buenos Aires: Editorial Sudamericana.

Palazzolo, Gaetano. 2014. Sub specie aeternitatis. Architettura della memoria in forma di rotonda nel periodo tra le due guerre. Tecla $\mathrm{n}^{\circ}$ 9, Università degli Studi di Palermo, 30 di giugnio.

Paxton, Robert O. 2005. Anatomía del fascismo. Barcelona: Península.

Peña, J. M. y Martín, J. X. 1967. La Ornamentación en la Arquitectura de Buenos Aires, 1900-1940. Buenos Aires: IAA FAU.

Petriella, Dionisio y Miatello, Sara Sosa. Diccionario Biográfico italo-argentino, Dante Alighieri. Consultado julio 2013 http://www.dante.edu.ar/web/dic/m.pdf

Pevsner, Nikolaus. 1977 (1936). Pioneros del diseño moderno. De William Morris a Walter Gropius. Buenos Aires: Infinito.

Piccioni, Raúl. 2010. La arquitectura de Buenos Aires bajo el influjo de la Academia de Bellas Artes de Brera. El caso de Angel F. Valdemarca. VIII Jornadas de Estudios e investigaciones. "Arte y cultura, continuidades y rupturas en vísperas del bicentenario" (Buenos Aires: Instituto de Teoría e 
Historia del Arte "Julio E. Payró”)

Véase el texto de Alicia Novick, "Alberto Prebisch. La vanguardia clásica", Cuadernos de Historia IAA 9 (junio de 1998) y Alberto Prebisch, Colección "Maestros de la Arquitectura Argentina Buenos Aires: Clarín, 2014)

Presidencia de la Nación. 1955. Monumento a Eva Perón, Buenos Aires, Presidencia de la Nación, Secretaría de Prensa y Difusión.

Presley, Leticia. 2004. La Voluntad de Creer y Organizar: Ideas, Creencias y Redes Fascistas en la Argentina de Los '30 Tempranos. Prismas 8 Buenos Aires. 59-79

Prins, Arturo. 1915. La arquitectura gótica. Origen y característica de la fórmula gótica. Revista de Arquitectura, $\mathrm{N}^{\circ} 2$.

Quintana de Uña, Javier. 2006. Sueño y frustración. El rascacielos en Europa.1900-1939. Madrid: Alianza.

Ramos Carranza, Amadeo. 2005. Dibujos y arquitectura: la Fiat Lingotto (1916-1927), tesis doctoral dirigida por M. trillo de Leyva y J. L. trillo de Leyva, (Escuela Técnica Superior de Arquitectura, Universidad de Sevilla. Diciembre.

Reynés, Juan Carlos. 2003. Un dirigible sobre el palacio. Montevideo: Ediciones de la Plaza.

Ricci, Giuliana (a cura di). 1992. L'architettura nelle Accademie riformate: insegnamento, dibattito culturale, interventi pubblici. Milano: Angelo Ass.

1992. L'Architettura all'Accademia di Belle Arti di Brera: insegnamento e dibattito. En L'Architettura nelle Accademie riformate: insegnamento, dibattito culturale, interventi pubblici. Milano: Angelo Guerini.

2003. Tradition and modernity in the training of italian Project designers towards the late 1800s and early 1900s. Architectural Culture Around 1900, critical reappraisal and heritage preservation. Buenos Aires: Universidad Torcuato di Tella.

Ricci, Giuliana y D’Amia, Giovanna (eds.). 2002. La cultura architettonica nell'età della restauraz̧ione (Milano: Mimesis edizioni.

Rigotti, Ana María. 2003. Many plans, the Plan. Practices on Argentine Cities around 1900. En Architecture Culture around 1900. Critical Reappraisal and Heritage Preservation, eds. Jorge Francisco Liernur, Fabio Grementieri y Claudia Shmidt. Buenos Aires: UNESCO World's Heritage y UTDT.

Robuschi, Luigi. Alla ricerca di un'identità naz̧ionale. La teorizzazione architettonica di Camillo Boito nella Milano post unitaria. https://www.academia.edu/5597542/Alla_ricerca_di_unidentit\%C3\%A0_ nazionale._La_teorizzazione_architettonica_di_Camillo_Boito_nella_Milano_post_unitaria (consultado: 15 de abril de 2015) 
Rocchi, Fernando. 1994. La armonía de los opuestos: Industria, importaciones y la construcción urbana de Buenos Aires en el período 1880-1920. Entrepasados, año IV, Nº 7.

2000. El péndulo de la riqueza: la economía argentina en el período 1880 1916. En Nueva Historia Argentina. El progreso la modernización y sus límites (1180-1916), (dir. M. Z. Lobato). Buenos Aires: Sudamericana.

2006. Chimneys in the dessert: industrialization in Argentina during the export boom years, 1870-1930.: Standford University Press.

Rodríguez Aycaguer, Ana María. 2007. La República del compromiso. 1919-1933. AA.VV, Historia del Uruguay en el siglo XX (1890-2005). Montevideo: Ediciones de la Banda Oriental.

Rodríguez Villamil. 1989. Proteccionismo y librecambio: El programa de la Liga Industrial de 1880. En Industria uruguaya: dos perspectivas, Bruxedas, Martín y Jacob, Raúl. Montevideo: Editorial Fondo de Cultura Universitaria.

Romero, José Luis. 2008 (1976). Latianoamérica, las ciudades y las ideas. Buenos Aires: Siglo XXI.

Santangelo, Mariana. 2014. Un mundial a colores: arqueología de un predio en Registros (Mar del Plata, año 10 (n.11): 134-149. Julio.

Sabugo, Mario. 2005. Pasaje Barolo. Vanguardias Argentinas, obras y movimientos en el Siglo XX. Buenos Aires.

Salvati, Mauriccia. 1995. Da piccola borghesia a ceti medi. En Il regime fascista, (a cura di) A. del Boca, M. Legnani, M.G. Rossi. Roma-Bari: Laterza.

Saratsola, Osvaldo. 2005. Función completa, por favor: un siglo de cine en Montevideo. Montevideo: Ediciones Trilce.

Sarlo, Beatriz. 1992. La imaginación técnica. Sueños modernos de la cultura argentina. Buenos Aires: Nueva Visión,

1988. Una modernidad periférica: Buenos Aires 1920 y 1930. Buenos Aires: Nueva Visión.

Savorra, Massimiliano. 2007. La rappresentazione del dolore e l'immagine dell'eroe: il monumento al Fante. En L'architettura della memoria in Italia Cimiteri: monumenti e città 1750-1939, (a cura di) Giuffrè, Mangone, Pace y Selvafolta. Skira.

2011. La monumentomania e i concorsi artistici nell'Italia unita. En Architettare l'Unità. Architettura e istituzioni nelle città della nuova Italia, catalogo della mostra (Roma 26 aprile-28 maggio 2011), (a cura di) Mangone y Tampieri. Napoli.

Schere, Rolando. 2008. Concursos 1825-2006. Buenos Aires: SCA.

Schorske, Carl E. 1980. Fin-de-siécle Vienna. Politics and Culture. New York: Alfred A. Knopf.

Schumacher, Thomas L. 1983. Terragni e il Damteum. Roma: Oficina di Edizioni. 
1993 (1985). The Danteum: architecture, poetics, and politics under Italian fascism. Princeton Architectural Press.

Schvarzer, Jorge. 1991. Empresarios del pasado. La Unión Industrial Argentina. Buenos Aires: CISEA.

Scott, John Beldon. 2011. El timonel del Estado. Un proyecto de Mario Palanti para la Italia fascista. Conferencia dictada en la Facultad de Arquitectura. UdelaR. Viernes 3 de junio.

Seidel, Beatriz. 1999. Crónicas de la semana trágica enero de 1919. Buenos Aires: Corregidor.

Selvafolta, Ornella. 2005. Milano e la Lombardia. Storia della Architettura Italiana, l'ottocento, (a cura di) Amerigo Restucci. Milano: Electa.

2012. Gli studi di ingenieria civile e di architettura al Politecnico di Milano: territorio, costruzioni, architetture. En, L'Università e l'Unità d'Italia (1848-1870), (a cura di) Alessandra Ferraresi, Elisa Signori. Bologna: Clueb.

2011. Una scuola per l' Italia unita: la formazione di ingegneri e architetti al Politecnico di Milano. En Scienza, tecnica e industria nei 150 anni di unità d'Itaia, (a cura di) C. G. Lacaita, P. P. Poggio. Jaca Book: Milano.

Shmidt, Claudia. 2012. Palacios sin reyes. Arquitectura pública para la "capital permanente". Buenos Aires, 1880-1890. Rosario: Prohistoria Ediciones.

Silvestri, Graciela. 2003. El color del rio: historia cultural del paisaje del riachuelo. Bernal: UNQUI.

2004. Voz "Historiografía y crítica de la arquitectura". En Diccionario de Arquitectura en la Argentina. Buenos Aires: Clarín Arquitectura.

Summerson, John. 1980. Viollet-le-Duc and the rational point of view. Architectural Design 3, $\mathrm{n}^{\circ}$ 4.

Sternhell, Zeev. 1994. Los orígenes de la ideología fascista. Madrid: Siglo XXI.

Tafuri, Manfredo. 1973. La montaña desencantada. El rascacielos y la ciudad. En La ciudad americana: de la guerra civil al New Deal, Ciucci, Dal Co, Manieri-Elia, Tafuri. Barcelona: GG.

1973. Teorías e bistoria de la arquitectura. Hacia una nueva concepción del espacio arquitectónico. Barcelona: Laia.

1978. Il soggetto e la maschera. Una introduzione a Terragni. Lotus, nº 20, set.

Tafuri, Manfredo. 1983. Entrevista colectiva realizada en Buenos Aires jul-ago, 1981, Programa de Estudios Históricos de la Construcción del Habitar., Publicada en Materiales, mes de marzo.

Barcelona: Gustavo Gili. 
1995 (1992). Sobre el renacimiento. Principios, ciudades, arquitectos. Madrid: Catedra.

Tafuri, Manfredo y Francesco Dal Co. 1982. Arquitectura Contemporánea, Vol.1. FALTA LUGAR: Viscontea.

Tartarini, Jorge. 1992. "El Plan Bouvard para Buenos Aires (1907-1911). Algunos antecedentes". Anales, $N^{\circ}$ 27-28. Buenos Aires: IAA-FADU-UBA.

Tasca, Angelo. 1983. El nacimiento del fascismo. Barcelona: Ariel.

Tedeschi, Enrico. 1937. Concorso per il Monumento alla Vittoria in Milano. Architettura. Rivista del sindicato nazionale fascita architetti. XVI Nov. fasc.XI.

Tella, Guillermo. 1995. Palacio Barolo. Los rasgos de una arquitectura. Vivienda, no 395, junio.

Torre, Juan Carlos (dir). 2002. Los años peronistas: 1943-1955. Buenos Aires : Sudamericana.

Tournikiotis, Panayotis. 1999. The Historiography of Modern Architecture. Massachusetts: MIT Press.

Tranfaglia, Nicola. 1995. La modernizzazione contradittoria negli anni della stabilizzazione del regime (1926-1936). En Il regime fascista, (a cura di) A. del Boca, M. Legnani, M.G. Rossi. Roma-Bari: Laterza.

Tuzi, Stefania. 2014. Mario palanti architetto visionario tra italia e Argentina. En Contributi italiani all' architettura argentina. Progetti e opere tra il XIX e il XX secolo, (a cura di) Tuzi, Sabugo. Roma: DEI Tipografia del genio civile.

Urien, Carlos María y Colombo, Ezio. 1910. La República Argentina en 1910. Estudio bistórico, físico, politico, social y económico. Honorable Comisión del Centenario de la Independencia Argentina y Junta de Historia y Numismática Americana. Buenos Aires: Maucci Hnos.

Van Zanten, David y Egbert, Donal Drew. 1980. The Beaux-Arts Tradition in French Architecture. Princeton: Princeton University Press.

Vattuone, Juan Emilio. s/f. El Barolo, Junta Central Histórica de la Ciudad de Bs. As., IHCBA Carpeta 1559.

Velarde González Irigoin. 2006. La torre del espejo. Montevideo: Suma.

Vidler, Anthony. 1977. The idea of type: the transformation of the academic Ideal. 1750-1830. Oppositions, $\mathrm{n}^{\circ} 8$.

Waisman, Marina (cord.). 1978. Summa Historia: Documentos para una Historia de la Arquitectura. Buenos Aires: Summa.

Willis, Carol. 1995. Form follows finance: skyscrapres and skylines in new York and Chicago. New York: Pinceton Architectural Press.

Zevi, Bruno. 1954 (1950). Historia de la Arquitectura Moderna. Buenos Aires: Emecé.

Zucconi, Guido. 1997. L'invenzione del passato: Camillo Boito e l'architettura neomedievale, 1855-1890. Venezia: Marsilio. 